\title{
Einbecker Vereine im Kaiserreich 1871 bis 1914
}

Eine exemplarische Untersuchung zum Vereinsleben einer Kreisstadt in der preußischen Provinz Hannover von der Reichsgründung bis zum Ersten Weltkrieg.

\author{
Dissertation zur Erlangung des Doktorgrades \\ der Philosophischen Fakultät der \\ Georg-August-Universität \\ zu Göttingen.
}

\author{
vorgelegt von \\ Martin Jungmann \\ aus Markoldendorf
}

Göttingen 2002 
Meinen Eltern 


\section{Danksagung}

Zunächst gilt mein Dank Herrn Prof. Dr. Karl-Heinrich Kaufhold, der mich zu meinem Forschungsvorhaben ermutigte und mir während der Arbeit an dieser Untersuchung betreuend zur Seite stand.

Ferner möchte ich mich bei all jenen Einbeckern bedanken, die durch ihre Unterstützung Anteil am Zustandekommen der Untersuchung hatten; Frau Stefani Stöckemann für die Vermittlung von Kontakt zu den einzelnen Vereinsvorständen, Herrn Klaus Rudloff für die großzügige Leihgabe von Stücken aus seiner privaten Sammlung von Schrifttum über die Stadt Einbeck und ihre Vereine, Herrn Karl-Heinz Just, Ehrenpräsident des Kreisschützenverbandes Einbeck, für die leihweise Überlassung von Literatur über die Geschichte des Schützenwesens und Frau Dr. Elke Heege und dem Team von Stadtarchiv und Museum in Einbeck, die mir hervorragende Arbeitsbedingungen schufen.

Auch danke ich all jenen Funktionsträgern verschiedener Vereine, die mir freundlicherweise Zugang zu ihren Archivalien gewährt haben; Frau Renate Jus und Herrn Wolfgang Sckopp (Sportverein Eintracht), Frau Silke Schulte-Rosniewski und Herrn HeinPeter Balshüsemann (Turn-Club Einbeck), Frau Kerstin Hundertmark (Einbecker Schützengilde) und Herrn Peter Siemer (Männergesangverein Harmonie).

$\mathrm{Zu}$ guter Letzt gilt mein besonderer und inniger Dank meinem lieben Vater, Dr. med. Wolf Bernd Jungmann, dessen großzügige Unterstützung in materieller Hinsicht die vorliegende Untersuchung erst ermöglicht hat und der mir durch Aufmunterung und gedankliche Anregungen während der Bearbeitungszeit und seine unermüdliche Korrekturtätigkeit in der Phase der Niederschrift stets ein helfender Begleiter war. 


\section{Inhalt}

$\begin{array}{lll}\text { 1. Einführung } & \text { S. } 1\end{array}$

1. 1. Methodische Vorbemerkungen S. 1

1.1. 1. Vereine als Gegenstand wissenschaftlicher Forschung S. 1

1. 1. 2. Zur Methodik und Fragestellung der vorliegenden Arbeit S.8

1. 1. 2. 1. Vereine im Sinne der vorliegenden Untersuchung S.8

1. 1. 2. 2. Aufbau und Fragestellung der vorliegenden Arbeit S. 11

1.2. Die Quellenlage S. 14

1.3. Zur Wahl des Untersuchungszeitraumes S. 16

1.4. Die rechtlichen Grundlagen des Vereinswesens im Kaiserreich S. 18

1. 5. Zur Entwicklung der Stadt Einbeck bis zum Beginn des Ersten Weltkrieges $\quad$ S. 22

1.6. Die Verwaltungsstruktur Einbecks im Kaiserreich S. 27

$\begin{array}{lll}\text { 1. } 7 & \text { Einbecker Vereine vor dem Untersuchungszeitraum } & \text { S. } 29\end{array}$

2. Einbecker Vereine im Kaiserreich $1871-1914 \quad$ S. 36

$\begin{array}{ll}\text { 2. } 1 . \quad \text { Die Gesangvereine } & \text { S. } 36\end{array}$

2.1.1. Zur Geschichte des Gesangvereinswesens in Deutschland S. 36

$\begin{array}{ll}\text { 2. 1. 2. Der Gesangverein Germania } & \text { S. } 39\end{array}$

2. 1.3. Die Liedertafel Lassallia / Concordia S. 41

2. 1.4. Weitere sozialdemokratische Gesangvereine S. 45

$\begin{array}{ll}\text { 2. 1. 5. Der Liederkranz Einbeck S. } 49 & \end{array}$

2. 1. 6. Der Gesangverein Concordia S. 51

2. 1. 7. Der Männergesangverein Harmonie S. 52

2. 1. 8. Die Liedertafel Eintracht S. 56

2. 1.9. Die Graphische Liedertafel S. 57

2. 1. 10. Der Männergesangverein Sachsenroß S. 58

2. 1. 11. Der Gesangverein Cäcilia S. 60

2. 1. 12. Der Männergesangverein Deutsches Lied S. 62

2. 1. 13. Weitere Gesangvereine S. 64

2. 1. 14. Einbecks Gesangvereine vor dem Ersten Weltkrieg

$\begin{array}{ll}\text { - eine Gesamtschau } & \text { S. } 65\end{array}$

$\begin{array}{lll}\text { 2. } 2 . & \text { Musik- und Theatervereine } 69\end{array}$

$\begin{array}{ll}\text { 2. 2. 1. Die Musikvereine S. } 69 & \end{array}$ 


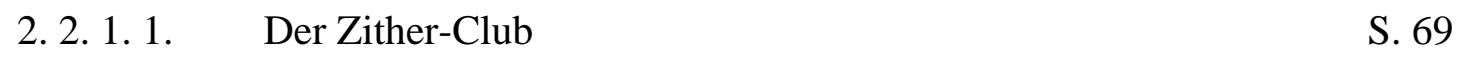

2. 2. 1. 2. Der Conzertina-Club S. 71

2.2.1.3. Weitere Musikvereine S.73

$\begin{array}{ll}\text { 2.2.2. Die Theatervereine S. } 74 & \end{array}$

2. 2. 2. 1. Der Dilettanten-Club Walhalla S. 74

$\begin{array}{ll}\text { 2. 2. 2. 2. Der Dramatische Club Thalia } & \text { S. } 77\end{array}$

$\begin{array}{ll}\text { 2.3. Die Turn- und Sportvereine } & \text { S.78 }\end{array}$

$\begin{array}{lll}\text { 2.3. 1. Die Turnvereine S. } 78 & \end{array}$

2.3. 1. 1. Zur Geschichte der Turnbewegung in Deutschland S. 78

2.3. 1.2. Der Männer-Turn-Verein Einbeck S. 82

2.3.1.2.1. Gründung und Entwicklung S. 82

2.3. 1. 2.2. Die Vereinsaktivitäten S. 91

2.3. 1.3. Der Turn-Club Einbeck S. 101

2.3.1.3.1. Gründung und Entwicklung S. 101

$\begin{array}{ll}\text { 2.3. 1.3.2. Die Vereinsaktivitäten } & \text { S. } 107\end{array}$

2.3. 1.4. Der Turnverein Germania S. 113

2.3.1.5. Der Turn- und Fechtclub S. 116

$\begin{array}{ll}\text { 2.3. 1.6. Der Turnclub Eintracht Einbeck } & \text { S. } 119\end{array}$

2.3. 1.6.1. Gründung, Entwicklung und Aktivitäten S. 119

2. 3. 1. 6. 2. Eintracht Einbeck in der Arbeiterbewegung S. 128

2.3. 1. 7. Einbecks Turnvereine von der Reichsgründung bis zum Ersten Weltkrieg - Gesamtschau und Ausblick $\quad$ S. 137

2.3. 2. Die Radfahrvereine S. 142

2. 3. 2. 1. Zur Geschichte des Radfahrens in Deutschland S. 142

2. 3. 2. 2. Der Radfahrer-Verein Einbeck von $1887 \quad$ S. 145

$\begin{array}{lll}\text { 2. 3. 2. 3. Der Radfahrer-Club S. } 148 & \end{array}$

$\begin{array}{lll}\text { 2. 3. 2. 4. Der Bicycle Club Einbeck } 1898 & \text { S. } 149\end{array}$

2. 3. 2. 5. Der Arbeiter-Radfahrer-Verein Vorwärts S. 151

2. 3. 2. 6. Der Einbecker Radfahrerverein 1911 S. 153

2.3. 2.7. Einbecks Radfahrvereine vor dem Ersten Weltkrieg S. 154

2.3.3. Die Fußballvereine S. 156

2.3.3.1. Zur Geschichte des Fußballsports S. 156

$\begin{array}{lll}\text { 2.3.3.2. Einbecks Fußballsport im Kaiserreich } & \text { S. } 159\end{array}$

2.3.3.2.1. Vereinsgründungen und Fusionen - Organisationsgeschichte S. 159

2.3. 3. 2. 2. Zur ökonomischen Situation Einbecker Fußballvereine S. 165 
$\begin{array}{ll}\text { 2. 3. 3. 2.3. Mitgliederentwicklung und -struktur } & \text { S. } 167\end{array}$

2. 3. 3. 2. 4. Das Verhältnis der Fußballer zur Stadtgemeinde S. 168

$\begin{array}{lll}\text { 2.3.4. Weitere Sportvereine } & \text { S. } 172\end{array}$

2. 3. 4. 1. Der Athleten-Club Vorwärts $\quad$ S. 172

$\begin{array}{ll}\text { 2. 3. 4. 2. Der Fechtclub S. } 173 & \end{array}$

2. 3. 5. Die organisierten Leibesübungen in Einbeck

- eine kurze Gesamtschau $\quad$ S. 174

$\begin{array}{lll}2.4 . & \text { Die Schützenvereine } 176\end{array}$

2. 4. 1. Zur Geschichte des Schützenwesens in Deutschland

$\begin{array}{ll}\text { und Niedersachsen } & \text { S. } 176\end{array}$

$\begin{array}{ll}\text { 2. 4. 2. Der Schützenverein Einbeck } & \text { S. } 179\end{array}$

2. 4. 3. Der Schützen-Zimmerstutzenklub S. 190

2. 4. 4. Die Schießsportabteilungen des MTV

und des Landwehr- und Reservevereins $\quad$ S. 191

$\begin{array}{lll}\text { 2. 5. Verschiedene Kegelvereine } & \text { S. } 192\end{array}$

$\begin{array}{ll}\text { 2. } 6 . & \text { Der Naturheilverein } 195\end{array}$

2.6. 1. Zur Geschichte der Naturheilbewegung in Deutschland S. 195

2. 6. 2. Der Verein für Gesundheitspflege und arzneilose Heilweise S. 198

$\begin{array}{ll}\text { 2.6. 2. 1. Vereinsgründung und Tätigkeit } & \text { S. } 197\end{array}$

$\begin{array}{lll}\text { 2. 6. 2. 2. Zur Mitgliederstruktur des Vereins } & \text { S. } 204\end{array}$

$\begin{array}{lll}\text { 2.7. Das Militärvereinswesen } & \text { S. } 207\end{array}$

2.7. 1. Das Militärvereinswesen in Preußen und im Reich S. 207

2. 7. 2. Der Kriegerverein Einbeck S. 212

$\begin{array}{lll}\text { 2. 7. 3. Der Landwehr- und Reserveverein Einbeck } & \text { S. } 217\end{array}$

$\begin{array}{lll}\text { 2.7.4. Der Kriegerverein Kameradschaft } & \text { S. } 221\end{array}$

$\begin{array}{ll}\text { 2.7.5. Der Militäranwärter-Verein } & \text { S. } 224\end{array}$

2. 7.6. Der Verein ehemaliger Artilleristen für Einbeck und Umgegend S. 225

2.7.7. Das Einbecker Militärvereinswesen - ein Gesamtbild $\quad$ S. 226

$\begin{array}{ll}2.8 . & \text { Die politischen Vereine } 228\end{array}$

2. 8. 1. Zur Entwicklung der Parteien im 19. und frühen 20. Jahrhundert S. 228

2. 8. 2. Die Vereine der Sozialdemokratischen Partei S. 231

2. 8. 3. Die Vereine der Deutsch-Hannoverschen Partei S. 243

$\begin{array}{ll}\text { 2. 8. 4. Der Nationalliberale Verein } & \text { S. } 250\end{array}$ 
$\begin{array}{ll}\text { 2. 8. 5. Der Freisinnige Wahlverein } & \text { S. } 254\end{array}$

$\begin{array}{ll}\text { 2. 8.6. Die Konservative Vereinigung } & \text { S. } 256\end{array}$

$\begin{array}{ll}\text { 2. 8. } 7 . & \text { Der Bund der Landwirte }\end{array}$

$\begin{array}{ll}\text { 2. 8. 8. Der Club Gemüthlichkeit } & \text { S. } 259\end{array}$

2. 8. 9. Die Ortsgruppe Einbeck des Reichsverbandes $\begin{array}{ll}\text { gegen die Sozialdemokratie } & \text { S. } 262\end{array}$

2. 8. 10. Die politischen Vereine Einbecks vor dem Ersten Weltkrieg S. 263

2. 9. Der Verein für Geschichte und Alterthümer $\quad$ S. 265

$\begin{array}{ll}\text { 2.9. 1. Geschichtsvereine in Deutschland S. } 265 & \end{array}$

2. 9. 2. Der Verein für Geschichte und Alterthümer $\begin{array}{ll}\text { der Stadt Einbeck und Umgegend } & \text { S. } 267\end{array}$

$\begin{array}{lll}2.10 . & \text { Caritative Vereine } 276\end{array}$

$\begin{array}{ll}2.10 .1 . & \text { Die Frauenvereine } 276\end{array}$

2. 10. 1. 1. Der Frauenverein Einbeck S. 276

$\begin{array}{ll}2.10 .1 .2 . & \text { Der Vaterländische Frauenverein } 278\end{array}$

2. 10. 1.3. Der evangelische Frauen- und Jungfrauenverein $\quad$ S. 280

$\begin{array}{ll}\text { 2. 10. 1. 4. Der Elisabethverein } & \text { S. } 281\end{array}$

2. 10. 2. Der Zweigverein vom Roten Kreuz und seine Sanitätskolonne S. 282

$\begin{array}{lll}\text { 2. 11. Religiöse Vereine S. } 285 & \end{array}$

2. 11. 1. Die evangelischen Vereine S. 285

2. 11. 1. 1. Der christliche Männer- und Jünglingsverein $\quad$ S. 285

$\begin{array}{ll}\text { 2. 11. 1.2. Weitere evangelische Vereine S. } 288 & \end{array}$

2. 11.2. Die katholischen Vereine S. 290

$\begin{array}{ll}\text { 2. 11.3. Der jüdische Frauenverein } & \text { S. } 291\end{array}$

$\begin{array}{lll}\text { 2. } 12 . & \text { Sonstige Einbecker Vereine } 1871-1914 & \text { S. } 293\end{array}$

2. 12. 1. Der Verschönerungsverein und

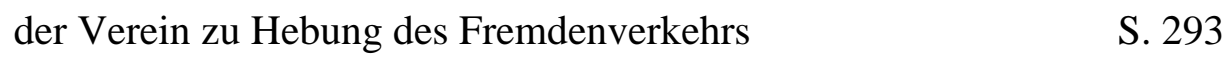

2. 12. 2. Verschiedene gesellige Vereine S. 296

2. 12.3. Die Bürgervereine S. 298

$\begin{array}{ll}\text { 2. 12. 4. Die Freiwillige Feuerwehr } & \text { S. } 301\end{array}$

$\begin{array}{ll}\text { 2. 12.5. Weitere Vereine } & \text { S. } 303\end{array}$ 
3. Gesamtschau und Ausblick

S. 304

3. 1. Zur statistischen Entwicklung des Einbecker Vereinswesens

S. 304

3. 2. Zur sozialen Integrationskraft der untersuchten Vereine

S. 310

3. 3 .

Die innere Struktur der Vereine und der "Obrigkeitsstaat"

S. 313

3. 4.

Vereine als Hort der Geselligkeit

S. 316

3. 5 .

Schlussbemerkungen und Ausblick

S. 321

4. Verzeichnis der benutzten Quellen und Literatur

S. 324 


\section{Einführung}

\section{1. Methodische Vorbemerkungen}

\section{1. 1. Vereine als Gegenstand wissenschaftlicher Forschung}

Im Jahre 1910, auf dem ersten Deutschen Soziologentag, richtete Max Weber an seine Fachkollegen den Appell, sich der empirischen Untersuchung des Vereinswesens in Deutschland als einem relevanten sozialen Phänomen zuzuwenden. Es sei Aufgabe der Soziologen, "diejenigen Gebilde zum Gegenstand ihrer Arbeiten $\mathrm{zu}$ machen, welche man konventionell als 'gesellschaftliche' bezeichnet, d. h. alles das, was zwischen den politisch organisierten oder anerkannten Gewalten - Staat, Gemeinde und offizielle Kirche - auf der einen Seite und der naturgewachsenen Gemeinschaft ${ }^{1}$ der Familie auf der anderen Seite in der Mitte liegt. Also eine Soziologie des Vereinswesens im weitesten Sinne des Wortes, vom Kegelclub - sagen wir es ganz drastisch! - angefangen bis zur politischen Partei und zur religiösen oder künstlerischen oder literarischen Sekte." 2

Zwar gab es bereits vor diesem Appell Webers vereinzelte Ansätze einer soziologisch-politischen Betrachtung von Vereinen, doch steht in ihnen das Vereinswesen nicht an zentraler Stelle, und es kann von empirischer Untersuchung nicht die Rede sein. ${ }^{3}$

Wenn wir nun also davon ausgehen, dass Weber das Vereinswesen seiner Zeit als relevantes und daher untersuchenswertes Phänomen begriff, so muss sich freilich, nunmehr mehr als neunzig Jahre nach seinem Aufruf, dieser sich bedingt durch den zeitlichen Abstand weniger an die Soziologen denn an die Historiker wenden.

Dezidiert an die Historikerzunft wandte sich Thomas Nipperdey Anfang der siebziger Jahre des vergangenen Jahrhunderts. Am Ende seines Aufsatzes "Verein als soziale Struktur im 18. und 19. Jahrhundert" beschließt er seine Ausführungen mit den Worten: "Bislang gibt es, von einzelnen

\footnotetext{
${ }^{1}$ Wenn Erwin K. Scheuch den Weberschen Begriff "Naturgewachsene Gemeinschaft" mit "private Lebenswelt" übersetzt, so ist dies eher verwirrend denn erhellend. Vgl.: Scheuch, Erwin K.: Verein als Teil der Privatgesellschaft. In: Best, Heinrich: Vereine in Deutschland. Vom Geheimbund zur freien gesellschaftlichen Organisation. Bonn 1993. SS.: 143 -208. S.150

${ }^{2}$ Weber, Max: Geschäftsbericht. in: Verhandlungen des Ersten Deutschen Soziologentages vom 19. - 22. Oktober 1910 in Frankfurt am Main. Tübingen 1911. SS. 52f.

${ }^{3}$ Vgl.: Schäffle, Albert: Bau und Leben des sozialen Körpers. Tübingen 1875 - 1878.
} 
Vereinsgeschichten abgesehen, im wesentlichen nur - meist ältere Untersuchungen über bestimmte Typen und Gruppen von Vereinen. Die Bedeutung des Vereinswesens für die soziale, kulturelle und politische Welt des Bürgertums, den Stellenwert des Vereins für das Leben des Einzelnen, der Gruppe und der Gesellschaft im Gesamtgefüge anderer sozialer Strukturen Familie, Nachbarschaft, Arbeitsstätte, Orts- und Kirchengemeinde - , die Bedeutung des sozialen und sozial-psychischen Faktums Verein für die Politik, für die politische Orientierung von Einzelnen und Gruppen zumal, - das wird sich erst auf Grund von neuen Lokal- und Regionalstudien erhellen lassen; erst dann lassen sich auch hier [im zitierten Aufsatz, d. A.] vernachlässigte Differenzierungen untersuchen, wie die zwischen stärker und weniger stark industrialisierten Gebieten oder zwischen dem sozial-ökonomisch liberalen und politisch obrigkeitlich strukturierten Preußen und den sozial-ökonomisch konservativen und politisch konstitutionellen süddeutschen Staaten."4

Wie Weber über sechzig Jahre zuvor, so erachtete auch Nipperdey das Vereinswesen in seiner Gesamtheit als relevant, wenn er in seiner Schlussbemerkung verschiedene Gesichtspunkte andeutete. Eine wesentliche Weiterentwicklung des Weberschen Ansatzes stellt bei Nipperdey die Forderung dar, die wissenschaftliche historische Betrachtung von Vereinen auf dem Wege relativ kleinräumiger Lokal- oder Regionalstudien zu betreiben.

Einen ähnlichen Standpunkt bezüglich der Relevanz des Phänomens "Verein" für die deutsche Sozialgeschichte nahm auch Erwin K. Scheuch ein, wenn er konstatierte: "Deutschland gilt neben einigen kleinen westeuropäischen Demokratien als ein besonders durch Vereine geprägtes Land. Das dürfte tatsächlich für lange Abschnitte des sich modernisierenden Deutschlands zutreffen, wenngleich die inhaltliche Deutung des Faktums umstritten ist." 5

Die genannten Beiträge verdeutlichen, dass der soziologische und der historische Ansatz bei der Betrachtung von Vereinen und Vereinswesen weitgehend identisch sind und sich im Wesentlichen nur durch den zeitlichen Abstand des Betrachters von den zu untersuchenden Vorgängen und Prozessen unterscheiden.

\footnotetext{
${ }^{4}$ Vgl.: Nipperdey, Thomas: Vereine als soziale Struktur im späten 18. und frühen 19. Jahrhundert. in: Boockmann, Hartmut u. a.: Geschichtswissenschaft und Vereinswesen im 19. Jahrhundert. Beiräge zur Geschichte historischer Forschung in Deutschland.

(Veröffentlichungen des Max-Planck-Instituts für Geschichte. Bd. 1) Göttingen 1972. SS. 1-44,

S. 43

5 Scheuch, Erwin K.: op. cit., S. 150
} 
Diese Basis verließ, zum Teil zumindest, H.-Jörg Siewert, indem er schrieb: "Wenn Organisationen wie Parteien und Gewerkschaften zusammen mit Sportund Freizeitvereinen, religiösen und kulturellen Vereinigungen, Bürgerinitiativen und Kirchen samt ihren Dachverbänden gemeinsam unter einem Vereinsbegriff subsumiert werden, so ist es zweifelhaft, ob ein derart weit gefasstes Spektrum von nach Ziel, Struktur und Funktion so unterschiedlichen Institutionen homogen genug ist, um soziologisch fruchtbare generelle Aussagen zu ermöglichen." 6

Diese Zweifel sind mit Sicherheit legitim, solange sie sich, wie wohl auch von Siewert intendiert, auf die Gegenwart der Bundesrepublik Deutschland beziehen, in der es die Sozialwissenschaften auf der einen Seite mit einer entwickelten und in sich stabilen Gesellschaftsformation und auf der anderen Seite mit einer hochgradig ausgebildeten administrativen Binnenstruktur und einer nahezu unüberschaubaren Vielfalt von Vereinen, Vereinigungen, Bürgerinitiativen und dergleichen Organisationen zu tun hatten und auch heute noch haben. Für den für die vorliegende Arbeit gewählten Untersuchungszeitraum, auf den Weber und Nipperdey Bezug nehmen, sind sie jedoch als nachrangig und möglicherweise gar als einengend zu erachten. Denn gerade die relative Überschaubarkeit des sich erst formierenden Vereinssystems des Kaiserreiches bietet dem Forscher die Chance, in einem weit gesteckten Rahmen die verschiedenen freiwilligen Vereine und Vereinigungen in ihrer Gesamtheit zu betrachten. Dieser Rahmen wird für die vorliegende Untersuchung im folgenden Abschnitt definiert werden.

Die wissenschaftliche historische Vereinsforschung seit 1945 stellt sich in ihrer Gesamtheit relativ heterogen dar. 1959 forderte Hermann Bausinger einen kombinierten soziologisch-volkskundlichen Ansatz, in dem sich eine "geschichtlich orientierte Kulturwissenschaft" auch der Methoden der Soziologie bedient. ${ }^{7}$ Als Arbeiten, die auf diesem Forschungsansatz aufbauen, sind die Studien Heinz Schmitts über das Vereinsleben in Weinheim an der Bergstraße $^{8}$ und Herbert Freudenthals über Hamburger Vereine ${ }^{9}$ aus den

\footnotetext{
${ }^{6}$ Siewert, H.-Jörg: Vereinswesen in der deutschen Soziologie. in: Dann, Otto (Hg.):

Vereinswesen und bürgerliche Gesellschaft in Deutschland. (Schieder, Theodor (Hg.):

Historische Zeitschrift. Beihefte (Neue Folge). Beiheft 9) München 1984. SS.: 151-180. S. 152

${ }^{7}$ Bausinger, Hermann: Vereine als Gegenstand volkskundlicher Forschung. in: Zeitschrift für

Volkskunde, Band 55 (1959), SS. 98 - 104, hier: SS. 101 ff.

${ }^{8}$ Schmitt, Heinz: Das Vereinsleben der Stadt Weinheim an der Bergstraße. Volkskundliche Untersuchung zum kulturellen Leben einer Mittelstadt. (Weinheimer Gecshichtsblatt, Band 25). Weinheim a. d. B. 1963
} 
sechziger Jahren des 20. Jahrhunderts zu nennen. Diese Arbeiten weisen, wie auch die 1957 erschienene Studie Werner Querfelds über das Vereinsleben in Greiz $^{10}$ bereits vor Nipperdey auf eine mögliche Notwendigkeit der lokalen Eingrenzung des Untersuchungsgegenstandes hin; die genannten drei Autoren verfassten reine Regionalstudien über Vereine und deren Aktivitäten.

Ohne solches $\mathrm{zu}$ intendieren, legen auch verschiedene Arbeiten und Aufsätze, welche sich mit dem historischen Phänomen des Vereins für den ganzen deutschen Raum beschäftigen, eine regionale Begrenzung nahe. Indem sich Heinz Sahner ${ }^{11}$ und Otto Dann ${ }^{12}$ auf verschiedene frühe Vereinsgründungen in großen Städten beziehen, die auch Nipperdey in seinem oben zitierten Aufsatz nennt, konstatieren beide Autoren einen weitgehenden Durchbruch des Vereinsgedankens und der Vereinsgründungen bereits vor der Mitte des 19. Jahrhunderts. Ein solch früher Durchbruch lässt sich für den Fall der für die vorliegende Untersuchung gewählten Kleinstadt im ländlichen Raum ungeachtet einzelner früher Vereinsgründungen nicht nachweisen.

Dieser Befund ist wenig erstaunlich. Klaus Tenfelde weist verschiedentlich auf eine zeitliche Verzögerung der Vereinsgründungen in ländlich strukturierten Gebieten gegenüber den industriell weiter entwickelten Städten hin, ${ }^{13}$ insbesondere präsentiert er das Ergebnis eines Vergleiches des Vereinslebens von Bochum mit dem des damals noch nicht von der

${ }^{9}$ Freudenthal, Herbert, Vereine in Hamburg. Ein Beitrag zur Geschichte und Volkskunde der Geselligkeit. (Hävernick, Walter; Freudenthal, Herbert (Hgg.): Volkskundliche Studien, Band IV) Hamburg 1968

${ }^{10}$ Querfeld, Werner: Kultur- und Vereinsleben in der Stadt Greiz während des 19.

Jahrhunderts. Ein Beitrag zur Geschichte des Partikularismus in Deutschland. (Beiträge zur mittelalterlichen, neueren und allgemeinen Geschichte, Band 27). Jena 1957

${ }^{11}$ Sahner, Heinz: Vereine und Verbände in der modernen Gesellschaft. in: Best, Heinrich (Hg.): Vereine in Deutschland. Vom Geheimbund zur freien gesellschaftlichen Organisation. Mit einer Literatur- und Forschungsdokumentation von Helmut M. Artus. Bonn 1993, SS. 11 118

${ }^{12}$ Dann, Otto: Vereinsbildung in Deutschland in historischer Perspektive. in: Best, Heinrich (Hg.): Vereine in Deutschland. Vom Geheimbund zur freien gesellschaftlichen Organisation. Mit einer Literatur- und Forschungsdokumentation von Helmut M. Artus. Bonn 1993, SS. 119 $-142$

${ }^{13}$ Tenfelde, Klaus: Die Entfaltung des Vereinswesens während der industriellen Revolution in Deutschland (1850 - 1873). in: Dann, Otto (Hg.): Vereinswesen und bürgerliche Gesellschaft in Deutschland (Historische Zeitschrift. Beihefte (Neue Folge), Beiheft 9). München 1984, SS. 55 
Ausdehnung des Ruhrgebietes erreichten Gebietes in und um Recklinghausen. ${ }^{14}$

Auch Ernst Schubert konstatiert in einer Betrachtung des Vereinslebens im gesamten Königreich Hannover, dass zwar bereits um 1840 von Zeitgenossen von einer "Zeit der Vereine" gesprochen worden sei, die eigentliche Vereinsgründungswelle zu diesem Zeitpunkt allerdings noch bevorgestanden habe. 15

Neben die lokale Eingrenzung traten in späteren Arbeiten weiterer Autoren zusätzliche Einschränkungen. Eberhard Illner begrenzt seine Studie über das Vereinsleben der Stadt Elberfeld auf den Zeitraum der Jahre 1775 bis $1850^{16}$. Andere Autoren wählten für ihre regionalen Studien eine weitere Dimension der Eingrenzung des Forschungsgegenstandes; so beschränkte sich Thea Braatz in ihrer Untersuchung über München auf die Schicht der Kleinbürger von 1830 bis $1870^{17}$, Norbert Schloßmacher untersuchte die politischen Vereine Düsseldorfs im Kaiserreich ${ }^{18}$, Lydia Maria Hüskens untersuchte diese Vereine für den Kreis Geldern in den Jahren der Reichsgründung und des Kulturkampfes 19 und Annegret Heemann untersuchte die Männergesangvereine in Münster in Westfalen im 19. und frühen 20. Jahrhundert. 20

14 ibid.: SS. $66 \mathrm{f}$.

${ }^{15}$ Vgl.: Schubert, Ernst: Die Veränderung eines Königreichs. in: Hucker, Bernd Ulrich u. a. (Hgg.)Niedersächsische Geschichte. Göttingen 1997, SS. 374 - 418, S. 409

${ }^{16}$ Illner, Eberhard: Bürgerliche Organisation in Elberfeld 1775 - 1850. (Bergische Forschungen, Band 18). Neustadt/Aisch 1982

${ }^{17}$ Braatz, Thea: Das Kleinbürgertum in München und seine Öffentlichkeit von 1830 - 1870.

Ein Beitrag zur Mentalitätsforschung. (Miscellanea Bavarica Monacensia, Band 68). München 1977

${ }^{18}$ Schloßmacher, Norbert: Düsseldorf im Bismarckreich. Politik und Wahlen, Parteien und Vereine. (Düsseldorfer Schriften zur Neueren Landesgeschichte und zur Geschichte Nordrhein Westfalens, Band 15). Düsseldorf 1985

${ }^{19}$ Hüskens, Lydia Marie: Vereine und Politik - politische Vereine exemplarisch untersucht für den Kreis Geldern in den Reichsgründungsjahren und während des Kulturkampfes. Diss.

Münster 1990

${ }^{20}$ Heemann, Annegret: Männergesangvereine im 19. und frühen 20. Jahrhundert. Ein Beitrag zur städtischen Musikgeschichte Münsters. (Europäische Hochschulschriften: Reihe 36,

Musikwissenschaft, Band 74) Frankfurt am Main, Bern, New York, Paris 1992 (Zugl.:

Dissertation, Münster (Westfalen) 1991) 
Diese Aufzählung verschiedener Forschungsarbeiten zum Themenkomplex "Verein" erhebt keineswegs den Anspruch auf Vollständigkeit, doch belegen schon diese Studien exemplarisch die Vielfalt, wie sich Wissenschaftler dieses Forschungsgegenstandes annehmen können. Während Braatz sich methodisch in die Tradition eines eher volkskundlich orientierten Ansatzes stellte, bedienen sich die anderen Forscher eher einer soziologisch-historischen Fragestellung. Die jeweiligen Unterschiede bezüglich des Untersuchungszeitraumes und des Forschungsgegenstandes im engeren Sinne beruhen auf verschiedenen, individuell unterschiedlichen historischen, sozioökonomischen und politischen Gegebenheiten und Strukturen in den untersuchten Städten und Gebieten. Auch der erhaltene Bestand an historisch aussagefähigen Dokumenten und Archivalien kann eine Ausweitung oder Einengung der Untersuchungsgegenstände in den gezeigten Dimensionen determiniert haben.

Neben diesen regionalen Einzelstudien finden sich in der neueren Forschung verschiedene Arbeiten, die sich überregional mit einem einzelnen Vereinstypus beschäftigen, stellvertretend für viele andere sei hier auf die Arbeiten Thomas Rohkrämers über die Kriegervereine ${ }^{21}$ und Gunnar Stollbergs über die Naturheilvereine ${ }^{22}$ verwiesen. Diese beiden letztzitierten stellen neben anderen Arbeiten $\mathrm{zu}$ anderen Vereinstypen mitunter die einzigen neueren Forschungsergebnisse auf ihrem Gebiet dar; in einigen Kapiteln der vorliegenden Arbeit muss deshalb nahezu ausschließlich auf solche einzelne Standardveröffentlichungen Bezug genommen werden.

Ferner gibt es Arbeiten, die sich mit der Geschichte einzelner Großvereine, insbesondere prominenter Fußballvereine, über einen langen Zeitraum befassen, so beispielsweise die Untersuchungen Dietrich Schulze-Marmelings und Werner Steffens über den BV Borussia Dortmund ${ }^{23}$ oder René Martens' über den FC St. Pauli 24.

Zusammenfassend ist zu sagen, dass sich die wissenschaftliche historische Vereinsforschung bezüglich sowohl der Methodik als auch der thematischen, räumlichen und zeitlichen Eingrenzung der einzelnen Arbeiten äußerst uneinheitlich darstellt.

\footnotetext{
${ }^{21}$ Rohkrämer, Thomas: Der Militarismus der "kleinen Leute". Die Kriegervereine im Deutschen Kaiserreich 1871 - 1914. (Beiträge zur Militärgeschichte, Band 29) München 1990 ${ }^{22}$ Stollberg, Gunnar: Die Naturheilvereine im Deutschen Kaiserreich. in: Archiv für Sozialgeschichte, Band 28 (1988), SS. 287 - 305

${ }^{2}{ }^{3}$ Schulze-Marmeling, Dietrich; Steffen, Werner: Borussia Dortmund. Der Ruhm, der Traum und das Geld. Göttingen 1994

${ }^{24}$ Martens, René: FC St. Pauli. You'll never walk alone. Göttingen 1997
} 
Vielfach kommt es zu Berührungen und Überschneidungen mit den Methoden benachbarter oder komplementärer wissenschaftlicher Disziplinen wie der Volkskunde (Kulturanthropologie) oder der Soziologie, wie auch zu einem Miteinander der verschiedenen historischen Unterdisziplinen wie der Sozial-, der Wirtschafts-, der Alltags- und der Sportgeschichte, das es erst ermöglicht, ein differenziertes Bild historischer Vereinsentwicklung zu entwickeln.

Vorerst festzuhalten ist allerdings, dass es in der wissenschaftlichen Vereinsforschung, zumal in der historischen, keinen allgemein akzeptierten Forschungsansatz gibt, der dem Forscher ein verbindliches methodisches Instrumentarium oder einen von einem wissenschaftlichen Konsensus getragenen Fragenkatalog an die Hand gibt, welche Vorgehensweise oder Aufbau einer Arbeit zur Vereinsforschung determinieren. 


\section{1. Zur Methodik und Fragestellung der vorliegenden Arbeit.}

\section{1. 2. 1. Vereine im Sinne der vorliegenden Untersuchung}

Die vorliegende Arbeit soll, in Anlehnung an den oben skizzierten Weberschen / Nipperdeyschen Ansatz, eine regionale Studie zum Vereinsleben einer Kreisstadt in der preußischen Provinz Hannover von der Gründung des Kaiserreiches bis zum Beginn des Ersten Weltkrieges sein.

Während Untersuchungsgebiet und -zeitraum relativ eng eingegrenzt sind, liegt der vorliegenden Untersuchung ein sehr weit gefasster Vereinsbegriff zu Grunde. Eine weithin anerkannten These besagt, dass das entstehende und sich entwickelnde Vereinswesen eine Reaktion auf die Erosion einer vorindustriellen sozialen Binnenstruktur war. An die Stelle der alten sozialen Subsysteme, der Korporationen, denen der einzelne durch Geburt oder seines Berufsstandes wegen angehörte, trat als neues Phänomen der Verein. Die Gesamtheit der Vereine stellte eine zunehmend weit reichende gesellschaftliche Zwischensphäre zwischen dem durch die Erosion der Korporationen vereinzelten Menschen und der Gesamtgesellschaft dar. Eben dieses Phänomen einer umfassenden Gesamtheit sozialer Subsysteme bildet den Hintergrund des eingangs zitierten Appells Max Webers. Wenn Weber auf die Notwendigkeit hinweist, die Vereine, so unterschiedlich sie sich auch auf den ersten Blick darstellen mögen, als eine Gesamtheit zu begreifen und zu untersuchen, so weist er implizit auf deren Gemeinsamkeit hin. Was alle Vereine über ihre durchaus verschiedenen Vereinszwecke hinweg eint, sind wenige fundamentale Strukturprinzipien.

Einen für eine oben skizzierte historische Betrachtung fruchtbaren, recht weit gefassten Definitionsansatz für den Begriff "Verein", welcher der vorliegenden Arbeit zu Grunde liegen wird, stellte Hans-Friedrich Foltin vor. Foltin definiert den Verein als freiwilligen Zusammenschluss von mehreren Menschen. Dieser Zusammenschluss wird von ihnen genutzt, um in ihrer Freizeit mindestens ein gemeinsames Ziel zu verfolgen. Dieses Ziel ist weder finanzieller noch anderweitig materieller Natur. Kennzeichnend für einen Verein sind persönliche Kontakte der Mitglieder untereinander und eine gewisse Regelmässigkeit der Organisation. ${ }^{25}$ Ein weiteres Kriterium für einen Verein im Sinne der vorliegenden Untersuchung stellt eine auf Dauer angelegte

\footnotetext{
${ }^{25}$ Vgl.: Foltin, Hans-Friedrich: Geschichte und Perspektiven der Vereinsforschung. in: Foltin, Hans-Friedrich; Kramer, Dieter (Hgg.): Hessische Blätter zur Volks- und Kulturforschung.

Giessen 1984, SS. 3 - 31, S. 8 und Hüskens, Lydia Marie: op. cit., S. 2
} 
Vereinszielsetzung dar. Dies gilt sowohl für das Bestehen der Organisation als solcher, als auch für die Vereinszugehörigkeit des einzelnen Mitgliedes.

Diese Begriffsdefinition subsumiert im Wesentlichen alle im oben angeführten Zitat Max Webers benannten und gedachten Vereine verschiedensten Typs. Gleichzeitig grenzt er den Untersuchungsgegenstand sowohl gegen reine Träger-, Unterstützungs- und Versicherungsvereine, als auch gegen den Organisationstypus der Verbände ab, wie sie Hans-Peter Ullmann auch für den Untersuchungszeitraum beschreibt. ${ }^{26}$ Diese Verbände, wie beispielsweise Handwerks-, Handels- oder Agrarverbände waren zwar auch freiwillige Zusammenschlüsse einzelner, doch dienten sie entweder zur beruflichen Weiterbildung ihrer Mitglieder oder zur politischen Durchsetzung der kollektiven Interessen der in ihnen Organisierten. $\mathrm{Zu}$ den Vereinigungen, welche die berufliche Qualifikation ihrer Mitglieder erhöhen sollten, gehörten auch die im Untersuchungszeitraum recht verbreiteten Stenographenvereine. Die Zwecke dieser Vereinigungen, die häufig die Bezeichnung "Verein" trugen, waren also zumindest mittelbar materieller Natur. Auch die im 19. und frühen 20. Jahrhundert vielerorts gegründeten Tierzuchtvereine verfolgten letztlich wirtschaftliche Ziele. Der materielle Charakter von Träger-27, Unterstützungs- und Versicherungsvereinen ist evident und bedarf keiner näheren Diskussion. ${ }^{28}$

Eine gewisse Unschärfe weist der oben skizzierte Definitionsansatz allerdings in der Frage auf, inwieweit gewerkschaftliche Vereine und die lokalen Organisationen der politischen Parteien, deren Struktur für den Untersuchungszeitraum noch nicht einheitlich durch landes- oder reichsweit geltende Organisationsstatuten der Parteien geregelt waren, unter den Vereinsbegriff zu fassen sind. ${ }^{29}$ Es scheint in diesem Falle sinnvoll, die rein berufsständisch organisierten gewerkschaftlichen Vereine, die allesamt auch

\footnotetext{
26 Ullmann, Hans-Peter: Interessenverbände in Deutschland. Frankfurt am Main 1988

${ }^{27}$ Gemeint sind solche Vereinigungen, die als einzigen oder wesentlichen Vereinszweck den Aufbau oder Betrieb irgendeiner Einrichtung, e. g. eines Krankenhauses, einer Sportstätte oder einer Ver- oder Entsorgungsinfrastruktur, haben.

${ }^{28}$ Ein Beispiel für diesen Vereinstyp stellt der zur Zeit der Erstellung der vorliegenden Arbeit noch bestehende "Versicherungsverein auf Gegenseitigkeit der Eigentümer von Spiegelscheiben in Einbeck" aus dem letzten Jahrzehnt des neunzehnten Jahrhunderts dar. Zu diesem Versicherungsverein vgl.: StAEin 065 - 33

${ }^{29}$ Zur Binnenorganisation der politischen Parteien vor dem Ersten Weltkrieg vgl.: Nipperdey, Thomas: Die Organisation der deutschen Parteien vor 1918. (Beiträge zur Geschichte des Parlamentarismus und der politischen Parteien, Bd. 18). Düsseldorf 1961
} 
Unterstützungskassen unterhielten, von der allgemeinen Betrachtung des Vereinslebens auszunehmen. Den Lokalorganisationen der Parteien wird hingegen ein so weit von unmittelbar pekuniären oder anderweitig materiellen Interessen entfernter Charakter beizumessen sein, dass es zulässig ist, diese örtlichen Partei- und Wahlvereine wie andere Vereine im Sinne der vorliegenden Untersuchung zu behandeln. Sinngemäß gilt dieses auch für allgemeine Vereinigungen von Arbeitern verschiedener Gewerke.

Ein wesentlicher Aspekt ist derjenige, dass das Vereinsleben in der Freizeit der Vereinsmitglieder stattfindet. Allein dieser Umstand macht es verständlich, dass Vereine überhaupt $\mathrm{zu}$ einem dauerhaften Massenphänomen werden konnten. Waren die frühen Vereinsgründungen des 17., 18. und frühen 19. Jahrhunderts ausschliesslich von solchen Bürgern getragen, die sich aufgrund ihres sozialen und ökonomischen Status für nichtberufliche Aktivitäten selbstbestimmt Zeit nehmen konnten, so brachte das Industriezeitalter für weitere Bevölkerungskreise geregelte Arbeitszeiten und damit auch geregelte Freizeit. Solch eine zu allen Jahreszeiten verlässliche Struktur der täglichen Abfolge von Arbeit und Freizeit stellt eine Grundbedingung für das Entstehen eines dauerhaften Vereinslebens dar. 30

\footnotetext{
${ }^{30}$ Vgl. für den Bereich des Sports: Güldenpfennig, Sven: Der politische Diskurs des Sports.

Zeitgeschichtliche Beobachtungen und theoretische Grundlagen. (Edition Sport \&

Wissenschaft Band 16) Aachen 1992, SS. 176 ff.
} 


\section{1. 2. Aufbau und Fragestellung der vorliegenden Arbeit}

Die vorliegende Arbeit gliedert sich in drei Hauptteile auf. Im weiteren Verlauf des ersten Teiles sollen die Quellenlage dargestellt und die Wahl des zu untersuchenden Zeitraums erläutert werden. Diesem wird sich eine kurze Darstellung der gesetzlichen Grundlagen von Vereinsgründungen und deren Entwickung im 19. und frühen zwanzigsten Jahrhundert anschließen. Den Abschluss der Einführung in die Gegenstände der vorliegenden Untersuchung wird eine kurze Darstellung der Entwicklung der Stadt Einbeck bis zum Beginn des Ersten Weltkrieges bilden.

Der zweite Hauptteil wird aus einer Betrachtung der einzelnen Vereine selbst bestehen. $\mathrm{Zu}$ diesem Zweck werden die Vereine, wo dies möglich ist, anhand ihrer Vereinszwecke $\mathrm{zu}$ verschiedenen Gruppen und eventuell Untergruppen zusammengefasst, e. g. die Turn- und Sportvereine zu einer Gruppe mit einer Untergruppe Fußballvereine, die Gesangvereine etc.. Der Behandlung der Vereine wird eine allgemeine thematische Einführung zum jeweiligen Vereinstyp vorangestellt, die es ermöglichen soll, die Forschungsergebnisse über Einbecks Vereine in einen allgemeineren historischen Kontext zu stellen und mit diesem in Beziehung zu setzen. Diese einführenden Worte mögen dem einschlägig Vorgebildeten mitunter etwas weitschweifig und trivial erscheinen, doch wurden sie im Interesse einer allgemeineren Verständlichkeit bewusst ausführlich gestaltet.

Die Betrachtung der zu Gruppen zusammengefassten Vereine wird in der Regel einzeln, Verein für Verein, erfolgen. Lässt sich ein Verein nicht sinnvoll mit anderen Vereinen zu einer Vereinsgruppe zusammenfassen, wie e. g. der Naturheilverein Einbeck, so wird er für sich mit einer allgemeinen Einleitung und einer einzelnen Betrachtung behandelt. Umgekehrt kann es, beispielsweise im Falle der Fußballvereine, auf Grund der Kürze ihrer Tätigkeit oder der schlechten Quellenlage sinnvoll erscheinen, verschiedene Vereine nicht einzeln, sondern als Gruppe zu behandeln. Auch in solchen Fällen wird jedoch nicht grundsätzlich von der oben skizzierten Vorgehensweise abgegangen.

Den Einzeluntersuchungen im zweiten Hauptteil wird jeweils ein Katalog von Leitfragen zu Grunde liegen. Einen ersten Komplex stellen die Fragen nach temporal und quantitativ belegbaren Fakten dar. So sollen für die einzelnen Vereine die wichtigsten Daten ihres Bestehens wie Vereinsgründung, Anschaffung einer Fahne, etwaige Diversifikation in verschiedene Abteilungen etc. ermittelt werden. Daneben sollen auch quantitative Daten wie Mitgliederzahl und -entwicklung sowie die wirtschaftliche Entwicklung des Vereins erhoben werden. 
Einen zweiten Fragenkomplex stellen die strukturellen Fragen dar. Hier sollen vor allem die Statuten und Satzungen, dies sind häufig die einzigen Quellen über die innere Ordnung der jeweiligen Vereine, auf auffällige Bestimmungen untersucht werden. ${ }^{31}$ Anhand der Dauerhaftigkeit der Statuten soll, wie auch anhand von Ergebnissen über Mitgliederfluktuation und Amtsdauer von Funktionären versucht werden, Aussagen über die organisatorische Festigkeit und Dauerhaftigkeit der Vereine zu treffen.

Eine wesentliche Frage bei der Untersuchung der verschiedenen Vereine wird die klassische sozialhistorische Frage nach der sozialen Zusammensetzung der Vereine sein.

Ein weiterer Fragenkomplex ist eher alltagshistorischer oder volkskundlicher Natur. Durch die Auswertung verschiedener Quellen, neben Textquellen auch historischer Photographien und Realien, soll versucht werden, die Aktivitäten der Vereine, und, wo dies möglich ist, auch deren Selbstdarstellung zu rekonstruieren.

In einem weiteren Komplex von Leitfragen soll dem oben angedeuteten Charakter der Vereine als gesellschaftliche Subsysteme Rechnung getragen werden. Es soll untersucht werden, wie sich das Verhältnis des jeweiligen Vereins $\mathrm{zu}$ anderen sozialen oder politischen Gruppen, seien dies andere Vereine, kommunalpolitische oder polizeiliche Organe oder umfassendere Gruppen wie die Stadtgemeinde, darstellte.

Schon die Form, in der diese Leitfragen und -gedanken vorgestellt werden, soll andeuten, dass es sich bei ihnen nicht um einen feststehenden Katalog handelt, der, Verein für Verein, systematisch, in einer festen Reihenfolge und vollständig abgearbeitet werden wird. Ein solches Vorhaben wäre schon der überaus heterogenen Quellenlage wegen nicht durchzuführen; in zahlreichen Fällen werden die Quellen nicht Antwort auf alle genannten Leitfragen geben können. Vielmehr handelt es sich bei den oben umrissenen Leitfragen und gedanken um einen weit gefassten Hintergrund an Fragemöglichkeiten vom Standpunkt verschiedener historischer Teil-, Nachbar- und Komplementärdisziplinen, vor dem die Behandlung der einzelnen Vereine und Vereinsgruppen in narrativ-interpretatorischer Art und Weise unternommen werden soll.

\footnotetext{
${ }^{31}$ Vielfach gab es weit gehende Kongruenzen der verschiedenen Vereinsstatuten; es erscheint daher sinnvoll, im gedachten zweiten Hauptteil eher die Ausnahmen von der Regel zu thematisieren, die Regel selbst aber in der für den dritten Hauptteil vorgesehenen Gesamtschau darzustellen.
} 
Im Schlussteil dieser Arbeit wird dann der Versuch unternommen werden, unter verschiedenen Gesichtspunkten ein differenziertes Gesamtbild der Vereine und des Vereinslebens der Stadt Einbeck im Kaiserreich zu entwickeln und grundlegende Aspekte und Tendenzen der Entwicklung des Einbecker Vereinslebens vor dem Ersten Weltkrieg aufzuzeigen.

Neben den grundsätzlichen Forschungsgesichtspunkten, die auf eine zeitliche und quantitative Darstellung des Einbecker Vereinswesens hinzielen, steht die allgemeine Frage nach Gemeinsamkeiten und Besonderheiten der Vereine in struktureller Hinsicht.

Darüber hinaus soll die Rolle der Vereine in der Durchbruchsphase der modernen industriellen Gesellschaft ${ }^{32}$, beleuchtet werden. Dieser Umbruch hat sich in Einbeck zweifelsohne im Wesentlichen im Untersuchungszeitraum vollzogen.

32 Jürgen Kocka, der die Formierung sozial kohärenter Gruppen im Zuge der Industrialisierung für die Arbeiterschaft untersucht hat, spricht vom "Klassenbildungsprozess". Kocka weist ausdrücklich darauf hin, dass die Formierung kohärenter Gruppen durch eine Angleichung von Lebensstilen und Denkgewohnheiten geprägt ist. Vgl.: Kocka, Jürgen: Lohnarbeit und Klassenbildung. Arbeiter und Arbeiterbewegung in Deutschland 1800 - 1875. Berlin, Bonn 1983, SS. 23 ff. et passim. Ein gemeinsames Vereinslebens dürfte sowohl zu einer solchen Angleichung beigetragen haben, wie es auch als gewisser Indikator für eine bereits erfolgte Angleichung angesehen werden kann. 


\section{2. Die Quellenlage}

Die vorliegende Arbeit stützt sich auf eine Vielzahl von zeitgenössischen Quellen. Insbesondere die Bestände des Stadtarchivs Einbeck erwiesen sich für dieses Forschungsvorhaben als äußerst ergiebig; die Akten von Magistrat und Polizeiverwaltung, die für die Konzessionierung und Überwachung des Vereinswesens zuständig waren, haben die beiden Kriege, zumindest, was die für diese Arbeit aufschlussreichen Unterlagen anbetrifft, unbeschadet überstanden, so dass neben den Vereinsstatuten und zahlreichen Mitgliederverzeichnissen auch Schriftwechsel zwischen den Vereinen und den Behörden sowie, insbesondere bei den politischen Vereinen, auch Polizeiberichte und Briefwechsel mit den übergeordneten Behörden sich fanden. Allein der Aktenbestand über die Feuerwehr ist weitgehend abgängig.

Auch findet sich im Stadtarchiv Einbeck ein umfangreicher Bestand an lokalen Zeitungen aus dem Untersuchungszeitraum, doch erwiesen sich diese für die Arbeit an der vorliegenden Untersuchung als wenig hilfreich, da die Berichterstattung über Vereinsaktivitäten aller Art eher die Ausnahme als die Regel darstellte. Eine Stichprobenuntersuchung einzelner Jahrgänge hatte zum Ergebnis, dass die Einbecker Zeitungen allenfalls bedingt als Quellen für die Untersuchung herangezogen werden können.

Neben diesen Beständen verfügt das Einbecker Stadtarchiv auch über eine umfangreiche Sammlung von historischen Photographien, die mitunter die einzigen Zeugnisse von im übrigen nicht überlieferten Vereinen darstellen, aber auch Kenntnisse über bekannte und in den Akten dokumentierte Vereine erweitern und vertiefen konnten.

Eine wichtige sozialhistorische Quelle stellt ein Bestand verschiedener Adressbücher für die Stadt Einbeck dar, der sich, beginnend mit dem Adressbuch aus dem Jahre 1881 bis zu einem solchen aus dem Juli 1912, ebenfalls im Stadtarchiv befindet.

Das Archiv des Landkreises Einbeck, welches möglicherweise einigen Aufschluss über die Aktivitäten Einbecker Vereine im Umland der Stadt hätte geben können, steht bedauerlicherweise der Forschung nicht mehr zur Verfügung. Wie in Erfahrung zu bringen war, ist das Kreisarchiv im Umfeld der Neuorganisation der Verwaltungsstrukturen und der damit verbundenen Auflösung des Landkreises Einbeck im Jahre 1974 verloren gegangen.

Weitere ergiebige Quellen stellen die Unterlagensammlungen der noch existierenden Vereine dar. So haben sich beispielweise sämtliche Monatsprotokolle des Sportvereins "Eintracht" aus dem Untersuchungszeitraum erhalten, ebenso alle Protokolle der jährlichen 
Jahreshauptversammlungen des Turn-Clubs Einbeck, in dessen Besitz sich auch überraschenderweise zahlreiche Unterlagen des seit der Zeit des Nationalsozialismus nicht mehr bestehenden Männerturnvereins Einbeck fanden.

Auch der letzte noch bestehende Gesangverein aus jener Zeit, der Männergesangverein "Harmonie", besitzt noch zahlreiche Archivalien aus dem vorletzten Jahrhundert.

Ebenso verfügt der Einbecker Schützenverein noch über ein Protokollbuch, welches von seiner Gründung im Jahre 1862 über den Untersuchungszeitraum hinaus verschiedene Protokolle und Statuten enthält.

All diese Primärquellen wurden mir von den jeweiligen Besitzern freundlicherweise zugänglich gemacht.

Neben den zeitgenössischen Quellen wurden auch verschiedene Festschriften zu Vereinsjubiläen für die vorliegenden Arbeit herangezogen; während sich hiervon nur wenige im Stadtarchiv befinden, machte mir ein privater Sammler großzügigerweise seine Sammlung zugänglich.

Unterlagen über nicht mehr bestehende Vereine allerdings sind, soweit sie sich nicht im Stadtarchiv Einbeck befinden, bis auf die oben erwähnte Ausnahme, vollständig verloren gegangen; diese Lücken sind bedauerlicherweise nicht mehr zu schliessen. 


\section{3. Zur Wahl des Untersuchungszeitraumes}

Als Untersuchungszeitraum für die vorliegende Arbeit wurde die Periode von 1871 bis 1914, also vom Beginn des Deutschen Kaiserreiches bis zum Ausbruch jenes Krieges, der später als Erster Weltkrieg in die Geschichte eingehen sollte, gewählt.

Als Beginn der zu betrachtenden zeitlichen Spanne wäre auch das Jahr 1866, in dem das Königreich Hannover, und mit ihm auch Einbeck, von Preußen annektiert wurde, durchaus denkbar und plausibel. Horst Hülse lässt beispielsweise das einschlägige Kapitel "Einbeck in der Gründerzeit" in der Gesamtdarstellung zur Geschichte der Stadt in eben diesem Jahre beginnen ${ }^{33}$, wie auch Gordon Alexander Craig seine Gesamtdarstellung der Geschichte Deutschlands ${ }^{34}$. Auch Thomas Nipperdey teilt seine Betrachtungen über die Deutsche Geschichte von 1800 bis 1918 in die Zeit vor und die Zeit nach 1866 ein. ${ }^{35}$ Jedoch stellt sich der Übergang vom Königreich Hannover zum Königreich Preußen in wirtschaftlicher und sozialer Hinsicht nicht als ein so wesentlicher Einschnitt dar, der den Beginn des Untersuchungszeitraumes gleichsam erzwänge; es ist daher legitim, abweichend von der Periodisierung der oben genannten Autoren sich die Zeiteinteilung, derer sich beispielsweise Reinhard Rürup oder Hans-Ulrich Wehler bedienen, wenn sie ihre Untersuchungen mit dem Jahr 1871 beginnen lassen ${ }^{36}$, zu eigen zu machen.

Für das Ende des Untersuchungszeitraumes gilt Ähnliches: Der Titel legte es eigentlich nahe, das Vereinsleben in der Stadt Einbeck bis zum tatsächlichen Ende des Kaiserreiches, dem Kriegsende des Jahres 1918 zu untersuchen. Jedoch stellen moderne Kriege in sozialgeschichtlicher nicht minder als

\footnotetext{
${ }^{33}$ Hülse, Horst: Einbeck in der Gründerzeit (1866 - 1918). in: Einbecker Geschichtsverein (Hg.): Geschichte der Stadt Einbeck. Band 2: Vom Ende des 18. Jahrhunderts bis zum Ende des Zweiten Weltkrieges. Einbeck 1992, SS. 71 - 138

${ }^{34}$ Craig, Gordon A[lexander]: Deutsche Geschichte 1866 - 1945. Vom Norddeutschen Bund bis zum Ende des Dritten Reiches. München 1980.
}

${ }^{35}$ Nipperdey, Thomas: Deutsche Geschichte 1866 - 1918. Erster Band: Arbeitswelt und Bürgergeist. Sonderdruck, München 1998. ders.: Deutsche Geschichte 1866 - 1918. Zweiter Band: Machtstaat vor der Demokratie. München 1992. ders.: Deutsche Geschichte 1806 1866. Bürgerwelt und starker Staat. München 1983

${ }^{36}$ Rürup, Reinhard: Deutschland im 19. Jahrhundert 1815 - 1871. in: Rürup, Reinhard; Wehler, Hans-Ulrich; Schulz, Gerhard: Deutsche Geschichte. Sonderausgabe. Band 3: 19. und 20. Jahrhundert. Göttingen 1985, SS. 1 - 200; Wehler, Hans-Ulrich: Das deutsche Kaiserreich 1871 - 1918. ibid., SS. 201 - 404 
beispielsweise in politik- oder wirtschaftsgeschichtlicher Hinsicht, Perioden dar, in denen Richtung und Dynamik historischer Prozesse unter gravierend veränderten Bedingungen einem starken Wandel unterliegen können. Es erscheint daher erforderlich, solchen "Sonderphasen" eingehende eigenständige Betrachtungen zu widmen. 37

Daher beschränkt sich die vorliegende Untersuchung auf die Zeit zwischen jenen beiden Kriegen, die den Beginn und das Ende des Kaiserreiches markieren.

${ }^{37}$ Vgl.: Kocka, Jürgen: Klassengesellschaft im Krieg. Deutsche Sozialgeschichte 1914 - 1918. Neuauflage Frankfurt am Main 1988 


\section{4. Die rechtlichen Grundlagen des Vereinswesens im Kaiserreich}

Das Grundrecht auf Bildung von Vereinen oder Vereinigungen zählt nicht zum Kanon jener klassischen menschlichen Grundrechte, wie sie in der zweiten Hälfte des achtzehnten Jahrhunderts formuliert wurden. ${ }^{38}$ In Deutschland erhielt die Vereinsfreiheit erstmals durch den $§ 162$ der Paulskirchenverfassung von 1849 den Rang eines schriftlich kodifizierten Grundrechtes ${ }^{39}$, den sie auch in späteren deutschen Verfassungen erhalten sollte. Der erste Satz des $\S$ 162 der Paulskirchenverfassung findet sich im wesentlichen unverändert in Artikel 124 der Weimarer Verfassung und im Artikel 9 des Grundgesetzes für die Bundesrepublik Deutschland. Zwar wurde die in Frankfurt am Main proklamierte Verfassung bald außer Kraft gesetzt und die Entwicklung der Vereinsbewegung der Revolutionszeit gestoppt, doch auch nach dem Scheitern der Revolution ging die Vereinsfreiheit nicht völlig verloren. In Preußen wurde das Vereinsrecht durch das Gesetz vom 11. März 1850 geregelt. Es stellte die Gründung von Vereinen, welche sich nicht mit öffentlichen Angelegenheiten beschäftigen wollten, frei. Vereine, welche die Erörterung von öffentlichen Angelegenheiten beabsichtigten, unterlagen gegenüber der Polizeibehörde einer Meldepflicht, was Statut und Mitgliederverzeichnis anbelangte. Solche Vereine durften keine Frauen und Jugendliche aufnehmen. Außerdem durften sie sich nicht mit anderen Vereinen gleicher Zielsetzung durch gemeinsame übergeordnete Organisationen und Presseerzeugnisse verbinden; es bestand ein so genanntes Affiliationsverbot. In der Praxis wurde der Begriff "öffentliche Angelegenheiten" sehr weit ausgelegt, so dass eine Vielzahl von Vereinen unter die gesetzlichen Beschränkungen fiel. 40

Nach der Annexion Hannovers 1866 erlangte das preußische Vereinsgesetz vom 11. März 1850 auch in der neu entstandenen Provinz Hannover Gültigkeit.

\footnotetext{
${ }^{38}$ Weder in der amerikanischen "Bill of Rights", noch in der französischen "Déclaration des droits de l'homme et du citoyen" ist es zu finden. Vgl. hierzu: Baron, Josef: Das deutsche Vereinswesen und der Staat im 19. Jahrhundert. Jur. Diss., Göttingen 1962, S. 47

${ }^{39}$ Zwar weisen sowohl Baron als auch Hueber auf den $§ 28$ der Verfassung von Sachsen-

Meiningen vom 23. August 1829 hin, doch scheint Barons Relativierung stichhaltig, dass die Gewährung des allgemeinen Rechts auf Vereinigung in diesem Falle so stark eingeschränkt wurde, dass es nicht den Charakter eines Grundrechts trug. Vgl.: Hueber, Alfons: Das Vereinsrecht im Deutschland des 19. Jahrhunderts. in: Dann, Otto (Hg.): Vereinswesen und bürgerliche Gesellschaft in Deutschland (Historische Zeitschrift. Beihefte (Neue Folge), Beiheft 9). München 1984, SS. 115 - 132, SS. 117 f. und Baron, Josef: op. cit., S. 48 ${ }^{40}$ Vgl.: Baron, Josef: op. cit., SS. $61 \mathrm{f}$.
} 
Artikel 4 der Reichsverfassung von 1871 räumte zwar ausdrücklich die Möglichkeit ein, das private und öffentliche Vereinsrecht in Deutschland reichseinheitlich gesetzlich zu regeln. Doch von dieser Möglichkeit wurde zunächst kein Gebrauch gemacht. Alfons Hueber erblickt in diesem Umstand die Furcht des Gesetzgebers, unerwünschte politische Bewegungen auszulösen. ${ }^{41}$ So galten im Falle der Stadt Einbeck die preußischen Bestimmungen fort. 42

Die ersten reichsweiten Gesetze, welche auf der Grundlage der verfassungsmäßigen Gesetzgebungskompetenz über das Vereinswesen in Deutschland verabschiedet wurden, waren negativer Natur. Durch Reichsgesetz vom 4. Juli 1872 wurde der Orden der Gesellschaft Jesu verboten. Bekannter und folgenreicher als dieses erste negative Reichsvereinsgesetz war das Reichsgesetz vom 21. Oktober 1878 gegen die gemeingefährlichen Bestrebungen der Sozialdemokratie, das so genannte Sozialistengesetz. Dieses Gesetz, von dessen praktischer Umsetzung und letztlicher Wirkung im zweiten Hauptteil der vorliegenden Arbeit noch zu reden sein wird, verbot alle Vereine, "in welchen sozialdemokratische, sozialistische oder kommunistische auf den Umsturz der bestehenden Staats- und Gesellschaftsordnung gerichtete Bestrebungen in einer den öffentlichen Frieden, insbesondere die Eintracht der Bevölkerungsklassen gefährdenden Weise zu Tage treten" 43 und stellte die Beteiligung an solchen durch das Gesetz verbotenen Vereinen unter schwere Strafandrohung.

Die etwas vage Umschreibung der $\mathrm{zu}$ verbietenden Vereine und Vereinigungen gab den Polizeibehörden eine rechtliche Handhabe, alle Vereinigungen der sich formierenden sozialdemokratischen Arbeiterbewegung aufzulösen. Die praktische Umsetzung des Gesetzes war nach seinem Inkrafttreten, zumindest in Preußen ${ }^{4}$, rigoros und erstreckte sich, auch in

\footnotetext{
${ }^{41}$ Vgl.: Hueber, Alfons: op. cit., S. 130

${ }^{42}$ Neben dem zitierten Gesetz von 1850 waren dieses die unten erläuterten Allerhöchsten Kabinettsordres aus den vierziger Jahren, in welchen die Militärvereine bezüglich der Veranstaltung von Beerdigungen für ihre Mitglieder privilegiert waren. Diese Bestimmungen hatten über den gesamten Untersuchungszeitraum Gültigkeit. Vgl. hierzu das einschlägige Kapitel der vorliegenden Arbeit.

${ }^{43}$ Wörtliches Zitat aus Reichsgesetzblatt Nr. 34, Faksimiliert in: Döring, Dieter; Kempen, Otto Ernst (Hgg.): Sozialistengesetz, Arbeiterbewegung und Demokratie. Köln; Frankfurt am Main 1979, SS. $119 \mathrm{ff}$.

${ }^{44}$ Thomas Nipperdey schreibt, dass sie in anderen deutschen Staaten von jener in Preußen zumindest leicht abwich. Vgl.: Nipperdey, Thomas: Machtstaat vor der Demokratie, S. 399
} 
Einbeck, über unmittelbar politische und gewerkschaftliche Vereinigungen hinaus auch auf gesellige Vereine. Das Sozialistengesetz, ursprünglich bis zum 31. März 1881 befristet, wurde mehrfach verlängert und trat erst 1890 außer Kraft.

Die erste positive reichsweit geltende Gesetzesbestimmung über das Vereinsrecht war die Abschaffung des Affiliationsverbotes im Dezember 1899.45

Das mit Beginn des Jahres 1900 in Kraft getretene Bürgerliche Gesetzbuch (BGB) erlaubte den Vereinen, durch staatlich genehmigten Eintrag in die bei den zuständigen Amtsgerichten neu angelegten Vereinsregister die Rechtsfähigkeit zu erlangen. Die Eintragung ins Vereinsregister war jedoch keineswegs Pflicht. Eine Auswertung der einschlägigen Jahrgänge beim für die vorliegende Arbeit relevanten Amtsgericht Einbeck ergab den Befund, dass nur wenige Vereinigungen von dieser Möglichkeit Gebrauch machten und diese nach den oben aufgestellten Kriterien für Vereine im Sinne dieser Untersuchung eher den Interessenverbänden zuzuordnen sind. ${ }^{46}$ Für die meisten im Folgenden zu untersuchenden Vereine blieb die durch das BGB gegebene Möglichkeit der gerichtlichen Registrierung im Untersuchungszeitraum uninteressant.

Eine reichseinheitliche umfassende gesetzliche Regelung des Vereinswesens brachte erst das Reichsvereinsgesetz vom 19. April 1908. Durch die Einführung dieses Gesetzes entfielen viele der gesetzlichen Einschränkungen der Vereinigungsfreiheit. Nunmehr konnten auch Frauen und Jugendliche unter achtzehn Jahren Mitglieder in Vereinen werden. ${ }^{47}$ Vereine konnten nur noch dann aufgelöst werden, wenn Vereinszwecke oder -aktivitäten den Strafgesetzen zuwiderliefen. Eine etwaige staatlich angeordnete Auflösung konnte in einem Verwaltungsgerichtsverfahren angefochten werden. ${ }^{48}$ Durch das Reichsvereinsgesetz von 1908 wurden die Beschränkungen, die bis dahin für politische Vereine gegolten hatten, deutlich verringert. Dennoch unterlagen die politischen Vereine auch nach Inkrafttreten des Gesetzes in stärkerem Maße als andere Vereine einer behördlichen Kontrolle. Sie mussten ihre

\footnotetext{
${ }^{45}$ Vgl.: Hueber, Alfons: op. cit., S. 130 und Baron, Josef: op. cit., S. 65

${ }^{46}$ So fallen beispielsweise die im Vereinsregister eingetragenen Vereinigungen "Ärzteverein des Kreises Einbeck", "Rabatt- und Sparverein Einbeck" und "Verein zur Zucht des schweren Hannoverschen Pferdes mit Sitz in Einbeck" nicht unter die dieser Arbeit zu Grunde liegenden Vereinsdefinition.

${ }^{47}$ Vgl.: Hueber, Alfons: op. cit., S. 131

${ }^{48}$ Vgl.: Hueber, Alfons: op. cit., S. 131
} 
Statuten und ein Verzeichnis der Vereinsmitglieder und des Vorstandes bei der zuständigen Ortspolizeibehörde einreichen, auch Änderungen statutarischer und personeller Dinge mussten den Behörden zur Kenntnis gebracht werden. 49 Auch blieben Jugendliche und Frauen von den Versammlungen politischer Vereine weiterhin ausgeschlossen.

Darüber hinaus wurden in Preußen nach Inkrafttreten des Reichsvereinsgesetzes von 1908 die örtlichen Polizeibehörden vom preussischen Innenministerium ausdrücklich darauf hingewiesen, dass die Veranstaltungen der politischen Vereine nach wie vor $\mathrm{zu}$ überwachen und gegebenenfalls aufzulösen seien 50 . Ferner erging erst drei Jahre später die Anweisung, die genannten Überwachungen sollten Vereine aller politischen Strömungen betreffen und es seien polizeiliche "Schikanen" zu vermeiden. 51

Nimmt man zusätzlich noch den Umstand zur Kenntnis, dass der Begriff des "politischen Vereins" von den Behörden wie von der Justiz recht weit ausgelegt wurde - beispielsweise wurde auch nach 1908 an der juristischen Praxis festgehalten, Mitgliedsvereine des Arbeiter-Turner-Bundes allein auf Grund dieser Mitgliedschaft als politische Vereine zu klassifizieren und sie den entsprechenden Bestimmungen zu unterwerfen ${ }^{52}$ - so ist die Aussage Alfons Huebers, dass im Reichsvereinsgesetz von 1908 die Tradition der Benachteiligung der politischen Verein kaum mehr zu erkennen sei ${ }^{53}$, deutlich zu relativieren.

\footnotetext{
${ }^{49}$ Vgl.: Baron, Josef. op. cit., S. 65

${ }^{50} \mathrm{Vgl}$.: StAEin 06 - 8, 5. Oktober 1908 et passim

${ }^{51}$ Vgl.: StAEin 065 - 8, 6. November 1911

${ }^{52}$ Vgl.: StAEin 065 - 8, Anlagen zu 12. Juli 1911 und 22. Oktober 1913

${ }^{5} \mathrm{Vgl}$.: Hueber, Alfons: op. cit., S. 131
} 


\section{5. Zur Entwicklung der Stadt Einbeck bis zum Beginn des Ersten Weltkrieges}

Die Stadt Einbeck war im Mittelalter eine bedeutende und wohlhabende Hansestadt. Ihren Wohlstand verdankte sie in erster Linie der Produktion und dem Export von Bier. Doch ab der frühen Neuzeit setzte ein rapider Niedergang der Stadt und ihrer Wirtschaft ein, von dem sie sich über eine lange Zeit nicht erholen konnte: Noch im Jahre 1808 sagte der Einbecker Bürgermeister Ernst über seine Stadt, sie sei "im ganzen ein ärmlicher Ort".54 Und in einem 1820 erschienenen Bericht nannte der schottische Reisende Thomas Hodgskin Einbeck "a little dirty black town". 55

Im zweiten Viertel des 19. Jahrhunderts setzte dann jedoch eine Wachstumsentwicklung ein. Zunächst nahm die Textilbranche einen Aufschwung. Die bereits 1710 als "fabrique" gegründete, aber seit dem Siebenjährigen Krieg nur als Färberei geführte Wollspinnerei und -weberei Kayser nahm 1832 ihren Betrieb wieder auf, ab 1843 entwickelte sich die Jarandsche Roßhaarspinnerei, ab 1848 die Gurt- und Bandweberei Oppermann. Die Rolle, die die Textilbranche in Einbecks Wirtschaft spielte, kann daran ersehen werden, dass 1861 eine Webschule begründet wurde. Diese Webschule war die Vorläuferin der Höheren Preußischen Fachschule für Textiltechnik, die von 1888 bis 1903 in Einbeck bestand. Neben der Textilindustrie entwickelten sich auch andere Gewerbezweige in der Stadt, so die tabakverarbeitende Industrie ${ }^{56}$, und ab 1839 die Tapetenindustrie mit ihren Hilfshandwerken. 57 Im Jahre 1857 wurde in Einbeck die erste Zuckerfabrik in Hannover gegründet, 1865 kam eine Ziegelei mit Dachpappenfabrik hinzu. ${ }^{58}$ Ab 1846 braute eine

\footnotetext{
${ }^{54}$ Vgl:: Mittendorf, Hans-Norbert: Einbecker Geschichte vom Ende des 18. Jahrhunderts bis zur Annexion des Königreichs Hannover durch Preußen. in: Einbecker Geschichtsverein (Hg.): Geschichte der Stadt Einbeck. Band 2: Vom Ende des 18. Jahrhunderts bis zum Ende des zweiten Weltkrieges. Einbeck 1992, SS. 7 - 70, SS. 13 ff.

${ }^{55}$ Zitiert nach Schubert, Ernst: Der Zustand des Landes um 1820. in.: Hucker, Bernd Ulrich u.

a. (Hgg.)Niedersächsische Geschichte. Göttingen 1997, SS. 337 - 349, S. 345

56 Vgl.: Koch, Eberhard: Geschichte der SPD in Einbeck und Uslar. Von den Anfängen bis zum Wiederaufbau der lokalen Organisationen nach 1945. Eine vergleichende Studie.

Examensarbeit, ungedruckt. Göttingen 1976, S. 4

57Vgl.: Meyer, Erich: Biedermeier und Revolution. Die Zeit von 1813 bis 1850 im Spiegel des Einbeckschen Wochenblattes. 2 Halbbände (Schriftenreihe zur Geschichte der Stadt Einbeck, Band 3) Einbeck 1982, SS 15 f.

${ }^{58}$ Vgl.: Mittendorf, Hans-Norbert: op. cit., SS. 41 ff.
} 
neue, unter städtischer Regie stehende Brauerei, an deren Seite im Jahre 1873 die private Brauerei Domeier und Boden trat. ${ }^{59}$ Erstmals seit über 200 Jahren wurde in Einbeck wieder Bier für den Export gebraut. 60

Diese frühe Phase der gewerblichen Expansion war allerdings noch keineswegs der Durchbruch der Industrialisierung in Einbeck. Die oben genannten Firmen waren zwar die Keimzellen späterer Industriebetriebe, doch bis in den Untersuchungszeitraum hinein dürfte noch die handwerkliche Produktion, wenn auch als Serienfertigung für einen über die Stadt hinausreichenden Markt ${ }^{61}$, dominiert haben. Im Jahre 1866 zählte man in der Stadt lediglich zwei Dampfmaschinen. In diesem Jahr wurde Einbeck durch die Annexion des Königreichs Hannover preußisch. In der Folgezeit entwickelte sich das lokale Gewebe deutlich in Richtung einer industriellen Struktur. Doch diese Entwicklung ist nicht als Folge der nunmehrigen Zugehörigkeit zu Preußen zu deuten. Ernst Schubert charakterisiert den um diese Zeit in weiten Teilen der Provinz stattgefundenen Durchbruch der industriellen Produktionsweise als einen "auf Vorgaben der Vergangenheit beruhenden selbsttragenden Prozeß, zu dem dem die preußische Verwaltung [...] nicht viel beitrug.". 62

1873 gab es in Einbeck bereits vierzehn stationäre Dampf- und zwei Gaskraftmaschinen. ${ }^{63} \mathrm{Im}$ Kaiserreich setzte sich die wirtschaftliche Entwicklung fort, neben Unternehmensexpansionen und -neugründungen in den oben genannten Branchen trat ein Unternehmen neuen Typs: Aus einer kleinen 1890 gegründeten Fahrradhandlung entwickelte sich die Firma August Stukenbrok zu einem der größten Versandhäuser Deutschlands.

${ }^{59}$ Vgl.: Aumann, Stefan: ...und wird gar weit geführet.Die Geschichte des Einbecker Bieres. (Studien zur Einbecker Geschichte; Bd. 14). Oldenburg 1998, SS. 93 f.

${ }^{60} \mathrm{Vgl}$.: Burschel, Peter: Erstarrung und Wandel. Einbeck 1600 - 1750. in: Einbecker Geschichtsverein (Hg.): Geschichte der Stadt Einbeck. Band 1.Von den Anfängen bis zum Ende des 18. Jahrhunderts. Einbeck 1990, SS. 191 - 202, S. 200

${ }^{61}$ Spörer, Claus: Einbeck im Jahre 1853. Bürgerliches Leben am Vorabend der Industrialisierung. Die Königliche Familie in Rotenkirchen. Ein Zeitbild. Aus dem Jahrgang 1853 des "Einbeckschen Wochenblattes" zusammengestellt und eingeleitet von C. S..

(Schriftenreihe zur Geschichte der Stadt Einbeck, Band 2) Einbeck 1980, S, 27

${ }^{62}$ Schubert, Ernst: Niedersachsen um 1900. in: Hucker, Bernd Ulrich u. a. (Hgg.)Niedersächsische Geschichte. Göttingen 1997, SS. 480 - 493, S. 488

${ }^{63}$ Vgl.: Hülse, Horst: Einbeck in der Gründerzeit. in: Einbecker Geschichtsverein (Hg.): Geschichte der Stadt Einbeck. Band 2: Vom Ende des 18. Jahrhunderts bis zum Ende des zweiten Weltkrieges. Einbeck 1992, SS. 71 - 138, S. 91 
Analog zu der wirtschaftlichen Entwicklung Einbecks wuchs auch die Zahl der Einwohner, wie die folgenden Tabellen zeigen.

Bevölkerungsentwicklung der Stadt Einbeck von der Mitte des 19. Jahrhunderts bis zum Ersten Weltkrieg 64

\begin{tabular}{llll} 
Jahr & Einwohner & \multicolumn{2}{c}{ Veränderung } \\
& & absolut & relativ \\
1845 & 5195 & +248 & $+4,8 \mathrm{v} . \mathrm{H}$. \\
1848 & 5443 & +214 & $+3,9 \mathrm{v} . \mathrm{H}$. \\
1858 & 5657 & +175 & $+3,1 \mathrm{v} . \mathrm{H}$. \\
1865 & 5832 & +358 & $+6,1 \mathrm{v} . \mathrm{H}$. \\
1871 & 6190 & +901 & $+14,6 \mathrm{v} . \mathrm{H}$. \\
1885 & 7091 & -25 & $-0,4 \mathrm{v} . \mathrm{H}$. \\
1890 & 7066 & +848 & $+12,0 \mathrm{v} . \mathrm{H}$. \\
1905 & 7914 & +795 & $+10,0 \mathrm{v} . \mathrm{H}$. \\
1910 & 8709 & +722 & $+8,3 \mathrm{v} . \mathrm{H}$.
\end{tabular}

Auch wenn die Bevölkerungsentwicklung nicht mit der wirtschaftlichen Entwicklung in direktem Verhältnis stehen muss, so kann die Bevölkerungsentwicklung freilich Tendenzen in der Dynamik der Entwicklung einer Stadt aufzeigen. Dies gilt insbesondere, wenn die zeitlichen Abstände der miteinander zu vergleichenden Daten wie im vorliegenden Falle relativ gering sind.

Durchschnittliche jährliche Bevölkerungszunahme ${ }^{65}$

$\begin{array}{lll}\text { Zeitraum } & \text { absolut } & \text { relativ } \\ 1845-1848 & +82,7 & +1,6 \mathrm{v} . \mathrm{H} . \mathrm{Pt} . \\ 1848-1858 & +21,4 & +0,4 \mathrm{v} . \mathrm{H} . \mathrm{Pt} . \\ 1858-1865 & +25,0 & +0,4 \mathrm{v} . \mathrm{H} . \mathrm{Pt} . \\ 1865-1871 & +59,7 & +1,0 \mathrm{v} . \mathrm{H} . \mathrm{Pt} . \\ 1871-1885 & +64,4 & +1,0 \mathrm{v} . \mathrm{H} . \mathrm{Pt} . \\ 1885-1890 & -5,0 & -0,1 \mathrm{v} . \mathrm{H} . \mathrm{Pt} .\end{array}$

\footnotetext{
${ }^{64}$ Berechnet nach: Wiese, Hartmut: Industrie und Stadtentwicklung ausgewählter Kleinstädte Südniedersachsens. -Alfeld, Einbeck und Northeim- (Forschungen zur niedersächsischen Landeskunde, Band 110) Göttingen, Hannover 1978 (zugl. Dissertation, Kiel 1978), Tab. 5 und Walter, Hubert: Bevölkerungsgeschichte der Stadt Einbeck. Hildesheim 1960,Tab. 2;

${ }^{65}$ Siehe Anmerkung 64
} 


$$
\begin{array}{lll}
1890-1905 & +56,5 & +0,8 \text { v. H. Pt. } \\
1905-1910 & +159,0 & +2,0 \text { v. H. Pt. } \\
1910-1913 & +240,1 & +2,8 \text { v. H. Pt. }
\end{array}
$$

Bemerkenswert an der vorstehenden Bevölkerungsstatistik erscheint, dass die Bevölkerungszahl der Stadt Einbeck erst um das Jahr 1880 jenen historischen Höchststand von 7000 Einwohnern erreichte, den sie vermutlich am Ausgang des Mittelalters im Jahre 1500 hatte. Bereits etwa vierzig Jahre früher hatte die städtische Siedlungsfläche erstmals die Grenzen der mittelalterlichen Stadtbefestigung überschritten, im Jahre 1843 wurde das erste Wohnhaus außerhalb der Wälle gebaut. ${ }^{66}$ In größerem Maße wuchs die Stadt allerdings erst $a b$ dem vierten Viertel des 19. Jahrhunderts über ihre alten Mauern und Wälle hinaus. 67

Im Untersuchungszeitraum war die Stadt Einbeck eine im Wachstum befindliche Kreisstadt im Süden der preußischen Provinz Hannover. Sie verfügte über die üblichen Verwaltungseinrichtungen. An Bildungseinrichtungen hatte die Stadt eine Volksschule, eine Bürgerschule (ab 1905 Mittelschule), eine Höhere Töchterschule, ein Realprogymnasium, das sich ab $1901 \mathrm{zu}$ einem Realgymnasium entwickelte, an dem ab 1904 Abiturprüfungen durchgeführt wurden und eine Gewerbeschule (Berufsschule). Ab 1880 kam zu diesen Einrichtungen eine Handelsschule. 1903 wurde die oben genannte Webeschule aufgelöst, in ihren Räumen wurde 1904 eine Haushaltungs- und Gewerbeschule für Mädchen eingerichtet. Eine Besonderheit im Bildungswesen Einbecks stellte das so genannte "Technikum" dar. Im Jahre 1871 zog die private Maschinenbauschule eines Dr. Kirchner von Hildesheim nach Einbeck um. Nachdem der Schulleiter sich bald nach seinem Eintreffen als Sozialdemokrat betätigte - worin wohl auch der Grund seines Weggangs von Hildesheim zu vermuten sein dürfte - forderten ihn die städtischen Kollegien auf, solches in Zukunft zu unterlassen. Da Kirchner dieser Aufforderung nicht folgte, richtete die Stadt zum Sommersemester 1874 ein Konkurrenzinstitut unter der Leitung eines abgeworbenen Mitarbeiters Kirchners ein. Nach diesem Semester verließ Kirchner mit seinen Studenten Einbeck und eröffnete ein neues Institut im thüringischen Langensalza. Die städtische Konkurrenzgründung hingegen blieb bestehen, ab 1900 wurde sie unter staatlicher Regie als "Königliche Maschinenbauschule" weitergeführt, bis sie 1907 mangels interessierter Studenten aufgegeben wurde.

\footnotetext{
${ }^{6}{ }^{\text {Vgl.: }}$ Meyer, Erich: op. cit., S. 6

${ }^{67}$ Vgl.: Hülse, Horst: op. cit., S. 85
} 
Ab 1892 gab es in Einbeck eine so genannte "Präparandenanstalt", eine Vorbereitungsschule für den späteren Besuch eines Lehrerseminars. Ein solches Lehrerseminar nahm seinen Betrieb 1909 auf. 68

Eine weitere Bildungseinrichtung war die 1899 eröffnete preußische Gendarmerieschule. Diese Einrichtung war in Einbeck angesiedelt worden, um den Verlust der 1896 aufgehobenen Garnison - in Einbeck war ab 1871 das Füsilier-Bataillon des 82. Infanterieregiments stationiert - zu kompensieren. 69

Ab 1879 war die Stadt durch eine Stichbahn an die Bahnstrecke HannoverGöttingen angebunden, und im Laufe des Untersuchungszeitraums unternahmen die städtischen Behörden zahlreiche Maßnahmen, die Infrastruktur der Stadt an die Erfordernisse des Industriezeitalters anzupassen.

Aus dem "little dirty black town" war hinsichtlich sowohl der wachsenden Wirtschaft als auch der Verwaltungs- und Bildungseinrichtungen ein sich dynamisch entwickelndes regionales Unterzentrum geworden.

${ }^{68}$ Zum gesamten Bildungswesen vgl.: Hülse, Horst: op. cit, SS. 122 ff.

${ }^{69}$ Vgl.: Hülse, Horst: op. cit., S. 91 


\section{6. Die Verwaltungsstruktur Einbecks im Kaiserreich 70}

Auch nach der Annexion Hannovers durch Preußen blieb in der nunmehrigen Provinz Hannover die bisherige revidierte hannoversche Städteordnung vom 24. Juni 1858 in Gültigkeit. 71 Nach dieser Städteordnung war Einbeck eine von mehreren selbständigen Städten der Provinz. Verwaltet wurde die Stadt durch den Magistrat als Stadtobrigkeit. Dieser setzte sich aus dem Bürgermeister, zwei Senatoren und bis 1893/94 einem Stadtsyndikus zusammen. Das Amt des Stadtsyndikus (Verwaltungsjuristen) wurde 1894 aufgehoben und mit dem Amt des Bürgermeisters vereinigt.

Prinzipiell wurden die Magistratsmitglieder auf Lebenszeit gewählt, sie konnten jedoch nach zwölf Jahren in den Ruhestand versetzt werden.

Sämtliche für die Verwaltung der Stadt notwendigen Verwaltungsbeamten wie Kämmerer und gegebenenfalls Stadtsekretär, Stadtförster und Registrator etc. und die anderen Dienstkräfte wie Feldhüter, Forstaufseher und dergleichen unterstanden direkt dem Magistrat.

Neben der Verwaltungsfunktion hatte der Magistrat auch die Polizeigewalt im Stadtgebiete inne, war also zugleich die städtische Polizeibehörde mit eigenen Polizeibeamten.

Die unmittelbar dem Magistrat vorgesetzte Verwaltungsbehörde war das Königliche Regierungspräsidium in Hildesheim, das bis zur Einführung des Preußischen Gesetzes über die allgemeine Landesverwaltung vom 30. Juli 1883 die alte hannoversche Bezeichnung Landdrostei trug.

Eine Verantwortlichkeit der städtischen Behörden gegenüber dem in Einbeck sitzenden Landrat gab es nicht.

\footnotetext{
${ }^{70}$ Zum gesamten folgenden Absatz, soweit die Aussagen sich auf generelle, die ganze Provinz Hannover betreffende Verwaltungsgrundsätze beziehen, vgl.: Tecklenburg, A[ugust];

Dageförde, K[arl]: Geschichte der Provinz Hannover für Lehrer, Lehrerbildungs- und andere Lehranstalten der Provinz sowie für Schul- und Volksbibliotheken. Hannover-List, Berlin 1906. SS. $186 \mathrm{ff}$.
}

Für speziellere, sich nur auf die Stadt Einbeck beziehende Aussagen, vgl.: Hülse,Horst: Gründerzeit, SS. 76 ff.

${ }^{71}$ Ebenso blieben andere Ordnungen des Königreichs Hannover über dessen Bestehen hinaus in Kraft, so die hannoversche Landgemeindeordnung, vgl.: Tecklenburg, August; Dageförde, Karl: op. cit., SS. 183 ff., und die innere Struktur der hannoverschen Landeskirche, vgl.: Jungmann, Wolf Bernd: Baugeschichte der Martinskirche in Markoldendorf. in: Einbecker Jahrbuch, Band 45 (1996), SS.97 - 132, SS. 99 f. 
Neben dem Magistrat als einem der beiden städtischen Kollegien bestand als ein zweites das Bürgervorsteherkollegium. Es vertrat als gewähltes Gremium die Stadtgemeinde gegenüber dem Magistrat. Das Bürgervorsteherkollegium bestand aus zwölf ehrenamtlichen, auf sechs Jahre gewählten Bürgervorstehern, die aus ihrer Mitte einen sogenannten Worthalter als primus inter pares wählten.

Das aktive und passive Wahlrecht zu diesem Kollegium war neben dem Mindestalter von fünfundzwanzig Jahren an das Bürgerrecht gebunden. Berechtigt zum Erwerb desselben waren alle in der Stadt wohnberechtigten unbescholtenen Einwohner. Sofern der das Bürgerrecht Anstrebende nicht Geistlicher, Lehrer oder Staatsbeamter war, mußte er ein sogenanntes Bürgergewinngeld an die Stadtkasse entrichten. Jeder, der Bürger werden wollte, musste vor dem Magistrat einen Bürgereid leisten, in dem er sich verpflichetete, die Bürgerpflichten übernehmen zu wollen.

Der Magistrat und das Bürgervorsteherkollegium bildeten zusammen die städtischen Kollegien, sie tagten häufig in gemeinsamer Sitzung und fassten gemeinschaftliche Beschlüsse. Ein Ausschuss aus den verbleibenden Magistratsmitgliedern und einer gleichen Anzahl von Bürgervorstehern führte auch etwa vorkommende Ergänzungswahlen zum Magistrat durch. 


\section{7. Einbecker Vereine vor dem Untersuchungszeitraum}

Die erste Nachricht über einen Verein in Einbeck findet sich in den Annalen der Braunschweig-Lüneburgischen Churlande aus dem Jahre 1788, in denen aus Einbeck über einen "hiesigen Clubb" berichtet wird, dieser habe für einen armen blinden Juden aus Kuventhal Geld gesammelt. Claus Spörer erblickt in ihm eine "Aufklärungsgesellschaft", in der sich gebildete Männer, Zivilisten wie Militärs im Gashof zum Kronprinzen zu Konversation und Spiel versammelt hätten, und der möglicherweise aus einer früheren Lesegesellschaft hervorgegangen sein könnte, ${ }^{72}$ doch bleibt alles, was über das pure Faktum der Existenz dieses Clubs hinausgeht, reine Spekulation.

Die erste belegte Gründung einer Lesegesellschaft in Einbeck fand im Jahre 1844 statt.

Ab dem Jahre 1796 gab es eine Freimaurervereinigung in Einbeck. Dies war eine so genannte Bauhütte, eine Vorform einer Freimauerloge. Diese wurde im Jahre 1797 mit dem Namen "Georg zu den drei Säulen" errichtet. ${ }^{73}$ Die Ausbreitung der Freimaurerei war ein Phänomen der zweiten Hälfte des 18. Jahrhunderts; um 1800 bestanden in Deutschland um die 300 Logen. Im Jahre 1798 umfasste die Loge 21 Mitglieder, allesamt aus dem gehobenen Bürgertum, von denen 11 in Einbeck lebten, weitere 9 in der näheren und ferneren Umgebung bis hin nach Hannoversch Münden. Ein Logenbruder lebte im nahezu 200 Kilometer entfernten Bremen. Im Jahre 1801 umfasste die Loge bereits 41 Mitglieder. 74

Eine erste Frühform einer Turnvereinsgründung stellte eine 1839 von einem Dr. jur. Eckels ins Leben gerufene Turngruppe dar, aus der laut Hans-Norbert Mittendorf ein Turnliederkranz hervorging, der die Keimzelle weiterer Gesangvereine gewesen sein soll. ${ }^{75}$ Dieser Turngruppe, deren

\footnotetext{
72 Vgl.: Spörer, Claus: Einbeck im späten 18. Jahrhundert (1765 - 1800). Lebensformen und Lebensumstände der Bürger einer südhannoverschen Landstadt im Zeitalter der Aufklärung und der Französischen Revolution. Ein Beitrag zur Kulturgeschichte des Alltags. 2 Teilbände. (Studien zur Einbecker Geschichte Geschichte, Band 11) Einbeck; Oldenburg 1997, SS. 95 ff. ;343

73Vgl.: Festschrift 200 Jahre Freimaurerloge "Georg zu den drei Säulen" 1797 - 1997, Einbeck 1997, S. 24 f.

${ }^{74}$ Vgl.: Spörer, Claus: Spätes 18. Jahrhundert, S. 98

${ }^{75}$ Vgl.: Mittendorf, Hans-Norbert: op. cit., S. 64
} 
Vereinscharakter fraglich ist ${ }^{76}$, war jedoch weder ein langes Leben noch große Wirksamkeit beschieden. Bereits im Jahre 1843 löste sich der Verein auf, nachdem Dr. Eckels Einbeck verliess. Der Verein geriet schnell in Vergessenheit. In einem Gründungsaufruf für einen Turnverein aus dem Jahre 1848 heißt es: "An vielen Orten bestehen schon seit langer Zeit Turnvereine[...]. Daß Einbeck einen ähnlichen Turnverein bisher nicht aufzuweisen hatte, liegt vielleicht daran, daß sich noch niemand fand, der die Bildung desselben in Anregung gebracht hätte[...]."77 Die Gründung erfolgte tatsächlich. Der neue Verein hatte eine Turn-, eine Fecht- und eine Gesangsabteilung. Über seine Entwicklung war nichts zu ermitteln. Zwar schreibt Herbert Blank, dass der Turnverein von 1848 bis 1866 bestanden habe ${ }^{78}$, doch spricht vieles gegen diese Annahme. Keine der dem Autor bekannten Primär- und Sekundärquellen aus der Zeit vor dem Ersten Weltkrieg erwähnt den Turnverein von 1848. ${ }^{79}$ Auch die neuere Literatur skizziert einen Niedergang der Turnbewegung nach der Revolution durch staatliche Repressionsmaßnahmen. ${ }^{80}$ Dass auch im Königreich Hannover solche Repressionen gegen Turner stattfanden, belegt unter anderem ein Erlebnisbericht eines wandernden Turnlehrers aus den fünfziger Jahren des 19. Jahrhunderts, der in Northeim und Lamspringe "verhaftet und wie ein gefährlicher Staatsverbrecher des Ortes verwiesen" wurde. 81

Vermutlich ist der Turnverein von 1848 bereits in der unmittelbaren Folgezeit der Revolution eingegangen.

\footnotetext{
${ }^{76}$ Vgl:: Blank, Herbert: Die Turnerei in Einbeck: in: Festbuch für das 4. Bezirksturnfest vom 30. Juli bis 2. Juli 1961 in Einbeck. Einbeck 1961, SS. 25 - 54, S. 25

77 Zitiert nach: Meyer, Erich: op. cit., 2,. Halbbd, S. 31

${ }^{78}$ Vgl.: Blank, Herbert: op. cit., S. 25.2

${ }^{79}$ So trägt die den MTV Einbeck von 1861 betreffende Akte der städtischen Behörden den Titel "Der hiesige Männer-Turn-Verein", siehe StAEin I: G: F: I: -7. Auch ein mit "R. K." gezeichneter Beitrag über die Entwicklung des Einbecker Turnwesens im Festbuch für das XV. Gauturnfest des Ober-Leine Gaues am 5., 6., und 7. Juli 1902 in Einbeck, der die Turnerei ab dem Beginn der sechziger Jahre des 19. Jahrhunderts behandelt, erwähnt den fraglichen Verein nicht.
}

80 Vgl:: Neumann, Hannes: Leibesübungen im Dienste nationaler Bestrebungen: Jahn und die deutsche Turnbewegung. Teil I: Von den Anfängen bis zur Reichsgründung. in: Ueberhorst, Horst (Hg.). Geschichte der Leibesübungen, Band 3/1. Berlin, München, Frankfurt am Main 1980, SS. 257 - 277, S. 272

${ }^{81}$ Zitiert nach: Martens, René: FC St. Pauli. You'll never walk alone. Göttingen 1997, SS. 61 ff. 
Eine weitere Vereinsgründung des Revolutionsjahres 1848 war die der Bürgerwehr der Stadt Einbeck. Vor dem Hintergrund der revolutionären Ereignisse des März 1848 wurde in Einbeck wie auch in anderen Städten und Gemeinden eine bewaffnete Bürgerwehr ins Leben gerufen, durch die die Bürgerschaft selbst für die öffentliche Ordnung Sorge tragen wollte. Diese Bürgerwehr nahm bald nach ihrer Errichtung einen deutlichen Vereinscharakter an. Die Anschaffung einer schwarz-rot-goldenen Bürgerwehrfahne wurde zügig in Angriff genommen, und mit einem großen Fest wurde wurde bereits im Juli 1848 die Fahnenweihe gefeiert, doch die Begeisterung für den aktiven Dienst in der Bürgerwehr, der auch gelegentliche nächtliche Wachdienste beinhaltete, blieb deutlich hinter den Erwartungen zurück. ${ }^{82}$ Nach dem Scheitern der Revolution löste sich die Bürgerwehr der Stadt Einbeck 1849 auf.83 Als Nachfolgeorganisation dieser Bürgerwehr entstand nach Hans-Norbert Mittendorf eine "Bürger-Schützenkompagnie", aus der im Jahre 1862 der Einbecker Schützenverein hervorgegangen sein soll. 84

Für das Jahr 1848 sind fernerhin nachzuweisen ein Enthaltsamkeitsverein, ein caritativ tätiger Frauenverein, ein Gesangverein 85 sowie verschiedene berufsständische Vereinigungen die nicht unter den Vereinsbegriff der vorliegenden Untersuchung fallen, wie der Mietskutscher-Verein und der Handwerker- und Gewerbeverein. 86

Im Jahre 1850 wurde der erste Arbeiterverein Einbecks gegründet. Bei ihm handelte es sich, wie ein Aufsatz im Einbeckschen Wochenblatt deutlich machte, um einen Verein, der bezweckte, das Bildungsniveau der Arbeiter durch Belehrung zu heben. ${ }^{87}$ Mit dieser Zielsetzung stand er in der Tradition der frühen Arbeiterbewegung der Vormärzzeit, die häufig von liberalen Bürgern initiiert und getragen wurde. ${ }^{8} 8$ Erich Meyer vermutet, der Einbecker

\footnotetext{
${ }^{82}$ Vgl.: Meyer, Erich: op. cit., 2. Halbbd., SS. 17; 20 ff.

${ }^{83}$ Vgl.: Heege, Elke: "Laßt die jetzt passende Zeit nicht verstreichen, Bürger!". Die Revolution in Einbeck im Frühjahr 1848. in: Seeliger, Matthias (Hg.): 1848. (K)eine Revolution an Weser und Leine. Bielefeld, Gütersloh 1999, SS. 79 - 115, SS. 144 f.

${ }^{84}$ Vgl.: Mittendorf, Hans-Norbert: op. cit., S. 64

${ }^{85}$ Der Verein wird im Wochenblatt als "der hiesige Gesangsverein" bezeichnet und ist daher als einziger Gesangverein zu jener Zeit anzusehen.

${ }^{86}$ Dies ergab eine Auswertung des Jahrgangs 1848 des Einbeckschen Wochenblattes.

${ }^{87}$ Vgl.: Meyer, Erich: op. cit., 2. Halbbd., SS. $111 \mathrm{f}$.

${ }^{8} 8$ Vgl.: Kocka, Jürgen: op. cit., SS. 167 ff.
} 
Arbeiterverein sei eine Gliederung der Allgemeinen Deutschen Arbeiterverbrüderung gewesen, ohne dies allerdings näher zu erläutern. 89

Im Jahre 1858 entstand in Einbeck ein weiterer Arbeiterbildungsverein, dieser, laut Eberhard Koch, unter liberaler Führung. Dieser Verein ist auch für das Jahr 1868 nachweisbar - zu jener Zeit umfasste er 30 Mitglieder - nach 1870 ist seine Existenz wie auch die des vorgenannten Arbeitervereines nicht mehr belegbar. Von dem liberalen Arbeiterbildungsverein soll sich um die Wende zu den sechziger Jahren des 19. Jahrhunderts ein sozialdemokratischer Gesangverein abgespalten haben, der später den Namen "Lassallia" annahm.

Zwei weitere Gesangsvereine, allerdings eher dem Bürgertum zuzuordnen, wurden in dieser Zeit gegründet, die Männergesangvereine "Germania" im Jahre $1860^{90}$ und der Gesangverein "Liederkranz", der bis zu seiner Abspaltung eine Unterabteilung des Männerturnvereins von 1861 war. ${ }^{91}$

Wie der Vereinsname "Lassallia" vermuten lässt, gab es in Einbeck bereits in jener Zeit eine organisierte sozialistische Arbeiterbewegung; ab dem Jahre 1867 ist eine Mitgliedschaft des "Allgemeinen Deutschen Zigarrenarbeiterverbandes" nachweisbar, und auf der Generalversammlung des Allgemeinen Deutschen Arbeitervereines des Jahres 1869 vertrat ein Delegierter den Einbecker Ortsverein mit 110 Mitgliedern. ${ }^{92}$

Aus den sechziger Jahren datiert auch die Gründung des ersten wirklich dauerhaften Turnvereins. Im Jahre 1861 trat der "Männer-Turn-Verein Einbeck" ins Leben. ${ }^{93}$ Er bildete ab 1867 mit dem so genannten "TurnerRettungs-Corps", in dem jeder aktive Turner Mitglied sein musste, eine Freiwillige Feuerwehr. Diese war unmittelbare Nachfolgerin einer unabhängigen Freiwilligen Feuerwehr, die nur ein Jahr bestanden hatte. Bereits um die Mitte des 19. Jahrhunderts hatte es einen Feuer-Retttungsverein gegeben. ${ }^{94}$ Die Turnerfeuerwehr existierte nur bis 1872, wohingegen der

\footnotetext{
${ }^{89}$ Vgl.: Meyer, Erich: op. cit., 2. Halbbd., S. 112

90Vgl.: MTV Einbeck, Protokoll 4. März 1903

91Vgl.: MTV Einbeck, Protokoll 8. April 1887 und StAEin 065 - 28/11, 19. April 1892

${ }^{92}$ Für alle der sozialdemokratischen Arbeiterbewegung zuzurechnenden Vereine Vgl.: Koch,

Eberhard: Geschichte der SPD in Einbeck und Uslar. Von den Anfängen bis zum

Wiederaufbau der lokalen Organisationen nach 1945. Eine vergleichende Studie.

Examensarbeit, ungedruckt. Göttingen 1976, SS. 19 ff.

93Vgl.: StAEin I: G: F: I: -7, 21. Juli 1861

${ }^{94}$ Vgl.: Heege, Elke: Brandschutz und Feuerlöschwesen am Beispiel der Stadt Einbeck.

Unveröffentlichtes Manuskript, SS. 4 f.
} 
Turnverein selbst bis zum Ende des Untersuchungszeitraum fortbestand. ${ }^{95}$ Die Gründung von Turnerfeuerwehren war in jener Zeit durchaus nicht ungewöhnlich, Beispiele für solche Turnerfeuerwehren finden sich in verschiedenen Städten des Königreichs Hannover. 96

Ende der sechziger Jahre des 19. Jahrhunderts wurde in Einbeck als weitere gemeinnützige Vereinigung ein Zweigverein des Roten Kreuzes gegründet. 97

Ende 1860 wurde ein christlicher Männer- und Jünglingsverein konstituiert. ${ }^{98}$ Nach den Statuten diente der Verein seinen Mitliedern "zur Stärkung ihres Glaubens, zur Übung in der Gottseligkeit und zur geselligen Erholung nach Ordnung des Wortes Gottes." 99 In einem Begleitschreiben zu den Statuten wird dies präzisiert: "Die Haupttendenz des Vereins ist die, solchen Männern und Jünglingen, die an den Sonntag- und Montag- Abenden passenden Verkehr suchen und in den Wirtshauslokalen u. dergl. keine Befriedigung finden, eine Gelegenheit $\mathrm{zu}$ nützlicher und erbaulicher Beschäftigung zu bieten."100 Bereits im Mai 1861 zählte der Verein 40 Mitglieder. Neben der christlichen Erbauung, die sich auch gegen den "verderblichen Einfluß anderer Vereine [...] die in politischer wie religiöser Weise destructiv auf die Handwerker-Jugend einwirken" richtete, beabsichtigte man, für die sich im Wesentlichen aus der Handwerkerschaft und dem Arbeiterstand rekrutierenden Mitglieder Unterricht in "gewerblichen Gegenständen" anzubieten. Hierfür beantragte man Zuschüsse beim Innenministerium in Hannover. ${ }^{101}$ Dieser Bitte wurde, wie eine Stellungnahme der Landdrostei in Hildesheim vermuten lässt, nicht entsprochen. ${ }^{102}$ Weiteres ist über den Männer- und Jünglingsverein von 1860 nicht bekannt. Es scheint jedoch außer Frage zu stehen, dass er bereits am Beginn des Untersuchungszeitraumes nicht mehr bestand.

\footnotetext{
95Vgl.: Plümer, Erich: Aus der Geschichte des Einbecker Feuerlöschwesens. in der Festschrift: 125 Jahre Freiwillige Feuerwehr Stadt Einbeck. 25 Jahre Feuerwehr-Musikzug Einbeck-Moringen, SS. 31 - 57, S. 45

96 Vgl.: Schubert, Ernst: Veränderung, S. 416

97Vgl.: Hülse, Horst: Einbeck in der Gründerzeit. in: Einbecker Geschichtsverein (Hg.): Geschichte der Stadt Einbeck. Band 2: Vom Ende des 18. Jahrhunderts bis zum Ende des zweiten Weltkrieges. Einbeck 1992, SS. 71 - 138, S. 106

98 Vgl.: StAEin 065 - 13, 27. November 1860

${ }^{99}$ StAEin 065 - 13, 25. November 1860

100 StAEin 065 - 13, 27. November 1860

${ }^{101}$ Vgl.: StAEin 065 - 13, 27. Mai 1861

102 Vgl.: StAEin 065 - 13, Anlage zu 27. Mai 1861
} 
Über den gesamten Untersuchungszeitraum hin tätig war der Frauenverein, eine caritative Einrichtung, in der sich Frauen aus dem gehobenen Bürgertum der Pflege und Unterstützung kranker und armer Mitmenschen widmeten. Es ist unklar, ob dieser Verein mit dem bereits 1848 bestehenden Verein identisch war. Der älteste dem Autor bekannte Rechenschaftsbericht datiert aus dem Jahr 1869.103

Neben den genannten Vereinen sind vier Vereine aus den Jahren 1858 bis 1860 nachzuweisen, die eher den Charakter eines geselligen Clubs hatten. Die Vereinsziele waren äußerst allgemein definiert, und drei der vier Vereine verfügten nicht über einen Namen, sondern definierten sich allein über das Versammlungslokal. Ihre Klientel waren ausschließlich Angehörige des gehobenen Bürgertums. Der älteste dieser vier Vereine nannte sich Concordia. Der im August 1858 gegründete Club hatte zum Ziel, "durch alle Woche an einem Abende stattfindende Zusammenkunft, zum Singen, zu declamatorischen und anderen erheiternden oder belehrenden Vorträgen, sowie durch [...] Tanzvergnügen sich von gehabten Arbeitsstunden zu erholen".104 Mitglied in diesem Verein konnten gemäß seiner Satzung nur Selbständige werden.

Ebenfalls im Jahre 1858 wurde ein weiterer Club gegründet, dessen Mitglieder sich einmal pro Woche behufs "Conversation, Lectüre und Spiel" im Cammererschen Lokal trafen. Er hatte bei seiner Gründung 23 Mitglieder, von denen 15 Offiziere waren. ${ }^{105}$ Der Charakter dieses Vereins ähnelt dem eines englischen Clubs, was sowohl für die Zeit als auch für den südhannoverschen Raum als ungewöhnlich zu erachten ist. ${ }^{106}$

Im darauf folgenden Jahr entstand der "Club im Goldenen Löwen zu Einbeck". Auch dieser Verein war rein geselliger Natur. Statutarisch hatte die Gründung kein erklärtes Vereinsziel, doch ist in den Satzungen, wenn potenzielle Vereinsaktivitäten behandelt werden, fast ausschließlich von Bällen zu lesen. Dem Club gehörten 63 Männer aus dem gehobenen Bürgertum an. ${ }^{107}$ Die Namen zweier dieser Vereinsmitglieder finden sich auf einem Schreiben aus dem Jahre 1860, in dem dem Magistrat der Stadt angezeigt wird, es bestehe ein "behuf geselliger Unterhaltung ins Leben gerufener Klubb zum Gasthause im goldenen Löwen allhier", der keine Satzung habe und sich der

\footnotetext{
${ }^{103}$ StAEin 065 - 14, 1869

${ }^{104}$ StAEin 065 - 11, 25. August 1858

${ }^{105}$ StAEin 065 - 11, 30. Oktober 1858

106 Vgl.: Schubert, Ernst: Veränderung, S. 409

${ }^{107}$ Vgl.: StAEin 065 - 11, 15. Oktober 1859
} 
Pflege von Geselligkeit und Gemütlichkeit widmen wolle. 108 Über weitere Aktivitäten dieser Clubs ist ebensowenig in Erfahrung zu bringen gewesen wie über ihre Lebensdauer. Ob es neben den vier genannten weitere Clubs oder rein gesellige Vereine von Bürgern gab, ist auch nicht bekannt.

Zusammenfassend ist zu sagen, dass der Vereinsgedanke zum Beginn des Untersuchungszeitraumes bereits in Einbeck Fuß gefasst und ein erstes sowohl sozial wie auch thematisch differenziertes Vereinsleben hervorgebracht hatte. Die nachfolgenden Ausführungen werden jedoch verdeutlichen können, dass die Durchbruchsphase von Vereinen als weit reichendes Netz sozialer und politischer Subsysteme und eine umfassende Entfaltung eines von weiten Teilen der Stadtbevölkerung getragenen Vereinslebens in Einbeck noch bevorstand. 


\section{Einbecker Vereine im Kaiserreich 1871 - 1914}

\section{1. Die Gesangvereine}

\section{1. 1. Zur Geschichte des Gesangvereinswesens in Deutschland}

Die Sängerbewegung ist eine der ältesten Vereinsbewegungen in Deutschland. Sie nahm ihren Ausgang zu Beginn des 19. Jahrhunderts. Hierbei ist zwischen zwei zeitgleich entstandenen Ursprüngen dieser Bewegung zu unterscheiden. Im nördlichen Deutschland begründete Carl Friedrich Zelter im Umfeld der bereits bestehenden Berliner Singakademie seines Vorgängers Fasch im Jahre 1809 die erste Liedertafel.109 Der andere "Gründervater" der deutschsprachigen Männergesangvereinsbewegung, der Schweizer Musikpädagoge Hans Georg Nägeli, gliederte im Jahre 1810 seinem fünf Jahre zuvor in Zürich gegründeten Singinstitut eine Männerchorabteilung an.110 Beide Organisationen fanden in der Folgezeit Nachahmungen; im niederdeutschen Raum kam es zur Gründung verschiedener Liedertafeln, im oberdeutschen Raum einschließlich der deutschsprachigen Schweiz wurden zahlreiche so genannte Liederkränze gegründet. ${ }^{111}$ Diese Organisationstypen unterschieden sich zunächst deutlich. Die Zelterschen Liedertafeln - die Bezeichnung spielt auf die sagenumwobene Tafelrunde König Artus' an ${ }^{112}$ waren abgeschlossene Zirkel von musikalischen Fachleuten, die in ihren Vereinen die Dicht- und Tonkunst fördern wollten, während die Liederkränze von vornherein breitere Bevölkerungskreise ansprachen und sich eher der Pflege des volkstümlichen Gesanges und des Volksliedgutes widmeten. Bis zur Jahrhundertmitte hatte die Sängerbewegung großen Zulauf. Im Laufe der Jahre verschwammen auch die Grenzen zwischen der norddeutschen und der süddeutschen Traditionslinie; zunehmend traten auch im Norden Vereine mit dem Namen Liederkranz auf, ebenso gaben sich verschiedene Gesangvereine im Süden den Namen Liedertafel. Die Bezeichnungen verloren an Bedeutung;

${ }^{109}$ Vgl.: Heemann, Annegret: Männergesangvereine im 19. und frühen 20. Jahrhundert. Ein Beitrag zur städtischen Musikgeschichte Münsters. (Europäische Hochschulschriften: Reihe 36, Musikwissenschaft, Band 74) Frankfurt am Main, Bern, New York, Paris 1992 (Zugl.: Dissertation, Münster (Westfalen) 1991), SS. 63 ff.

110 Vgl.: Heemann, Annegret, op. cit., SS. 70 f.

${ }^{111}$ Vgl.: Kötzschke, Richard: Geschichte des deutschen Männergesanges hauptsächlich des Vereinswesens. Dresden 1927, SS. $70 \mathrm{ff}$.

${ }^{112}$ Vgl.: Kötzschke, Richard: op. cit., SS. 59; 62, und Heemann, Annegret: op. cit., S. 67 
auch das norddeutsche Gesangvereinswesen wurde volkstümlicher und nahm so die oberdeutsche Tradition an. ${ }^{113}$ So bildete sich zunehmend eine den gesamten deutschen Sprachraum umfassende Sängerbewegung heraus.

Diese von weiten Teilen des Bürgertums getragene Bewegung wurde bis zum Beginn der Revolution von 1848 wie auch die deutsche Turnbewegung ein wesentlicher Bestandteil der liberalen deutschen Nationalbewegung. ${ }^{114}$ Anders als die Turner konnten die Sänger schon durch ihren Hauptvereinszweck politisch in Erscheinung treten; durch öffentlichen Vortrag von Liedern war es möglich, unmittelbar politische Botschaften oder Idealvorstellungen $\mathrm{zu}$ artikulieren. $\mathrm{Ab}$ dem zweiten Viertel des 19. Jahrhunderts wurden zunehmend überregionale Sängerfeste abgehalten, die durch das gemeinsame Singen patriotischer Lieder den Charakter von öffentlichen Kundgebungen für die nationale Sache annahmen. ${ }^{115}$

Das Scheitern der Revolution beendete die erste Blüte des deutschen Männerchorwesens. Wie andere Vereinigungen, so unterlagen auch die Gesangvereine in der so genannten Zeit der Reaktion einer intensiven behördlichen Überwachung. Daher nahm ihre Zahl so weit ab, dass, nach Annegret Heemann, "in den 50er Jahren des 19. Jahrhunderts von einer nationalen Männergesangvereinsbewegung gar nicht mehr die Rede sein konnte". ${ }^{116}$ Erst ab den sechziger Jahren nahm die Bewegung, wie auch die anderen Vereinsbewegungen ihrer Zeit, wieder einen gewissen Aufschwung; insbesondere die Gründung des Deutschen Sängerbundes im Jahre 1862 gab dem organisierten Männergesang einen neuen Wachstumsimpuls. Nach der Gründung des kleindeutschen Reiches vollzog der national gesonnene Teil der deutschen Sängerschaft den Wechsel von einem liberal-großdeutschen hin zu einem affirmativ-kleindeutschen Patriotismus, der bis zum Ende des Untersuchungszeitraumes Leitbild der Bewegung blieb. 117

Neben der national gesonnenen Sängerbewegung entwickelte sich parallel zur allgemeinen Arbeiterbewegung ab den sechziger Jahren in Deutschland auch eine, teilweise aus Gesangsabteilungen von Arbeiterbildungsvereinen hervorgehende, eigenständige Arbeitersängerbewegung als eine erste vorpolitische Massenorganisation im sozialdemokratischen Spektrum. Die Entwicklung dieser Bewegung wurde durch das von 1878 bis 1890 geltende

\footnotetext{
113 Vgl.: Kötzschke, Richard: op. cit., S. 77

$1{ }^{4} \mathrm{Vgl}$.: Heemann, Annegret, op. cit., SS. 26 f.

115 Vgl.: Heemann, Annegret, op. cit., SS. 78 ff.

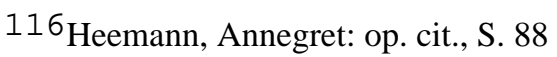

${ }^{117}$ Vgl.: Heemann, Annegret, op. cit., SS. 90 ff.
} 
Sozialistengesetz unterbrochen, jedoch nicht beendet. Nach 1890 kam es erneut zur Gründung von Arbeitergesangvereinen, die sich bereits 1892 mit der Gründung der "Liedergemeinschaft der Arbeiter-Sängervereinigungen Deutschlands" ein gemeinsames Gremium schufen, aus dem 1908 mit dem Deutschen Arbeiter-Sängerbund ein reichsweiter Dachverband hervorging. ${ }^{118}$

${ }^{118} \mathrm{Zu}$ allem über die Arbeitersängerbewegung Gesagten vgl.: Kötzschke, Richard: op. cit., SS. $208 \mathrm{ff}$. 


\section{1. 2 Der Gesangverein Germania}

Der älteste Gesangvereins Einbecks im Kaiserreich, dessen Gründungsjahr ermittelt werden konnte, war der Gesangverein Germania. Nach einem Protokoll des Männerturnvereins Einbeck aus dem Jahre 1903 lud der Verein in diesem Jahr zu seinem 43. Stiftungsfest ein ${ }^{119}$; demnach wurde er bereits im Jahre 1860, also zu Beginn der Phase der Wiederbelebung des organisierten Männergesanges in Deutschland, gegründet. Dies belegt auch die in den Protokollen des MGV Harmonie Einbeck dokumentierte Feier des 50jährigen Stiftungsfestes im Jahre 1910. ${ }^{120}$ Im Stadtarchiv Einbeck finden sich nur vereinzelt Hinweise auf diesen Verein. Die unmittelbar auf den GV Germania bezogene Akte enthält lediglich den Schriftwechsel über ein vom Verein veranstaltetes zweitägiges Sängerfest im Sommer 1888.121 In einer undatierten Liste in der allgemeinen Akte "Vereine, Versammlungen und öffentliche Aufzüge", die auf den Sommer $1893 \mathrm{zu}$ datieren ist, wird der Verein mit dem Vermerk "Verkehr im Schusterkrug", geführt. ${ }^{122}$ Der Schusterkrug war in jener Zeit das bevorzugte Versammlungslokal der Arbeitervereine. Die Akten über die Volksfeste 1898 und 1899 belegen erneut die Existenz des Vereins. Im ersten Falle nahm der GV Germania nicht am vom Magistrat organisierten Fest teil, da er sich außer Stande sah, den Gesang beim Festzug allein zu bestreiten, im zweiten Falle wirkte er wie verschiedene andere Vereine an den Planungen mit. ${ }^{123}$ Die Protokolle des MTV Einbeck dokumentieren unregelmäßige Kontakte zwischen dem GV Germania und dem MTV124, in den Protokollen des Turnclub Eintracht Einbeck sind unregelmäßige Kontakte zwischen beiden Vereinen in den ersten Jahren des 20. Jahrhunderts nachweisbar. ${ }^{125}$ Die Adressbücher 1902 und 1904 führen den Verein mit dem Vereinslokal Brodhaus, die Adressbücher 1907, 1911/12 und Juli 1912 nennen als Vereinslokal das Gasthaus zum Kronprinzen. Eine Photographie, die offenbar aus Anlass des 50jährigen Stiftungsfestes

\footnotetext{
119 Vgl.: MTV Einbeck, Protokoll 4. März 1903

120 Vgl.: MGV Harmonie Einbeck, Protokolle 4. Quartal 1909, 10. April 1910

${ }^{121}$ Vgl.: StAEin 065 - 28, Unterakte GV Germania, 11. Juli 1888, 12. Juli 1888

122 Vgl.: StAEin $065-17$

123 Vgl.: StAEin 340 - 4, 340 - 5

${ }^{124}$ Vgl.: MTV Einbeck, Protokolle 23. April 1888, 25 Juni 1888, 30. Juni 1890, 14. März

1900, 4. Juli 1900, 4. März 1903, 2. November 1904

${ }^{125}$ Vgl.: Eintracht Einbeck, Protokolle 7. April 1900, 1. September 1900, 3. Januar 1903, 5.

November 1904
} 
aufgenommen wurde, zeigt 61 festlich gekleidete und mit Vereinsabzeichen geschmückte Männer, die gemeinsam mit 31 weiß gekleideten Frauen zum Gruppenbild mit Vereinsfahne Aufstellung genommen haben.126 Das Festbuch für einen großen Sängerwettbewerb, den der Männergesangverein Harmonie Einbeck im Sommer 1913 veranstaltete, ist eines der wenigen Zeugnisse über die tatsächliche Aktivität des Vereins. Bei diesem Wettstreit trat der GV Germania mit 40 Sängern an und brachte die Lieder "Auf hoher See" und "Lützows wilde Jagd" zu Gehör. ${ }^{127}$ Aus einem Protokoll des MGV Harmonie aus dem selben Jahr geht hervor, dass der GV Germania ein öffentliches Konzert veranstaltete. ${ }^{128}$

126 StAEin, Photosammlung, Abteilung 34

${ }^{127}$ Vgl: Fest-Buch zum Gesang-Wettstreit Deutscher Männer-Gesang-Vereine in Einbeck am 15. Juni 1913 veranstaltet vom Männer-Gesang-Verein "Harmonie". Einbeck 1913, SS. 9, 17 f. 128 Vgl.: MGV Harmonie Einbeck, Protokoll 25. Oktober 1913 


\section{1. 3. Die Liedertafel Lassallia/Concordia}

Ein weiterer jener Gesangvereine, die zum Beginn des Untersuchungszeitraumes bereits bestanden, war der Gesangverein Lassallia. Die Ursprünge dieses Vereins liegen im Dunklen; wie oben bereits gesagt, war er nach Eberhard Koch um die Wende von den fünfziger zu den sechziger Jahren des 19. Jahrhunderts als Abspaltung aus einem liberalen Arbeiterbildungsverein hervorgegangen. Dass der Verein den Namen Lassallia nicht vor 1863, dem Jahr des Erscheinens Ferdinand Lassalles auf der politischen Bühne, angenommen haben kann, ist evident. Auch erübrigen sich angesichts des programmatischen Vereinsnamens alle Fragen über einen etwaigen politischen Charakter dieses Gesangvereins. Der Name "Lassallia" war in jener Zeit durchaus nicht ungewöhnlich; gleichnamige Vereine bestanden beispielsweise in Lübeck, Pforzheim, Frankfurt am Main, Oberhausen und Stuttgart. 129

Der Gesangverein soll auch die Keimzelle des Einbecker Zweigvereins des ADAV sowie zweier örtlicher Gewerkschaftsvereine gewesen sein. Zigarrenmacher und Schneider stellten den weitaus größten Teil der Mitgliedschaft; generell waren Angehörige dieser Berufe die Hauptträger der frühen Arbeiterbewegung in Einbeck. ${ }^{130}$

Den städtischen Behörden Einbecks waren sowohl die Existenz als auch die sozialdemokratische Ausrichtung des Vereins bekannt, die Vereinsmitglieder wiederum waren sich über diesen Umstand im Klaren. Daher wussten sie im Jahre 1878, dass sie nach dem Inkrafttreten des Reichsgesetzes vom 21. Oktober gegen die gemeingefährlichen Bestrebungen der Sozialdemokratie (Sozialistengesetz) ein Verbot ihres Gesangvereins zu gewärtigen hatten. Um dieses zu vermeiden, entschieden sie sich zu einem Täuschungsmanöver. Sie änderten bei Inkrafttreten des Gesetzes kurzerhand den verräterischen Vereinsnamen in "Concordia". Ein neues Statut wurde allerdings nicht erstellt. Auf dem offiziellen Statutenexemplar von 1876 wurde lediglich der vorangestellte Schriftzug "Statuten der Liedertafel Lassallia Einbeck" mit einem Stück Papier mit der Aufschrift "Statuten der Liedertafel Concordia Einbeck" überklebt; die überklebte Passage blieb sogar noch lesbar. ${ }^{131}$ Der

\footnotetext{
129 Vgl.: StAEin 065 - 5, 24. November 1878

${ }^{130}$ Vgl.: Verschiedene Mitgliederverzeichnisse des Gesangvereins Lassallia in STAEin 065 -

5, 1878 passim und Koch, Eberhard: Woher wir kommen - 125 Jahre SPD in Einbeck. in:

Einbecker Jahrbuch, Band 44 (1995), SS. 165 - 178, SS. 166 ff.
}

${ }^{131}$ StAEin 065 - 5, Anlage zu 24. Januar 1879 
Magistrat ließ sich durch dieses simple Manöver jedoch nicht in die Irre führen. Er brachte umgehend das besagte Statutenexemplar und eines der vom Verein benutzten Liederbücher in seinen Besitz. Mit einem Anschreiben vom 16. November 1878 wurden die Unterlagen an die Königliche Landdrostei in Hildesheim übersandt. In diesem Schreiben wird berichtet, dass der Verein sich nahezu ausschließlich aus stadtbekannten Sozialdemokraten zusammensetze und die Namensänderung keinerlei inhaltliche Konsequenzen habe, sondern lediglich dazu dienen solle, den Einbecker Sozialdemokraten eine Tarnorganisation zu schaffen. Daher empfehle man der Landdrostei, den Verein auf Grundlage des Sozialistengesetzes $\mathrm{zu}$ verbieten. ${ }^{132}$ Als Unterstützung der Aussagen über die politische Tätigkeit des Vereins wies der Magistrat in diesem Schreiben auf die in dem Liederbuch enthaltene ArbeiterMarseillaise hin. Dieses Lied von Jakob Audorf, das auf die Melodie der Marseillaise gesungen wurde, war ab 1875 das wichtigste Kampflied der sozialdemokratischen Arbeiterbewegung. ${ }^{133}$

Die Landdrostei in Hildesheim wurde umgehend in dieser Sache tätig. Bereits am 24. November 1878, vier Tage nachdem das Schreiben aus Einbeck abgesandt worden war, wurde der Gesangverein Lassallia/Concordia auf Grund der $\S \S 1$ und 6 des Gesetzes gegen die gemeingefährlichen Bestrebungen der Sozialdemokratie verboten; das Verbot wurde am 30. November im Kreisblatt für den Kreis Einbeck bekannt gemacht. Ein entsprechender behördlicher Bescheid wurde dem Vorsitzenden des Vereins ausgehändigt, die Vereinskasse mit einem Barbestand von 3,46 Mark und sämtliches Vereinsinventar, bestehend aus 30 Liederbüchern, 17 Abzeichen, 72 Eintrittskarten, 7 Stearinlichtern, 8 Laternen, einem Statutenheft, einem roten Band und einer Glocke, wurden umgehend beschlagnahmt. Der Vereinswirt und der Dirigent wurden über das Verbot in Kenntnis gesetzt. 134

Der Vorsitzende des Vereins, Schuhmachergeselle Klages, legte am 2. Dezember 1878 gegen die Auflösung Beschwerde ein und wurde daraufhin auf das Rathaus zu einer Vernehmung vorgeladen. Er räumte nach dem Protokoll ein, Anfang der siebziger Jahre in Hamburg Mitglied der sozialdemokratischen

\footnotetext{
132 Vgl.: StAEin 065 - 5, 16. November 1878

${ }^{13}{ }^{3}$ Vgl.: Ritter, Gerhard A.: Arbeiter, Arbeiterbewegung und soziale Ideen in Deutschland. Beiträge zur Geschichte des 19. und 20. Jahrhunderts. München 1996, S. 123. Der ursprüngliche Text verherrlichte im Refrain die Person Ferdinand Lassalles, es gab allerdings auch eine neutralere Fassung, in der statt auf Lassalle auf die Rote Fahne Bezug genommen wurde

${ }^{134}$ Vgl.: StAEin 065 - 5, 28. November 1878
} 
Partei gewesen zu sein, mittlerweile sei er aber nicht mehr aktiv, da er "mehr und mehr zu der Einsicht gelangte, daß diese Partei auf Schwindel beruhe". Ebenso wie in seinem Falle habe auch bei anderen Mitgliedern die Begeisterung für die Sozialdemokratie nachgelassen, so dass bereits früher der Gedanke an eine Namensänderung aufgekommen sei, die sich aber wegen des Widerstandes der Zigarrenarbeiter erst nach dem Attentat auf den Kaiser habe durchsetzen können. Die Zigarrenarbeiter seien überzeugte Sozialdemokraten, die "übrigen Mitglieder [...] trieben die Sache sonst nicht so arg". Die Beschwerde vom 2. Dezember wurde von Klages fallen gelassen. 135

Doch kaum zwei Wochen später richteten Klages und der Schriftführer des Gesangvereins Lassallia/Concordia ein Gesuch an den Magistrat, die beschlagnahmten Gegenstände zurückzuerhalten, um einen neuen Gesangverein gründen zu können; das inkriminierte Lied wolle man überkleben. ${ }^{136}$ Der Magistrat antwortete hierauf, erst müsse der neu zu gründende Verein ein Exemplar seiner Statuten vorlegen. Daraufhin erarbeitete man noch im Januar eine neue Satzung, die im Wesentlichen die Paragraphen der alten Satzung der Lassallia in veränderter Reihenfolge enthielt. Die einzige bedeutsame Abweichung zu der ursprünglichen Statutenfassung war der neu formulierte $\S 12$; dieser lautete nunmehr: "Der Vorstand ist verpflichtet, strengstens auf zu achten daß bei Versammlungen, oder sonst vorkommenden Vergnügungen keine Social-Demokratische, Socialistische oder Communistische Tendenzen welche auf den Umsturz der bestehenden Staats oder Geschäfftliche [sic] Ordnung zu Tage treten. Sollte jedoch ein Mitglied diesen Paragraf sich nicht fügen so wird dasselbe aus den Verein gestoßen". 137

Diese Formulierung war dem Originaltext des Sozialistengesetzes entlehnt; $\S 1$ Satz 1 diese Gesetzes lautete: "Vereine, welche durch sozialdemokratische, sozialistische oder kommunistische Bestrebungen den Umsturz der bestehenden Staats- oder Gesellschaftsordnung bezwecken, sind zu verbieten.". ${ }^{138}$ Doch auch dieser Versuch, die Behörden zu täuschen, schlug fehl. Der Magistrat berichtete erneut den Stand der Dinge nach Hildesheim; die Landdrostei entsprach der Empfehlung der Einbecker Behörde und versagte

\footnotetext{
135 StAEin 065 - 5, 14. Dezember 1878

136 Vgl.: StAEin 065 - 5, 1. Januar 1879

${ }^{137}$ Statut des Gesang-Vereines "Concordia" zu Einbeck, undatiert, in: StAEin 065 - 5, nach

14. Februar 1879.

138 Reichsgesetzblatt No. 34/1878, Nr. 1271
} 
dem Verein die Zulassung. ${ }^{139}$ Die Liederbücher und das sonstige neutrale Vereinsinventar $^{140}$ kamen zur Versteigerung durch einen städtischen Polizeibeamten. Alle zur Versteigerung angebotenen Gegenstände wurden vom vormaligen Vereinswirt für insgesamt 2,20 Mark ersteigert. ${ }^{141}$

${ }^{139}$ Vgl.: StAEin 065 - 5, 21. Januar 1879, 11. Februar 1879, 15. Februar 1879, 140 Die Vereinsabzeichen, die Eintrittskarten und das rote Band blieben asserviert. ${ }^{141}$ Vgl.: StAEin 065 - 5, 20. Februar 1879 


\section{1. 4. Weitere sozialdemokratische Gesangvereine}

Bereits im selben Jahr, in dem der Gesangverein Lassallia/Concordia endgültig von den Behörden aufgelöst wurde, wurde mit dem ZigarrenarbeiterGesangverein ein neuer Arbeitergesangverein gegründet. Dieser Gesangverein hatte das gleiche Vereinslokal wie die verbotene Liedertafel Lassallia/Concordia. Der Umstand, dass das Inventar des alten Vereins vollständig vom Wirt des Schusterkruges aufgekauft worden war, legt bereits, wie auch der hohe Anteil von Zigarrenarbeitern im aufgelösten Verein, die Vermutung nahe, dass es sich bei dem neuen Verein um eine Nachfolgeorganisation gehandelt hat. Tatsächlich wurde im ZigarrenarbeiterGesangverein, der von den Behörden als eine berufsständische Vereinigung angesehen wurde, konspirativ die Organisation der Sozialdemokratie in Einbeck fortgeführt. ${ }^{142}$

Der sozialdemokratische Charakter des Zigarrenarbeiter-Gesangvereines war den Behörden spätestens ab dem Jahre 1890 bekannt. In einem Bericht des Magistrats über ein öffentliches Sommerfest des Vereins nach Außerkrafttreten des Sozialistengesetzes ist von einem "ausschließlich aus socialdemokratischen Cigarrenarbeitern bestehenden Gesangverein" die Rede. Es sei von den Mitgliedern bei diesem Fest "sorgfältig Alles vermieden, was den geringsten Anstoß hätte geben können. Sogar die Mitglieder unseres MagistratsKollegiums sowie unser Polizeikommissair waren von dem Vereinsvorstande in einem höflichen Schreiben ersucht worden, doch auf dem Feste gleichfalls zu erscheinen." 143

Dieses Fest war nur dem äußeren Anschein nach ein Sängerfest. Tatsächlich jedoch stellte es die erste sozialdemokratische Parteiversammlung nach dem Sozialistengesetz dar; auf dem Fest wurde ein Delegierter für den Parteitag von Halle gewählt, dessen Entsendung durch den Überschuß aus den Festeinnahmen finanziert wurde. ${ }^{144}$

142 Vgl.: Hülse, Horst: Einbeck in der Gründerzeit. in: Einbecker Geschichtsverein (Hg.): Geschichte der Stadt Einbeck. Band 2: Vom Ende des 18. Jahrhunderts bis zum Ende des zweiten Weltkrieges. Einbeck 1992, SS. 71 - 138, S. 101 und Koch, Eberhard: Woher wir kommen - 125 Jahre SPD in Einbeck. in: Einbecker Jahrbuch, Band 44 (1995), SS. 165 - 178 ,

S. 167

143 StAEin 065 - 34, 5. September 1890

144 Vgl.: Koch, Eberhard: Geschichte der SPD in Einbeck und Uslar. Von den Anfängen bis zum Wiederaufbau der lokalen Organisationen nach 1945. Eine vergleichende Studie.

Examensarbeit, ungedruckt. Göttingen 1976, S. 59 
Im Jahre 1885 gründete eine Anzahl von Angehörigen einer Berufsgruppe, die zunehmend in Einbeck an Bedeutung gewann ${ }^{145}$, mit dem Webergesangverein einen weiteren berufsständischen Gesangverein.

Als Motivation der Vereinsgründer gibt $§ 20$ der Statuten an: "Dieser Verein ist darum gegründet, ein reelles Leben zwischen den jungen Webern zu gewinnen."

Dieser Verein tarnte sich als gewissermaßen tugendbündlerische Organisation. So lautet $\S 2$ der ersten Satzung des Webergesangvereins: "Jedes Mitglied des Vereins verpflichtet sich mit seinem Ehrenwort, den Verein Treue und Liebe und ein orntliches [sic] Leben, innerhalb und außerhalb des Vereins zu bewaren [sic]."; in $\S 17$ wird dieses präzisiert: "Jeder Weber des Vereins hat sich vern [sic] zu halten von verrufenen Kneipen.". Selbstverständlich versuchte man, behördliche Bedenken in Zeiten des Sozialistengesetzes zu zerstreuen; $§ 16$ lautete: "Politische Reden dürfen durchaus im dem Vereine nicht geführt werden."146

Wie auch der Zigarrenarbeitergesangverein wurde auch dieser neue Verein, der das gleiche Vereinslokal hatte, geduldet und keiner näheren polizeilichen Überwachung unterworfen.

Ein Mitgliederverzeichnis aus dem Jahre 1890 zeigt, dass nicht nur Weber dem Verein beitraten. Zwar stellten sie mit 18 von 30 Mitgliedern die bei weitem größte Berufsgruppe im Verein, doch mit vier Fuhrknechten, je zwei Tabak- und Brauereiarbeitern sowie einem Schmied, einem Schlosser, einem Friseur und einem Gastwirt waren immerhin 40 v. H. der Mitglieder des Webergesangvereins weder Weber noch Angehörige verwandter Berufe. 147

Im Frühjahr des Jahres 1892 wurde der Arbeitergesangverein Einbeck gegründet; ein behördeninterner Vermerk über den Erhalt der Statuten trägt das Datum 2. Mai 1892. Zumindest in den ersten Jahren seines Bestehens existierte er neben den beiden oben genannten berufsständischen Gesangvereinen der Zigarrenarbeiter und der Weber. Dies geht aus einer undatierten behördeninternen Vereinsliste, die im Jahre 1893 entstanden sein muss ${ }^{148}$, ebenso hervor wie aus einem Schreiben der städtischen Behörden aus dem

\footnotetext{
${ }^{145}$ Vgl:: Wilhelms, Günter: Vom Handwerksbetrieb zum Fabrikunternehmen. 147 Jahre Unternehmensgeschichte der Firma Gurt- und Bandweberei E. Oppermann, Einbeck. in:

Einbecker Jahrbuch, Band 44 (1995), SS. 129 - 164, passim

146 StAEin 065 - 28, Unterakte Webergesangverein, Statut, Eingangsvermerk 28. Mai 1885

${ }^{147}$ Vgl:: StAEin 065 - 28, Unterakte Webergesangverein, Anlage zum Statut vom März 1890 148 StAEin $065-17$
} 
Februar 1894. In diesem Schreiben wird dem Kommando der Einbecker Garnison auf eine entsprechende Anfrage hin eine Aufstellung derjenigen Vereine übermittelt, die eine sozialdemokratische Gesinnung hatten. ${ }^{149}$ In beiden Schriftstücken werden unter anderem der Zigarrenarbeiter-, der Weberund der Arbeitergesangverein als eigenständige Vereine aufgeführt. Der Aussage Eberhard Kochs, dass der Arbeitergesangverein mit dem Zigarrenarbeitergesangverein identisch gewesen sei und im Jahre 1892 eine Namensänderung stattgefunden habe, ist daher $\mathrm{zu}$ widersprechen. ${ }^{150}$ Dass allerdings die beiden Berufsgruppenvereine noch in den neunziger Jahren des 19. Jahrhunderts im Arbeitergesangverein aufgingen, ist durchaus plausibel; für das 20. Jahrhundert ist die Existenz beider Vereine nicht mehr nachweisbar.

Der Arbeitergesangverein Einbeck entwickelte sich von seiner Gründung an recht erfolgreich; bereits im Sommer 1894 konnte man sich eine Fahne anschaffen. Im Zusammenhang mit der Abhaltung der Fahnenweihefeier kam es zum einzigen anhand der vorliegenden Archivalien nachweisbaren Konflikt mit den städtischen Behörden. Der Verein wollte dieses Fest unter Mitwirkung verschiedener einheimischer Vereine sowie zweier Arbeitergesangvereine aus Hannover, der Liedertafel Waldesgrün und des dortigen Arbeitersängerbundes, mit einer Kundgebung auf dem Marktplatz feiern, Festredner sollte der stadtbekannte Sozialdemokrat Kallmeier sein. Nachdem die Behörden bei der hannoverschen Polizei über die beiden eingeladenen dortigen Vereine Erkundigungen eingezogen hatten, wurde die Feier auf dem Marktplatz untersagt. Die ebenfalls beantragte Genehmigung, einen Festzug durch die Stadt zu veranstalten, wurde allerdings erteilt. ${ }^{151}$

Auch in der Folgezeit hatte der Arbeitergesangverein keine Schikanen durch die Behörden der Stadt Einbeck zu erleiden. So ergingen vom Magistrat auch an den Arbeitergesangverein Einladungen zur Teilnahme an den Volksfesten 1898 und 1899; im Falle des letzteren beteiligte sich der Verein sowohl an der Planung wie auch an der Feier. ${ }^{152}$ Auch zur Teilnahme an einer großen städtischen Hundertjahrfeier der Völkerschlacht bei Leipzig im Jahre 1913 wurde der Arbeitergesangverein vom Magistrat der Stadt eingeladen. Doch der Vorsitzende des Vereins lehnte diese Einladung mit einem selbstbewußten

\footnotetext{
149 Vgl.: StAEin 065 - 34, 16. Februar 1894

${ }^{150}$ Vgl.: Koch, Eberhard: Geschichte der SPD in Einbeck und Uslar. Von den Anfängen bis zum Wiederaufbau der lokalen Organisationen nach 1945. Eine vergleichende Studie.

Examensarbeit, ungedruckt. Göttingen 1976, S. 60

${ }^{151}$ Vgl.: StAEin 065 - 28, Unterakte Arbeitergesangverein, Schriftwechsel 1894

152 Vgl.: StAEin 340 - 4 und 340 - 5
} 
Schreiben ab: "Auf Ihre sehr geschätzte Mitteilung betreffs der JahrhundertFeier am 18. Ockt. beschloß unsere letzte Midgliederversamml. nicht teilnehmen zu können, (ich war leider zu dieser Versamml. verhindert) da viele Midglieder mit am Streik beteiligt und finanziell sehr gelitten, andererseits unsere Midglieder über die Feier geteilter Meinung sind. Da das deutsche arbeitende Volk, der klein kleiner Landwirt, durch den Einzug von Napoleon, zu manchen mildern Unterjochungs Gesetzen die Leibeigenschaft bei Seite geschleudert, Reformen eingefürt, natürlich um diesen Teil der Bevölkerung auf seiner Seite zu haben gekommen ist. Natürlich erkennt man an, das man den Napolion einmahl wieder loß werden mußte.

Vom Nationalen Standpunkte aus ist der Ihrige richtige, vom persönlichen aber auch der entgegen gesetzte.

Immerhin wird ihnen ohne der Arbeiterschaft noch ein großer Anhang zur Verfügung stehn, diesen Tag vom Nationalen Standpunkte aus würdig zu feiern.

Achtungsvoll Ihr ergebener Vorstand des Arbeiter Gesangvereins". 153

Die Mitgliedschaft des Arbeitergesangvereins Einbeck im 1908 gegründeten Arbeitersängerbund ist für das Jahr 1914 nachweisbar; in diesem Jahr wurde der Verein auch den gesetzlichen Beschränkungen für politische Vereine unterworfen; der Verein durfte nur noch Männer über 18 Jahren aufnehmen und musste die städtische Polizeibehörde über personelle Änderungen im Vorstand umgehend informieren. ${ }^{154}$

${ }^{153}$ StAEin I: L: D: - 5. Die Transskription folgt dem Original; eine Anpassung an korrekte Orthographie und Grammatik erschien dem Autor unmöglich. Eine nur sinngemäße Wiedergabe des Zitats würde dem dokumentarischen Wert der zitierten Quelle nicht entsprechen.

${ }^{154}$ Vgl.: StAEin 065 - 28, Unterakte Arbeitergesangverein, 23. Juli 1914, 25. Juli 1914. 


\section{1. 5. Der Liederkranz Einbeck}

Ein weiterer Gesangverein aus der Zeit vor der Gründung des Kaiserreiches war der Liederkranz Einbeck. Dieser war als Abspaltung aus dem Männerturnverein Einbeck hervorgegangen. ${ }^{155}$ Die den Verein betreffende Akte im Stadtarchiv Einbeck enthält lediglich den Schriftwechsel, den der Verein mit dem Magistrat über die Abhaltung des 25. Stiftungsfestes hatte. Dieses Fest wurde im Sommer 1892 mit einem Festumzug durch die Stadt und einer zweitägigen Feier im Schützenhausgarten und auf dem benachbarten Tummelplatz begangen. ${ }^{156}$ Demnach sah der Verein 1867 als sein Gründungsjahr an. Das in diesem Jahr beschlossene Statut des MTV Einbeck enthält in der zweiten Abteilung des Nachtrages ein Statut für einen TurnerLiederkranz, der als Unterabteilung des Vereins einen weitgehend autonomen Status genoss. ${ }^{157}$ Diese Schaffung einer Abteilung des MTV wurde offenbar als Gründungsakt des Vereins angesehen. Der Zeitpunkt der Abspaltung ist nicht mehr zu ermitteln. Da in den erhaltenen Protokollen des Turnvereins die Sezession nicht unmittelbar erwähnt wird, ist der 26. Februar 1875 als terminus ante quem anzusehen. Ein Bild in der Photosammlung des Stadtarchivs Einbeck zeigt vier mit Schärpen geschmückte Männer vor einer Fahne, welche die Jahreszahl 1886 trägt. ${ }^{158}$ In einem Protokoll des Männerturnvereins aus dem Jahre 1886 heißt es im Kontext von Vorbereitungen zum Stiftungsfest des MTV: "Der sich vor mehreren Jahren von dem Verein abgetrennte GesangVerein Liederkranz soll zu dieser Festlichkeit eingeladen werden."159 Diese Einladung war nur eine von mehreren Einladungen des einen Vereins an den anderen. Auch fanden mindestens zwei der Turnfahrten des MTV Einbeck mit Beteiligung des Gesangvereins Liederkranz statt. ${ }^{160}$ Diese freundschaftlichen Kontakte zwischen beiden Vereinen zeigen deutlich, dass die Loslösung der Gesangsabteilung vom Männerturnverein zumindest keine dauerhaften Animositäten hinterlassen hatte. Neben einer in einem Jahresbericht des Männergesangvereins Harmonie dokumentierten Einladung zu einem

\footnotetext{
155Vgl.: MTV Einbeck, Protokoll 8. April 1886

${ }^{156}$ Vgl.: StAEin 065 - 28, Unterakte Liederkranz

${ }^{157} \mathrm{Vgl}$.: Druckexemplar in StAEin $065-24$

${ }^{158}$ StAEin, Photosammlung, Abteilung 34

${ }^{159}$ MTV Einbeck, Protokoll 8 April 1886

${ }^{160}$ Vgl.: MTV Einbeck, Protokolle 2. Juli 1877, 4. März 1887, 30. Juni 1890, 4. April 1892,

1. Mai 1901, 4. März 1903
} 
Sängerfest im Jahre 1908, die von der Harmonie angenommen wurde ${ }^{161}$, sind die einzigen weiteren Quellen, in denen der Liederkranz erwähnt ist, die Adressbücher für die Stadt Einbeck. Ihnen ist freilich nicht mehr als der Nachweis zu entnehmen, dass der Liederkranz Einbeck bis über das Ende des Untersuchungszeitraumes hinaus existierte. Vereinslokal war das Gasthaus zum goldenen Roß.

${ }^{161}$ Vgl.: MGV Harmonie Einbeck, Jahresbericht 1908/09 in: Männergesangverein Harmonie Einbeck: Protokollbuch 19. Juli 1903 - 8. April 1931, S. 44 


\section{1. 6. Der Gesangverein Concordia}

1886 wurde erneut ein Gesangverein mit dem Namen Concordia gegründet; das bei den städtischen Behörden eingereichte Gründungsstatut trägt einen Eingangsvermerk vom 29. September 1886. Zweck des Vereins war, nach der Präambel seines Gründungsstatuts, den vierstimmigen deutschen Männergesang zu pflegen. Dabei waren, nach § 27 dieses Statuts, politische Angelegenheiten "gänzlich ausgeschlossen". Der Verein zielte vor allem auf junge Männer ab; in $\S 12$ des Statuts ist ausdrücklich davon die Rede, dass Eltern der Vereinsmitglieder an Vereinsvergnügen teilnehmen könnten. Nach den Statuten bezweckte der Gesangverein Concordia, auf seine jungen Mitglieder einen positiven erzieherischen Einfluss zu nehmen; § 4 der zitierten Satzung lautete: "Jedem Mitglied wird ein sittliches Benehmen in und außer dem Verein anempfohlen.". ${ }^{162}$

Das Statut enthält keinerlei Hinweis auf einen etwaigen politischen Charakter des Männergesangvereins Concordia. Doch die anliegende Mitgliederliste, die die Namen von elf Arbeitern und Handwerkern verschiedener Gewerke enthält, weist mit dem Tapetendrucker Dörge und dem Gärtner Kellermann zwei ehemalige Mitglieder des unmittelbar nach Inkrafttreten des Sozialistengesetzes verbotenen Gesangvereins Lassallia aus. ${ }^{163}$ Ferner zählte auch der Tapetendrucker Heinrich Brandt, der wenige Jahre später, nach Ablauf des Sozialistengesetzes, zunächst als Mitglied, später als Funktionär des Sozialdemokratischen Wahlvereines in Erscheinung trat, zu den Gründern des Vereins. ${ }^{164}$ Zwar stellen auch diese Befunde keine Beweise dafür dar, dass der neue Verein einen sozialdemokratischen Charakter hatte, doch legen sie den Verdacht nahe, dass die neue Concordia nicht nur dem Namen nach, sondern auch in weltanschaulicher Hinsicht in der Tradition der verbotenen Liedertafel Lassallia/Concordia stand. Allerdings bleibt die Wirkungsgeschichte dieses Vereins im Dunklen. Da jeglicher Beleg für eine Tätigkeit des MGV Concordia fehlt, ist davon auszugehen, dass die Gründung ein Misserfolg war und der Verein niemals regelmäßige Vereinsaktivitäten entwickelte.

\footnotetext{
${ }^{162}$ Gründungsstatut in: StAEin 065 - 28, Unterakte Concordia

${ }^{163}$ Vgl.: StAEin 065 - 5, Anlage zu 24. November 1878

${ }^{164}$ Vgl.: StAEin 065 - 34, 30. Januar 1891; 065 - 36, 28. November 1894, 5. März 1895, 16.

März 1895
} 


\section{1. 7. Der Männergesangverein Harmonie}

Am 1. Juli 1888 bildeten sieben Männer ${ }^{165}$ mit dem Gesang-Club Harmonie einen organisatorisch losen Zusammenschluss zwecks gemeinsamen Singens. Im März des Jahres 1889 beschloss eine Versammlung, dass diese Vereinigung, der mittlerweile 22 aktive Sänger angehörten, in einen Gesangverein umgewandelt werden solle. Man wählte eine Kommission, welche die Vereinsstatuten ausarbeiten sollte. Mit dem Datum vom 4. April 1889 übersandte der Vorsitzende des Vereins das ausgearbeitete Statut an den Magistrat zur Genehmigung; seitens der Behörde bestanden keine Bedenken. 166

Über die ersten fünfzehn Jahre des Bestehens des Männergesangvereins Harmonie war nur wenig zu erfahren; das älteste erhaltene Protokollbuch beginnt mit dem Jahre 1903. Lediglich in den Protokollen des Turnclubs Eintracht Einbeck finden sich vereinzelt Nachrichten über den Verein. Fünf Jahre nach der Gründung und vier Jahre nach der Umwandlung vom eher informellen Club in einen regelrechten Verein wurde im Sommer 1893 eine Vereinsfahne angeschafft; aus diesem Anlass wurde eine Fahnenweihefeier veranstaltet, $\mathrm{zu}$ welcher der zu diesem Zeitpunkt gerade gegründete Turnclub Eintracht eingeladen wurde. ${ }^{167}$ Im Jahre 1898 wurde das zehnjährige Stiftungsfest in einem größeren Rahmen begangen. ${ }^{168}$

Diese Nähe zum Turnclub Eintracht, der sich mit Gegeneinladungen an den MGV Harmonie revanchierte ${ }^{169}$, lässt den Schluss nahe liegend erscheinen, dass der Verein bereits vor 1893 sein Vereinslokal vom Brodhaus, in dem er ausweislich des oben genannten Schreibens von 1889 gegründet wurde, nach dem Rheinischen Hof verlegt hat, der auch das Vereinslokal der Eintracht war. Zweifelsfrei ist der Rheinische Hof als Vereinslokal erst ab 1902 anhand der ersten in einem Adressbuch enthaltenen Vereinsliste nachzuweisen. Im Jahre 1909 wurde das Vereinslokal wieder ins Brodhaus verlegt. ${ }^{170}$

\footnotetext{
${ }^{165}$ Vgl.: 90 Jahre Männer-Gesang-Verein "Harmonie" Einbeck. Einbeck 1978, S. 11

${ }^{166}$ Vgl.: StAEin 065 - 30, 4. April 1888. Dass sich dieses Schreiben (das Statut wurde offenbar zurückgereicht) in der Akte über den Turn-Club Einbeck befindet, muss auf einem Irrtum beruhen.

167Vgl.: Eintracht Einbeck, Protokoll 12. April 1893 und StAEin 065 - 28, Unterakte MGV

Harmonie, 1. Juni 1893

168 Vgl.: Eintracht Einbeck, Protokolle 2. April 1898, 9. Juli 1898

${ }^{169}$ Vgl.: Eintracht Einbeck, Protokolle 1. September 1900, 3. Januar 1903

170 Vgl.: MGV Harmonie Einbeck, Protokoll 4. Dezember 1909
} 
Über die Mitgliederentwicklung des MGV Harmonie sind nur wenige exakte Werte bekannt:

Mitgliederentwicklung des MGV Harmonie Einbeck ${ }^{171}$ :

Zeit

Mitgliederzahl

04/1903

$04 / 1904$

59

04/1907

52

$04 / 1908$

64

04/1909

64

$04 / 1910$

68

$07 / 1910$

80

$10 / 1910$

75

Auch die ab dem ersten Quartal 1910 erhaltenen Kassenunterlagen lassen eine genaue Ermittlung der Mitgliederzahl des Vereins nicht zu. Aus ihnen ist allerdings zu ersehen, dass die Zahl der Vereinsmitglieder bis zum Ende des Untersuchungszeitraumes stets zwischen 80 und 90 Personen betrug. 172

Über die soziale Zusammensetzung der Mitgliedschaft des MGV Harmonie gibt die seit der Clubgründung geführte Stammrolle Aufschluss. In ihr sind die Namen von 186 Männern verzeichnet, die dem Verein bis zum Ersten Weltkrieg beitraten. Für 119 dieser Personen konnte anhand von Adressbüchern ein Beruf ermittelt werden. Eine Auswertung ergab, dass die überwiegende Mehrzahl der Mitglieder des MGV Harmonie Handwerker oder Arbeiter waren; diese Gruppe stellte 96 Männer oder 80,7 v. H. derjenigen, deren Beruf ermittelt werden konnte. Diesen standen mithin 23 Personen oder 19,7 v. H. gegenüber, die nicht dem Handwerk entstammten. Diese Gruppe war recht heterogen und umfasste Angehörige verschiedener Formationen des städtischen Bürgertums; die Spanne reichte von städtischen Unterbeamten über Händler und Gastwirte bis hin zu zwei Angehörigen des wohlhabenden Besitzbürgertums, einem Druckerei- und einem Mühlenbesitzer.

${ }^{171}$ Vgl.: MGV Harmonie Einbeck, Protokollbuch 19. Juli 1903 bis 8. April 1931:

Jahresberichte 1904/05 (S. 8), 1907/08 (S. 33), 1908/09 (S. 44), 1909/10 (S. 52) und Protokolle 16. Juli 1910, 8. Oktober 1910

172 Vgl:: MGV Harmonie Einbeck, Kassenbuch 1910 - 1935, passim 
Zusammenfassend ist festzuhalten, dass der MGV Harmonie über den gesamten Untersuchungszeitraum ein von Arbeitern und Kleinbürgern dominierter Verein war.

Dies spiegelt sich auch in einem Passus wider, der im Jahre 1908 in die Statuten eingefügt wurde und in dem geregelt wurde, dass Mitglieder im Falle einer mehr als vierwöchigen Krankheit für das betreffende Quartal beitragsfrei gestellt wurden. ${ }^{173} 1911$ wurde zusätzlich beschlossen, arbeitslosen Sangesbrüdern eine Unterstützung aus der Vereinskasse zu zahlen. ${ }^{174}$

Auch eine im Jahre 1914 geführte Diskussion belegt, dass zumindest ein wesentlicher Teil der Mitglieder des MGV Harmonie in bescheidenen wirtschaftlichen Verhältnissen lebte. Da der Verein zu dieser Zeit über recht viel Geld verfügte, wurde angeregt, 1000 Mark zinsbringend als Grundkapital einer Sterbekasse anzulegen. Dem wurde in einer zu diesem Behufe einberufenen Versamlung entgegengehalten, man solle "lieber den Mitgliedern bei Lebzeiten mehr bieten und vielleicht den Beitrag ermäßigen, da im Verein viele Mitglieder wären, deren Familien es groß nötig hätten". ${ }^{175}$

Die Person des oben genannten Buchdruckereibesitzers, Heinrich Rüttgerodt, war Anlass, eine stichprobenartige Untersuchung über eine etwaige dominierende politische Tendenz im Verein durchzuführen, war Rüttgerodt doch der exponierteste Vertreter der organisierten welfischen Bewegung in der Stadt. Jedoch ließen sich in der Mitgliedschaft durchaus auch Anhänger der Sozialdemokratie nachweisen. Daher ist zu konstatieren, dass der Verein eine über politische Differenzen hinaus reichende Integrationskraft hatte und einen unpolitischen Charakter gehabt haben muss.

Die Vereinsaktivitäten reichten, wie die erhaltenen Protokolle belegen, weit über die Pflege des Chorgesanges hinaus. Ein Sommer- und zwei bis drei Wintervergnügen, von denen in der Regel eines als Karnevalsfest gefeiert wurde, bildeten eine relativ feste alljährlich wiederkehrende Abfolge von Feiern. ${ }^{176}$ Darüber hinaus wurden Ausflüge in die nähere Umgebung der

\footnotetext{
173Vgl.: MGV Harmonie Einbeck, Protokoll 19. Januar 1908

174 Vgl.: MGV Harmonie Einbeck, Protokoll 16. Juli 1911

${ }^{175}$ MGV Harmonie Einbeck, Protokoll 27. Juni 1914. Ein Beschluss über die Frage kam nicht zu Stande; diese Sitzung, in der von dem Antragsteller dargelegt wurde, dass in der Vereinsgeschichte nur wenige Sterbefälle vorgekommen seien, war die letzte Vereinsversammlung vor dem Krieg.

176 Vgl.: MGV Harmonie Einbeck, Protokolle, passim
} 
Stadt, in der Regel in Form einer "Bierpartie" unternommen ${ }^{177}$; für die Jahre 1907 und 1908 sind größere Fahrten, die erste nach Stadtoldendorf und die zweite an die Weser nachweisbar. 178

Den Höhepunkt in der Folge der Feste des MGV Harmonie vor dem Ersten Weltkrieg stellte das 25jährige Stiftungsfest im Sommer 1913 dar. Die Vorbereitungen zu diesem Fest, welches das bis dahin größte seiner Art in Einbeck werden sollte, begannen bereits ein Jahr vorher. ${ }^{179}$ Das Fest wurde am 15., 16. und 22. Juni 1913 als großes Volksfest mit einem Festumzug und verschiedenen Feierlichkeiten in Festzelten begangen. Über diese zu jener Zeit nicht ungewöhnlichen Elemente eines großen Vereinsfestes hinaus wurde erstmals in Einbeck ein Gesangswettstreit verschiedener Gesangvereine abgehalten. In vier Stärkeklassen konkurrierten insgesamt 23 Gesangvereine aus dem ganzen südniedersächsischen Raum um verschiedene Ehrenpreise. Diese waren teils von Mitgliedern und deren Angehörigen, teils von verschiedenen Unternehmen der Stadt gestiftet worden. Auch die Stadt hatte einen Ehrenpreis beigesteuert. Der gastgebende Verein und der MGV Hullersen beteiligten sich außer Konkurrenz an diesem Sängerfest, so dass insgesamt 25 Gesangvereine an den Feierlichkeiten teilnahmen. ${ }^{180}$

Das 25jährige Stiftungsfest war ein großer Erfolg, auch in finanzieller Hinsicht; die Abrechnung nach dem Fest ergab einen Überschuss in Höhe von 1020,20 Mark für die Vereinskasse.

Die gelungene Durchführung dieses größten bis dahin in Einbeck stattgefundenen Sängerfestes wie auch der oben dokumentierte zunächst wachsende und dann auf einem hohen Stand stagnierende Mitgliederbestand lassen die Aussage zu, dass der MGV Harmonie Einbeck ein sehr erfolgreicher Gesangverein war. Dies ließe sich noch akzentuierter in einer Gesamtschau des Einbecker Gesangvereinswesens bis in die Gegenwart konstatieren; von allen Gesangvereinen Einbecks aus der Zeit vor dem Ersten Weltkrieg ist der MGV Harmonie zur Zeit der Niederschrift der vorliegenden Studie der einzige, der noch besteht.

${ }^{177}$ MGV Harmonie Einbeck, Protokolle 19. Juli 1903, 16. Juli 1905, 25. Juli 1907, 5. April 1908, 3. Quartal 1909, 16. Juli 1910, 16. Juli 1912, 19. Juli 1913, 26. Juni 1914

${ }^{178}$ Vgl:: MGV Harmonie Einbeck, Protokoll 14. Juli 1907, Jahresbericht 1907/08

${ }^{179}$ Vgl:: StAEin 065 - 28, Unterakte MGV Harmonie, 26 Juni 1912 und MGV Harmonie

Einbeck, Protokoll 7. Juli 1912

180 Vgl: Fest-Buch zum Gesang-Wettstreit Deutscher Männer-Gesang-Vereine in Einbeck am 15. Juni 1913 veranstaltet vom Männer-Gesang-Verein "Harmonie". Einbeck 1913, SS. 5 ff., MGV Harmonie Einbeck, Protokolle 19. Januar 1913, 1. Juni 1913 


\section{1. 8. Die Liedertafel Eintracht}

Am 25. März 1892 ging bei den Behörden ein Schreiben von vier Männern ein, welches besagte, dass im Gasthaus zur Stadt Hannover ein Gesangverein mit Namen Liedertafel Eintracht gegründet worden sei; die vier zeichneten als Vorstand. In der Anlage übersandten sie das Gründungsstatut. § 1 definiert ein sehr weit gefasstes Vereinsziel, das isoliert betrachtet eher einen frühen Arbeiterbildungsverein denn einen Gesangverein vermuten ließe: "Der Verein heißt Liedertafel-Eintracht und bezweckt, die Vereinsmitglieder durch Gesang und sonstige geeignete Vorträge wissenschaftlich zu bilden sich jedoch aller politischen Dinge zu enthalten.".181 Das Statut weckte keinerlei behördliches Misstrauen; die Frage, ob eine Mitgliederliste einzureichen sei, wurde verneint, wie ein behördeninterner Vermerk auf dem genannten Anschreiben zeigt. Auch auf der bereits zitierten behördeninternen Vereinsliste aus dem Jahre 1893 ist der Verein im Gegensatz zu anderen sozialdemokratischen Vereinen nicht markiert. ${ }^{182}$ Allerdings legen die Personen der Vorstandsmitglieder im Nachhinein die Vermutung nahe, dass die Liedertafel Eintracht eine sozialdemokratische Ausrichtung gehabt haben könnte; zwei der vier Vorstandsmitglieder, der Weber Kraus und der Arbeiter und Haussschlachter Marienhagen, traten später in der sich nach dem Sozialistengesetz reorganisierenden lokalen sozialdemokratischen Parteiorganisation in Erscheinung. ${ }^{183}$ Wie die zweite Concordia, so konnte auch die Liedertafel Eintracht keine nennenswerte Wirkung entfalten; die bereits zitierte Ewähnung des Vereins in der Vereinsliste aus dem Jahre 1893 ist der einzige weitere Beleg für die tatsächliche Existenz dieses Gesangvereins.

\footnotetext{
${ }^{181}$ StAEin 065 - 28, Unterakte Liedertafel Eintracht, Anlage zu 25. März 1892

182 Vereinsliste in StAEin 065 - 17

183 Vgl.: Kraus: StAEin 065 - 34, 28. November 1894, 5. März 1895; Marienhagen: StAEin

065 - 36, Januar 1904, 1. Mai 1907; 065 - 37, 6. Februar 1906
} 


\section{1. 9. Die Graphische Liedertafel}

Als ein weiterer berufsständischer Gesangverein nach den bereits erwähnten Vereinsgründungen von Zigarrenarbeitern und Webern wurde im Oktober 1898 im Gasthof zur Stadt Hannover die Graphische Liedertafel gegründet. Der Zweck dieses Vereins war nach $\S 1$ seines Statuts: "Ausübung und Pflege des mehrstimmigen Männergesangs und Förderung eines allgemeinen Freundschaftsverhältnisses unter den Collegen". Der Gesangverein richtete sich nach $§ 2$ seiner Satzung an alle "graphischen Arbeiter", also vor allem an die durch die Einbecker Tapetenindustrie recht zahlreichen Formstecher und Tapetendrucker, doch auch die Aufnahme anderer Personen war möglich. ${ }^{184}$ Da über diesen Verein nicht mehr als seine Gründung zu erfahren war, ist eine Aussage über einen etwaigen politischen Hintergrund nicht möglich. Allerdings fand die Vereinsgründung in einer Zeit statt, in der Angehörige der genannten Berufe bereits eine wesentliche Rolle innerhalb der Gewerkschaften Einbecks spielten. ${ }^{185}$

Weder in der Vereinsliste des Adressbuches des Jahres 1902 noch in einer späteren wird der Verein erwähnt. Daher muss konstatiert werden, dass die Graphische Liedertafel Einbeck, wenn sie denn überhaupt jemals über das Stadium eines Vereinsgründungsprojektes hinaus kam, allenfalls kurze Zeit Bestand hatte.

${ }^{184}$ StAEin 065 - 28, Unterakte Graphische Liedertafel, Statut vom 5. Oktober 1898

185Vgl.: StAEin 065 - 34 und 065 - 38, passim 


\section{1. 10. Der Männergesangverein Sachsenroß}

Im August 1900 wurde im Gasthof zur Krone der Männergesangverein Sachsenroß gegründet. Seine Gründer bezweckten nach $\S 1$ der Statuten, "den Gesang zu heben und zu pflegen". 186 Über den Kreis der Vereinsgründer ist nur wenig bekannt; lediglich die Namen der ersten Vorstandsmitglieder finden sich auf dem zitierten, den städtischen Behörden zur Begutachtung eingereichten Gründungsstatut. Daher ist eine Aussage über die Sozialstruktur der Mitgliedschaft dieses Vereins nicht möglich. Die soziale Zusammensetzung des Vorstandes lässt allenfalls die vage Vermutung $\mathrm{zu}$, dass es sich bei den Gründern um Angehörige des mittleren bis niederen Bürgertums gehandelt haben könnte. Allerdings könnte $§ 2$ des Statuts Rückschlüsse auf die soziale Selbstverortung der Vereinsmitglieder ermöglichen. Darin heißt es: "Wer Mitglied werden will muß im Vollbesitz der bürgerlichen Ehrenrechte sein und sich selbstständig ernähren."187 Interpretiert man die Anforderung der Selbständigkeit dahin gehend, dass damit nicht allein die Bestreitung des Lebensunterhaltes durch ein eigenes Einkommen gemeint war, sondern vielmehr die wirtschaftliche Unabhängigkeit, so spricht dieser Passus, wenn nicht für ein hohes Maß an Exklusivität, so doch für eine deutliche Abgrenzung gegenüber unterbürgerlich-proletarischen Schichten.

Die Wahl des Vereinsnamens für den neuen Verein ist als klare programmatische Aussage der Gründer über ihre politische Einstellung zu werten. Der Bezug auf das Wappentier der Herzöge von Braunschweig und Lüneburg war in der preußischen Provinz Hannover eine eindeutige Loyalitätsbezeugung für das 1866 von Preußen seiner Herrschaft enthobene Königshaus von Hannover und damit ein eindeutiges Bekenntnis zur oppositionellen Welfenpartei. Hierin dürfte auch der Grund zu erblicken sein, dass Bürgermeister Troje die Anmeldung des Vereins nicht einfach zu den Akten gab, sondern sie mit dem Vermerk versah, dass diese ihm nach Verstreichen eines Jahres mit einem Bericht über eine etwaige politische Tätigkeit erneut vorzulegen sei. Der Wiedervorlagevermerk vom August 1901 trägt die Notiz eines städtischen Polizisten, dass sich der Verein in politischer Hinsicht nicht bemerkbar gemacht habe. ${ }^{188}$ Über die Aktivitäten des Vereins ist nur bekannt, dass er im Sommer 1901 sein Vereinslokal in den Gasthof zur

\footnotetext{
186 StAEin 065 - 28, Unterakte MGV Sachsenroß, Anlage zu 13. August 1900

187 ibid.

${ }^{188}$ Vgl:: StAEin 065 - 28, Unterakte MGV Sachsenroß, 13. August 1900, Vermerke
} 
Deutschen Eiche verlegte. ${ }^{189}$ Ausweislich des Adressbuches von 1904 existierte der Verein zum Zeitpunkt dessen Erscheinens noch, auch das Vereinslokal war immer noch die Deutsche Eiche; weitere Belege für den Fortbestand des Gesangvereins Sachsenroß fehlen. 


\section{1. 11. Der Gesangverein Cäcilia}

Im Jahre 1905 gründeten 23 Männer den Gesangverein Cäcilia. Als Vereinszweck gaben sie in $\S 1$ der Statuten "die Veredlung des Volksgesanges"190 an. Bereits die Wahl des Vereinsnamens legt eine Vermutung über die Gründungsmotive dieser Männer nahe. Die Benennung von Gesang- und Musikvereinen nach der heiligen Cäcilia, die in der Zeit der römischen Christenverfolgung das Martyrium erlitten haben soll, war für katholisch geprägte Gegenden nicht ungewöhnlich ${ }^{191}$; diese Heilige war der Überlieferung nach außerordentlich musikalisch und daher die Schutzpatronin unter anderem der Musiker und Sänger. Für die weitgehend evangelischlutherisch geprägte Stadt Einbeck stellt die Benennung eines Vereins nach einer Heiligen jedoch einen absolut singulären Fall dar. Daher muss schon aus diesem Grunde angenommen werden, dass die 22 ortsansässigen Gründer ${ }^{192}$ Angehörige der kleinen katholischen Minderheit waren. Der Anteil der Katholiken in Einbeck lag zu dieser Zeit bei etwa 5 v. H. der Gesamtbevölkerung. ${ }^{193} \S 8$ der Statuten bestätigt die Vermutung; er enthält die Verfügung, dass im Falle einer Auflösung des Vereins das Vereinsvermögen, soweit vorhanden, der katholischen Kirchengemeinde in Einbeck zufallen sollte. ${ }^{194}$

Die Vereinsgründer, die sich in 16 aktive und 7 passive Mitglieder aufteilten, entstammten sämtlich dem Bürgertum; Handwerker auf der einen und Kaufleute und Angestellte auf der anderen Seite hielten sich in etwa die Waage. ${ }^{195}$

Über die weitere Entwicklung des Vereins, wenn es denn überhaupt eine gab, ist nichts zu ermitteln gewesen. In den Listen der Adressbücher der Folgezeit, beginnend mit dem Jahrgang 1907 wird ein Verein diesen Namens

\footnotetext{
${ }^{190}$ StAEin 065 - 28, 21. Februar 1905, Unterakte GV Cäcilia. Das mit diesem Datum eingereichte Statut mit beigefügter Mitgliederliste ist das einzige Zeugnis über den GV Cäcilia ${ }^{191}$ Vgl.: Heemann, Annegret, op. cit., S. 95

${ }^{192}$ Eines der passiven Gründungsmitglieder war nicht in Einbeck, sondern im thüringischen Sangerhausen ansässig.

1931886 betrug der Anteil 4,8 v. H., im Jahre 1910 waren 5,8 v. H. der Einbecker römischkatholischer Konfession. Vgl. hierzu: Hülse, Horst: Einbeck in der Gründerzeit. in: Einbecker Geschichtsverein (Hg.): Geschichte der Stadt Einbeck. Band 2: Vom Ende des 18. Jahrhunderts bis zum Ende des zweiten Weltkrieges. Einbeck 1992, SS. 71 - 138, S.72

194 Vgl.: StAEin 065 - 28, Unterakte GV Cäcilia, 21. Februar 1905

195 Vgl.: ibid.
} 
weder unter den Gesangvereinen noch unter den kirchlichen Vereinen aufgeführt. Daher muss angenommen werden, dass die Gründung des Gesangvereins Cäcilia nicht erfolgreich war und sich ein regelrechtes Vereinsleben dieses katholischen Vereins in der Diaspora nicht entwickeln konnte. 


\section{1. 12. Der Männergesangverein Deutsches Lied}

Die letzte nachweisbare Gründung eines Gesangvereines vor dem Ersten Weltkrieg erfolgte im Jahre 1907. Im Juni dieses Jahres wurde im kleinen Saal des Hotels zur Traube der Männergesangverein Deutsches Lied gegründet, um "sangesfreudige unbescholtene Personen heranzuziehen, um den deutschen Männergesang zu pflegen und zu fördern, sowie allezeit einen gemütlichen, geselligen Verkehr unter den Mitgliedern bezw. Familienangehörigen zu unterhalten". ${ }^{196}$ Nach $\S 5$ des Statuts konnte jeder unbescholtene Mann ab 20 Jahren dem Verein beitreten. Der Verein war der einzige Gesangverein Einbecks, für den eine statutarische Bestmmung über die Vereinsfarben nachgewiesen werden konnte; bei der Auswahl zeigte man sich der Heimatstadt verbunden und wählte die Stadtfarben Einbecks, Rot und Gelb. Der Verein entwickelte sich, anders als viele oben dokumentierte Vereine, recht erfolgreich. Kaum zwei Jahre nach der Gründung konnte eine Fahne angeschafft werden. Auch bei der Wahl des Fahnenmotivs wurde Lokalpatriotismus bewiesen. Man beschloss, das Wappen der Stadt Einbeck als Motiv zu nehmen und richtete ein entsprechendes Gesuch mit der Bitte um ein leihweises Überlassen eines Stadtwappens an den Magistrat. Dieser Bitte wurde seitens der Behörde entsprochen; eine Ehre, die, wie unten im Falle eines Fußballvereins gezeigt werden wird, nicht jedem Verein zu Teil wurde. ${ }^{197}$ Im Sommer 1909 wurde mit einem Sängerfest, zu dem auch andere Vereine eingeladen wurden, die Fahnenweihe gefeiert. ${ }^{198}$ Der Verein bestand, wie die entsprechenden Adressbücher beweisen, bis über den Untersuchungszeitraum hinaus fort.

Über die Mitgliederentwicklung des Vereins können nur wenige Angaben gemacht werden. Wenig mehr als einen Monat nach seiner Gründung zählte der Verein 30 aktive und zwei passive Mitglieder ${ }^{199}$, im Sommer 1913 trat man zum großen Sängerwettstreit beim MGV Harmonie mit 48 Sängern $\mathrm{an}^{200}$.

\footnotetext{
$196 \S 1$ des Statuts vom 31. Juli 1907 in StAEin 065 - 28, Unterakte MGV Deutsches Lied 197Vgl.: StAEin 011 - 2, 1. Mai 1909 und das einschlägige Kapitel der vorliegenden Arbeit. 198Vgl.: MGV Harmonie Einbeck, Protokoll 1. Quartal 1909 und Schützenverein Einbeck, Protokoll 5. Juni 1909

${ }^{199}$ Vgl.: Mitgliederliste in der Anlage zum Statut vom 31. Juli 1907 in StAEin 065 - 28, Unterakte MGV Deutsches Lied ${ }^{200}$ Vgl.: Fest-Buch zum Gesang-Wettstreit Deutscher Männer-Gesang-Vereine in Einbeck am 15. Juni 1913 veranstaltet vom Männer-Gesang-Verein "Harmonie". Einbeck 1913, S. 9
} 
Die Mitgliederliste, die der Verein zusammen mit seinem ersten Statut bei den städtischen Behörden einreichte, gibt einen Aufschluss über die soziale Zusammensetzung des Männergesangvereins Deutsches Lied. Für 21 der 32 Mitglieder konnte anhand von Adressbüchern eine zeitgenössische Berufsbezeichnung ermittelt werden. Die dominierende Gruppe waren die Angestellten und Kaufleute mit zusammen 14 Personen, ergänzt wurden diese durch einen Fabrikanten und verschiedene qualifizierte Handwerker, so beispielsweise einem Konditor und zwei Uhrmachern.

Auch wenn diese Angaben relativ vage sind, so kann doch konstatiert werden, dass der MGV Deutsches Lied ein Verein mit einer von Angehörigen gehobener bürgerlicher Schichten dominierten Mitgliedschaft war, in dem gerade Angehörige des neuen Mittelstandes stark vertreten waren. 


\section{1. 13. Weitere Gesangvereine}

Drei weitere Gesangvereine Einbecks im Untersuchungszeitraum waren der Gesangverein Liedertafel Einbeck, der Männer-Gesangverein Einbeck und der Gemischte Chor. Über diese drei Vereine liegen bis auf die schon häufiger angeführte Vereinsliste von $1893^{201}$ keine Akten in den Beständen des Stadtarchivs vor; ihre Existenz ist ferner nur anhand der Adressbücher ab der Ausgabe von 1902, dem ersten vorliegenden Adressbuch mit einer Auflistung der Vereine, nachzuweisen. Der Männer-Gesangverein erscheint 1902 als "Gesangverein Einbeck", in der Ausgabe von 1904 als "MännerGesangverein". In beiden Fällen ist als Vereinslokal das Gasthaus zur Krone genannt. Die Liedertafel Einbeck und der Gemischte Chor werden in allen Adressbüchern von 1902 bis zum Ersten Weltkrieg aufgeführt. Im Jahre 1902 wird für beide Vereine das Hotel zum Kronprinz angegeben, vor 1904 zogen beide Vereine in das Hotel zur Traube um, das mindestens bis zum Jahre 1912, dem Jahr des Erscheinens des letzten vorliegenden Adressbuches vor dem Ersten Weltkrieg Vereinslokal beider Vereine blieb. Ob über das gemeinsame Lokal hinaus weitere Verbindungen zwischen ihnen bestanden, kann freilich anhand der vorliegenden Quellen nicht mehr rekonstruiert werden.

Sowohl die Vereinsbezeichnungen ohne Eigennamen als auch der Umstand, dass in den Akten der städtischen Behörden, die für die untersuchte Periode vollständig erhalten sein dürften, jeder Hinweis auf eine Gründung dieser Vereine fehlt, legen die Vermutung nahe, dass sie wie auch der Gesangverein Germania bereits vor der Reichsgründung gegründet wurden. Allerdings fehlen der Männer-Gesangverein wie auch der gemischte Chor in einer Auflistung der in Einbeck bestehenden Vereine, welche das Kreisblatt für den Kreis Einbeck in seiner Ausgabe vom 5. Januar 1881 veröffentlichte. Ob diese Liste, der die Einführung "Kürzlich hat sich Jemand den Spaß gemacht, die Namen sämmtlicher hiesigen Vereine zusammenzustellen[...]" voransteht, allerdings vollständig ist, muss als fraglich angesehen werden. Jedoch können nur weitere Quellenfunde die Lösung der Frage, wann die genannten Vereine entstanden, ermöglichen. Als bemerkenswert ist jedoch festzuhalten, dass mit dem Gemischten Chor ein Gesangverein existierte, in dem auch Frauen sangen und der damit nicht in der eingangs dieses Kapitels kurz dargestellten Tradition des organisierten Gesanges stand, der ausschließlich von Männerchören gepflegt wurde. 


\section{1. 14. Einbecks Gesangvereine vor dem Ersten Weltkrieg - eine Gesamtschau}

Das Vorhaben, über die Gesangvereine in Einbeck in der Zeit von der Reichsgründung bis zum Beginn des Ersten Weltkrieges ein Gesamtbild zu entwerfen, das über alle in der Einleitung dieser Arbeit angerissenen Fragen Aufschluss gibt, ist zum Scheitern verurteilt; schon allein der dem Autor vorliegende Bestand an historischen Quellen lässt dies nicht zu. So war anhand des Materials nicht einmal genau zu ermitteln, wie viele der behandelten Vereine bereits am Beginn des Untersuchungszeitraumes bestanden; im Falle dreier Vereine, des Gesangvereins Germania, des Liederkranzes und der Liedertafel Lassallia, kann dies als gesichert angesehen werden. Fernerhin ist als wahrscheinlich anzunehmen, dass die Gründung weiterer drei Gesangvereine, des Männergesangvereins Einbeck, der Liedertafel Einbeck und des Gemischten Chores vor 1871 erfolgte.

Ebensowenig ist die genaue Zahl der Vereine, die zum Zeitpunkt des Beginns des Ersten Weltkrieges bestanden, zu ermitteln. Das Adressbuch von 1912 weist mit dem Liederkranz, der Liedertafel, dem Arbeitergesangverein, den Gesangvereinen Germania, Harmonie und Deutsches Lied sowie dem Gemischten Chor sieben Gesangvereine aus. Das nächst ältere vorliegende Adressbuch von 1922 führt neben verschiedenen neugegründeten Gesangvereinen nur noch sechs dieser sieben Vereine auf; der Gemischte Chor bestand zu dieser Zeit nicht mehr.

Festzuhalten bleibt, dass im Jahre 1871 drei bis sechs Gesangvereine bestanden, 1914 sechs oder sieben. Diesem insgesamt eher geringen Zuwachs bei der Gesamtzahl der Gesangvereine in Einbeck steht eine hohe Zahl von Gründungen gegenüber; über den gesamten Untersuchungszeitraum ist die Neugründung von nicht weniger als zehn Gesangvereinen belegt. Lediglich drei dieser neugegründeten Vereine waren längerfristg erfolgreich; am Ende des Untersuchungszeitraums und darüber hinaus hatten nur der MGV Harmonie von 1888/89, der Arbeitergesangverein von 1892 und der MGV Deutsches Lied von 1907 Bestand. Mithin waren sieben der neun dokumentierten Vereinsgründungen nicht von nachhaltigem Erfolg.

Über die Gründe des Scheiterns dieser Neugründungen kann allenfalls spekuliert werden. Für die Fälle des Zigarrenarbeiter- und des Webergesangvereins scheint die Sache relativ klar zu liegen; diese Vereine hatten nach dem Auslaufen des Sozialistengesetzes ihre Funktion als sozialdemokratische Tarnorganisationen verloren. Da sich die Spuren dieser beiden Vereine bald nach der Gründung des offen sozialdemokratischen 
Arbeitergesangvereins am Beginn der neunziger Jahre des 19. Jahrhunderts verlieren, scheint es wahrscheinlich, dass sie im neuen Massenverein aufgingen oder ihre Mitglieder an diesen verloren. Der Gesangverein Cäcilia hatte als Verein einer kleinen konfessionellen Minderheit vermutlich eine zu geringe Anzahl an potenziellen Mitgliedern in Einbeck. Für den Misserfolg der anderen erfolglosen Gesangvereine Einbecks vor dem Ersten Weltkrieg kann nur die pauschale ökonomische Erklärung gefunden werden, dass das Angebot an verschiedenen Möglichkeiten, sich an den Aktivitäten eines Gesangvereins zu beteiligen, die Nachfrage überstieg.

Ebenso wenig wie über die Gründe der Erfolglosigkeit zahlreicher Gesangvereine ist über die Faktoren zu sagen, die den Erfolg der anderen Vereine begünstigten. Für den Fall des Gesangvereins Deutsches Lied scheint die Tendenz zu Tage zu treten, dass dieser Verein als erster die soziale Basis der potenziellen Gesangvereinsmitglieder erweiterte. Durch die Gründung dieses Vereins scheint das organisierte Männergesangswesen in Einbeck, das offenbar bis zum Zeitpunkt der Gründung des Vereins im Jahre 1907 kleinbürgerlich-proletarisch dominiert war, für Angehörige des gehobenen Bürgertums, insbesondere des neuen Mittelstandes der Angestellten, geöffnet worden zu sein.

Der Arbeitergesangverein von 1892 dürfte sich nach dem Fall des Sozialistengesetzes rasch $\mathrm{zu}$ einem integralen Bestandteil der sich reorganisierenden sozialdemokratischen Arbeiterbewegung entwickelt und, wie oben gesagt, die beiden konspirativen berufsständischen Gesangvereine an Wirksamkeit überflügelt haben.

Über die Entwicklung der Zahl der in den verschiedenen Gesangvereinen organisierten Personen kann auf Grund der Quellenlage keine Aussage getroffen werden. Auch jeder Versuch einer Schätzung, so vage sie auch gehalten sein möge, wäre völlig unseriös.

$\mathrm{Zu}$ den eigentlichen Vereinsaktivitäten der Gesangvereine Einbecks ist zu sagen, dass diese deutlich über die reine Pflege des Gesanges hinaus reichten. In acht von neun erhaltenen Statuten von Gesangvereinen finden sich Hinweise auf Abhaltung von Vereinsfesten und/oder Pflege der Geselligkeit. Belege für stattgefundene Feste verschiedener Gesangvereine finden sich verstreut in behördlichen Quellen wie auch in Protokollen ausserhalb der Sängerschaft stehender Vereine. Anhand der Protokolle des MGV Harmonie ist eine überaus rege Festkultur nachweisbar; es besteht kein Grund zu der Annahme, dass dies bei den anderen Vereinen, deren Protokolle nicht mehr erhalten sind, anders gewesen sein sollte. 
Über die soziale Integrationskraft der Gesangvereine in Einbeck vor dem Ersten Weltkrieg kann auf Grund des Quellenmaterials nur konstatiert werden, dass vom organisierten Männergesang lediglich eine Tendenz der Zusammenführung von Angehörigen des Kleinbürgertums und der unterbürgerlichen Arbeiterschaft für den Fall des Männergesangvereins Harmonie nachgewiesen werden konnte.

Eine politisch-ideologische Aufspaltung des Männergesangvereinswesens in eine sozialdemokratisch gesonnene und eine bürgerliche Sängerschaft hatte in Einbeck bereits, wie das Beispiel der Liedertafel Lassallia zeigt, Jahre vor dem Beginn des Untersuchungszeitraumes stattgefunden. Diese Trennung des Vereinswesens in mindestens zwei politische Sphären kann kaum überraschen. Gerade die Sängerbewegung muss als prädestiniert für eine politische Segregation erscheinen; die Auswahl der zu singenden Lieder kann eine Entscheidung für unmittelbar politische Aussagen des Vereins sein, da durch den Vortrag von Liedern verbale Botschaften vermittelt werden. Dies belegt die Beanstandung des von der Liedertafel Lassallia benutzten Liederbuches ebenso wie die Absage des Arbeitergesangvereins auf die Einladung zur Feier des Jahrestages der Völkerschlacht bei Leipzig, auf der sicherlich auch das einschlägige national-antifranzösische Liedgut zum Vortrag kam.

Der geringe Umfang des im Stadtarchiv Einbeck erhaltenen Quellenmaterials über die Gesangvereine, an dessen Vollständigkeit kein Zweifel besteht, belegt, dass es zwischen den städtischen Behörden und den Gesangvereinen der Stadt nur wenig Kontakt gab. Eine Ausnahme hiervon bildete lediglich die Liedertafel Lassallia/Concordia, an deren Fall sich die praktische Umsetzung des Sozialistengesetzes auf lokaler Ebene studieren lässt. Bezeichnenderweise finden sich die Unterlagen über diesen Vorgang allerdings auch nicht in der Akte über die Gesangvereine, sondern in jener über das Gesetz gegen die gemeingefährlichen Bestrebungen der Sozialdemokratie. Die eingehende Beschäftigung der Behörden der Stadt Einbeck mit diesem Verein scheint sich aus der allgemeinen Stimmung des Jahres 1878 zu erklären. In diesem Jahr wurden zwei Attentate auf Kaiser Wilhelm I. verübt. Diese Mordversuche führten in Deutschland zu einer großen öffentlichen Erregung und einem Klima der Sozialistenfurcht, das es Bismarck ermöglichte, sein bereits länger geplantes und bereits einmal gescheitertes Vorhaben eines Sondergesetzes gegen die Sozialdemokratie nun ins Werk zu setzen.

Die Phase der Verfolgung und Überwachung etwaiger sozialistischer Bestrebungen im Gesangvereinswesen Einbecks durch die Behörden währte nur kurz; wie oben gezeigt, konnten bald nach der Auflösung der Lassallia/Concordia zwei neue sozialdemokratische Gesangvereine gegründet 
werden, deren Tätigkeit nicht durch obrigkeitliche Maßnahmen beeinträchtigt wurde.

Nach dem Sozialistengesetz begegneten die Behörden dem bald einzigen sozialdemokratischen Gesangverein, ebenso wie allen anderen Gesangvereinen, mit einem weitgehenden Desinteresse; auch wurde der Verein wie die bürgerlichen Gesangvereine zu den großen öffentlichen Festen eingeladen. Daher kann von einer Diskriminierung oder Schikanierung der Sozialdemokraten auf dem Gebiete des Männergesangvereinswesens ebensowenig wie von einer behördlichen Förderung des Gesangvereinswesens in seiner Gesamtheit die Rede sein. 


\section{2. Musik- und Theatervereine}

\section{2. 1 Die Musikvereine}

\section{2. 1. 1. Der Zither-Club}

Am 7. Oktober 1899 wurde der Zither-Club Einbeck gegründet. 1903 erschien der Vorstand des Vereins im Rathaus, legte zwei Exemplare einer Satzung von 1902 vor und ersuchte um die behördliche Genehmigung. ${ }^{202}$ Dieses Statut stellt die einzige bekannte Quelle über den Zither-Club dar. Da es recht detailliert ist, gibt es einige Einblicke in die Aktivitäten des Vereins. § 1 nennt das oben genannte Datum der Vereinsgründung und definiert als Vereinszweck, "seine Mitglieder im Einzel- sowie Gesamt-Spiel auszubilden, und die Zither und ihre Musik in der Achtung des Volkes zu heben." Dies sollte durch mindestens ein öffentliches Konzert im Jahr erreicht werden, wie § 14 vorsieht. Ferner sollte in jedem Jahr ein Stiftungsfest gefeiert werden "bestehend in Konzert-, Theater- oder sonstigen Aufführungen und evtl. darauf folgenden Tanz. Aktives Mitglied konnte nach $\S 2$, Absatz b, werden "wer die Zither oder ein ähnliches Instrument spielt." Anfänger konnten sich gegen 50 Pfennig Monatsgebühr ein Instrument aus dem Vereinsbestand ausleihen. Geübt wurde einmal wöchentlich für jeweils zwei Stunden. An den Übungsabenden hatte ein vorher bestimmtes Mitglied ein Solo vorzutragen, welches dann von den anderen Anwesenden der Reihe nach nachzuspielen war. Die vier bekannten Vorstandsmitglieder waren ein Kaufmann, ein Schriftsetzer, ein Werkmeister und ein Tapezierer mit eigener Möbelhandlung, also Angehörige des Bürgertums. Eine gewisse soziale Exklusivität war durch die Vereinsgebühren gegeben: Bei Beitritt zum Zither-Club war eine Mark zu bezahlen, der Monatsbeitrag betrug 30 Pfennig für Aktive und 40 Pfennig für Passive. Von einem stadtbürgerlichen Selbstverständnis zeugt eine Bestimmung des $\S 18$ : Im Falle der Auflösung sollte das Vereinsvermögen "dem Magistrate der Stadt Einbeck deponiert werden, um eine erneute VereinsGründung, evtl. späterhin leichter zu ermöglichen. Falls solche Neu-Gründung innerhalb 5 Jahren nicht erfolgt, verfällt das Vermögen den Armen der Stadt

\footnotetext{
202 Vgl.: StAEin 065 - 28, Unterakte Zither-Club, 2. Februar 1903. Die behördliche Genehmigung war allerdings, wie aus einem Schreiben Bürgermeiter Trojes in dieser Sache an den Vorstand hervorgeht, nicht erforderlich. Vgl. hierzu: StAEin 065 - 28, Unterakte ZitherClub, 14. Februar 1903
} 
Einbeck."203 Auch die Wahl des Vereinslokals zeugt von bürgerlichem Selbstbewußtsein; das Adressbuch von 1904 gibt als Sitz des Vereins das vornehme Hotel zum Goldenen Löwen an.

Es scheint wahrscheinlich, dass der zuletzt zitierte Statutenpassus recht schnell zur Anwendung kam: die Erwähnung im Adressbuch von 1904 ist der letzte bekannte Beleg für die Existenz des Vereins, in späteren Vereinslisten erscheint er nicht mehr.

${ }^{203} \mathrm{Zu}$ allem über den Verein und seine Tätigkeit Gesagten vgl.: StAEin 065 - 28, Unterakte Zither-Club, 1. Oktober 1902 


\section{2. 1. 2. Der Conzertina-Club}

Aus dem Jahr 1910 stammt ein Statut des Einbecker Conzertina-Clubs. 204 Dies ist der älteste Beleg für die Existenz diese Vereins. Dass es sich bei diesem trotz einer geringen Dichte an erhaltenen Primärquellen um eine zumindest in zeitlicher Hinsicht relativ erfolgreiche Vereinsgründung handelte, belegt zunächst der Umstand, dass bereits wenige Monate nach der Verfassung der genannten und als Gründungsstatut anzunehmenden Satzung diese weitgehend textidentisch - gedruckt wurde. ${ }^{205}$ Nach $\S 1$ bezweckte der Verein "die Conzertina-Musik zu fördern und $\mathrm{zu}$ pflegen und den Mitgliedern genußreiche Stunden zu verschaffen." Neben den Noten für die zu spielenden Musikstücke besaß der Verein ein Schlagzeug; die Conzertinen waren Eigentum der Mitglieder. ${ }^{206}$ Eine mit dem handschriftlichen Statutenexemplar den Behörden eingereichte Mitgliederliste vom März 1911 weist zehn Mitglieder aus. ${ }^{207}$ Auch wenn eine vollständige Zuordnung von Berufen nicht möglich war, so tritt eine deutliche Tendenz bezüglich der sozialen Herkunft zu Tage. Neben dem Wirt des Rheinischen Hofes, der Vereinslokal gewesen sein dürfte, gehörten acht Männer zweifellos der Arbeiterschaft oder dem unteren Kleinbürgertum an.

Bemerkenswert an der Mitgliederstruktur muss erscheinen, dass drei der zehn bekannten Mitglieder nicht aus Einbeck, sondern aus dem etwa sechs Kilometer enfernten Dorf Dassensen stammten. Auch der einzige bekannte Vorsitzende des Vereins, ein G. Nüsse, wohnte dort. Dies legt die Vermutung nahe, dass der Impuls zur Vereinsgründung von Dassensen ausging. Dies würde zumindest teilweise einen Gegenbefund zu Ernst M. Wallners plausiblen und weithin gültigen Schema bilden, dass sich die Idee der Gründung von Freizeitvereinen in Stadt-Land-Richtung ausbreitete. 208

\footnotetext{
204 Die Conzertina ist eine chromatische Ziehharmonika. Zum Statut: StAEin 065 - 28, Unterakte Conzertina-Club, 1. August 1910

205 StAEin 065 - 28, Unterakte Conzertina-Club, 9. März 1911

206 Vgl.: StAEin 065 - 28, Unterakte Conzertina-Club, Statuten vom 1. August 1910 und 9.

März 1911, jeweils $\S \S 1,11,12$

207Vgl:: StAEin 065 - 28, Unterakte Conzertina-Club, 15. März 1911

${ }^{208}$ Vgl. hierzu: Wallner, Ernst M.: Die Rezeption stadtbürgerlichen Vereinswesens durch die Bevölkerung auf dem Lande. in: Wiegelmann, Günter (Hg.): Kultureller Wandel im 19.

Jahrhundert. Verhandlungen des 18. Deutschen Volkskunde-Kongresses in Trier vom 13. bis

18. September 1971. (Studien zum Wandel von Gesellschaft und Bildung im Neunzehnten Jahrhundert, Band 5). Göttingen 1973, SS. 160 - 173
} 
Eine gewisse Nähe des Conzertina-Clubs zur Arbeiterbewegung lässt sich an Hand der Protokolle des dem Arbeiter-Turnerbund (ATB) angehörenden Turnklub Eintracht Einbeck 209 nachweisen. 1911 musizierte der Club auf dem ATB-Kreisturnfest 210 , später auch $\mathrm{zu}$ verschiedenen Vergnügen des TC Eintracht. ${ }^{211}$ Auch kooperierte man mit den Einbecker Arbeitervereinen indem man versprach, nicht zeitgleich zu etwaigen Vergnügungen dieser Vereine zu spielen. ${ }^{212}$ Allerdings scheute sich der Conzertina-Club bis zum Ende des Untersuchungszeitraumes, sich über den noch im Kapitel über den Turnklub Eintracht näher $\mathrm{zu}$ behandelnden Bildungsausschuss der Arbeitervereine in die Organisationsstruktur der Arbeiterbewegung einzugliedern. Entsprechende Bemühungen, den Verein zum Beitritt zu bewegen, blieben ohne Erfolg. 213

Weitere Belege über Mitgliederzahl und -struktur wie auch über die Aktivitäten des Conzertina-Clubs sind nicht bekannt.

209 Zur Rolle des Turnklub Eintracht in der Arbeiterbewegung vgl. das einschlägige Kapitel der vorliegenden Untersuchung

210 Vgl.: Eintracht Einbeck, Protokoll 9. Juli 1911

${ }^{211}$ Vgl.: Eintracht Einbeck, Protokolle 7. September 1912, 2. August 1913, 6. Dezember 1913

212 Vgl.: Eintracht Einbeck, Protokoll 10. Dezember 1912

213 Vgl.: Eintracht Einbeck, Protokolle 2. Dezember 1911, 7. Februar 1912, 10. Dezember 1912, 2. Mai 1914 


\section{2. 1. 3. Weitere Musikvereine}

In der bereits zitierten undatierten behördeninternen Vereinsliste vom Sommer $1893^{214}$ werden zwei weitere Musikvereine genannt, der Zither Verein Club Vorwärts und der Posaunenchor.

Aufgrund des Namens ist ersterer der Sphäre der sozialdemokratisch gesonnenen Vereine zuzuordnen. Dieser Beleg für die Existenz ist singulär, daher sind weitere Aussagen über den Verein unmöglich.

Auch über letzteren finden sich kaum weitere Belege. In einer Vereinsliste im Bildband zum 100-jährigen Bestehen des Einbecker Geschichtsvereins ist von einem Posaunenchore zu erfahren. Allerdings wird der Beleg nicht präzise genannt, es wird lediglich mitgeteilt, dass der Posaunenchor zwischen 1870 bis 1914 in der örtlichenZeitung erwähnt wurde. ${ }^{215}$ Denkbar ist, dass es sich beim Posaunenchor um eine teilautonome Untereinheit einer oder mehrerer Kirchengemeinden handelte.

Die selbe Liste nennnt für den Untersuchungszeitraum daneben einen Musikverein in Einbeck. ${ }^{216}$ Auch für das Bestehen dieses Vereines fehlen weitere Belege. Möglicherweise liegt hier eine Verwechslung mit dem 1898 gegründeten Musikerverein vor. Dieser war kein Verein im Sinne der vorliegenden Studie, sondern ein Interessenverband von Berufsmusikern. ${ }^{217}$

\footnotetext{
${ }^{214}$ StAEin $065-17$

${ }^{215}$ Vgl.: Einbecker Geschichtsverein (Hg.): Stadt Einbeck. Zeitgenössische Fotografien und Dokumente. Gesammelt und bearbeitet von Erich Strauß, Hellmut Hainski und Andreas Heege. Duderstadt 1995, S. 159

216 Vgl.: ibid.

${ }^{217}$ Zum Musikerverein vgl. die entsprechende Unterakte in StAEin 065 - 28
} 


\section{2. 2. Die Theatervereine}

\section{2. 2. 1. Der Dilettanten-Club Walhalla}

Im Jahr 1892 wurde unter der Bezeichnung Dilettanten-Club Walhalla ein Amateur-Theaterverein gegründet. Die Statuten wurden mit einem Anschreiben vom 27. November jenes Jahres den städtischen Behörden eingereicht. 218 Schrift, Sprachstil, Orthographie und Umfang des nur sechs Paragraphen umfassenden Statuts lassen den eindeutigen Schluss zu, dass es sich bei den Vereinsgründern um Angehörige bildungsfernerer Schichten gehandelt haben muss. So lautet der erste Paragraf, der den Zweck des Vereins definiert, wörtlich: "Der Diletanten Club Walhalla hat sich zur Aufgabe gemacht, humoristische Sachen und kleine Theaterstüken zur Aufführung zu bringen." 219 Der Schluss, dass es sich bei den Vereinsgründern nicht um Angehörige des Bildungsbürgertums handelte, wird durch die Person des Gründungsvorsitzenden bestätigt. Von diesem ist aus den Akten lediglich der Familienname Binnewies 220 bekannt. Nach dem zeitnächsten Adressbuch für die Stadt handelte es sich bei diesem ersten Präsidenten entweder um einen Heizer oder einen Postassistenten.

Die Aufführungen harmloser Schwänke und nicht sehr anspruchsvoller Darbietungen der Anfangszeit waren offenbar in bunte Abendveranstaltungen eingebunden. Eine kurze Zeitungsnotiz aus dem Januar 1893 berichtet von einer solchen Veranstaltung: "Am Sonnabend, den 22. d. M. hielt der erst vor einiger Zeit gegründete Dilettanten-Club 'Walhalla' sein 2. Kränzchen, verbunden mit theatralischen Aufführungen ab, welche von dem zahlreich anwesenden Publikum mit großem Beifall aufgenommen wurden. Hervorzuheben sind die beiden plattdeutschen Lustspiele: 'Jeder Pott findt sin Deckel' und 'De Schulinspekschon', sowie 'Die dumme Auguste' und einige humoristische Gesangsvorträge. Ganz besonders hervorzuheben ist noch das lebende Bild 'Dornröschens Erwachen aus dem 100jährigen Schlafe', welches mit enthusiastischem Beifall aufgenommen wurde. In nächster Zeit kommen 'Der Goldonkel', große Posse mit Gesang und Tanz zur Aufführung."221

\footnotetext{
218 StAEin 065 - 23, 27. November 1892

${ }^{219} \mathrm{Zu}$ diesen wie auch allen weiteren das Gründungsstaut betreffenden Dingen vgl.: StAEin 065 - 23, Anlage zu 23. Novmber 1892

220 Vgl.: StAEin 065 - 23, 27. November 1892, 1. Dezember 1892, 13. Dezember 1892

221 Einbecker Zeitung, 25. Januar 1893
} 
Wie auch andere Vereine nahm die Walhalla offenbar nicht nur "runde" Gründungsungsjubiläen als willkommenen Anlass, Feste $\mathrm{zu}$ feiern. Ein Protokoll des Turnklub Eintracht erwähnt eine Einladung zum zweijährigen Stiftungsfest. 222

Die auf Grund des durch die oben erwähnte relative Bildungsferne seiner Gründer nahe liegende Vermutung, dass es sich bei dem Verein um eine der in jener Zeit vielfach in Deutschland gegründeten Arbeiterbühnen 223 gehandelt haben könnte, wird durch ein späteres Schriftstück widerlegt. Im Jahre 1903 sandte der Verein den städtischen Behörden erneut ein Statut zur Genehmigung ein. Das Anschreiben wurde auf einem gedruckten, reich verzierten Briefbogen verfasst. Aus dem Druck geht hervor, dass der Verein im Schusterkrug beheimatet war, ferner, dass er dem Verband der Privat-Theater-Vereine Deutschlands angehörte. Im Briefkopf ist als Motto ein Zitat Friedrich von Schillers enthalten: "Ernst ist das Leben, heiter die Kunst". ${ }^{24}$ Der Verein gehörte also einem zweifelsohne nicht der Sphäre der sozialdemokratischproletarisch orientierten Vorfeldorganisationen zuzuordnenden Dachverband an. Auch das zum Leitspruch erwählte Schillerwort kann, trotz der für Kreise der organisierten Arbeiterbewegung vor dem Ersten Weltkrieg hinreichend dokumentierten Verehrung für diesen Dichter ${ }^{225}$, nicht als Beleg für eine Nähe der Walhalla zur klassenbewussten Arbeiterschaft gedeutet werden. Gegenüber dem ersten Statut weist die Satzung von 1903 einen deutlich gehobenen Sprachduktus auf, so liest sich $\S 1$ in der Fassung von 1903: "Der Dilettanten-Club 'Walhalla' hat seinen Sitz in Einbeck und verfolgt den Zweck, seinen Mitgliedern auf dem Gebiete der dramatischen Kunst durch entsprechende Vorlesungen, Rezitationen, Deklamationen und Theateraufführungen auszubilden und hierdurch die dramatische Kunst, sowie die Geselligkeit zu pflegen. Der Club ist stimmberechtigtes Mitglied des

\footnotetext{
222 Vgl.: Eintracht Einbeck, Protokoll 11. August 1894. Der TK Eintracht war zu jener Zeit noch nicht der organisierten Arbeiterbewegung zuzurechnen, doch davon unten mehr.

223 Vgl. hierzu e. g.: Ritter, Gerhard A.: Arbeiter, Arbeiterbewegung und soziale Ideen in Deutschland. Beiträge zur Geschichte des 19. und 20. Jahrhunderts. München 1996, SS. 121 ff. 224 Das Zitat entstammt dem Prolog zu "Wallensteins Lager", gesprochen bei der Wiedereröffnung der Schaubühne in Weimar im Oktober 1798 ${ }^{225}$ Zur Schillerverehrung in der deutschen Arbeiterbewegung vgl. e. g.: Vierhaus, Rudolf: Bürgerliche Hegemonie oder proletarische Emanzipation: der Beitrag der Bildung. in: Kocka, Jürgen (Hg.): Arbeiter und Bürger im 19. Jahrhundert. Varianten ihres Verhältnisses im europäischen Vergleich. (Schriften des Historischen Kollegs, Kolloquien 7). München 1986, SS. 53 - 64, SS. 60 f.
} 
Verbandes der Privat-Theater-Vereine Deutschlands und hat Anteil an sämtlichen Einrichtungen des Verbandes."226

Über die Person des 1903 als Vereinsvorsitzende fungierenden Martin Cohn 227 war nichts in Erfahrung zu bringen, ebenso fehlen über die bereits oben erwähnten Vereinslisten in den Adressbüchern hinaus weitere Quellen, die mehr als das Bestehen des Dilettanten-Club Walhalle bis über das Ende des Untersuchungszeitraums hinaus belegen. 


\section{2. 2. Der Dramatische Club Thalia}

Ebenfalls gegen die Annahme, dass Walhalla ein Arbeiterverein war, spricht die Gründung eines zweifellos dem Arbeitermilieu zuzuordnenden Theatervereins in Einbeck im frühen 20. Jahrhundert. Dieser im September $1901^{228}$ gegründete Verein trug den Namen "Dramatischer Club Thalia". Über die frühe Geschichte des Vereins, der - anders als der Dilettanten-Club Walhalla - bis in die Zeit nach dem Zweiten Weltkrieg hinein bestand, war aus den untersuchten Quellen kaum etwas in Erfahrung $\mathrm{zu}$ bringen. In den einschlägigen Vereinslisten der verschiedenen Adressbücher, die es ab 1902 gab, erscheint der Verein durchgehend. In den Adressbüchern der Jahre 1902 bis 1907 ist als Vereinslokal der Schusterkrug angegeben, laut Liste für 1911/12 war der Verein in den Rheinischen Hof umgezogen. Auf einer historischen Photographie von der Maifeier 1919 auf dem Einbecker Marktplatz ist eine Vereinsfahne des Dramatischen Clubs Thalia zu erkennen. Diese trägt die Jahreszahl 1910, das somit als Jahr der Anschaffung und Weihe der Fahne anzusehen ist. ${ }^{229}$ Kontakte des Clubs zur organisierten Arbeiterbewegung sind ab dem Jahr 1905 nachzuweisen. In diesem Jahr lud man den den Turnklub Eintracht zu einem Fest ein. ${ }^{230}$ Weitere Einladungen dieser Art an den selben Verein sind für die Jahre 1909 und 1911 nachzuweisen. ${ }^{231}$ Eine Gegeneinladung der Turner an den Dramatischen Club Thalia ist für das Jahr 1907 belegt. ${ }^{232} \mathrm{Ab} 1912$ gehörte der Verein dem Deutschen Arbeiter-Theater-Bund an. ${ }^{233}$

Aus den bekannten Quellen war nichts über die Vereinsmitglieder, die gespielten Stücke oder sonstige Vereinsaktivitäten zu erfahren.

\footnotetext{
228Zum Gründungsdatum vgl.: Einbecker Geschichtsverein (Hg.): Stadt Einbeck.

Zeitgenössische Fotografien und Dokumente. Gesammelt und bearbeitet von Erich Strauß, Hellmut Hainski und Andreas Heege. Duderstadt 1995, S. 159

229 Die Photographie befindet sich in Privatbesitz. Sie wurde in der Ausgabe der Einbecker Morgenpost vom 29./30. April 2001 abgedruckt. Allerdings ist in dieser Reproduktion aus drucktechnischen Gründen die Jahreszahl nicht zu erkennen.

230 Vgl.: Eintracht Einbeck, Protokoll 2. September 1905

${ }^{231}$ Vgl.: Eintracht Einbeck, Protokolle 4. September 1909, 9. Juli 1911

232 Vgl.: Eintracht Einbeck, Protokoll 2. November 1907

${ }^{233}$ Vgl.: Brinckmann, Ilse: Dokumentation zur Geschichte der Stadt Einbeck 1918 - 1945.

Einbeck o. J., S.12
} 


\section{3. Die Turn- und Sportvereine}

\section{3. 1. Die Turnvereine}

\section{3. 1. 1. Zur Geschichte der Turnbewegung in Deutschland}

Die Turnbewegung ist die älteste aller deutschen organisierten Bewegungen im Bereich der Bewegungskultur. Als ihr Begründer gilt der Pädagoge Friedrich Ludwig Jahn. Er führte die Idee der Ausbildung des Körpers als Mittel zur Erziehung des Menschen mit dem im ersten Jahrzehnt des 19. Jahrhunderts entstehenden deutschen Nationalismus zusammen. Jahn ersetzte die Bezeichnung "Gymnastik" durch "Turnen", da dieses Wort seiner Ansicht nach germanischen Ursprungs und daher einem Gräzismus vorzuziehen sei. 234

Von Anfang anorganisierte er seine Turnbewegung als Vereinsbewegung. 1811 eröffnete Jahn auf der Hasenheide in Berlin den ersten deutschen Turnplatz und gründete den ersten deutschen Turnverein. Das Jahnsche Turnen umfasste ein weites Spektrum der damals bekannten Leibesübungen. Neben dem Turnen im heutigen, eingeschränkten Sinne mit den von Jahn kreierten Geräten wie Barren und Reck betrieb man Bewegungsspiele, Lauf- und Wurfübungen, Schwimmen, Fechten und Wanderungen. ${ }^{235}$ Dem Turnen lag ein unverkennbar militärisch-kollektivistisches Ideal zu Grunde. Viele der Übungen waren eindeutig paramilitärischer Natur. ${ }^{236}$

234 Jahn irrte allerdings; das Wort "turnen" geht auf das lateinische "tornare", drehen, zurück. Vgl. hierzu: Düding, Dieter: Von der Opposition zur Akklamation - Die Turnbewegung im 19. Jahrhundert als politische Bewegung. in: Diekmann, Irene; Teichler, Joachim H. (Hgg.): Körper, Kultur und Ideologie. Sport und Zeitgeist im 19. und 20. Jahrhundert. (Studien zur Geistesgeschichte, Band 19). Bodenheim 1997, SS. 79 - 97, S. 82 und die einschlägigen etymologischen Nachschlagewerke.

${ }^{235}$ Vgl.: Neumann, Hannes: Leibesübungen im Dienste nationaler Bestrebungen: Jahn und die deutsche Turnbewegung. Teil I: Von den Anfängen bis zur Reichsgründung. in: Ueberhorst, Horst (Hg.). Geschichte der Leibesübungen, Band 3/1. Berlin, München, Frankfurt am Main 1980, SS. 257 - 277, S. 258 und Pfister, Gertrud: Zur Geschichte des Körpers und seiner Kultur - Gymnastik und Turnen im gesellschaftlichen Modernisierungsprozeß. in: Diekmann, Irene; Teichler, Joachim H. (Hgg.): Körper, Kultur und Ideologie. Sport und Zeitgeist im 19. und 20. Jahrhundert. (Studien zur Geistesgeschichte, Band 19). Bodenheim 1997, SS. 11 - 47. SS. $30 \mathrm{f}$.

${ }^{236}$ Vgl.: Pfister, Gertrud: op. cit., SS. 31 f. 
Der Jahnsche Turnverein verzeichnete nach seiner Gründung regen Zulauf. Nach dem Ende der so genannten Befreiungskriege expandierte die Turnbewegung vor allem in Preußen und Mitteldeutschland stark. Bereits 1818 existierten in 150 Städten Turnvereine mit insgesamt 12.000 Mitgliedern. ${ }^{237}$ Die Turnbewegung entwickelte sich zu einem wesentlichen Bestandteil der oppositionellen frühen Nationalbewegung.

Die Karlsbader Beschlüsse und deren Folgen betrafen dann auch die Turnbewegung wesentlich. Jahn wurde vorübergehend in Haft genommen, Turnvereine wurden verboten. ${ }^{238}$ Damit war die Entwicklung des Turnvereinswesens zunächst unterbrochen, nicht aber jene des Turnens generell. Staatlicherseits war der Nutzen der Leibesübungen für die vormilitärische Ausbildung der Jugend erkannt worden. Daher wurde das Turnen in der Folgezeit unter staatlicher Aufsicht als Schulsport fortgeführt. 239

Erst in den vorrevolutionären vierziger Jahren des 19. Jahrhunderts wurde die Turnvereinsbewegung wieder belebt. Allerdings hatte sie sich gewandelt. Waren in der Gründungszeit vor allem Schüler und Studenten Turner gewesen, so rekrutierte sich nun die Mehrheit der Turner aus erwerbstätigen Männern aus den verschiedensten bürgerlichen Schichten. Am Vorabend der Revolution gab es etwa 90.000 organisierte Turner in Deutschland. ${ }^{240}$ Das Scheitern der Revolution brachte eine Verschärfung der Vereinsgesetzgebung in den deutschen Staaten, durch die auch die Entwicklung der Turnbewegung erneut zurück geworfen wurde. Am Beginn der sechziger Jahre waren von den etwa 300 Vereinen der Jahre 1848/49 nur noch etwa 100 übrig geblieben; die Turnbewegung hatte den Charakter einer politischen Massenbewegung eingebüßt. Lediglich im Bereich der schulischen Leibesübungen blieb das Jahnsche Turnen dominant. 241

Mit dem Beginn der sechziger Jahre kam es zu einer erneuten Gründungswelle von Turnvereinen. Allein in den ersten beiden Jahren dieser Dekade wurden über 1.000 Turnvereine gegründet. ${ }^{242} 1863$ gab es annähernd 135.000 in Vereinen organisierte Turner ${ }^{243}, 1864$ zählte man fast 170.000.244

\footnotetext{
237 Vgl.: Düding, Dieter: op. cit., SS. 82 ff.

238 Vgl.: Düding, Dieter: op. cit., SS. 85 f.

239 Vgl.: Neumann, Hannes: op. cit., SS. 261, 264

24 0Vgl.: Düding, Dieter: op. cit., SS. 86 f.

241 Vgl.: Neumann, Hannes: op. cit., S. 272

242 Vgl.: Neumann, Hannes: op. cit., S. 273

243 Vgl.: Düding, Dieter: op. cit., S. 88
} 
Erstmals erfasste die Turnbewegung auch Deutsch-Österreicher und Industriearbeiter. ${ }^{245}$ Doch bereits 1869 war die Zahl der Turner wieder auf 130.000 Männer in weniger als 1.600 Vereinen gesunken. 246

In die sechziger Jahre des 19. Jahrhunderts fiel auch die Gründung der Deutschen Turnerschaft (DT) als deutschlandweiten Dachverband. Bereits 1861 wurde die Satzung von einem Ausschuss der deutschen Turnvereine formuliert und beschlossen, doch erst 1868 wurde die DT de jure gegründet. Sie schloss auch die Turner Deutsch-Österreichs mit ein. Nach der Satzung bezweckte die Deutsche Turnerschaft, "dem Vaterlande ganze tüchtige Männer zu erziehen; jedwede politische Parteistellung jedoch muß den Turnvereinen als solchen unbedingt fernbleiben.". 247

Nach der Reichsgründung im Jahre 1871 gehörten die Turner zu den eifrigsten Propagandisten des neuen Reiches. Die durchaus in der Turnbewegung des Vormärz vertretenen demokratisch-republikanischen Strömungen 248 traten in der Deutschen Turnerschaft des Kaiserreiches nicht mehr in Erscheinung; die einstmalige Oppositionsbewegung vertrat nunmehr einen affirmativen illiberalen Reichsnationalismus. Dieser neue Nationalismus richtete sich, wie die Reichspolitik, zunächst in erster Linie gegen den westlichen Nachbarn Frankreich, im Zuge der innenpolitischen Konflikte des Reiches aber auch gegen die Katholiken und später vor allem gegen die Sozialdemokraten. 249

Dennoch konnte die DT, insbesondere nach dem Fall des Sozialistengesetzes, nicht die Gründung einer unabhängigen Arbeiterturnbewegung verhindern, die 1893 in die Gründung eines reichsweiten Konkurrenzverbandes, des Arbeiter-Turner-Bundes (ATB) gipfelte. Dieser neue Verband hatte sofort nach seiner Gründung einen beachtlichen Zulauf zu verzeichnen. Viele der neueingetretenen Vereine und

\footnotetext{
244 Vgl.: Neumann, Hannes: op. cit., S. 274

245 Vgl.: Düding, Dieter: op. cit., S. 88

246 Vgl.: Neumann, Hannes: op. cit., S. 275

247 Zitiert nach John, Hans-Georg: Leibesübungen im Dienste nationaler Bestrebungen: Jahn und die deutsche Turnbewegung. Teil II: Die Turnbewegung im deutschen Kaiserreich von 1871 bis 1918. in: Ueberhorst, Horst (Hg.). Geschichte der Leibesübungen, Band 3/1. Berlin, München, Frankfurt am Main 1980, SS. 278 - 324, S. 281

248 Vgl.: Neumann, Hannes: op. cit., passim

249 Vgl.: Düding, Dieter: op. cit., SS. $91 \mathrm{f}$.
} 
Turner waren ehemalige Mitglieder der DT.250 Doch in der Folgezeit entstanden auch viele neue Arbeiterturnvereine. Zwar gelag es dem ATB niemals, alle turnenden Arbeiter an sich zu binden ${ }^{251}$, dennoch konnte er von seiner Gründung bis zum Ende des Untersuchungszeitraumes ein beachtliches Wachstum erzielen. Betrug der Mitgliederbestand des ATB am Ende des Jahres seiner Gründung etwa 3.500 Mitglieder in 42 Vereinen, so wuchs er bis zum Ersten Weltkrieg auf ungefähr 187.000 Turner in über 2.400 Vereinen an. ${ }^{252}$ Allerdings blieb der ATB mit diesen Zahlen immer noch weit hinter der DT zurück, die am Vorabend des Ersten Weltkrieges etwa 1,5 Millionen Turner $^{253}$ in etwa 11.500 Vereinen $^{254}$ umfasste.

Eine weitere alternative Verbandsgründung entstand im Jahre 1897. Als Reaktion auf den zunehmenden Antisemitismus innerhalb der DT bildete sich in diesem Jahr die Jüdische Turnerschaft. Dieser Verband hatte allerdings nur in großen Städten Mitglieder und umfasste 1914 2.400 Mitglieder. ${ }^{255}$

250 Vgl:: Nipperdey, Thomas: Deutsche Geschichte 1866 - 1918. Erster Band: Arbeitswelt und Bürgergeist. München 1990, S. 174

${ }^{251}$ Vgl.: Ritter, Gerhard A.: Arbeiter, Arbeiterbewegung und soziale Ideen in Deutschland. Beiträge zur Geschichte des 19. und 20. Jahrhunderts. München 1996, S. 126 ${ }^{252}$ Vgl.: Teichler, Hans-Joachim: Arbeitersport als soziales und politisches Phänomen im wilhelminischen Klassenstaat. in: Ueberhorst, Horst (Hg.). Geschichte der Leibesübungen, Band 3/1. Berlin, München, Frankfurt am Main 1980, SS. 443 - 484, S. 484

253 Vgl.: Nipperdey, Thomas: op. cit., S. 172

254 Vgl.: John, Hans-Georg: op. cit., S. 324

${ }^{255}$ Vgl.: Mayer, Paul Yogi: Deutsche Juden und Sport. in: Diekmann, Irene; Teichler, Joachim H. (Hgg.): Körper, Kultur und Ideologie. Sport und Zeitgeist im 19. und 20. Jahrhundert. (Studien zur Geistesgeschichte, Band 19). Bodenheim 1997, SS. 119 - 146, SS. $127 \mathrm{f}$. 


\section{3. 1. 2. Der Männer-Turn-Verein Einbeck}

\section{3. 1. 2. Gründung und Entwicklung}

Der Männer-Turn-Verein Einbeck wurde, wie oben bereits gesagt, im Jahre 1861 gegründet. Diese Vereinsgründung ging auf die Initiative des Leiters der Webschule, Schreiber, und des Oberlehrers Bickmeyer zurück. Über die frühen Jahre des Vereins ist recht wenig zu ermitteln. Die erhaltenen Protokolle setzen mit jenem vom 26. Februar 1875 ein und sind bis zum Protokoll der Generalversammlung vom 10. Mai 1905 vollständig erhalten. Für die Zeit nach dem Mai 1905 gibt es kaum Nachrichten über den Verein, die mehr als seine pure Weiterexistenz belegen. Die älteste erhaltene Statutenhandschrift des Vereins stammt vom 2. August 1867.256 Das älteste gedruckte Statutenexemplar ist auf den 2. Dezember 1867 datiert. ${ }^{257}$ Dem erstgenannten Statut ist eine Mitgliederliste von Juli 1874 bis Januar 1878 angeschlossen. Diese ist jedoch für die Erstellung einer zuverlässigen Mitgliederstatistik ebenso untauglich wie eine weitere erhaltene Kladde, in der zwei Mitgliederlisten mit den Laufzeiten Februar 1879 bis Juni 1888 und Juni 1888 bis Januar 1901 überliefert sind; alle diese erhaltenen Listen dokumentieren zwar sämtliche Eintritte in den Verein und stellen so eine gute Basis für recht zuverlässige soziostrukturelle Aussagen dar, doch sind die Austritte aus dem Verein über viele Jahre hinweg so unvollständig dokumentiert, dass sich Angaben über die Mitgliederzahl und -entwicklung aus ihnen nicht errechnen lassen. Die einzigen zuverlässigen Quellen für eine solche Statistik stellen, neben einigen vereinzelten Belegen in den überlieferten Protokollen, die in den dem Statut von 1867 beigefügten Kassenlisten von 1880 bis 1884 und in einem separaten Kassenbuch mit der Laufzeit 1884 - 1895 enthaltenen vierteljährlichen Abrechnungen der Mitgliedsbeiträge dar. Nach den genannten Quellen stellt sich die quantitative Mitgliederentwicklung des MTV Einbeck wie folgt dar:

$\begin{array}{lrrr}\text { Zeit } & \text { Mitglieder } & 09.1880 & 36 \\ 03.1878 & 52 & 12.1880 & 56 \\ 03.1879 & 53 & 03.1881 & 57 \\ & & 06.1881 & 54\end{array}$

256 Enthalten in: Männer-Turn-Verein Einbeck: Statuten-, Mitglieder- und Kassenbuch 1867 1884

257 StAEin 065 - 24, 2. Dezember 1867 


\begin{tabular}{|c|c|c|}
\hline 09.1881 & 57 & 03.1888 \\
\hline 12. 1881 & 68 & 06. 1888 \\
\hline 03.1882 & 61 & 09.1888 \\
\hline \multirow[t]{2}{*}{06.1882} & 52 & 12. 1888 \\
\hline & & 03.1889 \\
\hline 12. 1882 & 55 & 06. 1889 \\
\hline 03.1883 & 30 & 09. 1889 \\
\hline 06. 1883 & 25 & 12. 1889 \\
\hline 09.1883 & 23 & 03.1890 \\
\hline 12. 1883 & 22 & 06. 1890 \\
\hline 03.1884 & 31 & 09.1890 \\
\hline 06. 1884 & 31 & 12. 1890 \\
\hline 09.1884 & 40 & 03.1891 \\
\hline 12. 1884 & 41 & 06.1891 \\
\hline 03.1885 & 44 & 09.1891 \\
\hline 06.1885 & 39 & 12. 1891 \\
\hline 09.1885 & 32 & 03.1892 \\
\hline 12. 1885 & 38 & 06.1892 \\
\hline 03. 1886 & 43 & 09.1892 \\
\hline 06. 1886 & 47 & 12. 1892 \\
\hline 09.1886 & 47 & 03.1893 \\
\hline 12. 1886 & 55 & 06.1893 \\
\hline 03.1887 & 54 & 09.1893 \\
\hline Zeit & Mitglieder & 12. 1893 \\
\hline 06.1887 & 54 & 03.1894 \\
\hline 09.1887 & 50 & 06.1894 \\
\hline 12. 1887 & 46 & 09.1894 \\
\hline 12. 1894 & 66 & \\
\hline 03.1895 & 66 & \\
\hline 06.1895 & 62 & \\
\hline 09.1895 & 63 & \\
\hline 12. 1895 & 59 & \\
\hline
\end{tabular}


Hieraus lassen sich folgende Jahresdurchnittswerte errechnen:

Jahr

durchschnittliche Mitgliederzahl

1881

59

1882

56

1883

25

$1884 \quad 36$

$1885 \quad 38$

$1886 \quad 48$

$1887 \quad 51$

$1888 \quad 51$

$1889 \quad 48$

$1890 \quad 44$

$1891 \quad 40$

$1892 \quad 48$

$1893 \quad 51$

$1894 \quad 53$

$1895 \quad 63$

In beiden vorstehenden Mitgliederstatistiken sind sämtliche Personen berücksichtigt, welche regelmäßige Beiträge an die Vereinskasse zahlten. Dies waren gemäß der für den gesamten Zeitraum der Erfassung gültigen Statuten von 1867 neben den aktiven und passiven Turnern die Turnschüler (Turner unter 18 Jahren) und die Turnfreunde, fördernde Mitglieder ohne Stimmrecht in den Versammlungen. Nicht berücksichtigt sind die Ehrenmitglieder, da diese von Beitragszahlungen befreit waren.

Die oben dargestellte Statistik macht deutlich, dass die Jahresdurchschnittswerte der Mitgliederzahl, sieht man einmal von dem Wert für das Jahr $1883 \mathrm{ab}$, von dem im Abschnitt über den TV Germania noch zu reden sein wird, keinen starken Schwankungen unterlagen und erst gegen Ende des Erfassungszeitraumes den Wert von sechzig Mitgliedern übertreffen.

Diesen eher geringen Werten steht jedoch eine hohe Anzahl von dokumentierten Eintritten in den Verein gegenüber. So umfassen die oben erwähnten drei erhaltenen Mitgliederlisten eine deutlich höhere Anzahl von Personen; die Liste, welche im Juli 1874 angelegt wurde und bis zum Januar 1878 reicht, umfasst 207 Namen, die Liste vom Februar 1879 bis zum Juni 1888 enthält 342 Personen und jene von Juni 1888 bis zum Januar 1901407 Männer. Diese Werte weisen auf eine hohe Mitgliederfluktuation hin. Diese Fluktuation lässt sich für die Eintrittsjahrgänge 1879, 1882, 1893 und 1896 nur für diese Jahrgänge liegen halbwegs verlässliche Daten über die 
Vereinsaustritte vor - dokumentieren. So verliessen sämtliche 27 Turner, die im Jahre 1879 dem Verein beitraten, den MTV Einbeck bis zum Juni 1888 wieder. In 26 Fällen war die Verweildauer im Verein zu ermitteln; sie variierte von 2 bis 35 Monaten, im Durchschnitt blieben die Turner des Eintrittsjahres 18797 Monate Mitglied des MTV Einbeck. Von den 34 Männern, die 1882 eintraten, war im Juni 1888 nur noch einer Mitglied des MTV. In 26 Fällen ist die Dauer der Mitgliedschaft überliefert, sie betrug im längsten Falle 18 , durchschnittlich jedoch nur 5 Monate. Auch für die 20 Neumitglieder des Jahres 1893 ist in allen Fällen das Ausscheiden aus dem Verein belegt und für 12 Turner datierbar; die durchschnittliche Mitgliedschaft dauerte in diesen Fällen 11 Monate. Von den im Jahre 1896 eingetretenen 44 Personen hatten im Januar 1901 bereits 41 wieder den Verein verlassen. Jene 33 Mitglieder, deren Verweildauer zu ermitteln war, gehörten im Durchschnitt 12 Monate dem MTV Einbeck an.

Eine solche extreme Fluktuation der Vereinsmitglieder war für Turnvereine im Untersuchungszeitraum durchaus nicht untypisch. Christiane Eisenberg berichtet, dass in vielen dieser Vereine die Zahl der Zu- und Abgänge eines Jahres bisweilen die Zahl der Mitglieder erreichen konnte ${ }^{258}$; auch wenn, wie oben gesagt, die Mitgliederfluktuation des MTV Einbeck für viele Jahre nicht exakt zu ermitteln ist, bestätigen die Quellen diese Aussage tendenziell.

Ein wesentlicher Grund für die Mitgliederbewegung ist in der sozialen Zusammensetzung der Vereinsmitglieder $\mathrm{zu}$ sehen. Eine berufsstrukturelle Analyse der in den oben genannten Mitgliederlisten dokumentierten Vereinsbeitritte erbrachte für drei Zeiträume die folgenden Ergebnisse:

Berufsstruktur der neu eingetretenen Mitglieder Juli 1874 - Januar 1878

$\begin{array}{lll} & \text { total } & \text { in v. H. } \\ \text { Handwerker } & 118 & 57,0 \\ \text { Fachschüler } & 40 & 19,3 \\ \text { Kaufleute } & 13 & 6,3 \\ \text { Angestellte } & 7 & 3,4 \\ \text { Unselbständige } & & \\ \text { Dienstleister } & 7 & 3,4 \\ \text { Selbständige } & 3 & 1,4\end{array}$

${ }^{258}$ Vgl.: Eisenberg, Christiane: "English sports" und deutsche Bürger. Eine Gesellschaftsgeschichte 1800 - 1939. Paderborn, München, Wien, Zürich 1999 (Zugl.:

Dissertation, Hamburg 1996), SS. $131 \mathrm{f}$. 
Sonstige/

Nicht kategorisierbar $\quad 19 \quad 9,4$

$\begin{array}{lll}\text { Summe } & 207 & 100,0\end{array}$

Berufsstruktur der neu eingetretenen Mitglieder

Februar 1879 - Juni 1888 total in v. $\mathrm{H}$.

Handwerker $\quad 262 \quad 76,6$

Angestellte $\quad 31 \quad 9,1$

$\begin{array}{lll}\text { Fachschüler } & 14 & 4,1\end{array}$

Unselbständige

$\begin{array}{lll}\text { Dienstleister } & 10 & 2,9\end{array}$

Kaufleute 61,8

Selbständige $\quad 11 \quad 3,2$

Sonstige/

Nicht kategorisierbar $\quad 8 \quad 2,3$

$\begin{array}{lll}\text { Summe } & 342 & 100,0\end{array}$

Berufsstruktur der neu eingetretenen Mitglieder Juni 1888 - Januar 1901

total in v. H.

$\begin{array}{lll}\text { Handwerker } & 241 & 59,2 \\ \text { Angestellte } & 63 & 15,5 \\ \text { Kaufleute } & 12 & 4,4 \\ \text { Selbständige } & 12 & 3.0 \\ \text { Fachschüler } & 5 & 1,2 \\ \text { Sonstige/ } & & \\ \text { Nicht kategorisierbar } & 68 & 16,7 \\ \text { Summe } & 407 & 100,0\end{array}$

Bei allen Unschärfen vor allem in der zuverlässigen Unterscheidung von Angestellten und Kaufleuten zeigen diese Ergebnisse dennoch Verschiedenes deutlich. Über den dokumentierten Zeitraum hinweg stellten die Handwerker die bei weitem dominierende Gruppe innerhalb der in den MTV Einbeck aufgenommenen Personen dar; ihr Anteil sank bis um die Jahrhundertwende nie unter 57 v. H.. Zieht man nun zusätzlich in Betracht, dass die aktiven 
Turner jünger als dreißig Jahre alt waren ${ }^{259}$, so erklärt sich die hohe Mitgliederfluktuation zumindest zum Teil bereits aus der zahlenmäßigen Dominanz der Handwerker. Die jüngeren Handwerker ${ }^{260}$ stellten über den Untersuchungszeitraum, in dem die gesamte Stadt Einbeck eine starke Fluktuation ihrer Bevölkerung zu verzeichnen hatte ${ }^{261}$, den Personenkreis mit der höchsten lokalen Mobilität dar. ${ }^{262}$ Ähnliches gilt für die jungen Handlungsgehilfen, derer sich einige in der Gruppe der Kaufleute gefunden haben dürften. Der temporäre Charakter des Aufenthalts von Fachschülern in Einbeck, die gerade am Beginn des dokumentierten Zeitraums einen bedeutenden Teil der Vereinsmitglieder stellten, ist evident.

Auch wenn über den gesamten Untersuchungszeitraum eine zuverlässige Trennung von Handwerkern in traditionellen Handwerken und Angehörigen der entstehenden Arbeiterschaft nicht präzise vorgenommen werden kann, so ist doch festzuhalten, dass es sich bei den in den oben aufgeführten Statistiken genannten Handwerkern in der Regel um Handwerker im traditionellen Sinne handelte, wie eine inhaltliche Auswertung der den genannten Statistiken zu Grunde liegenden Quellen ergab. Ein Beschluss aus dem Jahre 1883 illustriert zudem deutlich ein bürgerliches Selbstverständnis des Vereins. Am 20. September dieses Jahres wurde ein Kellner namens Klages in den MTV Einbeck aufgenommen, "nur wurde bemerkt, daß wenn p. Klages diese Stellung als Kellner dereinst verlassen würde, und eine andere Stellung z. B. als Hausknecht, sodann solle der p. Klages wieder gestrichen werden."263 Auch wenn dieser Beschluss im April 1885 aufgehoben wurde, so zeigt er doch eine Tendenz zur Abgrenzung eines vom Bürger- und Kleinbürgertum dominierten Vereins gegen unterbürgerliche Schichten.

${ }^{259}$ Vgl.: MTV Einbeck, Statut vom 2. Dezember 1867, Druckexemplar in StAEin 065 - 24, § 6

260 In der in diesem Zusammenhang in der folgenden Anmerkung zitierten Untersuchung werden diese auf Grund der Schwierigkeiten der Unterscheidung mit gelernten Angehörigen der entstehenden Arbeiterklasse und den niederen Beamten zu einer sozialen Gruppe zusammengefasst.

${ }^{261}$ Der Mobilitätskoeffizient (Zahl der Wanderungsfälle auf 1.000 der mittleren Wohnbevölkerung) lag während des gesamten Untersuchungszeitraumes der vorliegenden Arbeit selten unter 100, teilweise war er sogar höher als 350, vgl. hierzu: Walter, Hubert: Bevölkerungsgeschichte der Stadt Einbeck. Hildesheim 1960, Tab. 28, S. 123 262 Vgl.: Walter, Hubert: op. cit., Tab. 29, S. 124; Tab 30, S. 125; Abb. 42, S. 125 und Tab 32, S. 127

263 [sic!] MTV Einbeck, Protokoll 20. September 1883 
Im Kontrast zu der oben aufgezeigten hohen Mitgliederfluktuation stehen recht lange Amtszeiten verschiedener Vorstandsmitglieder. Insbesondere die administrativen Vorstandsämter, die nicht unmittelbar mit dem Turnbetrieb zusammenhängen, also die des Präsidenten und des Kassen- und Schriftführers wurden im dokumentierten Zeitraum häufig für lange Zeit von jeweils ein und derselben Person bekleidet.

Für den durch die Protokolle dokumentierbaren Zeitraum lässt sich beispielsweise die durchschnittliche Amtszeit des Vereinspräsidenten auf über zwei Jahre beziffern. ${ }^{264}$ Für den gesamten Untersuchungszeitraum der vorliegenden Arbeit dürfte die durchschnittliche Amtsdauer der Vereinspräsidenten sogar weit länger gewesen sein; der in der letzten dokumentierten Versammlung vom 10. Mai 1905 wiedergewählte Präsident Seidel, dessen Amtszeit nicht in der oben aufgestellten Berechnung berücksichtigt wurde, konnte zu diesem Zeitpunkt bereits auf eine Amtszeit von 54 Monaten zurück blicken. Da dieser in einem Druckexemplar der revidierten Statuten des Vereins vom 7. Mai 1914 als Vorsitzender erscheint $^{265}$ und auf der konstituierenden Sitzung der Einbecker Turnerschaft am 20. Oktober des selben Jahres als ältester Vorsitzender die Verhandlungen leitete ${ }^{266}$, gibt es durchaus Grund zu der Annahme, dass Seidel bis zu diesem Zeitpunkt Vorsitzender des MTV Einbeck war. Sollte dieses zutreffen, so hätte Seidel das Amt genau 9 1/2 Jahre (114 Monate) bekleidet. Diese Annahme ist durchaus plausibel, kam doch Seidels unmittelbarer Amtsvorgänger Henze auf 113 Präsidentschaftsmonate, ehe er vom Verein zum Ehrenvorsitzenden ernannt wurde. ${ }^{267}$ Dieser langfristige Trend zu mehrjährigen Amtszeiten gilt auch für die beiden anderen administrativen Vorstandsämter. Von der Generalversammlung im Mai 1882 bis zum Mai 1905 hatte der Verein nur zwei Kassenwarte - der oben genannte Präsident Henze bekleidete dieses Amt

\footnotetext{
264 Je nachdem, ob man die für über zwei Jahre unterbrochene Amtszeit des Vorsitzenden Bünger als eine oder zwei Amtszeiten rechnet, ergibt sich ein Durchschnittswert von 28,2 respektive 25,6 Monaten. Nimmt man eine von Anfang Mai 1888 bis Ende Mai 1889 währende Zeit interner Streitigkeiten von der Betrachtung aus, in der innerhalb von 13 Monaten 3 Präsidenten amtierten, so errechnet sich gar ein Wert von 33,6 Monaten.

${ }^{265}$ Vgl:: MTV Einbeck, Revidierte Statuten vom 7. Mai 1914, Druckexemplar im Besitz des Turn-Club Einbeck

266 Diese Organisation wird unten näher betrachtet werden. Zur konstituierenden Sitzung vgl.: Einbecker Turnerschaft, Protokoll 20. Oktober 1914

${ }^{267}$ Vgl:: MTV Einbeck, Protokolle, passim, insbesondere 26. Juli 1900 und 7. November 1900
} 
vom Mai 1882 bis zu seiner Wahl zum Vorsitzenden am 2. Juni 1890, ihm folgte Arnke, der dieses Amt bis zum 10. Juni 1905 bekleidete. In dem mehr als 22 Jahre dauernden Zeitraum vom 31. Mai 1883 bis zum 10. Juni 1905 hatte der MTV Einbeck lediglich drei Schriftführer, von denen der spätere Präsident Arnke annähernd 15 Jahre lang diesen Posten versah.

Auch in organisatorischer Hinsicht wurde der Verein im Laufe des Untersuchungszeitraumes immer stabiler. Nachdem das älteste erhaltene Statut von 1867 im Jahre 1878 durch ein neues ersetzt wurde ${ }^{268}$, welches seinerseits bereits nach neun Jahren $1887 \mathrm{zu}$ Gunsten eines neuen Statuts außer Kraft gesetzt wurde 269 - beide Statuten sind nicht überliefert - sind für die Folgezeit bis zum Mai 1914 bis auf eine geringe Änderung im Jahre $1903^{270}$ keine weiteren Statutenänderungen nachzuweisen.

Diejenigen Vorstandsämter, welche unmittelbar mit dem eigentlichen Turnbetrieb zu tun hatten, dies waren die des Turnwarts und seiner beiden Anmänner (Assistenten) sowie des Gerätewarts, wiesen den administrativen gegenüber eine wesentlich höhere Fluktuation auf. Die Gründe hierfür dürften weitgehend mit jenen identisch sein, die für die hohe Mitgliederfluktuation im allgemeinen gelten, da diese Ämter ausschließlich von aktiven Turnern ausgefüllt werden konnten. In mehreren Fällen ist belegt, dass Vorstandsmitglieder auf Grund ihres Weggangs von Einbeck ihr Amt niederlegten. 271

Die Befunde über die Struktur des Männer-Turn-Vereins Einbeck - eine hohe Stabilität in organisatorischer Hinsicht wie auch bezüglich des Führungspersonals einerseits, eine starke Fluktuationsrate und somit auch eine gewisse Instabilität der Gesamtmitgliedschaft und insbesondere der Gruppe der aktiven Turner andererseits - legen den Schluss nahe, dass es innerhalb des Vereins einen recht stabilen Kern von Mitgliedern gab, die sowohl ortsfest als auch vereinstreu waren. Diesen Kern umgab eine Sphäre von Mitgliedern, die sich nicht dauerhaft an den Verein banden - sei es aus persönlichen oder aus beruflichen Motiven. Über die Austritte und deren Gründe ist den Protokollen nur in den seltensten Fällen etwas zu entnehmen; neben den bereits erwähnten

\footnotetext{
268Vgl.: MTV Einbeck, Protokolle 4. Februar 1878, 1. November 1878

${ }^{269}$ Vgl.: MTV Einbeck, Protokoll 15. Dezember 1887

270 Vgl.: MTV Einbeck, Protokoll 2. Dezember 1903

${ }^{271}$ Vgl.: MTV Einbeck, Protokolle 30. September 1875, 31. Juli 1882, 31. Juli 1890, 2.

Januar 1893, 16. September 1895, 2. Dezember 1896, 1. September 1897, 2. März 1898, 3.

August 1898, 4. Oktober 1899, 7. November 1900, 9. Januar 1901, 2. September 1903, 7.

Oktober 1903
} 
Austritten von Vorstandsmitgliedern sind lediglich drei Fälle, in denen Vereinsmitglieder wegen vereinsinterner Streitigkeiten ihren Austritt erklärten ${ }^{272}$, sowie 15 Vereinsausschlüsse aus disziplinarischen Gründen273 dokumentiert.

Die These von einem relativ stabilen personellen Vereinskern innerhalb des Gesamtvereins stützt auch eine Gegenüberstellung der durchschnittlichen Mitgliederzahl mit der durchschnittlichen Teilnehmerzahl an den Vereinsversammlungen:

$\begin{array}{llll}\text { Jahr } & \begin{array}{l}\text { Durchschnitt } \\ \text { Mitglieder }\end{array} & \begin{array}{l}\text { Durchschnitt } \\ \text { Versammlungs- } \\ \text { teilnehmer }\end{array} & \begin{array}{l}\text { Verhältnis } \\ \text { in v. H. }\end{array} \\ 1881 & 59 & 28,9 & 49,0 \\ 1882 & 56 & 30,0 & 53,6 \\ 1883 & 25 & 13,5 & 54,0 \\ 1884 & 36 & 18,8 & 52,2 \\ 1885 & 38 & 16,7 & 43,9 \\ 1886 & 48 & 20,3 & 42,3 \\ 1887 & 51 & 18,5 & 36,3 \\ 1888 & 51 & 19,6 & 38,4 \\ 1889 & 48 & 20,0 & 41,7 \\ 1890 & 44 & 18,8 & 42,7 \\ 1891 & 40 & 17,4 & 43,5 \\ 1892 & 48 & 18,6 & 38,8 \\ 1893 & 51 & 21,1 & 41,4 \\ 1894 & 53 & 20,7 & 39,1 \\ 1895 & 63 & 22,3 & 35,4\end{array}$

Diese Statistik ermöglicht zudem eine ungefähre Schätzung der Stärke dieser Gruppe. Die Vereinsversammlungen fanden in der Regel im Anschluss an die Übungsstunden der aktiven Turner statt. Daher hat vermutlich die überwiegende Mehrzahl derer, die an diesen Übungsstunden teilnahmen, wie dauerhaft ihre Vereinsbindung auch gewesen sein mag, diese Versammlungen

272 Vgl.: MTV Einbeck, Protokolle 22. August 1877, 5. Mai 1882, 5. Juli 1899, 4. Oktober
1899

${ }^{273}$ Vgl.: MTV Einbeck, Protokolle 4. Februar 1878, 2. September 1878, 14. Oktober 1878, 6. Oktober 1879, 12. Januar 1880, 10. Januar 1881, 7. März 1881, 10. Oktober 1881, 1. August 1887, 8. September 1890, 3. März 1892, 11. Februar 1895, 5. Oktober 1898, 8. November 1899, 1. August 1900 
besucht. ${ }^{274}$ Der Anteil der dauerhaft an den Verein gebundenen Männer dürfte daher noch deutlich geringer sein als der Anteil derer, die die Versammlungen besuchten und auf maximal 1/3 der Vereinsmitglieder zu beziffern sein.

\section{3. 1. 2. 2. Die Vereinsaktivitäten}

Die Annahme ist plausibel, dass die Vereinsarbeit im ersten Jahrzehnt seines Bestehens durch die verschiedenen Kriege sehr beeinträchtigt gewesen sein dürfte. Dennoch ist die Aussage eines mit "R. K." zeichnenden Autors aus dem Jahre 1902 als falsch anzusehen, dass von 1863 bis 1872 die Turnerei völlig geruht habe. 275 Zumindest punktuell sind für den von "R. K." angesprochenen Zeitraum turnerische Aktivitäten nachzuweisen. Für den Winter 1864/65 beantragte der MTV die Benutzung der großen Halle des Rathauses für seine Übungen im Geräteturnen, was auch genehmigt wurde. ${ }^{276}$ Auch in den folgenden Jahren wurde offenbar in der Rathaushalle geturnt. ${ }^{277}$ Im Sommer 1867 weihte der Verein einen neuen Sommerturnplatz ein ${ }^{278}$. Diese Nachrichten sind zweifelsohne als Beleg für einen regelmäßigen, wenn auch möglicherweise durch die Kriegsereignisse zeitweilig eingeschränkten oder vorübergehend ruhenden Turnbetrieb anzusehen.

Nach dem oben erwähnten Statut von 1867, das bis weit in den Untersuchungszeitraum hinein Gültigkeit hatte, setzte sich der MTV Einbeck in $\S 1$ das Vereinsziel, "die körperliche Ausbildung seiner Mitglieder und überhaupt die Turnerei zu fördern.". Nach $\S 2$ bedient sich der Verein für diese Zwecke "des Turnens, der Turnspiele und der Turnfahrten."279 Der MTV Einbeck stand mit diesen drei statutenmäßig festgelegten Hauptaktivitäten ganz in der Tradition Jahns, dessen Deutsches Turnen, wie bereits oben gesagt, aus Leibesübungen im engeren Sinne, Bewegungsspielen und Wanderungen, "Turnfahrten" genannt, bestand. Da außer den wenigen zitierten Quellen keine

\footnotetext{
${ }^{274}$ Im Anschluss an den offiziellen Teil solcher Sitzungen kam es häufig zu einem inoffiziellen gemütlichen Beisammensein, was den Besuch für ohnehin im Versammlungslokal anwesende Mitglieder sicherlich attraktiv machte. Vgl.: MTV Einbeck, Protokolle, passim ${ }^{275}$ Vgl.: Festbuch für das XV. Gauturnfest des Ober-Leine Gaues am 5., 6., und 7. Juli 1902 in Einbeck. Einbeck 1902, S. 17. Bei dem mit R. K. zeichnenden Autor dürfte es sich um Robert Kaufmann handeln, der zu dieser Zeit Vorstandsmitglied des Turn-Club Einbeck war. 276 Vgl.: StAEin I: G: F: I: - 7, 5. September 1864 277 Vgl.: StAEin I: G: F: I: - 7, 4. September 1881 278 Vgl.: StAEin I: G: F: I: - 7, 5. August 1867 279 MTV Einbeck, Statut vom 2. Dezember 1867, Druckexemplar in StAEin 065 - 24
} 
Zeugnisse aus der Frühzeit des Vereins erhalten sind, ist es nicht möglich, Aussagen über die Vereinsaktivitäten der Zeit vor dem Jahre 1875 zu treffen.

Im Jahre 1875 war der MTV Einbeck bereits Mitglied in der Deutschen Turnerschaft (DT). Im März 1875 wurden Delegierte zu DT-Bezirksaktivitäten gewählt 280 und im Mai des selben Jahres fand das Bezirksturnfest in Einbeck statt. $^{281}$ Die Abhaltung dieses Festes lässt den Schluss zu, dass der MTV Einbeck bereits seit längerer Zeit Mitglied des Dachverbandes war und sich über diese Zeit regelmäßig an verschiedenen Aktivitäten der DT zumindest auf Gau- und Bezirksebene beteiligt hatte. Ferner deutet die Abhaltung des Bezirksturnfestes darauf hin, dass zu diesem Zeitpunkt ein regelmäßiger Übungs- und Turnbetrieb stattfand. Auch für die Folgezeit ist eine regelmäßige Beteiligung des Vereins an den Aktivitäten des Verbandes nachweisbar. Die Bezirksvorturnerstunden und -turntage wurden regelmäßig durch Delegierte beschickt, ebenso die Gauturntage und -feste. Seltener ist - wohl auf Grund des höheren Reiseaufwandes - eine Beteiligung an Aktivitäten auf Turnkreisebene nachzuweisen. ${ }^{282}$

Über den Kanon der turnerischen Leibesübungen beim MTV Einbeck gibt ein Protokoll von 1876 Aufschluss, in dem die Planungen für ein vom MTV auszurichtendes Preisturnen dokumentiert werden. Neben Wettbewerben im Geräteturnen im heutigen Sinne wurden auch Preise für Weitsprung und Wettlauf ausgelobt; Disziplinen also, die im modernen Sprachgebrauch in den Bereich der Leichtathletik fallen. ${ }^{283}$ Für die Folgezeit lassen sich anhand der Protokolle vornehmlich turnerische Aktivitäten im engeren Sinne zweifelsfrei nachweisen, vor allem solche mit den traditionellen Jahnschen Turngeräten wie Barren ${ }^{284}$, Reck ${ }^{285}$, Pferd ${ }^{286}$ und Bock ${ }^{287}$. Darüber hinaus sind auch

\footnotetext{
280 Vgl.: MTV Einbeck, Protokoll 11. März 1875

${ }^{281}$ Vgl.: MTV Einbeck, Protokoll 3. Mai 1875

282Zu allen Aktivitäten des MTV Einbeck innerhalb der DT vgl.: MTV Einbeck, Protokolle, passim. Die DT war in Turnkreise aufgegliedert, diese wiederum umfassten mehrere Gaue, die ihrerseits in Bezirke untergliedert waren.
}

283 Vgl:: MTV Einbeck, Protokoll 11. Juli 1876

284 Vgl.: MTV Einbeck, Protokolle 5. Juni 1878, 5. Oktober 1891, 21. Mai 1902

${ }^{285}$ Vgl.: MTV Einbeck, Protokolle September 1880, 3. August 1891, 5. Juli 1892, 12.

September 1892, 3. Oktober 1892, 7. November 1892, 8. März 1899

${ }^{286}$ Vgl.: MTV Einbeck, Protokolle 6. Juli 1891 (hier ist von einem Sprungbrett zu lesen, diese sind für den Pferdsprung unverzichtbar), 27. November 1895, 4. Mai 1898, 8. Juni 1898, 6. Mai 1899, 4. Oktober 1900 ${ }^{287}$ Vgl.: MTV Einbeck, Protokoll 8. Juni 1891 
athletische Übungen mit Gewichten wie Hanteln und Eisenstäben ${ }^{288}$ sowie mit dem Schleuderball 289 belegbar. Alle diese Belege beruhen auf Protokollen von Vereinsversammlungen, in denen jeweils Neuanschaffungen oder Reparaturen von Turngeräten und -artikeln besprochen wurden. Daher können für den Untersuchungszeitraum leichtathletische Übungen, für die keine Geräte benötigt werden - so beispielsweise Laufen oder Weitsprung - oder für die Turngeräte zweckentfremdet gebraucht werden können, wie Hochsprung, keineswegs ausgeschlossen werden. Allerdings ist in der in den Statuten von 1867 enthaltenen Turnordnung lediglich von Geräteturnen und Turnspielen die Rede. ${ }^{290}$

Für das Jahr 1878 ist eine Musterriege belegt ${ }^{291}$. Aktivitäten auf dem Gebiet des in der DT eigentlich verpönten Wett- und Preisturnens ${ }^{292}$ sind ab den 1890er Jahren vereinzelt, aber doch mit einer gewissen Regelmäßigkeit, nachzuweisen. ${ }^{293}$

Im Sommer fand das Turnen auf dem städtischen Turnplatz statt. ${ }^{294}$ In der Winterzeit wurde zumindest in den ersten Jahren des Vereins in der großen Halle des Rathauses geturnt. ${ }^{295}$ Doch spätestens 1878 wurde dem MTV die Genehmigung zum Turnen in der Rathaushalle entzogen. ${ }^{296}$ Daher musste der Turnbetrieb in der Winterzeit ruhen ${ }^{297}$. Als Ersatz boten sich für die Turner regelmäßige Zusammenkünfte im Vereinslokal, um dort "gemüthlich zu kneipen". 298

Ab dem Winter 1882/83 wurde dem MTV Einbeck gestattet, gegen Miete in der neu errichteten städtischen Turnhalle am Realprogymnasium vor dem Hullerser Tor zu turnen. ${ }^{299}$ Doch nach verschiedenen Unstimmigkeiten mit

\footnotetext{
${ }^{288}$ Vgl.: MTV Einbeck, Protokolle 4. April 1892, 1. Dezember 1897, 5. Oktober 1898, 2.

November 1898, 2. August 1900

$28{ }^{2}$ Vgl.: MTV Einbeck, Protokoll 13. April 1903

290 Vgl.: Statuten vom 2. Dezember 1867 ff., $§ 24$ - 34

${ }^{291}$ Vgl.: MTV Einbeck, Protokoll 5. Juni 1878

292 Vgl.: Eisenberg, Christiane: op. cit., SS. 137 f.

293Vgl.: MTV Einbeck, Protokolle 7. Juni 1890, 5. Juni 1892, 4. September 1893, 7. Juni

1897, 5. Juni 1900, 10. September 1902, 18. Juli 1903, 13. April 1904, 8. März 1905

294 Vgl.: StAEin I: G: F: I: -7, 13. Mai 1862

295Vgl.: StAEin I: G: F: I: -7, 5. September 1864

296 Vgl.: MTV Einbeck, Protokoll 13. Oktober 1878

297Vgl.: MTV Einbeck, Protokoll 2. Mai 1881

298MTV Einbeck, Protokoll 29. August 1881

${ }^{299}$ Vgl.: MTV Einbeck, Protokoll 4. Oktober 1882
} 
dem Magistrat wurde eine Alternative zur städtischen Turnhalle gefunden. Im Dezember 1892 zog man in die vom damaligen Wirt des Gasthofes zur Deutschen Eiche, August Hümme, im Hinterhaus seines Gasthauses in der Hullerser Straße neu ausgebaute Turnhalle um. 300

Das offizielle Vereinslokal des MTV Einbeck blieb jedoch bis zum Ende des Untersuchungszeitraumes das Hotel Goldener Löwe. Ursprüngliches Vereinslokal war das Gasthaus von Langhagen gewesen, doch hat man dieses Lokal, das man 1884 zwischenzeitlich zugunsten des Rheinischen Hofes verlassen hatte, im Jahre 1889 im Streit mit Vereinswirt Langhagen endgültig aufgegeben und war in den Löwen umgezogen. 301

Neben dem eigentlichen Turnen stellten die so genannten Turnfahrten, also Wanderungen und Ausflüge, eine weitere statutarisch bestimmte Aktivität des MTV Einbeck dar. Die ersten nachweisbaren Turnfahrten führten zu Zielen in der unmittelbaren Umgebung Einbecks; beliebtestes Ziel war das nur wenige Kilometer entfernte Rotenkirchen mit der benachbarten Burgruine Grubenhagen. Dieses Ziel konnte durchaus in einer eintägigen Wanderung besucht werden, wie es wohl auch in den Jahren 1875 und 1877 geschah. 302 Nahmen allerdings Damen an einer solchen Turnfahrt teil, so reiste man per Wagen. 303

Andere Ausflüge unternahm man in den Einbecker Stadtwald zur Hube und den Teichen und zur im Leinetal gelegenen Clus. 304

Ab dem Jahre 1878 wurden die Turnfahrten weiträumiger. In diesem Jahre führte eine Turnfahrt ins über 20 Kilometer entfernte Lamspringe; zu einer solchen Fahrt war man zumindet für Teilstrecken auf Wagen oder die Eisenbahn angewiesen. Im Sommer 1881 wählte man das unweit Bovenden gelegene Mariaspring, "nachdem", wie im entsprechenden Protokoll zu lesen ist, "mehrere faule Witze von gewissen Mitgliedern gemacht wurden", als Ziel, in den Jahren 1882, 1883 und 1884 führten die Turnfahrten nach Gandersheim. Zumindest die ersten beiden Fahrten wurden mit einem Besuch beim dortigen Turnverein verbunden. 1887 besuchte man Winzenburg im Leinebergland, 1888 reiste der MTV nach Northeim und 1891 war erneut Mariaspring das Ziel. Im Sommer 1894 führte die Turnfahrt per Eisenbahn nach Kassel und von

\footnotetext{
300 Vgl.: MTV Einbeck, Protokolle 8.September 1890, 7. Dezember 1891, 5. Dezember 1892 ${ }^{301}$ Vgl.: MTV Einbeck, Protokolle 21. Juni 1884, 10. Juli 1884, 1. August 1884, 19.

September 1887, 21. Februar 1889, 8. März 1889 8. April 1889, 27. Mai 1889

302 Vgl.: MTV Einbeck, Protokolle 2. August 1875, 2. Juli 1877

303 Vgl.: MTV Einbeck, Protokoll 30. Juni 1879

304 Vgl.: MTV Einbeck, Protokolle 7. April 1879, 13. Mai 1880
} 
dort zu Fuß nach Wilhelmshöhe. 1895 war das Hermannsdenkmal am Teutoburger Wald Ziel der MTV-Turnfahrt. Nachdem man im Jahre 1896 Mariaspring und die Plesse besucht hatte, reiste man 1897 erstmals in den Harz; die Turnfahrt führte über Goslar in das Okertal; 1898 wurden Sachsa und Lauterberg besucht.

1901 schloss man sich, nachdem ursprünglich eine Turnfahrt zum Kyffhäuser geplant war, einem Ausflug des Gesangvereins Liederkranz nach der Porta Westfalica an. Die letzte belegte Turnfahrt führte im Jahre 1903 per Leiterwagen zum am Solling bei Mackensen gelegenen Grenzkrug. Von dort wanderten die Turner nach Holzminden, fuhren mit dem Schiff nach Karlshafen, dort wurde per Eisenbahn die Heimfahrt angetreten. 305

Die Turnfahrten hatten sich also im Laufe der Zeit von reinen Wanderungen von Turnern in regelrechte touristische Aktivitäten gewandelt; Distanzen von bis zu 200 Kilometern wurden an einem Tage zurückgelegt. Ausflüge und Wanderungen in die unmittelbare Umgebung der Stadt wurden neben diesen Turnfahrten zunächst weiterhin in etwa jährlichem Turnus unternommen, ab der Mitte der achtziger Jahre wurden sie dann seltener und fanden in der Regel nur noch in solchen Jahren statt, in denen keine größeren Ausfahrten unternommen wurden. 306

Die Ausdehnung der Fahrten ab der Wende zu den achtziger Jahren wie auch die weitere Diversifikation der Ziele in den südlichen Harzraum und an die Oberweser folgte unmittelbar zunächst dem Anschluss Einbecks an die hannoversche Südbahn und später dem Ausbau der Eisenbahn in den bezeichneten Räumen durch die Eisenbahnlinie Altenbeken - Uslar - Northeim - Nordhausen. Der MTV Einbeck war mit seinem Tagestourismus stets auf der Höhe seiner Zeit. Die Auswahl der Ziele solcher Fahrten in die weitere Umgebung verdeutlicht eine gewisse Bedeutungsverschiebung der Turnfahrten. Sie dienten in immer geringerem Maße der Erholung und Geselligkeit in freier Natur und wurden zunehmend zu Reisen an Orte, an denen sich ein auf das Deutsche Reich bezogener nationaler Patriotimus in monumentalen

\footnotetext{
${ }^{305}$ Vgl.: MTV Einbeck, Protokolle 23. Mai 1878, 4. August 1881, 31. Juli 1882, 23. August 1883 10. Juli 1884, 4. Juli 1887, 3. September 1888, 31. August 1891, 2. Juni 1894, 8. Juli 1895, 6. Mai 1896, 4. August 1897, 3. August 1898, 10. April 1901, 1. Mai 1901, 10. Juni 1903 306 Vgl.: MTV Einbeck, Protokolle 3. April 1882, 30. April 1883, 4. Mai 1885, 8. Juli 1886, 13. August 1888, 12. August 1889, 2. Juni 1890, 7. Mai 1892, 1. Mai 1893, 5. Juli 1899, 10. Mai 1905
} 
Denkmälern manifestierte 307 ; manche Ausflüge wurden gewissermaßen zu patriotischen Pilgerreisen.

Neben den Turnfahrten stellten weitere gesellige Veranstaltungen einen wesentlichen Teil der Aktivitäten des MTV Einbeck dar. Im Schlussatz der Statuten vom 2. Dezember 1867 ist von "Tanzvergnügen" zu lesen, in einem Statutennachtrag vom 29. August 1875 werden die Geselligkeiten als "VereinsVergnügungen, Bälle, Kränzchen [...] u. dgl." erwähnt. 308

Die als "Kränzchen" bezeichneten Feste waren die häufigsten Feierlichkeiten des Vereins. Sie wurden - mehr oder minder regelmäßig ausschließlich im Winterhalbjahr abgehalten. Bei ihnen handelte es sich um bunte Abende mit einem von verschiedenen Mitgliedern gestalteten Programm unterhaltender Darbietungen. Diese konnten in verschiedenen Vorführungen der Turner wie Geräteturnen oder den damals sehr populären "Marmorgruppen"309 bestehen, darüber hinaus sind auch Deklamationen und kurze humoristische Laienaufführungen überliefert. Diese Veranstaltungen wurden umrahmt mit Musik von bezahlten Musikern, die nach Ende des Programms zum Tanz spielten. ${ }^{310} \mathrm{Zu}$ den Kränzchen waren die Mitglieder und deren Angehörige sowie häufig auch vereinsfremde Personen zugelassen.

Zur Ausgestaltung der Kränzchen bildeten einige Mitglieder ab dem Herbst 1875 eine Laienspielgruppe als weitgehend autonome Unterabteilung des MTV.311 Dieser Theatergruppe war offenbar nur eine kurze Lebenszeit beschieden, bereits für die Jahre 1878 und 1879 ist die Abteilung nicht mehr nachzuweisen. Im Januar 1880 wurde erneut eine solche Laienbühne gegründet, 312 über deren Bestandsdauer allerdings keine Aussagen zu treffen

\footnotetext{
${ }^{307}$ Der Bezug auf das Deutsche Reich ist im Falle der Kaiser-Wilhelm-I.-Denkmäler auf dem Kyffhäuser und an der Porta Westfalica evident und bedarf keiner Diskussion. Das im Text Gesagte gilt jedoch auch für das Hermannsdenkmal bei Detmold. Zwar hatte Ernst von Bandel das Projekt bereits 1838 begonnen und als Denkmal für einen großdeutschen Nationalstaat intendiert, doch hatte das Denkmalsprojekt bis zu seiner Fertigstellung im Jahre 1875 einen Bedeutungswandel hin zu einem Nationaldenkmal des 1871 gegründeten kleindeutschen Reiches erfahren. Vgl.: Scharf, Helmut: Kleine Kunstgeschichte des deutschen Denkmals. Darmstadt 1984, SS. 174, 178, 197 ff.

308 Vgl.: MTV Einbeck Statuten-, Mitglieder- und Kassenbuch 1867 - 1884

309 In diesen Darbietungen posierten die Turner gruppenweise als "lebende Statuen".

310 Vgl.: MTV Einbeck, Protokolle, passim

${ }^{31}$ Vgl.: MTV Einbeck, Protokoll 27. September 1875, 30. September 1876, 15. Januar 1877,

19. März 1877

312 Vgl.: MTV Einbeck, Protokolle 26. Januar 1880, 9. Februar 1880
} 
sind; da für die Folgezeit nur sehr vereinzelt Theateraufführungen nachweisbar sind, ist anzunehmen, dass es sich bei der Laienbühne allenfalls um einen lockeren Verbund interessierter Mitglieder und nicht um eine feste Unterabteilung des Vereins handelte.

In den Jahren 1886/87 versuchte man, eine Musikgruppe innerhalb des Vereins zu gründen und schaffte auf Vereinskosten im August 1886 diverse gebrauchte Blasinstrumente an, doch wurde die Musikabteilung des Vereins bereits im März des darauffolgenden Jahres wieder aufgelöst. 313

Neben diesen Kränzchen fanden in vielen Jahren Maskenbälle und Weihnachtfeiern statt.

Bis in die neunziger Jahre ist belegt, dass die Entscheidung, welche von den Turnern vorgeschlagenen Frauen zu den Festen zugelassen werden sollten, beim Vorstand und dem Festkomittee lagen. Bei dieser Regelung handelte es sich keineswegs um eine bloße Formalie; es sind Fälle belegt, in denen ernste Diskussionen um einzelne Frauen geführt wurden. So ist im Protokoll der Vorstandsitzung vom 7. März 1879 zu lesen: "Es wurde über Fräulein Spintler ballotiert (Rehsen seine Braut) diese fiel glänzend durch. Dann über Fräulein Meyer b. Appel dieselbe wurde erst durch Stimmengleichheit, dann durch das unglückliche Loose aufgenommen. Durch Aufnahme der Fräulein Meyer sollte die Fräulein Spindler [sic] auch eingeladen werden, weil sonst der Herr Bräutigam auch nicht zum Vergnügen nicht [sic] gekommen wäre."

Die Entscheidungen der Komission wurden von den Turnern mit Spannung erwartet und, wenn ihre Freundinnen eingeladen wurden, mit regelrechten Freudenausbrüchen quittiert. So berichtet das Protokoll einer Monatsversammlung, die über eine Frau abstimmen musste, weil der Vorstand über die betreffende Freundin keine Einigung erzielt hatte, dass ein Turner, nachdem seine Braut zugelassen wurde, gar nicht abwartete, bis man "die Karte für seine Geliebte ausgefertigt hatte, sondern sprang für Freude wie ein reitender Barbier [sic]. jetzt ging es im Galopp zur Henriette um die frohe Botschaft und die Einladungskarte zu überbringen, und auch zugleich seine Belohnung zu holen.". 314

Die zunehmend touristischen Charakter annehmenden Fahrten wie auch die Feste des Vereins zeigen deutlich, dass sich die Tätigkeit des MTV Einbeck weit über die statutarisch festgelegten turnerischen Aktivitäten hinaus erstreckte. Dies gilt auch für eine Untergliederung des Vereins, welche gegen Ende des Untersuchungszeitraumes entstand. Das Adressbuch vom Juli 1912

\footnotetext{
${ }^{313}$ Vgl.: MTV Einbeck, Protokolle 2. August 1886, 13. September 1886, 7. März 1887

${ }^{314}$ MTV Einbeck, Protokoll 6. Januar 1879.
} 
weist unter der Rubrik Schützenvereine eine "Schießklub-Abteilung des Männer-Turnverein" aus. Diese Abteilung muss einen weit gehend autonomen Status gehabt haben, erscheint sie doch in der Liste als eigenständiger Verein, der zudem ein anderes Vereinslokal als der Mutterverein hatte.

Adressaten für die über die eigentlichen Vereinszwecke hinaus gehenden Vergnügungsangbote waren in erster Linie die Mitglieder und deren Angehörige. Ein Hinweis auf die relative Jugend vieler Mitglieder ist darin zu sehen, dass in der Planung von Vereinsvergnügungen häufig explizit die Eltern der Vereinsmitglieder erwähnt werden. ${ }^{315}$ Über diesen Personenkreis hinaus konnten, allerdings nahezu ausschließlich bei Tanzveranstaltungen, auch Vereinsfremde an den Vergnügen des MTV Einbeck teilnehmen. Die Zulassung von Fremden dürfte nicht primär der Rekrutierung neuer Mitglieder gedient haben. Eine solche Absicht ist lediglich in einem einzigen Falle definitiv nachzuweisen, in dem zu einem Stiftungsfest den Mitgliedern das Recht eingeräumt wurde, "junge Leute, die sich für den Verein interessieren [...] mitzubringen."316 In einem früheren Falle ist die Absicht, neue Vereinsmitglieder über den Besuch einer Vereinsfeier $\mathrm{zu}$ werben, als sehr wahrscheinlich anzunehmen, da die einzuführenden Herren freien Eintritt haben sollten und die fragliche Veranstaltung zu einer Zeit stattfand, in der die Vorrangstellung des MTV innerhalb der Einbecker Turnbewegung in Gefahr geriet. 317 In den vielen übrigen Fällen, in denen Nichtmitglieder zu Festen des MTV zugelassen wurden, dürften vornehmlich finanzielle Erwägungen entscheidend gewesen sein. Gerade die Kränzchen mit Tanz und die Maskenbälle verursachten für die Saalmiete wie auch die Bezahlung der Musiker und der Dekorationen hohe Kosten, die durch die Eintrittsgelder der Vereinsmitglieder allein nicht zu decken gewesen wären.

An die Öffentlichkeit im weiteren Sinne trat der Verein eher selten. Doch wenn dies geschah, so legte man durchaus auf ein repräsentatives Erscheinungsbild Wert. Der erste anhand der erhaltenen Unterlagen nachweisbare größere öffentliche Auftritt des Vereins war das bereits oben erwähnte Bezirksturnfest im Frühjahr 1875. Im Vorfeld dieses Festes fasste man den Beschluss, sich eine einheitliche Bekleidung zuzulegen, jeder Turner

${ }^{315}$ Vgl. e. g.: MTV Einbeck, Protokolle 20. November 1881, 7. Januar 1895, 8. Januar 1896,

4. November 1903

316 MTV Einbeck, Protokoll 4. Mai 1891

${ }^{317}$ Hierüber wird in der Zusammenfassung am Schluss des Kapitels noch zu reden sein. Vgl::

MTV Einbeck, Protokoll 12. Februar 1883 
sollte sich eine "Drelljacke und eine weiße Tuchmütze" anschaffen. ${ }^{318}$ Spätere Anschaffungen von einheitlicher Vereinskleidung waren einheitliche Vereinshüte, "um ein einigermaßen gleiches Aussehen der Theilnehmer [...] zu erzielen"319, zum festlichen Ausmarsch anlässlich des Gauturnfestes 1902 traten die Vereinsmitglieder einheitlich in weiße Hosen gekleidet an. 320

Ein weiterer großer öffentlicher Auftritt des Vereins war die Feier des 100. Geburtstages des "Turnvaters" Friedrich Ludwig Jahn. Unter der Leitung des Vereinsgründers und Ehrenmitgliedes Bickmeyer gestaltete der MTV Einbeck unter Mitwirkung der höheren Bürgerschule eine halbtägige Feier. Den Auftakt bildete ein Festzug mit Musik. In diesem Festzug wurde ein von acht Turnern zu tragendes Bildnis Jahns mitgeführt. Nach der Ankunft auf dem Turnplatz folgte eine Ansprache Lehrer Bickmeyers, danach erfolgte das gemeinsame Absingen des Deutschlandliedes und der Lieder "Lützows Jagd" 321 und "Die Wacht am Rhein". Diesem schlossen sich Freiübungen und Riegenturnen an, den Schluss der Feier bildeten ein Konzert im Schützenhaus und ein Ball im Vereinslokal. 322

Andere Anlässe für den MTV, öffentlich innerhalb der Stadt in Erscheinung zu treten, waren Festumzüge, Beerdigungen von verdienten Vereinsmitgliedern und abendliche Fackelzüge zu Ehren neu ernannter Ehrenmitglieder.323 Spätestens ab 1879 konnte man zu solchen Anlässen eine Vereinsfahne mit sich führen. ${ }^{324}$ Ab 1887 verfügte der Verein gar über zwei Fahnen, die von je einem Fahnenträger mit zwei Männern als Fahnenbegleiter geführt wurden. ${ }^{325} \mathrm{Zu}$ solchen Anlässen schmückten sich zumindest die Vorstandsmitglieder mit Schärpen ${ }^{326}$, zu besonderen Anlässen rundeten auch

\footnotetext{
${ }^{318}$ MTV Einbeck, Protokoll 22. März 1875

319 MTV Einbeck, Protokolle 21. Februar 1889, 18. März 1889, 6. August 1894, 21. Mai

1905; das Zitat stammt aus dem Protokoll von 1894

320 Vgl.: MTV Einbeck, Protokoll 11. Juni 1902

${ }^{32}{ }^{1}$ Friedrich Ludwig Jahn war in den so genannten Befreiungskriegen Mitglied des

Lützowschen Freikorps.

${ }^{322}$ Vgl.: MTV Einbeck, Protokolle 27. Juli 1878, 31. Juli 1878

$323^{2}$ gl.: MTV Einbeck, Protokolle 28. August 1875, 6. Dezember 1880, 28. September 1889,

MGV Harmonie Einbeck, Protokoll 2. April 1911

324 Vgl.: MTV Einbeck, Protokoll 4. August 1879

${ }^{325}$ Vgl.: MTV Einbeck, Protokolle 4. März 1887, 19. März 1888, 19. Juli 1888

326 Vgl.: MTV Einbeck, Protokolle 1. August 1887, 2. April 1902
} 
so genannte Ehrendamen das Erscheinungsbild eines sich selbstbewusst präsentierenden Vereines ab. 327 


\section{3. 1. 3. Der Turn-Club Einbeck}

\subsection{3. 1. Gründung und Entwicklung}

Im Sommer des Jahres 1880 wurde ein weiterer Turnverein in Einbeck gegründet. Durch Rundschreiben wurde zu einer Versammlung am 14. Juni 1880 in die Gaststätte von Sprenger in der Marktstraße eingeladen. Zu dieser Gründungsversammlung erschienen 22 Personen und gründeten den neuen Verein, den sie Turn-Club Einbeck nannten. Aus ihrer Mitte wählten die Männer einen fünfköpfigen Vorstand. Die verschiedenen Vorstandsämter wurden - ganz in der Tradition Jahns - teilweise mit eigentümlichen Bezeichnungen versehen, die den Gebrauch von Fremdworten vermieden. So hieß der Vereinspräsident "Sprechwart", der Kassierer war der "Säckelwart". Schriftwart, Turnwart und Turnwartammann (= Assistent des Turnwartes) ${ }^{328}$ vervollständigten den Vorstand.

Man wählte das Hotel zum Kronprinzen zum Vereinslokal und beschloss, bei der Stadt die Genehmigung zur Benutzung des städtischen Turnplatzes zu beantragen. Ferner sollte ein Gesuch an den MTV Einbeck gerichtet werden, dass dieser Verein dem neuen Turn-Club gestatten möge, die dem MTV gehörenden Turngeräte mit zu benutzen. An den Vorstand erging der Auftrag, binnen vier Tagen ein Statut auszuarbeiten und dieses einer für den 18. Juni anberaumten Generalversammlung vorzulegen. 329

Auf einer Vorstandssitzung am 16. Juni 1880 wurden die Statuten beraten. Als Muster hatte man sich die Satzung des Hannoverschen Turnclubs beschafft, die in modifizierter Form übernommen wurde. Der Vorstand wurde um einen Zeugwart erweitert, und man entschloss sich, zur Aufnahme gemeldete Mitglieder einer Ballotage zu unterziehen. Das Eintrittsgeld wurde auf 1,50 Mark festgesetzt. 330

Die vom Vorstand ausgearbeiteten Statuten wurden von der ersten Generalversammlung ohne Änderungen akzeptiert und verabschiedet. 331

Der MTV Einbeck hatte bereits am Tag vor der Versammlung beschlossen, dem TCE bis auf weiteres die Benutzung seiner Turngeräte zu gestatten. Eine Miete erhob der MTV nicht, allerdings sollte sich der Turn-Club an

\footnotetext{
328Während der MTV die Schreibweise "Anmann" benutzte, wird in den Protokollen des

TCE dieses Amt mit dem Wort "Ammann" bezeichnet.

32 Vgl.: Turn-Club Einbeck, Protokoll 14. Juni 1880

330 Vgl.: Turn-Club Einbeck, Protokoll 16. Juni 1880

${ }^{331}$ Vgl.: Turn-Club Einbeck, Protokoll 18. Juni 1880
} 
anfallenden Reparaturen mit 50 v. H. der Kosten beteiligen, ohne hierdurch Vermögensrechte an den Sachen zu erwerben. Auch die Genehmigung der Stadt wurde erteilt. ${ }^{332}$ Von einem Beitritt zur Deutschen Turnerschaft wurde einstweilen Abstand genommen. ${ }^{33}$ Doch diese reservierte Haltung gegenüber dem Dachverband wurde sehr rasch aufgegeben. Nachdem man vom MännerTurn-Verein zu einer Gau-Vorturnerversammlung im August 1880 eingeladen worden war und an dieser auch teilnahm, wurde noch im gleichen Monat die Aufnahme in die Deutsche Turnerschaft beantragt. Diese Aufnahme erfolgte am 27. August 1880.334

Über die Mitgliederentwicklung in den frühen Jahren des Vereins lassen sich keine präzisen Angaben machen. Die einzige überlieferte Archivalie des Vereins aus der Zeit vor dem Ersten Weltkrieg ist das Protokollbuch, in dem zwar die Eintritte neuer Mitglieder notiert wurden, das Ausscheiden von Vereinsmitgliedern jedoch allenfalls, wenn es sich bei den durch Weggang oder Tod Ausgeschiedenen um Mitglieder des Vereinsvorstandes handelte 335 oder wenn ein Mitglied aus dem Verein ausgeschlossen wurde. ${ }^{336}$ Weitere Belege für den Weggang von Mitgliedern finden sich nur in pauschaler Form in Zitaten aus den Jahresberichten des Vorsitzenden, in denen er beispielsweise an die Turner appellierte, häufiger an den Übungsabenden teilzunehmen, "um einigermaßen den Verlust durch Abgang verschiedener unserer besten Turner auszugleichen"337, oder berichtete, "daß zwar die aktive Mitgliederzahl zugenommen, der Verein aber trotzdem durch Abgang einiger sehr gewandter Turner geschwächt sei.".338

Eine erste quantitative Angabe über die Mitgliederzahl des Turn-Club Einbeck ist in dem Protokoll der Generalversammlung vom Januar 1894 enthalten. Aus dem Jahresbericht des Vorsitzenden, der in diesem Protokoll erstmals inhaltlich wiedergegeben wurde, ist zu entnehmen, dass der Verein zum Jahreswechsel 1893/94 210 Mitglieder zählte. ${ }^{339}$ Damit betrug die

\footnotetext{
${ }^{332}$ Vgl.: StAEin 065 - 30, undatierte Anlage an das Gesuch vom 21. Juli 1880

333 Vgl.: MTV Einbeck, Protokoll 17. Juni 1880

${ }^{334}$ Vgl.: Turn-Club Einbeck, Protokoll 3. August 1880, Vermerk im Protokollbuch 27.

August 1880

${ }^{335}$ Vgl.: Turn-Club Einbeck, Protokolle 2. Februar 1881, 12. Juli 1882, 24. Januar 1900, 28.

Oktober 1908, 17. Januar 1912

336 Vgl.: Turn-Club Einbeck, Protokolle 8. Juli 1881, 25. Januar 1899

${ }^{337}$ Turn-Club Einbeck, Protokoll 14. Januar 1885

${ }^{338}$ Turn-Club Einbeck, Protokoll 17. Februar 1886

339 Vgl.: Turn-Club Einbeck, Protokoll 24. Januar 1894
} 
Mitgliederzahl des TCE zu diesem Zeitpunkt mehr als das Vierfache der Mitgliederzahl des MTV Einbeck, der im Dezember 189350 Mitglieder hatte. ${ }^{340} \mathrm{Da}$ auch für den 1883 gegründeten TV Germania Einbeck keine Mitgliederzahl nachzuweisen ist, welche die Marke von 100 überschritten hätte, ${ }^{341}$ so ist ohne Zweifel zu konstatieren, dass der Turn-Club Einbeck sich - zumindest, was die Zahl seiner Mitglieder anbelangt - zum führenden Verein innerhalb des Einbecker Turnwesens entwickelt hatte. Wenn die Mitgliederentwicklung des Vereins nur annähernd kontinuierlich verlaufen ist, so muss dieser spätestens in der zweiten Hälfte der achtziger Jahre der Turnverein mit den meisten Mitgliedern geworden sein.

Die im Protokollbuch des TCE festgehaltenen Neuaufnahmen von Vereinsmitgliedern summieren sich mit den 22 Gründungsmitgliedern auf die Zahl von 225 Personen bis zum Ende des Jahres 1893. Diese Aufzeichnungen sind für die meisten Jahre durchaus als annähernd vollständig anzunehmen, da die Neuaufnahmen monatsweise aufgelistet sind. Lediglich für das Jahr 1889 ist anzunehmen, dass verschiedene neue Mitglieder unerwähnt bleiben; es sind nur für die Monate Januar und Februar je eine Neuaufnahme verzeichnet. Daher ist die Aussage zulässig, dass die Mitgliederflukuation im Turn-Club Einbeck, anders als im MTV Einbeck und in der Deutschen Turnerschaft überhaupt ${ }^{342}$, eher gering war und die meisten Mitglieder eine dauerhafte Bindung an den Verein aufbauen konnten. Doch mit dem Mitgliederstand von 1893/94 war der TCE bereits kurz vor seinem Zenit angelangt. Die nachweisbare Mitgliederentwicklung bis zum Ende des Untersuchungszeitraumes stellte - nach den Berichten des Sprechwartes auf den Generalversammlungen - sich wie folgt dar:

Mitgliederbestand TCE (jeweils zum Jahresbeginn)

$\begin{array}{lll}\text { Jahr } & \text { Mitglieder } & \begin{array}{l}\text { davon Aktive } \\ \text { incl. Turnschüler }\end{array} \\ 1894 & 210 & 70(33,3 \text { v. H. }) \\ 1895 & 230 & 78(33,9 \text { v. H. }) \\ 1896 & 222 & 68(30,6 \text { v. H. }) \\ 1897 & 208 & 54(26,0 \text { v. H. }) \\ 1898 & 196 & 51(26,0 \text { v. H. }) \\ 1899 & 182 & 40(22,0 \text { v. H. })\end{array}$

\footnotetext{
34 0Vgl.: MTV Einbeck, Kassenbuch 1884 - 1895

${ }^{341} \mathrm{Vgl}$. hierzu das folgende Kapitel

342 Vgl. hierzu das vorige Kapitel
} 


$\begin{array}{lll}1900 & 172 & 36(20,9 \text { v. H. }) \\ 1902 & 145 & 35(24,1 \text { v. H. }) \\ 1903 & 155 & 38(24,5 \text { v. H. }) \\ 1904 & 52(32,5 \text { v. H. }) \\ 1905 & 160 & 52(32,9 \text { v. H. }) \\ 1906 & 158 & 70(37,2 \text { v. H. }) \\ 1907 & 188 & 56(30,6 \text { v. H. }) \\ & 183 & 70(40,7 \text { v. H. }) \\ 1909 & & 72(40,9 \text { v. H. }) \\ 1910 & 172 & 63(43,2 \text { v. H. }) \\ 1911 & 171 & 56(39,4 \text { v. H. }) \\ 1912 & 146 & 63(44,4 \text { v. H. }) \\ 1913 & 140 & 66(40,7 \text { v. H. }) \\ 1914 & 142 & \end{array}$

Die hohe Zahl von passiven Mitgliedern illustriert die These vom vergleichsweise hohen Grad der Bindungstreue der Mitglieder an den Verein über deren aktive Turnerzeit hinaus. Des weiteren zeigt die Entwicklung der aktiven Mitglieder, dass es dem Verein über die Dauer des gesamten dokumentierten Zeitraumes gelang, auch in Zeiten des vermehrten Erscheinens alternativer Sportarten 343 immer wieder neuen Turnernachwuchs in Einbeck zu rekrutieren. Gerade innerhalb der Gruppe der aktiven Turner gab es auf Grund der Tatsache, dass in der Regel nur die Mitglieder unter 25 Jahren am Turnbetrieb teilnahmen, eine stetige Fluktuation, die eine effektive Rekrutierung junger Mitglieder erforderte. Es sind konkrete Maßnahmen des Vorstandes zur Werbung von neuen Mitgliedern nachweisbar, in denen man gezielt die Studenten des Technikums, also der Königlichen Maschinenbauschule, die ohnedies recht zahlreich im TCE vertreten waren, ansprach, sich jedoch ferner an die gesamte männliche Jugend der Stadt wandte. So beschloss der Vorstand im Frühjahr 1893, "um dem Verein mehr junge Kräfte zuzuführen, am schwarzen Brett des hies. Technikums, eine Aufforderung zum Eintritt in den Verein zu erlassen, sowie bis auf Weiteres auf dem Turnplatz Sonntag Nachmittags öffentliche Turnspiele zu veranstalten. Ein diesbezüglicher Aufruf in den hies. Zeitungen sowie Einladungen an den [sic] beiden anderen hies. Vereinen, sollen bewirkt werden.". 344

\footnotetext{
343 Von diesen neuen Sportarten wird unten noch zu reden sein.

344 Turn-Club Einbeck, Protokoll 13. März 1893
} 
Trotz der zeitweiligen Mitgliederrückgänge blieb der TCE so über den gesamten Untersuchungszeitraum hinweg der bei weitem mitgliederstärkste Einbecker Turnverein, ja sogar - hier sei der unten stattfindenden Gesamtanalyse des Einbecker Vereinswesens vorgegriffen - einer der größten Vereine der Stadt überhaupt.

Der oben aufgezeigten vergleichsweise hohen Dauerhaftigkeit der Bindung der Mitglieder an den Verein entspricht eine bereits früh sehr ausgeprägte Kontinuität in organisatorischer Hinsicht, wie auch bezüglich der Amtsdauer der Vorstandsmitglieder. Im gesamten Zeitraum von der Konstituierung des Vereins bis zum Ersten Weltkrieg fand, bis auf einige kleinere Änderungen, nur eine umfassendere Statutenrevision im Jahre 1893 statt. Diese organisatorische Stabilität dürfte vor allem darauf zurückzuführen sein, dass man sich bei der Vereinsgründung keine neue und unerprobte Satzung gegeben hatte, sondern, wie oben erwähnt, auf ein bereits bewährtes Statut eines anderen Vereins zurückgegriffen hatte.

Vom Juni 1880 bis zum Beginn des Ersten Weltkrieges 1914 wurden die sechs respektive sieben Vorstandsämter ${ }^{345}$ von insgesamt nur 34 Männern bekleidet. Amtszeiten von weniger als einem Jahr stellten eine seltene Ausnahme dar. Zwar wäre es durchaus möglich, einen Durchschnittswert für die Verweildauer der Vorstandsmitglieder in ihren Ämtern respektive im Vorstand überhaupt ${ }^{346} \mathrm{zu}$ errechnen, doch würde eine solche Statistik in diesem Falle von der zentralen Figur in der Geschichte des Vereins vor dem Ersten Weltkrieg ablenken, deren herausragende Amtsdauer in einem Durchschnittswert unterginge. Diese besondere Stellung muss hier dem Gründungsmitglied Carl Friede zugemessen werden, der von der Gründung des Vereins im Juni 1880 bis zu seinem freiwilligen Rücktritt von diesem Amt im Januar 1906 das Amt des Turnwartes versah und der daneben wie darüber hinaus vom Januar 1885 bis zu seiner Ernennung zum Ehrenvorsitzenden im Januar 1910 Sprechwart, also Vorsitzender des TCE war. In Friede ist zweifelsohne, auch wenn in dieser Zeit auch andere Männer durchaus über mehrere Jahre ihre Ämter inne hatten, eine Person zu sehen, auf die zum einen

\footnotetext{
${ }^{345}$ In der Zeit von Januar 1888 bis Januar 1893 gab es das Amt eines stellvertretenden Gerätewarts, von Januar 1902 bis März 1903 hatte der Verein einen stellvertretenden Schriftwart. Vgl. hierzu die entsprechenden Protokolle der Generalversammlungen der genannten Jahre ${ }^{34}{ }^{6}$ In verschiedenen Fällen bekleidete ein und dieselbe Person im Laufe der Jahre zwei oder mehr Ämter.
} 
die Gründungsinitiative des Vereins zurückzuführen ist ${ }^{347}$, und der zum anderen durch seine Person einen wesentlichen Anteil an dem großen Erfolg dieser Vereinsgründung gehabt haben dürfte.

Eine berufsstrukturelle Analyse der erwähnten Vorstandsmitglieder ${ }^{348}$ hatte folgendes Ergebnis: Von den 34 Vorstandsmitgliedern war für 22 Männer der Beruf nachweisbar; acht von ihnen waren Angestellte, sieben waren Kaufleute - von diesen sieben zweifelsohne vier mit einem eigenen Geschäft, und weitere acht Männer waren selbständige Gewerbetreibende wie Handwerksmeister oder Fabrikanten. 349

Die einzigen neu aufgenommenen Mitglieder, deren Stand stets im Protokollbuch vermerkt ist, sind die bereits erwähnten Studenten des so genannten Technikums. Diese stellten in den Jahren 1886 bis 1897 insgesamt 73 der insgesamt 194 als aktive Turner aufgenommenen, also immerhin 37,6 v. H..

Das Ergebnis der Berufsgruppenanalyse der Vorstandsmitglieder legt in Verbindung mit diesem Befund und weiteren, vereinzelt im Protokollbuch zu findenden Berufsangaben oder Firmenvermerken den Schluss nahe, dass es sich beim Turn-Club Einbeck um einen Verein handelte, der von den gehobenen Teilen des Bürgertums und insbesondere vom sich im Untersuchungszeitraum herausbildenden neuen Mittelstand getragen wurde.

Dies würde auch die geringe Mitgliederfluktuation und die lange Amtsdauer der Vorstandsmitglieder zumindest zum Teil erklären, da diese Personenkreise eine wesentlich geringere lokale Mobilität aufwiesen, als Angehörige der kleinoder unterbürgerlichen Schichten. 350

\footnotetext{
${ }^{347}$ In einem Protokoll des MTV Einbeck aus dem Sommer 1880 heißt es, dass der TCE "unter der Leitung des Herrn Carl Friede jr." gegründet worden sei. Vgl.: MTV Einbeck, Protokoll 17. Juni 1880
}

348 Von einer solchen Analyse für alle Personen, deren Eintritt in den TCE dokumentiert ist, musste abgesehen werden. In den Protokollen des Turn-Clubs fehlen diese Angaben in der Regel und sie sind aus zwei Gründen nur in wenigen Fällen rekonstruierbar. Zum einen liegen für den Zeitraum von 1881 bis 1895 keine Adressbücher für die Stadt Einbeck vor, zum anderen waren die neuen Mitglieder in diesen nur in den seltenen Fällen aufgeführt, wenn sie Haushaltsvorstände waren.

349 Der Umstand, dass 22 Personen sich nach der Analyse auf 23 Kategorisierte summieren liegt daran, dass W. Appel, Turnwart-Ammann von 1906 bis 1907 Klempner mit eigenem Betrieb war, in diesem aber auch nicht selbst hergestellte Sanitärapparate vertrieb. ${ }^{350}$ Vgl. hierzu: Walter, Hubert: Bevölkerungsgeschichte der Stadt Einbeck. Hildesheim 1960, 


\section{3. 1. 3. 2. Die Vereinsaktivitäten}

Nach $\S 1$ der Statuten war der Vereinszweck des Turn-Club Einbeck äußerst eng definiert: "Der Zweck des Turn-Clubs ist: Ausübung und Förderung des Turnens.".351 Doch bereits die Vereinsgründer waren sich offensichtlich darüber im Klaren, dass es im Verein durchaus Aktivitäten geben würde, die über dieses unmittelbare Vereinsziel hinaus reichten. So beschlossen sie zum einen, dass "zur Einübung der jeden Turner nothwendigen Lieder ein Gesanglehrer genommen werden" solle, zum anderen, dass die Versammlungen der Vereinsmitglieder ,"damit die Zusammenkünfte nicht ausarten" spätestens um 23.30 Uhr beendet sein müssten. ${ }^{352}$ Noch im selben Jahr wurde der Entschluss gefasst, alle acht Wochen einen gemütlichen Abend $\mathrm{zu}$ veranstalten. ${ }^{353} \mathrm{Ab} 1888$ sind mehr oder weniger regelmäßige Vereinsfeierlichkeiten belegbar. ${ }^{354}$ Diese Feste gestalteten sich ähnlich wie die im vorigen Abschnitt beschriebenen "Kränzchen" des Männer-TurnVereins, waren also bunte Abende mit verschiedenen Vorträgen ${ }^{355}$; neben Vorführungen an Turngeräten ${ }^{356}$ und den in jener Zeit beliebten Marmorgruppen 357 sind auch Theatervorträge 358 und musikalische Darbietungen von einem befreundeten Gesangverein 359 belegt. Die vielfach in den Protokollen gebrauchte Bezeichnung "Gastabend" belegt, dass zu diesen Festen auch Nichtmitglieder eingeladen wurden. Im Stadtarchiv Einbeck sind verschiedene Einladungen $\mathrm{zu}$ solchen Festen erhalten, die an den Magistrat gerichtet waren; in mindestens einem Falle nahm der Bürgermeister Troje an einem solchen Abend teil, wie eine Notiz auf einer Einladung belegt. ${ }^{360} \mathrm{Im}$ Unterschied $\mathrm{zu}$ anderen Vereinen erhob der Turn-Club Einbeck zu solchen

\footnotetext{
${ }^{351}$ Nach einem undatierten Druckexemplar in StAEin 065 - 30

${ }^{352}$ Beide Zitate in: Turn-Club Einbeck, Protokoll 17. August 1880

${ }^{353}$ Vgl.: Turn-Club Einbeck, Protokoll 4. November 1888

${ }^{354} \mathrm{Vgl}$.: Turn-Club Einbeck, Protokolle 19. Januar 1888 ff. passim

${ }^{355}$ Vgl.: Turn-Club Einbeck, Protokoll 25. Januar 1892, 15.Januar 1896, 2. April 1900

356 Vgl.: Turn-Club Einbeck, Protokolle 19. Januar 1888, 24. Januar 1893, 24. Januar 1894,

13. Januar 1904, 15. Januar 1910

${ }^{357}$ Vgl.: Turn-Club Einbeck, Protokoll 15. Januar 1910

358 Vgl.: Turn-Club Einbeck, Protokolle 1. Oktober 1903, 15. Januar 1910

359 Vgl:: Turn-Club Einbeck, Protokoll 17. Januar 1912

${ }^{360}$ Vgl.: StAEin 065 - 30, 24. November. 1883, 8. März 1884, 2. Dezember. 1882, 2. Februar. 1893, auf letzterer der handschriftliche Vermerk: "Tr. geht hin"
} 
Festen in der Regel kein Eintrittsgeld. ${ }^{361}$ Daher stellten die Feste eine hohe Belastung für die Vereinskasse dar ${ }^{362}$, die den TCE im Winter 1901/1902 in eine derartige Finanznot brachten, dass nur die Stundung der Vereinsschulden durch den Vereinswirt und einige Vorstandsmitglieder den Verein vor dem wirtschaftlichen Ruin bewahren konnten. ${ }^{363}$ Doch da die Einnahmen aus dem Gauturnfest 1902 die Vereinsfinanzen wieder konsolidierten, behielt der TurnClub auch in der Folgezeit seine Tradition von regelmäßigen kostspieligen Festen bei.

Neben den großen Festen fanden auch informelle gesellige Zusammenkünfte, vor allem im Anschluss an die Turnabende und Versammlungen statt. Bei diesen Anlässen wurde Bier getrunken ${ }^{364}$ und wurden offenbar die Trink- und Geselligkeitsrituale der studentischen Verbindungen imitiert. So ist im Protokollbuch zu lesen, dass der Sprechwart die Versammelten aufforderte, "einen Turnerischen Salamander zu reiben"365 oder das Protokoll berichtet von einem Umtrunk mit einer in der Verbindungssprache gebräuchlichen Formulierung: "nachher Fidelitas". 366

Im Jahre 1888 hatte der Verein die nötigen Mittel aufgebracht, um sich eine Fahne anzuschaffen. Zur Feier der Fahnenweihe wurden alle Vereine des DTGaues eingeladen. Als Termin für die zweitägige Feier mit Umzug, Turnen, Konzert und zwei Bällen wählte man den 8. und 9. Juli 1888. ${ }^{367}$ Doch dieser Termin konnte nicht eingehalten werden; auf Grund der Krankheit Kaiser Friedrichs III. beschloss man am 13. Juni, das Fest um zwei Wochen zu verschieben. ${ }^{368}$ Bereits am darauf folgenden Tage starb der Kaiser. Der neue

\footnotetext{
${ }^{361}$ Die Erhebung eines Eintrittsgeldes von Vereinsfremden ist nur für ein Fest belegt; aus dem entspechenden Protokoll geht deutlich hervor, dass der Gedanke, eine Unkostenbeteiligung für einen Gastabend zu erheben, im Verein erstmals aufkam. Vgl.: TurnClub Einbeck, Protokoll 22. Oktober 1908

362 Vgl.: Turn-Club Einbeck, Protokolle 15. Januar 1893, 24. Januar 1896, 22. Januar 1902, ${ }^{363}$ Vgl.: Turn-Club Einbeck, Protokoll 22. Januar 1902

${ }^{364}$ Vgl.: Turn-Club Einbeck, Protokoll 24. Januar 1894

${ }^{365}$ Turn-Club Einbeck, Protokoll 15. Januar 1896. Ein Salamander ist ein Trinkritual der studentischen Verbindungen. Auf ein Kommando des Erstchargierten werden die gefüllten Biergläser oder -krüge auf der Tischplatte hin und her gerieben, simultan auf einen Zug geleert, anschließend auf der Tischplatte mehrfach rhythmisch aufgeschlagen und dann gleichzeitig lautstark abgestellt.

366 Turn-Club Einbeck, Protokoll 6. Mai 1914

${ }^{367}$ Vgl.: Turn-Club Einbeck, Protokoll 30. Mai 1888

368Vgl.: Turn-Club Einbeck, Protokoll 13. Juni 1888
} 
Termin, der 22. und 23. Juli, fiel in die auf Grund des Todes des Kaisers ausgerufene Landestrauer, so dass der Magistrat die Genehmigung zu dem geplanten Fest auf dem Tummelplatz versagte. ${ }^{369}$ Daraufhin richtete der Sprechwart des TCE ein Schreiben an den Magistrat. Darin teilte er diesem schriftlich "ergebenst mit, daß es sich zu unserem lebhaften Bedauern nicht ermöglichen läßt das Fest nochmal zu verschieben.

Gern hätten wir selbst gesehen die Landestrauer einhalten zu können, was sich aber aus folgenden Gründen nicht machen läßt.

Der nächste Sonntag und Montag nach unseren bestimmten Festtagen, also der 29. u. 30. Juli sind von einem anderen hiesigen Vereine belegt, acht Tage später ist die Musik durch auswärtiges Engagement behindert, weiterhin ist die Musik im Manöver, außerdem können die Zelte nur 14 Tage stehen bleiben.

Sie bittend uns Ihre Genehmigung zu dem Feste nicht zu versagen, zeichnet

Ergebenst

Der Vorstand des Turnclubbs

I. A. Carl Friede jr."

Einer solchen Argumentation konnte man sich seitens der städtischen Behörden nicht verschließen; das zitierte Schriftstück wurde mit dem internen Vermerk "Unter obwaltenden Umständen Genehmigung zu ertheilen. D. M." versehen 370 , die Veranstaltung konnte wie geplant trotz allgemeiner Landestrauer als öffentliches Volksfest stattfinden ${ }^{371}$, an dem sich der TurnClub selbstbewusst in einheitlicher Kleidung in weißen Hosen, dunklem Rock und schwarzem Schlapphut ${ }^{372}$ der städtischen Öffentlichkeit präsentierte.

Allerdings sollte dieses Beispiel keinen Zweifel an der grundsätzlich patriotischen Haltung des Turn-Clubs Einbeck nahe legen. Eine der ersten Sorgen des Vorstandes des soeben gegründeten Vereins galt einer etwaigen Feier des Jahrestages der Schlacht bei Sedan ${ }^{373}$, und in einem Protokoll aus dem Jahre 1913 ist zu lesen: "Es wird beschlossen, die 100 jährige Wiederkehr des Aufruf [sic] an mein Volk am 17. März durch Fackelzug, Abbrennen eines Holzstoßes am Berge und nach dem Commers zu feiern. Mit den anderen Turnvereinen soll sich $\mathrm{zu}$ diesem Zwecke in Verbindung gesetzt werden. Ferner verliest der Vorsitzende einen Bericht aus der deutschen Turnzeitung

\footnotetext{
${ }^{369}$ Vgl.: StAEin 065 - 30, 23. Juni 1888

370 StAEin 065 - 30, 11. Juli 1888

${ }^{371}$ Vgl.: StAEin 065 - 30, 13. Juli 1888, 15. Juli 1888, 18. Juli 1888, 20. Juli 1888 nebst

Anlage

372 Vgl.: Turn-Club Einbeck, Protokoll 13. Juni 1888

373 Vgl.: Turn-Club Einbeck, Protokoll 17. August 1880
} 
vor [sic], wonach von der deutschen Turnerschaft ein Stafettenlauf aus allen Teilen Deutschlands zur Einweihung des Völker-Schlachtendenkmals geplant wird. Der Bericht wird mit großer Begeisterung aufgenommen, und soll es nicht verfehlt werden, sich an dem Lauf zu beteiligen."374

Doch weitere Möglichkeiten der Selbstrepräsentation ließ der TCE ungenutzt verstreichen. Das erste Stiftungsfest, welches gefeiert wurde, war das 25jährige im Jahre 1905 - und auch dieses Fest wurde nur im Kreise der Mitglieder begangen. 375

Offenbar lag der Schwerpunkt der Bestrebungen des Turn-Club Einbeck tatsächlich im Bereich des eigentlichen Turnens. Man fasste bereits in der ersten Zusammenkunft den ehrgeizigen Beschluss, regelmäßig zweimal wöchentlich zu turnen. ${ }^{376}$ Auch wenn dieser Vorsatz nicht einmal ein volles Jahr gehalten werden konnte ${ }^{377}$, so überholte der TCE, wie oben gezeigt wurde, den MTV Einbeck in seiner Entwicklung recht bald und konnte auch von späteren Vereinsgründungen nicht mehr von der Spitze der Einbecker Turnbewegung verdrängt werden. Der Umstand, dass der Turn-Club zumindest in seiner Anfangszeit die Turngeräte des MTV leihweise mitbenutzte, belegt, dass im neuen Verein die gleichen Leibesübungen wie im MTV betrieben wurden. Im Laufe der Jahre schaffte man dann offenbar zunehmend eigene Geräte an; im Jahre 1897 kündigte man dem MTV und dem TV Germania einen offenbar schon länger bestehenden Mietvertrag, durch den diesen Vereinen die Benutzung der dem TCE gehörenden Turngeräte gestattet wurde. Im einzelnen sind als Turngeräte im Besitz des TCE nachweisbar die Jahnschen Geräte Bock, Barren, Pferd und Reck sowie ein Hangeltau. ${ }^{378}$ Für den Sommer 1888 ist erstmalig die Teilnahme von Turnern des TCE an auswärtigen Turnwettbewerben belegt. ${ }^{379}$ Im Jahre 1890 wurde durch die Gründung einer so genannten Altersriege der Versuch unternommen, auch die Mitglieder zwischen 25 und 30 Jahren in den aktiven Turnbetrieb einzubinden. 380 Dieser Versuch war jedoch allenfalls kurzfristig erfolgreich; für das Frühjahr 1901 ist erneut ein Versuch, eine solche Altersriege ins Leben

\footnotetext{
374 Turn-Club Einbeck, Protokoll 15. Januar 1913

375 Vgl:: Turn-Club Einbeck, Protokoll 11. Januar 1905

376 Vgl.: Turn-Club Einbeck, Protokoll 14. Juni 1880

${ }^{377}$ Vgl.: Turn-Club Einbeck, Protokoll 2. Mai 1880

378Vgl.: Turn-Club Einbeck, Protokolle 4. März 1903, 1. Oktober 1903, 13. Januar 1907, 5.

Februar 1908

${ }^{379}$ Vgl.: Turn-Club Einbeck, Protokoll 13. Juni 1888

${ }^{380}$ Vgl.: Turn-Club Einbeck, Protokoll 12. Mai 1890
} 
zu rufen, nachweisbar ${ }^{381}$; dieser wurde jedoch nicht in die Tat umgesetzt. 382 Im Januar 1904 gründete man eine Vorturnerriege, auf der selben Versammlung wurde die Bildung einer Damenriege angeregt. Von letzterem Vorhaben nahm man allerdings Abstand, stellte es interessierten Damen jedoch frei, an einem gesonderten Abend unter der Leitung des Turnwart-Ammannes Kaufmann zu turnen. ${ }^{383}$ Ein Protokoll vom Januar 1911 berichtet von der erfolgten Gründung einer so genannten Herrenriege. ${ }^{384}$ Hierbei dürfte es sich um eine Gruppe von Turnern gehandelt haben, die Wert auf die Teilnahme an Turnwettkämpfen legten, denn erst ab diesem Zeitpunkt sind Erfolge von Turnern des Vereins bei auswärtigen Wettturnen in den Protokollen erwähnt. ${ }^{385}$ Obwohl im TCE ab 1887 Turnschüler nachzuweisen sind und die Jugendarbeit des Vereins, wie oben gezeigt, recht erfolgreich war, kam es erst im Jahre 1914 zur Gründung einer gesonderten Jugendriege. 386

Ein einziger Versuch, den Kanon der im TCE $\mathrm{zu}$ betreibenden Leibesübungen zu erweitern, ist für den Sommer 1897 nachzuweisen. Auf ein nicht mehr erhaltenes Gesuch des Vereins an den Magistrat gestattete die dafür zuständige Intendantur des 10. Armeecorps in Hannover in einem Schreiben dem Turn-Club die Benutzung des Hofes der Einbecker Kaserne, um sich dort im Fahrradfahren zu üben; dem Schriftwart Heinemann wurde ein Schlüssel für das Hoftor ausgehändigt. ${ }^{387}$ Doch das Radfahren wurde nur kurze Zeit betrieben; in seinem Jahresbricht für das Jahr 1899 erklärte der Turn- und Sprechwart Friede, dass der Mitgliederrückgang jenes Jahres unter anderem auf die zunehmende Popularität des Radsports zurückzuführen sei. 388

Neben dem Turnen im engeren Sinne unternahm der Verein auch die in der Tradition des Jahnschen Turnens stehenden Turnfahrten. Diese nahmen allerdings, anders als oben für den Fall des MTV Einbeck berichtet, kaum touristische Züge an, sondern führten fast ausnahmslos in die nähere Umgebung Einbecks; Ziele von Turnfahrten und Besuchen bei anderen Vereinen waren die Clus im Leinetal, das unweit gelegene Dorf Dörrigsen und wiederholt der Solling. Weitere Touren führten nach Uslar, Holzminden und

\footnotetext{
${ }^{381}$ Vgl.: Turn-Club Einbeck, Protokoll 24. April 1901

382 Vgl.: Turn-Club Einbeck, Protokoll 22. Januar 1902

383 Vgl:: Turn-Club Einbeck, Protokoll 13. Januar 1904

${ }^{384}$ Vgl.: Turn-Club Einbeck, Protokoll 11. Januar 1911

${ }^{385}$ Vgl.: Turn-Club Einbeck, Protokolle 11. Januar 1911, 17. Januar 1912, 15. Januar 1913

386 Vgl.: Turn-Club Einbeck, Protokolle 14. Januar 1914, 6. Mai 1914

387 Vgl.: StAEin 065 - 30, 14. Juni 1897 und Vermerk auf diesem Schriftstück

388 Vgl.: Turn-Club Einbeck, Protokoll 24. Januar 1900
} 
Grünenplan. Als einzige Exkursion über eine größere Distanz ist eine Fahrt nach Grund belegt. 389

${ }^{38}$ 9 Vgl.: Turn-Club Einbeck, Protokolle 8. Juli 1903, 22. Mai 1907, 17. Januar 1912, 15.

Januar 1913 


\section{3. 1. 4. Der Turnverein Germania}

Im Jahre 1883 kam es in Einbeck zur Gründung eines weiteren Turnvereins; am 8. Januar dieses Jahres wurde der Turnverein Germania ins Leben gerufen. Im Festbuch für das XV. Gauturnfest berichtet der bereits oben zitierte, "R. K." zeichnende Autor, dass es sich bei dieser Vereinsgründung um eine Abspaltung von etwa 20 Mitgliedern des MTV Einbeck gehandelt habe. ${ }^{390}$ Da sich über den TV Germania nur sehr wenig Unterlagen erhalten haben, ist diese Aussage nur schwer zu überprüfen; allerdings sprechen verschiedene Indizien für die Richtigkeit dieser Aussage. Der unter dem ältesten erhaltenen Schriftstück des Vereins unterzeichnete Schriftwart Kappey war bis zum Januar 1883 Schriftführer des MTV. Auch weist die Mitgliederstatistik des MTV Einbeck, wie bereits im einschlägigen Kapitel dargelegt wurde, für 1883, Germanias Gründungsjahr, einen auffälligen Rückgang auf.

Der MTV grenzte sich auffallend deutlich gegen den neuen Verein ab. In einem Protokoll des MTV Einbeck vom 22. Januar 1883 ist zu lesen, dass "allseitig erörtert [wurde], daß die Personen, die dem Turnverein Germania angehörten, sollen nicht in unseren Verein aufgenommen werden"391, im Jahre 1884 wurde beschlossen, sich aus nicht mehr rekonstrierbaren Gründen beim Dachverband über den TV Germania zu beschweren, und wider alle Gepflogenheit innerhalb der DT Turnkarten dieses Vereins nicht zu akzeptieren. ${ }^{392}$ All dies könnte als Indiz dafür gesehen werden, dass man von Seiten des MTV die Gründer des neuen Vereins als Abtrünnige ansah.

Dessen ungeachtet gestaltete sich die Entwicklung des Turnvereins Germania in der Zeit nach seiner Gründung offenbar recht günstig. Spätestens 1884 war der Verein Mitglied in der Deutschen Turnerschaft. ${ }^{393}$ Auch konnte in diesem Jahr bereits eine Vereinsfahne angeschafft werden. Am 2. Juni 1884 fand unter Beteiligung auswärtiger Vereine eine Fahnenweihefeier statt. Nach einem Festzug wurde die neue Fahne auf dem Marktplatz feierlich übergeben. Im Anschluss hieran fanden Schau- und Preisturnen statt, den Abschluss

\footnotetext{
390 Vgl.: Festbuch für das XV. Gauturnfest des Ober-Leine Gaues am 5., 6., und 7. Juli 1902 in Einbeck. Einbeck 1902, S. 18

${ }^{391}$ MTV Einbeck, Protokoll 22. Januar 1883. Es wurde trotz der fehlerhaften Satzkonstruktion wörtlich aus der Quelle zitiert, um die nicht auflösbaren Unklarheiten, die sich aus dem Originaldokument ergeben, nicht durch eine eigenmächtige Umschreibung verschwinden zu lassen.

392 Vgl.: MTV Einbeck Protokolle 6. März 1884, 10 Juli 1884, 9. September 1884

393Vgl.: MTV Einbeck, Protokoll 6. März 1884
} 
bildeten Konzert und Ball im Schützenhaus. ${ }^{394}$ Im selben Jahr war der Verein bereits erstmalig Gastgeber einer Gauvorturnerstunde. 395

Über die weitere Entwicklung des Vereins ist nur noch wenig in Erfahrung zu bringen. Im November 1888 war der Verein Gastgeber für die Vorturnerstunde des DT- Bezirks ${ }^{396}$, ein weiteres Mal 1898.397

Wie auch der MTV und der TCE verlegte der TV Germania sein Turnlokal von der städtischen Turnhalle in die Halle des Gasthauses zur Deutschen Eiche. Für die Turnerei schaffte der Verein keine eigenen Geräte an, sondern benutzte gegen Miete die Geräte des Turn-Clubs. ${ }^{398}$ Später zog man erneut um und turnte dann im Gasthaus zur Linde am Hubeweg. 399

Im Jahre 1893 beging der Verein sein zehnjähriges Stiftungsfest, an dem auch der MTV Einbeck, der zu diesem Zeitpunkt offenbar seine Aversionen gegen den TV Germania abgelegt hatte, teilnahm. 400

Beim Gauturnfest 1902 in Einbeck trat der Verein gemeinsam mit den beiden anderen DT-Vereinen als Veranstalter auf, im Festbuch zu dieser Veranstaltung wird die Mitgliederzahl des Turnvereins Germania zu jener Zeit auf "nahe an 100 Mitglieder" beziffert. 401

Eine Photographie aus dem Jahre 1904 belegt eine elf Erwachsene und zwei Jugendliche umfassende Musterriege des TV Germania. ${ }^{402} 1908$ beging der Verein sein 25. Stiftungsfest, zu dem er den Magistrat schriftlich einlud. ${ }^{403} \mathrm{Im}$ Sommer 1912 erweiterte man den Kanon der Leibesübungen und begann, Fußball zu spielen. ${ }^{404}$ Allerdings wurde dieser Sport nicht wettkampfmäßig

${ }^{394}$ Vgl.: StAEin 025 - 26, 16. März 1884, 19. März 1884, 24. März 1884, 5. Mai 1884 mit Anlage, 7. Mai 1884

395Vgl.: StAEin 231 - 2, 2. November 1884

396 Vgl.: MTV Einbeck, Protokoll 5. November 1888

397Vgl.: MTV Einbeck, Protokoll 1. Dezember 1897

398 Vgl:: Turn-Club Einbeck, Protokolle 20. Januar 1897, 16. Februar 1898

${ }^{399}$ Vgl.: Festbuch für das XV. Gauturnfest des Ober-Leine Gaues am 5., 6., und 7. Juli 1902 in Einbeck. Einbeck 1902, S. 18

400 Vgl.: MTV Einbeck, Protokoll 13. März 1893

${ }^{401}$ Vgl:: Festbuch für das XV. Gauturnfest des Ober-Leine Gaues am 5., 6., und 7. Juli 1902

in Einbeck. Einbeck 1902, S. 18

402 Einbecker Geschichtsverein (Hg.): Stadt Einbeck. Zeitgenössische Fotografien und

Dokumente. Gesammelt und bearbeitet von Erich Strauß, Hellmut Hainski und Andreas Heege.

Duderstadt 1995, S. 164

403 Vgl.: StAEin I: L: D: 6, 3. Juli 1908

404 Vgl.: StAEin 572 - 1, 13. Juni 1912 
betrieben, sondern dürfte eher dazu benutzt worden sein, die körperlichen Aktivitäten etwas abwechslungsreicher zu gestalten.

Zum 30. Stiftungsfest im Jahre 1913, zu dem erneut der Magistrat eingeladen wurde, erfolgte die "Neubildung einer Knabenabteilung". 405 Als im Jahre 1914 die Einbecker Turnerschaft gegründet wurde, gehörte der Turnverein Germania dem Kreis der Gründer an. 406 


\section{3. 1. 5. Der Turn- und Fechtclub}

Als vierter Turnverein in der Stadt Einbeck wurde am 6. August 1884 der Turn- und Fechtclub gegründet. ${ }^{407}$ Über seine Statuten ist nicht mehr zu erfahren, als dass diese am 7. November des Gründungsjahres von einem Buchbinder namens Tinne den städtischen Behörden zur Genehmigung vorgelegt wurden. Bei dieser Gelegenheit beantragte Tinne gleichzeitig für den neuen Verein die Genehmigung, die städtische Turnhalle am Sonnabendabend benutzen zu dürfen. Diesem Ersuchen wurde stattgegeben; dem Turn- und Fechtclub wurde die Genehmigung zu den gleichen Bedingungen wie dem Turn-Club, das heißt gegen eine jährlich im voraus zu entrichtende Hallenmiete von 48 Mark erteilt. 408

Da der Verein zu diesem Zeitpunkt nur über geringe finanzielle Mittel verfügte, beantragten der Vorsitzende Tinne und der Fechtwart Simon, die Miete für 1885 quartalsweise zahlen zu dürfen. Auch wies man darauf hin, dass der Verein nur selten an den Turngeräten turnen wolle, sondern sich hauptsächlich dem Fechten und Stabturnen widmen wolle. Auch diesem Antrag wurde stattgegeben. 409

Über die weitere Entwicklung des Vereins gibt ein Schreiben aus dem Frühjahr 1886 Aufschluss. Erstmals ist auf diesem Schriftstück ein Vereinsstempel überliefert. Dieser hat als Motive das Turnerkreuz, welches aus den vier F's besteht und das Jahnsche Motto "Frisch, Fromm, Fröhlich, Frei" symbolisiert, und zwei gekreuzte Klingen. Die Verwendung des Turnkreuzes könnte ein Indiz für den Beitritt zur Deutschen Turnerschaft sein; zweifelsohne erfolgte der Beitritt vor dem 3. September 1888.410 In dem erwähnten Schreiben ersucht der Vorstand des Clubs den Magistrat, die Hallenmiete zu senken: "Die Turnhalle, sowie die Geräthe werden von den VereinsMitgliedern, welches, nebenbei bemerkt, größtentheils steuerzahlende Bürger Einbecks sind,nur am Sonnabend jeder Woche, sowie auch dann nur ca 1/2 bis 3/4 Stunden von uns sehr wenig activen Mitgliedern benutzt und scheint die zu zahlende Miethe ad 48 Mark den Verhältnissen nach zu hoch bemessen zu sein, weshalb der wohllöbliche Magistrat gebeten wird, diese Angelegenheit einer näheren Erörterung $\mathrm{zu}$ unterziehen und $\mathrm{zu}$ beschließen, dem Verein die Benutzung der städtischen Turnhalle, sowie der darin sich befindlichen Geräthe

\footnotetext{
407 Vgl.: Statut des Bürger-Vereins der Stadt Einbeck vom 4. Juni 1895 in StAEin 065 - 24

408 Vgl.: StAEin 065 - 24, 7. November 1884, 15. November 1884, 17. November 1884

$40{ }^{V}$ Vgl.: StAEin 065 - 24, 12. Dezember 1884, 19. Dezember 1884, 20. Februar 1885

410 Vgl.: MTV Einbeck, Protokoll 3. September 1888
} 
wenn nicht frei, so doch gegen einen erheblich minderen Betrag zu gestatten." 411 Der Vereinsbetrieb entwickelte sich offenbar, obwohl man nun auch, wie dies die Unterschrift eines Turn- und Fechtwartes schließen lässt, sich mehr dem Geräteturnen zugewandt hatte, allenfalls bescheiden.

Für die folgenden Jahre ist über die weitere Entwicklung des Turn- und Fechtclubs nur sehr wenig zu erfahren. Doch die Nachricht, dass der Verein, obwohl ihm die Hallenmiete um 75 v. H. ermäßigt worden war, in den Jahren 1886 und 1887 mit den Mietzahlungen im Rückstand war ${ }^{412}$, ist als deutliches Zeichen zu werten, dass die Vereinsentwicklung bestenfalls stagnierte. Spätestens in den frühen neunziger Jahren des 19. Jahrhunderts kam der Turnund Fechtbetrieb vollends zum Erliegen. Vor dem 12. September 1892 schied der Turn- und Fechtclub Einbeck aus der Deutschen Turnerschaft aus. ${ }^{413} \mathrm{Im}$ Jahre 1893 kam das vorhandene Vereinsinventar zur Versteigerung. Dieses Inventar dürfte nicht allzu umfangreich gewesen sein; in einem Protokoll des MTV-Einbeck heißt es zu diesem Thema: "Die [sic] Einladung des verstorbenen hiesigen Turn- und Fecht-Clubs zu dessen Auktion von Turnsachen wurde nicht Folge gegeben, da bei diesen [sic] Verein keine Turnsachen vermuthet werden." 414

Die Mitglieder des Vereins hatten jedoch keineswegs die Absicht, den Turnund Fechtclub aufzulösen. Zwar betrieben sie keinerlei Leibesübungen mehr, doch sie wollten die Geselligkeit innerhalb des Vereins dessen ungeachtet weiter pflegen. Daher beschlossen sie, den Verein in einen allgemeinen geselligen Verein umzuwandeln. In einem Schreiben aus dem Jahre 1893 an den Magistrat der Stadt heißt es: "Unterzeichneter Vorstand des seitherigen Vereins 'Turn- und Fecht-Club' erlaubt sich einen wohllöblichen Magistrat zu ersuchen, die Namensänderung für unseren Verein genehmigen zu wollen.

Die Mitglieder unseres Vereins sind fast sämmtlich bejahrte Bürger, Turnerei wird seit Jahren nicht mehr betrieben, wir wurden deshalb gezwungen, aus dem Gau-Turn-Verband auszutreten; um nun zu entgehen, daß andere Turn-Vereine, uns, wegen des hochklingenden Namens 'Turn \& Fechtclub' nicht verspotten, haben wir beschlossen, unseren Verein jetzt 'Bürger-Verein' zu nennen." 415

\footnotetext{
${ }^{411}$ StAEin 065 - 24, 10. April 1886

${ }^{412}$ Vgl.: StAEin 065 - 24, 9. Februar 1887

413 Vgl.: MTV Einbeck, Protokoll 12. September 1892

${ }^{414}$ MTV Einbeck, Protokoll 4. September 1893

${ }^{415}$ StAEin 065 - 24, 20. August 1893
} 
Der Magistrat verweigerte zu dieser Namensänderung seine Zustimmung. Er wies darauf hin, dass unter Bürgervereinen solche Vereine $\mathrm{zu}$ verstehen seien, die sich der Erörterung kommunalpolitischer Angelegenheiten widmeten. ${ }^{416}$ Daraufhin beschlossen die Vereinsmitglieder in einer Generalversammlung am 27. August 1893, den ehemaligen Turn- und Fechtclub in "Bürger-Klub" umzubenennen und den Verein als eine rein gesellige Vereinigung von Einbecker Bürgern fortbestehen zu lassen. ${ }^{417}$ Über die weitere Entwicklung dieses Bürger-Klubs wird an anderer Stelle in der vorliegenden Arbeit zu berichten sein. 


\section{3. 1. 6. Der Turnclub Eintracht Einbeck}

\section{3. 1. 6. 1. Gründung, Entwicklung und Aktivitäten}

Die Gründung des jüngsten Einbecker Turnvereins des Untersuchungszeitraumes erfolgte im Januar des Jahres 1893. Am 29. dieses Monats versammelten sich 13 Männer an einem nicht mehr bekannten Ort, um einen weiteren Turnverein zu gründen. Im Gründungsprotokoll ist zu lesen: "Er wurde getauft mit den [sic] Namen Turn-Club Eintracht". ${ }^{418}$ Man wählte aus der Mitte der Versammelten einen Präses (Vorsitzenden) und einen Schriftwart und beschloss, für den soeben gegründeten Verein Statuten zu erarbeiten und diese bei den städtischen Behörden einzureichen. ${ }^{419}$

Diese hatten gegen die eingereichte Satzung nichts einzuwenden, und so nahm der Verein seinen Turnbetrieb im Saal des Rheinischen Hofes auf. 420 Die im Verein mündlich und schriftlich überlieferte Geschichte, dass der Magistrat der Stadt dem neuen Verein die von diesem gewünschte Genehmigung zur Benutzung der städtischen Turnhalle verweigert habe ${ }^{421}$, ist als äußerst unwahrscheinlich anzusehen. Weder in den vollständig erhaltenen Monatsprotokollen noch in den im Stadtarchiv Einbeck erhaltenen Schriftwechseln ist ein entsprechendes Gesuch nachweisbar. Vielmehr bot der Magistrat dem Verein im Jahre 1901 die Benutzung einer neu errichteten Turnhalle an, worauf der Verein unter Hinweis auf sein umfangreiches Mobiliar und die günstige Saalmiete im Rheinischen Hof verzichtete. ${ }^{422}$ Es scheint wahrscheinlicher, dass die Turner von Beginn an den oben angedeuteten Querelen der anderen Turnvereine mit dem Magistrat als Hausherrn der städtischen Turnhalle, die in einer Stadt von der Größe Einbecks ein offenes Geheimnis gewesen sein dürften, aus dem Weg gingen.

Über die Mitgliederentwicklung des Vereins sind für die ersten Jahre keine präzisen Angaben zu ermitteln. Zwar wurden die Neuaufnahmen von Anfang an, die Austritte einfacher Mitglieder jedoch erstmals im Oktober 1897, regelmäßig erst ab dem Jahre 1898 protokolliert. ${ }^{423}$ Erst ab dem Jahr 1902

\footnotetext{
${ }^{418}$ Eintracht Einbeck, Protokoll 29. Januar 1893

419 Vgl.: ibid.

420 Vgl.: Eintracht Einbeck, Protokoll 26. März 1893, 12. April 1893

${ }^{421}$ Vgl.: 100 Jahre SV Eintracht Einbeck von 1893. Einbeck 1993, S. 20

422 Vgl.: StAEin 211 - 2, 5. März 1901 und Eintracht Einbeck, Protokoll 6. April 1901

423 Vgl.: Eintracht Einbeck, Protokolle 2. 10. 1897, 2. April ff.
} 
sind Angaben zum Mitgliederbestand protokolliert. ${ }^{424}$ Eine nachträgliche Berechnung der Mitgliedszahlen für die Jahre 1899 bis 1902 nach den protokollierten Ein- und Austritten wäre nicht seriös; eine Kontrollberechnung für die durch Bestandsangaben und Bewegungsangaben gleichsam doppelt dokumentierten Jahre hatte zum Ergebnis, dass die in den Monatsprotokollen erhaltenen Angaben über Ein- respektive Austritte mehr oder weniger unvollständig sind. Nach den gesicherten Angaben stellt sich die Mitgliederentwicklung für den dokumentierten Zeitraum wie folgt dar:

Mitgliederbestand Eintracht Einbeck jeweils am Monatsbeginn

\begin{tabular}{|c|c|c|}
\hline Zeit & Mitglieder gesamt & Turnschüler/Anteil \\
\hline 04/1902 & 76 & 14 / 18,4 v. H. \\
\hline $10 / 1902$ & 72 & 13 / 18,1 v. H. \\
\hline 04/1903 & 82 & 22 / 26,8 v. H. \\
\hline 04/1904 & 88 & 19 / 21,6 v. H. \\
\hline $10 / 1904$ & 95 & 23 / 24,2 v. H. \\
\hline $04 / 1905$ & 104 & 29 / 27,9 v. H. \\
\hline $10 / 1905$ & 106 & 27 / 25,5 v. H. \\
\hline 04/1906 & 111 & 24 / 21,6 v. H. \\
\hline $01 / 1907$ & 80 & 13 / 16,3 v. H. \\
\hline 01/1908 & 83 & 14 / 16,9 v. H. \\
\hline 01/1909 & 99 & 15 / 15,2 v. H. \\
\hline $01 / 1910$ & 131 & 33 / 25,2 v. H. \\
\hline 01/1911 & 137 & 29 / 21,2 v. H. \\
\hline $01 / 1912$ & 107 & \\
\hline $01 / 1913$ & 90 & 3 / 3,3 v. H. \\
\hline
\end{tabular}

Bereits die in dieser Statistik dokumentierten Schwankungen der Mitgliederzahl lassen auf eine relativ hohe Mitgliederfluktuation im Verein schließen. Diese Annahme ließ sich durch eine Auszählung der dokumentierten Vereinseintritte 425 verifizieren. Von der Gründung des Vereins im Januar 1893 bis zum Zeitpunkt der ersten gesicherten Angabe von 76 Mitgliedern am

\footnotetext{
$424 \mathrm{Vgl}$.: Eintracht Einbeck, Protokolle 6. April ff.

425 Die als Wiedereintritte gekenzeichneten Vereinsbeitritte wurden in dieser Auszählung ebensowenig mitgezählt wie die Aufnahmen von Turnschülern als aktive Turner, nachdem diese das 17. Lebensjahr vollendet hatten.
} 
1. April 1902 verzeichnen die Protokolle inklusive der dreizehn Gründungsmitglieder 367 Neubeitritte zum Turnclub Eintracht. Die Mitgliederfluktuation lag somit ungefähr in der Größenordnung, wie sie oben für den MTV Einbeck nachgewiesen worden ist.

Dass ein großer Teil der Austritte darin begründet lag, dass das betreffende Mitglied die Stadt verließ, ist für diesen Verein zweifelsfrei nachzuweisen; als Austrittsgründe sind, wo ein solcher Vermerk vorhanden, nahezu ausschließlich Abreise oder - weitaus seltener - Einberufung zum Militärdienst angegeben. 426

Diese nachgewiesene hohe Mitgliederfluktuation auf Grund der hohen lokalen Mobilität der Männer, die dem Verein beitraten, ist in zweierlei Hinsicht für Aussagen zur Sozialstruktur der Mitgliedschaft des Turnclubs Eintracht von Bedeutung. Zwar ist in der kurzen Verweildauer der Vereinsmitglieder in Einbeck ein wesentlicher Grund dafür zu sehen, dass die soziale Zusammensetzung des Turnclub Eintracht Einbeck vor dem Ersten Weltkrieg nicht detailliert rekonstruierbar ist. ${ }^{427}$ Andererseits lässt die nachgewiesene hohe lokale Mobilität eines wesentlichen Teils der Personen, deren Austritt aus dem Verein dokumentiert ist, insbesondere mit der Kenntnis, dass es sich bei diesen um recht junge Menschen handelte, den Schluss zu, dass die Mitglieder mit einer großen Wahrscheinlichkeit aus der Gruppe der Handwerker und Arbeiter stammten. 428

Zieht man zusätzlich in Betracht, dass der Verein, wie unten noch näher ausgeführt werden wird, dem Arbeiter-Turner-Bund angehörte und dass eine intensive Zusammenarbeit des Vereins mit den ortsansässigen Gewerkschaften 429 belegbar ist und, wie es in einem Protokoll aus dem Jahre

\footnotetext{
426 Auf eine Auszählung wurde in diesem Falle verzichtet. Zum einen ist in vielen Fällen nicht zu ermitteln, ob sich der Vermerk "wegen Abreise" am Ende einer Auflistung von Ausgetretenen auf den letzten, die letzten oder alle aufgelisteten Männer bezieht; zum anderen ist zu bezweifeln, dass alle wegen Weggang aus Einbeck erfolgten Austritte einen entsprechenden Vermerk tragen.

${ }^{427}$ Die Adressbücher, welche die Erstellung einer solchen Statistik für andere Vereine ermöglichten, liegen nur für relativ weit auseinander liegende Jahrgänge vor. Eine weitere Schwierigkeit stellt das häufig junge Alter der Mitglieder dar; diese waren, selbst wenn sie in einer Zeit am Orte lebten, für die ein entsprechendes Adressbuch vorliegt, häufig nicht Haushaltsvorstand und erscheinen daher nicht in diesen.
} 428 Vgl.: Walter, Hubert: Bevölkerungsgeschichte der Stadt Einbeck. Hildesheim 1960, Tab. 29, S. 124; Tab 30, S. 125; Abb. 42, S. 125 und Tab 32, S. 127 429 Hiervon wird unten noch zu reden sein 
1909 heißt, "der größte Teil der Mitglieder gewerkschaftlich organisiert"430 war, so ist zumindest für die Zeit nach der Wende zum Zwanzigsten Jahrhundert die Aussage zu treffen, dass sich die Mitglieder des Turnclubs Eintracht aus der im Untersuchungszeitraum im Entstehen begriffenen gesellschaftlichen Formation der Arbeiterschaft rekrutierten. Auch der Umstand, dass der Verein ab 1896 für beim Turnen verunglückte Mitglieder die Zahlung einer finanziellen Unterstützung für die Zeit der Erwerbslosigkeit beschloss, und hierzu 1897 eine eigene Unterstützungskasse bildete, die sich aus Strafgeldern und freiwilligen Beiträgen speiste, unterstützt diese These ebenso wie die statutarisch vorgesehene Möglichkeit, dass Mitgliedern bei Krankheit oder Arbeitslosigkeit die Beiträge gestundet oder erlassen werden konnten. 431

All dies lässt die Aussage zu, dass es sich beim Turnclub Eintracht Einbeck um einen Arbeiterverein handelte.

Der Kanon der turnerischen Aktivitäten der Eintracht glich jenem der bereits bestehenden Turnvereine, man betrieb Freiübungen 432 und turnte in Riegen 433 an den Jahnschen Geräten Barren ${ }^{434}$, Reck ${ }^{45}$, Pferd ${ }^{436}$ und Bock $^{437}$. Ferner betrieb man Krafttraining mit Hanteln ${ }^{438}$ und übte sich im Stabturnen439. Außerdem betrieb man Turnspiele mit Bällen und dem Schleuderball. ${ }^{40}$ Für das Jahr 1896 ist eine Fechtkasse belegt. ${ }^{411}$ Dennoch versuchten die Verantwortlichen von Eintracht Einbeck nicht einmal, den Weg anderer neugegründeter Turnvereine $\mathrm{zu}$ gehen und zumindest in der Anfangsphase die Turngeräte bereits etablierter Vereine mitzubenutzen.

\footnotetext{
430 Eintracht Einbeck, Protokoll 7. August 1909

${ }^{431}$ Vgl.: Eintracht Einbeck, Protokolle 1. Februar 1896, 23. Januar 1897 ff.; $\$ 7$ des Statuts vom 5. März 1898in StAEin 065 - 27

432 Vgl.: Eintracht Einbeck, Protokoll 11. April 1896

433 Vgl:: ibid.

434 Vgl.: Eintracht Einbeck, Protokolle 6. April 1894, 5. November 1904, 2. Januar 1909

${ }^{435}$ Vgl.: Eintracht Einbeck, Protokolle 5. September 1896, 4. Juli 1908

436 Vgl.: Eintracht Einbeck, Protokolle 9. Mai 1896, 9. August 1896, 5. September 1896, 6.

November 1897

437 Vgl.: Eintracht Einbeck, Protokoll 4. November 1899

4389. Mai 1896, 7. November 1896, 5. März 1896

439 Vgl.: Eintracht Einbeck, Protokolle 9. Mai 1896, 1. März 1902, 6. November 1911,

44 OVgl.: Eintracht Einbeck, Protokolle 5. Juli 1902, 11. Oktober 1902 3. April 1909, 5. Juni

1909, 4. April 1914, 2. Mai 1914

441 Vgl.: Eintracht Einbeck, Protokoll 11. April 1896
} 
Stattdessen schaffte man sich relativ rasch ein umfangreiches Inventar an. Hierfür brachten die Vereinsmitglieder nicht unerhebliche Geldsummen auf. Bis zum Jahre 1901 hatte der Verein ausweislich der seit 1899 protokollierten Inventursummen über 1300 Mark in Turngeräte und -zubehör investiert. ${ }^{4} 42$

Neben dem eigentlichen Männerturnen sind, wenn auch nur für jeweils relativ kurze Zeit, weitere Aktivitäten im Bereich der Leibesübungen nachzuweisen. Die ersten Aktivitäten auf dem Gebiet des Fußballs überhaupt in Einbeck entwickelte Eintracht Einbeck im Jahre 1898; im Juni dieses Jahres wurde der Ankauf eines Fußballes beschlossen. Zur Gründung einer Fußballabteilung kam es allerdings erst in den Jahren 1908/09. ${ }^{4} 3$ Da diese Fußballabteilung eine relativ autonome Stellung innerhalb des Vereins hatte, wird über sie im Kapitel über die Fußballvereine berichtet werden.

Im Juni 1910 wurde in einer Vereinsversammlung erstmals die Gründung einer Damenabteilung angeregt, in der darauf folgenden Monatsversammlung fasste man einen entsprechenden Beschluss. Die Bildung einer solchen Turnabteilung für Frauen stellte zwar für die Turnvereine in Einbeck ein Novum dar, entspricht jedoch der zu jener Zeit gängigen Praxis innerhalb des Arbeiter-Turner-Bundes. Dieser stellte sich in den Dienst der von der Arbeiterbewegung postulierten Gleichberechtigung von Männern und Frauen und sah daher von seiner Gründung im Jahre 1893 an statutarisch die Aufnahme von Frauen sowohl als Turner als auch als stimmberechtigte Mitglieder in den Arbeiterturnvereinen vor. ${ }^{44} 4$ So entstanden ab den neunziger Jahren des 19. Jahrhunderts an verschiedenen Mitgliedsvereinen des ATB Frauenabteilungen. Als Indiz für den Stellenwert des Frauenturnens innerhalb des ATB zum Zeitpunkt der Gründung der Eintracht-Damenabteilung kann

442 Vgl.: Eintracht Einbeck, Protokolle 8. April 1899, 1. September 1900, 6. April 1901 und StAEin 211 - 2, 5. März 1901

44 3Vgl.: Eintracht Einbeck, Protokolle 4. Juni 1898, 30. Mai 1908, 26. Juni 1909

444 Zwar gab es in verschiedenen Vereinen der Deutschen Turnerschaft Damenabteilungen, doch wurden die Frauen in der DT über den nahezu gesamten Untersuchungszeitraum der vorliegenden Arbeit nicht als stimmberechtigte Mitglieder geführt. Vgl. das über das Frauenturnen im TCE oben Gesagte und: Pfister, Gertrud; Langenfeld, Hans: Die Leibesübungen für das weibliche Geschlecht - ein Mittel zur Emanzipation der Frau? in: Ueberhorst, Horst (Hg.). Geschichte der Leibesübungen, Band 3/1. Berlin, München, Frankfurt am Main 1980, SS. 485 - 521, S. 510 
dienen, dass ab 1909 die Arbeiter-Turnerzeitung mit der Beilage "Die Freie Turnerin" erschien. ${ }^{445}$

Im Oktober des Jahres 1910 konnte der Vorsitzende dann erstmals eine nicht mehr zu ermittelnde Anzahl von Frauen bei einer Versammlung des Turnclubs Eintracht Einbeck begrüßen. In der selben Versammlung berichtete der Leiter der Damenriege, dass an den Übungen 15 Turnerinnen teilnähmen. Die Versammlung beschloss, dass auch Frauen $\mathrm{zu}$ reduzierten Beiträgen Mitglieder im Turnverein werden könnten. In der nächsten Monatsversammlung traten 13 Frauen, darunter zwei verheiratete, dem Verein bei. Diese Versammlung fasste den Beschluss, dass bei Vereinsvergnügen die Frauen den Männern insoweit gleichgestellt werden sollten, dass auch sie eine Begleitperson ihrer Wahl zu den Feiern einführen dürften. Der Vorstandsbericht in der Generalversammlung vom Januar 1911 nennt 13 weibliche Mitglieder. Doch noch im selben Jahr kam der Frauenturnbetrieb bereits wieder zum Erliegen. Das Protokoll der Märzversammlung vermerkt den Austritt zweier Turnerinnen. In der Versammlung im September wurde der Antrag gestellt, dass die Turnerinnen um ihr Erscheinen in der nächsten Versammlung gebeten werden sollten, um zu erklären, ob sie gewillt seien, auch weiterhin dem Verein anzugehören. Das Protokoll der Versammlung vom Dezember dokumentiert das Ende der kurzen Episode des Frauenturnens bei Eintracht Einbeck vor dem Ersten Weltkrieg: "Der Vorsitzende teilt der Versammlung weiter mit das die Damenabteilung als aufgelöst zu betrachten sei da dieselben trotz Aufforderung nicht zum Turnen kommen und auch keine Beiträge geleistet haben." 446

Neben den Leibesübungen betrieb Eintracht Einbeck, wie auch die anderen oben dargestellten Vereine sowohl Turnfahrten als auch regelmäßige Festveranstaltungen. Diese Feste, die vor allem im Winterhalbjahr abgehalten wurden, unterschieden sich in Bezug auf ihren Ablauf und die Darbietungen nicht von jenen der anderen Turnvereine; es wurde von einer bezahlten Kapelle zum Tanz gespielt ${ }^{44}$, und vielfach wurden turnerische und schauspielerische

445 Vgl.: Block, Sigrid: Frauen und Mädchen in der Arbeitersportbewegung. (Arbeiterkultur und Arbeiterbewegung, Band 19). Münster 1987, SS. 166 f.

446 Vgl.: Eintracht Einbeck, Protokolle 4. Juni 1910, 2. Juli 1910, 1. Oktober 1910, 5.

November 1910, 7. Januar 1911, 8. April 1911, 2. September 1911, 2. Dezember 1911

447 Die Belege für Tanzmusik auf Kränzchen und Vergnügen sind zu zahlreich, als dass sie hier im Einzelnen angegeben werden könnten; vgl.: Eintracht Einbeck, Protokolle passim 
Darbietungen von den Mitgliedern vorgeführt. ${ }^{48}$ Neben solchen Festen veranstaltete der Verein in vielen Jahren aufwändige Maskenbälle. 449

In aller Regel standen die Vereinsfeste von Eintracht Einbeck auch Nichtmitgliedern des Vereins gegen die Entrichtung von Eintritts- und Tanzgeld offen; so wurden diese Veranstaltungen zur Haupteinnahmequelle des Vereins. Von den 69 in den Protokollen dokumentierten Abrechnungen von Vereinsfeierlichkeiten weisen 54, das sind 78 v. H., zum Teil erhebliche Überschüsse aus. Insbesondere die Maskenbälle waren höchst profitabel. So weisen zum Beispiel die Abrechnungen der Maskeraden von 1898 und 1906 Reingewinne von 141, 27 resp. 148,15 Mark aus; zu jener Zeit betrug der Mitgliedsbeitrag 40 Pf. monatlich. ${ }^{450}$ Nachdem in den Jahren 1902 und 1903 kein Maskenball stattfand, geriet der Verein in eine ernsthafte finanzielle Notlage; der Kassenbericht der Generalversammlung vom April 1903 weist, obwohl die Ausgaben der Jahre 1902 und 1903 nicht signifikant höher als in den Vorjahren waren, durch geringere Einnahmen der genannten Jahre einen Bestand von nur 80 Pfennig aus. ${ }^{451} \mathrm{Im}$ darauffolgenden Winter wurde erneut eine Maskerade veranstaltet. Diese erbrachte einen Überschuss von 104,50 Mark - die Kassenverhältnisse konnten sich von dem "historischen" Tiefststand erholen. ${ }^{452}$ Eine Sonderstellung in der Festkultur ist den bereits ab 1894 nachweisbaren Abschiedsfeiern für zum Militär eingezogene Turner beizumessen. Hatten diese zunächst einen eher geselligen Charakter ${ }^{453}$, so dürften sie ab dem 20. Jahrhundert durchaus eine zusätzliche politische Bedeutung erhalten haben. 1905 plädierte der Arbeiter-Turner-Bund, dem der

448 Vgl.: Eintracht Einbeck, Protokolle 5. November 1893, 6. Februar 1895, 4. Januar 1896, 2. August 1902, 6. Dezember 1902, 3. Oktober 1903, 2. Januar 1904, 4. Februar 1905, 1 Dezember 1905

449 Vgl.: Eintracht Einbeck, Protokolle 19. Dezember 1896, 8. Januar 1898, 5. Februar 1898, 7. Januar 1899, 6. Januar 1900, 5. Januar 1901, 2. Januar 1904, 6. Januar 1906, 4. Februar 1910, 3. Dezember 1910, 7. Januar 1911, 6. Dezember 1913

450 Für die anderen Maskenbälle gilt Ähnliches. Auf eine detaillierte Berechnung der Festüberschüsse wurde verzichtet, da die Angaben in den Protokollen nicht vollständig sind; es sind mehr Feste nachweisbar, als Abrechnungen vorhanden sind. Da jedoch über längere Zeiträume sowohl Gewinne als auch Verluste zuverlässig dokumentiert sind, ist die oben gemachte Aussage, dass die Feste eine wesentliche Einnahmequelle für den Verein darstellten, zuverlässig belegbar.

451 Vgl.: Eintracht Einbeck, Protokoll 4. April 1903 et passim

452 Vgl.: Eintracht Einbeck, Protokolle 2. Januar 1904, 5. März 1904, 9. April 1904

453 Vgl.: Eintracht Einbeck, Protokoll 7. Okzober 1894 
Verein $\mathrm{zu}$ jener Zeit angehörte, dafür, dass seine Vereine solche Feste veranstalten sollten, um auf diesen die Verbundenheit der künftigen Soldaten mit dem Verein zu stärken und zugleich den antimilitaristischen Charakter der Arbeiterturnbewegung zu demonstrieren. In der Arbeiterturnerzeitung, die auch von Eintracht Einbeck abonniert wurde, war 1905 ein zu diesem Anlass zu singendes Lied abgedruckt. Darin heißt es: "Ihr Turngenossen, jung und frisch, bald weilet ihr uns fern. Dann tragt ihr einen Federwisch und wohnt in der Kasern. Dort drillen euch die Schranzen zu Krieg und Völkermord, dort müßt ihr willig tanzen nach dem Kommandowort. [...] Gedenkt der frohen Stunden, denkt an der Freiheit Glück, und ist das Joch entschwunden, kehrt bald zu uns zurück." 454

Der Gedanke, eine Turnfahrt zu veranstalten, kam bereits kurz nach der Vereinsgründung erstmals auf, doch wurde ein entsprechender Vorschlag zunächst verworfen. ${ }^{455}$ Eine erste Fahrt ist für das Jahr 1895 nachzuweisen. Bereits diese Turnfahrt ging über den traditionellen Rahmen der Jahnschen Turnfahrten, die, wie oben bereits gesagt, in der Regel Wanderungen waren, hinaus; man fuhr mit Leiterwagen ins braunschweigische Wangelnstedt. 456 Nachdem im folgenden Jahr eine geplante Fahrt nicht zu Stande kam, führte der Verein ab 1897 mindestens einmal jährlich eine Turnfahrt durch. Diese hatten häufig einen touristischen Charakter und führten zu relativ weit entfernten Zielen, die nur mit der Eisenbahn zu erreichen waren. Dabei war der Harz das bevorzugte Ziel solcher Touren; verschiedene Ziele im Harz wurden in den Jahren 1897, 1898, 1901, 1902, 1904, 1905, 1912, 1913 und 1914 gewählt. ${ }^{457}$ Weitere beliebte Ziele waren der Hils ${ }^{48}$ sowie Münden und Kassel ${ }^{459}$. Touren in die nähere Umgebung der Stadt kamen neben diesen weiteren Turnfahrten auch vor; diese wurden häufig als Ausflüge mit Damen

${ }^{45}$ Vgl.: Stiller, Eike: Jugend im Arbeitersport. Lebenswelten im Spannungsfeld von Verbandkultur und Sozialmilieu von 1893 - 1933. (Arbeiterkultur und Arbeiterbewegung, Band 26). Münster; Hamburg 1995, SS. 113 f.

455 Vgl.: Eintracht Einbeck, Protokoll 13. August 1893

456 Vgl.: Eintracht Einbeck, Protokoll 7. April 1895

457 Vgl.: Eintracht Einbeck, Protokolle 3. April 1897, 3. Mai 1897, 7. Mai 1898, 3.

September 1898, 6. Juni 1901, 7. Juni 1902, 7. Mai 1904, 3. Juni 1904, 6. Mai 1905, 16. April 1912, 4. Mai 1912, 12. April 1913, 2. Mai 1914

458 Vgl.: Eintracht Einbeck, Protokolle 6. April 1907, 4. Mai 1907, 1. Oktober 1910, 5.

November 1910, 2. November 1911

459 Vgl.: Eintracht Einbeck, Protokolle 5. Mai 1900, 5. Mai 1906, 9. Juni 1906 
oder als Bierpartien unternommen. 460 Vielfach dienten die genannten Ausflüge und Turnfahrten der Pflege des Kontaktes mit anderen Vereinen. ${ }^{461}$

So wenig sich die Vereinsaktivitäten von Eintracht Einbeck über den größten Teil des Untersuchungszeitraumes hinweg von jenen der anderen Turnvereine unterschieden, so sehr ähnelte auch die Selbstrepräsentation der Eintracht derjenigen anderer Vereine. Bei Auftritten in der Öffentlichkeit wurde Wert auf ein einheitliches Erscheinungsbild der Turner gelegt. Daher waren die Mitglieder gehalten, sich einen Turnerhut anzuschaffen. ${ }^{462}$ Im Jahre 1899 begann man durch die Schaffung eines speziellen Fonds, Geldmittel für eine Fahne anzusparen. Bereits im darauffolgenden Jahr war genügend Geld vorhanden, um sich für den Preis von 350 Mark, zahlbar in drei Raten, eine Fahne anzuschaffen; am 26. August feierte man unter Beteiligung verschiedener Einbecker und auswärtiger Vereine das Fest der Fahnenweihe. ${ }^{463} \mathrm{Zu}$ besonderen Anlässen, zu denen die Fahne mitgeführt wurde, wurde sie von zwei Fahnenjunkern begleitet. Das älteste Vereinsphoto zeigt, dass diese mit Prunkschlägern, wie sie aus dem Brauchtum der Waffenstudenten bekannt sind, ausgestattet waren. 464

$\mathrm{Zu}$ Festen und Ausmärschen schmückte sich der Vorstand des Vereins mit Schärpen in den Vereinsfarben. 465

Bei Festumzügen wurde der Verein von einem eigenen Trommler- und Pfeiferkorps begleitet. Diese Unterabteilung war, nachdem sie bereits 1898 ins Leben gerufen, aber rasch wieder eingegangen war, im Frühjahr 1901 erneut gegründet worden und bestand von da an bis zum Ende des

${ }^{460}$ Vgl.: Eintracht Einbeck, Protokolle 5. Mai 1900, 5. Juli 1902, 9. Mai 1903, 7. Mai 1904,

8. Mai 1909, 1. Juni 1912

461 Vgl.: Eintracht Einbeck, Protokolle 6. Januar 1901, 4. Juli 1903, 5. Mai 1906, 7.

September 1907, 7. März 1908, 2. September 1911

462 Vgl.: Eintracht Einbeck, Protokolle 3. April 1897, 2. April 1898, 10. März 1900, 4. August 1900, 1. Februar 1902

463 Vgl.: Eintracht Einbeck, Protokolle 2. Juli 1899, August 1899, 7. Oktober 1899, 7. April 1900, 5. Mai 1900, 2. Juni 1900, 7. Juli 1900, 1. September 1900

464 Dieses Photo aus dem Jahre 1901 befindet sich im Besitz des Vereins und schmückt den Besprechungsraum der Geschäftsstelle. Eine deutlich kleinere Reproduktion befindet sich in der Photosammlung des Stadtarchivs Einbeck, Ordner 34 a. Auf dieser Reproduktion sind die genannten Prunkschläger nur äusserst schwer zu erkennen.

${ }^{465}$ Vgl.: Eintracht Einbeck, Protokolle 3. Oktober 1908, 4. Juli 1914 und die oben erwähnte Photographie 
Untersuchungszeitraumes und machte Eintracht Einbeck $\mathrm{zu}$ einem gern gesehenen Gast auf Festumzügen von Arbeitervereinen in Südhannover. ${ }^{466}$

\section{3. 1. 6. 2. Eintracht Einbeck in der Arbeiterbewegung}

Der Gedanke, sich einem Dachverband anzuschließen, ist in den Protokollen des Vereins erstmals für den Sommer 1895 nachzuweisen; die Versammlung vom 3. August dieses Jahres sprach einstimmig die Absicht aus, einem Gau beitreten zu wollen. ${ }^{467}$ Die Formulierung "Gau" wie auch die zu der damaligen Zeit übliche Verwendung der DT-Grußformel "Gut Heil"468 verraten, dass offenbar der Beitritt zur Deutschen Turnerschaft intendiert war. ${ }^{469}$ Dies bestätigt auch ein Polizeibericht vom Dezember 1894. In diesem berichtete der mit Ermittlungen über die Einbecker Turnvereine beauftragte Wachtmeister, dass nach Aussage des Vorsitzenden und Turnwartes des TurnClub Einbeck, Carl Friede, Eintracht Einbeck bereits den Versuch unternommen habe, sich der Deutschen Turnerschaft anzuschließen. ${ }^{470}$ Doch dieser Beitritt kam nicht zu Stande. Offenbar bestanden ernsthafte Differenzen zwischen dem Verein und dem DT-Gau. In einem Protokoll aus dem Jahre 1898 betont der damalige Schriftführer, "daß es wegen Gehäßigkeiten des Oberleinegau unserem Verein gegenüber uns nicht möglich ist das Volksfest mitzumachen." 471 In der Zwischenzeit hatte man allerdings auch bereits Kontakt zu einem anderen Dachverband aufgenommen. Im Sommer 1897 war eine Einladung seitens des Arbeiter-Turner-Bundes Göttingen an den Verein gerichtet worden, woraufhin der Verein etwa zehn Delegierte zum Bezirksturnfest des ATB nach Göttingen entsandte, um sich über den Verband zu informieren und dem Verein Bericht zu erstatten. ${ }^{472}$ Doch zunächst nahm man auch vom Eintritt in diesen Verband Abstand. Erst über ein Jahr später kam das Thema erneut zur Sprache; im Protokoll der Versammlung im Januar

466 Vgl.: Eintracht Einbeck, Protokolle 8. Januar 1898, 5. März 1898, 4. August 1900, 2. März 1901, 6. April 1901, 1. August 1903, 1. Juni 1907, 3. Auguat 1907, 2. Mai 1908, 30. Mai 1908, 8. Mai 1909, 6. Juli 1913

467 Vgl.: Eintracht Einbeck, Protokoll 3. August 1895

468 Vgl.: Eintracht Einbeck, Protokolle 7. April 1895, 4. Mai 1895, 9. August 1896, 5. März

1898, 2. April 1898

${ }^{469}$ Die Untergliederung in Gaue war eine Eigenheit der DT

470 Vgl.: StAEin 065 - 37, 30. Dezember 1894

${ }^{471}$ Eintracht Einbeck, Protokoll 4. Juni 1898

472Vgl.: Eintracht Einbeck, Protokolle 7. August 1897, 4. September 1897 
1899 ist zu lesen, dass Turnwart Lohmann bekannt gegeben habe, dass "die Vorturnerschaft den Wunsch hege, dem Arbeiter-Turnerbunde beizutreten. Hierüber erklärte er den Mitgliedern den Unterschied zwischen der Deutschen Turnerschaft und dem Arbeiter-Turnerbunde. Ebenfalls sprach Turnbruder Ahnert über den Werth des Turnerbundes. Beide Redner traten dann zum Schluß für den Eintritt in den Arbeiter-Turnerbund ein.

Von einigen Mitgliedern wurde dann der Wunsch ausgesprochen, der Vorstand möge sich mit der Bundesleitung in Verbindung setzen zwecks Einholung der Statuten etc. um eventuell den Mitgliedern später ein klares Bild über die Sache geben zu können." 473 In der Märzversammlung des selben Jahres wurde endgültig über den Beitritt zum ATB entschieden; in geheimer Abstimmung sprachen sich 52 Mitglieder für den Beitritt aus, nur ein Mitglied stimmte dagegen. ${ }^{474}$ Dieser Entschluss wurde umgehend in die Tat umgesetzt, bereits im folgenden Monat wurde der Vorstand um das Amt eines Zeitungswartes erweitert. Dies ist als Beweis dafür anzusehen, dass zu diesem Zeitpunkt bereits die Arbeiter-Turnerzeitung, die Mitgliederzeitung des ATB, bezogen wurde. Ferner wurde in dieser Versammlung ein Delegierter zum ATB Bundesturntag in Nürnberg gewählt. ${ }^{475}$ Auch in der Folgezeit entsandte der Verein, trotz hoher Kosten, ${ }^{476}$ regelmäßig Delegierte zu überregionalen ATB-Konferenzen. Allerdings blieb die Beschickung der Bundesturntage aufgrund der Kosten eher die Ausnahme denn die Regel. Doch auch die Konferenzen und Vorturnerstunden auf Kreis- und Bezirksebene erforderten

473 Eintracht Einbeck, Protokoll 7. Januar 1899

474 Eintracht Einbeck, Protokoll 5. März 1899. In der Festschrift zum 100jährigen Bestehen des Vereins heißt es zum Beitritt in den Verband: "1898 erkannte man den Wert der Zugehörigkeit zu einem Dachverband und schloß sich dem Arbeiter-Turn- und Sportbund an." Zitiert nach: 100 Jahre SV Eintracht Einbeck von 1893. Einbeck 1993, S. 20. Die Aussage über den Zeitpunkt des Beitritts kann einer Überprüfung an den Quellen nicht standhalten. Ferner führte der Dachverband den genannten Namen erst ab dem 12. Bundesturntag im Jahre 1919. Vgl.: Stiller, Eike: Jugend im Arbeitersport. Lebenswelten im Spannungsfeld von Verbandkultur und Sozialmilieu von 1893 - 1933. (Arbeiterkultur und Arbeiterbewegung, Band 26). Münster; Hamburg 1995, S. 132

${ }^{475}$ Vgl.: Eintracht Einbeck, Protokoll 8. April 1899.

476 Den Delegierten wurden die Fahrtkosten bezahlt, hinzu kamen Tagegelder und, wenn diese Zusammenkünfte an Werktagen stattfanden, auch die Erstattung von Verdienstausfällen. Vgl. zu den Kosten e. g.: Eintracht Einbeck, Protokolle 1. Juni 1899, 2. Dezember 1899, 10. November 1900, 2. März 1901, 3. August 1901, 2. November 1901, 1. Februar 1902, 5. März 1904, 1. Juli 1905, 4. Mai 1907, 25. Juli 1909, 6. November 1909 
relativ weite Reisen, so beispielsweise nach Nienburg/Weser, Hannover, Bielefeld, Kassel, Osnabrück, Verden, Münden oder Eschwege. 477

Der Beitritt zum ATB barg darüber hinaus auch die moralische Verpflichtung, Vereine oder in besonderen Fällen auch einzelne Turner aus dem gesamten Reichsgebiet nach Kräften finanziell zu unterstützen, wenn diese bei anderen Vereinen um Hilfe baten.

In einem Protokoll aus dem Sommer 1899 heißt es beispielsweise : "Verlesung eines Circulars des 'Turn-Vereins Constanz' betr. Beisteuerung zur Erbauung einer eigenen Turn-Halle. Fast sämmtliche Turnbrüder waren der Meinung dem [sic] Turnverein Constanz durch Freiwillige Beiträge zu unterstützen, ehe wir denselben der 'Deutschen Turnerschaft' Preis gäben."4 78 Ähnliche Spendenaufrufe, die der Verein unterstützte, sind aus Burgstädt, Graua, München, Büdelsdorf, Frankenberg i. S. und Altenritte belegt, in zwei Fällen spendete man für verunglückte auswärtige Turngenossen. 479

Auf regionaler Ebene begannen die Verantwortlichen des Clubs ab den ersten Jahren des 20. Jahrhunderts, Kontakte zu Turnvereinen in der ländlichen Umgebung Einbecks zu knüpfen. Insbesondere wurden gezielt Vereine in Dörfern angesprochen, in denen sich eine ländliche Arbeiterschicht $\mathrm{zu}$ konstituieren begann; die ersten belegbaren Kontakte nahm man zu Turnern in Hilwartshausen 480 und Sievershausen 481 auf. 482

Im Sommer 1903 kam dann erstmalig der Gedanke auf, gemeinsam mit den Vereinen im Umland einen eigenen Bezirk des ATB für Einbeck und Umgebung zu bilden; im Winter 1903/1904 fand zu diesem Zweck in

477Vgl.: Eintracht Einbeck, Protokolle August 1899, 6. Januar 1900, 10. November 1900, 2. Februar 1901, 2. November 1901, 7. Februar 1903, 9. Mai 1903, 1. Juli 1905, 2. März 1907, 5. September 1908, 6. November 1909, 5. März 1910, 2. April 1910, 2. Juli 1910, 6. August 1910, 4. März 1911, 4. November 1913. August 1912, 4. Januar 19133. Januar 1914, 2. Mai 1914

478 Eintracht Einbeck, Protokoll 2. Juni 1899

${ }^{479}$ Vgl.: Eintracht Einbeck, Protokolle 10. November 1900, 5. Januar 1901, 5. Dezember 1903, 6. August 1904, 2. September 1905, 7. April 1906, 7. Januar 1908, 4. Mai 1912 480 Vgl.: Eintracht Einbeck, Protokoll 2. August 1902 ${ }^{481}$ Vgl.: Eintracht Einbeck, Protokoll 4. Juli 1903 482Zur Sozialstruktur dieser beiden Ortschaften vgl.: Poggel, Marianne: Soziale Voraussetzungen für die Bildung einer gewerkschaftlichen Organisation in der Papierindustrie. Examensarbeit, ungedruckt. Göttingen 1979 und Quest, Thorsten: Soziale Merkmale der Entwicklung der Arbeiterbewegung im ländlichen Raum. Examensarbeit, ungedruckt. Göttingen 1979, passim 
Sievershausen eine Konferenz statt. Dass die Initiative zu der geplanten Bezirksgründung von den Aktivisten der Eintracht ausging, steht außer Frage; bildete der Verein doch zu dieser Zeit eine Agitationskomission, die auch bei weiteren Vereinen des Umlandes für die Ideen der Arbeiterturnbewegung werben sollte. ${ }^{483}$ Die Agitation für die Sache des Arbeiterturnerbundes war zunächst recht erfolgreich. Bereits im Januar 1904 wurde beim 11. Kreis des ATB die Teilung des 3. Bezirkes beantragt; der Kreisvorstand befürwortete dieses Anliegen und bereits vor dem 9. April 1904 wurde vom zuständigen Kreisturntag die Bildung des 5. Bezirks des 11. Kreises für Einbeck und Umgegend beschlossen. Bis zu diesem Zeitpunkt waren die Turnvereine aus Hilwartshausen und Fredelsloh dem Arbeiter-Turner-Bund beigetreten, der Turnverein Dassensen folgte nur wenig später. ${ }^{484}$ Auch nach der Bezirksgründung setzte man die Agitation im Einbecker Umland fort; 1904 beschloss eine Vereinsversammlung, dem gerade gegründeten Salzderheldener Turnverein durch die Überlassung von überzähligen Turngeräten unter die Arme zu greifen ${ }^{485}$, später unterstützte man dessen Fahnenkasse durch eine Sammlung 486; auch die Agitationskomission bestand weiterhin. ${ }^{487}$ Doch der Beitritt des Salzderheldener Vereins zum ATB, der vor dem April 1907 erfolgt sein muss, 488 war der letzte Erfolg der Werbebemühungen in einer Zeit, in der die Sache des Arbeiterturnens im Einbecker Umland bereits wieder viele Anhänger verlor.

Bereits 1905 waren die Fredelsloher Turner wieder aus dem Verband ausgetreten, im Winter 1905/1906 folgte der Dassenser Turnverein, zwei Jahre

\footnotetext{
483 Vgl.: Eintracht Einbeck, Protokolle 5. September 1903, 5. Dezember 1903

${ }^{484}$ Vgl.: Eintracht Einbeck, Protokolle 2. Januar 1904, 6. Februar 1904, 5. März 1904, 9.
}

April 1904, 7. Mai 1904. Vermutlich war auch ein Turnverein aus Sievershausen Mitglied im ATB. Dort hatte sich bereits im Jahre 1901 ein Turnverein namens "Einigkeit" vom bestehenden Männerturnverein abgespalten. Eine Mitgliedschaft dieses Vereins ist allerdings aus den dieser Arbeit zu Grunde liegenden Quellen nicht zweifelsfrei nachzuweisen; nach Aussage des Sievershäuser Heimatpflegers Willi Heise existieren über die Zeit vor dem ersten Weltkrieg keine Unterlagen über den bis heute bestehenden TV Einigkeit.

485 Vgl.: Eintracht Einbeck, Protokoll 2. Juli 1904

486 Vgl.: Eintracht Einbeck, Protokoll1. August 1908

487 Vgl.: Eintracht Einbeck, Protokolle 7. Dezember 1907, 1. Februar 1908, 2. Januar 1909, 1.

Juni 1912

488 Vgl.: Eintracht Einbeck, Protokoll 7. April 1906 
später verließen auch die Hilwartshäuser den Arbeiter-Turner-Bund. Über die Austrittgründe ist den Protokollen nichts zu entnehmen. 489

Die Verantwortlichen von Eintracht Einbeck waren in der Folgezeit bemüht, die ausgetretenen Vereine wieder zum Beitritt zum ATB zu bewegen. In einem Protokoll aus dem Jahre 1908 ist zu lesen: "Turngenosse Lohmann ergreift nochmals das Wort und führt aus das diesen Herbst wieder mehrere Mitglieder des Dassenser und Hilwartshausener Turnvereins zurück vom Militair kommen werden und das es uns vieleicht mit Unterstützung dieser gelingen werde oben genannte Vereine wieder für uns zu gewinnen."490 Doch diese Bemühungen hatten keinen Erfolg. ${ }^{491}$ Bis zum Ende des Untersuchungszeitraumes gelang es weder, die ausgetretenen Vereine erneut an den Dachverband zu binden, noch, neue Turnvereine zum Beitritt zum ATB zu bewegen. Zwar sind vereinzelte Kontakte zu den fraglichen Vereinen durchaus nachweisbar, ${ }^{492}$ doch ist der Versuch, im ländlichen Raum um die Stadt ein Netzwerk von Arbeiterturnvereinen zu schaffen, als weitgehend gescheitert anzusehen.

Nachdem der Verein bereits seit seiner Gründung Kontakte zu anderen Arbeitervereinigungen wie beispielsweise dem Arbeiter-Gesangverein 493 und verschiedenen gewerkschaftlichen Organisationen ${ }^{494}$ unterhalten hatte, wurden ab dem Jahr 1908 die eher informellen Beziehungen auf eine neue organisatorische Grundlage gestellt. Im Frühjahr dieses Jahres hob das seit 1903 bestehende Kartell der verschiedenen am Ort vertretenen Gewerkschaften einen gemeinsamen Bildungsausschuss aus der Taufe; an dieser Gründung beteiligte sich auch der Turnclub Eintracht Einbeck in inhaltlicher wie auch personeller Hinsicht. ${ }^{495}$ Dieser Ausschuss richtete Vorträge und kulturelle Veranstaltungen aus, ferner wurden in ihm die Feste der verschiedenen Mitgliedsvereine und -verbände koordiniert. Auch bemühte man sich, möglichst viele Vereine zur Mitarbeit $\mathrm{zu}$ gewinnen und so in die Arbeiterbewegung zu integrieren. ${ }^{496}$ In den Jahren 1910 und 1912 kam es

\footnotetext{
489 Vgl.: Eintracht Einbeck, Protokolle 4. März 1905, 6. Januar 1906, 4. Januar 1908

490 Eintracht Einbeck, Protokoll 5. September 1908

${ }^{491}$ Vgl.: Eintracht Einbeck, Protokoll 4. Mai 1912

492 Vgl.: Eintracht Einbeck, Protokolle 5. Dezember 1908, 12. April 1914, 2. Mai 1914

493 Vgl.: Eintracht Einbeck, Protokolle 6. Mai 1894, 1. September 1900, 1. März 1902, 3.

Januar 1903, 5. März 1904 13. Oktober 1905, 2. März 1907, 1. Juni 1907, 2. November 1907

494 Vgl.: Eintracht Einbeck, Protokolle 3. Juli 1897, 5. September 1903, 6. Juli 1907, 7. März

1908

495 Vgl.: Eintracht Einbeck, Protokolle 7. März 1908, 2. Mai 1908

496 Vgl.: Eintracht Einbeck, Protokolle 7. März 1908 ff., passim
} 
sogar zu Bestrebungen, über den Ausschuss eine Vereinigung aller Arbeitervereinigungen zu einem einzigen Arbeiterverein zu erreichen, doch die Verschmelzung konnte in beiden Fällen nicht realisiert werden. ${ }^{497}$

Obwohl Eintracht Einbeck dem Arbeiter-Turner-Bund angehörte und die oben angeführten engen Kontakte des Vereins zu den Gewerkschaften den städtischen Behörden bekannt waren, sind über den größten Teil des Untersuchungszeitraumes hinweg keinerlei Schwierigkeiten des Vereins im Umgang mit den Behörden nachzuweisen; der Schriftverkehr beschränkte sich auf die Einreichung von Statuten und deren Genehmigung sowie Korrespondenz über die Nutzung städtischer Anlagen. Auch eine Aufforderung des Regierungspräsidiums in Hildesheim aus dem Jahre 1906 an die örtlichen Behörden des Regierungsbezirkes, das Jugendturnen von ATB-Vereinen zu überwachen, blieb unbeachtet. ${ }^{498}$ Erst ab dem Jahr 1911 änderte sich das Verhältnis. In diesem Jahr wurde durch ein Urteil des Preußischen Oberverwaltungsgerichtes die Freie Turnerschaft Königsberg auf Grund der Mitgliedschaft im ATB und ihrer Nähe zur Sozialdemokratie zu einem politischen Verein im Sinne des Reichsvereinsgesetzes von 1908 erklärt. Ein politischer Verein musste nach diesem Gesetz die Polizeibehörden unverzüglich über vorkommende Statutenänderungen wie auch über personelle Änderungen im Vorstand in Kenntnis setzen. Außerdem - und hierin ist die eigentliche Intention des Urteils und der daraus resultierenden behördlichen Maßnahmen zu sehen - war es politischen Vereinen nicht gestattet, Jugendliche als Mitglieder aufzunehmen. Kurz nach der Urteilsverkündung übersandte das Preußische Innenministerium den Urteilstext an die nachgeordneten Polizeibehörden und forderte diese zu einem polizeilichen Einschreiten gegen die ATB-Vereine auf. ${ }^{49}$ Vor dem 2. September wurde daraufhin dem Vorsitzenden der Eintracht mündlich unter Hinweis auf das Gerichtsurteil gegen die Freie Turnerschaft Königsberg eröffnet, dass Eintracht Einbeck behördlicherseits als politischer Verein angesehen werde und dass der Verein daher den oben angeführten Beschränkungen des Reichsvereinsgesetzes unterliege. Daher seien ein Verzeichnis der Vorstandsmitglieder und ein Statutenexemplar einzureichen und es sei dem Verein untersagt, bei seinen

\footnotetext{
497 Vgl.: Eintracht Einbeck, Protokolle 5. Februar 1910, 5. März 1910, 7. Dezember 1912

498 Vgl.: StAEin 065 - 37, 20. November 1906

${ }^{499}$ Vgl.: Teichler, Hans-Joachim: Arbeitersport als soziales und politisches Phänomen im wilhelminischen Klassenstaat. in: Ueberhorst, Horst (Hg.). Geschichte der Leibesübungen, Band 3/1. Berlin, München, Frankfurt am Main 1980, SS. 443 - 484, S. 465 und StAEin 065 8, 12. Juli 1911
} 
Versammlungen und Turnabenden Jugendliche zuzulassen. 500 Der Verein wandte sich in dieser Angelegenheit an den Dachverband. Da im ganzen Land ATB-Vereine von solchen polizeilichen Maßnahmen betroffen waren, sandte dieser dem Verein ein hektographiertes Protestschreiben an die Polizeibehörde, in welches nur der Ort und der Vereinsname einzutragen waren. In diesem Schreiben heißt es: "Der Turnverein Turnklub "Eintracht" zu Einbeck bezweckt die Förderung der Leibesübungen als Mittel zur körperlichen und geistigen Ausbildung seiner Mitglieder. Die Erörterung politischer oder religiöser Fragen in den Versammlungen ist ausgeschlossen.

Nach diesem Zweck gehört der Verein unter diejenigen gesellschaftlichen Gebilde, welche durch freiwilligen Zusammenschluß bestimmte ideale Bestrebungen durch Selbsthilfe zu fördern suchen.

Diese Selbsthilfe besteht einmal in der Leistung von Geldmitteln zur Anschaffung von Geräten und sonstigen Utensilien, die zur Ausübung der Leibesübungen notwendig sind, in der Ausbildung von Vorturnern, welche die Leitung und Aufsicht der Turnübungen zu übernehmen haben, und in der Beschaffung geeigneter Literatur, die die Ausbildung unterstützt.

Dem Arbeiter-Turnerbund gehört der Verein an, um die Vorteile, die dieser Verband bietet, mit geniessen $\mathrm{zu}$ können. Diese Vorteile sind die Bestrebungen, die dieser Verband unternimmt, um die Pflege der Leibesübungen $\mathrm{zu}$ fördern. Daneben besitzt diese Organisation freiwillige Unterstützungseinrichtungen für etwa vorkommende Unfälle beim Turnen, die aber nur in Anspruch genommen werden können, wenn das einzelne Mitglied einen gewissen Beitrag leistet

Die Zugehörigkeit zu diesem Verbande ist im Grunde genommen eine persönliche und geschieht aus Zweckmässigkeitsgründen. Zudem ist uns nicht bekannt, dass der Arbeiter-Turnerbund ein politischer Verein sei." Daher seien die behördlichen Auflagen unzulässig. 501 Daraufhin wurde ein städtischer Polizeibeamter beauftragt, Erkundigungen über den Verein anzustellen. Dieser berichtete unter anderem, dass der Verein an einem Umzug anlässlich eines Gewerkschaftsfestes teilgenommen habe und dass nach seiner Vermutung alle Mitglieder des Vereins Anhänger der Sozialdemokratie seien; ein politischer Charakter des Vereins sei daher wahrscheinlich. 502 So erging, in diesem Falle schriftlich, erneut ein Bescheid der städtischen Polizeibehörde an den Vorsitzenden, in dem Vorstandsverzeichnis und Statut eingefordert und das

\footnotetext{
500 Vgl.: Eintracht Einbeck, Protokoll 2. September 1911

$50{ }^{1}$ StAEin 065 - 27, Eingangsvermerk 11. September 1911

502 Vgl.: StAEin 065 - 27, 13./21. September 1911
} 
Jugendturnverbot ausgesprochen wurden. ${ }^{503}$ Erneut reagierte der Verein mit einem vom ATB erhaltenen, annähernd gleichlautenden hektographierten Protestschreiben, in dem die Auflagen als rechtswidrig bezeichnet und daher zurückgewiesen wurden. 504

In der Folgezeit verlief die Sache zunächst im Sande; der Verein änderte weder seine Statuten noch seine Praxis, Jugendliche ab 14 Jahren als Turnschüler aufzunehmen.

Erst im November 1913 beschloss der Verein gemäß den Beschlüssen einer ATB-Konferenz in Kassel, um weiteren Konflikten aus dem Wege zu gehen, sich den gesetzlichen Bestimmungen für politische Vereine zu unterwerfen; man strich den Passus, der die Aufnahme von Jugendlichen regelte, aus den Statuten und reichte sein Statut und eine Liste der Vorstandsmitglieder ein. Auch in der Folgezeit befolgte der Verein die gesetzlichen Bestimmungen und informierte die Behörden über Veränderungen des Vorstandes. 505

Der statutarische Verzicht auf das Jugendturnen war jedoch ein reines Täuschungsmanöver; die Jugendlichen wurden zwar nicht formell in den Verein aufgenommen, doch wurden sie als "Turngäste" weiterhin zu den Turnabenden zugelassen, bis im Ersten Weltkrieg das Jugendturnverbot wieder aufgehoben wurde. 506

Doch offenbar wäre die genannte Statutenänderung im Falle Eintrachts nicht dringend vonnöten gewesen. Auch nach der oben skizzierten Verschärfung des Verhältnisses der Preußischen Regierung zum Arbeiter-Turner-Bund war Eintracht keiner intensiven Repression durch die städtischen Polizeiorgane ausgesetzt. In einem Schreiben vom Jahresende 1911 berichtete man seitens der städtischen Behörden dem Regierungspräsidenten in Hildesheim, dass ein politischer Charakter des Turnclub Eintracht nicht nachzuweisen sei. ${ }^{507}$ Auch zeigte die Einbecker Polizeibehörde bis 1913 keinerlei Tendenz, auf eine Statutenänderung zu drängen oder das Jugendturnen bei Eintracht Einbeck zu unterbinden.508 Auch die Umgehung des staatlich angeordneten Jugendturnverbots wurde stillschweigend ignoriert. Als der Verein im Jahre

\footnotetext{
$50{ }^{3}$ Vgl.: StAEin 065 - 27, 17. November 1911 und Eintracht Einbeck, Protokoll 2. Dezember 1911

504 Vgl.: StAEin 065 - 27, Eingangsvermerk 25. November 1911

505 Vgl.: Eintracht Einbeck, Protokoll 1. November 1913; StAEin 065 - 27, 1. Dezember 1913

ff.

506 Vgl.: Eintracht Einbeck, Protokolle 6. Dezember 1913, 2. Januar 1915

507 Vgl.: StAEin 065 - 27, 29. Dezember 1911

508 Vgl.: Eintracht Einbeck, Protokolle 6. Januar 1912 - 4. Oktober 1913, passim
} 
1914 beim Magistrat um die Zuweisung eines Platzes für Turnspiele nachsuchte, wurde diesem Ansinnen umgehend entsprochen. 509 


\section{3. 1. 7 Einbecks Turnvereine von der Reichsgründung bis zum Ersten Weltkrieg - Gesamtschau und Ausblick}

Eine Gesamtschau der vereinsmäßigen Turnerei in Einbeck von der Reichsgründung bis zum Beginn der Ersten Weltkrieges hat zuallererst das Ergebnis, dass in diesem Zeitraum sowohl hinsichtlich der Zahl der Turnvereine als auch der Zahl der in diesen Vereinen organisierten Mitglieder ein beachtliches Wachstum zu beobachten ist. Auch wenn die Quellenlage die Ermittlung exakter Werte nicht ermöglicht, so sind auf der Basis des vorliegenden Materials doch recht zuverlässige Schätzungen zu machen. Zum Beginn des Untersuchungszeitraumes existierte in Einbeck lediglich ein Turnverein. Dieser Verein, der MTV Einbeck von 1861, hatte am Ende der siebziger Jahre des 19. Jahrhunderts, also noch vor der Gründung des zweiten Turnvereins der Stadt, knapp über fünfzig Mitglieder; er dürfte zu Beginn des Untersuchungszeitraumes kaum mehr gehabt haben. Am Vorabend des Krieges gab es in Einbeck vier 510 Turnvereine. Für den TCE und Eintracht sind für diesen Zeitpunkt Mitgliederzahlen von 162 respektive 90 nachweisbar, für die beiden anderen sind selbst bei vorsichtigster Schätzung auf der Basis des in den vorigen Kapiteln Gesagten insgesamt mindestens 120 Mitglieder anzunehmen. Die niedrigste Schätzung aller in Turnvereinen organisierten Männer beläuft sich demgemäß für das Jahr 1914 auf etwa 370 Personen. Mithin hat sich die Zahl der Turnvereine in Einbeck vervierfacht, die der Turnvereinsmitglieder selbst bei vorsichtigster Schätzung mehr als versiebenfacht, während die Gesamtbevölkerung der Stadt im gleichen Zeitraum nur um etwa 50 v. H. zunahm.

Allerdings hatte sich in dieser Zeit die Zahl der in Dachverbänden organisierten Turnvereine ungefähr verneunfacht, die Gesamtzahl ihrer Mitglieder gar verdreizehnfacht. 511 Dass diese auf das gesamte Reich bezogenen Zuwächse deutlich höher sind, kann jedoch kaum verwundern, wenn man zur Kenntnis nimmt, dass sich die Turnbewegung in der Zeit von der Reichsgründung bis zum Ersten Weltkrieg erstmals im größeren Maßstab auch in die Kleinstädte und Dörfer ausbreitete.

\footnotetext{
510 In dieser kurzen Gesamtdarstellung wird auf den nur wenige Jahre aktiven Turn- und Fechtclub nicht eingegangen; dieser war für den Untersuchungszeitraum insgesamt bedeutungslos.

${ }^{51}{ }^{1}$ Berücksichtigt wurden die Zahlen für die Deutsche Turnerschaft und den Arbeiter-TurnerBund. Zur Berechnungsgrundlage vgl. die in der Einleitung des Abschnittes über die Turnvereine vorgestellten Daten.
} 
Die eigentlichen Vereinsaktivitäten der Turnvereine waren im Wesentlichen ähnlich, wenn nicht identisch.

Die Gründe dafür, dass zu einem weitgehend einheitlichen Vereinsziel im Laufe des Untersuchungszeitraumes verschiedene, in der Regel dauerhafte, Vereine gegründet wurden, können also nicht unmittelbar in der Vereinspraxis, sei es im Bereich der Leibesübungen oder in der Fahrt- und Festkultur, liegen. Auch ein eher lebenspraktisch motivierter Antwortansatz, nämlich dass kohärente soziale Gruppen eine Maximalgröße nicht überschreiten können, und dass bei einer bestimmten Gruppen-, im vorliegenden Falle Vereinsgröße, eine Tendenz zu Abspaltungen respektive Konkurrenzgründungen entsteht, kann einer Überprüfung am oben vorgestellten Quellenmaterial nicht standhalten.

Die einzig nachweisbaren wesentlichen Unterschiede zwischen den vier bis zum Ersten Weltkrieg bestehenden Turnvereinen in Einbeck sind, zumindest bis in die Mitte der neunziger Jahre des 19. Jahrhunderts, Unterschiede hinsichtlich der sozialen Struktur der jeweiligen Mitgliederschaften.

War der bereits vor dem Beginn des Untersuchungszeitraumes gegründete MTV Einbeck handwerklich-kleinbürgerlich dominiert, so setzte sich der TurnClub Einbeck von 1880 eher aus Angehörigen der selbständigen Kaufmannschaft und des entstehenden neuen Mittelstandes zusammen. Über die Sozialstruktur des Turnvereins Germania sind keine Angaben zu machen. Da jedoch keine der Neugründungen zu bedeutsamen Rückgängen der Mitgliedsstärke der bereits bestehenden Vereine führte und die Gesamtmitgliedschaft der Turnvereine über den gesamten Untersuchungszeitraum deutlich anwuchs, so tritt die Tendenz zu Tage, dass der jeweils neue Verein den Kreis der potenziellen Turnvereinsmitglieder innerhalb der Stadt erweiterte, die Turnbewegung für Personenkreise öffnete, die sich ohne eine solche Neugründung nicht für den Beitritt zu einem Turnverein entschlossen hätten. Daher sind zumindest die drei Vereine, die der Deutschen Turnerschaft angehörten, weniger als Konkurrenz-, sondern vielmehr als Komplementärvereine anzusehen. Hierüber dürfen auch verschiedene kleinere Konflikte und Eifersüchteleien, die zwischen den DTVereinen Einbecks nachweisbar sind, nicht hinwegtäuschen. Insgesamt betrachtet dominieren die Belege für eine recht weit gehende Gemeinschaft dieser Vereine; man gestattete einander die Benutzung von Turngeräten und lud sich untereinander zu kleineren und größeren Festen ein. ${ }^{512}$ Ein beredtes

512 Vgl.: MTV Einbeck, Protokolle 17. Juni 1880, 12. Februar 1883, 24. September 1885, 24.

März 1887, 30. Juni 1890, 16. März 1891, 13. März 1893, 1. Mai 1893, 8. Juni 1893, 2.

Oktober 1894, 12. November 1894, 6. Mai 1895, 2. November 1898, 6. November 1901, 4. 
Zeugnis über das Verhältnis der DT-Vereine in Einbeck gibt der bereits mehrfach zitierte, "R. K." zeichnende Autor im Festbuch für das Gauturnfest 1902 in Einbeck. Dort heißt es: "Zwischen den erstgenannten drei Vereinen [MTV,TCE und Germania, M. J.] bestehen die besten Beziehungen unter einander, und mit Vertrauen können wir das Herannahen des Festes erwarten. Der Zweck unseres ganzen Turnens ist: dem Vaterland zu dienen und deutsche Kraft und deutsche Sitte zu pflegen, weiterzuwandeln im Sinne unseres grossen Turnvaters Jahn."

Im selben Aufsatz deutet der Autor beiläufig an, dass das Verhältnis der drei DT-Vereine zum vierten Turnverein, dem TC Eintracht, weniger harmonisch war: "Jetzt ist aber leider noch ein Turnverein hier am Platze, welcher sich nicht zur deutschen Turnerschaft bekennt, sein Gruss ist 'Frei Heil'." 513 Mit der Anspielung auf den Gruß der Arbeiterturner ersparte sich der Autor die Zumutung, Eintracht und den ATB beim Namen nennen zu müssen. Über die Entstehung der zwischen den drei etablierten Vereinen auf der einen und dem 1893 gegründeten Turnclub Eintracht auf der anderen Seite bestehenden Kluft ist inhaltlich nichts bekannt. Eintracht Einbeck übte die gleichen Leibesübungen aus und strebte einige Jahre nach der Vereinsgründung den Beitritt zur Deutschen Turnerschaft an. Ob eine soziale Abgrenzung der sich selbst als dem Bürgertum zugehörig fühlenden Mitglieder der bestehenden Turnvereine gegenüber dem neuen Verein oder bereits politische Gründe Auslöser der Streitigkeiten waren, die den TC Eintracht dazu brachten, sich dem Arbeiter-Turner-Bund anzuschliessen, ist nicht mehr zu klären. Spätestens ab der Jahrhundertwende ist eine deutliche beiderseitige Gegnerschaft zwischen den drei DT-Vereinen und Eintracht Einbeck zu konstatieren. Die erste und zugleich letzte nachweisbar gemeinsame Aktivität der vier Vereine war eine gemeinschaftliche Turnvorführung auf dem Volksfest von 1899.514 Nur in der 1908 vom Einbecker Zweigverein des Roten Kreuzes gegründeten freiwilligen Sanitätskolonne waren Turner der verschiedenen Vereine gemeinsam tätig. 515

Dezember 1901 und Turn-Club Einbeck, Protokolle 14. Juni 1880, 3. August 1880, 20. Januar 1897, 16. Februar 1898, 15. Januar 1913

513 Festbuch für das XV. Gauturnfest des Ober-Leine Gaues am 5., 6., und 7. Juli 1902 in

Einbeck. Einbeck 1902, S. 18

514 Vgl.: MTV Einbeck, Protokoll 6. Mai 1899

515Vgl:: StAEin 431 - 2, 8. September 1908 und Eintracht Einbeck, Protokolle 7. März 1908,

4. April 1908, 6. November 1909 
Die städtischen Behörden standen den Turnern im Allgemeinen, von einigen Querelen über die Benutzungsbedingungen und -gebühren für die städtische Turnhalle abgesehen, recht wohlwollend gegenüber. Auch den direkten Aufforderungen der übergeordneten Behörden, den Turnclub Eintracht seiner Mitgliedschaft im ATB wegen zu überwachen und zu schikanieren, kam der Magistrat allenfalls lustlos und inkonsequent nach. Bezüglich der Behandlung von Anfragen und Bitten der Turnvereine an den Magistrat ist eine Ungleichbehandlung nicht feststellbar.

Der Erste Weltkrieg beendete vorerst die Entwicklung der Turnbewegung. Hatte man im Winter 1911/1912 noch die Gauturnfahrt der Deutschen Turnerschaft als Kriegsspiel begangen 516 , so mussten die Turner das spielerisch Erlernte schon bald in die Praxis umsetzen. Ab August 1914 wurden viele Mitglieder der Vereine zum Militär einberufen, so dass der Turnbetrieb zum Erliegen kam. Bereits Ende September trafen sich die Vorstände der drei DT-Vereine, um über die Möglichkeiten zu sprechen, wie man gemeinsam über die Kriegszeit hinweg einen regelmäßigen Übungsbetrieb organisieren könne. ${ }^{517}$ Man kam überein, sich zusammenzuschließen; am 20. Oktober 1914 fand die konstituierende Sitzung des vorläufigen gemeinsamen Vereins, der Einbecker Turnerschaft, statt. In dieser Sitzung wurde seitens des neu gewählten Vorsitzenden die Hoffnung ausgesprochen, dass diese Vereinigung auch über das Kriegsende hinaus Bestand haben möge. ${ }^{518}$ Die Burgfriedenspolitik der Kriegszeit führte auch dazu, dass die DT-Turner ihr Verhältnis zum TC Eintracht überdachten. Bereits in der zweiten Sitzung der Einbecker Turnerschaft - in der im übrigen der Name endgültig beschlossen wurde - wurde angeregt, "mit dem hiesigen sozialdemokratischen Turnverein zwecks gemeinsamen Wirkens zu versuchen, in Verhandlungen zu treten.". Allerdings beschloss man "bei der Kreisleitung erst anzufragen, ob solche Verhandlungen im Interesse der deutschen Turnsache erwünscht seien oder nicht". ${ }^{519}$ Eine Antwort auf diese Anfrage ist nicht überliefert, die Integration von Eintracht Einbeck in die neue Einbecker Turnerschaft fand nicht statt.

Auch die anfangs projektierte dauerhafte Vereinigung der DT-Vereine kam nicht zu Stande. Bereits im März 1915 fasste eine Versammlung einen

\footnotetext{
${ }^{516}$ Vgl.: Turn-Club Einbeck, Protokoll 17. Januar 1912. Die Praxis von Kriegsspielen war in der DT, besonders nach der Marokkokrise 1911, nicht unüblich. Vgl.: John, Hans-Georg: op. cit., SS. $307 \mathrm{ff}$.

${ }^{517}$ Vgl.: Turn-Club Einbeck, Protokoll 23. September 1914

${ }^{518}$ Vgl.: Einbecker Turnerschaft, Protokoll 20. Oktober 1914

${ }^{519}$ Einbecker Turnerschaft, Protokoll 6. November 1914
} 
Beschluss, nach dem Neumitglieder der Einbecker Turnerschaft nach deren etwaiger Auflösung entscheiden dürften, welchem der drei Einzelvereine sie angehören wollten. Auch wenn die spätere Auflösung im entsprechenden Protokoll als unwahrscheinlich bezeichnet wird, so ist dieser Beschluss doch ein deutliches Indiz dafür, dass einige der Beteiligten die Einbecker Turnerschaft nur als eine Notgemeinschaft für die Kriegszeit ansahen. 520

Obwohl zunehmend mehr Mitglieder zum Kriegsdienst einberufen wurden und die ersten Kriegstoten zu beklagen waren, unterhielt die Einbecker Turnerschaft noch einen recht regen Vereinsbetrieb; man turnte, ging auf Turnfahrten und hielt gar im Januar 1915 noch eine öffentliche Festveranstaltung in Form eines volkstümlichen Abends ab. ${ }^{521}$ Doch auch gemeinschaftlich war ein solcher Vereinsbetrieb wie in Friedenszeiten nicht lange aufrechtzuerhalten. Berichtet das Protokoll vom 6. Juli 1915 noch: "Die Anwesenden unterhielten beim Bier gemütlich über die Kriegslage"[sic], so endeten die Aktivitäten der Einbecker Turnerschaft im März 1916 völlig. 522 Auch bei Eintracht Einbeck konnte das Vereinsleben nach Kriegsbeginn nur für kurze Zeit weiter geführt werden. Da der Saal des Rheinischen Hofes zum Lazarett umgewandelt worden war, beantragte man beim Magistrat die Genehmigung zur Benutzung der Turnhalle an der Volksschule und verlegte, nachdem dies genehmigt worden war, die Übungen dorthin. 523 Doch noch im selben Winter kam der Vereinsbetrieb zum Erliegen. Das Protokoll vom 6. Februar 1915, in dem auf Grund der im Zeichen der Burgfriedenspolitik erfolgten Aufhebung des Jugendturnverbots der Eintritt von 16 Turnschülern vermerkt ist, ist das letzte Protokoll aus der Zeit des Ersten Weltkrieges.

Nach dem Krieg nahmen alle vier Turnvereine ihre Tätigkeit wieder auf. Im Nationalsozialismus wurden die drei Vereine der Deutschen Turnerschaft gleichgeschaltet; Eintracht Einbeck als Mitgliedsverein des nunmehrigen Arbeiter-Turn- und Sportbundes wurde aufgelöst und für verboten erklärt. Nach dem Zweiten Weltkrieg wurden nur der Turn-Club und Eintracht wieder gegründet - sie bestehen zum Zeitpunkt der Niederschrift dieser Untersuchung als mitgliederstarke Sportvereine.

\footnotetext{
520 Vgl.: Einbecker Turnerschaft, Protokoll 16. März 1915

${ }^{52}$ Vgl.: Einbecker Turnerschaft, Protokolle 6. November 1914, 8. Dezember 1914, 5. Januar 1915, 13. April 1915, 4. Mai 1915, 7. September 1915

522 Das letzte Protokoll datiert vom 29. Februar 1916

523 Vgl.: Eintracht Einbeck, Protokolle 12. September 1914, 7. November 1914
} 


\section{3. 2. Die Radfahrvereine}

\section{3. 2. 1. Zur Geschichte des Radfahrens in Deutschland}

Nachdem am Beginn des Jahrhunderts das Laufrad erfunden worden war, und nach der Jahrhundertmitte erstmals Fahrräder mit direktem Kurbelantrieb auf den Markt kamen, setzte ab den ausgehenden sechziger Jahren des 19. Jahrhunderts die Entwicklung zum Hochrad ein, mit dem erstmals die Geschwindigkeit von Reitern erzielt werden konnte. Doch dieses konnte sich nicht als Verkerhsmittel oder Sportgerät für breitere Bevölerungsschichten durchsetzen: Die Produktion von Hochrädern war aufwändig und die Fahrräder daher recht teuer. Ferner war die Beherrschung des Hochrades schwer zu erlernen, und das Hochradfahren war recht unfallträchtig.

$\mathrm{Ab}$ der Mitte der achtziger Jahre des Jahrhunderts kam dann, beginnend mit dem Modell "Rover" aus England, das Niederrad mit zwei etwa gleich großen Rädern und Kettenantrieb auf und löste das Hochrad allmählich ab. 524

Mit den modernen Niederrädern begann ein regelrechter Siegeszug des Fahrrades. Rüdiger Rabenstein ermittelte aus zeitgenössischen Publikationen für die Jahre 1890 bis 1897 eine Verzehnfachung der Radfahrer in Deutschland von 50.000 auf eine halbe Million. ${ }^{52}$ Mit der Ausweitung des potenziellen Kundenkreises stieg in jener Zeit auch die Fahrradproduktion in Deutschland stark an. Wurden im Jahre 1882 in Deutschland nur etwa 2.500 Fahrräder produziert, so stieg diese Zahl über etwa 20.000 im Jahre 1888 und circa 120.000 Stück 1894 auf eine Jahresproduktion deutscher Fahrradhersteller von ungefähr 350.000 Rädern im Jahre 1897.526 Diese Steigerung des Angebotes führte zu einem deutlichen Absinken der Fahrradpreise, ohne welches die skizzierte Zunahme der Zahl der Radfahrer in Deutschland nicht denkbar gewesen wäre. Kostete am Beginn des Untersuchungszeitraumes eine Michauline noch mindestens 600 Mark und war ein Hochrad in den achtziger Jahren des 19. Jahrhunderts nicht unter 400 Mark zu bekommen, so sanken die

524 Zur gesamten technischen Entwicklung von der Draisine zum Niederrad vgl.: Eichberg, Henning: Sport im 19. Jahrhundert - Genese einer industriellen Verhaltensform. in: Ueberhorst, Horst (Hg.). Geschichte der Leibesübungen, Band 3/1. Berlin, München, Frankfurt am Main 1980, SS. 350 - 412, S. 356 und Rabenstein, Rüdiger: Radsport und Gesellschaft. Ihre sozialgeschichtlichen Zusammenhänge in der Zeit von 1867 bis 1914. 2. Auflage, Hildesheim, München, Zürich 1996, SS. 8 ff.; 26 ff.

525 Vgl.: Rabenstein, Rüdiger: op. cit., S. 53

526 Vgl.: ibid., S. 49 
untersten Preise für Niederräder von 230 Mark um 1890 über 110 Mark um die Jahrhundertwende und 70 Mark im Jahre 1904 noch im ersten Jahrzehnt des 20. Jahrhunderts auf unter 40 Mark. 527 Das Fahrrad entwickelte sich von einem äußerst kostspieligen Sportgerät für wenige wohlhabende Menschen zu einem für weite Teile der Bevölkerung erschwinglichen Massenprodukt.

Diese Entwicklung fand ihre Entsprechung im Radfahrvereinswesen. Die ersten Vereine, die sich ab den ausgehenden sechziger Jahren des 19. Jahrhunderts gründeten 528 , waren eine Domäne des etablierten Großbürgertums. Im August 1884 entstand der Deutsche Radfahrer-Bund als Dachverband durch eine Fusion der beiden 1882 gegründeten Verbände Deutscher und Deutsch-Österreichischer Velocipädisten-Bund (zunächst nur Deutscher Velocipädisten-Bund) und Norddeutscher Velocipädisten-Bund und dem im Mai 1884 gegründeten Rheinischen Velocipädisten-Bund. In der Mitgliedschaft dieses ersten umfassenden Dachverbandes deutscher Radfahrer weist Rabenstein für die unmittelbare Zeit nach dessen Gründung eine Dominanz der Kaufmannschaft mit mehr als 50 v. H. nach. Diese Dominanz ging bis 1905 deutlich zurück, während die Handwerksberufe in den berufsstatistischen Angaben des DRB signifikant zunahmen. 529

$\mathrm{Ab}$ den neunziger Jahren wurde das Fahrrad allmählich auch für die unterbürgerlichen Schichten attraktiv. Im Jahre 1896 wurde der ArbeiterRadfahrerbund "Solidarität" ins Leben gerufen. Dieser sozialdemokratische Verband, der im Gründungsjahr lediglich 476 Mitglieder umfasste, wuchs bis zur Jahrhundertwende auf 6.500 Mitglieder an. Im ersten Jahrzehnt des 20. Jahrhunderts stieg die Mitgliederzahl, begünstigt durch das deutliche Sinken der Fahrradpreise, explosionsartig. Spätestens 1906 überstieg die Mitgliederzahl des ARB "Solidarität" mit 62.000 jene des DRB, der 1904 ca. 41.000 Mitglieder hatte. 1908 zählte der Verband über 103.000 Mitglieder und übertraf damit die Gesamtmitgliederzahl aller bürgerlichen Radfahrerverbände. ${ }^{530}$ Am Vorabend des Ersten Weltkrieges hatte der ARB "Solidarität" annähernd 150.000 Mitglieder. 531

\footnotetext{
527 Vgl:: ibid.

528 Vgl.: Eichberg, Henning: op. cit., S. 356 f.

529 Vgl.: Rabenstein, Rüdiger: op. cit., SS. 202 ff.

530 Neben dem Deutschen Radfahrerbund gab es verschiedene weitere bürgerliche Verbände, die sich teilweise auf bestimmte Regionen, teilweise auf einzelne Unterdisziplinen des

Radfahrens beschränkten.

${ }^{531}$ Vgl: Rabenstein, Rüdiger: op. cit., SS 183 ff.
} 
Zieht man bei all diesen Zahlen zum Einen in Betracht, dass es dem ARB "Solidarität" nur gelang, die sozialdemokratisch gesonnenen Arbeiter an sich zu binden, zum Anderen, dass viele Radfahrer nicht in Vereinen organisiert waren, so scheint die Aussage, dass sich im Laufe des Untersuchungszeitraumes die Radfahrerei von einem Vergnügen einiger weniger betuchter Bürger und Adliger $\mathrm{zu}$ einem weite Teile aller Bevölkerungsgruppen und -schichten umfassenden Massenphänomen wandelte, um so zulässiger. 


\section{3. 2. 2. Der Radfahrer-Verein Einbeck von 1887}

Am 1. November 1887 wurde der erste nachweisbare Radfahrverein Einbecks gegründet. Das erste Statut wurde vor dem 3. Dezember dieses Jahres von einem Studenten des Einbecker Technikums namens Frucht beim Magistrat eingereicht. Dieser reichte es mit dem Bemerken an Frucht zurück, dass wegen des unpolitischen Charakters des gegründeten Vereins eine polizeiliche Genehmigung nicht vonnöten sei. 532

Die nächsten weiteren und zugleich letzten schriftlichen Zeugnisse über den Radfahrerverein von 1887 in den Aktenbeständen des Stadtarchivs Einbeck stellen ein Statut aus dem Jahre 1895 und ein diesem beigelegtes behördeninternes Schriftstück dar. Nach dem von dem damaligen Vorsitzenden, dem Goldarbeiter Burgtorff, unterzeichneten Statut vom 15. September 1895 bezweckte der Verein, der zu diesem Zeitpunkt bereits dem Deutschen Radfahrerbund angehörte, "durch Touren-, Saal- und evtl. Wettfahren, durch Pflege des Clublebens unter den Mitgliedern in wöchentlichen Zusammenkünften sowie durch Veranstaltungen von Vergnügen ectr. den Radfahrsport zu heben und den kameradschaftlichen Geist zu fördern". 533

Die einzige der drei genannten Radfahrdisziplinen, über deren Betrieb aus dem Statut von 1895 Näheres zu erfahren ist, ist das Tourenfahren. Dieses sollte in zwei Abteilungen geschehen; einer älteren und einer jüngeren Herrenriege, beide Riegen sollten bei Touren unter der Leitung jeweils eines der beiden Fahrwarte stehen. ${ }^{534}$ Doch obwohl in $\S 19$ nur von Herrenriegen zu lesen ist, war an anderer Stelle in dem Statut die Aufnahme von Frauen ausdrücklich vorgesehen. 535

Der Radfahrerverein von 1887 war eine recht exklusive Organisation; Neueintretende hatten neben dem jährlich zu entrichtenden Beitrag von 6 Mark ein einmaliges Eintrittsgeld von 3 Mark zu zahlen, ferner mussten sie ein Vereinsabzeichen für 3 Mark erwerben, von denen allerdings 1,50 Mark im Falle des Austritts zurückerstattet werden. Wer dem Verein beitreten wollte, musste also in der Lage sein, die nicht unbeträchtliche Summe von 12 Mark

\footnotetext{
532 Vgl.: StAEin 065 - 25, 3. Dezember 1887

$533 \S \S 1 ; 2$, Statut des Radfahrer-Vereins Einbeck von 1887 vom 15. September 1895, in StAEin 065 - 25
}

Das oben genannte exakte Gründungsdatum findet sich ebenfalls im $\S 1$ des genannten Statuts.

534 Vgl.: §§ 11; 19 des genannten Statuts.

535 Vgl.: $§ 8$ des genannten Statuts. 
auf einmal aufzubringen. ${ }^{536}$ Dieser Betrag lag etwa in der Größenordnung des Wochenlohnes eines Arbeiters. An den Besitz eines Fahrrades war die Aufnahme in den Verein nicht gebunden.

Über die tatsächlichen Aktivitäten des RV von 1887 geben wenige erhaltene Photographien Aufschluss. Eine undatierte Aufnahme, die aus der unmittelbaren Zeit nach der Vereinsgründung stammen dürfte, zeigt sechs selbstbewusst in einem Photoatelier posierende dunkel gekleidete Männer mit Vereinsmützen, links und rechts von dieser kleinen Gruppe ist je ein Hochrad zu erkennen. Da die Vereinsgründung bereits nach der Erfindung des Niederrades erfolgte, legt dies die Vermutung nahe, dass die Mitglieder, die noch ein Hochrad benutzten, bereits vor der Gründung des Vereins Radfahrer waren. $\mathrm{Ob}$ allerdings das Fahrradfahren eventuell von zugereisten Studenten des Technikums in Einbeck bekannt gemacht wurde, ist nicht zu ermitteln gewesen. Imposante Uhrenketten, getragen an den Sportsakkos, weisen die sechs Herren als relativ wohlhabende Leute aus. Dass vor der Gruppe, offenbar als Vereinsmaskottchen, ein großer Hund liegt, obwohl der Hund doch eigentlich der natürliche Feind des Radfahrers im allgemeinen und des Hochradfahrers im Speziellen war, sei lediglich am Rande erwähnt.

Ein weiteres im Atelier aufgenommenes Photo unbekannten Alters zeigt eine andere Gruppe von sieben Herren in der gleichen Kleidung; diese werden flankiert von zwei Jünglingen in hellen Hosen und geringelten Sporthemden, die jeweils ein Hochrad halten.

Spätere Photographien belegen, dass sich auch im RV von 1887 im Laufe der neunziger Jahre des 19. Jahrhunderts das Niederrad durchsetzte. Eine ebenfalls undatierte Aufnahme des Vereins zeigt 22 Männer mit diesmal weißen Kappen, die von je einem Nieder- und einem Hochrad eingerahmt werden. Zwei weitere Aufnahmen aus der Zeit der Wende vom 19. zum 20. Jahrhundert, die Radtouren dokumentieren, zeigen die Aktiven ausschließlich mit modernen Niederrädern. Eine der beiden Photographien zeigt zehn Radfahrer bei einer Tour im kleinen Kreise; die andere zeigt 26 Personen an einem nicht zu ermittelnden Ort in Freizeitkleidung mit Rädern, Vereinsfahne und -banner. Bemerkenswert an letzterer Aufnahme, die im Jahre 1899 gemacht wurde, ist, dass sich unter den Männern auch eine Frau mit ihrem Fahrrad befindet. 537

\footnotetext{
536 Vgl.: $§ \S 9 ; 20$ des genannten Statuts.

${ }^{537}$ Bis auf das Photo mit der Dame sind alle Photographien als Reproduktionen im Stadtarchiv Einbeck, Photosammlung, Abteilung 34 a erhalten. Das zuerst beschriebene Bild ist ebenso wie das letztgenannte abgedruckt in: Einbecker Geschichtsverein (Hg.): Stadt
} 
Insgesamt belegen die erhaltenen Photographien lediglich, dass der Verein Tourenfahrten unternahm, für Aktivitäten im Saal- oder Rennfahren sind dem Autor keine Belege aus der Zeit vor dem Ersten Weltkrieg bekannt.

Auf mindestens zwei der genannten Photos ist August Stukenbrok zu erkennen, ein Mann, dessen Name untrennbar mit dem Radfahren in Einbeck verbunden ist. Aus einer von ihm 1890 eröffneten kleinen Fahrradhandlung, die im ersten Geschäftsjahr 26 Fahrräder absetzen konnte, machte er, eine neue Vertriebsmethode nutzend, im Verlaufe der Zeit vor dem Ersten Weltkrieg Deutschlands grösstes Versandhaus für Fahrräder, das in seinem erfolgreichsten Jahr 190622.000 Stück absetzen konnte. Der durch den eingangs beschriebenen Radfahrboom begünstigte Versandhandel von Fahrrädern, die aus fertig gekauften Einzelteilen nach Wünschen der Kunden in Einbeck montiert und unter dem Markennamen Deutschland-Fahrräder vertrieben wurden, machte Stukenbrok zum wohlhabendsten Mann der Stadt und begründete eine bis ins letzte Viertel des 20. Jahrhunderts in Einbeck bestehende Fahrradindustrie. 538

Der Radfahrer-Verein Einbeck von 1887 bestand, wie die einschlägigen Vereinslisten der Adressbücher ab 1902 belegen, zumindest bis ins Jahr 1912 fort. Die Vereinsliste des Jahres 1922, die älteste vorliegende aus der Zeit nach dem Ersten Weltkrieg, führt den Verein nicht mehr auf.

Einbeck. Zeitgenössische Fotografien und Dokumente. Gesammelt und bearbeitet von Erich Strauß, Hellmut Hainski und Andreas Heege. Duderstadt 1995, S. 161

538 Vgl.: Hülse, Horst: Einbeck in der Gründerzeit. in: Einbecker Geschichtsverein (Hg.): Geschichte der Stadt Einbeck. Band 2: Vom Ende des 18. Jahrhunderts bis zum Ende des zweiten Weltkrieges. Einbeck 1992, SS. 96 ff., und Ernst, Georg; Sindermann, Edmund (Bearbb.): Heimatchronik des Kreises Einbeck. (Heimatchroniken der Städte und Kreise des Bundesgebiets, Band 14) Köln 1955, SS. 179 f.; 238 


\section{3. 2. 3. Der Radfahrer-Club}

In der Anlage zu einem Schreiben vom 15. September 1897 übersandte der Kreisbote Johannes Meyer dem Magistrat ein Druckexemplar der Statuten des zweiten in Einbeck gegründeten Radfahrvereins. Nach $\S 1$ dieses Statuts wurde der Verein am 14. August 1897 unter dem Namen Radfahrer-Club Einbeck gegründet. Der Beitritt zum Deutschen Radfahrerbund war beabsichtigt.

Die Statuten des neugegründeten Vereins weisen eine verblüffende Ähnlichkeit mit jenen des Radfahrervereins von 1887 auf. Zwar weichen beide Satzungen inhaltlich voneinander ab - so sollte der Radfahrer-Club nur aus aktiven Mitgliedern bestehen, die sich nicht wöchentlich, sondern zweimal im Monat treffen sollten, die Beiträge sollten niedriger sein und quartalsweise erhoben werden und der neue Verein sah nur einen Fahrwart vor - doch alle übrigen Paragraphen der Statuten sind im Wortlaut nahezu und in der Reihenfolge vollkommen identisch. 539

Für diesen bemerkenswerten Umstand sind zwei Erklärungen denkbar. Zum Einen könnten sich die Gründer des Radfahrer-Clubs die Satzungen des seit annähernd zehn Jahren erfolgreich bestehenden Radfahrervereins von 1887 als Muster für den neu zu gründenden Verein beschafft haben, zum Anderen ist denkbar, dass es sich bei den Vereinsgründern um ehemalige Mitglieder des älteren Vereins gehandelt haben könnte, die mit dem Vereinsleben des alten Vereins unzufrieden waren, für die bewährte Organisationsstruktur hingegen keinen Änderungsbedarf sahen. Da jedoch das zitierte Statut und das dazugehörige Anschreiben das einzige vorliegende Zeugnis über den Verein darstellen, kann weder die eine noch die andere Vermutung verifiziert respektive falsifiziert werden.

Da keine weiteren Quellen über den Radfahrer-Club Einbeck bekannt sind und der Verein auch in den Adressbüchern ab 1902 nicht erwähnt wird, ist im übrigen davon auszugehen, dass ihm allenfalls ein kurzes Leben beschieden war.

${ }^{539}$ Vgl.: Das oben zitierte Statut des Radfahrer-Vereins Einbeck von 1887 vom 15. 


\section{3. 2. 4. Der Bicycle-Club Einbeck 1898}

Am 20. Februar 1898 gründete ein nicht näher zu ermittelnder Kreis von Personen einen weiteren Radfahrerverein und schickte die beschlossenen Statuten wenige Tage später zur Bestätigung an die Polizeiverwaltung in Einbeck. Um einer Verwechslung mit dem oder den bestehenden Verein respektive Vereinen aus dem Wege zu gehen, hatte man sich in Rückgriff auf die Frühzeit des organisierten Radsports in Deutschland den Namen "BicycleClub Einbeck 1898" gegeben. 540 Dem ersten der sechzehn mit römischen Ziffern nummerierten Paragraphen ist zu entnehmen, dass der neue Verein sich gleichzeitig mit seiner Gründung beim Deutschen Radfahrerbund als Mitgliedsverein registrieren ließ.

$\S$ II der eingereichten Statuten definierte den Vereinszweck; er lautete: "Der Club verfolgt den Zweck den Radler-Sport nach allen Richtungen hin zu hegen \& zu pflegen, sowie die Geselligkeit unter seinen Mitgliedern zu fördern".

Im Wesentlichen weist der Rest des Statuts keine Auffälligkeiten auf; in deutlich unbeholfenerem Deutsch als in den Statuten der anderen Radfahrvereine werden verschiedene Bestimmungen über die Struktur des Vereins getroffen.

Lediglich zwei sehr ungewöhnliche Passus zeigen deutlich, dass der oder die Verfasser des Vereinsstatuts mit dem praktischen Vereinsleben in einem oder mehreren anderen Vereinen sehr unzufrieden war oder waren: In § IV heißt es: "Der Club darf die Mitgliederzahl von 25 nicht überschreiten," und auf den letzten Paragraph folgt ein sehr deutlicher Nachsatz: "Besondere Bestimmungen!

Im Clubleben ist jedes hineintragen von Geschäftsinteressen strengstens verboten, auch werden bei Verheiratungen u. s. w. absolut keine Geschenke gegeben.". 541

In welchem Verein die diesen Bestimmungen $\mathrm{zu}$ Grunde liegenden negativen Erfahrungen gemacht wurden, war freilich nicht zu ermitteln.

Wie auch im Falle des Radfahrer-Clubs Einbeck stellt das den Behörden eingesandte Statut nebst Anschreiben den einzigen bekannten Beleg für die Gründung des Vereins dar; auch für den Bicycle-Club Einbeck 1898 muss

\footnotetext{
$54{ }^{0}$ Einer der ersten Radfahrervereine in Deutschland war e. g. der Altonaer Bicycle-Club von 1869. Vgl.: Eichberg, Henning: op. cit., SS. 356 f.

${ }^{54}{ }^{1} \mathrm{Zu}$ allem über den Bicycle-Club Einbeck 1898 Gesagten vgl:: StAEin 065 - 25,

Schriftstück mit Eingangsvermerk 25. Februar 1898 und das anliegende Statut
} 
konstatiert werden, dass er nur kurz bestand, wenn er denn überhaupt jemals irgendwelche Aktivitäten aufnahm. 


\section{3. 2. 5. Der Arbeiter-Radfahrer-Verein Vorwärts}

Über die Gründung des Arbeiter-Radfahrervereins Vorwärts Einbeck ist nichts bekannt. Der älteste explizite Beleg über die Existenz eines ArbeiterRadfahrervereins in Einbeck findet sich im Protokoll der Sitzung vom 3. April 1909 des Turnclub Eintracht Einbeck; in dieser Sitzung beschloss die Vereinsversammlung, einer vom Arbeiter-Radfahrerverein an die Eintracht gerichteten Einladung zur Feier der Fahnenweihe am 21., 22. und 27 Juni 1909 Folge zu leisten. ${ }^{542}$ In der Eintracht-Versammlung vom 5. Dezember 1908 wurde das Problem von Doppelmitgliedschaften im TC Eintracht und einem nicht näher bezeichneten Radfahrerverein erörtert ${ }^{543}$; da es jedoch als äußerst unwahrscheinlich angesehen werden kann, dass Mitglieder des Arbeitervereins Eintracht gleichzeitig dem bürgerlichen Radfahrerverein von 1887 angehörten, muss diese Protokollnotiz als erste Erwähnung des Einbecker ArbeiterRadfahrervereins, und somit der 5. Dezember1908 bezüglich der Vereinsgründung als terminus ante quem angesehen werden. Da in der Vereinsliste des Adressbuches von 1907 der Verein noch nicht erwähnt ist, muss der Verein im Laufe der Jahre 1907 und 1908 gegründet worden sein.

Eine undatierte Photographie des Vereins, die zweifelsohne auf der bereits erwähnten Fahnenweihe im Sommer 1909 aufgenommen wurde ${ }^{54}$, zeigt 18 männliche Mitglieder verschiedenen Alters. Der Schriftzug auf der Vereinsfahne ist der erste Beleg, dass der Arbeiter-Radfahrerverein Einbeck den Namen "Vorwärts" führte, durch den er dem sozialdemokratischen Spektrum zuzuordnen ist. ${ }^{54}$ Im den Aktenbeständen des Stadtarchivs Einbeck finden sich keine Unterlagen über den Verein.

Schriftliche Belege über die Mitgliedschaft des Arbeiter-Radfahrervereins "Vorwärts" fehlen gänzlich. In der behördlichen Akte über den Sozialdemokratischen Wahlverein findet sich jedoch disparat ein Druckexemplar der Statuten des Arbeiter-Radfahrerbundes Solidarität, des in Chemnitz domizilierenden sozialdemokratischen Dachverbandes der deutschen Arbeiter-Radfahrer ${ }^{546}$. Bereits dieser Umstand legt die Vermutung nahe, dass

\footnotetext{
542 Vgl.: Eintracht Einbeck, Protokoll 3. April 1909

543 Vgl.: Eintracht Einbeck, Protokoll 5. Dezember 1908

544 Alle abgebildeten Personen, insbesondere die zwei Begleiter der Fahne, welche im

Zentrum des Bildes steht, sind festlich gekleidet, ferner ist die Fahne mit Girlanden geschmückt und von zwei Ehrendamen flankiert.

545 Eine Reproduktion des Photos ist enthalten in: StAEin, Photosammlung, Abteilung 34 a

546 StAEin $065-36$
} 
der ARV "Vorwärts" Einbeck diesem Verband angehörte. Diese Vermutung wird durch eine Ansichtskarte verifiziert, die anlässlich der Fahnenweihe 547 vom Lieferanten der Vereinsfahne, der Thüringer Fahnenfabrik in Coburg 548 , gedruckt wurde. Die Karte gibt Vorder- und Rückseite der Vereinsfahne wieder. Im unteren Bereich der Vorderseite ist das Emblem des besagten Arbeiter-Radfahrer-Bundes "Solidarität" zu erkennen, ein Geschwungenes "S" vor einem Speichenrad, an dessen Fuß die Abkürzung "A.R.B." steht. 549 Der Arbeiter-Radfahrervereins "Vorwärts" gehörte also im Juni 1909 dem genannten Dachverband an.

Die Adressbücher der Jahrgänge 1911/12 und 1912 weisen den Verein mit dem Vereinslokal Rheinischer Hof aus; im Adressbuch von 1922 erscheint der Verein ohne den Eigennamen Vorwärts unter gleicher Adresse. Es handelte sich beim Arbeiter-Radfahrerverein Vorwärts Einbeck mithin um eine über den Untersuchungszeitraum der vorliegenden Arbeit hinaus erfolgreiche Vereinsgründung, über deren Wirksamkeit das vorliegende Quellenmaterial jedoch keinen Aufschluss geben kann.

\footnotetext{
${ }^{547}$ Die Karte trägt den Schriftzug "Bannerweihe am 20. Juni 1909". Diese Angabe weicht von dem oben aus den Protokollen der TC "Eintracht" zitierten ab. Das genaue Datum der Fahnenweihefeier war nicht mehr zu ermitteln, jedoch erscheint der 20. Juni 1909 als plausibelster Hauptfesttag, da es sich bei diesem Tag um einen Sonntag handelte.

548 Coburg war zu jener Zeit Residenz der thüringischen Fürsten von Sachsen-Coburg-Gotha. 1918 trennte sich Coburg von Gotha, 1920 wurde es dem Ergebnis einer Volksabstimmung entsprechend Bayern angegliedert.

549 Ein erhaltenes Exemplar dieser Ansichtskarte befindet sich im Privatarchiv eines Einbecker Postkartensammlers.
} 


\section{3. 2. 6. Der Einbecker Radfahrerverein 1911}

Am 1. Juni 1911 kam es zur letzten bekannten Gründung eines Radfahrervereins in Einbeck im Untersuchungszeitraum. Über die Gründung ist kaum mehr bekannt, als dass neun Männer den Einbecker Radfahrer-Verein 1911 gründeten. Da sich über den Verein Primärquellen weder im Stadtarchiv noch in Privatbesitz erhalten haben, ist eine von der damaligen Vorsitzenden des Vereins, Marie-Luise Ziegenhagen, anlässlich des 65jährigen Vereinsjubiläums verfasste Vereinschronik das einzige Zeugnis über den ERV 1911, das über den bloßen Beweis der Existenz dieses Vereins hinaus geht. Die Autorin schreibt, dass sich unter den neun Gründern auch Mitglieder eines alten Radfahrvereins von 1890 befunden hätten. Da sie fortfährt, dass diesem älteren Verein auch August Stukenbrok angehört habe, wird es sich bei dem gedachten Verein um den oben bereits behandelten Radfahrer-Verein Einbeck von 1887 handeln, der zu diesem Zeitpunkt zweifelsohne noch bestand. Nach den Statuten bezweckte der ERV 1911 "die Förderung des Radfahrersportes durch Pflege des Kunst- und Reigenfahrens, sowie sonstiger sportlicher Übungen wie Rennsport und Wanderfahren"550. Belege über die Tätigkeit des Vereins vor dem Ersten Weltkrieg fehlen bedauerlicherweise zur Gänze, über die Existenz des Vereins bis über den Untersuchungszeitraum hinaus kann kein Zweifel bestehen, da er zum Zeitpunkt der Niederschrift der vorliegenden Untersuchung noch immer, wenn auch nach der Abspaltung der Radsportsparte im Jahre 1965 in erster Linie als erfolgreicher Rollsportverein, besteht.

550 Festschrift zum 75-jährigen Vereinsjubiläum. Radportverein 1911 Einbeck e. v. Abteilung Rollsport. Einbeck 1986, S. 9. Bei dem Zitat aus der Vereinschronik dürfte es sich um ein, wenn auch nicht als solches gekennzeichnet, wörtliches Zitat aus dem Statut des ERV 1911 handeln, welches, wie Frau Ziegenhagen dem Autor mündlich mitteilte, zur Zeit der Erstellung der Festschrift zum Vereinsjubiläum des Jahres 1986 noch existierte und ihr vorlag. 


\section{3. 2. 7. Einbecks Radfahrervereine vor dem Ersten Weltkrieg}

Wie schon die vorangehenden Einzeldarstellungen der Radfahrvereine Einbecks vor dem Ersten Weltkrieg, so muss auch der Versuch einer Gesamtschau auf Grund der überaus bescheidenen Quellenlage zwangsläufig eher kurz ausfallen und viele Fragen offen lassen.

Im Untersuchungszeitraum von der Reichsgründung bis zum Ersten Weltkrieg wurden fünf verschiedene Radfahrvereine in Einbeck gegründet, von denen allenfalls drei bei Kriegsbeginn noch bestanden; das Adressbuch von 1922, das älteste vorliegende aus der Zeit zwischen den Weltkriegen, weist mit dem Arbeiter-Radfahrerverein und dem Radfahrer-Verein 1911 nur noch zwei der fünf genannten Vereine aus. Über die Gründe des Misserfolges der übrigen Vereine kann des geringen erhaltenen Materials wegen nicht einmal ernsthaft spekuliert werden.

An fundierten Erkenntnissen konnte lediglich gewonnen werden, dass ähnlich wie im Falle der Gesangvereine eine Gründungsaktivität entwickelt wurde, der keine adäquate Nachfrage potenzieller Vereinsmitglieder gegenüber stand; es gab für zu wenig organisationsbereite Radfahrer zu viele Vereine. Dass dieses Überangebot ausschliesslich in der bürgerlichen Sphäre der städtischen Gesellschaft bestanden haben dürfte, während für die Angehörigen der sich konstituierenden Arbeiterklasse, zumindest für jene, welche sozialdemokratisch gesonnen waren, nur ein Verein bestand, zu dem ein Beitritt nahe lag, ist eine weitere Analogie sowohl zum Sänger- als auch zum Turnerwesen.

Ferner bleibt festzuhalten, dass die Entwicklung des organisierten Radsports in Einbeck - erste Vereinsgründung von wenigen Hochradfahrern aus dem gehobenen Bürgertum, ein quantitatives Anwachsen der Zahl derVereinsmitglieder 551 wie auch der Vereine zunächst innerhalb des Bürgertums, später das Auftreten einer sozialdemokratisch-proletarischen Radfahrerschaft - anhand der allgemeinen Literatur als durchaus typisch für die Entwicklung in ganz Deutschland charakterisiert werden kann. Ob die ab 1890 in Einbeck entstehende Fahrradproduktion des August Stukenbrok dem Radfahrvereinswesen der Stadt wesentliche Impulse gegeben hat, ist daher stark anzuzweifeln; insbesondere, weil Stukenbrok als Pionier des Versandhandels seine Räder in alle Teile Deutschlands vertrieb. Daher dürfte es für den einzelnen Radfahrer kaum einen Unterschied gemacht haben, ob er

\footnotetext{
${ }^{551}$ Auch wenn kein statistisches Material vorliegt oder erarbeitet werden kann, so legen die genannten Photographien die Annahme einer solchen Tendenz nahe.
} 
sein Deutschland-Fahrrad in Einbeck kaufte oder etliche hundert Kilometer entfernt bestellte. Zumindest der Endverbraucherpreis dürfte, da die Angebote Stukenbroks sehr knapp kalkuliert waren ${ }^{552}$, sich nicht unterschieden haben. Dass eine ortsansässige grossgewerbliche Fahrradmontage die Neugierde des örtlichen Publikums auf das weithin bekannte Produkt besonders stimuliert haben könnte, ist eher unwahrscheinlich.

552 Vgl.: Heege, Elke; Plümer, Erich: Fahrrad-Fabrik August Stukenbrok Einbeck. Die Geschichte eines Versandhauses. (Kleine Schriften des städtischen Museums Einbeck, Heft 4) Oldenburg 1996, SS. 12 ff. 


\section{3. 3. Die Fußballvereine}

\section{3. 3. 1. Zur Geschichte des Fußballsports}

Das Fußballspiel stammt ursprünglich aus England. Ab der Mitte des 18. Jahrhunderts wurden traditionelle, zum Teil noch aus dem Mittelalter stammende Ballspielformen an den "Public Schools" aufgegriffen. Ab etwa 1830 setzte eine Entwicklung ein, diese Spiele zu organisieren und verbindliche Regeln aufzustellen. ${ }^{55}$ Das Resultat war vorerst jedoch nicht ein einheitliches Regelwerk, sondern mehrere konkurrierende, die bekanntesten und für die Zukunft wirksamsten jenes der Rugby-Schule von $1845^{554}$ und das der im gleichen Jahr gegründeten Football-Association von 1863, welches in der Tradition der Eton- und Cambridge-Regeln stand. Letzteres verbot erstmals das Treten des Gegners und das Tragen und Werfen des Balles, es ist mithin trotz aller Abweichungen zu den heutigen Regeln als erstes Regelwerk des Fußballs, wie er in Deutschland gepflegt wird, anzusehen. 555

Erstmals nach Deutschland gelangte das Spiel durch Engländer, die sich mehr oder weniger lange in Deutschland aufhielten und neben anderen Gewohnheiten auch in der Fremde ihren gewohnten Sportarten nachgingen. 556 Doch dieser englische Einfluss, der auch junge Deutsche mit dem neuen Spiel bekannt machte, beschränkte sich auf jene Orte, an denen es regelrechte "Engländerkolonien" gab.

Als eigentlichen Begründer des deutschen Fußballs sieht die Literatur den Braunschweiger Gymnasiallehrer Konrad Koch an, der im Jahre 1874557

\footnotetext{
${ }^{553}$ Vgl.: Schulze-Marmeling, Dietrich: Der gezähmte Fußball. Zur Geschichte eines
} subversiven Sports. Göttingen 1992, SS. 15 ff.

554 Vgl.: Väth, Heinrich: Profifußball. Zur Soziologie der Bundesliga. Frankfurt am Main, New York 1994, S 49

${ }^{555}$ Vgl.: Dunning, Eric: Die Entstehung des Fußballsports. in: Hopf, Wilhelm (Hg.): Fussball. Soziologie und Sozialgeschichte einer populären Sportart. Bensheim 1979, SS. 42 - 53, S. 52 ${ }^{556}$ Vgl.: Eisenberg, Christiane: Deutschland. in: Eisenberg, Christiane (Hg.):Fußball, soccer, calcio. Ein englischer Sport auf seinem Weg um die Welt. München 1997, SS. 94 - 129, SS.95 ff.

557Vgl.: Hoffmeister Kurt: Ein Braunschweiger Lehrer als Begründer der Schulspiele in Deutschland. Prof. Dr. phil. Konrad Koch (1846 - 1911). in: Krüger, Arnd (Hg.): Beiträge zur niedersächsischen Sportgeschichte. Der Dr.-Bernhard-Zimmermann- Preis 1984 (Schriftenreihe des niedersächsischen Instituts für Sportgeschichte, Hoya, Band 4). Duderstadt 1986, SS. 14 - 67, SS. 19 f. 
beide Spielarten des Fußballs am dortigen Martino-Katharineum einführte. 558 Bis in die neunziger Jahre des 19. Jahrhunderts blieb der Sport in Deutschland die Domäne von Schülern höherer Lehranstalten. Auch das erste Wettspiel zwischen Mannschaften aus unterschiedlichen Orten, es fand 1886 zwischen Braunschweig und Göttingen statt, war ein Vergleich zweier Schulmannschaften. 559

$\mathrm{Ab}$ den ausgehenden achtziger Jahren setzte dann eine erste Welle von Vereinsgründungen ein. In den Fußballvereinen dieser Zeit dominierten Gymnasiasten und Studenten, Fußball war bis ins erste Jahrzehnt des zwanzigsten Jahrhunderts eine Domäne des gebildeten Bürgertums. 560

Die immer zahlreicher werdenden Vereine schlossen sich in regionalen Dachverbänden zusammen; im Januar 1900 wurde in Leipzig der Deutsche Fußball-Bund als erster reichsweiter Dachverband gegründet. In diesem neuen Verband waren zunächst noch Vertreter beider Spielarten organisiert. Doch die noch im selben Jahr ausgearbeiteten einheitlichen Verbandsregeln verboten das Aufnehmen des Balles, spätestens 1904 war der DFB ein reiner AssociationsFußball-Verband. ${ }^{561}$ Als der Fußball als eigenständiges Sportspiel nach Einbeck kam, hatte sich also der Association-Football durchgesetzt.

Bis zum Ersten Weltkrieg blieb Fußball eher eine aufstrebende Randsportart und war von seiner heutigen Stellung als dominierende Volkssportart in Deutschland noch weit entfernt. Joachim H. Knoll konstatiert für den Fußball um die Jahrhundertwende ein gänzliches Fehlen von gesellschaftlicher, politischer, selbst volkstümlich gesonnener Zustimmung. ${ }^{62}$ Umfasste der

558 Koch unterschied zwischem "gemischten Spiel", d. h. jene Variante, in der das Aufnehmen und Tragen des Balles gestattet war, und "einfachen Spiel" ohne Gebrauch der Hände. Er vertrat auf zwanzigjährige Erfahrungen zurückschauend die Ansicht, dass ersteres, da es einfacher zu erlernen sei, für jüngere Schüler geeigneter sei, aber dass man darüber letzteres nicht vernachlässigen dürfe. Vgl. hierzu einen Brief Kochs an Hermann Schnell, vom 11. Januar 1894, zitiert in Hoffmeister, Kurt: op. cit., S. 46

559 Vgl.: Hoffmeister, Kurt: op. cit., S. 48

560 Vgl.: Väth, Heinrich: op. cit., S. 49

${ }^{561}$ Vgl.: Hopf, Wilhelm: "Wie konnte Fußball ein deutsches Spiel werden?". in: Hopf, Wilhelm (Hg.): Fussball. Soziologie und Sozialgeschichte einer populären Sportart. Bensheim 1979, SS. 54 - 80, S. 74

562 Vgl.: Knoll, Joachim H.: "Der Ball ist rund und das Spiel dauert 90 Minuten" - Fußball und Zeitgeist im 20. Jahrhundert. in: Diekmann, Irene; Teichler, Joachim H. (Hgg.): Körper, Kultur und Ideologie. Sport und Zeitgeist im 19. und 20. Jahrhundert. (Studien zur Geistesgeschichte, Band 19). Bodenheim 1997, SS. 248 - 276, SS. 250 ff. 
DFB 190514.000 und 1910 82.000 Mitglieder, so konnte allein die Deutsche Turnerschaft zum gleichen Zeitpunkt mit 800.000 respektive 1.080 .000 Mitgliedern aufwarten. 563

Die organisierten Turner bekämpften die aufstrebende Konkurrenz in ihren Anfangsjahren vehement. Das bekannteste Beispiel hierfür ist die erstmals 1894 erschienene Schrift des bekannten Turnführers Prof. Karl Planck mit dem programmatischen Titel "Fusslümmelei. Über Stauchballspiel und englische Krankheit.". Hierin heißt es unter anderem: "Zunächst ist jene Bewegung ja schon, auf die bloße Form hin angesehen, häßlich. Das Einsinken des Standbeins ins Knie, die Wölbung des Schnitzbuckels, das tierische Vorstrecken des Kinns erniedrigt den Menschen zum Affen." 564

563 Vgl.: Eisenberg, Christiane: op. cit., S. 97

564 zitiert nach: Schulze - Marmeling, Dietrich: op. cit., S. 67 


\section{3. 3. 2. Einbecks Fußballsport im Kaiserreich}

\section{3. 3. 2. 1. Vereinsgründungen und Fusionen - Organisationsgeschichte}

Wie bereits oben erwähnt, wurde in Einbeck seit dem Jahr 1898 beim Turnclub Eintracht der Fußballsport praktiziert ${ }^{565}$. Schon dies stellt in zweierlei Hinsicht einen besonderen Befund dar. Zum einen waren es gerade Turner, die in der Frühphase dieses Sports dem Fußballspiel ablehnend, ja sogar feindselig gegenüberstanden. Zum anderen handelt es sich beim Turnclub Eintracht ab 1899 um einen Arbeitersportverein innerhalb des Arbeiter-Turnerbundes, also eines Dachverbandes, der sich zu jener Zeit noch kategorisch vom Gedanken des sportlichen Wettkampfes distanzierte ${ }^{566}$, der jedoch wie jedem Mannschaftsballspiel auch dem Fußball innewohnt, ja ihn geradezu konstituiert. Offenbar kam es auch nicht zur Bildung einer kontinuierlich spielenden, Wettspiele suchenden Fußballmannschaft oder -riege. Eine Durchsicht der Protokolle des Turnclub Eintracht ergab in dieser Hinsicht keinerlei Belege; vermutlich wurde lediglich durch gelegentliches Fußballspielen in den Sommermonaten das Spektrum der im Freien zu betreibenden Turnspiele erweitert. Eine sinngemäße Deutung legt auch der wesentlich spätere singuläre Aktenbefund nahe, dass dem Turnverein "Germania" im Sommer 1912 die Benutzung des Tummelplatzes zum Fußballspielen gestattet wurde. 567

Zur Gründung von reinen Fußballvereinen kam es erst später, im ersten Jahrzehnt des zwanzigsten Jahrhunderts.

Am 20. Mai 1905 gründeten mehrere junge Männer, Näheres ist nicht überliefert, den Fußballclub Einbeck und nahmen den Spielbetrieb auf. Die Statuten dieses Vereins sind zwar dem Magistrat eingereicht worden, doch sind diese nicht mehr erhalten. 568 Schon die Übungszeiten belegen, dass Fußball in jener Zeit noch eine Randsportart war; gespielt wurde im wochenweisen Wechsel mittwochs und donnerstags von 20.30 Uhr bis $22 \mathrm{Uhr}$ abends und jeden Sonntag von 6 bis 8 Uhr morgens. 569

\footnotetext{
565Vgl.: Eintracht Einbeck, Protokoll 4. Juni 1898

${ }^{56}$ Dass diese Haltung auch gegen entgegengesetzte Strömungen innerhalb des ArbeiterTurnerbundes von der "Eintracht" mitgetragen wurde, belegen verschiedene Protokolle: beispielsweise 4. April 1903; 6. Oktober 1907

567 Vgl.: StAEin 572 - 1, 13. Juni 1912

568 Vgl.:Eingangsvermerk aus StAEin 065 - 25, 21. Mai 1905

569 Vgl.: StAEin 065-25, 21. Mai 1905
} 
Der Magistrat erlaubte diesem Verein die Benutzung des städtischen Tummelplatzes zum Fußballspielen. Neben diesem offiziellen Verein wurde der Sport auch von anderen nichtorganisierten Fußballern ausgeübt. Für einige von diesen hatte die Gründung eines Fußballvereins offenbar Vorbildcharakter. Im August des Jahres 1906 baten namens einer nicht näher bezeichneten Gruppe solcher junger Männer Friedrich Leiffhold, August Martin und August Meyer um die Genehmigung, ebenfalls den Tummelplatz zum Fußballspielen benutzen zu dürfen; man beabsichtige einen Fußballverein zu gründen. 570 Bereits Anfang September $1906 \mathrm{kam}$ es zu dieser Vereinsneugründung, der Fußballclub Sport wurde ins Leben gerufen.

Auch wenn in $\S 1$ des Vereinsstatuts andere Sportarten ausdrücklich nicht ausgeschlossen wurden, so war der Hauptzweck des Vereins "durch Betreibung des Fußballsports den Körper zu kräftigen und ihm Gewandtheit zu verleihen". 571

Prinzipiell stand die Mitgliedschaft jedem unbescholtenen Mann ab siebzehn Jahren offen. Über die Zulassung zur Abstimmung entschied der Vorstand, über die Neuaufnahme eines Mitgliedes wurde in geheimer Abstimmung beschlossen. Aktive waren die Männer von siebzehn bis fünfundzwanzig Jahren. Wer älter als fünfundzwanzig Jahre war oder "physisch zur Ausübung des Sports nicht geeignet", konnte als passives Mitglied dem Verein angehören, ab vierzehn Jahren konnte ein Jugendlicher als Fußballschüler beim FC Sport aktiv sein.

Obwohl der Club durch sein Statut eine klare innere Struktur mit Vorstand, Mitgliedsbeiträgen, Strafgeldern etc. aufwies, so konnte er den "wilden" Charakter der Zeit vor der Gründung dennoch nicht ablegen. Er erachtete die seit 1900 für den Bereich des Deutschen Fußball-Bundes verbindlichen Fußballregeln nicht als bindend. Nach $\S 10$ Absatz 5 seiner Statuten hatte jeder die Fußballregeln, welche vom Vorstand herausgegeben wurden, zu befolgen.

Diese Fußballregeln sind nicht mehr erhalten. Auch wenn man annimmt, dass diese weitgehend mit denen der Football Association und damit auch denen des DFB übereinstimmten, so müssen sie in mindestens einem für den Fußballsport wesentlichen Punkt vom allgemein als gültig erachteten Regelwerk abgewichen sein, nämlich in der Zahl der Spieler.

\footnotetext{
570 Vgl.: StAEin 065 - 25, 24. August 1906

${ }^{571}$ Alle Zitate aus den Statuten: StAEin 065 - 25, 3. September 1906
} 
Zur Zeit der Vereinsgründung gehörten lediglich zehn Mitglieder dem Verein an ${ }^{572}$, in $\S 11$ der Statuten heisst es, dass der Klub sich auflösen könne, wenn er länger als zwei Monate weniger als sechs Mitglieder zähle.

Doch dieser Zustand hat nicht allzu lange angehalten. Spätestens ab dem Jahr 1910 war der Verein Mitglied im Westdeutschen Spielverband und im diesem übergeordneten Deutschen Fußball-Bund, musste also sich deren Regelwerk angeschlossen haben. Die Mitgliedschaft im Westdeutschen Spielverband erklärt sich daraus, dass dessen Ausdehnung in jener Zeit weit über das Gebiet der heutigen Regionalliga West hinausging und auch Nordhessen, das Emsland und Südniedersachsen umfasste. 573 Diese frühen Verbandsmitgliedschaften deuten darauf hin, dass es sich beim FC Sport um die zunächst erfolgreichste Einbecker Fußballvereinsgründung handelte. Dies belegt auch ein späteres Schreiben des Vorsitzenden des FC Einbeck 05 aus dem Jahre 1912, in dem er angibt, dass Sport nahezu doppelt so viele Mitglieder wie sein Verein habe. 574

Im darauf folgenden Jahr, 1907, trat zu den genannten Vereinen ein weiterer hinzu. Am 26. Juni 1907 gründeten 15 junge Männer den Fußballklub Viktoria. ${ }^{575}$ Dieser Verein, der sich nach $\S 1$ seiner Statuten die "Hebung des Fußballspieles als Mittel zur körperlichen und sittlichen Kräftigung" als Vereinsziel setzte, ist dem sozialdemokratischen Arbeitermilieu zuzuordnen. Nach $\S 8$ der Statuten war die Befreiung von der Beitragspflicht bei Krankheit oder Arbeitslosigkeit möglich; eine solche Bestimmung findet sich ausschließlich in den Statuten von Arbeitervereinen. Der Umstand, dass nach $\S$ 4 der Satzung die Erörterung von politischen Gegenständen innerhalb des Vereins kategorisch ausgeschlossen wird, ist ein Hinweis darauf, dass es sich bei den Gründern um Sozialdemokraten handelte, die es gewohnt waren, dass ihre Aktivitäten von der Obrigkeit argwöhnisch beobachtet und nach Möglichkeit auch behindert wurden.

Nach $§ 9$ der Statuten waren Männer, die vorher anderen Fußballvereinen angehört hatten, vom Beitrittsgeld befreit. 576 Dies ist in zweierlei Hinsicht bedeutsam. Zum einen ist in dieser Regelung implizit die Möglichkeit enthalten, Mitglieder anderer Vereine abzuwerben, zum anderen ist dieser

\footnotetext{
572 Vgl.: ibid.

$573 \mathrm{Vgl}$.: Grüne, Hardy: op. cit. S. 38 f.

${ }^{574}$ Vgl.: StAEin 572 - 1, 10. Januar 1912 [irrtümlich datiert 1911]

575 Vgl.: StAEin 065 - 25, 1. Juni 1907

${ }^{576} \mathrm{Zu}$ allen zitierten Statutenbestimmungen der "Viktoria" vgl.: StAEin 065 - 25, 26. Juni 
Passus ein weiterer Hinweis auf den Charakter als Arbeitersportverein, der als Zielgruppe eben jenen Teil der Bevölkerung hatte, der die größte lokale Mobilität aufwies.

Wie den beiden anderen Vereinen, Einbeck und Sport, wurde auch der Viktoria die Benutzung des städtischen Tummelplatzes gestattet.

Der Fußballsport entwickelte sich also, seitdem er 1905 erstmals als Wettkampfsport nach Einbeck gelangt war, in den ersten Jahren recht beachtlich. Bereits aus dem Jahre 1907 datiert ein Bericht der Einbecker Zeitung über ein Wettspiel zwischen den Vereinen Einbeck und Sport, zu dem sich 500 Zuschauer auf dem Tummelplatz einfanden. 577

Im Jahre 1908 begann schliesslich mit dem Turnclub Eintracht jener Verein, der als erster den Fußball nach Einbeck brachte, sich dem organisierten Spielbetrieb zuzuwenden. In der Versammlung vom 30. Mai 1908 wurde die Gründung einer Fußballabteilung angeregt und beschlossen. Offenbar hatte man im Verein lange nicht mehr Fußball gespielt, denn die selbe Versammlung beschloß der Ankauf eines neuen Balles; 578 diese Anschaffung wurde jedoch in eine späteren Versammlung in das Jahr 1909 vertagt. ${ }^{579}$ In diesem Jahr nahm die Fußballabteilung dann tatsächlich den Spielbetrieb auf. Im Sommer des Jahres wurden einheitliche Sportanzüge angeschafft und vom Magistrat die Erlaubnis eingeholt, wie die anderen Fußballmannschaften auch den Tummelplatz benutzen zu dürfen. 580

Die nunmehr installierte Fußballabteilung war organisatorisch eine weitgehend autonome Vereinigung innerhalb des Vereins. Sie baute eine eigene Kasse auf; die aus der allgemeinen Vereinskasse geleisteten Zahlungen für die Belange der Fußballer waren keine Geschenke, sondern eher eine Art Anschubfinanzierung in Form von kurzfristigen Darlehen. ${ }^{581}$ Auch die organisatorischen Angelegenheiten der Fußballer waren nicht Gegenstand allgemeiner Versammlungen, sondern waren allenfalls vom Vorstand mit zu beraten. 582

\footnotetext{
577 vgl.: Einbecker Zeitung, 24. Juli 1909

578 Vgl.: Eintracht Einbeck, Protokoll 30. Mai 1908

579 Vgl.: Eintracht Einbeck, Protokolle 5. September 1908; 3. April 1909

${ }^{580}$ Vgl.: Eintracht Einbeck, Protokoll 26. Juni 1909

${ }^{581} \mathrm{Vgl}$.: ibid.

582Vgl.: Eintracht Einbeck, Protokoll 2. Oktober 1909
} 
Schon rasch wurden Kontakte über die Stadt Einbeck hinaus geknüpft; ein freundschaftliches Verhältnis zum FC Northeim ist aus einer Einladung desselben zu einem geselligen Anlass im Winter 1909/10 zu ersehen. ${ }^{583}$

So gingen ab dem Jahre 1908 vier Vereine organisiert auf dem Tummelplatz dem Fußballsport nach. Neben diesen Vereinen spielten auch, wie aus einem behördeninternen Aktenvermerk hervor geht, "eine ganze Anzahl Schüler und andere junge Burschen" unorganisiert auf dem Tummelplatz Fußball. 584

Dieser Platz vor dem Hullerser Tor war zu dieser Zeit noch weit davon entfernt, ein regelrechter Fußballplatz zu sein. Noch in einem Schreiben des Fußballclubs Einbeck aus dem Juli 1909 wird darum gebeten, "den Graben, der sich der Länge nach durch den Platz zieht, egal zu machen". 585 Doch derlei Widrigkeiten taten einem ersten Aufschwung des Fußballs in Einbeck keinen Abbruch.

Doch das fußballerische Potenzial der Stadt Einbeck erwies sich rasch als zu gering für vier Vereine.

Der Fußballclub Viktoria ging bereits vor dem Juni 1909 in der Fußballabteilung des Turnclubs Eintracht auf 586 , nachdem kurz zuvor drei Mitglieder von Viktoria zur Eintracht übergetreten waren. 587 Mit der schrittweisen Errichtung der Fußballsparte im Turnclub Eintracht ging der Niedergang Viktorias einher; faktisch bestanden also nie mehr als drei vollwertige Fußballmannschaften in der Stadt.

Doch auch die von Mitgliedern Viktorias verstärkte und organisatorisch konsolidierte "Eintracht"-Fußballabteilung stellte bereits nach kurzer Zeit den Spielbetrieb ein. Nachdem es in einem Wettspiel gegen den Fußballklub Einbeck im Mai 1910 zu einem Knöchelbruch des Einbeck-Spielers Grothjan gekommen war588 und dieser Vorfall der "Eintracht" angelastet wurde, beschloss der Verein in seiner Versammlung vom 4. Juni 1910, den Wettspielbetrieb auszusetzen. ${ }^{589}$ Zwar wurde in der Sitzung vom 2. Juli des selben Jahres ein Antrag, die "Fußballriege" aufzulösen, nicht angenommen, doch blieb der Wettspielbetrieb suspendiert. ${ }^{590}$ In einem Schreiben vom 25.

\footnotetext{
583 vgl.: Eintracht Einbeck, Protokoll 6. November 1909

584 StAEin 572 - 1, 9. Juni 1909

${ }^{585}$ Vgl.: StAEin 572 - 1, 27. Juli 1909

586 Vgl.: ibid.

${ }^{587}$ Vgl.: Eintracht Einbeck, Protokoll 8. Mai 1909

588 Südhannoversche Zeitung, 1. Juni 1910

${ }^{58}{ }^{9}$ Vgl.: Eintracht Einbeck, Protokoll 4. Juni 1910

590 Vgl.: Eintracht Einbeck, Protokoll 2. Juli 1910
} 
Oktober 1910 informierte der Schriftführer der "Eintracht", Hermann Beulshausen, auf ofiziellem Briefbogen namens des Vereines den Magistrat, dass "zur Zeit eine Fußballabteilung nicht mehr besteht". 591 Somit war derjenige Verein, der als erster den Fußballsport nach Einbeck brachte, vorerst erneut aus dem Kreise der Fußballvereine ausgeschieden.

Doch auch eine Reduzierung der Vereinszahl auf nunmehr zwei Fußballvereine war nicht das Ende des Schrumpfungsprozesses. Nachdem der Club Einbeck bereits 1910 in einem Schreiben an die Polizeiverwaltung über eine gemessen an der Vermögenslage des Vereins und der Einkommensverhältnisse der jungen Mitglieder überhöhte Mietforderung der Stadt für die Benutzung des Tummelplatzes geklagt hatte 592 und mit den Mietzahlungen im Rückstande geblieben war ${ }^{593}$, löste sich der Verein im Frühjahr 1911 auf. 594

Doch diese Auflösung war nicht von langer Dauer. Bereits am 1. September des gleichen Jahres wurde der Verein von ungefähr 15 Männern, darunter ein großer Anteil von Schülern, erneut gegründet. Mit der Wahl des Namens "Fußball-Club Einbeck 05" stellte man sich bewusst in die Traditionslinie des gerade erst eingegangenen ältesten reinen Fußballvereins der Stadt. ${ }^{595}$ Noch im gleichen Jahr schloß man sich wie auch Sport einem Dachverband an. 596 Und wie der Vorgängerverein, so befand sich auch der neugegründete FC Einbeck 05 bald in ernsthaften finanziellen Schwierigkeiten. Bereits die erste Rate der Platzmiete im Oktober 1911 wurde nicht bezahlt, daraufhin wurde gegen den Verein ein Platzverbot ausgesprochen. 597

Auch die finanzielle Lage des FC Sport war offenbar ungünstig. Auch dieser Verein konnte im Oktober 1911 seinen finanziellen Verpflichtungen nicht nachkommen. 598

\footnotetext{
${ }^{591}$ StAEin 572 - 1, 25. Oktober 1910. Der anonyme Chronist, der in der Festschrift zum einhundertjährigen Bestehen des Vereins für das Jahr 1910 die Begründung einer von 1893. Einbeck 1993, S.21

592 Vgl.: StAEin 572 - 1, 7. November 1910

${ }^{593}$ Vgl.: StAEin 572 - 1, 11. Dezember 1910

594 Vgl.: StAEin 572 - 1, 11. Juli 1911; 5. September 1911

${ }^{595}$ Vgl.: StAEin 572 - 1, 5. September 1911

596 Vgl.: StAEin 572 - 1, 10. November 1912 [irrtümlich datiert 1911]

597Vgl.: StAEin 572 - 1, 2. Oktober 1911; 2. Januar 1912

598Vgl.: StAEin 572 - 1, 2. Januar 1912
} Fussballabteilung vermeldet, irrt in diesem Punkt. Vgl. hierzu: 100 Jahre SV Eintracht Einbeck 
Im Jahre 1912 näherten sich die beiden Vereine erstmals nachweisbar in organisatorischer Hinsicht. Im Juni dieses Jahres erschienen die beiden Vorsitzenden Dörge (Sport) und Rasmussen (Einbeck 05) gemeinsam auf dem Polizeibüro, um dort mit einem Vertreter der Stadt organisatorische Angelegenheiten zu regeln. 599

Im Laufe des Sommers wurden die wirtschaftlichen und wohl auch die sportlichen Schwierigkeiten beider Vereine nicht geringer. In einem Schreiben vom 2. August 1912 meldete der genannte Albert Rasmussen dem Magistrat: "Wir machen Ihnen hiermit die ergebenste Mitteilung, daß sich die beiden hiesigen Fußballklubs, um besonders die Unkosten zu vermindern, weiter durch Hebung der Spielstärke Einbeck würdiger in den Meisterschaftsspielen des Bezirks Cassel vertreten zu können, zu einem Club zusammengeschlossen haben, der den Namen Einbecker Fussball-Verein v. 1905 trägt."600

\section{3. 3. 2. 2. Zur ökonomischen Situation Einbecker Fußballvereine}

Da keiner der vor dem Ersten Weltkrieg bestehenden Fußballvereine zur Zeit der Unteruchung mehr bestand, haben sich vereinsinterne Materialien wie Protokoll- und Kassenbücher nicht erhalten. Daher können keine quantitativen Angaben über Kassenlage und -entwicklung der genannten Vereine gemacht werden.

Festzustellen war jedoch, dass die Vereine über relativ geringe Einnahmen verfügten. Regelbeitrag waren bei Viktoria neben einem einmaligen Eintrittsgeld von einer Mark monatlich 30 Pfennig 601, bei Sport 50 Pfennig im Monat $^{602}$. Die Mitglieder im FC Einbeck zahlten im Jahre 191025 Pfennig pro Monat. ${ }^{603}$ Mitglieder unter 17, Schüler genannt, die einen großen Anteil an der Gesamtmitgliedschaft der Vereine hatten, zahlten bei Sport 25 Pfennig monatlich 604 , beim wiedergegründeten FC Einbeck 05 waren sie gänzlich beitragsfrei 605 .

Diesen Einnahmen standen umfangreiche Ausgaben gegenüber. Für die Benutzung des städtischen Tummelplatzes erhoben die städtischen Behörden

\footnotetext{
${ }^{599}$ Vgl.: StAEin 572 - 1, 4. Juni 1912

${ }^{600}$ StAEin $572-1,2$. August 1912

$601 \mathrm{Vgl}$.: StAEin 065-25, 26. Juni 1907

602 Vgl.: StAEin 065 - 25, 6. September 1906

$603 \mathrm{Vgl}$.: StAEin 572 - 1, 7. November 1910

604 Vgl.: StAEin 065 - 25, 6. September 1906

${ }^{605} \mathrm{Vgl}$.: StAEin 572 - 1, 5. September 1911
} 
ab 1909 eine jährliche Platzmiete von 10 Mark, die bereits im darauffolgenden Jahr verdreifacht wurde. 606

$\mathrm{Zu}$ diesen Fixkosten kamen die Ausgaben für den eigentlichen Sportbetrieb. Zwei Photographien aus der Frühzeit des FC Sport 607 belegen, dass man sich zumindest in den ersten Jahren bezüglich der Ausrüstung der Spieler auf ein Minimum beschränkte.Man spielte in normalen Straßenstiefeln, einige Spieler besaßen kein Trikot, die damals bereits geläufigen Schienbeinschoner sind nicht zu erkennen und als Hosen dienten vielfach, in den Worten des Fußballpioniers Philipp Heineken, "alte ausgebrauchte und amputierte Kleidungsstücke.". 608

Doch auch wenn man sich in der Ausrüstung nach Kräften einschränkte, so waren doch immer noch hohe Ausgaben zu bestreiten. Diese Ausgaben beschrieb Albert Rasmussen, der Vorsitzende des soeben wiedergegründeten FC Einbeck 05, in einem Brief an Bürgermeister Nedden vom Januar 1912: "Außerdem müssen wir dann \& wann mal wieder einen neuen Ball, der schon allein kostet ${ }^{609}$, auch sehr häufig Blasen hierzu, Sweater, Fahnenstangen, zu jedem Wettspiel Schlemmkreide etc. anschaffen, was ach [sic] alles viel Geld verschlingt." 610

Darüber hinaus waren an den Vereinswirt sowie an den Dachverband Zahlungen zu leisten. Auch die Fahrten zu auswärts gelegenen Spielorten mit der Eisenbahn waren teuer. 611

$\mathrm{Da}$ also geringen Einnahmen vergleichsweise große Ausgaben gegeüberstanden, litten die Einbecker Fußballvereine ständig unter einer angespannten Vermögenslage. Der im Sommer 1911 vorübergehend aufgelöste Fußballverein Einbeck von 1905 hinterließ seinen Wiedergründern Schulden in Höhe von 15 Mark $^{612}$, die Vereine blieben mit der Zahlung der Platzmiete

\footnotetext{
606 Vgl.: StAEin 572 - 1, 18. Juni 1909; 27. Oktober 1910; 11. Dezember 1910

${ }^{607}$ StAEin, Fotosammlung, Abteilung 34 a, Bild der Rekruten des Fußballvereins "Sport" von 1907 und Mannschaftsfotografie, datiert 1905 - 1907 [der Verein gründete sich erst 1906, d.
}

A.]

${ }^{608}$ Heineken, Phillipp: op. cit., S. 218, Heineken stellt eben diese "amputierten" Hosen als adäquaten Ersatz für die teuren Sporthosen dar.

609 Ein guter Fußball kostete bereits Ende des 19. Jahrhunderts mindestens 10 Mark, vgl. hierzu Heineken, Phillipp: op. cit., S. 221

${ }^{610}$ StAEin 572 - 1, 10. November 1912 [irrtümlich datiert 1911]

611 Vgl.: ibid.

612 Vgl:: ibid. 
häufig in Verzug und wurden mit Platzverbot bis $\mathrm{zu}$ erfolgter Zahlung belegt. 613

Es waren also neben sportlichen auch finanzielle Gründe, die die beiden verbliebenen Fußballvereine, Einbeck 05 und Sport, dazu bewogen, im Sommer 1912 zum Einbecker Fussball-Verein von 1905 zu fusionieren. 614

\section{3. 3. 2. 3. Mitgliederentwicklung und -struktur}

Zur Quellenlage bezüglich der Mitgliederentwicklung und -struktur gilt sinngemäß das, was oben im Abschnitt über die ökonomische Lage der Vereine bereits gesagt wurde.

Vom ersten Verein, Einbeck, ist nicht mehr bekannt, als dass er von "mehreren jungen Leuten" 615 gegründet wurde. Der FC Viktoria hatte zum Zeitpunkt seiner Gründung 190715 Mitglieder616, der FC Sport bestand anfangs, 1906, gar nur aus zehn jungen Männern. ${ }^{617}$ Die sich konsolidierende Fußballabteilung des Turnclubs Eintracht kaufte im Sommer 1909 zwölf Sportanzüge, dürfte demnach also dreizehn Aktive gehabt haben. 618

Noch unpräziser sind die Angaben für die Zeit nach diesen Vereinsgründungen. Fest steht, dass es Mitgliederbewegungen gab, so erscheinen immer wieder neue Namen in den Briefwechseln mit den Behörden. Auch unter den Vereinen sind Mitgliederbewegungen nachweisbar. So treten vier der zehn Viktoria-Gründer bereits ein Jahr später als Gründer des FC Sport in Erscheinung 619; von Übertritten von Viktoria zu Eintracht war oben bereits die Rede.

Für die Wiedergründung des FC Einbeck 05 ist eine Mitgliederzahl von "ca. 15" überliefert 620 , die sich bis zum Jahreswechsel 1911/12 verdoppelte $^{621}$;

\footnotetext{
613 Vgl.: StAEin 572 - 1, 11. Dezember 1910; 5. September 1911; 2. Oktober 1911; 2. Januar 1912

614 Vgl.: StAEin 572 - 1, 2. August 1912

615 StAEin 065 - 25, 21. Mai 1905

616 Vgl.: StAEin 065 - 25, 3. September 1906

617Vgl.: StAEin 065 - 25, 3. September 1906

${ }^{618}$ Der Torwart trägt grundsätzlich andere Kleidung als die Feldspieler, die Torwartkleidung jener Zeit war der Straßenkleidung in jener Zeit ähnlicher als ein "Sportanzug". Zum Ankauf vgl.: Eintracht Einbeck, Protokoll 26. Juni 1909

619Vgl.: StAEin 065 -25 3. September 1906; 1. Juli 1907

620 StAEin 572 - 1, 5. September 1911

621 Vgl.: StAEin 572 - 1, 10. November 1912 [irrtümlich datiert 1911]
} 
zur gleichen Zeit zählte der andere Verein, Sport, etwa doppelt so viele Mitglieder. Bei diesen 80 bis 90 Mitgliedern kann es sich jedoch kaum ausschließlich um Aktive gehandelt haben. Denn zum einen waren Spieler nur bis zum fünfundzwanzigsten Lebensjahr aktiv und zum anderen wurde die Fusion der beiden Fußballvereine im Jahre 1912 neben dem finanziellen auch mit dem sportlichen Argument begründet, das bei einem Potenzial von 80 und mehr aktiven Fußballspielern schwer nachvollziehbar wäre.

Zur Mitgliederstruktur der Einbecker Fußballclubs sind kaum Angaben zu machen, da die Mitglieder vielfach nicht in den Adressbüchern aufgeführt sind. Lediglich der Vorsitzende von Einbeck 05 und dessen Nachfolgevereins, dem Einbecker Fussball-Verein von 1905, Albert Rasmussen, konnte zweifelsfrei als Kaufmann, ein Mitglied von Viktoria als Korkschneider identifiziert werden. Eine Untersuchung der Familiennamen der anderen namentlich genannten Vereinsmitglieder ergab lediglich die vage Tendenz, dass die Einbecker Fußballer vornehmlich dem kleinbürgerlichen oder dem Arbeitermilieu entstammten.

\section{3. 3. 2. 4. Das Verhältnis der Fußballer zur Stadtgemeinde}

Erstmals im Frühjahr 1905 mit dem für ihn neuen Phänomen eines Fußballvereins konfrontiert, stand der Magistrat der Sache selbst zunächst abwartend, aber nicht prinzipiell ablehnend gegenüber. Auf die Bitte des neugegründeten Fußballklubs Einbeck an den Magistrat, das Tragen des Stadtwappens, des gekrönten E, auf seinen Sporthemden zu gestatten ${ }^{622}$, erging zwar der Bescheid: "Die Auszeichnung unser Wappen zu führen können wir zu unserem Bedauern einem Verein, welcher erst ins Leben treten soll, nicht zu teil werden lassen." Doch weiter hieß es in dem Schreiben, man sei "gern geneigt, der Genehmigung dann näher zu treten, wenn sich der Fußballklub bewährt haben wird." 623 In der Folgezeit sollte dieses prinzipielle Wohlwollen rasch abnehmen.

Das Auftauchen des neuen Sports löste bei Bevölkerung und Verwaltung gleichermaßen Befremden aus. Schon die Sportkleidung, welche sich fundamental von den bekannten Anzügen der Turner - weisse lange Hose, Turnergürtel, weisses Hemd - unterschied, irrtierte die Zeitgenossen. Die bunten Fußballhemden und Sweater, die für den Fußballsport aus Gründen der leichten Unterscheidbarkeit der Mannschaften unerlässlich sind und deren

\footnotetext{
622Vgl.: StAEin 065 - 25, 21. Mai 1905

623 ibid., Antwortentwurf auf selbem Blatt
} 
Mehrfarbigkeit die Gefahr verringert, dass zwei Teams die gleiche Trikotfarbe haben, standen im Gegensatz zu der gültigen ungeschriebenen Bekleidungsnorm für Männer, nach der Herrenbekleidung in der Regel einfarbig und dunkel, Sportbekleidung rein weiß zu sein hatte. ${ }^{624}$ In einem internen Polizeibericht über den Fußballklub Einbeck bezeichnet Polizeiwachtmeister Brüning die Kleidung der Fußballer als "sehr bunt, fast in Maskerade ausgeartet", und spricht von "albernen Anzügen", auf denen das Stadtwappen beim Publikum "Ärgernis erregen" würde.

Neben den bunten Fußballhemden waren auch die kurzen Hosen Gegenstand von Kritik. Das öffentlich zur Schau gestellte Knie verletzte das sittliche Empfinden. 625 Die für die Bewegungsfreiheit des Knies notwendigen kurzen Hosen 626 wurden allenfalls auf dem Sportplatz außerhalb der Stadt geduldet. In einem Rundschreiben des Bürgermeisters Nedden an die Vorstände der Fußballvereine aus dem Jahre 1914 heißt es hierzu: "Es ist wiederholt unangenehm aufgefallen, und Anstoß daran genommen, daß die Fußballspieler den Weg vom Vereinslokal durch die Stadt nach dem Tummelplatze und umgekehrt mit vollständig entblößten Beinen zurückgelegt haben. Ich ersuche sie mit allen Mitteln, dafür zu sorgen, daß dies unterbleibt. Wer die Straßen der Stadt passiert, hat auf alle Fälle in einem angemessenen Anzuge zu erscheinen. Die nackten Beine sind, da sich das Umziehen auf dem Spielplatze nicht machen läßt, durch Umhängen entsprechend langer und verschlossener Mäntel zu verdecken.

Künftige Zuwiderhandlungen werden empfindliche Strafen nach sich ziehen."627

624 Vgl. zur Mode des Kaiserreiches: Nipperdey, Thomas: Deutsche Geschichte 1866 - 1918. Erster Band: Arbeitswelt und Bürgergeist. München 1990, SS. 132 - 136

625 Joachim H. Knoll bemerkt hierzu: "Ein weiteres [...] fällt auf, nämlich daß das

Fußballspiel von der neuen Leiblichkeit" nicht profitierte [...], nur wenige Frauen wollten oder sollten das entblößte Kniegelenk des Mannes sehen." Knoll, Joachim H.: op. cit. S. 251, Auch Gertrud Pfister weist auf eine Kollision der Fußballer in ihrer Kleidung mit herrschenden Mode- und Moralvorstellungen hin. Vgl.: Pfister, Gertrud: Sportstätten und Sportvereine in Berlin an der Wende vom 19. zum 20. Jahrhundert. in: John, Hans Georg (Red.): Vom Verein zum Verband. Die Gründerzeit des Sports in Deutschland. 10. Fachtagung der dvs-Sektion Sportgeschichte vom 18. - 20. März 1986 in der Führungs- und Verwaltungsakademie des DSB in Berlin. Clausthal-Zellerfeld 1987, SS. 11 - 40, S. 16

626 Die heutigen weiten oder elastischen Trainingshosen sind eine Erfindung der Zwischenkriegs- respektive Nachkriegszeit. 
$\mathrm{Zu}$ diesen Äußerlichkeiten kam ein oftmals provokantes Verhalten der Fußballer. Auch wenn die Formulierung Hardy Grünes, die frühe Fußballbewegung sei "eine innerhalb der bürgerlichen Schicht stattfindende Protestbewegung" 628 gewesen, als zu weitreichend angesehen werden kann, so ist doch für die Einbecker Fußballspieler vor dem Ersten Weltkrieg zu konstatieren, dass sie nicht allzu große Anstrengungen unternahmen, sich in allgemein übliche Verhaltensmuster einzufügen. Es hat vielmehr den Anschein, dass sich diese jungen Männer gewissermaßen in der Rolle von juvenilen "Bürgerschrecks" gefielen. Besonders die Anwohner des Sportplatzes führten wiederholt Klage gegen die jungen Leute. Diese würden die anliegenden Gärten zum Zurückholen versehentlich hineingeschossener Bälle widerrechtlich betreten, verschlossene Gartentore aufbrechen, 629 Gartenhäuser beschädigen und Gartenfrüchte stehlen oder zertreten. Auch seien persönliche Gespräche der Anwohner mit den Fußballern ergebnislos verlaufen. In dem Beschwerdeschreiben einer Anliegerin des Tummelplatzes heißt es: "Ich, als alleinstehende Witwe, bin nicht in der Lage, den jungen Leuten gegenüber aufzutreten; im Gegenteil, wo ich es versucht habe, wurde ich obendrein verhöhnt, angeekelt und sogar beschimpft." 630

Auch im öffentlichen Raum fielen die Fußballer unangenehm auf. Auf Anfrage des Magistrats berichtete Polizeiwachtmeister Brüning: "Die Fußballspieler sind durch das fortwährende Spielen schon so verroht, daß zum Beispiel bei der An- und Abfahrt mit der Eisenbahn das ganze EisenbahnPersonal aufgeboten werden muß, um die Sicherheit herzustellen. Der Bahnhofs-Vorsteher hat sich schon dieserhalb bei mir beschwert." 631

Die städtischen Behörden taten deshalb auch wenig, um den neuen Sport in ihrer Stadt zu fördern.

Der Magistrat liess seine Polizeibeamten nachforschen, ob sich die Vereine politisch bemerkbar machten, ${ }^{632}$ zur sonntäglichen Spielzeit wurden die städtischen Feldhüter zur Überwachung des Geschehens abgestellt, zusätzlich wurde auch der Außendienst habende Polizeisergeant angewiesen, "den Tummelplatz in geeigneter Weise zu kontrollieren."633

\footnotetext{
628 Grüne, Hardy: op. cit., S. 29

629 Vgl.: StAEin 572 - 1, 8. Juli 1912

630 StAEin 572 - 1, 17. Mai 1909

631 StAEin 065 - 25, 13. Mai 1909

632 Vgl.: StAEin 065 - 25, 3. September 1906; 10. Januar 1907;

633 StAEin 572 - 1, 7. Juni 1909
} 
Auch die Einführung der oben erwähnten Platzmiete, die zu bezahlen den Vereinen sehr schwer fiel, kann als Zeichen einer repressiven Politik der städischen Behörden gedeutet werden. Ab 1912 wurde die Haltung der Behörden in dieser Frage jedoch etwas wohlwollender. Der Vorsitzende Albert Rasmussen bat in einem Schreiben, dem FC Einbeck 05 die Platzmiete von 30 auf 20 Mark zu reduzieren. Er wies auf die oben beschriebenen, durch die Mitgliederstruktur bedingten Geldnöte hin und bat ein wegen Säumigkeit verhängtes Platzverbot "gütigst wieder aufheben $\mathrm{zu}$ wollen, damit wir uns Sonntags in Gottes freier Natur von der Arbeit in der Woche erholen können \& durch unseren Sport unsere Körper ausbilden \& stählen zum Wohle unseres Vaterlandes." 634.

Einer solchen Argumentation konnte sich der Magistrat nicht verschließen, der Bitte wurde nachgegeben. 635

Doch der Weg zum heutigen Volkssport war noch lang. Für viele Mitbürger wie auch die Behörden stellte dieser neue Sport vor dem Ersten Weltkrieg in erster Linie ein Ärgernis dar, das mit Argwohn betrachtet und kaum gefördert wurde.

Über das Verhältnis der alteingesessenen Turnvereine der Deutschen Turnerschaft zu den Fußballspielern ist wenig bekannt. Doch zeugt ein Zitat des Schriftführers des Turn-Club Einbeck, August Saalfeld, allenfalls von Desinteresse. Dieser beantwortete ein irrtümlich an seinen Verein gerichtetes behördliches, den Fußballplatz betreffendes Schreiben mit der schriftlichen Mitteilung, "daß in unserem 'Turnclub Einbeck' weder eine Riege, welche Fußball spielt, besteht, noch sonst vom Verein aus diesem Sport in irgendeiner Weise gehuldigt wird.".636

\footnotetext{
${ }^{634}$ StAEin 572 - 1, 10. November 1912 [irrtümlich datiert 1911]

${ }^{635}$ Vgl.: StAEin 572 - 1, 15. Januar 1912

${ }^{636}$ StAEin 572 - 1, 1. September 1909
} 


\section{3. 4. Weitere Sportvereine}

\section{3. 4. 1. Der Athleten-Club Vorwärts}

Am 2. Mai 1893 erschien der Tischlergeselle Ferdinand Büter auf dem Rathaus und reichte das Statut und eine Mitgliederliste eines am 23. April gegründeten Vereins bei den städtischen Behörden ein. Ausweislich der eingereichten Statuten trug der neue Verein den Namen "Atleten-Club Vorwärts" [sic]. Nach $\S$ I sollte der Vereinszweck sein, "unter jungen Leuten kraftbildende Übungen und geselliges Verkehren zu befördern". Wenige weitere Paragraphen umrissen grob die Vereinsstruktur und die Aufnahmemodalitäten.

Der Vereinsname legt bereits die Vermutung nahe, dass dieser Verein für Schwerathletik der Sphäre der sozialdemokratischen Arbeiterbewegung zuzuordnen ist, wählten die Vereinsgründer doch den Namen der 1876 von Liebknecht und Hasenclever begründeten sozialdemokratischen Parteizeitung. Auch einer der insgesamt nur sieben Paragraphen deutet auf einen sozialdemokratischen Hintergrund hin. § IV schließt etwaige politische Bestrebungen kategorisch aus. ${ }^{637}$ Solche Statutenbestimmungen sind charakteristisch für Vereine aus dem Umfeld der Sozialdemokratie, da die Vereinsgründer gewohnt waren, dass ihnen seitens der Behörden mit Argwohn begegnet wurde und sie sich daher bemühten, mit solchen Bekenntnissen behördliche Bedenken zu zerstreuen. Das anliegende Mitgliederverzeichnis führt 21 Personen auf. 638 Von diesen war in sieben Fällen der Beruf zu ermitteln; sie waren Arbeiter und Handwerker in Industriebetrieben sowie dem Bauhandwerk. Für sechs weitere konnte ermittelt werden, dass sie mit an Sicherheit grenzender Wahrscheinlichkeit Söhne von Arbeitern waren.

Über die Aktivitäten des Athleten-Clubs Vorwärts, falls überhaupt jemals irgend welche entwickelt wurden, fehlt jedes Zeugnis. Dieses völlige Fehlen von Hinweisen auf eine weitere Existenz dürfte, zumal es sich ja um einen Verein aus einem Milieu handelte, das sich im Allgemeinen einer gewissen Aufmerksamkeit der städtischen Organe erfreuen durfte, den Schluss zulassen, dass es sich bei der Gründung des Clubs eher um ein gescheitertes Projekt denn um eine wirkliche Vereinsgründung gehandelt hat.

\footnotetext{
637 StAEin 065 - 29, 23. April 1893

638Vgl.: StAEin 065 - 29, Anlage zu 23. April 1893
} 


\section{3. 4. 2. Der Fechtclub}

Am 30 November 1897 wurde in Einbeck ein Fechtclub gegründet. In dem Anschreiben der Vereinsgründer an den Magistrat, durch das dieser von der erfolgten Vereinsgründung in Kenntnis gesetzt wurde, heißt es, es hätten sich "in hiesiger Stadt eine Anzahl jüngerer Kaufleute pp. zu einem 'Fechtclub' vereinigt, um sich in der edlen Fechtkunst weiter auszubilden". In der Anlage zu diesem Schreiben überreichten die Vereinsgründer einen Statutenentwurf mit der Bitte um Kenntnisnahme und Rückgabe. Da der Magistrat beiden Bitten entsprach, sind die Statuten dieses Vereins nicht im Stadtarchiv Einbeck erhalten. Vereinslokal dieses Vereins war das Gasthaus Holtegel.

Offenbar hatten die jungen Leute gehört, dass im Rathaus Fechtutensilien gelagert würden; falls dem so sei, so heißt es weiter in dem Schreiben, so wolle man den Magistrat um die leihweise Überlassung dieser Gegenstände bitten, bis man genug Geld habe, um diese dann dem Magistrat abzukaufen. 639

Dieses Schreiben stellt die einzige Primärquelle zum Fechtclub dar. Daher ist die weitere Vereinsgeschichte schlechterdings nicht zu rekonstruieren. Die einzigen dem Autor bekannten Belege dafür, dass der Verein überhaupt über einen längeren Zeitraum bestand, finden sich in den Adressbüchern der Stadt Einbeck. In diesen sind ab 1902 die Innungen und Vereine aufgelistet. Sowohl im Adressbuch für 1902 als auch in dem für 1904 erscheint der Fechtclub. 640 Die durchaus plausible Vermutung, dass diese Nennungen des Vereins auf einem Irrtum der Verwaltungsbehörde beruhen könnte, der das Eingehen des Vereins nicht bekannt geworden war, ist dadurch widerlegbar, dass im Adressbuch für 1902 noch der Termin der Übungsabende angegeben ist, und dass im darauf folgenden Adressbuch ein anderes Vereinslokal, das Hotel zum goldenen Löwen, genannt ist.

Im darauf folgenden Adressbuch für das Jahr 1907 ist der Fechtclub ebenso wenig erwähnt wie in allen folgenden für den Untersuchungszeitraum der vorliegenden Arbeit und darüber hinaus. Daher kann konstatiert werden, dass der Verein vor 1907, also nicht einmal zehn Jahre nach seiner Gründung, aufgehört hatte, zu bestehen.

${ }^{639}$ Vgl.: StAEin 065 - 22, 8. Dezember 1897. Das zitierte Schreiben ist das einzige

Schriftstück in dieser Akte

64 0Im Adressbuch für 1902 wird er als "Fecht-Club", in dem für 1904 als "Fecht-Klub" bezeichnet. 


\section{3. 5. Die organisierten Leibesübungen in Einbeck - eine kurze Gesamtschau}

Eine Gesamtbetrachtung der organisierten Leibesübungen in Einbeck von der Reichsgründung bis zum Ersten Weltkrieg hat als erstes Ergebnis, dass in diesem Zeitraum eine große quantitative Zunahme an Vereinen zu verzeichnen ist; bestand 1871 als einziger Turnverein der MTV von 1861, so war er 1914 nur noch einer von vier Vereinen diesen Typs. Die Ausbreitung des Sports als Alternative zur traditionellen deutschen Turnerei führte in Einbeck wie auch andernorts zu Sportvereinsgründungen, da die Turnvereine den Kanon ihrer Leibesübungen nicht oder nur zeitweise erweiterten - der TCE um den Radsport, der TC Eintracht um Fußball. Zwei Radfahrvereine und ein Fußballverein konnten sich in Einbeck dauerhaft etablieren. Zieht man zusätzlich diejenigen Vereine in Betracht, die nach mehr oder weniger langer Zeit wieder eingingen, so kann von einem Boom auf dem Gebiet der Turn- und Sportvereine gesprochen werden; ab dem Beginn der achtziger Jahre des 19 Jahrhunderts der Turnvereine, ab dem dritten Viertel der selben Dekade der Radfahrvereine und ab dem ersten Jahrzehnt des 20. Jahrhunderts der Fußballvereine. Dass die Einbecker Turnvereine allerdings bis zum Ende des Untersuchungszeitraumes bei Weitem mitgliederstärker als die Sportvereine waren, ist ebenfalls nicht untypisch; die Mitgliederzahlen der Dachverbände vermitteln für ganz Deutschland ein ähnliches Bild. Zwar waren Radfahren und Fußball nicht die einzigen Sportarten, die in Einbeck ausgeübt wurden beispielsweise gab es in Einbeck bereits vor dem Ersten Weltkrieg einen Tennisplatz 641 - doch bestand in der kleinen Stadt offenbar kein ausreichend großes Mitgliederpotenzial für Vereine weiterer Sportarten. Dies belegen auch die erfolglosen Versuche, Athletik und Fechten in Einbeck vereinsmäßig zu betreiben.

Die soziale Integrationskraft der Turn- und Sportvereine hatte offenbar deutliche Grenzen. In diesem Zusammenhang fiel vor allem auf, dass innerhalb des sich in den untersuchten 43 Jahren dynamisch verändernden Bügertums durchaus gewisse soziale Schranken zwischen dem Kleinbürgertum, den aufstrebenden Mittelschichten und den bürgerlichen Eliten existiert zu haben scheinen. Dieser Umstand scheint zumindest auf dem Gebiet der Turnerei zur Gründung mehrerer gleichartiger Vereine, die zudem noch dem gleichen

\footnotetext{
641 Vgl.: Einbecker Geschichtsverein (Hg.): Stadt Einbeck. Zeitgenössische Fotografien und Dokumente. Gesammelt und bearbeitet von Erich Strauß, Hellmut Hainski und Andreas Heege. Duderstadt 1995, S. 152
} 
Dachverband angehörten, geführt zu haben. So war offensichtlich der traditionell kleinbürgerlich-handwerklich dominierte Männerturnverein nicht in der Lage, Angestellte und Kaufleute voll zu integrieren, so dass sich diese mit dem Turn-Club Einbeck ihren eigenen Turnverein schufen. Andererseits legen die Ergebnisse der berufsstrukturellen Analyse der Mitgliedschaften der Turnvereine die These nahe, dass es zwischen der kleinbürgerlichen Handwerkerschaft und den nichtsozialdemokratischen Arbeitern eine nur unscharfe Abgrenzung gegeben hat. Die in der Literatur und in ihrer eigenen Diktion als Arbeitervereine bezeichneten Organisationen dürften sich zwar fast ausnahmslos aus Lohnarbeitern rekrutiert haben, doch hinderte ihr durchaus politischer Charakter viele andersdenkende Arbeiter, solchen Vereinen beizutreten - ein der Welfenpartei anhängender Weber wäre wohl eher dem MTV als dem sozialdemokratisch gesonnenen, dem Arbeiter-Turnerbund angehörenden Turnclub Eintracht beigetreten.

So exemplarisch das Einbecker Turn- und Sportvereinswesen in vielerlei Hinsicht für die Gesamtentwicklung im Reich stehen kann, brachte die Analyse doch eine Besonderheit ans Licht. Während der Fußballsport in seiner Frühzeit nach der Literatur vor allem von jungen Angehörigen des gehobenen Bildungsund Wirtschaftsbürgertums getragen wurde, bevor er allmählich von jungen Arbeitern adaptiert wurde, so wurde er in Einbeck von Beginn an offenbar hauptsächlich von Männern und Jünglingen betrieben, deren Herkunft eher kleinbürgerlich-proletarisch war. Ob dies tatsächlich ein Spezifikum der Sportgeschichte Einbecks darstellt, oder ob sich der Fußball in anderen Kleinstädten mit ähnlichen Strukturbedingungen wie in Einbeck ähnlich abweichend von den Aussagen der allgemeinen Literatur entwickelte - diese bezieht sich hauptsächlich auf Befunde aus größeren Städten mit deutlich anderen Strukturbedingungen - wird nur durch weitere Regionalstudien erhellt werden können. 


\section{4. Die Schützenvereine}

\section{4. 1. Zur Geschichte des Schützenwesens in Deutschland und Niedersachsen}

Dem Schützenwesen, das heute - zumindest in seiner täglichen Praxis - einen Bestandteil der Sportlandschaft darstellt, ist insbesondere im niedersächsischen Raum in historischer Hinsicht eine Sonderstellung außerhalb der allgemeinen Sportbewegung beizumessen. Die organisierten Schützen wurden bis zum Zweiten Weltkrieg stets als eigenständige Bewegung angesehen. 642

Die Ursprünge des niedersächsischen Schützenwesens liegen in der militärischen Binnenorganisation vieler faktisch von der Landesherrschaft autonomer Städte im Mittelalter und der frühen Neuzeit. Die Bürger dieser Städte waren persönlich verpflichtet, bewaffnet für die militärischen Belange der jeweiligen Stadt sowohl offensiv als auch defensiv einzustehen. Die Organisation des städtischen Militärwesens konnte in den Händen der Handwerksgilden und -zünfte, aber auch bei eigens $\mathrm{zu}$ diesen Zwecken konstituierten Bruderschaften oder Schützengilden liegen. Dass zu einer effizienten Militärorganisation damals wie heute auch regelmäßige Übungen und Leistungsüberprüfungen gehörten und gehören, ist evident. Bereits ab dem 15. Jahrhundert wurden diese Leistungsüberprüfungen häufig in Form überlokaler Wettkämpfe zwischen Schützen verschiedener Städte durchgeführt. 643

Die ursprüngliche unmittelbar militärische Bedeutung der städtischbürgerlichen Schützenorganisationen trat im Verlaufe der frühen Neuzeit zunehmend in den Hintergrund. Als Gründe hierfür sind sowohl die schwindende politische Eigenständigkeit der niedersächsischen Städte als auch die wehr- und artillerietechnischen Basisinnovationen im 16. und 17. Jahrhundert anzusehen. Das bürgerliche Schützenwesen verschwand jedoch nicht völlig, doch es erfuhr einen gravierenden Wandel sowohl in seiner praktischen Tätigkeit als auch in der Form der Organisation. Die regelmäßig übenden Schützenkorporationen der Stadtgemeinden verschwanden zusehends; die ursprünglichen Vergleichswettkämpfe der militärpflichtigen Bürger entwickelten sich zu ausufernden Volksfesten, auf denen das Preisschießen

\footnotetext{
642 Vgl.: Henze, Wilhelm: Schützenwesen und Schützensport in Niedersachsen. Bürgerwehr Tradition - Sport. (Niedersächsisches Institut für Sportgeschichte Hoya: Materialien zur Niedersächsichen Sportgeschichte, Band 5). Göttingen 1997, S. 109

643 Vgl.: Henze, Wilhelm: op. cit.,SS. 21 ff.
} 
allenfalls eine unter vielen anderen Belustigungen darstellte 644 und das Schützenwesen mehr oder weniger zu einer Art informeller Traditionspflege degenerierte. 645 Zwar berufen sich verschiedene Schützenvereine auf die spätmittelalterlichen/frühneuzeitlichen Schützengilden ${ }^{646}$, doch ist in diesen Fällen eine durchgehende organisatorische Traditionslinie in der Regel zu verneinen.

Erst das 19. Jahrhundert brachte wesentliche neue Impulse für das niedersächsische Schützenwesen. Durch die politischen Entwicklungen in der ersten Hälfte dieses Jahrhunderts gewann auch die Bewaffnung von Bürgern zur Erlangung der staatlichen Einheit und zur Erstreitung und Festigung von bürgerlichen Grundrechten an Bedeutung. 647 Ernst Schubert sieht in diesem Zusammenhang vor allem in den Unruhen des Revolutionsjahres 1848 die Inizialzündung für die Ausbildung des neueren Schützenwesens im heutigen Niedersachsen. In diesem Jahr wurden in diesem Gebiet landauf landab Bürgerwehren gebildet, bemerkenswerterweise auch in vielen Kleinstädten. Aus diesen Bürgerwehren, die häufig vereinsähnliche Strukturen aufwiesen, entwickelten sich nach deren Auflösung vielfach Schützenvereine. ${ }^{648}$ In der Folgezeit breitete sich - wie das Vereinswesen überhaupt - das in Vereinen organisierte Schützenwesen rasch aus. Im Jahre 1861, also zehn Jahre vor der Gründung des kleindeutschen Nationalstaats, wurde in Gotha anlässlich eines allgemeinen Turn- und Schützenfestes der Deutsche Schützenbund gegründet, dessen Ehrenvorsitzender nur wenige Wochen später der national gesonnene Herzog Ernst II. von Sachsen-Coburg-Gotha wurde. 649

Ein erster Versuch, einen Regionalverband im heutigen Niedersachsen zu gründen, wurde im darauf folgenden Jahr unternommen. Alle Schützen und Freunde des Schützenwesens im Herzogtum Braunschweig und den

644 Vgl.: Henze, Wilhelm: op. cit., SS. 25ff.; 31 ff.; SS. $61 \mathrm{ff}$.

645 Vgl:: Schubert, Ernst: Die Veränderung eines Königreichs. in: Hucker, Bernd Ulrich u. a.

(Hgg.)Niedersächsische Geschichte. Göttingen 1997, SS. 374 - 418, S. 415

646 Vgl.: Langenfeld, Hans: Die Entwicklung der deutschen Turn- und Sportvereine im 19.

Jahrhundert. in: Krüger, Arnd (Hg.): Die Entwicklung der Turn und Sportvereine.

Sporthistorisches Symposium 18. - 20. 11. 1980 in Berlin (West). (Jahrbuch des Forums für Sportgeschichte 1983) Berlin 1984, SS. 15 - 50, SS. 19 f.

647 Vgl.: Henze, Wilhelm: op. cit., S. 35

648 Vgl.: Schubert, Ernst: op. cit., S. 415

64 9Vgl.: Czwalinna, Erich; Trump, Kurt: 125 Jahre Niedersächsische Schützen im Deutschen Schützenbund 1868-1993. Eine geschichtliche Dokumentation über das deutsche

Schützenwesen im niedersächsischen Raum. Hannover 1993, S. 42 
umliegenden Gebieten der Königreiche Hannover und Preußen wurden 1862 aufgerufen, in Braunschweig die von Mitgliedern des Deutschen Schützenbundes aus Braunschweig, Hildesheim und Wolfsburg ausgearbeiteten Statuten eines zu gründenden "Niedersächsischen Schützenvereins" zu beschließen. Doch dieser Versuch schlug, wie andere spätere, fehl. 650

Im Jahre 1868 wurde dann ein erster Unterverband ins Leben gerufen, der unter anderem wesentliche Teile des heutigen Bundeslandes Niedersachsen umfasste: Im Januar dieses Jahres wurde in Hamburg der Nordwestdeutsche Bezirksverein des Deutschen Schützenbundes gegründet, der nach $\S 1$ seiner Satzung die "Großherzogthümer Oldenburg und Mecklenburg, die Herzogthümer Braunschweig und Lüneburg, die königlich Preußischen Provinzen Hannover, Holstein, Schleswig und die freien Städte Bremen, Hamburg und Lübeck" umfasste. 651

Ein regionaler Schützenverband in Südniedersachsen wurde 1882 gegründet. Der 1882 auf Betreiben der Privilegierten Schützengesellschaft Goslar zusammen mit den Schützengesellschaften Zellerfeld und Clausthal gegründete Harzer Schützenbund wuchs schnell über das eigentliche Gebiet des Harzes und des Harzvorlandes hinaus und reichte rasch bis an die Weser und ins Eichsfeld. 652

Die zweite Hälte des 19. Jahrhunderts brachte eine Welle von Schützenvereinsgründungen mit sich. Eine Auszählung der bei Wilhelm Henze aufgeführten Festschriften von Schützenvereinen und -verbänden im Besitz des Niedersächsischen Instituts für Sportgeschichte Hoya ergibt als Mindestzahl die Gründung von 83 Schützenvereinen im heutigen Niedersachsen und wenigen unmittelbar angrenzenden Gebieten von 1848 bis 1914, davon allein 62 im Untersuchungszeitraum der vorliegenden Arbeit. 653 Die tatsächliche Zahl ist deutlich höher zu veranschlagen.

\footnotetext{
650 Vgl.: Czwalinna, Erich; Trump, Kurt: op. cit., S.49

${ }^{651}$ Vgl.: Czwalinna, Erich; Trump, Kurt: op. cit., S. 50

${ }^{652}$ Vgl.: Czwalinna, Erich; Trump, Kurt: op. cit., SS. 429; 434

653 Vgl.: Henze, Wilhelm: op. cit., SS. 161 ff.
} 


\section{4. 2 Der Schützenverein Einbeck}

Im August 1862 wurde unter dem Namen "Bürgerschieß-Club zu Einbeck" der Schützenverein gegründet. Über eventuell vorhandene Vorgängerorganisationen dieses Vereins ist aus dem in einer sehr zeitnahen Abschrift erhaltenen Gründungsstatut 654 nichts zu erfahren. Nach Aussage Hans-Norbert Mittendorfs, entstand dieser Verein aus einer "BürgerSchützenkompagnie", die ihrerseits aus der Einbecker Bürgerwehr der Revolutionszeit 1848/49 hervorgegangen war. 655 Diese These ist, wenn man die Beispiele anderer kleinerer Städte Niedersachsens betrachtet, durchaus als plausibel zu erachten 656 , wenn auch aus dem ausgewerteten Quellenmaterial über eine solche Kontinuitätslinie nichts $\mathrm{zu}$ erfahren war. Ein möglicher Hinweis über eine Vorgängerinstitution aus der Zeit um die Jahrhundertmitte findet sich in einem Protokoll aus dem Jahr 1906: Die Vereinsversammlung beschloss in diesem Jahr, ein Volksfest anlässlich des 50-jährigen Bestehens des Schützenvereins $\mathrm{zu}$ feiern, bezog sich also auf das Jahr 1856.657 Allerdings scheint im frühen 20. Jahrhundert das Vereinsgründungsdatum etwas in Vergessenheit geraten zu sein oder je nach der Lust zu Feiern, variabel betrachtet worden zu sein: Im Sommer 1913 beschloss man, das alljährliche Silberpreisschießen als Jubiläumsschießen anlässlich des 50. Gründungsjubiläums zu feiern ${ }^{658}$, demnach wäre der Verein also erst 1863 gegründet worden. 1892, auch dies belegt ein Protokoll, in dem von Planungen $\mathrm{zu}$ einem runden Stiftungsfest zu lesen ist, sahen die Einbecker Schützen das Jahr 1862 als das Gründungsjahr ihres Vereins an. 659

\footnotetext{
Protokollbuch des Vereins der Jahre 1885 ff. mit eingebunden. zweiten Weltkrieges. Einbeck 1992, SS. 7 - 70, S. 64

656 Vgl.: Schubert, Ernst: op. cit., S. 415

657Vgl.: Schützenverein Einbeck, Protokoll 19. März 1906

658 Vgl.: Schützenverein Einbeck, Protokoll 25. Juni 1913

659 Vgl.: Schützenverein Einbeck, Protokoll 8. Juni 1892
}

${ }^{65}$ Die Gründung erfolgte nach einem undatierten Schriftstück aus der ersten Hälfte der sechziger Jahre des 19. Jahrhunderts am 4. August 1862, das handschriftliche Statutenexemplar mit den Unterschriften der Vereinsgründer ist auf den 25. August des selben Jahres datiert. Die zitierten Schriftstücke sind ebenso wie weitere Dokumente aus der Zeit vor 1885 ins erste

${ }^{655}$ Vgl.: Mittendorf, Hans-Norbert: Einbecker Geschichte vom Ende des 18. Jahrhunderts bis zur Annexion des Königreichs Hannover durch Preußen. in: Einbecker Geschichtsverein (Hg.): Geschichte der Stadt Einbeck. Band 2: Vom Ende des 18. Jahrhunderts bis zum Ende des 
Eine Organisationskontinuität von früheren Zeiten her wurde erst später vom Verein für sich reklamiert; heute trägt er den Namen "Einbecker Schützengilde von 1457 - Neugründung 1862 e. V.". Hiermit bezieht sich der Verein offensichtlich auf ein für 1457 belegtes Wettschießen in Einbeck, zu dem beispielsweise 400 Teilnehmer aus Göttingen nach Einbeck anreisten. 660 Mit dieser nachträglichen Rückführung der Vereinsgeschichte bis ins ausgehende Mittelalter steht der Verein nicht singulär da; Ernst Schubert berichtet von 16 niedersächsischen Städten, deren Schützenvereine sich auf frühere Organisationen des 15. Jahrhunderts berufen, nicht ohne anzumerken, dass diese Traditionslinien, wie oben bereits angedeutet, vielfach eher konstruiert und unterbrochen sind.661 Auch im Falle des Einbecker Schützenvereins ist der Bezug zu einer Organisation des ausgehenden Mittelalters respektive der frühen Neuzeit eindeutig als Konstrukt zu bewerten. In allen bekannten Quellen aus dem Untersuchungszeitraum der vorliegenden Arbeit fehlt jeder Hinweis auf eine angenommene Kontinuität des Schützenwesens in Einbeck seit dem späten Mittelalter. In einem kurzen historischen Abriss des Einbecker Schützenwesens von seinen Anfängen bis in die Zeit nach dem Zweiten Weltkrieg berichtet Erich Plümer, dass die Schützentradition in der frühen Neuzeit als alljährliches Schützenfest, dem so genannten "Schützenhof" fortlebte, nachdem ein städtisches Schützenwesen militärisch obsolet geworden war. Diese Tradition habe, unterbrochen durch die französische Besetzung zu Beginn des 19. Jahrhunderts, bis 1826 bestanden. Danach sei das Schießen nur noch mehr oder weniger unorganisiert von etwa 70 Schützen aus der Stadt betrieben worden. 1862 sei es dann, so führt Plümer aus, gelegentlich eines Scheibenschießens im Einbecker Umland zu einem Aufruf an die Bürger der Stadt gekommen, einen "Schieß-Club zu bilden". Über den oder die Urheber dieses Aufrufes ist dem Aufsatz Plümers nichts zu entnehmen. 662

Über die Geschichte des Einbecker Schützenvereins in den Jahren von 1862 bis 1885 war nur wenig in Erfahrung zu bringen; insbesondere für die ersten Jahre des Untersuchungszeitraumes fehlen Quellen, die wesentlich weiter gehende Aussagen ermöglichen, als jene, dass die Organisation kontinuierlich

\footnotetext{
660 Vgl.: Henze, Wilhelm: op. cit., S. 22

${ }^{661} \mathrm{Vgl}$.: Schubert, Ernst: op. cit., S. 415

${ }^{662}$ Vgl.: Plümer, Erich: Einbecker Schützenwesen. in: N. N. [Festschrift zum 100-jährigen

Bestehen des Schützenvereins Einbeck und/oder zum Schützenfest 1962]. o. O. [1962], SS. 15

- 25, SS. 17 - 23
} 
bestand. 663 Bereits im Jahre 1863 änderte man den Vereinsnamen in "BürgerSchützenverein". 664

Eine Mitgliederliste aus dem Juli 1880 enthält die Namen von 41 Männern. Diese Liste ist überschrieben mit dem Titel "Schützen-Verein".665 Möglicherweise hatte der Verein schon zu diesem Zeitpunkt eine Namensänderung vollzogen, die erst für das Jahr 1886 nachweisbar ist. Zwischen zwei Protokollen aus diesem Jahr sind ein Vereinsstatut und eine Schießordnung in das Protokollbuch eingeschrieben. In den Überschriften dieser beiden Satzungen findet sich die Bezeichnung "Schützen-Gesellschaft", die korrigiert wurde in "Schützen-Verein". ${ }^{666}$ Es ist anzunehmen, dass diese Korrektur bereits in der Phase der Statutenneufassung des Jahres 1886 erfolgte, definitiv ist die Führung des Namens "Schützen-Verein Einbeck" ab 1888 belegt. 667

Ungeachtet der Frage über den Zeitpunkt der Annahme des Namens "Schützenverein" ist jedoch zweifelsfrei nachzuweisen, dass ab spätestens 1886 die Vereinsmitgliedschaft, anders als nach dem Gründungsstatut des "BürgerSchießklubs" von 1862, auch für Männer offen stand, die nicht Bürger der Stadt Einbeck waren. 668

Die bereits erwähnte Mitgliederliste des Vereins von 1880 zeigt deutlich, dass es sich beim Einbecker Schützenverein um eine Organisation des gehobenen Bürgertums handelte; in ihr finden sich hauptsächlich die Namen von erfolgreichen Kaufleuten, selbständigen Handwerksmeistern und Fabrikanten; Kleinbürger oder gar Arbeiter fehlen gänzlich. 669

An der sozialen Zusammensetzung des Vereins änderte der - wann auch immer erfolgte - Fortfall der Beschränkung potenzieller Mitglieder auf den Kreis derer, die das Bürgerrecht der Stadt Einbeck besaßen, offenbar nichts.

Zwar sind keine weiteren Mitgliederlisten erhalten und auch die Neueintritte in den Verein nicht vollständig dokumentiert, doch hat sich eine Anzahl von Vermerken über die Aufnahme neuer Mitglieder erhalten, die als repräsentativ zu erachten ist. Nahezu alle Männer, deren Beitritt nachgewiesen werden kann,

\footnotetext{
663 Vgl. die ins Protokoll eingebundenen Schriftstücke, passim

${ }^{664}$ Vgl.: Schützenverein Einbeck, Protokoll 20. April 1863

665 Schützenverein Einbeck, Mitgliederliste 28. Juli 1880

$66{ }^{6}$ Schützenverein Einbeck, Statut und Schießordnung o. D. 1886

667 Schützenverein Einbeck, Protokolle 10. September 1888 ff., passim

668 Vgl.: Schützenverein Einbeck, Statut und Schießordnung o. D. 1886

$66{ }^{6}$ Vgl.: Schützenverein Einbeck, Mitgliederliste 28. Juli 1880
} 
sind durch ihren Beruf dem gehobenen Bürgertum zuzurechnen. 670 Die Aufnahme eines Schlossergehilfen stellt einen singulären Befund dar. ${ }^{671}$ Dies kann angesichts der Aufnahmegebühren und Beitragssätze kaum verwundern; im Jahre 1891 betrug das Eintrittsgeld 9, der jährliche Beitrag 4 Mark. ${ }^{672} \mathrm{Ab}$ 1911 waren 10 Mark als Aufnahmegebühr zu entrichten. 673

Auch war das regelmäßige Schießen vor dem Ersten Weltkrieg an sich schon ein kostspieliges Vergnügen: Die üblichen großkalibrigen Gewehre waren teuer, auch die verbrauchte Munition war nicht billig. Erst das nach dem Ersten Weltkrieg aus England nach Deutschland gekommene und sich allmählich ausbreitende Kleinkaliberschießen machten den Schießsport für weite Kreise der Bevölkerung attraktiver. 674

Ein weiteres Indiz für ein hohes Wohlstandsniveau unter den organisierten Schützen Einbecks findet sich im Kontext der Finanzierung von aufwendigen Bauvorhaben. Da das hierfür notwendige Kapital nicht durch die laufenden Einnahmen aufgebracht werden konnte, wurde es über den Verkauf von Anteilsscheinen an die Mitglieder beschafft. Die größte Anleihe dieser Art wurde 1891 aufgenommen. In jenem Jahr musste die beachtliche Summe von 3000 Mark für die Erbauung eines Schießhauses aufgebracht werden. Das Geld kam binnen kürzester Zeit durch den Verkauf von Anteilsscheinen zusammen. Der beachtliche Wert von 25 Mark pro Schein lässt bereits Rückschlüsse auf die Finanzkraft der Mitglieder zu. Einige der Herren erwarben gar bis zu vier dieser Scheine, konnten mithin 100 Mark aufbringen und auf längere Zeit entbehren. 675

Auch wenn eine detaillierte soziostrukturelle Analyse der Vereinsmitgliedschaft nicht geleistet werden kann, so muss vor dem Hintergrund des Gesagten die Aussage zulässig erscheinen, dass der Schützenverein eine Organisation mit einer hohen sozialen Exklusiviät war. Als Beleg für diese Exklusivität ist auch der Beitritt von Bürgermeister Gerhard W. Nedden im Jahre 1910 anzusehen. 676

\footnotetext{
670 Vgl.: Schützenverein Einbeck, Protokolle, passim

671 Vgl.: Schützenverein Einbeck, Protokoll 20. Mai 1894

672 Vgl.: Schützenverein Einbeck, Protokoll 18. April 1891

673 Vgl.: Schützenverein Einbeck, Protokoll 3. April 1911

674 Vgl.: Czwalinna, Erich; Trump, Kurt: op. cit., SS. 337 f. und Zimmermann, Ernst:
}

Gestern, heute und morgen. in: Deutscher Schützenbund (Hg.): Wir Schützen, Stuttgart 1961,

SS. 113 - 116, S. 113

675 Vgl.: Schützenverein Einbeck, Liste in Protokoll 14. Januar 1891

676 Vgl.: Schützenverein Einbeck, Protokoll 14. August 1910 
Aus Gründen der oben beschriebenen Quellenlage sind Angaben zur quantitativen Mitgliederentwicklung des Schützenvereins Einbeck kaum möglich. Von der Mitgliederzahl von 41 im Jahre 1880 war bereits zu lesen, eine weitere Nachricht stammt aus dem ausgehenden neunziger Jahren des 19. Jahrhunderts: 1897 bat der Schützenverein den Magistrat der Stadt um die Stiftung von Ehrenpreisen zu einem Preisschießen und verwies bei dieser Gelegenheit auf eine Zahl von 89 Mitgliedern. 677

Den statutenmäßigen Schwerpunkt der Vereinstätigkeit bildeten regelmäßige Schießübungen im Sommerhalbjahr. 678 Diese wurden bis in die neunziger Jahre des 19. Jahrhunderts auf einer Schießbahn abgehalten, die auch vom in Einbeck stationierten Militär genutzt wurde. ${ }^{679}$ Über das Eigentum an den zum Schießen genutzten Anlagen geben die Quellen keinen klaren Aufschluss. Ab der zweiten Hälfte der achtziger Jahre des Jahrhunderts sind vom Verein finanzierte Baumaßnahmen an Schießhaus und -stand belegt. 680 Das erste "Schießhaus" war jedoch ein Zelt - erst später bauten die Schützen ein "neues Schützenhaus", einen einräumigen Backsteinbau, der in der Zeit zwischen den Weltkriegen von einem größeren Gebäude ersetzt wurde. 681

Geschossen wurde regelmäßig zweimal wöchentlich, der Verein beschäftigte zur Ermittlung der Treffer bezahlte Scheibenseher.682 Die Annahme, dass die Schießtage durchaus einen geselligen Charakter haben konnten, belegt die Tatsache, dass das Schützenhaus über einen verpachteten Bierausschank verfügte. ${ }^{683}$ Ein Protokoll aus dem Jahr 1904 verdeutlicht gar, dass die Geselligkeit im Umfeld des Schießens manchem Schützen zu weit ging: "Herr Präsident Mellinghausen rügt nun noch die Sitte, daß beim ersten Zwanziger, welcher geschossen wird, ein moralischer Zwang bestünde, eine

\footnotetext{
677Vgl.: StAEin I: L: D: 6, Juli 1897

${ }^{678}$ Vgl.: Statuten des Vereins vom 25. August 1862, im Protokollbuch vorgeheftet, und aus dem Jahr 1886, im Protokollbuch zwischen den Protokollen 18. März 1886 und 24. Juni 1886 679 Vgl.: Schützenverein Einbeck, Protokolle 24. Juni 1886, 5. Mai 1888, 20. März 1889, 18. Januar 1890
} 68 OVgl.: Schützenverein Einbeck, Protokolle 19. Februar 1886, 24. Juni 1886, 12. März 1888, 14. Januar 1889, 18. April 1891, 17. Februar 1892, 28. März 1896, 13. August 1906, 29.

August 1906, 7. Mai 1910, 26. Juni 1912

681 Vgl.: Plümer, Erich: op. cit., S. 23

682 Vgl.: Schützenverein Einbeck, Protokolle, passim

683 Vgl. e. g.: Verpachtungsbedingungen vom 28. Januar 1902 mit Nachtrag vom 30. Januar 1902 und Beschlussvermerk 14. April 1902, im Protokollbuch in das Protokoll 28. Januar 1902 eingeklebt et passim 
Runde Bier auszugeben, es würde dies manchen Schützenbruder vom Besuche des Scheibenstandes zurück halten. Die Versammlung ist nun der Ansicht daß es nun nicht anliege, ein Verbot hierüber zu erlassen da es jeden sein freier Wille sei, eine Runde zu geben, jedoch soll auf keinen Fall zum Runden geben animiert werden.". 684

Der erste Kontakt des Schützenvereins Einbeck zu einem Dachverband ist für das Jahr 1886 nachzuweisen; in der Versammlung vom Juli dieses Jahres beantragte der Vereinspräsident, dass der Verein dem Harzer Schützenbund beitreten solle. Die Versammlung beschloss, dass man nicht in corpore dem Bund beitreten wolle, daher wurde an die einzelnen Mitglieder appelliert, sich als Einzelpersonen dem Verband anzuschließen.685 Dieser Bitte wurde offenbar von mehreren Männern entsprochen; im Jahre 1887 nahmen Einbecker Schützen am Harzer Bundesschießen in Lauterberg teil. ${ }^{686}$ Auch in der Folgezeit wurden die Bundesschießen häufiger, aber nicht immer, von Mitgliedern des Schützenvereins Einbeck besucht, welche, wie es üblich war, häufig aus der Vereinskassen bezahlte Ehrengaben mitbrachten. ${ }^{687}$ Im Jahre 1903 fand das Harzer Bundesschießen in Einbeck statt. Im Rahmen dieses drei Tage dauernden Festes wurde auch der Tummelplatz als städtischer Festplatz eingeweiht. 688

1905 wurde vom Präsidenten der Beitritt zum Deutschen Schützenbund angeregt. Wie schon im Falle des Harzer Schützenbundes trat eine nicht mehr zu ermittelnde Anzahl von einzelnen Vereinsmitgliedern diesem Dachverband bei. 689 Ebenso wurde im Jahre 1907 verfahren, als vom Deutschen Schützenbund schriftlich dazu eingeladen wurde, sich zusätzlich dem "Nordwestdeutschen Schützenbund"690 anzuschließen.691 Anders als im Falle des Harzer Schützenbundes sind allerdings so gut wie keine Kontakte zu

${ }^{684}$ Schützenverein Einbeck, Protokoll 3. Februar 1904

$685 \mathrm{Vgl}$.: Schützenverein Einbeck, Protokoll 13. Juli 1886

686 Vgl:: Schützenverein Einbeck, Protokoll 19. März 1887

687 Vgl.: Schützenverein Einbeck, Protokolle 7. Juni 1890, 23. August 1893, 19. Juli 1897,

13. September 1897, 4. August 1899, 18. Juni 1901, 6. Juli 1907, 4. Mai 1909, 17. Juni 1911

688 Vgl.: Schützenverein Einbeck, Protokolle 28. Januar 1903, 26. April 1903, 3. Mai 1903,

23. Juni 1903, 23.September 1903 und ein erhaltenes Druckexemplar des Festprogramms in

StAEin $340-1$

${ }^{689}$ Vgl.: Schützenverein Einbeck, Protokoll 11. Oktober1905

${ }^{690}$ Gemeint ist hiermit sicherlich der im einleitenden Teil dieses Kapitels erwähnte

Nordwestdeutsche Bezirksverein des Deutschen Schützenbundes.

${ }^{691}$ Vgl.: Schützenverein Einbeck, Protokoll 12. Februar 
den beiden zuletzt erwähnten Schützenverbänden nachzuweisen. Die Absendung eines Geldbetrages an einen verunglückten Schützen, zu dessen Unterstützung in einem Rundschreiben des Verbandes aufgerufen worden war, geschah noch, bevor Mitglieder des Einbecker Vereins nachweisbar dem Deutschen Schützenbund angehörten. 692 So stellt die Teilnahme eines einzelnen Schützen aus Einbeck am Deutschen Bundesschießen in Hamburg im Jahre 1909 den einzigen Beleg für einen Kontakt mit dem Deutschen Schützenbund dar. ${ }^{693}$ Für Kontakte zum Nordwestdeutschen Schützenbund fand sich neben dem oben zitierten über den Eintritt einer unbekannten Zahl von Vereinsmitgliedern in den ausgewerteten Quellen nicht ein einziger Nachweis.

Erste Belege über eine Integration des Schützenvereins in die allgemeine Vereinslandschaft Einbecks finden sich erst für die letzten Jahre des 19. Jahrhunderts. Im Zuge der Vorbereitungen für vom Magistrat organisierte große Volksfeste in den Jahren 1898 und 1899 erklärte der Schützenverein seine Bereitschaft, an den Festen als Verein teilzunehmen. 694

Direkte Kontakte zu anderen Vereinen in Einbeck sind erst ab dem 20. Jahrhundert belegt. Zum Harzer Bundesschießen 1903 wurden die drei Kriegervereine, der Männerturnverein und der Turn-Club, sowie der Bürgerverein, der Kaufmännische Verein, das Junggesellencorps und die Feuerwehr eingeladen.695 Diese Einladungen stellen die ersten dokumentierten Kontakte dieser Art seit dem Jahr 1863 dar. In diesem Jahr beschloss die Versammlung des damaligen Bürgerschützenvereins, gemeinsam mit den Turnern und den Sängern einen Ball zu feiern. Die diesbezügliche Formulierung im Protokoll verdeutlicht im übrigen, dass die Schützen keine besondere Nähe $\mathrm{zu}$ den Turnern sahen, die zu dieser Zeit Monopolisten auf dem Gebiet der organisierten Leibesübungen waren: Die Sänger, Turner und Schützen werden als "die 3 Corporationen" bezeichnet. 696

Noch im Jahre 1902 hatte der Verein trotz einer entsprechenden Einladung davon Abstand genommen, am Ausmarsch anlässlich des in Einbeck stattfindenden Gauturnfestes teilzunehmen, nur zwei Mitglieder des Schützenvereins erwarben Karten zu diesem Fest. 697

\footnotetext{
692 Vgl.: Schützenverein Einbeck, Protokolle 16. Dezember 1903, 9. Januar 1904

693Vgl.: Schützenverein Einbeck, Protokoll 4. Mai 1909

694 Vgl.: StAEin 340 - 4 und 340 - 5

695Vgl:: Schützenverein Einbeck, Protokoll 26. April 1903, 3. Mai 1903

${ }^{696}$ Schützenverein Einbeck, Protokoll 20. April 1863

697Vgl.: Schützenverein Einbeck, Protokoll 10. Juni 1902
} 
Dass die organisierten Schützen dem übrigen Vereinsleben gegenüber persönlich nicht abgeneigt waren, zeigt ein Protokoll aus dem Jahre 1907. In diesem Jahr wurde eine Einladung $\mathrm{zu}$ einem Fest des Gesangvereins "Liederkranz" nicht aus prinzipiellen Erwägungen zunächst abgelehnt, sondern weil viele Mitglieder des Schützenvereins in anderen teilnehmenden Vereinen Mitglieder waren. 698

Letztendlich nahm der Schützenverein doch an dem Festzug des Liederkranzes teil 699 und auch in der Folgezeit wurden die Kontakte zu anderen Vereinen intensiver. Im Jahre 1908 beteiligte man sich geschlossen am Ausmarsch des Einbecker Landwehr- und Reservevereins. 700 Weitere Festteilnahmen in den Jahren 1909 und 1910 scheiterten lediglich daran, dass zu viele der Schützen Mitglieder in anderen, ebenfalls eingeladenen Vereinen waren. 701

Auch zu den eigenen Festen wurden ab dem Ende des ersten Jahrzehnts des 20. Jahrhunderts nachweislich andere Vereine, in diesen Fällen auswärtige Schützenvereine, geladen. So wurden im Jahre 1909 Schützenvereine aus Nörten, Kreiensen, Northeim, Alfeld, Eschershausen, Moringen und Göttingen zum bereits oben erwähnten alljährlichen Silberpreisschießen eingeladen ${ }^{702}$, für das Jahr 1910 weist das entsprechende Protokoll die Einladungen an "die benachbarten Schützenvereine" aus ${ }^{703}$ und im Jahre 1913 wurden "verschiedene Einladungen" zum Silberpreisschießen ausgesprochen.704

Die Belege über die Kontakte des Schützenvereins Einbeck zu anderen Vereinen in der Stadt und zu weiteren Schützenvereinen im Süden der Provinz Hannover lassen den Schluß zu, dass sich der Verein ab den achtziger Jahren des 19. Jahrhunderts in das überlokale Schützenwesen, aber erst ab der Wende vom 19. zum 20. Jahrhundert allmählich in das allgemeine Vereinswesen der Stadt Einbeck integrierte. Dieser Befund deckt sich durchaus mit der eingangs skizzierten "Sonderstellung", die Wilhelm Henze den Schützen innerhalb der deutschen Sportgeschichte einräumt. ${ }^{705}$ Diese Aussage lässt sich, für den Fall des Schützenvereins Einbeck dahin gehend erweitern, dass eine Sonderstellung

\footnotetext{
698 Vgl.: Schützenverein Einbeck, Protokoll 9. April 1907

${ }^{699}$ Vgl.: Schützenverein Einbeck, Protokoll 6. Juli 1907

700 Vgl.: Schützenverein Einbeck, Protokoll 29. Februar 1908

701 Vgl.: Schützenverein Einbeck, Protokolle 5. Juni 1909, 21. Februar 1910

702 Vgl.: Schützenverein Einbeck, Protokoll 24. Juli 1909

703 Schützenverein Einbeck, Protokoll 16. Juli 1910

704 Schützenverein Einbeck, Protokoll 25. Juni 1913

${ }^{705}$ Vgl.: Henze, Wilhelm: op. cit., S. 109
} 
innerhalb des gesamten Systems von Vereinen bis ins 20. Jahrhundert bestanden haben dürfte.

Die erwähnten Silberpreisschießen waren spätestens ab den achtziger Jahren der jeweilige Höhepunkt eines Schützenjahres. An diesen zunächst zwei-, später drei- oder bisweilen gar viertägigen Festen wurde nicht nur, zunächst vereinsintern, später regional, um Preise geschossen. Vielmehr belegen die gemeinsamen Essen und Festbälle den durchaus geselligen Charakter dieser Veranstaltungen, an denen auch die Familien der Schützen teilnahmen. 706

$\mathrm{Ab}$ dem Jahr 1893 sind zudem auch regelmäßig einmal jährlich stattfindende "Wintervergnügen" nachweisbar. Im Januar 1893 beschloss die Mitgliederversammlung, es solle ein "musikalischer humoristischer Abend mit nachfolgendem Tanzkränzchen" abgehalten werden. Der Erlös aus diesem Fest sollte dem Fahnenfonds zufließen. ${ }^{707}$ Doch bereits ein Jahr später, die Fahne war längst angeschafft und geweiht worden 708 , ist in einem Protokoll vom "diesjährigen Wintervergnügen" die Rede ${ }^{709}$, für den Winter 1894/95 wurde erneut ein Vergnügungsabend beschlossen 710 und im darauf folgenden Winter hatte sich die Tradition bereits so verfestigt, dass fortan ohne gesonderten Beschluss ein alljährliches Wintervergnügen abgehalten werden sollte. ${ }^{711}$ Aus dem Jahr 1898 datiert eine Information über den Verlauf dieser alljährlichen Feste, sie waren "gewürzt durch einige Vorträge, beginnend mit Konzert", 712 ein spätererer Protokolleintrag spricht von wiederholten Bällen713. Die Einbecker Schützen entwickelten die Tradition eines zweiten Festes für sich und ihre Angehörigen im jährlichen Veranstaltungskalender und pflegten diese

\footnotetext{
706 Vgl.: Schützenverein Einbeck, Protokolle 10. September 1888, 28. August 1889, 2. Juli 1890, 5. September 1891, 15. Juni 1894, 1. Juni 1895, 29. Mai 1896, 19. Juli 1897, 22. August 1898, 5. September 1899, 17. Juli 1900, 18. Juni 1901, 1. August 1902, 23. September 1903, 14. Juli 1904, 31. Juli 1905, 13. August 1906, 26. Juli 1907, 17. Juli 1908, 24. Juli 1909, 16. Juli 1910, 17. Juni 1911, 26. Juni 1912, 25. Juni 1913, 19. Juni 1914 707 Schützenverein Einbeck, Protokoll 11. Januar 1893 708 Vgl.: Schützenverein Einbeck, Protokolle 22. März 1893, 17. Juni 1893 und den Vertrag vom 6. März 1893 zwischen dem Schützenverein und den Fahnenherstellern, den Eheleuten H. Lehmert und Emma Lehmert geb. Brandmüller aus Dassel, der im Protokollbuch ganz vorne eingeklebt ist.

709 Schützenverein Einbeck, Protokoll 2. Januar 1894

710 Vgl.: Schützenverein Einbeck, Protokoll 7. Dezember 1894

711 Vgl.: Schützenverein Einbeck, Protokoll 28. Dezember 1895

712 Schützenverein Einbeck, Protokoll 8. Januar 1898

713 Vgl.: Schützenverein Einbeck, Protokoll 5. Dezember 1907
} 
bis zum Ende des Untersuchungszeitraumes. ${ }^{714}$ Da diese jedoch häufig mit finanziellem Defizit abschlossen 715 , wurde verschiedentlich beschlossen, die Unkosten nicht aus der allgemeinen Vereinskasse $\mathrm{zu}$ tragen, sondern per Umlage nachträglich auf jene zu verteilen, die auch tatsächlich an der Feier teilgenommen hatten. 716

Insbesondere die Silberpreisschießen dokumentieren einen Bruch des Einbecker Schützenvereins mit der jahrhundertealten Schützentradition, auf die er sich mittlerweile wieder beruft. Diese Preisschießen standen nur im Verein organisierten Schützen offen, während bis ins 19. Jahrhundert alle Bürger der Stadt an den "Schützenhöfen" teilnehmen konnten. Solche allgemeinen Schützenfeste wurden im Untersuchungszeitraum der vorliegenden Arbeit nur drei Mal gefeiert, in den Jahren 1889, 1910 und 1912. 717

In seiner Außendarstellung trat der Schützenverein, wie es bis heute im Schützenwesen üblich ist, uniformiert auf. In einem Protokoll aus dem Januar 1863, also nicht einmal ein halbes Jahr nach der Vereinsgründung, heißt es: "Es wurde beschlossen, daß das Schützencorps zu erscheinen habe einmal in einer Joppe und zum anderen als Kopfbedeckung einen runden, braunen Hut zu tragen habe". ${ }^{118}$ Weitere Belege über die Uniformierung mit Joppe und Schützenhut finden sich, was kaum überraschen kann, bis ins 20. Jahrhundert. 719 In einem Protokoll aus dem Jahr 1910 ist von einem "Schützenanzug" zu lesen 720 . Ob dieser jedoch eine Uniform im eigentlichen Sinne aus Uniformrock und -hose, oder die althergebrachte Schützenkleidung Joppe zu schwarzer Hose 721 - bedeutet, ist unklar; Letzteres muss wahrscheinlicher scheinen. ${ }^{722}$

714 Vgl.: Schützenverein Einbeck, Protokolle 21. November 1899, 16. November 1900, 5. November 1901, 26. November 1902, 9. Dezember 1903, 16. Dezember 1904, 11. Oktober 1905, 12. Dezember 1906, 5. Dezember 1907, 23. November 1908, 1. Dezember 1909, 12. Dezember 1910, 22. November 1911, 4. Januar 1913, 2. Dezember 1913

${ }^{715}$ Vgl.: Schützenverein Einbeck, Protokolle 4. Februar 1895, 4. Februar 1896, 5. Februar 1897

716 Vgl.: Schützenverein Einbeck, Protokolle 8.Januar 1898, 9. Dezember 1903

717 Vgl.: Plümer, Erich: op. cit., SS. 17 - 23

${ }^{718}$ Schützenverein Einbeck, Protokoll 10. Januar 1863

719 Vgl.: Schützenverein Einbeck, Protokolle 20. Juni 1885, 20. März 1889, 3. Mai 1903und

e. g. die Festentwürfe 1892 und 1893 im Protokollbuch eingeklebt

${ }^{72}{ }^{0}$ Schützenverein Einbeck, Protokoll 7. Mai 1910

${ }^{721}$ Die schwarze Hose zur Schützenjoppe bei öffentlichem Auftreten ist bereits für die neunziger Jahre des 19. Jahrhunderts belegt, vgl. hierzu e. g. die oben zitierten Festentwürfe 
Der bereits oben erwähnte erste nach den ausgewerteten Unterlagen datierbare Ankauf einer Vereinsfahne im Jahre 1893 war mit Sicherheit nicht der erste überhaupt. Im Kontext der Planungen $\mathrm{zu}$ den Feierlichkeiten anlässlich des 30-jährigen Bestehens des Schützenvereins ist in einem Protokoll von der Wahl eines Fahnenträgers zu lesen. ${ }^{723}$ Über diese Fahne war nichts mehr in Erfahrung zu bringen, anders als über jene aus dem Jahre 1893, die zur Zeit der Niederschrift der vorliegenden Arbeit noch immer erhalten und im Vereinslokal der nunmehrigen "Einbecker Schützengilde von 1457 - Neugründung 1862", dem Gasthaus "Weißer Hirsch" an der Schützenstraße, zu sehen ist. Die bereits in den vorigen Kapiteln dieser Studie angesprochene Tendenz von Vereinen, sich möglichst rasch nach Gründung und Konsolidierung eine Vereinsfahne zuzulegen, legt die Vermutung nahe, dass eine erste Vereinsfahne bereits mehrere Jahre vor dem Untersuchungszeitraum angeschafft worden sein dürfte.

Zusammenfassend lässt sich festhalten, dass der Schützenverein Einbeck, einer der ältesten Vereine der Stadt, über den gesamten Untersuchungszeitraum hinweg ein sozial recht exklusiver Verein gewesen sein dürfte, der erst spät seinen Weg in das allgemeine Vereinsleben der Stadt fand. Mit seinen Aktivitäten, vielen über den statutarischen Vereinszweck im engeren Sinne hinausgehenden Festen und Feiern und einer selbstbewussten Repräsentation nach außen muss der Schützenverein als durchaus typischer Verein des Kaiserreiches angesehen werden. Möglicherweise wirkten alte und exklusive Vereine, die sich, wie der damalige Bürger-Schützenverein Einbeck, in der Übergangsphase von der ständisch geprägten zur industriellen Gesellschaft noch als Corporationen bezeichneten ${ }^{724}$, sogar als stilprägende Vorbilder für einen großen Teil des Vereinsspektrums vor dem Ersten Weltkrieg. Dies muss jedoch eine vermutlich nicht abschließend zu verifizierende oder falsifizierende Mutmaßung bleiben.

der Jahre 1892 und 1893. Außerdem wurden noch 1903 neue Joppen, aber keine Uniformhosen angeschafft. Vgl. hierzu: Schützenverein Einbeck, Protokoll 3. Mai 1903

${ }^{722}$ Es steht zu vermuten, dass die staatlichen Behörden Uniformen, die mit offizieller militärischer Bekleidung hätte verwechselt werden können, nicht geduldet hätten. Im Falle der Militärvereine wurden, wie die Akten über das Militärvereinswesen im Stadtarchiv Einbeck belegen, regelmäßig einschlägige Verbote durch preußische Regierungsstellen ausgesprochen und die nachgeordneten Polizeibehörden entsprechen angewiesen.

${ }^{723}$ Vgl.: Schützenverein Einbeck, Protokoll 8. Juni 1892

724 Vgl.: Schützenverein Einbeck, Protokoll 20. April 1863 


\section{4. 3. Der Schützen-Zimmerstutzenklub}

Mit dem dem Schützen-Zimmerstutzenklub ist ein weiterer Schützenverein der Stadt Einbeck zu erwähnen, über den jegliche Primärquelle fehlt. Das Protokoll einer Versammlung des Schützenvereins Einbeck vom 16. Juli 1910, in der

man beschloss, einer Einladung des Zimmerstutzenklubs nicht Folge zu leisten, ${ }^{725}$ markiert bezüglich der Vereinsgründung den terminus ante quem. Die Zurückweisungung der Einladung stützt die These von der Exklusivität des Schützenvereins Einbeck.

Der Vereinsname verrät, dass sich die Mitglieder vermutlich nur im Schießen auf kurze Distanzen mit Munition von geringem Kaliber mit Randzünder und einem Projektil aus Weichmetall übten.

Eine Erwähnung in der im Adressbuch vom Juli 1912 enthaltenen Vereinsliste stellt, soweit dem Autor bekannt ist, den einzigen weiteren Beleg für die Existenz dieses Schützenvereins dar. 


\section{4. 4. Die Schießsportabteilungen des MTV und des Landwehr- und Reservevereins}

Der Übersichtlichkeit und des thematischen Zusmmenhanges halber sei auf die Schießsportabteilungen zweier anderer Vereine hingewiesen. Dies ist bereits oben geschehen beziehungsweise wird unten geschehen ${ }^{726}$; dieser Verweis könnte mithin als redundant erachtet werden.

Ausweislich des Adressbuches vom Juli 1912, in dessen Vereinsliste erstmals die Unterkategorie "Schützenvereine" zu finden ist, bestanden neben den beiden genannten Schützenvereinen beim Männerturnverein und beim Landwehr- und Reserveverein jeweils eine so genannte "SchießklubAbteilung". Beide Abteilungen dürften, da sie als eigenständige Vereine geführt wurden, einen relativ autonomen Status gehabt haben. Die nominelle Unterabteilung des MTV hatte gar ein anderes Vereinslokal als der Mutterverein.

Die in den einschlägigen Kapiteln der vorliegenden Arbeit näher skizzierte kleinbürgerlich dominierte Mitgliederstruktur der beiden Vereine könnte die oben formulierte These von der geringen sozialen Integrationskraft und einem hohen Grad der sozialen Exklusivität des Schützenvereins Einbeck unterstützen. Offenbar bestanden für die Mitglieder von MTV und Landwehrund Reserveverein soziale Schranken, die sie am Beitritt zum etablierten Schützenverein hinderten.

Die Existenz der beiden Schießsportabteilungen kann im Gegenschluss auch als Indiz gedeutet werden, dass im beginnenden 20. Jahrhundert weitere Bevölkerungskreise Gefallen am Schießen fanden, als jene, die bisher, zumindest in Einbeck, im alten Schützenverein sozial repräsentiert waren.

Zudem kann die Existenz der "Schießklub-Abteilung" des MTV als Indiz dafür angesehen werden, dass sich bereits vor dem Ersten Weltkrieg die oben für das Jahr 1863 dokumentierte scharfe Abgrenzung von Turnerei und Schützenwesen, die bis heute in einer gewissen Sonderstellung der Schützen in der deutschen Sportlandschaft fortlebt, ein wenig an Bedeutung verlor. Dies würde durchaus in das Bild der oben skizzierten beginnenden Annäherung an und Integration in das allgemeine Vereinswesen der Stadt Einbeck passen, die der Schützenverein nach der Wende vom 19. zum 20. Jahrhundert allmählich begann.

\footnotetext{
726 Vgl.: die Abschnitte über den Männerturnverein Einbeck und den Landwehr- und Reserveverein der vorliegenden Arbeit.
} 


\section{5. Verschiedene Kegelvereine}

Wenn an dieser Stelle in der gebotenen Kürze die Kegelvereine und -clubs behandelt werden, dann geschieht dies im Grunde genommen nur, um dem am Beginn dieser Untersuchung stehenden Postulat Max Webers genüge zu tun, der, wie eingangs zitiert, gefordert hatte, es müsse eine Soziologie des Vereinswesens "vom Kegelclub [...] angefangen bis zur politischen Partei" entstehen. ${ }^{727}$ Der Umstand, dass Weber die Kegelclubs als Gegenpol zu den in dieser Zeit bereits recht stark auf Reichsebene durchorganisierten Parteien wählte, beleuchtet möglicherweise bereits das Grundproblem der Analyse dieser Vereinigungen. Zur Zeit der Erstellung der vorliegenden Studie stellen Kegelclubs in der Regel kleine und informelle Zusammenschlüsse von Personen dar. Die Pflege der allgemeinen Geselligkeit ist in ihnen häufig ebenso wichtig wie das Kegeln selbst, das häufig nicht mit dem Ernst betrieben wird, wie dies im Falle von Turnen oder Sport der Fall ist. ${ }^{728}$ Auch weisen solche Clubs häufig keine lange Organisationskontinuität auf. Es besteht kein Grund zu der Annahme, dass dies im Untersuchungszeitraum anders gewesen sein sollte.

So kann es auch nicht verwundern, dass die Quellenlage zu Kegelclubs in Einbeck vor dem Ersten Weltkrieg ausgesprochen dürftig ist. Die einzigen dem Autor bekannten Belege für solche Vereinigungen sind eine bereits im Zusammenhang mit einigen Gesangvereinen zitierte undatierte Vereinsliste in den Akten der Städtischen Behörden, deren Entstehenszeit bereits oben auf den Sommer des Jahres 1893 datiert werden konnte ${ }^{729}$, sowie ein den Behörden zur Genehmigung eingereichtes Statut mit Mitgliederliste des Kegelklubs Drei Lange aus dem Jahr 1908. 730

In der Vereinsliste von 1893731 erscheinen zehn verschiedene Kegelvereine, neun der Bezeichnungen sind noch lesbar: Constantia, Merkur, Krakelia, Hubeklub, Harmonie, Fidelitas, Concordia, Reinserthurm, und Postbeamten.

\footnotetext{
${ }^{727}$ Zitert nach: Weber, Max: Geschäftsbericht. in: Verhandlungen des Ersten Deutschen Soziologentages vom 19. - 22. Oktober 1910 in Frankfurt am Main. Tübingen 1911. SS. 52f. 728 Dies sind im übrigen die Gründe, weshalb sich die Kegelclubs nicht unter den Turn- und Sportvereinen behandelt werden.

729 StAEin $065-17$

730 In StAEin 065 - 11, der Umschlag trägt ein Genehmigungsvermerk vom 13. Juni 1909

${ }^{73}{ }^{\text {StAEin }} 065-17$
} 
Die Vereinsnamen geben kaum Aufschluss über die der Untersuchung zu Grunde liegenden Fragen. Hubeklub und Reinserthurm bezeichnen den Ort des Kegelns ${ }^{732}$, Postbeamte[nkegelklub] weist auf einen geselligen Zusammenschluss von Arbeitskollegen hin. Die meisten übrigen Namen stellen Beispiele für die zeittypische Vorliebe für latinisierende Vereinsnamen dar, die durch den Clubnamen Krakelia fröhlich persifliert wird. Der Vereinsname Harmonie war, wie der oben bereits erwähnte gleichnamige Gesangverein wie auch viele andernorts im Kaiserreich gegründete Vereine belegen, ebenfalls typisch für die Zeit.

Da weitere Belege über Kegeln, Kegler und Kegelvereine für den Untersuchungszeitraum fehlen, können keine weiter reichenden Aussagen gemacht werden. Die Liste aus dem Sommer 1893 stellt lediglich eine unscharfe Momentaufnahme dar.

Das im April 1908 beschlossene Statut des Kegelklubs Drei Lange gibt Aufschluss über Struktur und Aktivitäten des Vereins. Bereits $\S 1$ unterstreicht das oben über den geselligen Charakter von Kegelclubs Gesagte: "Der Kegelclub hat den Zweck, Kollegialität und gesellschaftlichen Verkehr unter sich zu fördern und nach tageslanger schwerer Arbeit ein paar heitere Stunden zu genießen." Wie der oben genannte Kegelclub von Postbeamten war auch der Kegelclub Drei Lange eine Vereinigung von Kollegen, die für den selben Arbeitgeber arbeiteten. $\S 2$ beschränkte die Mitgliedschaft prinzipiell auf Steinarbeiter der Firma Lauschke, Ausnahmen hiervon $\mathrm{zu}$ machen stand allerdings der Mitgliederversammlung zu. Zum Zeitpunkt der Einreichung, der zwischen der Verabschiedung des Statuts am 25. Juni 1908 und der Genehmigung durch die Behörden am 13. März 1909 lag, gehörten neun Männer dem Verein an. Der Mitgliedsbeitrag betrug 20 Pfennige. Gekegelt wurde wöchentlich Mittwochs, jeweils von 20.45 bis $22.30 \mathrm{Uhr}$. Die Spieler traten in zwei Mannschaften gegeneinander an, die unterlegene Partei zahlte nach einem Spiel 20, die siegreiche 5 Pfennig in die Vereinskasse. Neben Mitgliedsbeiträgen und Spielgeldern speiste sich die Vereinskasse, wie dies auch bei anderen Vereinen üblich war, aus verschiedenen Strafgeldern für Nichterscheinen oder Verspätungen. Ein ungewöhnlicher Passus über die Vereinskasse findet sich in $\S 11$. Für den Fall, dass ein Mitglied Einbeck verließ, stand ihm ein Anteil am Kassenbestand zu. Dies legt den Schluss nahe, dass unter den Steinschleifern und -metzen eine hohe, von den Kollegen akzeptierte Mobilität herrschte. Über die Lebensdauer des Vereins ist nichts

\footnotetext{
${ }^{732}$ Das Kegeln auf der Hube fand unter freiem Himmel statt, für den Fall des Reinserturmes war nichts Näheres in Erfahrung zu bringen.
} 
bekannt, über diesen wie auch etwaige andere Kegelklubs fehlen weitere bekannte Belege. 


\section{6. Der Naturheilverein}

\section{6. 1. Zur Geschichte der Naturheilbewegung in Deutschland}

Wenn im Folgenden von der Naturheilbewegung in Deutschland die Rede sein wird, so muss ausdrücklich erwähnt werden, dass Ideen über natürliche, arzneilose Heilverfahren so alt sind wie die Medizin selbst.

Bereits bei dem antiken Arzt Hippokrates heisst es im VI. Buch der "Epidemischen Krankheiten": "Die Natur ist Heilerin der Krankheiten."733 Gerade auf diese pointierte Formulierung bezogen sich spätere Anhänger der Naturheilkunde wie beispielsweise Alfred Brauchle. ${ }^{734}$ Unerwähnt blieb freilich in den Ausführungen Brauchles die hippokratische Erweiterung dieser These, dass der Arzt die Natur in ihrer Heilkraft unterstützen müsse, und dass ein solcher ärztlicher Dienst an den Heilungskräften der Natur ein wesentlicher Bestandteil der Naturheilkunde sei. ${ }^{735}$ Auch in den Schriften des Paracelsus (Theophrastus Bombastus von Hohenheim) aus dem 16. Jahrhundert nimmt die Naturheilkunde einen wesentlichen Raum ein. ${ }^{736}$ Viele weitere Autoren schlossen sich in der Folgezeit den Gedanken dieser prominenten Vordenker an. Die traditionelle medizinische Lehre war die Humoralpathologie, also die Deutung der Körperfunktionen und -dysfunktionen als Folgen einer richtigen beziehungsweise fehlerhaften Mischung der Körpersäfte (Blut, Schleim, gelbe und schwarze Galle).

Diese Humoralpathologie wurde durch die moderne, naturwissenschaftlichontologisch orientierte Medizin, so die wissenschaftliche Lehre von den Krankheiten (Nosologie) und die Betrachtung des menschlichen Körpers als ein Gebilde mit vielen funktionalen Untereinheiten (Iatrotechnik), zunehmend abgelöst. 737 Diese Neuerungen waren bedingt durch medizinische Basisinnovationen und brachten ihrerseits weitere neue wissenschaftliche

\footnotetext{
733Zitiert nach: Brauchle, Alfred: Handbuch der Naturheilkunde auf wissenschaftlicher Grundlage. 2. Auflage, Leipzig 1934, S. 153

${ }^{734}$ Dr. med Alfred Brauchle war nach eigenen Angaben "aus Gewissensnot in das Lager der Naturärzte" übergegangener Arzt (op. cit., S. V), ab 1929 Leiter des 1927 gegründeten naturheilkundlich orientierten "Prießnitz-Krankenhauses" in Berlin-Mahlow.(op. cit., S. 183) ${ }^{735}$ Vgl.: Glasscheib, H. S.: Das Labyrinth der Medizin. Irrwege und Triumphe der Heilkunde. Reinbek bei Hamburg 1961, S. 236 736 Vgl.: Brauchle, Alfred: op. cit., SS. 158 ff. ${ }^{737}$ Vgl.: Stollberg, Gunnar: Die Naturheilvereine im Deutschen Kaiserreich. in: Archiv für Sozialgeschichte, Band 28 (1988), SS. 287 - 305, S.287
} 
Erkenntnisse hervor. Es entstand so die moderne Medizin als eine Naturwissenschaft mit verschiedenen Teildisziplinen.

Die Folge dieses fundamentalen Paradigmenwandels innerhalb der Humanmedizin war ein Prozess der zunehmenden Professionalisierung der Ärzte. Es bildete sich zusehends ein Berufsstand mit systematisch wissenschaftlich erworbener, allgemein anerkannter Fachkompetenz in allen Krankheits- und Gesundheitsfragen heraus. 738

Dieser Paradigmenwechsel bedingte auf der anderen Seite eine Laisierung des Patienten. War dieser nach der traditionellen Medizin der an der Heilung mitwirkende verantwortungsvolle "Wirt seiner Säfte", so kam ihm in der neuen naturwissenschaftlichen Medizin eher eine passive Rolle zu. Er musste sich, nolens volens, auf die professionelle Kompetenz des Arztes und damit auch auf die für ihn nicht mehr verständliche Diagnostik und Therapie verlassen. 739

Diese zunehmende Entfremdung von Arzt und Patient rief Widerpruch hervor, es kam, wie Nipperdey schreibt, zu "Kritik gegen die Giftmedizin der Etablierten, voller Ressentiments der Unstudierten gegen die Studierten, voller Eifer für populäre, verständliche, elementar einfache Belehrung". 740

Das wachsende Bedürfnis vieler Menschen nach einer für sie plausiblen Diagnostik und Behandlungsweise erfüllten Naturheiler, in ihrer Mehrheit nicht akademisch ausgebildete Mediziner, sondern so genannte "Laienpraktiker", deren unterschiedliche, teilweise jedoch aufeinander fußende Lehren eine regelrechte, systematische Naturheilbewegung hervorbrachten.

Als Begründer der modernen Naturheilbewegung gilt der schlesische Bauer Vincenz Prießnitz, der 1826 in Gräfenberg die erste Kaltwasserheilanstalt gründete und damit die Hydrotherapie neu begründete. Der Pfarrer Johann Sebastian Kneipp entwickelte auf der Basis der Lehren Prießnitz' 1866 eine eigene Wasserkur, die weite Verbreitung fand. Bereits 1855 hatte der Schweizer Arnold Rikli741 in den slowenischen Karawanken eine Klinik eröffnet, in der die Patienten mit Licht- und Luftbädern behandelt wurden. Ein Mitschüler Prießnitz', der Fuhrmann Johann Schroth, begründete mit seiner noch heute populären Trockenkur die Naturheildisziplin der Diätetik. 742

\footnotetext{
738Vgl.: ibid.

${ }^{739}$ Vgl.: Stollberg, Gunnar: op. cit., S. 288, auch das Zitat in diesem Absatz findet sich dort.

740 Nipperdey, Thomas: Deutsche Geschichte 1866 - 1918. Erster Band: Arbeitswelt und

Bürgergeist. München 1990, S. 162

${ }^{741}$ Ein Beruf Riklis war nicht zu ermitteln, auch er war kein ausgebildeter Mediziner.

742 Vgl. zu den genannten Begründern der Naturheilkunde: Brauchle, Alfred: op. cit., SS. 178

ff.
} 
Hydrotherapie, Licht- und Luftbehandlung sowie Diätetik bilden das Fundament der gesamten Naturheilkunde und -bewegung seit dem 19. Jahrhundert.

Die moderne Naturheilkunde fand rasch Anklang in weiten Kreisen der Bevölkerung. Im Jahre 1832 wurde in Ansbach als erster deutscher Naturheilverein ein "Verein der Wasserfreunde" gegründet. ${ }^{743}$ Diesen Vereinsgründungen folgten weitere, so der "Hydrodiätetische Verein " in Dresden von 1835. Sachsen entwickelte sich zur Hochburg der Naturheilvereinsbewegung. 1872 kam es dort zur ersten Verbandsgründung, es entstand der "Zentralverein für Naturheilkunde in Sachsen", aus dem 1883 der reichsweite "Deutsche Verein für Naturheilkunde und volksverständliche Gesundheitspflege" hervorging. 1884 wurde der Konkurrenzverband "Centralverband der Vereine für volksverständliche Gesundheitspflege und arzneilose Heilweise"gegründet, der ersteren bald an Bedeutung und Mitgliederzahl überflügelte. Beide Verbände vereinigten sich Ende der achtziger Jahre ${ }^{74}$ zum "Deutschen Bund der Vereine für Gesundheitspflege und arzneilose Heilweise", der sich 1900 in "Deutscher Bund der Vereine für naturgemäße Lebens- und Heilweise" umbenannte. ${ }^{745}$

Diesem Verband gehörten 188919.000 Mitglieder in 142 Vereinen an. Diese Zahlen wuchsen stetig an und erreichten über 97.000 Mitglieder in 776 Vereinen im Jahre 1900 und 144.000 Mitgliedern in 861 Vereinen im Jahre 1910 ihren Höhepunkt im Jahre 1913, als der Verband 148.000 Mitglieder zählte, die in 885 Zweigvereinen organisiert waren.

\footnotetext{
743 Vgl.: Stollberg, Gunnar: op. cit., S. 288. Brauchle datiert diese Gründung bereits auf das Jahr 1822 (op. cit, S. 182), doch zitiert Stollberg eine zeitlich näher an der fraglichen Zeit stehende Quelle.

7441888 laut Stollberg, Gunnar: op. cit., S. 290 und Nipperdey, Thomas: op. cit., S. 162; 1889 laut Brauchle (op. cit., S. 182)

${ }^{74}{ }^{5}$ Zur Verbandsgeschichte vgl.: Stollberg, Gunnar: op. cit., SS. 288 ff.
} 


\section{6. 2. Der Verein für Gesundheitspflege und arzneilose Heilweise}

\section{6. 2. 1 Vereinsgründung und Tätigkeit}

Zehn Jahre nach der Gründung des "Deutschen Bundes" wurde auch in Einbeck ein Zweigverein gegründet. Am 1. Juli 1899 wurde der "Verein für Gesundheitspflege und arzneilose Heilweise (Naturheilverein) zu Einbeck" aus der Taufe gehoben. ${ }^{746}$ Dieser Vereinsgründung gingen offenbar nicht mehr belegbare Vorbereitungen voraus; der Verein reichte bereits sein Gründungsstatut in gedruckter Form bei den städtischen Behörden ein und war vom Zeitpunkt seiner Gründung an Mitglied im "Deutschen Bund der Vereine für Gesundheitspflege und für arzneilose Heilweise". ${ }^{747}$ Auch belegt $\S 8$ der Statuten die Nähe zum Dachverband. Nach ihm sollte bei einer etwaigen Vereinsauflösung das Vereinsvermögen an den "Deutschen Bund" fallen. 748

Auch die Satzung des neugegründeten Vereins ähnelte derjenigen des Dachverbandes deutlich. ${ }^{749}$ Zweck des Vereins war laut $§ 2$ der Statuten, "den Grundsätzen der naturgemäßen Gesundheitspflege und der arzneilosen Behandlung (Naturheilkunde) von Krankheiten in immer weiteren Kreisen Eingang zu verschaffen, eine gründliche Anleitung zur Erhaltung der Gesundheit zu geben und den Geheimmittelschwindel zu bekämpfen. Er will seine Mitglieder soweit zu belehren suchen, daß sie sich der in reichster Fülle in der Natur dargebotenen Mittel in vernünftiger Weise zur Gesunderhaltung bedienen und bis zur Ankunft des Arztes selbst beraten können. Er will ihnen zeigen, dass Licht, Luft, Wasser, Bewegung, Ruhe, vernünftige Ernährung und zweckmäßige Kleidung die einzigen Mittel sind, um sich gesund zu erhalten und gesund zu werden." 750

Dies sollte nach $\S 3$ erreicht werden

"a. mittelst regelmäßiger Vorträge, Besprechungen, Unterweisungen in den Anwendungsformen der arzneilosen Heilweise,

b. durch Anschaffung entsprechender Bücher, Zeitschriften, sowie einer Badeeinrichtung,

c. durch freie Zusendung der Bundeszeitschrift "Der Naturarzt",

$74{ }^{6}$ StAEin 065 - 10, 1. Juli 1899

747 ibid.

748 ibid.

749 Dies gilt zumindest für jene Teile der Satzungen des "Deutschen Bundes", die Stollberg zitiert, vgl.: Stollberg, Gunnar: op. cit., SS 294 f.

750 StAEin 065 - 10, 1. Juli 1899 
d. soweit zu erreichen durch naturärztliche Beratung der Mitglieder in Krankheitsfällen zu ermäßigten Preisen."751 Nach den statutarisch festgelegten Zwecken und Absichten des Vereins bestand also zum Zeitpunkt der Vereinsgründung ein gleichberechtigtes Nebeneinander der Heilung von Kranken durch naturheilkundliche Therapien einerseits, und der Hygiene im ursprünglichen Sinne, also der vorbeugenden Gesundheitspflege, nach den Lehren der Naturheilkundler andererseits.

In der praktischen Tätigkeit des Vereins stellte sich jedoch rasch ein Übergewicht der vorbeugenden Gesundheitspflege heraus. Ein erster Beleg über einen Vortrag datiert aus dem Jahre 1900752, weitere folgten. Doch die Vortragstätigkeit des Vereins ist für die Folgezeit weder zu qualifizieren noch zu quantifizieren.

Neben der Veranstaltung von Vorträgen begann der Verein rasch, auch praktisch in der vorbeugenden Gesundheitspflege im Sinne der Naturheilbewegung tätig zu werden. In einem Schreiben an den Magistrat aus dem Jahre 1900, in dem der Verein um eine Preisermäßigung für seine Mitglieder in der städtischen Flussbadeanstalt bittet, wird als Hauptvereinszweck die "Abhärtung der Mitglieder in gesunden Tagen, [...] im Wesentlichen durch Baden, und zwar möglichst im Freien" genannt. 753

Kaum zwei Jahre später hatte sich der Verein jedoch bereits von dieser Maxime entfernt und sich den Ideen des oben erwähnten Arnold Rikli angeschlossen. Am 5. März 1902 beantragte man beim Magistrat die Genehmigung zur Anlage eines Licht- und Luftbades an der Hubechaussee außerhalb des bebauten Stadtgebietes. ${ }^{754}$ Aus einer anliegenden Zeichnung geht hervor, dass es sich bei diesem projektierten Bad lediglich um einen knapp 240 Quadratmeter großen Platz handelte, der mit einer Umzäunung gegen neugierige Einblicke und drei "An- und Auskleide"-Kabinen versehen sein sollte. Solche Licht- und Luftbäder waren durchaus keine ungewöhlichen Einrichtungen in Deutschland. Gunnar Stollberg gibt ihre Zahl, allerdings ohne Jahresangabe, mit ungefähr 475 an, $80 \%$ von ihnen im Besitz von Naturheilvereinen. 755 Dennoch gab es seitens des Königlichen Kreisarztes, der vom Magistrat um eine Stellungnahme zu dem Antrag ersucht wurde,

\footnotetext{
$751_{\text {ibid. }}$

752 Vgl.: StAEin 065 - 10, 13. Februar 1909

${ }^{753}$ StAEin 065 - 10, 5. Juni 1900

754 Vgl.: StAEin 065 - 10, 5. März 1902

${ }^{755}$ Vgl.: Stollberg, Gunnar: op. cit., S. 291. Stollberg gibt lediglich die Zahl der "Luftbäder mit Spielplätzen" in Vereinsbesitz und den Anteil an der Gesamtzahl an.
} 
schwerwiegende Bedenken gegen das Projekt. Die Äußerung des Kreisarztes Dr. Buchholtz gibt ein beredtes Beispiel für den oben angedeuteten Gegensatz und das wechselseitige Misstrauen zwischen der Naturheilbewegung und der modernen Schulmedizin. Buchholtz antwortete "mit [...] dem ergebensten Bemerken, daß die Anlage des Licht- und Luftbades zweifellos bestimmt ist zur Heilung von Krankheiten durch Laien.

Solche Anlage kann a priori nur gestattet werden in Verbindung mit einer Heilanstalt, und zwar nur unter ärztlicher Leitung.

Nicht jeder Gesunde verträgt ohne Schädigung Licht- und Luftbäder, geschweige denn ein Kranker. Wer soll da individualisieren? Etwa Laien, deren Urteil durch keinerlei Sachkenntnis getrübt ist?

Selbst in dergl. ärztlich geleiteten Anstalten ereignen sich bei Anwendung von dergl. Bädern unvorhergesehene Zufälle bei den Kranken, die ein sofortiges ärztliches Eingreifen erfordern.

Die Genehmigung der Anlage in der projektierten Weise würde meines Erachtens nur dem Kurpfuschertum mit seinen schädlichen Folgen Vorschub leisten."756

Die städtischen Behörden machten sich die Auffassung des Kreisarztes zu eigen und verweigerten dem Naturheilverein die Genehmigung zur Errichtung des Licht- und Luftbades. Die Begründung hierfür war, dass die projektierte Einrichtung nicht in Verbindung mit einer Heilanstalt unter ärztlicher Leitung geplant war. ${ }^{757}$

Der Verein nahm die Absage nicht ohne Widerspruch hin. In einem neuerlichen Antrag präzisierte man die Zielsetzung und den Charakter eines Licht- und Luftbades wie folgt: "Dasselbe hat mit einer Heilanstalt absolut nichts zu thun, da eine Behandlung von Kranken [...] nicht stattfindet. Das Luftbad ist lediglich ein Sportplatz für die Mitglieder des Naturheilvereins, auf welchem sie sich nach Belieben und in beliebiger Kleidung durch Turnen pp. bewegen können, ohne besorgt zu sein, das Schamgefühl anderer Personen zu verletzen." Als Referenzen für solche Licht- Luftbäder werden ähnliche Einrichtungen in Zeulenroda, Rixdorf, Nowawes, Oranienburg und Colmar genannt. Eine diesbezügliche Nachfrage der Polizeiverwaltung bei den Behörden dieser Orte und Städte ergab zwar, dass die genannten Einrichtungen in Zeulenroda und Oranienburg keine Licht- und Luftbäder waren, aber aus den

${ }^{756}$ StAEin 065 - 10, 22. März 1902

757Vgl.: StAEin 065 - 10, 24. März 1902 
übrigen Kommunen wurden keinerlei negative Erfahrungen berichtet. ${ }^{758}$ Doch auch in einer erneuten Stellungnahme bezog Kreisarzt Dr Buchholtz vehement Stellung gegen das Vorhaben. Er lehnte die Idee, dass regelmäßige Bewegung an der Luft der vorbeugenden Gesundheitspflege dienen könne, ab. Darüber hinaus hegte er den Verdacht, dass die geplante Einrichtung eine getarnte Niederlassung des im zwölf Kilometer entfernt gelegenen Dorf Lüthorst ansässigen Naturheilers August Ebbecke werden sollte. Dieser Ebbecke unterhielt in Lüthorst seit 1888 eine staatlich konzessionierte Anstalt, in der er Kuren nach Schroth, Kneipp und Prießnitz anbot. ${ }^{759}$ In dem Gutachten des Kreisarztes heißt es: "Ein Sport, der darin gipfelt, daß seine Mitglieder sich auf ihrem sogenannten Sportplatz in möglichst adamitischem Kostüm versammeln, kann nicht als Sport, sondern muß als Unfug bezeichnet werden. Zur Hebung des körperlichen Wohlbefindens und zur allgemeinen Kräftigung des Körpers kann solch Unfug nicht beitragen.

Ich halte nach wie vor an der Ueberzeugung fest, daß die Einrichtung zur Krankenbehandlung für den Kurpfuscher Ebbecke-Lüthorst bestimmt ist, welcher hier eine Concession dazu nicht zu erwarten hat, weßwegen auf Umwegen durch den Naturheilverein solche erstrebt wird." 760

Auf Seiten der Stadt war man durchaus geneigt, sich der Ablehnung Buchholtz' anzuschließen. Dies belegt der Entwurf eines ablehnenden Bescheides an den Verein, in dem verschiedene Formulierungen des Kreisarztes übernommen waren. ${ }^{761}$ Doch weder dieser, noch irgend ein anderer Bescheid wurden an den Verein abgeschickt. Erst als der Vorsitzende des Naturheilvereins, Hahndorf, erneut um Genehmigung der Anlage nachsuchte ${ }^{762}$, befassten sich die Behörden erneut mit der Angelegenheit. Unsicher darüber, wie in der Sache zu verfahren sei, wandte man sich schriftlich an den Königlichen Regierungspräsidenten in Hildesheim mit der

\footnotetext{
758Vgl.: StAEin 065 - 10, 28. April 1902; 1. Mai 1902; 2. Mai 1902; 3. Mai 1902; 13. Mai 1902

${ }^{759}$ Vgl.: Rohmeyer, Berthold: Geschichte von Lüthorst und Portenhagen. Zugleich ein Beitrag zur Geschichte des ehemaligen Amtes, Gerichtes und der Parochie Luthardessen mit ihren vergangenen 7 Dörfern und eine Darstellung der Beziehungen Wilhelm Buschs zu Lüthorst als seiner zweiten Heimat und Dassel. 2. erw. Auflage unter Mitarbeit von Wilhelm Overdick. Dassel 1978, S.303. Verbindungen des Vereins mit dem genannten Ebbecke sind nicht nachweisbar.

760 StAEin 065 - 10, 3. Mai 1902.

${ }^{761}$ Vgl.: StAEin 065 - 10, 6. Mai 1902

762Vgl.: StAEin 065 - 10, 30. Mai 1902
} 
Bitte, dass dieser über die Erteilung einer Baugenehmigung entscheiden solle. ${ }^{763}$ Der Regierungspräsident sah, auch wenn er die Einwände des Kreisarztes teilte und eine scharfe sittenpolizeiliche Überwachung der Anlage empfahl, keine gesetzliche Möglichkeit, den Antrag des Vereins abzulehnen. ${ }^{764}$ Das Licht- und Luftbad konnte gebaut werden.

Das neu geschaffene Licht- und Luftbad wurde in den folgenen Jahren eine sehr beliebte Einrichtung. Die Mitgliedszahl des Naturheilvereins nahm stark $\mathrm{zu}$; zudem wurde das Bad auch von auswärtigen Benutzern, die nicht dem Verein angehörten, frequentiert. ${ }^{765}$ Aufgrund der großen Nachfrage sah sich der Naturheilverein im Jahre 1907 genötigt, die Anlage auf etwa die doppelte Größe zu erweitern. ${ }^{766}$ Die Bedenken des Kreisarztes hatten sich in der Zwischenzeit zerstreut; Dr. Buchholtz äußerte keinerlei sanitätspolizeiliche Bedenken mehr. ${ }^{767}$

Doch trotz des großen Erfolges konnte das Luftbad an der Hubechaussee nicht dauerhaft bestehen. Das Wachstum der Stadt Einbeck führte dazu, dass 1909 die Bebauungsgrenze das Bad erreichte. Dies machte zunächst eine Erhöhung des Sichtschutzzaunes erforderlich, doch bereits 1909 kam der Magistrat der Stadt zu der Auffassung, dass die Anlage möglichst bald verlegt werden müsse. ${ }^{768}$ Zunächst sträubte sich der Verein gegen diese Idee. Man sah sich wirtschaftlich außer Stande, einen Neubau zu errichten. ${ }^{769}$ Doch bereits im Jahre 1910 wurde dann ein Neubau geplant und errichtet. Aus verschiedenen möglichen Bauplätzen wurde ein als "Wittramscher Kamp" bezeichnetes Flurstück ausgewählt. Dieses Grundstück lag nordwestlich des bebauten Stadtgebietes am Kuventhaler Weg unweit des Krummen Wassers, aus dem auch das Wasser für die sanitären Einrichtungen entnommen wurde. 770

Das neue Licht- und Luftbad, welches bereits am 1. Mai des Jahres eingeweiht werden konnte, übertraf das vormalige an der Hubechaussee in seiner Ausdehnung; es umfasste etwa 600 Quadratmeter umfriedeten

\footnotetext{
763Vgl.: StAEin 065 - 10, 31. Mai 1902

764 Vgl.: StAEin 065 - 10, 4. Juni 1902

765 Vgl.: StAEin 065 - 10, 18. März 1907

766 Vgl:: ibid.

767Vgl.: StAEin 065 - 10, 4. April 1907

${ }^{768}$ Vgl.: StAEin 065 - 10, 15. September 1909

${ }^{769}$ Vgl.: ibid.

770 Vgl. zum Neubau insgesamt: StAEin 065 - 10, 7. Januar 1910; 12. Februar 1910; 8. März

1910 und die dazugehörige Anlage; 10. März 1910
} 
Raum. ${ }^{771}$ Ausgestattet war es mit Turngeräten und Wasseranlagen, ferner einer Überdachung, die Luftbäder bei ungünstiger Witterung zuliess und Ruhebänken für Sonnenbäder. 772

Das Bad war weit über den eigentlichen Naturheilverein hinaus beliebt. Es wurde von zahlreichen Gymnasiasten und Präparanden genutzt, auch die Turner des MTV Einbeck benutzten es regelmäßig. ${ }^{773}$ Auch blieb das Lichtund Luftbaden nicht mehr allein den Männern vorbehalten. Vormittags von 9 bis 11 Uhr und nachmittags von 15 bis 17 Uhr waren im neuen Luftbad Badezeiten ausschließlich für Frauen und Mädchen eingerichtet worden. 774 Doch diese wenigen Stunden reichten schon bald nicht mehr aus, um das wachsende Bedürfnis der weiblichen Bevölkerung nach Bewegung im Freien zu befriedigen. Im Jahre 1911 wurde daher der Bau eines separaten Licht- und Luftbades für Frauen neben dem bestehenden Bad geplant. Dieses Bad, etwa 430 Quadratmeter umfassend und mit einer Duschanlage versehen, wurde noch im Frühjahr 1911 errichtet und am 21. Mai 1911 eingeweiht. Erstmals hatte sich der Magistrat bereit gefunden, den Bau einer solchen Anlage mit 200 Mark, ungefähr 40 v. H. der gesamten Bausumme, zu unterstützen. 775

Innerhalb der 13 Jahre seit Gründung des Naturheilvereins hatte sich also das Verhältnis der städtischen Behörden zum Verein und seinen Anschauungen über die Nützlichkeit der vorbeugenden Gesundheitspflege grundlegend gewandelt. In der Genehmigungsphase des ersten Licht- und Luftbades hatten sich die Behörden noch die Ressentiments eines Schulmediziners gegen die neuen Ideen der Hygiene zu eigen gemacht. Doch nur wenig mehr als zehn Jahre später mochte man sich städtischerseits der Argumentation des Vereinsvorstandes über den Nutzen der Licht- und Luftbäder nicht mehr verschließen. Dieser erklärte in einem Schreiben an den Magistrat, "daß die körperliche Bewegung in frischer Luft, besonders in unbekleidetem Zustande, das beste Mittel zur Erhaltung der Gesundheit, Abhärtung gegen schädliche Einflüsse, insbesondere auch gefährliche Seuchenkrankheiten" sei, und "daß demnach nicht nur die Luftbäder im Interesse der persönlichen Gesundheitspflege liegen, sondern auch von einschneidender Bedeutung für die öffentliche Gesundheitspflege sind, und nicht zuletzt zu einem ganz

\footnotetext{
${ }^{771}$ Vgl:: StAEin 065 - 10, Anlage zu 8. März 1910

772 Vgl.: Südhannoversche Zeitung, 30. April 1910

773 Vgl.: StAEin 065 - 10, 24. März 1911

774 Vgl:: ibid.

${ }^{775}$ Zum gesamten Bauprojekt Damenbad vgl.: StAEin 065 - 10, 24. März 1911; 20. April

1911; 18. Mai 1911
} 
erheblichen Teil zur Erhaltung der Wehrkraft und Heranbildung einer kräftigen Generation beitragen." 776

\section{6. 2. 2 Zur Mitgliederstruktur des Vereins}

Über die Mitgliederentwicklung des Naturheilvereins Einbeck sind keine präzisen Angaben zu machen. Über die Zahl der Gründungsmitglieder ist nichts bekannt. Allein der Umstand, dass bereits die Gründungssatzung in gedruckter Form bei den Behörden eingereicht wurde und dass der Verein von seiner Gründung an Mitglied im "Deutschen Bund" der Naturheilvereine war, lässt vermuten, dass die Zahl der Gründungsmitglieder nicht gering war. Auf jeden Fall hat sie, anders als bei anderen Vereinen, ausgereicht, um mit dem Eintrittsgeld der Gründungsmitglieder von einer Mark pro Person 777 vom Moment der Gründung an eine funktionierende Vereinsstruktur zu errichten und darüber hinaus Gebühren an einen Dachverband entrichten zu können.

Auch für die weiteren Jahre sind keine Mitgliedszahlen überliefert, erst aus einem Schreiben des Vereins aus dem Jahre 1907 erfahren wir von "einer starken Zunahme der Mitgliederzahl". 778

Die einzige überlieferte Mitgliedsliste stammt aus dem Jahre 1909. 779 Diese Mitgliederliste erlaubt fundierte Aussagen über die Mitgliederstruktur des Naturheilvereins. Zu diesem Zeitpunkt umfasste der Verein 128 Mitglieder. Mit dieser Zahl lag er etwas unter der Durchschnittsgröße der deuschen Naturheilvereine, die 1906149 und 1910167 Mitglieder je Verein betrug. ${ }^{780}$ Zieht man jedoch in Betracht, dass es insbesondere in den Großstädten Vereine mit mehreren Hundert bis über Tausend Mitgliedern gab, die den Durchschnitt deutlich anhoben, so ist $\mathrm{zu}$ konstatieren, dass die Mitgliederzahl des Naturheilvereins, übrigens auch im Vergleich mit anderen Vereinen in Einbeck, eine bemerkenswerte Größe aufwies. ${ }^{781}$

In der Mitgliederschaft stellten die Männer die große Mehrheit. Die fünf dem Verein angehörenden Frauen stellten eine Minderheit von etwa 3,9 v. H.

\footnotetext{
776 StAEin 065 - 10; 24. März 1911

777 Vgl.: StAEin 065 -10, 1. Juli 1899

778 StAEin 065 -10, 18. März 1907

${ }^{779}$ StAEin 065 - 10, 15. September 1909, Anlage

${ }^{780}$ Errechnet nach Stollberg, Gunnar: op. cit., Tab. 1, S. 289

${ }^{781} \mathrm{Zu}$ den anderen Naturheilvereinen vgl.: Stollberg, Gunnar: op. cit., SS. 290 f., zu den anderen Einbecker Vereinen siehe die entsprechenden Angaben in der vorliegenden Arbeit, passim.
} 
dar, doch belegt der Bau eines separaten Damenbades, dass weit mehr als die genannten fünf Frauen die Anlagen des Naturheilvereins genutzt haben. ${ }^{782}$

Die Sozialstruktur des Naturheilvereins Einbeck stellte sich im Jahre 1909 wie folgt dar: 783

$\begin{array}{lll}\text { Gruppe } & \text { Zahl absolut } & \text { Anteil in v. H. } \\ \text { Kaufleute } & 38 & 29,7 \\ \text { Handwerker } & 25 & 19,5 \\ \text { Beamte und Lehrer } & 20 & 15,6 \\ \text { Angestellte } & 14 & 10,9 \\ \text { Gastwirte } & 9 & 7,0 \\ \text { Rentiers } & 6 & 4,7 \\ \text { Sonstige Männer } & 11 & 8,6 \\ \text { Frauen } & 5 & 3,9\end{array}$

Ein Vergleich mit der sozialen Zusammensetzung aller in Vereinen des Dachverbandes organisierten Mitglieder ergibt für die Sozialstruktur des Naturheilvereins Einbeck eine deutliche Abweichung vom Reichsdurchschnitt, in dem etwa 30 v. H. der Vereinsmitglieder Handwerker waren, die Kaufleute nur rund $15 \mathrm{v}$. H. der Mitglieder stellten und der einen Arbeiteranteil von etwa 25 v. H. aufwies. Einzig der Beamtenanteil und der Lehreranteil an der Mitgliedschaft entsprach mit zusammen knapp 16 v. H. ungefähr dem Reichsdurchschnittswert von etwa 18 v. H.. ${ }^{784}$

Im Falle des Einbecker Naturheilvereins war also das Bürgertum stärker repräsentiert. Auch der Einwand, dass viele Arbeiter, also Menschen in einer proletarischen Lebenslage, in Statistiken und Berufszählungen des Untersuchungszeitraums vielfach nicht als Arbeiter, sondern als Handwerker genannt werden, ist im vorliegenden Falle allenfalls von geringer Bedeutung. Von den in der Mitgliedsliste genannten 25 Handwerkern waren neun Handwerksmeister, weitere acht waren hoch qualifizierte Handwerker wie Uhrmacher, Goldschmied oder Mechaniker, teilweise mit eigenem Betrieb.

\footnotetext{
${ }^{782}$ Wie oben bereits erwähnt, gilt diese Aussage allerdings auch für die männliche Benutzerschaft desLicht- und Luftbades.

783 Alle Angaben ermittelt und errechnet nach oben zitierten Liste, welche auch die zeitgenössischen Berufsbezeichnungen enthält.

784 Alle Vergleichszahlen für den Reichsdurchschnitt finden sich bei Stollberg, Gunnar: op. cit., S. 294. Sie beziehen sich auf den Zeitraum von 1908 bis 1912 und bleiben so vage, wie sie oben wiedergegeben sind.
} 
Selbst wenn man die übrigen acht Handwerker als Arbeiter rechnete, zu diesen die zwei Gehilfen aus der Gruppe der Kaufleute, weitere drei Gehilfen aus der Gruppe der Angestellten und einen Invaliden aus der Kategorie "Sonstige" addierte, so käme man auf einen Maximalwert von 18 Vereinsmitgliedern (14,0 v. H.), die man als Arbeiter bezeichnen könnte. Faktisch waren es vermutlich deutlich weniger.

Auf der anderen Seite war das gehobene Bürgertum sehr stark im Naturheilverein vertreten. Selbst wenn man die Handwerksmeister, die hohen Beamten und die Kaufleute nicht in die Berechnungen miteinbezieht, so addieren sich die genannten sechs Rentiers mit einem Mühlen-, einem Brauereibesitzer, drei Fabrikanten, einer Verlegerin, einem Großbauern 785 und dem unzweifelhaft höchst vermögenden Kaufmann August Stukenbrok 786 zu einem Kreis von 14 Personen, das Besitzbürgertum machte also mindestens 11 v. H. der Mitglieder des Vereins aus. Angesichts der vorstehenden Einschränkungen dürfte der Anteil an Besitzbürgern deutlich höher gewesen sein.

Zusammenfassend lässt sich also sagen, dass der Naturheilverein ein nahezu ausschließlich bürgerlicher Verein war, der eher vom Groß- als vom Kleinbürgertum dominiert war, aber innerhalb des Bürgertums eine gewisse Integrationswirkung hinsichtlich der Zusammenführung von Besitz- und Bildungsbürgern mit der noch im Entstehen begriffenen Gruppe der Angestellten hatte. Dies geht auch aus der Zusammensetzung des Vorstandes $\mathrm{zu}$ jener Zeit hervor, aus welcher die der Erstellung der vorstehenden Strukturanalyse zu Grunde liegende Mitgliederliste stammt. Langjähriger Vorsitzender war ein Bürovorsteher, mithin ein leitender Angestellter, dem als weitere Vorstände zwei Rentiers zur Seite standen. ${ }^{787}$

$\mathrm{Ob}$ die Sozialstruktur des Vereins mit ihrem relativ großen Anteil von Personen sowohl aus dem Wirtschafts- als auch aus dem Bildungsbürgertum dazu beitrug, die anfängliche Ablehnung des Vereins und seiner Aktivitäten durch die städtischen Behörden binnen kurzer Zeit in eine fördernde Akzeptanz umzuwandeln, muss allerdings Spekulation bleiben.

\footnotetext{
${ }^{785}$ Die genannten Personen erscheinen in der vorstehenden Statistik unter "Sonstige"

786 Stukenbrok war Besitzer des größten deutschen Versandhauses. Er dürfte der wohlhabendste Privatmann Einbecks in jener Zeit gewesen sein. Zu August Stukenbrok und seinem Versandhaus vgl.: Hülse, Horst: Einbeck in der Gründerzeit. in: Einbecker Geschichtsverein (Hg.): Geschichte der Stadt Einbeck. Band 2: Vom Ende des 18. Jahrhunderts bis zum Ende des zweiten Weltkrieges. Einbeck 1992, SS. 71 - 138, hier SS. 96 f.

787 Vgl.: StAEin 065 - 10, passim
} 


\section{7. Das Militärvereinswesen}

\section{7. 1. Die Militärvereine in Preußen und im Reich}

In der Literatur und den meisten zeitgenössischen Quellen788 werden die Militärvereine in Deutschen Kaiserreich generell als "Kriegervereine" bezeichnet. Diese Bezeichnung ist jedoch für den gesamten Untersuchungszeitraum nicht präzise genug, um das Militärvereinswesen in seiner Gesamtheit treffend $\mathrm{zu}$ charakterisieren. Die Jahre von der Reichsgründung 1871 bis zum Beginn des Ersten Weltkrieges 1914 stellten eine 43-jährige Friedenszeit dar. Die Militärvereine, die nicht unmittelbar am Beginn dieser Periode gegründet wurden, setzten sich häufig aus ehemaligen Wehrdienstleistenden zusammen, die, wie dies auch verschiedene Vereinsnamen belegen, nie aktiv an einem Krieg teilgenommen hatten. Daher scheint der Begriff des Militärvereins dem Forschungsgegenstand angemessener zu sein.Für die Entstehungs- und die erste Ausbreitungsphase dieses Vereinstyps als umfassender Massenbewegung trifft die Bezeichnung "Kriegervereine" zu, da es sich bei den Vereinsgründern und -mitgliedern um Veteranen der so genannten Reichseinigungskriege handelte.

Den Beginn des Militärvereinswesens markiert das Jahr 1746. In diesem Jahr gründeten 40 ehemalige Füsiliere eines preußischen Infanterieregiments mit Genehmigung Friedrichs II. in Wangerin einen ersten Veteranenverein. ${ }^{789}$ Weitere Kriegervereine in Deutschland wurden nach den Befreiungskriegen gegen das napoleonische Frankreich von Kriegsveteranen gegründet. Die Hauptaufgabe dieser Vereine war es, den Mitgliedern nach deren Ableben ein ehrenvolles Begräbnis zu veranstalten. ${ }^{790}$ In dieser Funktion wurden die Kriegervereine in Preußen in den vierziger jahren durch Allerhöchste Cabinetsordres privilegiert, die im Untersuchungszeitraum der vorliegenden Arbeit noch Gültigkeit hatten. ${ }^{791}$ Nach den so genannten Einigungskriegen

\footnotetext{
788 Nicht in allen Quellen; beispielsweise ist in $\S 23$ des revidierten Statuts des Landwehrund Reservevereins zu Einbeck von "Militär-Vereinen" die Rede.

${ }^{789}$ Auf dieses Datum beruft sich der Kyffhäuserbund e. V., die Information entnahm der Autor der Internetseite des Verbandes, http://www.kyffhaeuserbund.de/, Stand November 1999 790Vgl.: Rohkrämer, Thomas: Der Militarismus der "kleinen Leute". Die Kriegervereine im Deutschen Kaiserreich 1871 - 1914. (Beiträge zur Militärgeschichte Band 29), München 1990, S. 27

${ }^{791}$ Vgl:: Baron, Josef: Das deutsche Vereinswesen und der Staat im 19. Jahrhundert. Jur. Diss., Göttingen 1962, SS. 107 ff. und STAEin 065 - 18, 28. Juni 1878
} 
1864, 1866 und 1870/71 entstanden unter dem Eindruck des Sieges und der Gründung des Kaiserreiches Kriegsteilnehmer im gesamten Reich lokale Veteranenvereine. ${ }^{792}$ Auch diese Vereine hatten die Zielsetzung, den Vereinsmitgliedern bei deren Tod eine Beerdigung mit militärischen Ehren auszurichten. Daneben sollte in diesen Kriegervereinen das gemeinsame Andenken an die Reichsgründungskriege wach gehalten und der nationale Gedanke gepflegt werden. ${ }^{793}$ Die Kriegervereinsbewegung breitete sich rasch aus und gewann den Charakter einer gesellschaftlich relevanten Massenbewegung. ${ }^{794}$ Bereits im Jahre 1873 wurde in Preußen der "Deutsche Kriegerbund" gegründet, der darauf ausgelegt war, sich zu einem reichsweiten Dachverband zu entwickeln. Doch dieses Vorhaben scheiterte, obwohl staatlicherseits und sogar vom Kaiser ein Zusammenschluss aller deutschen Kriegervereine als wünschenswert erachtet wurde. Vor allem Landesverbände der mittel- und süddeutschen Bundesstaaten verhinderten die Ausbreitung des preußischen "Deutschen Kriegerbundes" auf das gesamte Reichsgebiet. Dieses Faktum erkannte nach einer mehrjährigen konfliktreichen Phase der "Deutsche Kriegerbund" an und gab alle das gesamte Reichsgebiet betreffenden Ambitionen auf. 1897 wurde der "Preußische Landeskriegerverband" aus der Taufe gehoben.

Die Frage einer reichsweiten Kooperation und Koordinierung der Militärvereine hatte sich in der Zwischenzeit anderweitig gelöst. 1888 wurde im Vorstand des deutschen Kriegerbundes die Errichtung eines KaiserWilhelm-I.-Denkmals auf dem Kyffhäuserberg in Thüringen in Anregung gebracht. Dieser Vorschlag fand in allen Landeskriegerverbänden Anklang, und es bildete sich ein gemeinsamer Ausschuss für dieses Projekt, in dem sämtliche Landesverbände vertreten waren. Aus diesem Ausschuss ging im Jahre 1892, dem Jahr des Baubeginns, ein ständiger Ausschuss für die Verwaltung des Denkmals hervor, in dem ebenfalls alle Landeskriegerverbände vertreten waren. 1897 erhielt dieser Ausschuss die Kompetenz, "auch andere, die allgemeinen Interessen des deutschen Kriegervereinswesens berührende Fragen"795 beraten zu dürfen. 1899 ging aus dem Verwaltungsausschuss der Kyffhäuserbund der Deutschen Landes-Kriegerverbände hervor, in dem die jeweiligen Landesverbände in dem gleichen Maße repräsentiert waren, wie auf

\footnotetext{
792 Vgl.: Nipperdey, Thomas: Deutsche Geschichte 1866 - 1918. Zweiter Band: Machtstaat vor der Demokratie. München 1992, S. 232

793 Vgl.: Rohkrämer, Thomas: op. cit., SS. 17 f.

794 Vgl.: ibid., S. 27

${ }^{795}$ Zitiert nach Rohkrämer, Thomas: op. cit., S. 30
} 
der politischen Ebene das jeweilige Land im Bundesrat. ${ }^{796}$ Damit hatte das Militärvereinswesen seine endgültige Organisation erhalten.

Das Beziehungen der staatlichen Behörden zu den Militärvereinen waren in Preußen sehr eng. Einerseits genossen die Militärvereine, wie oben erwähnt, besondere staatliche Privilegien, die ihnen in der Öffentlichkeit eine bevorzugte Sonderstellung gegenüber allen anderen Vereinen einräumten. Doch diesen Privilegien standen auch besondere Verpflichtungen gegenüber den Behörden gegenüber.

Anders als alle anderen Vereine durften sich die Militärvereine nicht ohne weiteres eine Fahne anschaffen und diese in der Öffentlichkeit führen. Hierfür bedurfte es einer "Allerhöchsten Genehmigung", also formal einer Genehmigung durch den Kaiser und König, faktisch durch die preußischen Ministerien für Inneres und Krieg. Bei den Militärvereinen war, wie unten gezeigt werden wird, auch in Einbeck, das ohnehin bei den meisten Vereinen der damaligen Zeit vorhandene Bedürfnis nach einer Vereinsfahne ${ }^{797}$ auf Grund des militärischen Charakters besonders stark ausgeprägt. Dies gab den Behörden die Möglichkeit an die Hand, an die Genehmigung zur Führung einer Fahne Bedingungen zu knüpfen und auf diese Weise steuernd in das Militärvereinswesen einzugreifen. Eine Auszählung der im Stadtarchiv Einbeck erhaltenen, das Militärvereinswesen betreffenden Anweisungen der Preußischen Ministerien an die nachgeordneten Behörden ergab, dass von den 127 vorliegenden Rundschreiben 59, also annähernd die Hälfte, das Thema Fahnenführung und -gestaltung behandelten. 798

Die über das Recht zur Fahnengenehmigung und -entziehung ausgeübten staatlichen Einflüsse auf das Militärvereinswesen verfolgten zweierlei Zielsetzungen. Zum Einen sollte das preußische Militärvereinswesen eine einheitliche Struktur erhalten; das Recht zur Führung einer Fahne konnte nur ein Verein haben, der Mitglied im Deutschen Kriegerbund respektive im Preußischen Landeskriegerverband war. Ab 1891 galt für die Mitgliedsvereine des Dachverbandes eine einheitliche Normalsatzung. ${ }^{799}$

\footnotetext{
796Vgl.: ibid.

${ }^{797}$ Ernst Schubert weist auf die hohe Bedeutung von Fahnen für die Vereine des 19. Jahrhunderts deutlich hin, vgl. hierzu: Schubert, Ernst: Die Veränderung eines Königreichs. in: Hucker, Bernd Ulrich u. a. (Hgg.): Niedersächsische Geschichte. Göttingen 1997, SS. 374 -

418, S. 411

${ }^{798}$ Vgl.: StAEin $065-18$

${ }^{799}$ Vgl.: StAEin 065 - 18, 31. Juli 1991
} 
Eine andere Zielsetzung war es, die Militärvereinsbewegung zur Bekämpfung von dem Preußischen Staat unliebsamen politischen Strömungen zu instrumentalisieren. Die Behörden sahen das Streben nach Fahnen seitens der Militärvereine als ein wirksames Mittel im Kampf gegen innere Gegner des Staates an. 800 Dieser Kampf galt ab 1890, dem Jahr des Außerkrafttretens des Sozialistengesetzes, vor allem der Sozialdemokratie. Diese Bewegung liess sich nach Ansicht der Behörden nicht vereinbaren mit dem nach der Normalsatzung für Militärvereine obligatorischen Vereinszweck, "die Liebe und Treue für Kaiser und Reich, Landesfürst und Vaterland bei seinen Mitgliedern zu pflegen, zu betätigen und zu stärken." 801 Vereinen, welche Anhänger der Sozialdemokraten in ihren Reihen duldeten, wurde angedroht, dass sie, wenn sie die entsprechenden Personen nicht ausschlössen, des Rechtes zur Fahnenführung und aller weiteren Privilegien verlustig gingen. 802

Neben der Bekämpfung der Sozialdemokratie sollten die Militärvereine in der Provinz Hannover als ein Mittel der Borussifizierung des vormaligen Königreiches Hannover dienen. In Bezug auf die organisierte welfische Bewegung galt in diesem Falle das oben über den Kampf gegen die Sozialdemokraten Gesagte. ${ }^{803}$ Darüber hinaus bestanden in Preußen zahlreiche Vorschriften bezüglich der Gestaltung der Vereinsfahnen der Militärvereine, die als Indizien für die Borussifizierungsbestrebungen in Bezug auf das annektierte Königreich Hannover wie auch andere preußische Provinzen angesehen werden können. Diese sahen $\mathrm{zu}$ Beginn des Untersuchungszeitraumes als Emblem den preußischen Adler vor und untersagten die Verwendung des Reichsadlers.804 Später wurden Reichssymbole zwar zugelassen, jedoch nur für den Fall, dass der Preußenadler das Hauptelement der Fahne darstellte. ${ }^{805}$ Symbole, die auf andere Länder oder einzelne Provinzen hindeuteten, bedurften einer besonderen behördlichen

800 Vgl.: StAEin 065 - 18, Rundschreiben der übergeordneten Verwaltungsbehörden vom 23. Januar 1892

${ }^{801}$ Statutenpassus zitiert nach Druckexemplar der revidierten Statuten des Landwehr- und Reservevereins Einbeck, StAEin 065 - 31, 17. Mai 1903

802 Vgl:: StAEin 065 - 18, Rundschreiben der übergeordneten Verwaltungsbehörden vom 9.

August 1890

${ }^{803}$ Das in Anmerkung 13 genannte Schriftstück behandelt den Kampf gegen

Sozialdemokraten und Welfen als ein und dieselbe Aufgabe.

804 Vgl.: StAEin 065 - 18, 5. September 1873

805 Vgl.: StAEin 065 - 18, 21. März 1879 
Genehmigung. ${ }^{806}$ Es war also den Kriegervereinen in Preußen unmöglich, in ihrer Fahne einen symbolischen Bezug auf das annektierte Königreich Hannover wie auch andere ehemals selbständige Länder und nunmehrige preußische Provinzen zu nehmen. Auch eine ausschließlich reichspatriotische Gesinnung durfte nicht symbolisiert werden. 


\section{7. 2. Der Kriegerverein Einbeck}

Weniger als ein Jahr nach dem Deutsch-Französischen Krieg konstituierte sich in Einbeck unter dem Eindruck des Sieges und der Reichsgründung der Kriegerverein Einbeck. In der Präambel zu seiner Satzung heißt es dazu: "Die wichtigen Ereignisse in den Jahren 1870 und 1871 und die glänzenden Waffenthaten unseres Heeres haben bei vielen in der hiesigen Stadt wohnenden Kriegern den Wunsch hervorgerufen, sich zur Pflege des Nationalgefühls und des kameradschaftlichen Geistes periodisch $\mathrm{zu}$ versammeln. Um diesem Zwecke eine allgemeine Grundlage zu gewähren, wurde die förmliche Bildung eines Krieger-Vereins am 19. Februar 1872 beschlossen." 807 Neben der Pflege der patriotischen Gesinnung und der Kameradschaft unter den ehemaligen Soldaten machte es sich der Verein zur Aufgabe, verstorbenen Mitgliedern eine ehrenvolle Beerdigung auszurichten. 808

Als Mitglieder kamen nur solche ehemalige Soldaten in Betracht, die aktiv an den "Feldzügen" der Jahre 1864, 1866 und 1870/71 teilgenommen hatten und sich nicht mehr im stehenden Heer befanden. Der sich zur Aufnahme Anmeldende musste im Besitz der militärischen und bürgerlichen Ehrenrechte sein. ${ }^{809}$ Unerheblich für die potenzielle Mitgliedschaft war, in welchem Heer der betreffende Veteran gedient hatte. 810

Bereits einen Monat nach seiner Gründung trat der Verein bei einem Festumzug anlässlich des fünfundsiebzigsten Geburtstages Kaiser Wilhelms I. erstmals an die Öffentlichkeit. Bei dieser Gelegenheit erwachte der Wunsch des Vereins, eine Fahne führen $\mathrm{zu}$ wollen. ${ }^{811} \mathrm{Da}$ jedoch der eingereichte Entwurf nicht mit den Bestimmungen über die Gestaltung der Kriegervereinsfahnen in Preußen übereinstimmte, konnte bis zum Sedantag 1872 lediglich eine vorläufige Ausnahmegenehmigung zur Fahnenführung

807 Zitiert nach einem Druckexemplar der Statuten, StAEin 065 - 19, 22. Dezember 1899, frühere Statuten sind nicht erhalten.

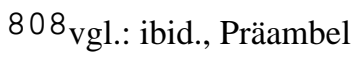

809 Vgl.: ibid., $\$ 1$

810 Dieser Umstand deckt sich mit Erlebnisberichten aus dem Krieg 1866, in denen vielfach der kameradschaftliche Umgang zwischen Soldaten der preußischen und der hannoverschen Armee betont wird. Vgl. hierzu e. g.: Steinberg, Georg: Beim 3. Jägerbataillon. Herausgegeben und mit einem Nachwort versehen von Rainer Sabelleck. (Jüdische Bibliothek, Band 1). Mannheim 1991, passim, und Freudenthal, Friedrich: Von Lüneburg nach Langensalza. 2.

Auflage 1895, Reprint Bremen 1999, passim

811 Vgl.: StAEin 065 - 19, 27. April 1872 
durch die Landdrostei in Hildesheim erlangt werden ${ }^{812}$; die eigentlich erforderliche "Allerhöchste Genehmigung" wurde nachträglich im Januar 1873 erteilt. 813

Über die weiteren Aktivitäten des Kriegervereins Einbeck in der Folgezeit ist nur wenig überliefert. Noch für das Gründungsjahr ist die Absicht nachzuweisen, regelmäßige Schießübungen durchzuführen.814 Ob diese allerdings überhaupt in die Tat umgesetzt wurde, ist nicht bekannt. Im Jahre 1892 bildete der Verein eine Sanitätskolonne. Dies war nicht die erste Sanitätskolonne des Vereins, doch ihre Vorgängerin ist nicht mehr nachweisbar. Die wiedergegründete Kolonne umfasste 17 Mann, etwa 20 v. H. der Vereinsmitglieder. ${ }^{815}$ Die Bildung solcher Sanitätskolonnen war in den Militärvereinen durchaus nicht unüblich. Im Bereich des Deutschen Kriegerbundes gab es 1891193 solcher Einrichtungen mit 4.406 Mitgliedern. Diese Zahl wuchs im Laufe der neunziger Jahre beständig an. Diese Sanitätskolonnen hatten einen paramilitärischen Charakter. Auch wenn sie in der Friedenszeit bei zivilen Unglücken Hilfe leisteten, so war die eigentliche Zielrichtung ihrer Gründung die Vorbereitung auf einen eventuellen Kriegsfall, in dem diese Kolonnen dem Roten Kreuz unterstellt werden sollten. ${ }^{816}$

Den paramilitärischen Charakter des Kriegervereins kann auch seine Bewaffnung belegen. Der Verein oder seine Mitglieder verfügten über mehrere Gewehre, um bei Beerdigungen seiner Mitglieder über dem offenen Grab Salut zu feuern. ${ }^{817}$ Spätestens 1894 erwarb der Verein auch schwerere Feuerwaffen. In diesem Jahr beantragte der Vorsitzende Danert beim Magistrat, "die Genehmigung der Aufstellung der dem Kriegerverein gehörigen Geschütze in der Rathaushalle", die auch erteilt und vollzogen wurde. 818

Im Jahre 1876 erweiterte der Verein seine Statuten dahingehend, dass neben der Pflege patriotischen und militärischen Gedankengutes und der Veranstaltung von Begräbnissen für verstorbene Vereinsmitglieder eine

\footnotetext{
812 Vgl.: StAEin 065 - 19, 29. August 1872

813 Vgl.: StAEin 065 - 19, 15. Januar 1873

814 Vgl.: StAEin 340 - 1, 14. März 1872

815 Dieser Wert konnte nur näherungsweise errechnet werden, die Zahl der

Kolonnenmitglieder datiert aus dem Jahre 1892, die einzige Mitgliederzahl des Kriegervereins stammt von 1896.

$816 \mathrm{Zu}$ den quantitativen Angaben wie zur Gründungsintention von Sanitätskolonnen vgl.:

Rohkrämer, Thomas: op. cit., S. 73

${ }^{817}$ Vgl.: Statuten des Vereins, StAEin 065 - 19, passim

818StAEin 065 - 19,28. Juli 1894 ff.
} 
Armen- und Krankenunterstützung für bedürftige Vereinsmitglieder ein Teilzweck des Vereins wurde. ${ }^{819}$

Ohne weitere nachweisbare Kontakte zu den Behörden vergingen die folgenden Jahre. Der Verein pflegte und betätigte, wie es in einem späteren Gutachten des Bezirkskommandos in Göttingen heißt, "stets königstreue und patriotische Gesinnung"820; zu Kontakten oder gar Konflikten zwischen Verein und Behörden gab es offensichtlich keinen Anlass. Erst nach 1890 folgten verschiedene, von den Behörden veranlasste, Änderungen der Statuten, auch solche, die, wie in der Einführung bereits erwähnt, sich gegen Anhänger der Sozialdemokratie und der Welfenpartei richteten. ${ }^{821}$ Diese Änderungen wurden ohne Diskussionen vom Verein vollzogen. Als anlässlich der Reichstagswahlen des Jahres 1890 drei Mitglieder des Kriegervereins in den Verdacht gerieten, sich am Wahlkampf des sozialdemokratischen bzw. welfischen Kandidaten beteiligt zu haben, wurden diese drei Personen nach Rücksprache Bürgermeister Grimsehls mit dem Vereinsvorstand umgehend aus dem Verein ausgeschlossen, wodurch, wie es in einem Bericht des Magistrats an die Landdrostei heißt, "in weiten Kreisen ein äußerst günstiger Eindruck hervorgerufen wurde". 822

Die Beziehung von Kriegerverein und städtischen Behörden war offenbar reibungslos, in den Augen des Vereinsvorsitzenden Danert gar geprägt durch "warme Sympathien". 823 Die Mitglieder der städtischen Kollegien wurden zu Herrschergeburtstagsfeiern des Vereins geladen und kamen solchen Einladungen auch vielfach nach, 824 und im Jahre 1896 wude Paul Troje, der Bürgermeister der Stadt Einbeck, zum Ehrenmitglied des Vereins ernannt. 825 Auch seinem Vorgänger Franz Grimsehl war diese Ehrung durch den Verein in den achtziger Jahren zu Teil geworden. ${ }^{826}$ Die städtischen Behörden ihrerseits unterstützten und förderten den Kriegerverein. Anlässlich des fünfundzwanzigjährigen Bestehens des Vereins erwirkte der Magistrat für den Verein die Verleihung eines von ihm sehr gewünschten Fahnenbandes durch

\footnotetext{
${ }^{819}$ Vgl.: StAEin 065 - 19, 12. Juni 1876

820 StAEin 065 - 19, 27. Dezember 1896

${ }^{821}$ Vgl.: StAEin 065 - 19, 8. Januar 1891; 11. Februar 1891; 11. Juni 1891

${ }^{822}$ StAEin 065 - 18, 3. September 1890

${ }^{823}$ StAEin 065 - 19, 29. Janaur 1892

$824 \mathrm{Vgl}$.: ibid.

${ }^{825}$ Vgl.: StAEin 065 - 19, 7. Dezember 1896

826 Vgl.: StAEin 065 - 18, 3. September 1890
} 
den Kaiser und König. ${ }^{827}$ Die städtischen Kollegien stifteten dem Verein zu diesem Jubiläum 150 Mark zur Verteilung an bedürftige Vereinsmitglieder aus der Kämmereikasse. ${ }^{828}$

Ein weiterer Beleg für ein überaus gutes, weit über das verwaltungstechnisch notwendige Maß hinausreichendes Miteinander von Behörden und Kriegerverein ist das fünfundzwanzigjährige Präsidentschaftsjubiläum des Vereinsvorsitzenden Danert im Jahre 1910. Die Behörden waren in der Vorbereitung dieses Tages so aktiv, als handele es sich um ein offizielles Dienstjubiläum: der Stadtsekretär beschaffte bei der Kirche und bei einem anderen Vorstandsmitglied biografische Angaben über Danert für eine Laudatio, und die Stadtkapelle brachte dem Vereinsvorsitzenden ein musikalisches Ständchen; die Kosten hierfür wurden zum größten Teil von der Kämmereikasse übernommen. 829

Der Kriegerverein Einbeck war, anders als viele andere Vereine der Stadt, ein sehr eng mit den städtischen Behörden zusammenarbeitender Verein, der sich auch in der Bürgerschaft der Stadt einer großen Wertschätzung erfreute. 830

Da vom Kriegerverein Einbeck keine Mitgliederlisten erhalten sind, müssen die Angaben über Mitgliederzahl und -struktur etwas vage bleiben. Allein für das Jahr 1896 ist eine Gesamtmitgliedschaft von 86 Männern belegbar. ${ }^{831}$ Auch auf einer undatierten Collage, vermutlich aus dem Jahre 1898, welche alle Mitglieder des Vereins vor dem Panorama der Stadt zeigt, sind 86 Personen zu sehen. ${ }^{832}$ In Anbetracht des Umstandes, dass der Verein bereits zum Zeitpunkt seiner Gründung einen klar definierten Personenkreis als potenzielle Mitglieder hatte, der sich während des gesamten Untersuchungszeitraumes nicht erweiterte, dürfte diese Zahl annähernd den Höchststand der Mitglieder des Vereins markieren. Dieser Mitgliederbestand wird in den ersten Jahren des Bestehens des Vereines kontinuierlich zugenommen haben, da das im Vergleich mit anderen Vereinen enorm hohe Eintritsgeld von 10, ab 189720 und ab 189930 Mark für viele Eintrittswillige

${ }^{827}$ Vgl. einen umfangreichen Briefwechsel zwischen Kriegerverein, Magistrat, Landdrostei Hildesheim und Bezirkskommando Göttingen, StAEin 065 - 19, 7. Dezember 1896 bis 20.

Februar 1896

828 Vgl.: StAEin 065 - 19, 20. Februar 1897

829 Vgl.: StAEin 065 - 19, Briefwechsel aus dem Jahre 1910

830 Vgl.: StAEin 065 - 19, 7. Dezember 1897

${ }^{831}$ Vgl.: StAEin 065 - 19, 4. Dezember 1896

832 StAEin, Fotoammlung, Abteilung 34 a 
nicht ohne weiteres aufzubringen gewesen sein wird. Der Monatsbeitrag hingegen war mit 40 Pfennigen nicht sehr hoch.

Aus den oben erwähnten Eintrittsbedingungen kann es nicht verwundern, dass der Altersdurchschnitt der Mitglieder, nimmt man die Angaben für die Mitglieder der Sanitätskolonne für das Jahr 1892 als repräsentativ an, relativ hoch war. Von den 17 Mitgliedern gehörten 14 der Altersgruppe zwischen 40 und 50 Jahren an 833 - das Durchschnittsalter der Vereinsmitglieder dürfte eben in etwa dem Durschnittsalter der Soldaten im Mobilmachungszustand zuzüglich der Jahre seit 1871 entsprochen haben.

Über die Sozialstruktur der Vereinsmitgliedschaft ist ebenfalls wenig zu erfahren. Anhand der wenigen vorhandenen Belege lässt sich jedoch die Aussage Thomas Rohkrämers, dass das Militärvereinswesen eine Angelegenheit des niederen Bürgertums und der Arbeiterschaft gewesen sei, von dem sich die materiell besser gestellten bürgerlichen Schichten fernhielten, 834 für den Kriegerverein Einbeck widerlegen. In der Mitgliedschaft lassen sich zwar durchaus Kleinbürger nachweisen, doch von einer Abstinenz "höherer Kreise", kann nicht die Rede sein. Unter den nachweisbaren Mitgliedern und Vorstandsmitgliedern finden sich neben Handwerksmeistern und Kaufleuten mit dem Besitzer der örtlichen Zuckerfabrik, Kommerzienrat Rabbethge, und dem Begründer der Einbecker Gasanstalt und nachmalige Besitzer einer Ziegelei und einer Dachpappenfabrik, Major Lentze, mindestens zwei Männer, die zweifelsohne der Einbecker Oberschicht zuzurechnen sind. 835

Die oben erwähnten hohen Eintrittsgebühren dürften die Ursache dafür sein, dass der Kriegerverein Einbeck soziostrukturell vom Durchschnitt der deutschen Militärvereine abwich.

\footnotetext{
${ }^{833}$ Vgl.: StAEin 065 - 19, 17. Februar 1892

${ }^{834}$ Vgl.: Rohkrämer, Thomas: op.cit., SS. 34 ff.

${ }^{835} \mathrm{Zu}$ den Erwähnungen einzelner Mitglieder und Vorstandsmitglieder vgl.: StAEin 065 - 19, passim
} 


\section{7. 3. Der Landwehr- und Reserveverein Einbeck}

Sechseinhalb Jahre nach Gründung des Kriegervereins wurde in Einbeck ein zweiter Militärverein gegründet; am 8. August 1878 trat der Landwehr- und Reserveverein zu Einbeck ins Leben. 836

Analog zum Kriegerverein hatte der Landwehr- und Reserveverein gemäß seinen Statuten die vier Vereinszwecke, "1) die Treue gegen unser Königshaus, die Liebe zum Vaterlande, die Achtung gegen Gesetz und Ordnung zu befestigen; 2) die kameradschaftliche Liebe unter den Vereinsmitgliedern zu pflegen, daß sie gern einander mit Rath und That beistehen; 3) in Krankheitsfällen die Mitglieder zu unterstützen; 4) bei Ableben eines Vereinsmitgliedes für würdige Beerdigung zu sorgen". 837

Der Beitritt zum Verein stand jedem Mann offen, der seine dreijährige Dienstpflicht im Heer abgeleistet hatte und ins Reserve- oder Landwehrverhältnis übergetreten war.Die Aussagen hierüber in $\S 1$ des Statuts widersprechen einander. Es kann aufgrund eines späteren Statuts davon ausgegangen werden, dass die Mitgliedschaft allen offen stand, die ihre dreijährige Dienstzeit absolviert und noch nicht aus dem Landwehrverhältnis, das vor 1888 bis zum 39. Lebensjahr, danach bis zum 45. dauerte, ausgeschieden waren. ${ }^{838}$ Diese Bestimmung galt jedoch nur für den Zeitpunkt des Beitritts, es gibt in keiner Statutenfassung einen Passus, welcher besagte, dass die Mitgliedschaft mit dem Ende des Landwehrverhältnisses endete.

Wie in Bezug auf die Zugangsbestimmungen war der Landwehr- und Reserveverein auch durch die Höhe des Eintrittsgeldes von 1,50 Mark weit weniger exklusiv als der Kriegerverein. ${ }^{839}$ Dennoch versuchte der Landwehrund Reserveverein schon im ersten Jahr seines Bestehens, einen Zusammenschluss mit diesem herbeizuführen, doch lehnte der Kriegerverein ein solches Ansinnen mehrfach mit der Begründung ab, dass man von dem Prinzip, nur Feldzugsteilnehmer aufzunehmen, nicht abgehen wolle. 840

Im Sommer 1879 wurden die Bemühungen um eine Fusion der beiden Einbecker Militärvereine eingestellt; im Juli dieses Jahres beantragte der Verein die Genehmigung zur Führung einer eigenen Fahne. Im Vertrauen

\footnotetext{
836 Vgl.: gedrucktes Statutenexemplar in der Fassung vom 8. August in StAEin 065 - 31

837 Zitiert nach: ibid.

838 Als Vergleich diente ein gedrucktes Statutenexemplar der Fassung vom 18. Januar 1891 in StAEin 065 - 31

${ }^{839}$ Vgl.: gedrucktes Statutenexemplar in der Fassung vom 8. August in StAEin 065 - 31

840 Vgl.: StAEin 065 - 31, 28. November 1879
} 
darauf, dass diese Genehmigung erteilt werden würde, setzte man gleich einen Termin für die Fahnenweihefeier, bestehend in Umzug, Konzert und Ball. Da jedoch die erforderliche Genehmigung nicht rechtzeitig erteilt wurde, musste der Magistrat diese Feier verbieten, 841 obwohl der Verein sich bereits im Besitz einer Fahne befand. Diese Fahne war dem Verein von einer nicht mehr feststellbaren Person oder Personengruppe geschenkt worden, aus Vereinsmitteln wäre eine Fahne bei einem Eintrittsgeld von 1, 50 Mark und einem monatlichen Beitrag von 30 Pfennig so kurze Zeit nach der Vereinsgründung kaum zu bezahlen gewesen.842 Am 2. Januar 1880 teilte schließlich die Landdrostei in Hildesheim dem Magistrat der Stadt Einbeck mit, dass dem Landwehr- und Reserveverein durch Erlass der preußischen Minister des Innern und des Krieges vom 20. Dezember 1879 die Genehmigung zur Führung der Fahne, über die der Verein schon seit einem halben Jahr verfügte, erteilt worden sei. 843

Am 25. September 1885 trat der Verein dem Kreiskriegerverband Einbeck und damit auch dem Preußischen Landeskriegerverband bei.

Im Jahre 1908 feierte der Verein sein 30jähriges Stiftungsfest. Zu diesem Anlass schaffte sich der Verein eine neue Fahne an; die Fahnenweihefeier wurde mit dem Stiftungsfest verbunden. 844

$\mathrm{Ab}$ den ausgehenden achtziger Jahren des 19. Jahrhunderts war der Verein im Besitz von Schusswaffen; im Dezember 1893 berichtete der Magistrat der Stadt Einbeck auf eine entsprechende Anfrage an das Regierungspäsidium in Hildesheim, dass sich an älteren Militärgewehren 12 Chassepotgewehre seit 1888/89 und 12 Mausergewehre Typ 71 seit Juli 1893 in den Beständen Landwehr- und Reservevereins befänden. ${ }^{845}$ Im Adressbuch für die Stadt Einbeck vom Juli 1912 findet sich in der Abteilung Schützenvereine eine "Schießklub-Abteilung des Landwehr und Reserveverein".

Über die Mitgliederzahl vor der Jahrhundertwende sind quantitative Angaben nicht möglich, doch ist einem Schreiben des Magistrats an die Landdrostei in Hildesheim aus dem Jahre 1879 zu entnehmen, dass der Verein bereits im ersten Jahr seines Bestehens starken Zulauf hatte und die Behörden

\footnotetext{
841 Vgl.: StAEin 065 - 31, 17. September 1879

842 Vgl:: StAEin 065 - 31, 28. Oktober 1879 und das in Anmerkung Nr. 48 zitierte

Statutenexemplar

843 Vgl.: StAEin 065 - 31, 2. Januar 1880

844 Vgl:: MGV Harmonie Einbeck, Protokoll 5. April 1908

845 Vgl.: StAEin 065 - 5; 12. Dezember1893. Dass sich das zitierte Schriftstück in der Akte

über das Sozialistengesetz befindet, muss auf einem Versehen beruhen.
} 
mit einem weiteren Wachstum des Landwehr- und Reservevereins rechneten. ${ }^{846}$ Die älteste erhaltene Mitgliederliste aus dem Mai 1907 weist 126 Mitglieder aus. ${ }^{847} 1910$ gehörten 132 Personen dem Verein an. ${ }^{848}$ Aus dem Mitgliederverzeichnis von 1907 lässt sich auch die Sozialstruktur des Vereins ersehen. ${ }^{849}$ Anders als der oben genannte Kriegerverein Einbeck entsprach der Landwehr- und Reserveverein dem von Thomas Rohkrämer gezeichneten Bild, nach dem sich die deutschen Militärvereine aus "kleinen Leuten", aus Arbeitern, Handwerkern und kleinen Beamten zusammensetzten. 850

Fasst man für den Landwehr- und Reserveverein die explizit als Arbeiter bezeichneten Mitglieder, 14 Personen und 11,1 v. H. der Gesamtmitgliedschaft, mit den gehobenen Arbeitern wie Vorarbeitern und Werkführern (12 Personen, 9,5 v. H.), den Handwerksgesellen (26 Personen, 20,6 v. H.), den Packern (12 Personen, 9,5 v. H.) ${ }^{851}$, den nichtselbständigen Kutschern (9 Personen, 7,1 v. H.) und den Wärtern und Boten (7 Personen, 5,6 v. H.) zu einer Gruppe zusammen, so erhält man eine dominierende Gruppe von 80 Männern und 63,5 v. H. der Vereinsmitglieder, die sich unter dem zeitgenössischen Begriff der "arbeitenden Klassen" subsumieren lässt. Erweitert man diese Gruppe noch durch die 13 kleinen Beamten, wie e. g. Briefträger und Bahnbeamte, welche 13 Mitglieder und somit 10,3 v. H. stellten, zu der Rohkrämerschen Kategorie "Kleine Leute", so kommt man auf eine Gruppe von 93 Personen oder 73,8 v. H. aller Vereinsmitglieder.

Diesen "Kleinen Leuten" standen mit 17 Handwerksmeistern, 5 Selbständigen und 7 Angehörigen anderer Berufe, in der Hauptsache Kaufleuten, also 13,5, 4 und 5,6 v. H., maximal 29 Personen oder 23 v. h der Gesamtmitgliedschaft gegenüber, die dem Bürgertum zuzurechnen waren. 4 Vereinsmitglieder, also 3,2 v.H. aller Mitglieder, wurden in dem Verzeichnis als Invaliden aufgeführt und konnten nicht sozial klassifiziert werden.

Dem Magistrat der Stadt Einbeck war die soziale Struktur des Vereins, wie aus dem Schriftverkehr mit dem Regierungspräsidium bezüglich der

\footnotetext{
846 Vgl.: StAEin 065 - 31, 28. November 1879

847 StAEin 065 - 31, NN. Mai 1907

848 Vgl.: StAEin 065 - 31, 3. Februar 1911

849 Alle unten zur Mitgliederstruktur des Landwehr- und Reservevereins gemachten Angaben beruhen auf einer Auswertung dieser Mitgliederliste von 1907

850 Vgl.: Rohkrämer, Thomas: op. cit., SS. 35 ff.

${ }^{851}$ Die hohe Zahl der Packer dürfte sich aus der bereits im Jahre 1907 herausragenden

Stellung des Versandhauses Stukenbrok erklären.
} 
Genehmigung zur Anschaffung einer neuen Fahne hervorgeht, bekannt; er schrieb im Juni 1907, dass die Mitglieder des Vereins hauptsächlich "Kleine Arbeiter und Unterbeamte" 852 seien. Die Mitgliederstruktur dürfte bereits seit Gründung des Vereins ähnlich gewesen sein. In einem Gutachten des Magistrats für die Königliche Landdrostei aus dem Jahre 1879 heißt es bereits über den Landwehr- und Reserveverein Einbeck: "Er hat [...] eine große politische Bedeutung, da er den starken subversiven Strömungen in den unteren Volksschichten in wirksamster Weise entgegenzuwirken sich bestrebt."853 


\section{7. 4. Der Kriegerverein Kameradschaft}

Im Jahre 1896 entstand in Einbeck ein dritter Militärverein. Am 5. März dieses Jahres konstituierte sich der Krieger-Verein Kameradschaft. ${ }^{854}$ Dieser Verein stand allen ehemaligen Soldaten offen, ungeachtet ihrer Dienstzeit oder ihrer Waffengattung, ausdrücklich wurden in den Statuten auch ehemalige Marinesoldaten erwähnt. Vom Beginn seiner Tätigkeit an hatte der Verein die staatlich vorgeschriebene Formulierung in seinem Statut, nach der ein Zweck des Vereins war, "Die Liebe und Treue für Kaiser und Reich, Landesfürst und Vaterland bei seinen Mitgliedern zu pflegen, zu bethätigen und zu stärken, sowie die Anhänglichkeit an die Kriegs- und Soldatenzeit im Sinne kameradschaftlicher Treue und nationaler Gesinnung aufrecht zu erhalten". Darüber hinaus waren die Veranstaltung militärischer Beerdigungen für verstorbene Mitglieder und die Unterstützung von bedürftigen Kameraden im Krankheitsfalle wie bei den vorgenannten Vereinen weitere Vereinszwecke. Abweichend von diesen war beim Kriegerverein Kameradschaft auch die Feier von vaterländischen Gedenktagen einer der Vereinszwecke.855 Die anderen Militärvereine sahen solche Feiern lediglich als Möglichkeit vor.

Das Eintrittsgeld war mit 3 Mark doppelt so hoch wie beim Landwehr- und Reserveverein, betrug aber nur 30, ab 189715 und ab 1899 nur 10 v. H. des Eintrittsgeldes des Kriegervereins Einbeck. Die laufenden Beiträge waren mit 3 Mark jährlich geringer als bei den beiden anderen Militärvereinen, doch war das Geld jährlich und nicht monatlich zu entrichten, was für Personen mit geringerem Einkommen die Zahlung erschwerte. ${ }^{856}$ Wie ein Briefwechsel aus dem Jahre 1910 belegt, stellte der Kriegerverein Kameradschaft zumindest im Einzelfalle auch für aktive Soldaten des Krieges von 1870/71, die die hohe Eintrittsgebühr für den Kriegerverein nicht aufbringen konnten, eine Alternative zum Kriegerverein Einbeck dar. 857

Der Verein hatte von seiner Gründung an einen starken Zulauf. Bereits 3 Jahre nach seiner Gründung umfasste er 95 Mitglieder. 858

\footnotetext{
854 Vgl.: StAEin 065 - 32, Statut vom 5. März 1896 in der Anlage zu 12. März 1896 
Die soziale Zusammensetzung der Mitgliedschaft des Vereins zu diesem Zeitpunkt zeigt eine deutliche Dominanz des mittleren und gehobenen Bürgertums. 17 Mitglieder, das waren 17,9 v. H. aller Mitglieder, waren Handwerksmeister, 16 Männer, 16,8 v. H., waren Beamte, durchweg höheren Ranges als jene im Landwehr- und Reserveverein, so beispielsweise ein Pastor und drei Oberlehrer und der Stadtregistrateur. Ebenso fanden sich unter den 10 Angestellten innerhalb des Vereins, die 10, 5 v. H. der Mitgliedschaft stellten, neben Handlungsgehilfen vor allem Buchhalter und zwei Brauereidirektoren. Ferner gehörten dem Verein neben 6 Gastwirten (6,3 v. H.) und 5 Landwirten (5,3 v. H.) 8 weitere Selbständige an, die als Fabrikanten, Mühlenbesitzer, Arzt und Rechtsanwalt allesamt dem gehobenen Bürgertum zuzuordnen sind. Rechnet man all diesen genannten Personen noch zwei der vier nicht klassifizierbaren Personen 859 und die 13 Kaufleute hinzu (13,7 v. H.), die man, obwohl nicht nachweisbar ist, ob diese selbständig oder angestellt waren, zweifelsohne den bürgerlichen Schichten zurechnen muss, so kommt man zu dem Ergebnis, dass mindestens 77 Mitglieder oder 81,1 v. H. aller Mitglieder dem Bürgertum zuzurechnen sind, wobei in dieser Gruppe sowohl Besitz- als Bildungsbürgertum sowie der "neue Mittelstand" vertreten waren.

Dieser großen bürgerlichen Mehrheit standen neben zwei weiteren nicht klassifizierbaren Personen 860 lediglich 16 Handwerksgesellen (16,8 v. H.) gegenüber. Unter diesen finden sich allenfalls drei, die möglicherweise in einer Fabrik oder einem Großbetrieb arbeiteten. Als "Arbeiter" wird keines der Mitglieder bezeichnet. 861

Der Kriegerverein Kameradschaft war also ein Verein, in dem das gehobene Bürgertum in seinen verschiedensten Kategorien deutlich dominierte. Das oben skizzierte Bild Thomas Rohkrämers von der durchschnittlichen sozialen Zusammensetzung eines Militärvereins im Kaiserreich trifft auf diesen Verein nicht zu.

Im Frühjahr 1899 suchte der Kriegerverein Kameradschaft um Genehmigung zur Führung einer Fahne nach. Nachdem der Verein darüber behördlicherseits informiert worden war, dass Mitglieder auszuschließen seien, welche sich mit den Vereinszwecken, namentlich der "Pflege und Betätigung der Liebe und Treue zu Kaiser und Reich", in Widerspruch setzten und dass

\footnotetext{
859 Einen "Musikdirektor" und einen "Haussohn"

${ }^{860}$ Ein Lohndiener und ein Aufseher

${ }^{861}$ Alle vorstehenden Angaben ausgewertet und berechnet aus einer Mitgliederliste von 1899, StAEin 065 - 32, o. D. im Schriftwechsel über das Gesuch zur Genehmigung zur Führung einer Fahne
} 
nur bei Bestattungen von Feldzugteilnehmern Salutschüsse über das offene Grab abgegeben werden dürften und er dementsprechend sein Statut geändert hatte, wurde diese Genehmigung im Sommer 1899 auch erteilt.862 Die Fahnenweihe fand Mitte August statt. Die Unterlagen des Stadtarchivs Einbeck geben Aufschluss über den Rahmen einer solchen Feierlichkeit, die den Charakter eines Volksfestes hatte. Der veranstaltende Verein errichtete auf dem Tummelplatz je zwei Schank- und Tanzzelte, für die er Eintrittsgebühren erhob, ferner stellten auswärtige Schausteller Schaubuden auf. ${ }^{863}$ Ein solches öffentliches Fest sollte mindestens die Unkosten decken, doch war dies im Falle der Fahnenweihfeier des Kriegervereins Kameradschaft nicht der Fall, das Fest endete mit einem Defizit von etwa 400 Mark für den Verein und enttäuschenden Einnahmen der Festwirte. Daher beantragte der Vorstand die Genehmigung, am darauffolgenden Wochenende erneut die Tanz- und Festzelte öffnen zu dürfen. Bürgermeister Troje wollte zunächst die Erlaubnis hierzu versagen, doch eine Intervention der beiden Senatoren stimmte ihn um. Diese argumentierten, "eine Verweigerung derselben würde in den besten Kreisen unser [sic] Bürgerschaft, von denen viele dem Verein Kameradschaft angehören, große Mißstimmung erregen". 864

862 Vgl.: StAEin 065 - 32, 29. März 1899; 4. April 1899; 28. Juni 1899; 8. Juli 1899

$863 \mathrm{Vgl} .:$ StAEin 065 - 32, 6. Juli 1899

${ }^{864}$ StAEin 065 - 32, 16. 17. und 18. August 1899 


\section{7. 5. Der Militäranwärter-Verein}

Ein Militärverein, über den nicht mehr als seine bloße Existenz nachweisbar ist, ist der Militäranwärter-Verein Einbeck. Seine Gründung muss in der zweiten Hälfte des Jahres 1911 oder der ersten Hälfte des Jahres 1912 erfolgt sein; erstmals erscheint er in der Vereinsliste des Adressbuches vom Juli 1912,im Adressbuch für die Jahre 1911/12 ist er noch nicht erwähnt.

Zielgruppe dieser Vereinsgründung waren die so genannten Militäranwärter. Bei diesen Personen handelte es sich um einfache Soldaten oder Unteroffiziere, die nach zwölfjähriger Dienstzeit oder eingetretener Invalidität mit einem Zivilversorgungsschein entlassen wurden. Ein solcher Zivilversorgungsschein gab den Anwärtern das Recht, in den staatlichen Dienst zu wechseln oder im Falle der Invalidität eine Pension zu beziehen oder in einem staatlichen Invalidenhaus Aufnahme zu finden.

Im einzigen erhaltenen Bericht der städtischen Behörden an das Regierungspräsidium über den Stand des Kriegervereinswesens aus der Zeit nach dem Gründungszeitpunkt des Militäranwärter-Vereins wird dieser nicht erwähnt. ${ }^{865}$ Dies könnte zum einen die Vermutung nahelegen, dass dieser Verein nur sehr kurze Zeit bestand. Eine andere Deutungsmöglichkeit wäre angesichts des sehr begrenzten Kreises potenzieller Mitglieder, dass es sich bei diesem Verein eher um eine Interessenvereinigung materiell schlecht gestellter ehemaliger Soldaten denn um einen Militärverein im engeren, oben dargelegten Sinne gehandelt haben könnte. 


\section{7. 6. Der Verein ehemaliger Artilleristen für Einbeck und Umgegend}

Als letzter im Untersuchungszeitraum gegründeter Militärverein ist der Verein ehemaliger Artilleristen für Einbeck und Umgegend zu erwähnen. Dieser Verein war der erste und einzige Militärverein in Einbeck, der sich nur an ehemalige Soldaten einer bestimmten Waffengattung richtete. Solche Vereinsgründungen waren, wie aus einem Rundschreiben der preußischen Regierung über die Landdrostei Hildesheim an die nachgeordneten Behörden hervorgeht, seit 1893 zulässig 866, und die Existenz solcher Waffengattungsvereine wie auch von Regimentsvereinen wurde in einem weiteren Rundschreiben im Jahre 1899 zur Normalität für größere Orte erklärt. 867

Im Jahre 1902 gehörten etwa 8 v. H. der Mitglieder des Kyffhäuserbundes solchen Spezialvereinen an.868 In der unweit Einbeck gelegenen braunschweigischen Kreisstadt Holzminden waren 1903 vier der sieben vorhandenen Militärvereine solche Spezialvereine und stellten in der Stadt nahezu ein Drittel der in den Militärvereinen organisierten Männer. 869

In Einbeck setzte eine solche Entwicklung sehr verspätet erst unmittelbar vor dem Ende des Untersuchungszeitraumes ein. Der Verein ehemaliger Artilleristen wurde im Oktober 1913 gegründet. 870 Er erhielt im Februar 1914 die Genehmigung durch die städtischen Behörden. Auf Grund seines kurzen Bestehens durfte er bis zum Ende des Untersuchungszeitraumes keine Fahne führen. ${ }^{871}$ Weiteres ist über diesen Verein für die Zeit vor dem August 1914 nicht überliefert, der Erste Weltkieg unterbrach die Entwicklung eines bei Kriegsausbruch im August 1914 noch nicht völlig konsolidierten Vereins. Nach dem Krieg schritt die unterbrochene Vereinsentwicklung jedoch vermutlich fort; in der Vereinsliste des Adressbuches vom 1922 erscheint der Verein ehemaliger Artilleristen wie auch alle anderen oben erwähnten Militärvereine.

\footnotetext{
866 Vgl.: StAEin 065 - 18; 1. Februar 1893

${ }^{867}$ Vgl.: StAEin 065 - 18, 2. November 1899

${ }^{868}$ Näherungsweise errechnet nach: Rohkrämer, Thomas: op. cit., Anhang: Tabelle 1, S. 271

und Tabelle 4, S. 273

${ }^{869}$ Errechnet nach: Seeliger, Matthias: Mit Gott für Fürst und Vaterland. Kriegervereine im

Kaiserreich. Holzminden 1993, Tabelle S. 13

870 Das Statut datiert vom 18. Oktober 1913

${ }^{871} \mathrm{Vgl}$. zu allem über den Verein StAEin 065-18, 26. Oktober 1914
} 


\section{7. 7. Das Einbecker Militärvereinswesen - ein Gesamtbild}

Das Militärvereinswesen in Einbeck ist in mehrfacher Hinsicht als durchaus typisch für den Untersuchungszeitraum anzusehen. Über die gesamte Zeit ist ein kontinuierliches Wachstum sowohl der Mitgliederzahlen wie auch der Zahl der Vereine zu verzeichnen, das in Einbeck bis 1913, dem Jahr, in dem der Verein ehemaliger Artilleristen gegründet wurde, anhielt und an deren Ende vier oder fünf Militärvereine mit mindestens 300 Mitgliedern standen. Eine solche Entwicklung gab es im gesamten Reich; Rohkrämer spricht bezogen auf das Militärvereinswesen im ganzen Reich von einer "schnell wachsenden Volksbewegung".872 Diese Ausbreitung des Militärvereinswesens über den gesamten Untersuchungszeitraum hinweg bedingte freilich eine Verschiebung der Beitritts- oder Gründungsmotivation. Die so genannten Einigungskriege und vor allem deren Ergebnis, die Reichsgründung, die von der weit überwiegenden Mehrheit der Bevölkerung begrüßt worden war, waren das ursprüngliche Gründungsmoment für Kriegervereine im Wortsinne gewesen. Rasch trat an die Seite der Glorifizierung der von ihrem Resultat her positiv beurteilten Kriegsereignisse die allgemeine Verehrung des Militärs als Institution und des Militärischen als Wertekonsens. So wogen das positive Sozialprestige des gewesenen Soldaten und der damit verbundene Reservistenstatus $^{873}$ für die Mitglieder der Militärvereine schwerer als die Unannehmlichkeiten und Plagen während des Militärdienstes. 874

Die in den jeweiligen Statuten als Vereinszweck vorgeschriebene "Pflege der Kameradschaft"875, gar der "kameradschaftlichen Liebe"876 oder der

\footnotetext{
872 Rohkrämer, Thomas: op. cit., S. 51

873 Vgl.: Rohkrämer, Thomas: op. cit., SS. 163 ff.

874 Vgl.: Rohkrämer, Thomas: op. cit., SS. 150 ff., der Autor legt umfassend die Rolle des Militärdienstes im Leben des einzelnen Wehrpflichtigen dar. Eine bekannte autobiographische Schilderung des dreijährigen Dienstes in der preußischen Armee, die nichts weniger intendiert, als diese Zeit zu glorifizieren findet sich in: Rehbein, Franz: Das Leben eines Landarbeiters. Herausgegeben und mit einem Nachwort von Urs J. Diederichs und Holger Rüdel.
} Unveränderter Nachdruck der von Paul Göhre bearbeiteten Ausgabe. Hamburg 1985, SS. 168 209

875 Kriegerverein Einbeck, StAEin 065 - 19, Statutenexemplar vom 22. Dezember 1898, Präambel

876 Landwehr und Reserveverein, StAEin 065 - 31, Statutenexemplar vom 8. August 1878, Präambel 
"kameradschaftlichen Treue"877, erstreckte sich im Falle der Einbecker Militärvereine, wie oben gezeigt, jedoch nicht auf die Gesamtheit aller ehemaligen Soldaten. Die Kriegsteilnehmer separierten sich von denjenigen, die ihren Militärdienst in Friedenszeiten geleistet hatten 878 , und auch der soziale Status eines Reservisten bestimmte, wenn auch möglicherweise unbewusst, welchem der beiden für Reservisten offen stehenden Vereine er beitrat.

Ungeachtet ihrer sozialen Zusammensetzung wurden alle Einbecker Militärvereine von den Behörden wohlwollend, teilweise fördernd behandelt; die staatliche Obrigkeit sah, wie in der Einleitung zu diesem Kapitel bereits dargelegt, im Militärvereinswesen unter anderem eine wirksame Waffe gegen "subversive Stömungen" 879. Dennoch sollten solche staatlichen Äußerungen, derer es reichlich gab, nicht über einen realen Umstand hinwegtäuschen. Das Militärvereinswesen in seiner Gesamtheit zeigte im Laufe der Zeit die Tendenz, sich mehr und mehr zu einem Hort der reinen Geselligkeit zu entwickeln. Rohkrämer konstatiert eine Entwicklung, in deren Verlauf die Versammlungen der Kriegervereine zunehmend "eine Art Stammtischcharakter" annahmen ${ }^{880}$; dies relativiert die politische Wirksamkeit der Militärvereinsbewegung. In einem Bericht des Magistrats der Stadt Einbeck an das Militär-Bezirkskommando Göttingen vom 18. Oktober 1912 heißt es hierzu: "Nach den heutigen Verhältnissen ist es leider nicht abzuleugnen, daß die Kriegervereine von mehr oder wenigeren Mitgliedern in erster Linie als Vergnügungszweck betrachtet werden und die Pflege der wirklichen Kameradschaft sowie der Liebe zu Kaiser und Reich in den Hintergrund tritt. Es ist auch sicher anzunehmen, daß die Sozialdemokratie bei den letzten Wahlen auch durch Kriegervereinsmitglieder unterstützt ist."881

${ }^{877}$ Krieger-Verein "Kameradschaft", StAEin 065 - 32, Statutenexemplar vom 5. März 1896

${ }^{878}$ Hierdurch wurden die andernorts im Laufe der Zeit auftretenden Konflikte zwischen Veteranen und Reservisten vermieden. Doch die selbstgewählte Exklusivität des Kriegervereins intendierte vermutlich nicht primär die Vermeidung solcher, zum Zeitpunkt der Gründung kaum vorhersehbarer Differenzen.

${ }^{879}$ Siehe Anmerkung Nr. 62

${ }^{880}$ Vgl.: Rohkrämer, Thomas: op. cit., SS. 70 f.

${ }^{881}$ StAEin 065 - 18, 18. Oktober 1912 


\section{8. Die politischen Vereine}

\section{8. 1. Zur Entwicklung der Parteien im 19. und frühen 20. Jahrhundert}

Zum Verständnis der Geschichte der lokalen Organisationen der politischen Parteien vor dem Ersten Weltkrieg ist es unerlässlich, den Parteibegriff des ausgehenden 19. und beginnenden 20. Jahrhunderts deutlich gegen jenen der Bundesrepublik Deutschland abzugrenzen. Bei den heutigen Parteien handelt es sich um auf Dauer angelegte politische Organisationen, die ein schriftliches Programm haben und von der Ebene des Gesamtstaates oder eines Bundeslandes bis zu ihren kleinsten lokalen Unterorganisationen nach einer festen Struktur gegliedert sind. Programm und eine feste innere Ordnung sind nach dem Gesetz über die politischen Parteien zwingend vorgeschrieben. 882 Abgeordnete einzelner oder mehrerer nicht miteinander konkurrierender Parteien im Bundestag oder in Länderparlamenten schließen sich in der Regel zu einer Fraktion zusammen.

Historisch gesehen bilden die Fraktionen der Frankfurter Nationalversammlung von 1848 den Ursprung der bürgerlichen politischen Parteien in Deutschland. In der Paulskirchenversammlung schlossen sich im Zuge der verfassungspolitischen Auseinandersetzungen Abgeordnete mit gleichen oder ähnlichen Grundüberzeugungen zu Fraktionen zusammen. Es kristallisierten sich die drei Grundströmungen der Konservativen, der Liberalen und der Demokraten heraus. 883

Es entwickelte sich in Deutschland ein Parteibegriff, der eine Parlamentsfraktion und einen Kreis von Anhängern, die sich mit den Ideen und Überzeugungen der Abgeordneten identifizierten, umfasste. Die Zugehörigkeit zu einer Partei war also in der individuellen Meinung des Einzelnen begründet; es bedurfte keiner Registrierung oder regelmäßiger Beitragszahlung an irgendeine Organisation. Der Begriff Parteimitglied oder Parteigenosse konnte

\footnotetext{
${ }^{8} 82$ Um sich mit dieser sehr allgemeinen Formulierung begnügen zu dürfen, verweist der Autor auf die entsprechenden Bestimmungen des Parteiengesetzes der Bundesrepublik, insbesondere auf die $\$ \S 6-16$ ${ }^{883}$ Vgl.: Siemann, Wolfram: Die deutsche Revolution von 1848/49. (Moderne Deutsche Geschichte, Band 5). Frankfurt am Main 1985, SS. 127 ff.
} 
bis weit in den Zeitraum der vorliegenden Untersuchung hinein einfach einen dezidierten Anhänger einer politischen Anschauung bedeuten. 884

Auf lokaler Ebene kam es allmählich zu mehr oder weniger informellen Zusammenschlüssen verschiedener Anhänger der einzelnen politischen Richtungen. Die Mitglieder solcher vor allem im Vorfeld von Wahlen in Erscheinung tretenden Komitees waren zunächst nur wenige Angehörige des gebildeten und besitzenden Bürgertums; die Literatur spricht von Honoratiorenkomitees, welche alle bürgerlichen Parteiungen dominierten. 885

Im Laufe des Untersuchungszeitraumes entwickelte sich die Struktur der Parteien allmählich zu einer kontinuierlichen flächendeckenden Gesamtorganisation. Dies hatte verschiedene Gründe. Zum Einen diversifizierten sich die politischen Grundanschauungen zunehmend in verschiedene parlamentarische Fraktionen, was eine gesamtliberale oder gesamtkonservative Parteiung zunehmend in den Hintergrund treten ließ, zum Anderen wurde die politische Sphäre mit dem Durchbruch der pluralistischen Massengesellschaft von immer weiteren Kreisen der Bevölkerung als relevant erachtet und eine Beteiligung am Meinungsbildungsprozess für immer mehr Menschen attraktiv, wie das Ansteigen der Wahlbeteiligung an den Reichstagswahlen von etwa 50 v. H. im Jahre 1871 auf mehr als 84 v. H. in den Jahren 1907 und 1912 belegt.886 So wurden die informellen Honoratiorenkomitees allmählich von organisatorisch stabileren Vereinen verdrängt. Allerdings wurde die lokale Organisation der Parteien bei Weitem nicht so einheitlich und umfassend, dass von einer Parteizentrale und nachgeordneten Parteigliederungen oder -organen gesprochen werden könnte. Eine solche Struktur war schon der gesetzlichen Bestimmungen wegen ausgeschlossen; bis 1899 war es politischen Vereinen untersagt, überlokale Zusammenarbeit in einem Zentralverein o. ä. zu betreiben; die Kommunikation zwischen den örtlichen Vereinen mit anderen Organisationen der selben Partei musste daher wie zu Zeiten der Honoratiorenkomitees personal und informell

\footnotetext{
${ }^{884}$ Vgl.: Nipperdey, Thomas: Die Organisation der deutschen Parteien vor 1918. (Beiträge zur Geschichte des Parlamentarismus und der politischen Parteien, Bd. 18). Düsseldorf 1961, SS. 9,11

885 Vgl.: Nipperdey, Thomas: Deutsche Geschichte 1866 - 1918. Zweiter Band: Machtstaat vor der Demokratie. München 1992, SS. 514 ff.

886 Vgl.: Born, Karl Erich: Von der Reichsgründung bis zum Ersten Weltkrieg. (Grundmann, Herbert: Gebhardt Handbuch der Deutschen Geschichte, Taschenbuchausgabe, Band 16) 16. Auflage, München 1999, S. 26
} 
erfolgen 887 , auch hatten die lokalen Parteivereine verschiedene, mitunter wechselnde Erscheinungsformen.

Eine von dem oben Geschilderten abweichende Entwicklung hatten die sozialdemokratischen Parteien ${ }^{88}$, die sich von ihrer Gründung an als programmatische Massenorganisationen verstanden. Doch hinsichtlich sowohl der Organisationsstruktur mit formal unabhängigen lokalen Vereinigungen verschiedenster Erscheinungsform wie auch der auf Personenverbindungen beruhenden innerparteilichen Kommunikation ähnelte der Aufbau bis ins erste Jahrzehnt des 20. Jahrhunderts dem der bürgerlichen Parteien. 889

Die oben genannten politischen Grundströmungen mit ihren Organisationen waren in Hannover mehr oder weniger stark präsent. Daneben wies das Parteienspektrum in der Provinz zwei Besonderheiten auf: Das Zentrum oder andere Organisationen des politischen Katholizismus konnten allenfalls in den nordwestlichen Gebieten Wirkung entfalten - im Kernland Hannovers gab es schlicht zu wenig Menschen römisch-katholischer Konfession, um eine wirksame Organisation zu entfalten oder Wahlerfolge $\mathrm{zu}$ erringen. Eine bedeutende Rolle hingegen spielte die Deutsch-Hannoversche Partei, die ihre Ursprünge in der Annexion des Königreichs Hannover durch Preußen hatte und von der unten noch zu reden sein wird.

Die Ziele der verschiedenen sich entwickelnden Parteien waren durchweg positiver Natur; jede politische Partei oder Strömung hatte eine wie auch immer geartete und wie diffus auch immer artikulierte Zielvorstellung für ihr Handeln. Als Reaktion auf das zunehmende Gewicht von solchen positiv sich definierenden Vereinigungen entstanden bisweilen Organisationen und Strömungen, deren Zielsetzung negativer Natur waren, Organisationen also, die sich in erster Linie gegen eine bereits bestehende Parteiung oder Strömung wandten. Auch die lokalen Organisationen solcher negativ definierter politischen Bewegungen werden, aus nahe liegenden Gründen, in diesem Abschnitt der Untersuchung behandelt.

\footnotetext{
${ }^{887}$ Vgl.: Nipperdey, Thomas: Machstaat, SS. 515 ff.

${ }^{888}$ Am Beginn des Untersuchungszeitraumes existierten mit dem Allgemeinen Deutschen Arbeiterverein (ADAV) und der Sozialdemokratischen Arbeiterpartei (SDAP) zwei sozialdemokratische Parteien. Diese schlossen sich 1875 zur Sozialistischen Arbeiterpartei (SAP) zusammen, die sich 1890 in Sozialdemokratische Partei Deutschlands (SPD) umbenannte. 889 Vgl.: Nipperdey, Thomas: Organisation, SS. 319 ff.
} 


\section{8. 2 Die Vereine der Sozialdemokratischen Partei}

Die Sozialdemokratische Partei war die erste politische Bewegung, die von ihrem Beginn an ein Netzwerk von lokalen Vereinen entwickelte. Die erste sozialdemokratische Organisation in Einbeck war ein möglicherweise im Laufe der sechziger Jahre aus einem liberalen Arbeiterbildungsverein hervorgegangener Ortsverein des 1863 von Lassalle begründeten Allgemeinen Deutschen Arbeitervereins (ADAV). Für das Jahr 1869 ist eine 110 Mitglieder umfassende Mitgliedschaft des ADAV in Einbeck belegt.890 Eine lokale Organisation der anderen sozialdemokratischen Partei, der von Bebel und Liebknecht 1869 gegründeten Sozialdemokratischen Arbeiterpartei (SDAP) bestand in Einbeck nicht. Die im Jahre 1875 auf dem Gothaer Parteitag erfolgte Vereinigung der beiden Parteien zur Sozialistischen Arbeiterpartei Deutschlands (SAP) hatte zur Folge, dass sich der Einbecker Zweigverein des ADAV im Dezember 1875 auflöste. An seine Stelle trat zunächst offenbar ein Ortsverein der neuen Partei. Nachdem die Tätigkeit der SAP im Jahre 1876 gerichtlich untersagt wurde, gründeten die Einbecker Sozialdemokraten einen Arbeiterwahlverein, eine Zweigorganisation des Deutschen Arbeiterwahlvereines. Zwar heisst es in der einschlägigen Literatur stets, dass der Einbecker Arbeiterwahlverein unmittelbar aus dem ADAV-Ortsverein hervorgegangen sei,891 doch in einem zeitnahen Bericht des Einbecker Magistrats an die Landdrostei in Hildesheim ist zu lesen: "Wir bemerken dazu, daß früher hierselbst auch ein Zweigverein des 'Allgemeinen Deutschen Arbeitervereins', der bekanntlich mehr den Lehren Lassalle's huldigte, bestand [...]. Derselbe hat sich im December 1875 freiwillig aufgelöst, sicherlich in Folge des Vereinigungscongresses zu Gotha vom 22. bis 27. Mai 1875. Eine Thätigkeit des 1876 gerichtlich geschlossenen Vereins 'Socialistische ArbeiterParthei Deutschlands' zu Hamburg hat sich nur insofern bemerklich gemacht,

${ }^{890}$ Vgl.: Koch, Eberhard: Geschichte der SPD in Einbeck und Uslar. Von den Anfängen bis zum Wiederaufbau der lokalen Organisationen nach 1945. Eine vergleichende Studie.

Examensarbeit, ungedruckt. Göttingen 1976, SS. 20 ff.

${ }^{891}$ Vgl.: Koch, Eberhard: Geschichte der SPD, S. 28; Koch, Eberhard: Woher wir kommen -

Die 120-jährige Geschichte der Einbecker Sozialdemokratie. in: Sozialdemokratie in Einbeck 1869 - 1889, Einbeck 1989, S. 3; Koch, Eberhard: Woher wir kommen - 125 Jahre SPD in Einbeck. in: Einbecker Jahrbuch, Band 44 (1995), SS. 165 - 178, SS. 166 f.; Hülse, Horst: Einbeck in der Gründerzeit. in: Einbecker Geschichtsverein (Hg.): Geschichte der Stadt Einbeck. Band 2: Vom Ende des 18. Jahrhunderts bis zum Ende des zweiten Weltkrieges. Einbeck 1992, SS. 71 - 138, SS. 100 f. 
als die früheren Mitglieder desselben hier einen Zweigverein des als Nachfolger jenes Vereins anzusehenden 'Deutschen Arbeiter-Wahlvereines' [...] ins Leben gerufen haben." Im selben Schreiben wird auch über die öffentliche Wirkung der sozialdemokratischen Tätigkeit in Einbeck berichtet. Diese zeigte sich vor allem bei öffentlichen Volksversammlungen, zu denen regelmäßig 200 bis 300 Personen erschienen. Allerdings fanden solche Versammlungen recht selten, in der Regel nur ein- bis zweimal jährlich statt. Lediglich in den Jahren 1874 und 1875 fanden vier bzw. drei Versammlungen statt.

Diese Intensivierung der sozialdemokratischen Öffentlichkeitsarbeit führten die Einbecker Behörden auf die Anwesenheit des bereits in der Einleitung erwähnten Dr. Emil Kirchner zurück. ${ }^{892}$ Dieser hatte im Jahre 1871 seine private Technikerschule von Hildesheim nach Einbeck verlegt und sich neben seiner Tätigkeit als Schulleiter intensiv im Sinne der Sozialdemokratie betätigt. Kirchner bewarb sich in jener Zeit auch als sozialdemokratischer Kandidat um das Reichstagsmandat im 11. Hannoverschen Wahlkreis. Nachdem es wegen seiner politischen Aktivitäten zu ernsthaften Konflikten mit den städtischen Behörden gekommen war, verlegte Kirchner sein Institut 1874 in das thüringische Langensalza. 893

Die Mitglieder der frühen sozialdemokratischen Vereine rekrutierten sich vor allem aus der Gruppe der in der Tabakverarbeitung beschäftigten Arbeiter, daneben traten auch Handwerksgesellen verschiedener anderer Gewerke, vornehmlich aus der Textilbranche, den Vereinen bei. ${ }^{894}$ Die Tabakarbeiter und die Schneider hatten darüber hinaus eigene Gewerkschaftsorganisationen in Einbeck, welche nach dem Inkrafttreten des Sozialistengesetzes im Oktober 1878 umgehend verboten und aufgelöst wurden. So weit hatten es die organisierten Parteigänger der Sozialdemokratie in Einbeck nicht kommen lassen. Bereits im Sommer 1878 wurde der Arbeiterwahlverein Einbeck in Erwartung des Sondergesetzes aufgelöst und die Vorbereitungen für die Fortführung der Parteiarbeit unter der bevorstehenden Illegalität getroffen. 895 Dies sollte, wie bereits oben dargelegt, unter dem Dach des Gesangvereins Lassallia/Concordia geschehen. Da dieses Vorhaben jedoch von den Behörden

\footnotetext{
892 StAEin 065 - 35, 9. August 1878

893 Füllner, Gustav: Dr. Emil Kirchner und sein Institut. Aus der Geschichte des Einbecker

"Technikums" 1871 - 1907. in: Einbecker Jahrbuch, Band 30 (1974), SS. 70 - 78, SS. 72 f.

${ }^{894}$ Vgl.: Koch, Eberhard: Geschichte der SPD, S. 26 und Koch, Eberhard: Woher wir

kommen (1995), S. 166

${ }^{895}$ Vgl.: Koch, Eberhard: Geschichte der SPD, S. 31
} 
erkannt und vereitelt wurde, diente ab 1879 der Zigarrenarbeiter-Gesangverein als Tarnorganisation für die konspirative sozialdemokratische Parteiarbeit. 896

Nach außen hin verhielten sich die Einbecker Sozialdemokraten vom Inkrafttreten des Sozialistengesetzes an ausgesprochen ruhig. So berichtete der Magistrat im Dezember 1878 an die Landdrostei in Hildesheim: "Die nervöse Aufregung [...] hat einer friedlichen Ruhe Platz gemacht, in der auch nicht eine Spur von Groll über staatliche Vergewaltigung sich bemerkbar macht". Auch in den späteren regelmäßigen Berichten an die vorgesetzte Behörde über den Stand der sozialdemokratischen Bewegung ist in aller Regel zu lesen, dass die Bewegung nicht oder allenfalls in geringem Maße öffentlich in Erscheinung getreten sei. 897

Lediglich im Umfeld der Reichstagswahlen kam es in Einbeck zu, auch während der Zeit des Sozialistengesetzes legalen, öffentlichen Wahlkundgebungen. 898 Die Wahlwerbung verfehlte ihre Wirkung nicht; auch in der Zeit der Illegalität einer dauerhaften lokalen Parteiorganisation konnte die Stimmenzahl bei den Reichstagswahlen gesteigert werden. In einem Bericht des Magistrats an das Regierungspräsidium aus dem Jahre 1885 heißt es exemplarisch über die politische Agitation der Einbecker Sozialdemokraten, diese seien "im Anlaß der Reichstagswahlen einmal wieder etwas mehr aus ihrer sonstigen Zurückgezogenheit hervorgetreten. Nicht nur wurde von ihnen eine eigene, polizeilich von uns sorgfältig überwachte, Wahlversammlung abgehalten, auch in den öffentlichen Versammlungen der übrigen politischen Partheien erschienen die Social-Demokraten und gelangten auch theilweise zum Worte. Ihre Redner hielten sich jedoch durchweg - selbst bei der Wahlversammlung der eigenen Parthei - in den Schranken der Ordnung und der Mäßigung, und stellten als das Hauptziel ihrer Bestrebungen lediglich eine Hebung und Besserung der Lage des Arbeiterstandes hin. $\mathrm{Zu}$ einem polizeilichen Einschreiten hat sich deshalb kein Anlaß geboten. Eine Zunahme der social-demokratischen Stimmen bei der Reichstagswahl, wenngleich in

${ }^{896}$ Vgl.: Koch, Eberhard: Woher wir kommen (1989), S. 6

897Vgl.: StAEin 065 - 34, 17. Dezember 1878, 10. März 1879, 7. Juli 1879, 9. September

1879, 20. September 1879, 9. Dezember 1879,13. März 1880, 9. Juni 1880, 8. September 1880,

9. März 1881, 4. September 1882, 14. März 1883, 15. Februar 1884, 27. August 1884, 31.

August 1885, 5. März 1886, 6. September 1886, 30. August 1887, 3. März 1888, 26. Februar 1889; 065 - 5, 8. März 1882, 17. März 1890

${ }^{898}$ Vgl.: StAEin 065 - 34, 15. Februar 1884, 18. Februar 1885, 10. März 1887, 11. März

1887, 31. August 1889, 28. März 1890 
nicht erheblichem Umfange, ist übrigens leider auch hier $\mathrm{zu}$ Tage getreten." 899

Insgesamt ergibt sich für das Verhältnis der sozialdemokratischen Aktivisten und der städtischen Behörden zur Zeit des Sozialistengesetzes ein Bild, das beinahe mit dem Begriff "Friedliche Koexistenz" beschrieben werden könnte. Nachdem, wie oben am Beispiel des Gesangvereins Lassallia/Concordia gezeigt wurde, zunächst das neue Gesetz mit großer Schärfe gegen die Organisationen der Sozialdemokraten angewandt worden war, wurden in den achtziger Jahren des 19. Jahrhunderts deren Aktivitäten zwar polizeilich überwacht, doch sahen die Behörden, so lange die Aktivitäten "in den Schranken der Ordnung" blieben, von Repressalien oder Schikanen weit gehend ab. Die Annahme, dass es in einer eng bebauten Kleinstadt von ungefähr 7.000 Einwohnern möglich gewesen sei, eine regelmäßige Parteiorganisation unter dem Dach eines Gesangvereins aufrecht zu erhalten, ohne dass dieses in einem Zeitraum von über einem Jahrzehnt bekannt geworden wäre, scheint abwegig. Selbst der in seiner Beurteilung der Dinge kaum neutrale Chronist der Einbecker SPD, Eberhard Koch, weiß nur über wenige konkrete Fälle von polizeilichen Maßnahmen gegen die stadtbekannten Sozialdemokraten in Einbeck zu berichten 900 und spricht von einer ab 1881 "milden Praxis" der Behörden. 901

Die über den Verlauf der achtziger Jahre des 19. Jahrhunderts recht stabile Situation veränderte sich erst ab dem Sommer des Jahres 1889. Am 20. Juni 1889 meldete sich der wandernde Tischlergeselle Johann Carl Gotthilf Strienz auf dem Polizeibüro in Einbeck an. ${ }^{902}$ Bereits wenige Tage später kam es zur von Strienz initiierten Gründung eines Arbeitervereins, des Vereinigten Arbeiterclubs zu Einbeck. ${ }^{903}$ Rein formal wurde im Statut auf die geltenden gesetzlichen Bestimmungen Rücksicht genommen: Zweck des Vereins sollte nach $\S 1$ des Gründungsstatuts "die allseitige Vertretung seiner Mitglieder, mit Ausschluß aller politischen und religiösen Fragen, und dient zur Erzielung möglichst günstiger Arbeitsbedingungen auf gesetzlichem Wege gemäß $§ 152$. R. G. O.." sein. Die praktische Umsetzung dieses generellen Vereinszweckes wurde in acht Unterpunkten präzisiert, die, wie e. g. "Pflege der Geselligkeit"

\footnotetext{
${ }^{899}$ StAEin 065 - 34, 18. Februar 1885

900 Vgl.: Koch, Eberhard: opp. citt., passim

$90{ }^{1}$ Vgl.: Koch, Eberhard: Geschichte der SPD, S. 54

902 Vgl.: StAEin 065 - 5, 16. Juli 1889

903 Das in StAEin 065 - 5 erhaltene Statut wurde vom Verfasser nur mit der Zeitangabe "Juni 1889" versehen. Es trägt einen behördlichen Vermerk vom 26. Juni 1889.
} 
und "Pflege der Berufsstatistik" 904 , offenbar eventuelle behördliche Bedenken gegen die Legalität dieses neuen Vereins zerstreuen sollten. Dennoch forderten die Behörden von Strienz, der als Vorsitzender allein das eingereichte Statut unterzeichnet hatte, eine Mitgliederliste an. Diese enthielt die Namen von 34 Männern, unter denen sich auch die führenden Köpfe der sozialdemokratischen Bewegung Einbecks wie der Zigarrenarbeiter August Müller fanden. ${ }^{905}$ Dies veranlasste die städtische Polizeibehörde, die Versammlungen des Vereins zu überwachen. 906

Das älteste erhaltene Protokoll über den mündlichen Bericht eines städtischen Polizisten gibt den Verlauf einer Versammlung vom 15. Juli 1889 wieder. Nachdem der Vorsitzende Strienz diese von etwa 50 Männern besuchte Zusammenkunft eröffnet hatte, erfolgte zunächst eine mehr als einstündige Vorlesung August Müllers "aus einem roth eingebundenen Buche über englische Arbeiterverhältnisse" 907. Im Anschluss an diesen Vortrag, der nach Aussage des Polizeisergeanten Brünings die Anwesenden eher gelangweilt habe, sprach Strienz über Fragen der Lehrlingsausbildung, wetterte gegen die in Land- und Reichstag zahlreich vertretenen Großgrundbesitzer und unterstützte die nach umlaufenden Gerüchten bestehenden Streikabsichten der Brauereiarbeiter. Zum Schluss der etwa zweieinhalbstündigen Versammlung rief der Vorsitzende die Anwesenden zum Beitritt in den Arbeiterclub auf und führte eine Geldsammlung zu Gunsten der Vereinskasse durch. 908

Spätestens nach diesem Bericht war dem Magistrat bewusst, dass einer der in dieser Zeit nicht selten auftretenden illegalen sozialdemokratischen Wanderagitatoren seine Tätigkeit in Einbeck aufgenommen hatte. Umgehend wurden bei den Behörden seines Geburtsortes Heilbronn und seiner bekannten früheren Aufenthaltsorte Mannheim und Kassel vertraulich Informationen über Gotthilf Strienz angefordert. Diese besagten, dass dieser in Mannheim und Kassel als Redner auf Versammlungen der Deutschen Tischlerverbandes in Erscheinung getreten, in beiden Städten jedoch nur kurz anwesend gewesen

\footnotetext{
904 StAEin 065 - 5, Statut des Vereinigten Arbeiterclubs zu Einbeck, Juni 1889, § 1

905 Vgl.: Undatierter Behördenvermerk auf dem zitierten Statut und eine undatierte Mitgliederliste in StAEin 065 - 5.

906 Vgl.: StAEin 065 - 34, 31. August 1889

907 Möglicherweise handelte es sich bei diesem Buch um das 1845 erschienene Werk Friedrich Engels' "Die Lage der arbeitenden Klassen in England".

908 Vgl.: StAEin 065 - 5, 16. Juli 1889
} 
sei. 909 Offenbar sah sich Gotthilf Strienz in Einbeck zur Gründung eines Vereins für Arbeiter und Handwerker aller Gewerke genötigt, da er in der Stadt weder einen Zweigverein des Tischlerverbandes vorfand, noch genügend Berufskollegen antraf, um einen reinen Tischlerverein zu gründen. Dass er sich dem Deutschen Tischlerverband immer noch verbunden fühlte, zeigt der die Auflösung des Arbeiterclubs betreffende Statutenparagraph. Dieser verfügt, dass im Falle der Auflösung etwaiges noch bestehendes Vereinsvermögen unter anderen Arbeitervereinen am Ort zu verteilen sei. Falls solche zu diesem Zeitpunkt nicht bestünden, fiele das Vermögen der räumlich am nächsten gelegenen Zahlstelle des Tischlerverbandes zu. 910

Eine weitere Versammlung des Arbeiterclubs am 20. Juli 1889 wurde von dem überwachenden Polizeisergeanten Bock aufgelöst, nachdem ein auswärtiger Gast in einem Redebeitrag wiederholt Kritik an der staatlichen Kolonialpolitik geübt hatte. ${ }^{911}$ Bereits am darauf folgenden Tag protestierte Strienz in einem sehr selbstbewußt formulierten Schreiben gegen diese Auflösung und kündigte rechtliche Schritte gegen den Polizeibeamten an. 912 Doch bereits wenige Tage später verließ der Vorsitzende des Arbeiterclubs Einbeck mit unbekanntem Ziel. ${ }^{913}$ Ein weiteres in den Beständen des Stadtarchivs Einbeck erhaltenes Schriftstück, in dem Strienz' Name erwähnt wird, ist ein Rundschreiben des Regierungspräsidenten in Hildesheim vom 3. August 1889, in dem alle nachgeordneten Behörden vor diesem Wanderagitator, der zuletzt in Einbeck gewesen sei, gewarnt wurden. 914

Zwar beauftragte der Magistrat einen Polizisten, auch weiterhin den Arbeiterclub zu überwachen, doch ging er davon aus, dass sich der Verein nach der Abreise seines Gründers und Vorsitzenden umgehend von selbst auflösen würde. ${ }^{915}$ Doch dies erwies sich zumindest zunächst als Irrtum; der Verein bestand unter dem Vorsitz des bisherigen 2. Vorsitzenden August Kallmeier fort. Dieser wurde daher am 24. August 1889 auf das Polizeibüro vorgeladen, um über den Verein Auskunft zu erteilen. Auf entsprechendes Befragen teilte Kallmeier mit, dass man den Verein einstweilen mit dem Gründungsstatut

\footnotetext{
909 Vgl.: StAEin 065 - 5, 16. Juli 1889 und Antwort auf selbem Bogen, 17. Juli 1889, 23. Juli 1889 und Antwort auf selbem Bogen

910 Vgl.: StAEin 065 - 5, Statut des Vereinigten Arbeiterclubs zu Einbeck, Juni 1889, § 24

$91{ }^{1}$ Vgl.: StAEin 065 - 5, Protokoll über 20. Juli 1889

912 Vgl.: StAEin 065 - 5, 21. Juli 1889

913 Vgl.: StAEin 065 - 5, 25. Juli 1889

914 Vgl.: StAEin 065 - 5, 3. August 1889

915Vgl.: StAEin 065 - 5, 28. Juli 1889; 065 - 34, 31. Augst 1889
} 
fortbestehen lassen wolle; für den Oktober 1889 sei eine Statutenneufassung geplant. ${ }^{916}$ Dieses Vorhaben wurde in die Tat umgesetzt; in der einschlägigen Akte im Stadtarchiv Einbeck finden sich ein Statut und eine Mitgliederliste des Vereinigten Arbeiterclubs zu Einbeck vom Oktober 1889. Das Statut ist im Wesentlichen mit jenem aus dem Juni des selben Jahres identisch, allerdings wurde der Passus über den Verbleib des Vereinsvermögens im Falle der Auflösung dahingehend modifiziert, dass das Geld, falls keine anderen Arbeitervereine am Orte bestünden, an bedürftige Arbeiterfamilien zu verteilen sei. Die Mitgliederliste gleichen Datums zeigt, dass der Verein entgegen der Erwartung der Behörden gewachsen war; im Oktober 1889 zählte er 47 Mitglieder. 917 Ein Bericht des Magistrats an das Regierungspräsidium in Hildesheim aus dem März 1890 belegt, dass der Arbeiterclub zu diesem Zeitpunkt immer noch bestand und tätig war. 918

Der unterdessen erfolgte Fall des Sozialistengesetzes im Januar 1890 eröffnete den Parteigängern der Sozialdemokraten nach annähernd zwölf Jahren erneut die Möglichkeit, sich wie die Anhänger aller anderen Parteien in politischen Vereinen lokal $\mathrm{zu}$ organisieren. Für die Einbecker Sozialdemokraten bestand jedoch kein akuter Bedarf einer sofortigen Reorganisation, hatte man doch mit dem Vereinigten Arbeiterclub und nach wie vor mit dem Zigarrenarbeiter-Gesangverein eine prinzipiell funktionsfähige lokale Parteiorganisation - das oben bereits erwähnte Sommerfest dieses Vereins im Jahre 1890, auf dem ein Delegierter zum Parteitag der SAP/SPD ${ }^{919}$ gewählt wurde, verdeutlicht dies. 920

In der Zeit des Sozialistengesetzes, in der die lokale Organisation der Einbecker Sozialdemokraten zwar erschwert, aber nicht unmöglich gemacht war, konnte auch der Stimmenanteil bei den Reichstagswahlen kontinuierlich gesteigert werden. Dieser war zu Beginn der achtziger Jahre des 19. Jahrhunderts zunächst stark zurückgegangen. Waren im ersten Wahlgang des Jahres 1877 in der Stadt noch 168 Stimmen auf den sozialdemokratischen Kandidaten entfallen, so konnten 1881 nur 32 Stimmen erzielt werden. Bei der

\footnotetext{
916 Vgl.: StAEin 065 - 5, 24. August 1889

917Vgl.: StAEin 065 - 5, Statut und Mitgliederliste des Vereinigten Arbeiterclubs zu

Einbeck, 15. Oktober 1889

918 Vgl.: StAEin 065 - 34, 28. März 1890

${ }^{919}$ Auf dem betreffenden Parteitag erfolgte die Umbenennung der Sozialistischen

Arbeiterpartei Deutschlands in Sozialdemokratische Partei Deutschlands.

920 Vgl. den Abschnitt über den Zigarrenarbeiter-Gesangverein in der vorliegenden Arbeit und Koch, Eberhard: Geschichte der SPD, S. 59
} 
Reichstagswahl 1887 stimmten dann bereits 240 Wähler für den Kandidaten der SAP, 1890 konnten gar 521 Stimmen erzielt werden. Mit diesem Ergebnis wurden die Sozialdemokraten, bezogen auf die Ergebnisse der Reichstagswahlen, die stärkste politische Kraft in Einbeck. ${ }^{921}$

Am Beginn des Jahres 1891 kamen, möglicherweise weil der Arbeiterclub nicht mehr bestand, ${ }^{922}$ erneute Bestrebungen auf, einen sozialdemokratischen Wahlverein ins Leben $\mathrm{zu}$ rufen. Unter dem Tagesordnungspunkt "Verschiedenes" einer öffentlichen Versammlung am 30. Januar 1891, deren Hauptthema Fragen der Alters- und Invalidenversicherung waren, wurde eine Wahlvereinsgründung angeregt und $\mathrm{zu}$ diesem Zwecke eine siebenköpfige Kommission gewählt. 923 Die Vereinsgründung sollte auf einer auf den 21. Februar angesetzten Versammlung vonstatten gehen. Da jedoch am gleichen Abend zwei Tanzveranstaltungen in anderen Gaststätten stattfanden, erschienen zu der Gründungsveranstaltung zu wenige Teilnehmer, als dass die Absicht in die Tat hätte umgesetzt werden können. 924

Ein erneuter Anlauf, einen sozialdemokratischen Verein zu gründen, wurde noch im selben Jahr unternommen. Im Anschluss an die Festreden der Maifeier 1891 regten der aus Hannover stammende Redner Magnus und der Einbecker August Müller erneut eine Wahlvereinsgründung an; wieder wurde zu diesem Behufe ein Komitee gewählt. 925 Über die tatsächliche Gründung oder gar Aktivitäten dieses Wahlvereins war den ausgewerteten Quellen nichts zu entnehmen; Eberhard Koch gibt die erwähnte Maifeier als Gründungsdatum an und sagt, dass der Verein kurzfristig bestanden, sich aber noch im Jahre 1891 wieder aufgelöst habe. ${ }^{926}$

Die organisatorische Schwäche der Einbecker Sozialdemokraten spiegelt sich auch in den regelmäßigen Berichten des Einbecker Magistrats an das Regierungspräsidium in Hildesheim wider. In diesen wurde das Verhalten der örtlichen Parteianhänger in den ersten Jahren nach dem Fall des

921 Vgl.: Koch, Eberhard: Geschichte der SPD, Anhang Nr. 4 und Koch, Eberhard: Woher wir kommen (1995), S. 167

922 Der oben zitierte Bericht (StAEin 065 - 34, 28. März 1890) stellt den letzten bekannten Beleg für die Existenz des Vereinigten Arbeiterclubs dar.

923 Vgl.: StAEin 065 - 34, 28./30. Januar 1891

924 Vgl.: StAEin 065 - 17, 20./21. Februar 1891

925Vgl:: StAEin 065 - 5, 16. April/3. Mai 1891 und

926 Vgl.: Koch, Eberhard: Geschichte der SPD, S. 60 f. und Koch, Eberhard: Woher wir kommen (1989), S. 6 
Sozialistengesetzes nahezu durchgängig als ruhig bezeichnet. 927 Allein im Bericht aus dem Frühjahr 1891, der Zeit der vergeblichen Reorganisationsbemühungen, wurde der vorgesetzten Behörde von "sehr rührigen" Sozialdemokraten berichtet. 928

Die Wahlergebnisse der Sozialdemokraten in dieser Zeit stehen in einem bemerkenswerten Kontrast zu ihrer lokalen Organisationsschwäche. Bei den Reichstagswahlen 1893 konnte das gute Wahlergebnis des Jahres 1890 sogar in geringem Maße gesteigert werden; bei dieser Wahl entfielen in Einbeck auf den sozialdemokratischen Kandidaten 526 Stimmen. ${ }^{929}$ Dieses Ergebnis konnte jedoch nur mit Hilfe von auswärts erzielt werden; der Wahlkampf vor dieser Reichstagswahl wurde in Einbeck von Osteroder Sozialdemokraten geführt. 930

$\mathrm{Zu}$ einer erneuten Vereinsgründung kam es gegen Ende des Jahres 1894; die einem undatierten Statut beiliegende Mitgliedsliste trägt einen behördlichen Eingangsvermerk vom 28. November 1894. Nach einem Bericht des Magistrats an das Regierungspräsidium wurde dieses Statut in einer Versammlung am 25. November 1894 beschlossen. ${ }^{931}$ Der neue Verein führte die Bezeichnung "Socialdemokratischer Wahlverein für den 11. Hannoverschen Wahlkreis Distrikt Einbeck"; in der Mitgliederliste waren 34 Vereinsmitglieder aufgeführt. ${ }^{932}$ Verschiedene schriftliche Mitteilungen des Vereinsvorstandes an die städtischen Behörden belegen eine zunächst regelmäßige Vereinstätigkeit. ${ }^{933}$ Doch auch dieser Wahlverein bestand nicht sehr lange; mit Schreiben vom 9. Dezember 1895 wurde dem Magistrat die Auflösung des Wahlvereins bekannt gemacht. 934

Über die lokale Parteiorganisation der Sozialdemokraten in der Folgezeit geben die Quellen nur ungefähren Aufschluss. In der regelmäßigen Berichterstattung des Magistrats über den Stand der sozialdemokratischen

\footnotetext{
927Vgl.: StAEin 065 - 34, 5. September 1890, 11. März 1892, 31. August 1892, 15. März 1893, 10. März 1894

928 StAEin 065 - 34, 16. März 1891

${ }^{92}$ Vgl.: Koch, Eberhard: Geschichte der SPD, Anhang, Nr. 4

930 Vgl.: Koch, Eberhard: Woher wir kommen (1989), S. 6

${ }^{931}$ Vgl:: StAEin 065 - 34, 28. Februar 1895

932Vgl.: StAEin 065 - 36, Undatiertes Statut des Sozialdemokratischen Wahlvereins für den

11. Hannoverschen Wahlkreis Distrikt Einbeck und anliegende Mitgliederliste

933Vgl:: StAEin 065 - 36, 2. Januar 1895, 4. Februar 1895, 5. März 1895, 18. März 1895, 27.

April 1895

934 Vgl.: StAEin 065 - 36, 9. Dezember 1895
} 
Bewegung für die zweite Hälfte der neunziger Jahre des 19. Jahrhunderts ist nahezu ausnahmslos von "rühriger" Tätigkeit der Einbecker Sozialdemokraten $\mathrm{zu}$ lesen. Doch diese Aussage bezieht sich in der Regel nicht nur auf unmittelbare Parteiaktivitäten und umfasst so auch beispielsweise die Tätigkeit der lokalen Gewerkschaften. 935 Über die Organisationsform der Partei im eigentlichen Sinne ist aus diesen Berichten nur wenig zu erfahren; ein Gründungsdatum des nächsten Wahlvereins war nicht zu ermitteln. Da jedoch in den schriftlichen Anmeldungen von Versammlungen sozialdemokratisch gesonnener Männer ab dem Beginn des Jahres 1897 wiederholt die Ausdrücke "Partei" und "Parteiversammlung" verwandt wurden 936, dürfte der nächste sozialdemokratische Wahlverein spätestens Ende 1896 gegründet worden sein. Dieser Verein hatte allerdings auch keinen dauerhaften Bestand; er löste sich im Juli 1899 auf. Doch bereits einen Monat später erörterten Einbecks Sozialdemokraten eine erneute Wahlvereinsgründung. 937 Ob diese jedoch umgehend zu Stande kam, konnte nicht ermittelt werden.

Aus dem November 1900 datiert ein erhaltenes Statut einer weiteren lokalen Parteiorganisation, dem Sozialdemokratischen Verein für Einbeck und Umgegend. Das Statut zeigt deutlich, dass dieser Verein nach der Aufhebung des Affiliationsverbotes ein Bestandteil sowohl der provinzialen als auch der reichsweiten Parteiorganisation war; offizielles Vereinsorgan war nach § 15 der Volkswille in Hannover, "in besonderen Fällen das Centralorgan der deutschen Sozialdemokratie". 938 Nach einer erhaltenen Mitgliederliste vom Januar 1901 zählte der Verein zu diesem Zeitpunkt 26 Mitglieder. 939 Zum Zeitpunkt der Erstellung der nächsten erhaltenen Liste der vereinsmäßig organisierten Sozialdemokraten Einbecks im Januar 1904 firmiert der lokale sozialdemokratische Verein wieder als Wahlverein. Dieser hatte am Jahresbeginn 190484 Mitglieder. 940

Offenbar brachte das erste Jahrzehnt des 20. Jahrhunderts in Einbeck den Durchbruch der Sozialdemokratischen Partei zu einer Massenbewegung; im

935Vgl.: StAEin 034 - 34, 28. Februar 1895, 26. August 1895, 26. Februar 1896, 4.

September 1896, 17. Februar 1897, 20. August 1897, 10. März 1898, 2. September 1898, 3.

März 1899, 29. August 1899

936 Vgl.: StAEin 065 - 34, 16. Januar 1897, 26. Februar 1897, 17. September 1897, 2. Juni

1898, 22. Juli 1898, 13. Januar 1899, 7. April 1899, 7. Juli 1899

937 Vgl.: StAEin 065 - 34, 5. August 1899, 28. 8. 1899

938 StAEin 065 - 38, November 1900

939Vgl.: StAEin 065 - 36, 5. Januar 1901

940 Vgl.: StAEin 065 - 36, Januar 1904 
Jahre 1907 wurden bereits 157 Einwohner Einbecks als Mitglieder des Wahlvereins geführt. Daneben hatte der Verein auch erstmals Mitglieder aus kleineren Ortschaften; acht Mitglieder wohnten in Salzderhelden, drei in Lüthorst, je zwei in Sievershausen und Dassel sowie je eines in Ahlshausen, Lauenberg und Üssinghausen. ${ }^{941}$ Dass Mitglieder aus Ahlshausen und Üssinghausen dem Verein beitraten, hat seinen Grund darin, dass es in Northeim, das diesen beiden Orten näher liegt als Einbeck, vor dem Ersten Weltkrieg keine Lokalorganisation der Sozialdemokratischen Partei gab. 942

Dass die Werbung für die sozialdemokratische Sache im agrarisch dominierten Umland der Stadt vor dem Ersten Weltkrieg nicht einfach war und bisweilen auf starken Widerstand stieß, illustriert eine Begebenheit aus dem Jahre 1903. In einem Überwachungsbericht der Einbecker Polizei wird ein Redner zitiert, der auf einer Versammlung der Einbecker Sozialdemokraten über die Agitation auf dem Lande berichtete: "Die Nationalen scheuen vor keinem Mittel zurück, für sich Stimmen von allen Seiten zu gewinnen. So hatten wir eine Scheune in Odagsen, die von einem Genossen zur Abhaltung einer Versammlung uns zur Verfügung gestellt war, als die Versammlung an dem betreffenden Abend ihren Anfang nehmen sollte, von der Feuerwehr, die zu diesem Zwecke alarmiert war, als Uebungsobject ausersehen.[sic] Hierbei wurde versucht, uns naßzuspritzen. Nach der Uebung sollen 100 Ltr. Bier für die Feuerwehr zum Besten gegeben worden sein."943

Ein wesentliches Anliegen der Sozialdemokraten im Kaiserreich war die Förderung der Gleichberechtigung von Männern und Frauen. Auch in Einbeck wurden ab den neunziger Jahren des 19. Jahrhunderts wiederholt Versammlungen für Mädchen und Frauen angeboten, in denen deren rechtliche Ungleichstellung thematisiert wurde. ${ }^{94}$ Da nach den geltenden Gesetzen die Mitgliedschaft von Frauen in politischen Vereinen nicht erlaubt war, wurde 1907 ein der sozialdemokratischen Lokalorganisation angeschlossener Frauen-

${ }^{941} \mathrm{Vgl} .:$ StAEin 065 - 36, 1. Mai 1907

942 Vgl.: Grebing, Helga: Zur Geschichte der Arbeiterbewegung in Niedersachsen 1866 1914. in: Niedersächsisches Jahrbuch für Landesgeschichte, Band 53 (1981). SS. 87 - 106, S. 97

943 StAEin 065 - 38, 12. Juni 1903

944 Vgl.: StAEin 065 - 5, 17. März 1890; 065 - 34, 19. Januar 1890, 14. Mai 1897, 20. August 1897, 24. November 1898, 26. August 1911, 8. März 1914; 065 - 38, 18. April 1897; 065 - 39, 9. Februar 1914 
und Mädchenbildungsverein gegründet. ${ }^{945}$ Als weitere Nebenorganisation wurde 1912 ein Jugendausschuss gebildet. 946

Neben dem auf Einbeck und Umgegend beschränkten Lokalverein der Sozialdemokratischen Partei bestand ab 1903 auch eine den gesamten 11. Hannoverschen Reichstagswahlkreis umfassende Sozialdemokratische Parteiorganisation. Mit der Schaffung dieser Kreispartei wurde eine entsprechende Bestimmung des Jenaer Parteistatuts des Jahres 1905 vorweggenommen. ${ }^{947}$ Dass diese Kreispartei ihren Sitz in Einbeck hatte, und dass ferner sämtliche Vorsitzenden und Kassierer wie auch zahlreiche weitere Vorstandsmitglieder von den Einbecker Parteigenossen gestellt wurden, dürfte deutlich machen, dass die Einbecker Organisation der Sozialdemokratischen Partei im ersten Jahrzehnt des 20. Jahrhunderts ihre in der neunziger Jahren des 19. Jahrhunderts gezeigte Instabilität überwunden und sich $\mathrm{zu}$ einer wesentlichen politischen Kraft im südhannoverschen Raum entwickelt hatte. 948

945 Vgl.: StAEin 065 - 38, 18. April 1907; Koch, Eberhard: Geschichte der SPD, S. 93;

Eintracht Einbeck, Protokoll 1. Februar 1908

946 Vgl.: Koch, Eberhard: Geschichte der SPD, S. 93

947Vgl.: Koch, Eberhard: Geschichte der SPD, SS. 73 f.; Nipperdey, Thomas: Organisation,

S. 319

948Vgl.: StAEin 065 - 39, passim und Koch, Eberhard: Woher wir kommen (1989), S. 7 


\section{8. 3. Die Vereine der Deutsch-Hannoverschen Partei}

Die Deutsch-Hannoversche Partei wurde und wird häufig auch als Welfenpartei bezeichnet; letztere Bezeichnung gibt einen deutlicheren Aufschluss über die Ursprünge dieser politischen Bewegung, die in den Geschehnissen und vor allem den Folgen des innerdeutschen Krieges des Jahres 1866 liegen. In diesen Krieg, der in der Literatur häufig auch als Preußisch-Österreichischer Krieg bezeichnet wird, war das Königreich Hannover wie verschiedene andere deutsche Staaten involviert; die Folge für Hannover war die Absetzung Königs Georgs V. und die rechtlich fragwürdige Einverleibung Hannovers als eine Provinz in den Staatsverband des siegreichen Preußen. 949

Diese Annexion rief in weiten Kreisen der Bevölkerung Widerspruch hervor. Es entstand eine politische Bewegung, die in den Parlamenten als Deutsch-Hannoversche Partei in Erscheinung trat und ab 1869/70 mit dem Hannoverschen Wahlverein eine außerparlamentarische Zentralorganisation hatte. 950

Die Anhängerschaft der Deutsch-Hannoverschen Partei war sozial sehr heterogen; in ihr waren Teile der Beamtenschaft ebenso $\mathrm{zu}$ finden wie orthodoxe lutherische Geistliche; wesentliche Träger der Bewegung waren Angehörige des traditionellen Handwerks und der Bauernschaft.951 Die politische Grundtendenz der Partei war vor allem antipreußisch und konservativ; man erstrebte die Wiederherstellung des Königreichs Hannover unter der Herrschaft der Welfendynastie. Wenn Hans-Georg Aschoff als

\footnotetext{
949 Eine eingehendere Erörterung dieses Themenkomplexes kann und soll in dieser Arbeit nicht geleistet werden, verwiesen sei in diesem Zusammenhang vor allem auf die einschlägigen Aufsätze in: Sabelleck, Rainer (Hg.): Hannovers Übergang vom Königreich zur preußischen Provinz 1866. Beiträge zu einer Tagung am 2. 11. 1991 in Göttingen. (Schriftenreihe des Landschaftsverbandes Südniedersachsen, Band 1). Hannover 1995, sowie auf Barmeyer, Heide: Hannovers Eingliederung in den preußischen Staat, Annexion und administrative Integration. Hildesheim 1983. Zu der Frage der Annexion Hannovers durch Preußen, insbesondere deren Rechtmäßigkeit vgl.: Huber, Ernst Rudolf: Deutsche
} Verfassungsgeschichte seit 1789. Band III, Bismarck und das Reich. 3. überarbeitete Auflage, Stuttgart, Berlin, Köln, Mainz 1988, SS. 578 ff.

950 Vgl.: Aschoff, Hans Georg: Die welfische Bewegung und die Deutsch-hannoversche Partei zwischen 1866 und 1914. in: Niedersächsisches Jahrbuch für Landesgeschichte, Band 53 (1981). SS. 41 - 64, SS. 47 f.

951 Vgl.: Aschoff, Hans Georg: op. cit., S. 42 
Hauptgegner der DHP die Konservativen, die Nationalliberalen und die Sozialdemokraten nennt ${ }^{952}$, so verdeutlicht dies, dass sich die Partei im Grunde in die Rolle einer Fundamentalopposition begab, die sich einerseits zu einer regionalen Volkspartei 953 entwickelte, andererseits aber auch für Protestwähler attraktiv war.

In den einschlägigen Aktenbeständen des Einbecker Stadtarchivs finden sich für die ersten zwanzig Jahre des Untersuchungszeitraumes kaum Belege für Aktivitäten von Parteigängern der Welfenpartei. Im Jahre 1877 wurde den städtischen Behörden eine öffentliche Versammlung "von Männern der Deutsch-Hannoverschen Partei" angekündigt. ${ }^{954}$ Der nächstjüngere Beleg für eine solche Versammlung stammt aus dem Jahre 1893.955 Im Vorfeld der Reichstagswahlen kamen Mitglieder des Einbecker Kriegervereins in den Verdacht, Wahlwerbung für den Kandidaten der Deutsch-Hannoverschen Partei gemacht zu haben, was zu ihrem Ausschluss aus dem Verein führte. ${ }^{956}$ Im selben Jahr hatte der Magistrat an den Regierungspräsidenten in Hildesheim berichtet: "Die welfische Parthei ist in unserer Stadt sehr zusammengeschmolzen und hat hier für ihre Agitation kein geeignetes Feld mehr". 957

Der Mangel an Dokumenten über die Aktivitäten von welfisch gesonnenen Männern deutet darauf hin, dass die Anhänger der Deutsch-Hannoverschen Partei, die es, wie die Wahlergebnisse jener Zeit belegen ${ }^{958}$, zweifellos in Einbeck gab, allenfalls eine lose informelle Organisation hatten. Dies änderte sich erst mit der Gründung des Wahlvereins Jung Hannover für Einbeck und Umgegend.

Die Gründung dieses Vereins zeigte der Reisende Heinrich Rüttgerodt dem Magistrat in einem Schreiben vom 22. Januar 1896 an, dem eine Liste der Vorstandsmitglieder und das Gründungsstatut des Vereins beilagen.

Seinem Namen entsprechend bezweckte der Verein nach $§ 2$ die Erzielung möglichst guter Wahlergebnisse für die Deutsch-Hannoversche Partei. Allerdings wollte man nicht nur im Vorfeld von politischen Wahlen aktiv sein; $\S 7$ des Statuts legte regelmäßig alle 14 Tage stattfindende Vereinsabende

\footnotetext{
952 Vgl.: Aschoff, Hans Georg: op. cit., S. 59

953 Vgl.: Aschoff, Hans Georg: op. cit., S. 55

954 StAEin 065 - 41, 20. September 1877

955 Vgl.: StAEin 065 - 41, 12. Juni 1893

956Vgl.: StAEin 065 - 18, 3. September 1890

957 StAEin 065 - 5, 17./18. März 1890

958Vgl.: Koch, Eberhard: Geschichte der SPD, Anhang, Nr. 4
} 
fest. 959 Die mit der Absicht, regelmäßige Treffen welfisch gesonnener Männer abzuhalten, erfolgte Gründung des WV Jung Hannover in Einbeck folgte einem $a b$ den ausgehenden achtziger Jahren des 19. Jahrhunderts einsetzenden, die ganze Provinz umfassenden, Trend zur Gründung von örtlichen Vereinen von Anhängern der Deutsch-Hannoverschen Partei unter Namen wie "Ernst August", "Sachsenroß" oder eben "Jung Hannover". Diese zunehmende organisatorische Formierung ist als Reaktion auf die rückläufigen Stimmergebnisse der Welfenpartei bei den Reichstagswahlen anzusehen. 960

Der vierzehntägige Turnus der Vereinsversammlungen erwies sich rasch als zu kurz; noch im Gründungsjahr wurde beschlossen, sich nur im vierwöchentlichen Rhythmus $\mathrm{zu}$ treffen. ${ }^{961}$ Neben den regelmäßigen Versammlungen veranstaltete der WV Jung Hannover Feste zu besonderen Anlässen wie Geburtstagen von Mitgliedern der ehemaligen Hannoverschen Königsfamilie oder zu Jahrestagen der Schlacht bei Langensalza ${ }^{962}$, die bis über den Untersuchungszeitraum hinaus ein Symbol des welfischen Widerstandes gegen die Annexion Hannovers darstellte. ${ }^{963}$ Solche Feiern waren häufig kaum mehr als gemütliche Zusammenkünfte, auf denen althannoversche Nostalgie gepflegt und gebetsmühlenartig das Unrecht von 1866 beklagt wurde. 964

Bisweilen nahmen sie jedoch den Charakter einer politischen Kundgebung an. Als Beispiel mögen Auszüge aus einem polizeilichen Überwachungsbericht eines Festkommerses des Vereins anläßlich des Geburtstages Herzog ErnstAugusts von Cumberland, der als Sohn des 1878 gestorbenen letzten hannoverschen Königs Georg V. die Thronansprüche seiner Familie aufrecht erhielt, im Jahre 1896 dienen. Polizeisergeant Brüning berichtete von dieser Feier, auf der vier auswärtige Redner auftraten, über die Rede eines gewissen

959Vgl.: StAEin 065 - 41, 22. Januar 1896 mit Anlagen

960 Vgl.: Aschoff, Hans-Georg: op. cit., SS. 57 f.

961 Vgl.: StAEin 065 - 41, 28. Mai 1896

962 Vgl.: StAEin 065 - 41, passim

${ }^{963}$ Die Schlacht bei Langensalza in Thüringen war das letzte Gefecht der Hannoverschen

Armee 1866. In diesem Gefecht konnten preußische Truppen zwar besiegt werden, doch musste die Hannoversche Armee kurz darauf, da sie vom Feind umstellt war, kapitulieren. Zum Symbolcharakter der Schlacht vgl.: Schubert, Ernst: Die Schlacht bei Langensalza. in:

Sabelleck, Rainer (Hg.): Hannovers Übergang vom Königreich zur preußischen Provinz 1866.

Beiträge zu einer Tagung am 2. 11. 1991 in Göttingen. (Schriftenreihe des

Landschaftsverbandes Südniedersachsen, Band 1). Hannover 1995, SS. 101 - 124, S. 101 ff.

964 Vgl.: StAEin 065 - 41, passim 
Frick: "Derselbe verglich den früheren Minister Leonhardt mit dem Verräther Judas Ischariott [sic], weil derselbe erst dem König von Hannover und dann sofort nach der Annexion von Hannover dem König von Preußen die Treue gelobt habe. Der national-liberalen Parthei sei alles gleich ob sie heute Preußisch, morgen Russisch oder Türkisch würde, wenn sie nur ihren Vortheil davon hätten. Frick brachte dann ein Hoch auf die Herzogin von Cumberland aus." Ein weiterer Redner habe hinzugefügt, "daß er auch Soldat gewesen und daß sie ihn auch in die preußische Reserve geschleppt hätten. Mit seinem Herzen würde er aber niemals preußischer Soldat werden." 965

Auf Grund solcher Reden sahen die städtischen Behörden alle Festveranstaltungen des WV Jung Hannover als politische Versammlungen an und legten großen Wert darauf, dass zu diesen keine Frauen zugelassen wurden; Anträge des Vereins, zu verschiedenen welfischen Gedenktagen Festbälle veranstalten zu dürfen, wurden daher häufig abschlägig beschieden. 966

Im Mai 1900 war Einbeck Schauplatz einer der seit 1895 alljährlich abgehaltenen Landeskonferenzen der Deutsch-Hannoverschen Partei. Aus diesem Anlass versammelten sich ungefähr 500 Delegierte aus der gesamten Provinz im Rheinischen Hof. 967

Die unmittelbaren Aktivitäten des WV Jung Hannover beschränkten sich nicht auf die Stadt Einbeck. Versammlungen in den Dörfern des Landkreises sind nachweisbar ${ }^{968}$, auch hatte der Verein mehrere Mitglieder in verschiedenen Ortschaften des Landkreises. Dies ergab eine Auswertung der verschiedenen Nachrichten über Ein- und Austritte, die sich für die Zeit von Januar 1898 bis Dezember 1902 erhalten haben. 969

\footnotetext{
965StAEin 065 - 41, 28. September 1896 Vermerk; 8. August 1898

967Vgl.: StAEin 065 - 40 und 065 - 41, 1900, passim

968Vgl.: StAEin 065 - 41, 17. Februar 1901, 9. Juni 1901

${ }^{969} \mathrm{Vgl} .:$ StAEin 065 - 41, passim
}

966 Vgl.: StAEin 065 - 41, 10. August 1896, Vermerk vom 18. August 1896 ; 20. Januar 1898, 
Mitgliederbestand WV Jung Hannover Einbeck

$\begin{array}{lllll}\text { Zeit } & \begin{array}{l}\text { Mitgl. } \\ \text { gesamt }\end{array} & \begin{array}{l}\text { davon } \\ \text { nicht aus } \\ \text { Einbeck }\end{array} & \begin{array}{l}\text { Zahl der } \\ \text { Herkunftsorte der } \\ \text { Auswärtigen } \\ \text { Dörfer }\end{array} & \begin{array}{l}\text { Städte } \\ 01 / 98\end{array} \\ & 80 & 13 & 4 & 1 \\ 03 / 98 & 83 & 14 & 5 & 1 \\ 04 / 99 & 77 & 15 & 6 & 1 \\ 09 / 99 & 73 & 14 & 7 & 1 \\ 01 / 00 & 74 & 14 & 7 & 1 \\ 12 / 00 & 67 & 11 & 5 & 1 \\ 01 / 01 & 84 & 21 & 10 & 1 \\ 06 / 01 & 76 & 16 & 8 & 1 \\ 12 / 01 & 71 & 17 & 8 & 1\end{array}$

Der Wahlverein Jung Hannover Einbeck hatte trotz seiner organisatorischen Wirksamkeit nur wenige Jahre Bestand. Eine Vereinsversammlung beschloss am 1. Dezember 1901, dass der Verein in einer zu diesem Zwecke einzuberufenden Versammlung am 5. Januar 1902 aufgelöst werden solle. Dies sollte geschehen, um die Kräfte der Deutsch Hannoverschen Partei in der Region zu bündeln; die Aktivitäten im Sinne der Deutsch-Hannoverschen Partei sollten fortan unter dem Dach des in Northeim ansässigen Wahlvereins für den 11. Hannoverschen Reichstagswahlkreis betrieben werden. Die Versammlung vom 5. Januar fasste den beabsichtigten Beschluss; noch mit gleichem Datum wurde der Ortspolizeibehörde schriftlich die Auflösung Jung Hannovers bekannt gemacht. 970

Eine im Januar 1902 mit dem Vermerk "Vertraulich" vom Regierungspräsidenten an die städtische Polizeiverwaltung übersandte Liste vom 45 Einbecker Mitgliedern des Deutsch-Hannoverschen Wahlvereins für den 11. Hannoverschen Wahlkreis zeigt, dass der größte Teil der Einbecker Mitglieder des WV Jung Hannover die Fusion mit der Northeimer Wahlkreisorganisation vollzogen hatte. ${ }^{971}$

Die Fusion mit dem Northeimer Kreisverein verringerte die Frequenz der in Einbeck abgehaltenen Versammlungen und Feiern der Welfenpartei zunächst

970 Vgl.: StAEin 065 - 41, 1. Dezember 1901, 5. Januar 1902

971 Vgl.: StAEin 065 - 41, Anlage zu 29. Januar 1902 
nicht erkennbar. 972 Offenbar trafen sich die Einbecker Mitglieder häufiger unterhalb der Ebene des Northeimer Vereins. In einem Polizeibericht über eine Versammlung vom Mai 1902 ist gar von einer "Ortsgruppe Einbeck" zu lesen ${ }^{973}$, doch dürfte der Zusammenschluss der Einbecker Mitglieder einen eher informellen Charakter gehabt haben.

Ab 1903 werden die Belege für Aktivitäten der Welfenpartei in Einbeck in den Akten der städtischen Behörden sehr selten. 974 Dies kann allenfalls zum Teil auf ein nachlassendes Interesse der Behörden für die in Fundamentalopposition zum preußischen Staat stehende Organisation zu erklären sein; offenbar wirkte sich die Größe des Einzugsgebiets des Northeimer Wahlvereins doch hemmend auf die lokalen Aktivitäten der am Rande des Wahlkreises wohnenden Einbecker Anhänger der DeutschHannoverschen Partei aus.

Im Jahre 1907 kam es dann zu einer erneuten Gründung einer Einbecker Lokalorganisation der DHP. Mit Schreiben vom 16. April dieses Jahres wurde der städtischen Polizeibehörde die Gründung des Deutsch-Hannoverschen Vereins Einbeck angezeigt, das jenem des vormaligen Wahlvereins Jung Hannover in wesentlichen Bestimmungen sehr ähnliche Statut und eine Mitgliederliste lagen der Meldung bei. Die Mitgliederliste umfasst die Namen von 50 Männern; 40 Einwohnern Einbecks und 10 weiteren aus 7 Dörfern im Einbecker Umland. 975

Die Neugründung eines Ortsvereins der Welfenpartei brachte zumindest kurzfristig einen deutlichen Aufschwung für die Deutsch-Hannoversche Bewegung in Einbeck und Umgebung. In einem Schreiben aus dem Oktober 1907 vermeldet der Verein 42 Neueintritte. Die Agitation war offenbar besonders in den Dörfern erfolgreich; 20 der 42 Neumitglieder waren außerhalb der Stadt Einbeck ansässig. Besonders groß war der Zulauf in Edemissen; zu den zwei Edemisser Gründungsmitgliedern des DeutschHannoverschen Vereins Einbeck gesellten sich innerhalb eines guten halben Jahres 16 weitere aus dem selben Dorf. ${ }^{976}$ Da weitere Belege über Ein- und Austritte in den Verein fehlen, können über die Mitgliederentwicklung keine Angaben gemacht werden.

\footnotetext{
972 Vgl.: StAEin 065 - 41, 9. Februar 1902 bis 14. Juni 1903

${ }^{973}$ StAEin 065 - 41, 11. Mai 1902

974 Vgl.: StAEin 065 - 41, 14. Juni 1903 bis 18. August 1907

975 Vgl.: StAEin 065 - 40, 16. April 1907 mit Anlagen

976 Vgl.: StAEin 065 - 40, 18. Oktober 1907
} 
Mit dem Deutsch-Hannoverschen Verein gaben sich die Anhänger der welfischen Bewegung die bis über den Untersuchungszeitraum hinaus bestehende Organisation.

Über die Sozialstruktur der organisierten Mitglieder der Welfenpartei geben die oben angegebenen Quellen deutlichen Aufschluss. Wie bereits in der zitierten allgemeinen Literatur beschrieben, dominierten auch in Einbeck die Handwerker. Die große Zahl der Mitglieder in kleinen Dörfern des Landkreises zeigt, dass auch Landwirte sehr empfänglich für die Agitation der DHP waren. Neben diesen Gruppen finden sich in den verschiedenen Dokumenten über die Organisationen der Welfenpartei aber auch die Namen von selbständigen Kaufleuten und Gewerbetreibenden, sowie von Arbeitern und mit Fortschreiten der Zeit auch vereinzelt von Angestellten. Zusammenfassend kann daher gesagt werden, dass die Deutsch-Hannoversche Partei in Einbeck und Umgebung eine hohe sozial integrative Kraft entwickelte. Die Aussage Hans Georg Aschoffs, die DHP sei "eine Art Volkspartei auf regionaler Basis"977 gewesen, trifft für die Verhältnisse im Untersuchungsraum durchaus zu. 


\section{8. 4. Der Nationalliberale Verein}

Die Nationalliberale Partei stellte den rechten Flügel des in der Tradition der Paulskirchenfraktionen stehenden liberalen Parteienspektrums dar. Obwohl sie der preußischen Hegemonie im 1871 gegründeten deutschen Nationalstaat positiv gegenüberstand, war sie keine rein preußische Partei. Ihre Hochburgen lagen in Süddeutschland, in Mecklenburg und in dem erst seit 1866 zu Preußen gehörenden Hannover. ${ }^{978}$ Nachdem mit der Reichsgründung eines der Kernanliegen der Liberalen des 19. Jahrhunderts erfüllt worden war, wurde die innere Ausgestaltung des Reiches im Sinne einer Konstitutionalisierung und einer liberalen Wirtschaftsverfassung zu einem Hauptziel der Nationalliberalen. Dies führte spätestens ab 1879 im Streit um Zoll- und Steuerpolitik zu einem Bruch wesentlicher Teile der Partei mit dem preußischkonservativen Reichskanzler Bismarck, nachdem man bis dahin im Großen und Ganzen mit der Reichsregierung kooperiert hatte. ${ }^{979}$ Im Kontext dieses Konfliktes kam es zu Abspaltungen von der Partei. Zudem führte auch das allmähliche Erstarken der Sozialdemokratie für die Nationalliberale Partei, auf das gesamte Reich gesehen, zu einem Rückgang der Stimmanteile. Allerdings konnte die regionale Hochburg in der Provinz Hannover, wenn auch mit gewissen Verlusten, bis ins beginnende 20. Jahrhundert gehalten werden. 980

Die erste Gründung einer festen Lokalorganisation der Nationalliberalen Partei in Einbeck erfolgte im Frühjahr 1893; ein erhaltenes Druckexemplar der Vereinsstatuten aus dem Jahre 1907 nennt den 22. März 1893 als den Tag, an dem das Statut beschlossen wurde. ${ }^{981}$ Nach $\S 1$ der Statuten bezweckte der Verein "die Bestrebungen der nationalliberalen Partei in Deutschland, namentlich bei den Wahlen, zu fördern". Die folgende Präzisierung dieses Zweckes verdeutlicht, dass man unter einer Partei keine feste Organisation verstand; es sei die Zielsetzung des Vereins, "bei allen politischen Wahlen [...] für die Wahl gut deutsch gesinnter Männer zu wirken", ferner "alle politischen

978 Vgl.: Born, Karl Erich, op. cit., S. 27

979Vgl.: Born, Karl Erich, op. cit., SS. $131 \mathrm{ff}$.

$980 \mathrm{Zu}$ den Wahlergebnissen in der Provinz Hannover vgl.: Leuschner, Jörg: Osterode -

Politisches, verwaltungsmäßiges und wirtschaftliches Zentrum des Südwestharzes von 1807 bis 1918. in: Ders.(Hg.): Osterode. Welfensitz und Bürgerstadt im Wandel der Jahrhunderte.

Hildesheim, Zürich, New York 1993, SS.321 - 423, S. 338

${ }^{981}$ Das Statutenexemplar befindet sich in StAEin 065 - 21. Unterakte Nationalliberaler Verein 
Bestrebungen, welche auf Förderung der Landwirtschaft und des Gewerbes, sowie auf Bewahrung des sozialen Friedens abzielen, zu unterstützen".982

Voraussetzung für die Mitgliedschaft im Verein war das aktive Wahlrecht zum Reichstag. Die Mitglieder des Vereins wurden registriert, eine Verpflichtung zum Entrichten regelmäßiger Beiträge bestand jedoch nicht. 983 Ein Zirkular aus dem November des Gründungsjahres, mit dem die Mitglieder des Vereins zur Teilnahme an einer Volksversammlung mit dem Reichstagsabgeordneten Jorns aufgefordert wurden, trägt die Namen von 59 Mitgliedern. Mit dem noch im selben Jahr zum Bürgermeister ernannten Paul Troje, den beiden Senatoren Steinberg und Domeier sowie Stadtbaumeister Jürgens und Stadtkämmerer Banse findet sich unter den Mitgliedern die gesamte politisch-administrative Spitze der Stadtverwaltung. Die übrigen Mitglieder rekrutierten sich, so weit den aufgelisteten Namen ein Beruf zugeordnet werden konnte, mit Fabrikanten, wohlhabenden Kaufleuten und Handwerkern, Großbauern, zwei Oberlehrern und dem Königlichen Kreisarzt, aus den verschiedenen bürgerlichen Eliten der Stadt. ${ }^{984}$

Dass die politische Führung der Stadt in den Händen eines nationalliberalen Kommunalpolitikers lag, war kein Novum; bereits der von 1866 bis 1879 amtierende Bürgermeister Ludowieg war einer von zahlreichen städtischen Würdenträgern in der preußischen Provinz Hannover, die der Nationalliberalen Partei angehörten. ${ }^{985}$ Auch bei den Reichstagswahlen erreichten die Kandidaten der Nationalliberalen Partei bis in die achtziger Jahre des 19. Jahrhunderts in Einbeck stets die höchste Stimmenzahl. 986

Ob die Organisation der Einbecker Anhänger der Nationalliberalen Partei in einem festen Verein nur dem allgemeinen Trend zur Entstehung festerer Strukturen innerhalb der politischen Parteien folgte, oder ob die Vereinsgründung als eine Reaktion auf das Erstarken der Sozialdemokratie in Einbeck nach dem Fall des Sozialistengesetzes anzusehen ist, kann nicht mehr geklärt werden.

Die älteste Mitgliederliste des Nationalliberalen Vereins Einbeck im eigentlichen Sinne datiert aus dem Oktober 1896. Sie umfasst 66 Namen; eine

\footnotetext{
982 Vgl:: StAEin 065 - 21, Unterakte Nationalliberaler Verein, Statutenexemplar 1893/95, § 1

983 Vgl:: StAEin 065 - 21, Unterakte Nationalliberaler Verein, Statutenexemplar 1893/95, §§

$2,3,11$

984 Vgl:: StAEin 065 - 21, Unterakte Nationalliberaler Verein, 2. November 1893

985Vgl.: Hamann, Manfred: Politische Kräfte und Spannungen in der Provinz Hannover. in:

Niedersächsisches Jahrbuch für Landesgeschichte, Band 53 (1981). SS. 1 - 40, S. 27

986Vgl.: Koch, Eberhard: Geschichte der SPD, Anhang, Nr. 4
} 
berufsständische Analyse des verzeichneten Personenkreises hatte ein nahezu identisches Ergebnis wie jene der 59 für das Jahr 1893 nachgewiesenen Vereinsmitglieder. 987

In den folgenden Jahren nahm der organisierte Nationalliberalismus in Einbeck einen weiteren Aufschwung. Eine Mitgliederliste aus dem Jahre 1903 führt 92 Einwohner der Stadt Einbeck auf, deren soziale Zusammensetzung jener der früheren Jahre entspricht. Außerdem hatten sich auch Männer aus dem Umland der Stadt dem Nationalliberalen Verein angeschlossen. Neben dem Oberamtmann in Wetze und den beiden Fabrikanten und dem Gastwirt von der Juliusmühle führt die Liste auch 25 Einwohner des von Handwerk und Handel geprägten Fleckens Markoldendorf; wie die Einbecker, so stellten auch die Markoldendorfer Mitglieder mit dem Bürgermeister, dem Tierarzt und dem Apotheker, beiden Mühlenbesitzern und verschiedenen Kaufleuten und Handwerksmeistern die wirtschaftliche und politisch-administrative Elite ihrer Gemeinde dar. 988

Die Organisierung der Anhänger der Partei breitete sich im ersten Jahrzehnt des 20. Jahrhunderts weiter in das Einbecker Umland aus; am 31. Juli 1907 wurde in Dassel ein Nationalliberaler Verein gegründet. ${ }^{989}$ Die Markoldendorfer Nationalliberalen dürften sich entweder dem Dasseler Verein angeschlossen haben oder einen eigenen Ortsverein gegründet haben; sie fehlen in einer Mitgliederliste aus dem Jahre 1908. Diese Liste belegt ein starkes Anwachsen des Nationalliberalen Vereins; in diesem Jahr hatte er 211 Mitglieder in der Stadt Einbeck. Die bekannten bürgerlichen Wirtschafts-, Werte- und Funktionseliten waren weiterhin sehr stark vertreten, auch der nunmehrige Bürgermeister Gerhard W. Nedden gehörte dem Nationalliberalen Verein an. Der große Zuwachs der Mitgliederzahl lag darin begründet, dass sich neben vielen Selbständigen auch vermehrt Lehrer und Angehörige des Mittelstandes, insbesondere der wachsenden Gruppe der Angestellten, dem Verein angeschlossen hatten. Ferner werden die beiden Fabrikanten in Juliusmühle und sieben Dorfschullehrer der umliegenden Ortschaften Avendshausen, Edemissen, Hollenstedt, Hullersen, Immensen, Kuvental und Vardeilsen als Vereinsmitglieder aufgeführt. Dies ergibt eine Gesamtzahl von 220 im Einbecker Verein organisierten Nationalliberalen. 990

\footnotetext{
987 Vgl.: StAEin 065 - 21, Unterakte Nationalliberaler Verein, Anlage zu 21. Oktober 1896

988Vgl.: StAEin 065 - 21, Unterakte Nationalliberaler Verein, Mitgliederliste 1903

98 9 Vgl.: StAEin 065 - 21, Unterakte Nationalliberaler Verein, 7. August 1907

990 Vgl.: StAEin 065 - 21, Unterakte Nationalliberaler Verein, Mitgliederliste 1908.
} 
Über die tatsächliche Tätigkeit des Vereins gibt die einschlägige Akte im Stadtarchiv kaum Aufschluss. Lediglich sind vereinzelt, insbesondere im Vorfeld von Wahlen, öffentliche Versammlungen nachweisbar, auf denen Reichstagsabgeordnete als Redner auftraten. ${ }^{991} \mathrm{Ob}$ der Verein weitere, über das statutarisch festgelegte Mindestmaß von zunächst zwei Versammlungen, ab 1907 nur noch einer Generalversammlung pro Jahr ${ }^{992}$ hinaus reichende Aktivität entwickelte, ist anhand des bekannten Quellenmaterials nicht zu ermitteln gewesen.

${ }^{991}$ Vgl.: StAEin 065 - 21, Unterakte Nationalliberaler Verein, 2. November 1893, 21. Oktober 1896, 9. Februar 1911

992 Vgl.: StAEin 065 - 21, Unterakte Nationalliberaler Verein, Statutenexemplare 1893/95 und 1907, jeweils $§ 6$ 


\section{8. 5. Der Freisinnige Wahlverein}

Im Jahr der Gründung des Nationalliberalen Vereins erfolgte auch die Gründung einer linksliberalen Vereinigung in Einbeck. Am 28. Mai 1893 beschloss eine Versammlung von Anhängern der Freisinnigen Partei das Statut des Freisinnigen Wahlvereins Einbeck. Nach der Überschrift des Statuts war dieser Verein ein Unterverein der Deutschen Freisinnigen Partei. Statutenmäßiger Vereinszweck war, die Grundsätze dieser Partei "im Volke zu verbreiten und dadurch zu den Wahlen [...] die Wahl von Männern durchzusetzen, welche sich zu diesen Grundsätzen bekennen und kein Recht des Volkes aufgeben".993

Die Deutsche Freisinnige Partei war 1884 durch den Zusammenschluss einer 1880 von den Nationalliberalen abgespaltenen Vereinigung mit dem Namen Liberale Vereinigung und der älteren, bereits im ersten Reichstag vertretenen linksliberalen Fortschrittspartei entstanden. Im Jahre 1893 spaltete sich die Deutsche Freisinnigen Partei in die Freisinnige Volkspartei und die Freisinnige Vereinigung. ${ }^{994}$ Da das Statut des Einbecker Vereins vor dieser Spaltung formuliert und beschlossen wurde, war nicht $\mathrm{zu}$ ermitteln, welcher dieser beiden linksliberalen Parteien der Freisinnige Wahlverein später anhing.

Zum Zeitpunkt der Gründung des Vereins zählte dieser 49 Mitglieder, neben zwei Landwirten und einem Lehrer aus Odagsen und einem Kaufmann aus Juliusmühle gehörten ihm 45 Einwohner Einbecks an. Die Einbecker Mitglieder des Freisinnigen Wahlvereins rekrutierten sich vornehmlich aus dem Besitz-, in etwas geringerem Maße auch aus dem Bildungsbürgertum. ${ }^{995}$

Über die Tätigkeit des Vereins gaben die ausgewerteten Quellen nur geringen Aufschluss. Die dokumentierten Ergebnisse der Reichstagswahlen der Jahre 1898 und 1903 mit 153 und 116 in Einbeck erzielten Stimmen für den freisinnigen Kandidaten 996 sprechen für eine gewisse Wirksamkeit des Vereins. Eine undatierte Mitgliederliste aus der Zeit der Wende vom 19. zum 20. Jahrhundert zeigt jedoch, dass der Verein als Organisation weit weniger erfolgreich war; die Liste weist mit zwölf Namen eine äußerst geringe Mitgliederzahl aus. ${ }^{997}$ Diese Mitgliederliste stellt zugleich die letzte

\footnotetext{
993 StAEin 065 - 21, Unterakte Freisinniger Wahlverein, Statut vom 28. Mai 1893

994 Vgl.: Born, Karl Erich: op. cit., SS. 28, 137

995Vgl.: StAEin 065 - 21, Unterakte Freisinniger Wahlverein, Anlage zum Statut vom 28.

Mai 1893

996 Vgl.: Hülse, Horst: op. cit., S. 103

997Vgl.: StAEin 065 - 21, Unterakte Freisinniger Wahlverein, o. D. nach 11. Mai 1898
} 
Primärquelle über den Freisinnigen Wahlverein Einbeck dar. Die Adressbücher der Jahre ab 1902 führen den Verein in den einschlägigen Listen nicht auf. Der Umschlag zu der Unterakte über den Verein im Stadtarchiv Einbeck trägt einen Vermerk aus der Hand des städtischen Polizeibeamten Meyer vom 25. April 1913: "Der Verein ist nach Angabe des Fabrikanten Niemeyer schon seit langen Jahren aufgehoben". 998

998StAEin 065 - 21, Unterakte Freisinniger Wahlverein, Umschlag. Im April 1913 wurde Wachtmeister Meyer beauftragt, zu ermitteln, ob die Akten über die verschiedenen politischen Vereine noch auf dem neuesten Stande waren. Vgl. hierzu: StaEin 065 - 21, passim 


\section{8. 6. Die Konservative Vereinigung}

Der älteste vorliegende Beleg über eine Konservative Vereinigung datiert aus dem Sommer 1907. In der Anlage zu einem Schreiben vom 22. jenes Jahres übersandte der Landrat dem Magistrat der Stadt Einbeck ein Statutenexemplar der Konservativen Vereinigung des Kreises Einbeck zur Kenntnisnahme mit der Bitte um Rückgabe; da der Magistrat dieser Bitte nicht entsprach, blieb dieses undatierte Schriftstück im Stadtarchiv Einbeck erhalten.

Der Zeitpunkt der Sendung des Statuts lässt keinerlei Rückschlüsse auf den Gründungszeitpunkt des Vereins zu, da dieses Schriftstück im Zuge eines Briefwechsels zwischen Magistrat und Landrat angefordert wurde, der ursprünglich die Gründung des Nationalliberalen Vereins in Dassel zum Anlass hatte; der Magistrat hatte, nachdem sich der Landrat die Satzung des Nationalliberalen Vereins Einbeck leihweise erbeten hatte, im Gegenzug die Statuten politischer Vereine aus dessen Besitz angefordert. 999

Die Statuten der Konservativen Vereinigung des Kreises Einbeck befanden sich in der Behörde des Landrates, da der Verein seinen Sitz nicht in der Stadt Einbeck und damit außerhalb des Zuständigkeitsbereichs des Magistrats hatte; die Vereinigung hatte ihr Domizil in Oldendorf, einer etwa sieben Kilometer westlich von Einbeck gelegenen Ortschaft, die im Wesentlichen durch große landwirtschaftliche Betriebe gekennzeichnet war. 1000

Der Verein machte es sich zur Aufgabe, "die konservativ gesinnten Männer des Kreises Einbeck zu sammeln, konservative Gesinnung zu fördern und auf konservative Wahlergebnisse, insbesondere im Kreise Einbeck hinzuwirken". Dass das Tätigkeitsfeld über den Landkreis Einbeck hinaus reichen sollte impliziert die Bestimmung, dass als potenzielle Mitglieder alle Männer über 25 Jahre angesehen wurden, die im 11. Hannoverschen Reichstagswahlkreis wohnten. Wer dem Verein beitreten wollte, musste "unbescholten" sein und "einen guten Lebenswandel führen". Ein in den Augen der Funktionäre unguter Lebenswandel war ein möglicher Ausschlussgrund, die Eröffnung des

\footnotetext{
999Vgl:: StAEin 065 - 21, Unterakte Konservative Vereinigung, 22. August 1907 und Anlage; Unterakte Nationalliberaler Verein, 7. August 1907

1000 Vgl.: Plümer, Erich: Der Landkreis Einbeck. Geschichte und Gegenwart. Einbeck 1971,

S. 98. Oldendorf wurde 1936 mit dem bereits im Abschnitt über den Nationalliberalen Verein erwähnten Markoldendorf zu einer Ortschaft - Markoldendorf - vereinigt. Vgl. hierzu Jungmann, Wolf Bernd: Baugeschichte der Martinskirche in Markoldendorf. in: Einbecker Jahrbuch, Band 45 (1996), SS.97 - 132, S. 99
} 
Konkurses über das Vermögen eines Mitgliedes zog den Ausschluss zwingend nach sich. 1001

$\mathrm{Ob}$, und falls ja, wie viele Mitglieder der Verein in Einbeck hatte, ist auf Grund der Quellenlage nicht zu ermitteln gewesen.

Oldendorf war in der Folgezeit offenbar nicht der einzige Ort, an dem Vereinsversammlungen stattfanden. Eine Statutenneufassung wurde im Januar 1911 auf einer Versammlung in Northeim, also außerhalb des Landkreises Einbeck beschlossen. Mit diesem neuen Statut, das im Wesentlichen mit dem alten identisch war, wurde das statutenmäßige Einzugsgebiet auf den gesamten 11. Hannoverschen Reichstagswahlkreis ausgedehnt. Außerdem wurde die Konservative Vereinigung streng genommen erst $\mathrm{zu}$ diesem Zeitpunkt $\mathrm{zu}$ einem Verein, der in der vorliegenden Arbeit zu behandeln ist; Sitz der Konservativen Vereinigung war ab 1911 die Stadt Einbeck. 1002

Das vorhandene Quellenmaterial lässt kaum weiter gehende Aussagen über die Vereinigung und ihre Tätigkeit in Einbeck zu. Bekannt ist nur, dass 1911 mit dem Oberamtmann Rabbethge, dem Rendanten Wittram und Maurermeister Ohagen drei der zehn Vorstandsmitglieder in Einbeck ansässig waren 1003 und dass der Verein bis zum Ende des Untersuchungszeitraumes Bestand hatte. Vereinslokal der Konservativen Vereinigung des 11. Hannoverschen Wahlkreises war das Gasthaus zum Deutschen Haus. 1004

${ }^{1001}$ Vgl.: StAEin 065 - 21, Unterakte Konservative Vereinigung, Undatiertes Statut, §§ 1, 4, 5.

1002 Vgl.: StAEin 065 - 21, Unterakte Konservative Vereinigung, Statut vom 13. Januar 1911 1003 Vgl.: StAEin 065 - 21, Unterakte Konservative Vereinigung, Anlage zum Statut vom 13. Januar 1911

1004 Vgl.: Vereinslisten in den Adressbüchern 1911/12 und Juli 1912 


\section{8. 7. Der Bund der Landwirte}

Auch wenn es sich bei dem 1893 gegründeten Bund der Landwirte ohne jeden Zweifel in erster Linie um einen Interessenverband handelte und dessen Ortsgruppe somit nicht als Verein im Sinne der vorliegenden Untersuchung anzusehen ist, so muss der Einbecker Zweigverein des BdL an dieser Stelle erwähnt werden. Denn der Bund der Landwirte griff im Gegensatz zu anderen Verbänden des Kaiserreichs sehr direkt in das tagespolitische Geschehen ein. Er betrieb nicht nur die Interessenvertretung der im Verlaufe der Industrialisierung an Einfluss verlierenden Gruppe der vor allem in Nord- und Nordostdeutschland ansässigen Großagrarier, sondern bezog allgemeinpolitisch Stellung. Die Propaganda des Verbandes wird von Hans-Peter Ullmann als konservativ, nationalistisch, antisozialistisch, monarchistisch, antiliberal und nicht zuletzt antisemitisch charakterisiert. Auch übte man auf parlamentarischer Ebene großen Einfluss aus; eine nicht unbeträchtliche Anzahl der Reichstagsabgordneten hatte sich ab 1898 auf das Programm des Bundes verpflichtet, im Preußischen Abgeordnetenhaus waren 1908 gar mehr als die Hälfte der Mitglieder dem Bund der Landwirte zuzurechnen. 1005

Auch im 11. Hannoverschen Reichstagswahlkreis kandidierte bisweilen ein Vertreter des BdL; die in der Stadt erzielten Stimmenergebnisse in ersten Wahlgängen blieben jedoch mit 62 Stimmen im Jahre 1898, 60 im Jahre 1900 und 143 Stimmen 1907 recht bescheiden. 1912 kandidierte ein von BdL und Welfenpartei unterstützter Kandidat. Die 238 Stimmen, die dieser in Einbeck auf sich vereinigen konnte, dürften in der Mehrzahl von Anhängern der Welfenpartei gestammt haben. 1006

Primärquellen über eine Lokalorganisation des Bundes der Landwirte in Einbeck sind dem Autor nicht bekannt. Als erstes Adressbuch führt die Ausgabe für die Jahre 1911/12 einen Ortsverein des BdL in Einbeck auf. Da das nächst ältere Adressbuch diesen Verein noch nicht führt, muss die Zeit von 1907 bis 1911 als Gründungszeitraum angesehen werden. Das Vereinslokal des Einbecker Zweigvereins des Bundes der Landwirte war das Gasthaus zum Deutschen Haus.

1005 Vgl.: Ullmann, Hans-Peter: Interessenverbände in Deutschland. Frankfurt am Mai 1988, SS. $90 \mathrm{ff}$. 


\section{8. 8. Der Club Gemüthlichkeit}

Der Name des im Folgenden zu behandelnden Vereins legt zunächst Zweifel an dessen politischen Charakter nahe. Der Club Gemüthlichkeit wurde im Januar 1894 gegründet, Statut und Verzeichnis der Mitglieder wurden im darauf folgenden Monat beim Magistrat der Stadt Einbeck zur Genehmigung eingereicht. ${ }^{1007}$ Mit der Einordnung dieses Clubs unter die politischen Vereine folgt der Autor der Ansicht des Verfassers eines behördlichen Vermerks auf dem zitierten Schreiben. Dieser war der Meinung, dass die statutenmäßigen Vereinszwecke, nämlich "durch häufiges Zusammensein die Geselligkeit zu fördern, und einen gegenseitigen freundschaftlichen Verkehr zu bewirken und durch zeitweilige wissenschaftliche Vorträge, durch das Lesen patriotischer und jüdischer Zeitschriften auch die Interessen des Judentums nach Kräften zu fördern" 1008 einen durchaus politischen Charakter hätten. Der Verein schien "mit Rücksicht auf den Antisemitismus gegründet", und sei "daher als ein polit.[ischer] anzusehen".1009

Der Antisemitismus war eine nicht $\mathrm{zu}$ vernachlässigende politische Strömung im Kaiserreich. Insbesondere antijüdische Reden des Berliner Hofpredigers Stoecker und Publikationen des konservativen Historikers Treitschke machten verschiedene ab der Mitte der siebziger Jahre des 19. Jahrhunderts vereinzelt aufkommende antisemitische Polemiken ab dem Ende dieses Jahrzehnts für ein größeres Publikum akzeptabel. In jener Zeit entwickelte sich auch der pseudowissenschaftliche Begriff des "Antisemitismus" für die Abneigung oder den Hass gegen Juden. Ab den ausgehenden siebziger und frühen achtziger Jahren entstanden organisierte antisemitische Parteien und Sammlungsbewegungen. 1887 ließ sich mit dem Abgeordneten Boeckel erstmals ein Mitglied des Reichstages mit der Bezeichnung "Antisemit" in den Reichstagsalmanach eintragen. Im Reichstag von 1890 saßen fünf antisemitische Parlamentarier, derer vier die Fraktion der Antisemiten bildeten. Im Jahre 1893, also unmittelbar vor der Gründung des Clubs Gemüthlichkeit, stand der organisierte Antisemitismus auf dem Zenit seines Erfolges; in diesem Jahr konnten 16 Reichstagsmandate von den Antisemiten errungen werden. Zwar ging in der Folgezeit der Einfluss der antisemitischen Parteien zurück, doch hatten judenfeindliche Überzeugungen im konservativen Parteienspektrum wie auch in verschiedenen Verbänden wie

\footnotetext{
1007 Vgl.: StAEin 065 - 11, 19. Februar 1894 mit Anlagen

1008 StAEin 065 - 11, Vermerk auf 19. Februar 1894

1009 StAEin 065 - 11, Statut vom 19. Januar 1894 in der Anlage zu 19. Februar 1894
} 
dem Deutschnationalen Handlungsgehilfenverband, dem Bund der Landwirte oder Teilen der organisierten Studentenschaft Fuß gefasst. 1010

Vor diesem Hintergrund muss die auf zeitgenössischer Beobachtung beruhende behördliche Auffassung, dass es sich beim Club Gemüthlichkeit um eine anti-antisemitische Vereinsgründung gehandelt habe, durchaus plausibel erscheinen. Auch die soziale Zusammensetzung der Vereinsmitglieder ließe sich in diesem Sinne deuten. Der Verein zählte 24, durchweg jüdische, Mitglieder; neben 21 männlichen Einwohnern Einbecks gehörten ihm eine in Einbeck ansässige Witwe sowie ein Kaufmann und ein Schlachter aus Markoldendorf an. Unter den genannten 21 Männern aus Einbeck dominierten die selbständigen Kaufleute mit zehn Personen deutlich. Zu diesen gesellten sich zwei Fabrikanten und ein Lehrer sowie fünf Commis, von denen drei bei dem Verein angehörenden Kaufleuten angestellt waren. Dass sich wohlhabende Männer mit ihren eigenen Angestellten zur reinen Pflege der Geselligkeit zusammenschlossen, erscheint für den Untersuchungszeitraum, wie das Beispiel anderer Vereine zeigt, zumindest ungewöhnlich.

Allerdings wäre einer solchen Argumentation entgegenzuhalten, dass es sich bei den Mitgliedern des Clubs Gemüthlichkeit um Angehörige einer zwar de jure gleichberechtigten, jedoch nicht völlig assimilierten Minderheit handelte, was eventuell soziale Schranken innerhalb dieser Gruppe durchlässiger machte. Auch könnte $\mathrm{zu}$ bedenken gegeben werden, dass nähere oder weitere verwandtschaftliche Beziehungen zwischen jüdischen Kaufleuten und ihren Commis nicht selten waren. ${ }^{1011}$

Da weitere Belege für die Tätigkeit des Clubs Gemüthlichkeit fehlen, kann über die Frage, ob er, wenn er denn überhaupt ein regelrechtes Vereinsleben entwickelte, einen eher geselligen oder einen mehr politischen Charakter hatte, keine Aussage getroffen werden. Auch die städtischen Behörden waren sich in dieser Hinsicht möglicherweise nicht ganz so sicher, wie es der oben zitierte Beleg erscheinen lässt; die Unterlagen über den als politisch angesehenen Club

1010 Zur gesamten Entwicklung des Antisemitismus im Kaiserreich vgl.: Nipperdey, Thomas; Rürup, Reinhard: Antisemitismus - Entstehung, Funktion und Geschichte eines Begriffs. in: Nipperdey, Thomas(Hg.): Gesellschaft, Kultur, Theorie. Gesammelte Aufsätze zur Neueren Geschichte. (Kritische Studien zur Geschichtswissenschaft, Band 18). Göttingen 1976, SS. 113 - 132, SS. 119 ff. und Nipperdey, Thomas: Machtstaat, SS. 294 ff.

${ }^{1011}$ Vgl. e. g.: Gerdes, Susanne: Juden in Einbeck im 19. Jahrhundert. in: Heege, Elke (Hg.)Verloren aber nicht vergessen. Jüdisches Leben in Einbeck. (Studien zur Einbecker Geschichte, Bd. 15). Oldenburg 1998. SS. 17 - 72, S. 52 
befinden sich im Stadtarchiv Einbeck in der Akte mit dem Titel "GeselligkeitsVereine". 1012

1012 StAEin 065 - 11, Titel. Ob die Einordnung in diese Akte allerdings bereits in der Zeit der Vereinsgründung oder erst, womöglich wesentlich, später erfolgte, kann freilich nicht mehr geklärt werden. 


\section{8. 9. Die Ortsgruppe Einbeck des Reichsverbandes gegen die Sozialdemokratie}

Im Jahre 1908 wurde in Einbeck eine Ortsgruppe des 1906 gegründeten Reichsverbandes gegen die Sozialdemokratie gegründet. Zielsetzung des Dachverbandes, dessen Satzung für die Zweigvereine verbindlich war ${ }^{1013}$, sollte nach $\S 2$ seines Statuts sein, "alle in Treue zu Kaiser und Reich stehenden Deutschen ohne Unterschied ihrer religiösen und politischen Stellung zum Kampf gegen die antimonarchistischen und revolutionären Bestrebungen der Sozialdemokratie zu einigen".

Der Verband sollte nach seiner Satzung ein Sammelbecken aller antisozialistischen Kräfte im Reich werden; nicht nur natürliche Personen, sondern auch ganze Vereine konnten Mitglied werden. ${ }^{1014}$ So traten in Einbeck der Nationalliberale Verein wie auch die Konservative Vereinigung in corpore der Einbecker Ortsgruppe bei. Neben diesen beiden Vereinen waren 35 Männer, davon 29 in Einbeck ansässige, Mitglieder der Vereinigung. Allerdings waren verschiedene dieser Männer auch in der Konservativen Vereinigung oder im Nationalliberalen Verein Mitglied. ${ }^{1015}$ Die soziale Zusammensetzung entsprach jener der beiden Mitgliedsvereine, auch war die politische Führung der Stadt und des Landkreises durch den Bürgermeister und den Landrat repräsentiert. Auffällig ist die hohe Zahl der Gymnasiallehrer im Verein; ungefähr 2/3 der Oberlehrer des Einbecker Realgymnasiums gehörten der Einbecker Ortsgruppe an.

Der Einbecker Zweigverein des Reichsverbandes gegen die Sozialdemokratie bestand nur für kurze Zeit; er wird in keiner der einschlägigen Vereinslisten geführt und ein Vermerk aus dem Jahre 1913 auf der betreffenden Akte besagt, dass der Verein zu diesem Zeitpunkt bereits seit mehreren Jahren nicht mehr bestand.

\footnotetext{
1013Die den Behörden eingereichte Satzung des Einbecker Zweigvereins war ein vom Dachverband herausgegebenes Musterstatut, in das lediglich der Ortsname eingetragen war. 1014 Vgl.: StAEin 065 - 21, Unterakte Statut des Reichsverbandes gegen die Sozialdemokratie in Einbeck, Statut in der Anlage zu 20. Februar 1911 1015Vgl.: StAEin 065 - 21, Unterakte Statut des Reichsverbandes gegen die Sozialdemokratie in Einbeck, Mitgliederliste in der Anlage zu 20. Februar 1911 und Unterakten Nationalliberaler Verein und Konservative Vereinigung, passim. In der Mitgliederliste wird als Ort der Konservativen Vereinigung Einbeck genannt; dies dürfte auf einem Irrtum beruhen, da der Verein erst 1911 seinen Sitz nach Einbeck verlegte.
} 


\section{8. 10. Die politischen Vereine Einbecks vor dem Ersten Weltkrieg}

Eine Gesamtschau des politischen Vereinswesens Einbecks vor dem Ersten Weltkrieg muss als wesentliches Ergebnis haben, dass die oben im Einzelnen dargelegten Entwicklungen in mancher Hinsicht durchaus typisch für eine Stadt im Süden der preußischen Provinz Hannover gewesen sein dürften.

Das frühe Auftreten einer Lokalorganisation einer der beiden sozialdemokratischen Parteien ist vor dem Hintergrund der allgemeinen Literatur ebenso als zeittypisch anzusehen wie die Organisation der bürgerlichen Parteien, die sich ab den neunziger Jahren des 19. Jahrhunderts von Honoratiorenkomitees zu vereinsmäßig organisierten Massenparteien entwickelten - eine Entwicklung, die ihre Gründe im Wesentlichen in einer zunehmenden Politisierung breiterer Bevölkerungskreise und einer Intensivierung der Wahlkämpfe hatte. 1016

Die Dominanz der Nationalliberalen in der Lokalpolitik einer Stadt stellte für die gesamte Provinz Hannover keine Besonderheit dar ${ }^{1017}$, auch waren relativ erfolgreiche Vereine der Deutsch- Hannoverschen Partei überall in der Provinz anzutreffen. 1018

Das Fehlen einer lokalen Organisation des Zentrums, das im Nordwesten Hannovers eine starke Rolle im Parteienspektrum spielte, kann bei einem Katholikenanteil von ungefähr 5 v. H der Gesamtbevölkerung1019 nicht überraschen. Die geringe Anzahl der Parteigänger der Konservativen, die ihren Hauptrückhalt lokal in Altpreußen und sozial in der von der Landwirtschaft lebenden Bevölkerung hatten, 1020 dürfte typisch für eine von Handel und Gewerbe geprägte Stadt in einem erst seit $1866 \mathrm{zu}$ Preußen gehörenden Landesteil gewesen sein.

Die überaus wechselvolle Organisationsgeschichte der Einbecker Sozialdemokratie, vor allem die unübersichtliche, teilweise nicht mehr rekonstruierbare Phase der Reorganisation nach dem Sozialistengesetz im letzten Jahrzehnt des 19. Jahrhunderts, die von einer Zeit großer Stabilität und Wirksamkeit ab dem Beginn des 20. Jahrhunderts gefolgt wurde, ist vor dem

\footnotetext{
1016 Vgl.: Nipperdey, Thomas: Machtstaat, SS. 517 f.

1017 Vgl.: Hamann, Manfred. op. cit., S. 27

1018 Vgl.: Aschoff, Hans Georg: op. cit., passim

1019 Vgl.: Hülse, Horst:op. cit., S, S.72

1020 Vgl.: Nipperdey, Thomas: Machtstaat, SS. 332 ff.
} 
Hintergrund der allgemeinen Literatur über die Organisation der Parteien ebenfalls als nicht untypisch zu bewerten. ${ }^{1021}$

Die in diesem Kapitel wie auch schon in den Abschnitten über das Gesangvereinswesen und die Turn- und Sportvereine dargelegte relative milde Praxis der städtischen Behörden im Umgang mit den Organisationen der Sozialdemokraten, die nach einer kurzen Phase intensiver Verfolgung unmittelbar nach dem Inkrafttreten des Sozialistengesetzes zwar permanent beobachtet wurden, aber ansonsten weit gehend unbehelligt blieben, findet in der Betrachtung der politischen Vereine eine mögliche Erklärung. Der Umstand, dass die städtischen Behörden insbesondere an ihrer Spitze durchweg mit Männern der Nationalliberalen Partei besetzt waren, legt den Deutungsversuch nahe, dass sowohl eine prinzipielle liberale Wertorientierung als auch die spätestens ab 1879 manifeste Gegnerschaft vieler Mitglieder der Nationalliberalen Partei gegenüber Bismarck, dem Initiator des Sozialistengesetzes, den Magistrat davon absehen ließen, das Sondergesetz mit aller Härte gegen die - wie viele interne Dokumente belegen, den Behörden wohlbekannten - in Einbeck ansässigen Sozialdemokraten anzuwenden. Dass die behördliche Praxis, die mit dem weit verbreiteten Klischee von rücksichtsloser Verfolgung und Schikanierung nicht in Einklang zu bringen ist, keineswegs auf Desinteresse an oder gar einer gewissen Sympathie für die Bestrebungen und Aktivitäten der Sozialdemokratie zurückgeführt werden kann, scheint evident. 


\section{9. Der Verein für Geschichte und Alterthümer}

\section{9. 1. Geschichtsvereine in Deutschland}

Im Zusammenhang mit den in der zweiten Hälfte des 18. Jahrhunderts vermehrt anzutreffenden Lesegesellschaften und der ökonomischen oder patriotischen Vereinigungen entstanden um die Wende vom 18. zum 19. Jahrhundert erstmals Vereine, die sich mit der Geschichte beschäftigten. ${ }^{1022}$ Ein größere Gründungswelle gab es in der Zeit von den so genannten Befreiungskriegen bis zur Revolution von 1848. Hermann Heimpel wies darauf hin, dass diese Geschichtsvereine im Gegensatz zu den Turnern und Sängern jener Zeit, obwohl "deutsch-vaterländisch", weniger liberale oder gar demokratische, sondern zutiefst konservative Vereinigungen waren. Diese Vereine richteten das Augenmerk ihrer Zielgruppen fort von den tagespolitischen Streitigkeiten hin auf vaterlandsbezogene, aber politisch unverfängliche Betrachtungen des Mittelalters. Heimpel pointierte dieses Faktum mit der Aussage: "'gegen Demokraten' halfen nicht nur 'Soldaten', sondern auch Regesten." 1023

$\mathrm{Ab}$ den sechziger Jahren des 19. Jahrhunderts setzte eine Tendenz der Verwissenschaftlichung der Vereine ein. Die historisch-kritische Methodik Rankes drang in die Vereine ein; das Schwergewicht ihrer praktischen Tätigkeit wandelte sich von der unmittelbaren Heimatkunde und Archäologie hin zur wissenschaftlichen Auswertung und Bearbeitung schriftlicher Quellen. ${ }^{1024}$

Im ausgehenden 19. Jahrhundert war die Institution "Geschichtsverein" allgemein bekannt und unter den Rahmenbedingungen des Historismus entwickelten weite Teile des Bürgertum historisches Interesse - eine letzte große Gründungswelle war die Folge. Allein zwischen 1890 und 1900 entstanden in Deutschland dreißig Geschichtsvereine. ${ }^{1025}$

1022 Heimpel, Hermann: Geschichtsvereine einst und jetzt. in: Boockmann, Hartmut u. a.

(Hgg.): Geschichtswissenschaft und Vereinswesen im 19. Jahrhundert. (Veröffentlichungen des Max-Planck-Instituts für Geschichte, Band 1). Göttingen 1972, SS. 45 - 73, SS. 46 ff.

1023 Heimpel, Hermann: op. cit.: SS. $48 \mathrm{ff}$.

1024 Vgl.: Pabst, Klaus: Deutsche Geschichtsvereine vor dem Ersten Weltkrieg. in:

Geschichtsvereine. Entwicklungen und Perspektiven lokaler und regionaler Geschichtsarbeit (Bensberger Protokolle, Band 62). Bergisch Gladbach 1990, SS. 9 - 32, SS. 23 ff.

1025 Vgl.: Heimpel, Hermann: op. cit.: SS. 53 f. 
Über die Geschichtsvereine des Kaiserreiches in ihrer Gesamtheit ist weder in quantitativer noch in struktureller Hinsicht viel bekannt. Allenfalls bleibt festzuhalten, dass es um die Wende vom 19. zum 20. Jahrhundert ein umfassendes, aber recht heterogenes historisches Vereinswesen gab, das auch die kleineren Städte erfasst hatte. Diese Vereine brachten zahlreiche Periodika und Quellenpublikationen unterschiedlichster Qualität hervor. ${ }^{1026}$

Die regionalen Basen der verschiedenen Geschichtsvereine waren vielfältig. So konnten nicht mehr existente Territorien, die im Bewusstsein der Bevölkerung weiterlebten, ebenso Gegenstand eines historischen Vereines sein wie neugeschaffene Länder. Andere Vereine widmeten sich länderübergreifenden Geschichtslandschaften wie e. g. Niedersachsen oder Westfalen. Wieder andere hatten lediglich kleine räumliche Einheiten wie eine einzelne Stadt und deren Umland als Interessenschwerpunkt. ${ }^{1027}$ Die soziale Trägerschicht des Geschichtsvereinswesens über den gesamten Untersuchungszeitraum hinweg dürfte, wenn man die vereinzelten Aussagen der Wissenschaft über die Genese der historischen Vereine betrachtet, das gehobene Bürgertum mit seinen Untergruppen - mit einer gewissen Überrepräsentation des Bildungsbürgertums - gewesen sein.

\footnotetext{
1026 Vgl.: Pabst, Klaus: op. cit., S. 25

1027 Vgl.: Schneider, Karl Heinz: Geschichtsvereine und ihre Geschichtslandschaften.

Räumliche Organisation und regionale Probleme. in: Geschichtsvereine. Entwicklungen und Perspektiven lokaler und regionaler Geschichtsarbeit (Bensberger Protokolle, Band 62).

Bergisch Gladbach 1990, SS. 53 - 70, passim
} 


\section{9. 2. Der Verein für Geschichte und Alterthümer der Stadt Einbeck und Umgegend}

Die Gründung des Vereins für Geschichte und Alterthümer der Stadt Einbeck und Umgegend erfolgte im Jahre 1895; seit 1966 trägt er den Namen "Einbecker Geschichtsverein". Nach einem Schema Hermann Heimpels fiele er durch den Zeitpunkt seiner Gründung unter die Kategorie der "selbstverständlichen" Geschichtsvereine, deren Gründung erfolgte, "wenn sich die richtigen Männer finden".1028 Da nun der Einbecker Geschichtsverein einer der wenigen Vereine ist, für den auch die Vorgeschichte und die näheren Umstände der Vereinsgründung rekonstruierbar sind, ist nachzuweisen, dass in diesem Falle die Sache nicht so einfach war: "Der Einbecker Geschichtsverein war", wie Hellmut Hainski treffend schreibt, "allerdings, trotz des Zeitgeistes, kein spontaner Zusammenschluß Gleichgesinnter.".1029

Die Vorgeschichte des Vereins beginnt bereits spätestens im Dezember 1893. In der Magistratssitzung vom 5. jenes Monats bildete man eine Kommission aus einem Senator und zwei Bürgervorstehern, welche die Einrichtung eines Museums in der Kapelle des Hospitals St. Spiritus in die Wege leiten sollte. ${ }^{1030}$ Eine Einladung zu einer Sitzung dieses Gremiums im Hospital, zu der auch der Stadtbaumeister hinzugezogen werden sollte, belegt, dass die Kapelle zu diesem Zwecke eigens umgebaut werden musste. ${ }^{1031}$ Nach Angabe Hellmut Hainskis ging die eigentliche Initiative zur Museumsgründung allerdings vom Königlichen Regierungspräsidenten in Hildesheim aus, der wiederholt schriftlich auf die Gründung einer Altertumssammlung in Einbeck gedrängt habe, die dann einem zu gründenden Trägerverein übergeben werden solle. 1032

Im Frühjahr 1894 wurde das Museumsprojekt in die Tat umgesetzt. Der Bestand dieses ersten Museums speiste sich aus einer bereits 1890 erwähnten städtischen Sammlung, die in 15 Abteilungen untergliedert 1300 Urkunden und 233 Gegenstände enthielt und zahlreichen Antiquitäten, die anlässlich der Museumsgründung von Einbecker Einwohnern auf einen Aufruf des Magistrats

\footnotetext{
1028 Heimpel, Hermann: op. cit., S. 53

1029 Hainski, Hellmut: 100 Jahre Einbecker Geschichtsverein. Rückblick, Aktivitäten,

Ehrungen. In: Einbecker Jahrbuch, Band 44 (1995), SS. 5 - 26, S. 5

1030 Vgl:: StAEin 352 - 2, 5. Dezember 1893

${ }^{1031}$ Vgl.: StAEin 352 - 2, 4. Januar 1894

1032 Vgl.: Hainski, Hellmut: op. cit., S.5
} 
hin zur Verfügung gestellt worden waren. ${ }^{1033}$ Aus dem Februar 1895 datiert der erste Hinweis auf die konkrete Initiative, für das Museum einen Trägerverein gründen zu wollen; unter dem 11. jenes Monats berichtete der Einbecker Bürgermeister auf eine entsprechende Anfrage an den Regierungspräsidenten, dass man das im Entstehen begriffene Museum einem noch zu gründenden Verein übergeben wolle. ${ }^{1034}$ Am 17. April 1895 erschien in der Einbecker Zeitung eine am 2. April beschlossene Bekanntmachung des Magistrats: "Wir haben im vergangenen Jahre hier ein Alterthums-Museum in der zu dem Zwecke erneuerten Kapelle des Hospitals St. Spiritus eingerichtet. Es geht über die Aufgaben des Magistrats hinaus, das Museum dauernd zu leiten. Den Zwecken desselben förderlich würde seine Uebernahme durch einen zu gründenden Verein sein. Der Jahresbeitrag würde etwa $1 \mathrm{Mk}$. zu betragen haben. Wir sind gewillt den Versuch $\mathrm{zu}$ machen, einen entsprechenden Verein in's Leben zu rufen und werden zu dem Zwecke in den nächsten Tagen Unterschriften sammeln. Wir bitten um möglichst zahlreiche Betheiligung. Auf Grund der Unterschriften werden wir dann eine Versammlung einzuberufen uns gestatten."1035

Am selben Tag wurde der Büroassistent beauftragt, eine Liste all jener Personen aufzustellen, die für die Museumssammlung Leihgaben gemacht hatten 1036; diesen Personenkreis sah die Stadtverwaltung als potenzielle Mitglieder für den Museumsverein an. Mit der Liste und einem entsprechenden Anschreiben mit dem Datum vom 22. April 1895, in dem auch zur Gründungsversammlung auf den 27. April ins Hotel zum Kronprinz eingeladen wurde, wurde ein Lohndiener losgeschickt, der in dreieinhalb Tagen etwa 170 Unterschriften sammelte. $1037 \mathrm{Zu}$ der erwähnten Gründungsversammlung erschienen allerdings nur 16 Herren, darunter ein Senator und der Stadtsekretär; insgesamt fanden sich also mit 14 Männern weniger als $10 \mathrm{v}$. H. derjenigen Personen ein, die per Unterschrift ihre Bereitschaft zum Vereinsbeitritt erklärt hatten. Bereits auf dieser Sitzung beschloss man, den

\footnotetext{
1033Vgl.: Einbecker Geschichtsverein (Hg.): Stadt Einbeck. Zeitgenössische Fotografien und Dokumente. Gesammelt und bearbeitet von Erich Strauß, Hellmut Hainski und Andreas Heege. Duderstadt 1995 1034 Vgl.: ibid. 1035Einbecker Zeitung, 17. April 1895, vgl. auch: StAEin 352 - 1, 2. April 1895 1036 Vgl.: StAEin 352 - 1, 17. April 1895 1037Vgl.: StAEin 352 - 1, 22. April 1895, 6. Mai 1895. Der erste Jahresbericht des Vereins präzisiert diese Zahl auf 180. Vgl. hierzu: Jahresbericht des Vereins für Geschichte und Alterthümer der Stadt Einbeck für das Jahr 1895, S. 5
} 
Vereinszweck nicht auf den Unterhalt des Museums zu beschränken, sondern ein erheblich größeres Aufgabenspektrum anzustreben und daher einen Verein mit dem Namen "Verein für Geschichte und Alterthümer der Stadt Einbeck" ins Leben zu rufen. Man wählte eine sechsköpfige Kommission, welche die Statuten für den neuen Verein ausarbeiten sollte.1038 In der ersten Generalversammlung des Vereins am 28. Mai - diesen Tag betrachtet der Geschichtsverein Einbeck als sein Gründungsdatum - wurden die Satzungen des Vereins vorgelegt und beschlossen. In dieser Versammlung wurde zudem angeregt, den historischen Bezugsraum des neuen Vereins über die Grenzen der Stadt Einbeck hinaus auszudehnen. Dieser Vorschlag fand Zustimmung, so dass man den Verein schließlich "Verein für Geschichte und Alterthümer der Stadt Einbeck und Umgegend" taufte. 1039

Nach $\S 1$ der Statuten bezweckte der Verein "die Hebung des Interesses für die Geschichte der Stadt Einbeck sowie der umliegenden Ortschaften und deren Alterthümer." Diesem Zweck diene der Verein nach $§ 9$ "durch Veranstaltung von Vorträgen sowie durch Pflege und Vermehrung der Alterthumssammlung.". 1040

Vom Beginn seiner Vereinsgeschichte an veröffentlichte der Verein für Geschichte und Alterthümer mehr oder minder regelmäßig Publikationen, die neben nur wenigen erhaltenen Akten im Stadtarchiv Einbeck die einzigen Quellen zur Vereinsentwicklung im Kaiserreich darstellen. Anhand dieser Jahresberichte genannten Veröffentlichungen lässt sich die quantitative Entwicklung des Vereins recht genau rekonstruieren: Vor der Gründung des Vereins hatten, wie bereits oben gesagt, 180 Personen ihre Bereitschaft zum Beitritt erklärt. Hinzu kamen fünf Personen, die sich nachträglich meldeten, die Zahl verringerte sich um zwei verzogene Personen und sieben Eintrittswillige, die vom Beitritt durch Nichteinlösen der Mitgliedskarten Abstand nahmen, so dass sich hierdurch eine Zahl von 176 Gründungsmitgliedern ergibt. Bis zur ersten Generalversammlung traten weiter sechs Mitglieder ein, so dass der Verein am 15. Januar 1896182 Mitglieder zählte. ${ }^{1041}$ Bei der nächsten Generalversammlung am 4. Februar 1897 waren 183 Mitglieder zu

\footnotetext{
1038 Vgl.: StAEin 352 - 1, 27. April 1895 und Hainski, Hellmut: op. cit., S. 8

1039 Hainski, Hellmut: op. cit., S. 8

1040 Statut vom 28. Mai 1895, den städtischen Behörden eingereicht mit Anschreiben vom

11. Juni 1895 in StAEin 352 - 1

1041 Vgl.: Jahresbericht des Vereins für Geschichte und Alterthümer der Stadt Einbeck und Umgegend für das Jahr 1895, S. 5
} 
verzeichnen ${ }^{1042}$, diese Zahl verringerte sich auf 161 am Beginn des Jahres 1898.1043 Dieser leichte Abwärtstrend setzte sich auch im beginnenden 20. Jahrhundert fort: Am Ende des Jahres 1901 gehörten 151 Personen dem Verein für Geschichte und Alterthümer an, im Januar 1903 war die Mitgliedszahl gar auf 143 gesunken. 1044 Von der Generalversammlung 1907 ist mit 137 Mitgliedern der geringste bekannte Bestand im Untersuchungszeitraum überliefert, doch in diesem Jahr fand eine aus den bekannen Quellen nicht erklärbare Eintrittswelle statt - am 20. Januar 1908 konnte mit 182 Mitgliedern wieder das Niveau der ersten Jahre erreicht werden.1045 Anfang 1909 gehörten 183 Personen dem Verein für Geschichte und Altertümer ${ }^{1046}$ der Stadt Einbeck und Umgegend an 1047 , doch bis zum Ende des Kaiserreichs fiel diese Zahl wieder über 175 noch im gleichen Jahr, 159 im Jahre $1912^{1048}$ und 155 ein Jahr später auf 142 bei der Generalversammlung des Jahres 1916. 1049

In dreien der genannten Jahresberichte des Vereins, jenen für die Jahre 1896, 1898 und 1906, sind namentliche Mitliederlisten mit Berufsbezeichnungen abgedruckt. Nur im ersten Falle stimmt die Zahl der aufgeführten Mitglieder mit der an anderer Stelle genannten Mitgliedszahl überein. Dennoch geben sie, mit allen bereits in früheren Kapiteln gemachten Einschränkungen bezüglich verschiedener Fragestellungen der historischen Sozialstatistik, recht genaue Anhaltspunkte über die soziale Zusammensetzung

1042 Vgl.: Jahresbericht des Vereins für Geschichte und Alterthümer der Stadt Einbeck und Umgegend für das Jahr 1896, SS. 3 - 5

1043 Vgl.: Jahresbericht des Vereins für Geschichte und Alterthümer der Stadt Einbeck und Umgegend für das Jahr 1898, S. 7

1044 Vgl.: Jahresberichte des Vereins für Geschichte und Alterthümer der Stadt Einbeck und Umgegend für die Jahre 1901 und 1902, S. 26

1045 Vgl.: Jahresbericht des Vereins für Geschichte und Altertümer der Stadt Einbeck und Umgegend für das Jahr 1907,

S. 1

1046 Der Begriff "Altertümer" wurde ab dem Jahresbericht für 1906 in der moderneren Schreibweise ohne "th" verwendet.

1047 Vgl.: Jahresbericht des Vereins für Geschichte und Altertümer der Stadt Einbeck und Umgegend für das Jahr 1908,

S. 7

1048 Vgl.: Neunter Bericht des Vereins für Geschichte und Altertümer der Stadt Einbeck und Umgegend [über die Jahre 1909 bis 1912], S. 11

1049 Vgl.: Zehnter Bericht des Vereins für Geschichte und Altertümer der Stadt Einbeck und Umgegend [über die Jahre 1913 bis 1915], S. I 
des Vereins. Hellmut Hainski schreibt, dass im Verein für Geschichte und Alterthümer "quasi alle Einbecker Berufssparten vertreten waren. Es gab keine bestimmte Gruppierung oder Zuordnung, für die die Beschäftigung mit der Geschichte reserviert war"1050. Diese Aussage trifft, dies mag kaum verwundern, nur zum Teil zu, doch sie trägt eine gewichtige Wahrheit in sich: Wie kaum anders zu erwarten, speiste sich die Mitgliedschaft des Vereins nahezu ausschließlich aus Angehörigen des gehobenen Bürgertums Kleinbürger waren nur in geringem Maße, unterbürgerliche Schichten gar nicht vertreten. Aus dieser Klientel finden sich dann allerdings in der Tat Vertreter aller Untergruppen als Mitglieder des Vereins für Geschichte und Altertümer. Handwerksmeister, Mühlenbesizer und vor allem Kaufleute repräsentierten das Besitz- oder Wirtschaftsbürgertum, Lehrer, Geistliche und Angehörige der freien Berufe das Bildungsbürgertum und Beamte aus verschiedenen Bereichen und die Spitzen der örtlichen Politik wie der Bürgermeister und die Senatoren Funktionsbürgertum und -elite. So wird bereits durch eine grobe Analyse der bekannten Mitglieder im Falle des Vereins für Geschichte und Alterthümer der Stadt Einbeck und Umgegend die These Hainskis mit der oben gemachten Einschränkung ebenso bestätigt wie die in der Einführung zitierte Aussage Hermann Heimpels, dass im Zeitalter des Historismus in weiten Kreisen des gesamten Bürgertums, nicht nur des traditionellen Bildungsbürgertums, ein Interesse an Geschichte erwuchs, was der Gründung und dem Bestand von Geschichtsvereinen sehr förderlich war.

Ebenso wenig wie die Dominanz des gehobenen Bürgertums kann überraschen, dass der weitaus größte Teil der Mitglieder Männer waren: Die genannten Mitgliederlisten für die Jahre 1896, 1898 und 1906 weisen im ersten Falle neun, in den letztgenannten beiden Fällen jeweils sieben Frauen namentlich aus, was einem jeweiligen Frauenanteil von 4,9, 4,4 und 4,1 v. H. der Mitglieder entspricht.

Im Falle der Mitgliederliste für das Jahr 1906 wurden zur Berechnung nur die aufgeführten natürlichen Personen herangezogen. Daneben enthält diese Liste auch zwei juristische Personen - einen nicht näher präzisierten Kreisausschuss mit einem Jahresbeitrag von 20 und den Magistrat der Stadt Einbeck mit einem jährlichen Beitrag von 10 Mark. Da diese beiden Gremien unter den Neueintritten verzeichnet sind, kann vermutet werden, dass im Berichtsjahr 1906 erst die statutenmäßige Möglichkeit geschaffen wurde, dass auch juristische Personen Mitglied werden konnten. 
Obwohl der Verein von seiner Gründung an auch das Umland der Stadt in seinen historischen Bezugsraum mit eingeschlossen hatte, waren die Mitglieder zu ihrem weitaus größten Teil in der Stadt selbst ansässig. In der Mitgliederliste für 1898 findet sich erstmals ein vereinzelter Auswärtiger, Herr von Dassel in Hoppensen. Die Liste für 1906 verzeichnet bereits 11 Mitglieder, die ihren Wohnsitz außerhalb der Stadt hatten, allerdings wohnten nur fünf dieser Männer in Dörfern des Kreises Einbeck, sechs von ihnen wohnten in weiter entfernten Städten, so beispielsweise der von Einbeck fortgezogene ehemalige Bürgermeister Troje, der mittlerweile das Amt des Oberbürgermeisters im hessischen Marburg bekleidete. ${ }^{1051}$

Wie bereits oben gesagt, war neben der Pflege und Vermehrung der Altertumssammlung, also dem Heimatmuseum, das sich im Untersuchungszeitraum in der Kapelle des Hospitals St. Spiritus befand, auch die Abhaltung von Vorträgen zur Geschichte Einbecks und seines Umlandes statutarisch als Vereinsaktivität festgelegt. Bereits im ersten Jahr des Bestehens des Vereins fanden Vorträge statt. Oberlehrer Dr. Otto Adolf Ellissen, der Gründungsvorsitzende, sprach über die Geschichte des Fürstentums Grubenhagen, sein Kollege Hermann Schloemer über Gilden im Mittelalter ${ }^{1052}$, für das Jahr 1997 ist ein Vortrag Ellissens zum Thema "Einbeck in der deutschen Literatur" belegt. ${ }^{1053}$ Für das Jahr 1901 lassen sich weitere Vorträge nachweisen. Pastor Albert Firnhaber sprach über "Kriegsnöthe der Stadt", Wilhelm Feise über Nachbarschaften und Feste in Einbeck. ${ }^{1054}$ Mit der Zeit überschritten die Vortragsthemen den statutenmäßigen Bezugsraum des Vereins: Neben Ausführungen Firnhabers über seine Amtsvorgänger in der Kirchengemeinde St. Marien in Einbecks Neustadt und des seit 1906 das Präsidentenamt bekleidenden Wilhelm Feise über den sechsten Niedersachsentag in Bückeburg und die Herkunft des

${ }^{1051} \mathrm{Zu}$ allen auf die Mitgliederlisten sich beziehenden Aussagen vgl.: Jahresbericht des Vereins für Geschichte und Alterthümer der Stadt Einbeck und Umgegend für das Jahr 1896, o. S., Jahresbericht des Vereins für Geschichte und Alterthümer der Stadt Einbeck und Umgegend für das Jahr 1898, o. S., und Jahresbericht des Vereins für Geschichte und Altertümer der Stadt Einbeck und Umgegend für das Jahr 1906, SS. VII - X

1052 Jahresbericht des Vereins für Geschichte und Alterthümer der Stadt Einbeck und Umgegend für das Jahr 1896, S. 3

1053Jahresbericht des Vereins für Geschichte und Alterthümer der Stadt Einbeck und Umgegend für das Jahr 1898, S. 5

1054 Jahresbericht des Vereins für Geschichte und Alterthümer der Stadt Einbeck und Umgegend für die Jahre 1901 und 1902, S. 26 
Ortsnamens "Einbeck" erlebte das Jahr 1907 auch einen Vortrag Ellissens über die Belagerung Gibraltars 1779 bis 1882.1055

$\mathrm{Ab}$ dem beginnenden 20. Jahrhundert wurde der Verein für Geschichte und Alterthümer zudem als Veröffentlicher lokalhistorischen Schrifttums tätig: In den Jahresberichten, begonnen als reine Rechenschaftsberichte des Vereins, in denen von den Aktivitäten sowie über Inventar und Neuerwerbungen der Altertumssammlung berichtet wurde, wurden erstmals 1901 zwei kurze schriftliche Abhandlungen abgedruckt: "Die Pfarrkirchen Einbecks und ihre Sprengel" aus der Feder des bereits zitierten Schloemer und "Die Einnahme Einbecks durch Pappenheim im Jahre 1632", der Text eines Vortrages, den ein Dr. Adolf Ulrich 1888, also Jahre vor der Vereinsgründung, gehalten hatte. ${ }^{1056}$ Die Veröffentlichung solcher historischen Aufsätze und kommentierter Quellen nahm in der Folgezeit deutlich zu: Nachdem im Bericht für die Jahre 1901 und 1902 eine Abhandlung Oberlehrer Wilhelm Feises über einen Rechtsstreit der ersten Hälfte des 15. Jahrhunderts 25 Seiten beanspruchen konnte ${ }^{1057}$, nahmen im Jahresbericht für 1906 ein Aufsatz des Dassenser Pastors Th. Wedekind über die kirchliche Vergangenheit der Inspektion Einbeck und eine von Wilhelm Feise kommentierte Wiedergabe der Beschreibung Einbecks in der Merianschen Topographie von 1654 bereits insgesamt 46 Druckseiten ein. 1058 Diese Tendenz setzte sich auch in der Folgezeit fort. Bereits der Bericht für das Vereinsjahr 1907 umfasste neben dem eigentlichen Rechenschaftsbericht mehr als 100 Seiten mit Abhandlungen zu Themen der örtlichen Geschichte ${ }^{1059}$, der Bericht für die Jahre 1909 bis 1912 bietet ein ebensolches Bild. ${ }^{1060}$ Als eifrigster Autor von Beiträgen für den sich zu einem laienwissenschaftlichen Periodikum entwickelnden Bericht des Vereins für Geschichte und Altertümer tat sich der bereits genannte

${ }^{1055}$ Vgl.: Jahresbericht des Vereins für Geschichte und Alterthümer der Stadt Einbeck und Umgegend für das Jahr 1907, SS. 1 f.

1056 Jahresbericht des Vereins für Geschichte und Alterthümer der Stadt Einbeck und Umgegend für das Jahr 1901, SS. 5 ff.

1057Vgl.: Jahresbericht des Vereins für Geschichte und Alterthümer der Stadt Einbeck und Umgegend für die Jahre 1901 und 1902, SS. 1 - 25

1058 Vgl.: Jahresbericht des Vereins für Geschichte und Alterthümer der Stadt Einbeck und Umgegend für das Jahr 1906, SS. 1 - 46

${ }^{1059}$ Vgl.: Jahresbericht des Vereins für Geschichte und Altertümer der Stadt Einbeck und Umgegend für das Jahr 1907, passim

${ }^{1060}$ Vgl.: Jahresbericht des Vereins für Geschichte und Altertümer der Stadt Einbeck und Umgegend für die Jahre 1909 bis 1912, passim 
Oberlehrer Feise hervor. Auch die anderen Autoren waren dem Bildungsbürgertum zuzurechnen. Allein der Färbereibesitzer Ernst Wittram, der sich im Anhang zum Jahresbericht für 1907 schriftlich und mit einer Planskizze zu "Einbecks Entwicklung aus einem karolingischen Königshofe" äußerte, fällt nicht unmittelbar in diese Kategorie. Betrachtet man zusätzlich zu dem bekannten Autorenkreis noch die bekannten Vorstandsmitglieder, so muss die oben getroffene Aussage, dass im Verein alle Untergruppen des Bürgertums vertreten waren, dahingehend ergänzt werden, dass die inhaltlich und praktisch federführenden Personen vor dem Ersten weltkrieg nahezu ausschließlich dem Bildungs- und Funktionsbürgertum zuzuordnen sind. ${ }^{1061}$

Neben der Abhaltung von Vorträgen und der Veröffentlichung von lokalhistorischen Aufsätzen sind auch vereinzelt Aktivitäten des Vereins für Belange des Denkmalschutzes nachweisbar. 1898 wurde der Erhalt des Klapperturms, eines Bauwerks der ehemaligen Landwehr der Stadt, finanziell gefördert. ${ }^{1062}$ Anfang des 20. Jahrhunderts schaltete man sich in eine Debatte über die Errichtung einer Badehalle für Warmwasserbäder ein - der Verein argumentierte gegenüber dem Magistrat gegen einen projektierte Standort vor dem Hullerser Tor, das Gebiet beim Storchenturm weise einen "altertümlichen Charakter" auf, der durch ein modernes Bauwerk beeinträchtigt würde. ${ }^{1063}$ Im Jahre 1907 bezuschusste der Verein für Geschichte und Altertümer eine nicht näher präzisierte Initiative zum Erhalt der "Reste des alten Hubeturmes" mit dem Betrag von 50 Mark. ${ }^{1064}$

Aus der erwähnten publizistischen Tätigkeit des Vereins erwuchsen Kontakte mit anderen Geschichtsvereinen auf dem Wege des Schriftenaustausches. 1907 tauschte man mit 38 solcher Vereine und Gesellschaften in ganz Deutschland die Druckwerke aus, im darauf folgenden Jahr kamen noch sechs weitere hinzu. ${ }^{1065}$ Darüber hinaus berichtet Hellmut

${ }^{1061} \mathrm{Zu}$ den Vorstandmitgliedern vgl.: Die bereits mehrfach zitierten Veröffentlichungen des Vereins und StAEin 352 - 1, passim

1062 Vgl.: Jahresbericht des Vereins für Geschichte und Alterthümer der Stadt Einbeck und Umgegend für das Jahr 1898, S. 4

1063 Jahresbericht des Vereins für Geschichte und Alterthümer der Stadt Einbeck und Umgegend für die Jahre 1901 und 1902, S. 26 und StAEin 714 - 4, 13. Januar 1902

1064 Vgl.: Jahresbericht des Vereins für Geschichte und Altertümer der Stadt Einbeck und Umgegend für das Jahr 1907, S. 2

1065 Vgl.: Jahresbericht des Vereins für Geschichte und Altertümer der Stadt Einbeck und Umgegend für das Jahr 1907, SS. 1 - 4; 6 
Hainski, dass der Verein 1910 auch an der Gründung der Historischen Gesellschaft beteiligt war. 1066

Zusammenfassend lassen sich trotz der für die Zeit nach der Vereinsgründung eher spärlichen Quellenlage einige grundlegende Aussagen über den Verein für Geschichte und Altertümer der Stadt Einbeck und Umgegend treffen. Aus einer von der örtlichen Verwaltung gewünschten und maßgeblich initiierten Gründung eines reinen Trägervereins für das städtische Museum entwickelte sich ein für seine Zeit typischer Geschichtsverein. Dieser hatte, trotz gewisser Schwankungen der Mitgliederzahl, eine feste Basis in weiten Kreisen des gehobenen städtischen Bürgertums. Auch in diesem Punkt lassen sich einschlägige Äußerungen der allgemeineren Forschung bestätigen. Führend in Vereinsleben und -tätigkeit waren allerdings Vertreter des klassischen Bildungsbürgertums, allen voran die beiden Vorsitzenden im Untersuchungszeitraum, die Oberlehrer Dr. Ellissen und Feise. Der statutarische Zweck der "Hebung des Interesses für die Geschichte der Stadt Einbeck sowie der umliegenden Ortschaften und deren Alterthümer" wurde weit ausgelegt, so dass neben Vorträge rasch auch denkmalschützerische und vor allem publizistische Aktivitäten traten. Letztere fanden auch ein interessiertes Publikum außerhalb des eigentlichen Bezugsraumes und trugen ihren Teil zu einer überregionalen Vernetzung der frühen lokal- und regionalgeschichtlichen Geschichtsforschung in Norddeutschland und darüber hinaus bei. 


\section{10. Caritative Vereine}

\section{10. 1. Die Frauenvereine}

\section{10. 1. 1. Der Frauenverein Einbeck}

Wie bereits in dem Abschnitt über Einbecker Vereine vor dem Untersuchungszeitraum gesagt wurde, bestand spätestens ab den sechziger Jahren des 19. Jahrhunderts ein Frauenverein, der sich der Krankenpflege und der Unterstützung Bedüftiger annahm. Die Im Stadtarchiv erhaltenen Rechenschaftsberichte dieses Vereins für die Jahre 1869 bis 1871 geben einen Einblick in seine Tätigkeit. ${ }^{1067}$ In einer eigenen Spinnerei und Weberei wurden bis 1870 Garne und Textilien produziert, die zum Wohle der Vereinskasse teils verkauft, teils verlost wurden. ${ }^{1068}$ Daneben waren auf der Einnahmeseite laufende Beiträge und Spenden $\mathrm{zu}$ verbuchen. Die Zuwendungen an Kranke und Hilfsbedürftige wurden in Geld und in praktischer pflegerischer Tätigkeit, offenbar im Wesentlichen in Naturalien geleistet. Da eine Aufstellung der geleisteten Arbeitsstunden nicht vorliegt und neben den Ausgaben für Krankenpflege und Brotverteilung ein Pauschalposten "Anderweitige Unterstützungen in Geld, Kleidung und Krankenpflege" erscheint, kann über das Verhältnis der verschiedenen Unterstützungsformen zueinander keine Aussage getroffen werden. Ein besonderes System sorgte für eine regelmäßige Verteilung von Suppe an bedürftige Kranke: Wohlhabende Einbecker Familien kauften eine Summe von Suppenportionen, die Verteilung übernahm der Verein. Diese Suppen wurden bis 1871 in einer eigenen Suppenküche gekocht und offenbar mehr oder minder symbolisch an die Spender verkauft. Später wurde das Kochen von Privatleuten übernommen ${ }^{1069}$.

Außerdem beschäftigten sich die Frauen mit der Herstellung von Säuglingsund Kleinkinderbekleidung, die an arme Wöchnerinnen verschenkt wurde. 1070

\footnotetext{
1067 StAEin $065-14$

1068 Eine solche Lotterie ist für das Jahr 1869 belegt, für die beiden anderen Jahre nicht, 1871

dürften nur noch Lagerbestände verkauft worden sein.

1069 Vgl.: StAEin 065 - 14, 11. November 1871

$1070 \mathrm{Zu}$ allem über die Art der Hilfeleistungen Gesagten vgl.: StAEin 065 - 14,

Rechenschaftsberichte $1869,1870,1871$, passim
} 
Die städtischen Behörden unterstützten den Verein, indem sie die Miete für das "Spinnlocal" übernahmen. Diese regelmäßige jährliche Zuwendung wurde zunächst weiter gezahlt, nachdem die Spinnerei und Weberei aufgegeben wurde. 1874 wurden die Zahlungen eingestellt, Anträge auf Fortzahlung wurden abschlägig beschieden. ${ }^{1071} 1879$ beantragte der Verein erneut eine finanzielle Unterstützung für seine Tätigkeit durch die Stadt. In dem Schreiben wird als Hauptaufgabe die Versorgung von Armen mit Nahrungsmitteln und Kleidung genannt und erläutert, dass weder die städtische noch die kirchliche Armenpflege in dieser Hinsicht an Wirksamkeit mit dem Frauenverein zu vergleichen wäre. "Um nun weitere Beschränkungen und zuletzt die gänzliche Sistirung unserer Thätigkeit zu vermeiden, ersuchen Wohllöblichen Magistrat wir ganz gehorsamst, uns eine jährliche Beihülfe aus städtischen Mitteln bewilligen zu wollen".1072 Doch weder dieses Schreiben, noch der Versuch, über einflussreiche Männer des Bürgervorsteherkollegiums die Zuwendungen zu erhalten, trugen Früchte: Wie schon in früheren Jahren wurden die Anträge auf Unterstützung abschlägig beschieden. ${ }^{1073}$

Weitere Primärquellen zum Frauenverein fehlen. Doch es scheint nicht zu der befürchteten Einstellung seiner Tätigkeit gekommen zu sein: Die behördeninterne Vereinsliste von $1893^{1074}$ weist den Frauenverein aus, in den Adressbüchern von 1902 bis Juli 1912 erscheint ein "Städtischer Frauenverein", der mit diesem identisch sein dürfte.

${ }^{1071}$ Vgl.: StAEin 065 - 14, 31. Januar 1873, 11. April 1873, 28. Januar 1874,

1072 StAEin 065 - 14, 14. Januar 1879

1073 Vgl.: StAEin 065 - 14, 21. November 1879, 27. Dezember 1879

1074 StAEin 065 - 17, o. D. 


\section{10. 1. 2. Der Vaterländische Frauenverein}

1876 wurde in Einbeck ein weiterer Frauenverein ins Leben gerufen. Das Statut des Einbecker Zweigvereins des 1866 von der preußischen Königin gegründeten Vaterländischen Frauenvereins datiert vom 30. November jenen Jahres. ${ }^{1075}$ Zweck des Zweig- wie des Hauptvereins war die "Pflege im Felde verwundeter und erkrankter Krieger" in Kriegszeiten. In Friedenszeiten bezweckte man: "1. Linderung allgemeiner Notstände, die durch Seuchen, Teuerung, Ueberschwemmung, Feuersbrunst u. s. w. in dem einen oder anderen Teile des Vaterlandes entstehen. 2. Förderung der Krankenpflege durch Ausbildung von Pflegerinnen, sowie durch Mitwirkung bei der Begründung und Verbesserung von Krankenanstalten. 3. Armen- und Krankenpflege überhaupt und Beteiligung an sonstigen für das Wirken der Frau geeigneten Werken der Humanität, als: Warteschulen, Waisenanstalten, Pflege verwahrloster Kinder etc."

Aufgenommen werden konnten "unbescholtene Frauen und Jungfrauen". Der Jahresbeitrag betrug sechs Mark. Die Vereinsversammlung wählte auf jeweils drei Jahre sechs Frauen in den Vorstand, die ihrerseits zwei Männer als Vorstandsmitglieder zu kooptieren hatten. 1076

Zwar sah das Statut auch eine tätige Mitwirkung der Mitglieder an den caritativen Aufgaben des Vaterländischen Frauenvereins vor, doch die zahlreichen erhaltenen Quellen zeigen, dass sich der Verein rasch vor allem, wenn nicht ausschließlich, einem Teilzweck - der Begründung einer Krankenstation - zuwandte.

Bereits 1877 wurden mit dem Henriettenstift in Hannover Verhandlungen über die Anstellung einer dortigen Diakonisse für die Krankenpflege in Einbeck aufgenommen ${ }^{1077}$, die Anstellung erfolgte Anfang 18781078. In der Folgezeit widmete sich der Verein der Einrichtung eines Krankenhauses. Bereits im November 1878 konnte ein gemietetes Haus am Möncheplatz mit vier Krankenzimmern bezogen werden, das der Verein 1882 erwarb. ${ }^{1079}$ Erwerb und Unterhalt des Hauses wurden zunächst von den städtischen

\footnotetext{
1075 StAEin 548 - 2, 30. November 1876

1076 Vgl.: ibid.

1077 Vgl.: StAEin 548 - 2, 18. Mai 1877

1078 Vgl.: Hülse, Horst: Einbeck in der Gründerzeit. in: Einbecker Geschichtsverein (Hg.):

Geschichte der Stadt Einbeck. Band 2: Vom Ende des 18. Jahrhunderts bis zum Ende des

zweiten Weltkrieges. Einbeck 1992, SS. 71 - 138, S. 104

1079 Vgl.: StAEin 548 - 2, 3. August 1882
} 
Behörden gefördert, später war der Vaterländische Frauenverein in der Beschaffung der Mittel weit gehend auf sich allein gestellt. 1080 1902/3 wurde das neben dem genannten Vereinskrankenhaus bestehende städtische Krankenhaus in der Papenstraße, das sich schon zu Beginn des Untersuchungszeitraumes in einem desolaten Zustand befunden haben muss, durch einen Neubau am südwestlichen Rand der Stadt ersetzt. Dieses neue, weitgehend aus städtischen Mitteln erbaute Haus, das auch das alte Vereinskrankenhaus überflüssig machte, wurde dem Vaterländischen Frauenverein zu Betrieb und Verwaltung übergeben. 1081

Es gibt fast keine Belege, dass sich die Aktivitäten des Vereins über die Akkumulation von Mitteln und die Verwaltung der beiden Krankenhäuser hinaus erstreckten. ${ }^{1082}$ Es liegt somit die Vermutung nahe, dass sich der Vaterländische Frauenverein, wenn er dies nicht bereits vom Anbeginn seines Bestehens war, zu einem reinen Förder- oder Trägerverein entwickelte. Somit fiele der Verein, wie beispielsweise auch der Badehallenverein oder der Verein für eine allgemeine Volksbibliothek, nicht unter die der vorliegenden Untersuchung zu Grunde liegende Vereinsdefinition. Sicherlich wäre eine eingehendere Betrachtung dieses Vereinstyps ein lohnendes Unterfangen, doch muss solches in dieser Arbeit mit ihrer eingangs vorgestellten Fragestellung unterbleiben.

\footnotetext{
1080 Vgl.: StAEin 548 - 2, passim

1081 Vgl.: Hülse, Horst: op. cit., S.106

1082 Lediglich aus der unmittelbaren Vorkriegszeit ist die Teilnahme des Vereins an einer

Sanitätsübung belegt. Vgl. hierzu: Abschnitt über die Freiwillige Sanitätskolonne der vorliegenden Arbeit und StAEin 431 - 2, Jahresbericht der Freiwilligen Sanitätskolonne für 1913 o. D.
} 


\section{10. 1. 3. Der evangelische Frauen- und Jungfrauenverein}

In den Vereinslisten der Adressbücher von 1902 bis Juli 1912 ist neben den genannten Frauenvereinen mit caritativen Zielen ein evangelisch-lutherischer Frauen- und Jungfrauenverein aufgeführt. Als Gründungsdatum wird der 1, April 1900 angegeben. Dieser Verein dürfte mit dem 1905 in der Akte über den christlichen Männer- und Jünglingsverein erwähnten "Frauen- und Jungfrauenverein"1083 identisch sein.

Über diesen Verein war aus den bekannten Quellen nichts zu erfahren, was über den Nachweis seiner Existenz hinaus reicht. 


\section{10. 1. 4. Der Elisabethverein}

Neben den genannten Frauenvereinen erscheint in den Vereinslisten der Adressbücher 1911/12 und Juli 1912 unter der Kategorie der Wohlfahtsvereine der "Katholische Elisabethverein (Frauenverein)". Dies sind jedoch die einzigen bekannten Belege über den Bestand dieses Vereins.

Die Benennung von katholischen Frauenvereinen, die sich caritativen Zwecken widmeten, nach der heiligen Elisabeth von Thüringen liegt nahe; diese Heilige wird verehrt für ihre Mildtätigkeit gegenüber Kranken und Armen. Der erste Elisabethverein wurde 1840 in Trier gegründet, ein Dachverband der katholischen Elisabethvereine besteht noch zum Zeitpunkt der Niederschrift der vorliegenden Studie. 


\section{10. 2. Der Zweigverein vom Roten Kreuz und seine Sanitätskolonne}

Bereits im Abschnitt über die Turnvereine war von der Sanitätskolonne zu lesen, die 1908 vom Einbecker Zweigverein des Roten Kreuzes gegründet und unterhalten wurde und die sich aus Mitgliedern der verschiedenen Turnvereine und der Freiwilligen Feuerwehr zusammensetzte. ${ }^{1084}$ Die unmittelbaren caritativen Aufgaben wurden also von vereinsfremden Personen übernommen. Über den eigentlichen Zweigverein des Roten Kreuzes, der in keiner der bekannten Vereinslisten erscheint, war nicht viel in Erfahrung zu bringen. Nach Horst Hülse bestand er, wie bereits oben gesagt, schon seit dem Ende der sechziger Jahre des 19. Jahrhunderts. Für das Jahr 1908 gibt er, ohne auf eine Quelle zu verweisen, eine Mitgliederzahl von 154 an. 1085

Das Rote Kreuz war jenen Organisationen vorbehalten, die sich der Krankenpflege widmeten und im Kriegsfalle zur Pflege erkrankter oder verwundeter Soldaten bereit standen. Das Internationale Rote Kreuz entstand in den Jahren 1863/64 auf Initiative des Schweizers Henri Dunant.

Der Vaterländische Frauenverein, dessen statutarische Aufgaben oben genannt wurden, führte als Zeichen das Rote Kreuz ${ }^{1086}$ ebenso wie die Sanitätskolonne. Ab 1903 bedurfte es in Deutschland einer Bestätigung durch das Kriegsministerium, um das Recht zur Führung des Emblems zu erhalten. Dieses wurde sowohl dem Frauenverein wie auch der Kolonne erteilt. 1087

So wenig über den Zweigverein in Erfahrung zu bringen war, so dicht sind die Quellen über die Sanitätskolonne - im Stadtarchiv Einbeck haben sich verschiedene ausführliche Jahresberichte der Kolonne erhalten.

Diese hatte offenbar einen weit gehend autonomen Status innerhalb des Zweigvereins des Roten Kreuzes. Sie hatte eine eigene Satzung und einen Vorstand. 1088

1908 absolvierten bereits über 20 Mitglieder der Feuerwehr und der Turnvereine einen Ausbildungsskurs. Als zentral gelegener Stützpunkt diente das Rathaus. ${ }^{1089}$ Anfang 1909 zählte die Kolonne 36, zum 1. April 1910

\footnotetext{
1084 Vgl. auch: StAEin 431 - 2, passim

1085 Vgl.: Hülse, Horst: op. cit., S. 106

1086 Vgl: StAEin 548 - 2, 30. November 187

1087Vgl.: StAEin 431 - 1, 3. Juli 1903, 10. September 1903, 3. März 1909

1088 Vgl.: StAEin 431 - 2, 12. April 1910 und Anlage

1089 Vgl.: StAEin 431 - 2, 8. September 1908, Vermerk auf 2. Oktober 1908
} 
bereits 42 Aktive und 2 Inaktive. Daneben hatte man noch 22 fördernde Mitglieder. Die weitere Mitgliederentwicklung stellte sich wie folgt dar: 1090

$\begin{array}{llll}\text { Zeit } & \text { Aktive } & \text { Inaktive } & \text { Fördernde } \\ 04 / 1911 & 38 & 5 & 23 \\ 04 / 1912 & 42 & 5 & 38 \\ 04 / 1913 & 50 & 4 & 36 \\ 04 / 1914 & 45 & 4 & 32\end{array}$

Die Ausbildung der Kolonnenmitglieder beschänkte sich nicht auf Erste Hilfe im engeren Sinne. Im Sommer wurden verschiedene Außenübungen durchgeführt. Teilweise in Zusammenarbeit mit der Feuerwehr wurden komplexere Unfall- und Katastrophenszenarios wie eine Explosion im Kornhaus 1091 oder ein nächtliches "Automobilunglück"1092 durchgespielt. Geländeübungen und Exerzieren weisen ebenso auf die Ausrichtung der Kolonne auf den Kriegsfall hin wie eine Übung, die 1913 gemeinsam mit dem Vaterländischen Frauenverein durchgeführt wurde. Angenommen wurde die Ankunft eines Lazaretthilfszuges in der Stadt. ${ }^{1093}$

Im Anschluss an größere Übungen kam es mitunter zu organisierten Festen. So heißt es e. g. im Jahresbericht für 1909 über die bereits erwähnte Übung am Kornhaus: "Hat eine Photographie der Kolonne die Erinnerung an die ernste Seite der Uebung festzuhalten gesucht, so dürfte das in Gemeinschaft mit der Freiw. Feuerwehr abgehaltene Vergnügen gezeigt haben, dass auch der ernste Beruf des Sanitäters sich wohl vereinbaren lässt mit Frohsinn und Lebensfreude nach getaner Arbeit."1094

Die Mitglieder der Kolonne waren bei Einsätzen und Übungen uniformiert, sie trugen ein einheitliches Koppel und einen "Litevka" genannten Uniformrock ${ }^{1095}$ Im alltäglichen Betrieb war neben dem Sanitätsdienst für die Allgemeinheit die Ausführung von Krankentransporten das hauptsächliche Betätigungsfeld der Sanitätskolonne. Die Kranken wurden mit Tragen auf einem speziellen Handwagen gefahren. In den meisten Fällen wurden die Patienten ins Einbecker Vereinskrankenhaus gebracht, doch auch Transporte in

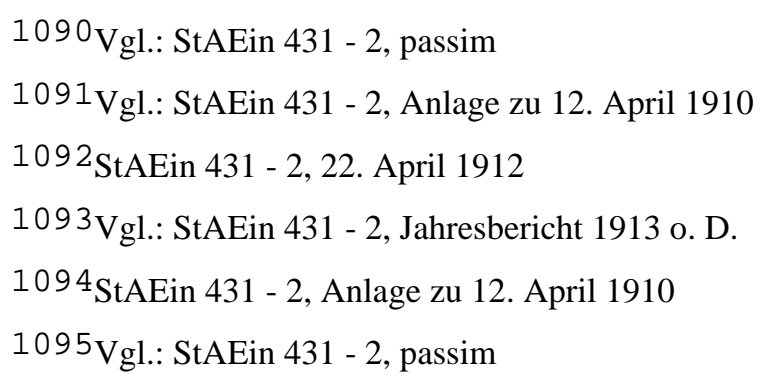


Göttinger Krankenhäuser waren nicht selten. Auch Einsätze als Ordnungsdienst bei größeren öffentlichen Veranstaltungen sind belegt. Bereits im ersten Jahr des Bestehens war man zudem im Katastrophenschutz tätig, als das benachbarte Salzderhelden von Hochwasser bedroht war. ${ }^{1096}$

Die Alarmierung der Sanitätskolonne geschah per Telefon. Verschiedene Besitzer der noch seltenen Anschlüsse in Einbeck und dem Umland erklärten sich bereit, ihre Apparate hierzu zur Verfügung zu stellen, ihre Häuser wurden mit Schildern als "Unfallmeldestation" gekennzeichnet. ${ }^{1097}$

1909 erfolgte der Beitritt zum Dachverband der Sanitätskolonnen vom Roten Kreuz für die Provinz Hannover. Verschiedene Mitglieder besuchten in der Folgezeit Großübungen im gesamten südniedersächsischen Raum,teils als Zuschauer, teils als aktive Teilnehmer. Auch die Verbandstage, die teilweise mehrere Hundert Kilometer entfernt stattfanden, wurden regelmäßig mit Vertretern beschickt. Auf dem Verbandstag 1913 in Soltau wurde die Kolonne mit dem Verbands-Wanderpreis für geleistete Erste Hilfe ausgezeichnet. 1098

\footnotetext{
1096 Vgl.: StAEin 431 - 2, passim

1097 Vgl.: StAEin 431 - 2, Anlage zu 12. April 1910

1098 Vgl.: StAEin 431 -2, passim, spec. Jahresbericht für 1913 o. D.
} 


\section{11. Religöse Vereine}

\section{11. 1. Die evangelischen Vereine}

\section{11. 1. 1. Der christliche Männer- und Jünglingsverein}

Im Jahr 1893 wurde als erster konfessioneller Verein im Untersuchungszeitraum der christliche Männer- und Jünglingsverein gegründet. In einem Schreiben an den Magistrat aus dem Jahr 1898 nennt der damalige Vereinsvorsitzende Karl Lemmermann, Pastor der Marktgemeinde St. Jacobi, dessen Zielsetzung: "Unser christlicher Männer- und Jünglingsverein bezweckt, den jungen Männern Einbecks und denen, die von außerhalb kommen und ohne Familienanschluß hier leben, eine christliche Heimstätte zu bereiten." $\mathrm{Zu}$ diesem Zeitpunkt residierte der Verein in einem Zimmer der Herberge zur Heimat. Als Unterabteilung existierten ein Posaunenund ein Männerchor. ${ }^{1099}$ Aus dem selben Jahr sind der Bestand einer Bibliothek und die einzige bekannte Mitgliederzahl überliefert; zu jener Zeit gehörten 70 Personen dem Verein an. 1100

Die oben zitierte Formulierung Lemmermanns über die Zielgruppe der Aktivitäten belegt bereits, dass ein besonderes Augenmerk auf denjenigen jungen Männern lag, die von außerhalb und ohne Familien nach Einbeck kamen. Um überhaupt zu wissen, wer für ein Ansprechen durch den Verein in Frage käme, bat Lemmermann die Polizeibehörde, ihm allmonatlich ein Verzeichnis der jungen Menschen evangelischer Konfession, die nach Einbeck gekommen waren, zukommen zu lassen. Er wies dabei darauf hin, dass ein solches Vorgehen andernorts gängige Praxis sei.1101 Ob dieser Bitte entsprochen wurde, ist nicht bekannt.

Im Jahre 1898 wurde beschlossen, auf publizistischem Gebiet tätig zu werden und einen "Monatlichen Anzeiger" des Vereins erscheinen zu lassen. 1102 Dieses Vorhaben wurde umgehend in die Tat umgesetzt; in der den Verein betreffenden Akte im Einbecker Stadtarchiv finden sich verschiedene Exemplare des Monatlichen Anzeigers des christlichen Männer- und Jünglingsvereins, beginnend mit der ersten Ausgabe vom 15. Juni 1898. Doch bereits mit der dritten Ausgabe konnte der monatliche Rhythmus nicht mehr

\footnotetext{
1099 Vgl.: StAEin 065 - 13, 3. Juni 1898

1100 Vgl.: StAEin 065 - 13, 8. August 1898

1101 Vgl.: StAEin 065 - 13, 7. November 1899

1102 Vgl.: StAEin 065 - 13, 3. Juni 1898
} 
eingehalten werden. Die letzte in der Akte erhaltene Ausgabe erschien im April 1899, 1103 über das weitere Schicksal des Periodikums ist nichts bekannt.

Wie die intendierte "Bereitung einer christlichen Heimstätte" sich gestaltete, präzisieren die wenigen erhaltenen Schriftstücke recht genau. So schrieb Lemmermann davon "in der Jugend unserer Stadt ein christliches, gottesfürchtiges Geschlecht"1104 heranzuziehen, später heißt es in diesem Zusammenhang, das heranzuziehende Geschlecht solle "gesinnungstüchtig, charakterfest"1105 werden. In einem weiteren Schreiben definiert der Vorsitzende als Vereinsziel, "die jungen Leute den vielfachen Versuchungen und Verführungen des Lebens zu entziehen und sie zu guten Bürgern des Reiches Gottes und damit auch zu guten Bürgern unseres Volkes $\mathrm{zu}$ erziehen."1106 Wie sich dies in der Praxis auswirkte, illustriert ein Programmentwurf $\mathrm{zu}$ einem Fest im Oktober 1895, das sich wie folgt darstellte:

"1. Einleitendes Posaunenspiel

2. Begrüßungsansprache und Festgruß

3. Allgemeines Lied: 'Deutschland Deutschland über alles'

4. Erste Ansprache: 'Die Veranlassung des Krieges 1870/71'

5. Erstes lebendes Bild: 'Der Abschied'

6. Posaunenstiuck

7. Gedicht: 'Feldinstruktion'

8. Zweite Ansprache: 'Die ersten deutschen Siege bis zur Schlacht bei Sedan.'

9. Posaunenstück

10. Festspiel: 'Durch Kampf zum Sieg.'

11. Posaunenstück

12. Dritte Ansprache: 'Von Sedan bis zum Friedensschluß.'

13. Lebendes Bild: 'Nach der Schlacht.'

14. Posaunenstück: 'Wie sie so sanft ruhen.'"

15. Lebendes Bild 'Friede.' unter allgem. Gesang: 'Es braust ein Ruf wie Donnerhall."'1107

\footnotetext{
1103 Vgl.: StAEin 065 - 13

1104 StAEin $065-13,8$. August 1898

1105 StAEin 065 - 13, 30. August 1898

1106 StAEin 065 - 13, 7. November 1899

1107 StAEin 065 - 13, 3. Juni 1898
} 
Derart praktiziertes Christentum rief bei den städtischen Behörden Zustimmung hervor, der Magistrat unterstützte diese Feier mit dem nicht unerheblichen Geldbetrag von 20 Mark. 


\section{11. 1. 2. Weitere evangelische Vereine}

Neben dem christlichen Männer- und Jünglingsverein bestanden im Untersuchungszeitraums verschiedene weitere evangelische Vereine.

Der 45. Jahresbericht des Göttinger Hauptvereins der evangelischen GustavAdolf-Stiftung enthält einen Geschäftsbericht eines Einbecker Zweigvereins für das Jahr 1900/01. Der Gustav-Adolf Verein war 1832 in Lepizig begründet worden und hatte zum Ziel, evangelische Gemeinden in katholischen Gebieten im In- und Ausland zu unterstützen. Dem genannten Geschäftsbericht ist zu entnehmen, dass der Einbecker Zweigverein um die Jahrhundertwende etwa 200 Mitglieder zählte. Wichtigste Ausgabenposten im betreffenden Jahr waren 80 Mark an den Hauptverein in Göttingen, 50 Mark für die Festversammlung der hannoverschen Gustav-Adolf-Vereine in Osnabrück und 40 Mark Zuschuss für den Kirchenbau in Nörten. Auf der Generalversammlung hielt Pastor Schnacke aus Nörten einen Vortrag zum Thema "Not und Hülfe der evangelischen Diaspora unter besonderer Berïcksichtigung unserer Heimat und Böhmen".

Mit dem Superintendenten Vordemann, den Pastoren Firnhaber [St. Marien] und Lemmermann [St. Jacobi], Senator Steinberg und Bürgermeister Troje gehörten neben anderen auch die Spitzen von Kirche, Politik und Verwaltung dem Verein an.

1904 tagten die zum Göttinger Hauptverein gehörenden Zweigvereine in Einbeck. An den Kosten der zweitägigen Versammlung beteiligte sich der Magistrat mit 50 Mark und nahm geschlossen am Festessen im Rahmen dieser Versammlung teil. 1108

Vom evangelischen Frauen- und Jungfauenverein war bereits oben unter den caritativen Vereinen zu lesen.

Unter der Kategorie Vereine zur Förderung kirchlicher Zwecke erscheinen ferner ab 1902 bis zum Ende des Untersuchungszeitraumes ein Zweigverein der Göttinger Bibelgesellschaft, die es sich zur Aufgabe gemacht hatte, die Bibel zu verbreiten und insbesondere jungen Paaren zu ihrer Hochzeit eine Traubibel zu schenken, der evangelische Verein als Zweigverein der Inneren Mission in Hannover und ein Zweigverein des Missionsvereins in den Fürstentümern Göttingen und Grubenhagen. Inwieweit diese Vereine allerdings regelmäßige Aktivitäten entfalteten, die über alljährliche Generalversammlungen und das Aufbringen finanzieller Mittel für die Anliegen der der jeweiligen Hauptvereine hinaus reichten und sie somit erst zu 
Vereinen im Sinne der vorliegenden Arbeit machten, war nicht mehr zu ermitteln. 


\section{11. 2. Die katholischen Vereine}

Die Zahl der Katholiken in der Stadt stieg über den gesamten Untersuchungszeitraum hinweg kontinuierlich an, so dass 1873 eine erste Kapelle und 1895 eine Kirche errichtet werden konnten und mussten. Doch überschritt der Anteil der Einbecker katholischen Bekenntnisses an der Gesamtbevölkerung vor dem Ersten Weltkrieg nie den Wert von 6 v. H.. Die höchste überlieferte Zahl an katholischen Einwohnern beträgt 552.1109 Daher kann es kaum verwundern, dass es nicht, anders als in anderen Gebieten des Reiches, zur Ausbildung eines komplexen katholischen Vereinssystems kam. Bereits im Abschnitt über die Gesangvereine wurde der 1905 gegründete und allenfalls für kurze Zeit bestehende Gesangverein Cäcilia behandelt, im Kapitel über die caritativen Vereine die Existenz des katholischen Elisabethvereins erwähnt. In den Quellen des Stadtarchives fanden sich keine weiteren Belege für sonstige katholische Vereine, die Adressbücher für 1911/12 und vom Juli 1912 weisen unter der Kategorie "Vereine zur Förderung kirchlicher Zwecke" einen katholischen Männer- und Jünglingsverein aus. Wie auch im Falle des Elisabethvereins sind dem Autor keine weiteren Erwähnungen bekannt, die über diesen Nachweis der Existenz hinaus reichen. 


\section{11. 3. Der jüdische Frauenverein}

Neben dem bereits im Abschnitt über die politischen Vereine behandelten Club Gemüthlichkeit ist für den Untersuchungszeitraum nur ein weiterer jüdischer Verein nachzuweisen - der jüdische Frauenverein. Er wurde in der vorliegenden Studie nicht, wie die anderen Frauenvereine, den caritativen Vereinen zugerechnet. Zwar wäre dies nach den statutarisch festgelegten Vereinszielen als "Besuch bei Kranken und Sterbenden" und "Unterstützung dürftiger Glaubensgenossen" zulässig. Doch die Tätigkeit der Mitglieder erstreckte sich darüber hinaus auf verschiedene religiöse Riten wie "das Nähen der Sterbegewänder" sowie "Waschen und Ankleiden weiblicher jüdischer Leichen"1110, so dass eine Einordnung in die Kategorie der religiösen Vereine angeraten erscheinen kann. Die Begleitung von Sterbenden und die dem Ritus entsprechende Behandlung Verstorbener war Sache der Gemeinde, die nicht von bezahlten Kräften übernommen werden durfte, sondern von den Angehörigen der jeweiligen Gemeinde selbst zu leisten war. ${ }^{1111}$

Gegründet wurde der Verein am 1. April 1897 als Bestandteil der Synagogengemeinde. Eine nach $\S 64$ der Allgemeinen Synagogen-Ordnung vom 31. Dezember 1860 erforderliche Genehmigung des für die Einbecker Juden zuständigen Landrabbiners in Hildesheim wurde eingeholt, ehe die Statuten den städtischen Behörden vorgelegt wurden. ${ }^{1112}$

In der Erweiterung der unmittelbar religiösen Pflichten um Krankenbesuche und materielle Unterstützung von bedürftigen Juden dürfte der Impuls zur Vereinsgründung zu suchen zu sein. Die finanziellen Mittel hierzu speisten sich, wie $\S 2$ der Satzung vorsah, aus Beiträgen und freiwilligen Zuwendungen Dritter. Die Beiträge waren relativ hoch, es wurden mindestens drei Mark jährlich erwartet. Weniger bemittelte Frauen konnten jedoch auch ohne Beitragszahlung $\mathrm{zu}$ den persönlichen Dienstleistungen eines Mitgliedes

\footnotetext{
$1110 \S 1$ des gedruckten Statuts, StAEin B XIV 103, Anlage zu 7. Mai 1897

${ }^{1111}$ E. g. heißt es dazu in den 1899 erschienenen Kindheitserinnerungen des aus dem nahe gelegenen Mackensen stammenden Autors Georg Steinberg: "Dat is nu mal bi us Juden Sitte, dat wi use Doen to'r letzten Reise sülwest torekt makt, un dat nich von batahlten Hännen maken latet. Dat düt nu grade nich so öffentlich makt ward, dat is ja nu woll ganz natürlich, un darüm hewt sick use christlichen Mitbörgers von so'n jüdischen Begräffnissen so allerhand Räubergeschichten vertellt [...]." Zitiert nach: Steinberg, Georg: Nahharkels. Jugenderinnerungen aus Mackensen in plattdeutscher Sprache. Nachdruck des Prosateils Vör föwtig Jahr up'n Dörpe aus Nahharkels, Hannover 1899, Einbeck 1986, S. 93 1112 Vgl.: StAEin B XIV 103, 7. Mai 1897 und Anlage
} 
zugelassen werden. Diese präzisiert $\S 6$ : "Jedes Mitglied, das von Seiten des Vereins dazu aufgefordert wird, ist verpflichtet, ein erkranktes Vereinsmitglied, oder ein schwer erkranktes weibliches Mitglied der hiesigen Gemeinde zu besuchen, bei eintretender Auflösung die üblichen Gebete in andachtsvoller Stille zu verrichten und nach erfolgten Tode sich an dem Anfertigen der Sterbegewänder, an dem Abheben, dem Waschen und Ankleiden der Leiche zu beteiligen [...]." Das Nichtbefolgen einer solchen Aufforderung wurde, dies betont die Wichtigkeit des persönlichen Einsatzes für den jüdischen Frauenverein, mit einer hohen Geldbuße von fünf Mark belegt. ${ }^{1113}$

Weitere Belege über den Fortbestand des Vereins fehlen zur Gänze, doch dies dürfte darin begründet sein, dass die individuelle Hilfeleistung für Kranke und Sterbende weitgehend im privaten Bereich stattfand. Ohne Zweifel bestand der jüdische Frauenverein bis weit über den Untersuchungszeitraum hinaus. ${ }^{1114}$ Vermutlich fiel er erst dem Nationalsozialismus zum Opfer.

1113 StAEin B XIV 103, Anlage zu 7. Mai 1897, passim

1114 Vgl.: Gerdes, Susanne: Juden in Einbeck im 19. Jahrhundert. in: Heege, Elke

(Hg.)Verloren aber nicht vergessen. Jüdisches Leben in Einbeck. (Studien zur Einbecker

Geschichte, Bd. 15). Oldenburg 1998. SS. 17 - 72, S. 63, Anmerkung 112 


\section{12. Sonstige Einbecker Vereine 1871 - 1914}

\section{12. 1. Der Verschönerungsverein und der Verein zu Hebung des Fremdenverkehrs}

Im Jahre 1877 gründeten verschiedene Einbecker den Verschönerungsverein. Dieser machte es sich zur Aufgabe, das Einbecker Stadtbild und Ausflugsziele in der nahen Umgebung der Stadt vor allem durch das Aufstellen von Bänken und das Anpflanzen von Bäumen und Sträuchern zu verschönern und verschiedene Wanderwege in Feld und Wald auszubauen.. ${ }^{1115}$ Bei den städtischen Behörden stieß diese Vereinsgründung auf große Sympathie. Zwar unterstützte der Magistrat den Verein nicht finanziell, doch wurden für verschiedene Projekte, beispielsweise die Gestaltung des bei Einbeckern beliebten Ausflugszieles der Teiche im Norden der Stadt, unentgeltlich städtische Arbeiter gestellt. ${ }^{1116}$ Der Einbecker Stadtförster Tegtmeyer war Mitglied des Vereins, er fungierte vielfach als Bindeglied zwischen Verschönerungsverein und Behörden. 1117

1896 ging der Verschönerungsverein ein ehrgeiziges Projekt an: Man plante den Bau eines steinernen Aussichtsturmes auf der Hube. Nach vielen Verhandlungen über den genauen Standort und der Aufbringung der halben vorveranschlagten Bausumme von 10000 Mark wurde am 8. Oktober 1898 der Grundstein zum Kaiser-Friedrich-Turm genannten Bauwerk gelegt, das zwei Jahre später vollendet und seiner Bestimmung übergeben wurde. ${ }^{1118}$

Die Schaffung eines schöneren Stadtbildes machte sich auch der Verein zur Hebung des Fremdenverkehrs zur Aufgabe. Wann dieser gegründet wurde, war nicht zu ermitteln, Primärquellen fehlen fast völlig. In den Vereinslisten der Adressbücher erscheint er von der ersten aus dem Jahre 1902 bis zu jener aus dem Juli 1912 durchgängig. Als Ansprechpartner werden in allen Listen Buchhändler Hermann Ehlers und ein nicht näher bezeichneter Kaufmann August Huch genannt. Es muss als wahrscheinlich angenommen werden, dass zumindest diese beiden Herren, anders als beispielsweise Hoteliers oder Gastronomen, kein unmittelbar materielles Interesse an einem regen Tourismus

\footnotetext{
1115 Vgl.: StAEin 350 - 1, 16. November 1877 et passim

1116 Vgl.: StAEin 350 - 1, 4. Dezember 1878

1117 Vgl.: StAEin 350 - 1, passim

1118 Zur Baugeschichte des Aussichtsturmes vgl.: Gerdes, Susanne: Juden in Einbeck im 19.

Jahrhundert. in: Heege, Elke (Hg.)Verloren aber nicht vergessen. Jüdisches Leben in Einbeck.

(Studien zur Einbecker Geschichte, Bd. 15). Oldenburg 1998. SS. 17 - 72 SS. 61 ff.
} 
hatten. Daher ist der Verein zur Hebung des Fremdenverkehrs nicht als Verband anzusehen.

Das Verhältnis der Verschönerer zur Stadtverwaltung und den Mitbürgern war nicht immer ungetrübt. So beabsichtigte der Verschönerungsverein 1894, die bei einem Pavillon in den Hopfenkuhlen stehenden Kiefern abzuholzen, um von dort einen schönen Ausblick über die Stadt zu ermöglichen. An der Stelle sollte nach Meinung des Vereins ein Forstgarten angelegt werden. Dies rief Widerspruch hervor. Senator Domeier schrieb in einer Stellungnahme zu diesem Vorschlag: "Zurück mit dem ergebensten Bemerken, daß mir das Gedeihen und Wachsen der Kiefern unterhalb des vom VerschönerungsVereine in den Hopfenkuhlen s. Zt. erbauten Pavillons (s. gen. Löwenburg) sehr wohl bekannt ist, und daß ich [...] mich über dieses Wachsen aufrichtig freue, auch ist nach meiner unmaßgeblichen Ansicht ein junger Nadelholzbestand schöner als der Pavillon, und würde ich mich deshalb nicht entschließen können einen Theil dieses Bestandes wieder abzuholzen, um freiere Aussicht zu gewinnen, um so weniger als Aussichten in das Einbecker Thal, wie diejenige vom Pavillon eben so schön, noch an hundert anderen Puncten vor unserem Walde vorhanden sind. Soll der Pavillon auch ferner eine weite Aussicht bieten, so braucht man denselben nur an die südost-Ecke oder die südwest-Ecke der Hopfenkuhlen zu versetzen, da an diesen Stellen die Aussicht nicht zuwachsen kann. Es ist nicht zu verkennen, daß mit dem Heranwachsen des Bestandes in den Hopfenkuhlen die Aussichtspuncte daselbst weniger werden. aber das ist der natürliche Lauf der Dinge, wie er sich von einer rationellen Forstwirtschaft nicht trennen läßt, dafür entstehen wieder an anderen Stellen des Stadtforst durch Abtrieb neue Aussichtspuncte. Was nun schließlich die Anlage eines Forstgartens unterhalb des Pavillons betrifft, so würde dieses dazu die denkbar ungünstigste Stelle sein [...]."1119

Im Sommer 1905 wurden an verschiedenen Stellen auf den ehemaligen Wallanlagen der Stadt Ruhebänke aufgestellt. Diese wurden von der Bevölkerung stark frequentiert, doch verschiedenen verärgerten Bürgern waren sie Anlass zur Beschwerde bei den städtischen Behörden. Fabrikbesitzer Peine gab im Rathaus zu Protokoll: "Ich bitte um Beseitigung der vom Verein zur Hebung des Fremdenverkehrs neben meiner Besitzung am Langenwall aufgestellten Bank für Ruhebedürftige.Der letztere Zweck wird verfehlt. Die Bank wird von Kindermädchen, Kindern, Liebesbedürftigen u. verschiedenen Zechbrüdern benutzt.Die Kinder brechen mein Stackett durch und stehlen Obst. 
Im vergangenen Jahr sind mir die Zwetschenbäume ruinirt."1120 Und ein anderer Fabrikant klagte: "Am Bürgermeisterwall, an der Westseite meiner Besitzung, ist seitens des Verschönerungs-Vereins eine Ruhebank für Erholungsbedürftige aufgestellt.Diese Bank wird vom Morgen ab schon von Kindermädchen in Anspruch genommen, welche die Kinderwagen mit den Kindern dort aufstellen. Die Mädchen bekümmern sich nicht weiter um die Kinder, ob diese schreien oder ruhig sind. Des Abends ist es die Zusammenkunft von Liebespärchen bis gegen Mitternacht und dann hinterher kommen die bezechten Leute. Die Ruhestörung dauert bis gegen $4 \mathrm{Uhr}$ morgens fast täglich. An Nachtschlaf ist für die Bewohner meiner Besitzung nicht zu denken. Meine Gemahlin ist schon ganz nervös."1121 


\section{12. 2. Verschiedene gesellige Vereine}

Geselligkeit spielt sich häufig im privaten oder halbprivaten Raum ab. Daher sind Quellenfunde über mehr oder weniger feste Vereinigungen, die sich ausschließlich der Pflege des freundschaftlichen Umgangs und der zweckfreien Muße widmeten, selten. Es gilt hier sinngemäß das bereits über die Kegelvereine Gesagte. Ein seltenes erhaltenes Statut einer solchen Geselligkeitsvereinigung stellt jenes des Formstecher-Pfeifenclubs Schwerer Lenz dar. Der Verein wurde am 1. November 1897 gegründet. Ein Statut wurde der städtischen Polizeibehörde zur Genehmigung eingereicht. ${ }^{1122}$ Der Club bezweckte nach seinem Statut "durch regelmäßige Zusammenkünfte, welche jeden Montag stattfinden, die Kollegialität zu fördern." Wie der Name bereits sagt, handelte es sich beim Schweren Lenz um einen berufsständischen Zusammenschluss von Formstechern, also Handwerkern, welche die Druckformen für die Einbecker Tapetenindustrie fertigten. Die Kollegialität wurde im Schusterkrug gefördert. Bei den im Vereinsnamen erwähnten Pfeifen handelte es sich um Tabakspfeifen, der Präsident des Vereins war gleichzeitig Pfeifenwart. Der verbrauchte Tabak wurde aus der Clubkasse bezahlt, in die jedes Mitglied 25 Pfennig bei seiner Aufnahme und 20 Pfennig Monatsbeitrag $\mathrm{zu}$ entrichten hatte. Zur Zeit der Einreichung der Statuten, etwa drei Wochen nach Vereinsgründung, zählte man 11 Mitglieder. Über die weiteren Geschicke des Vereins ist nichts bekannt.

Inwieweit der 1885 gegründete Unterhaltungsverein ein rein geselliger Zusammenschluss war, ist fraglich. Im Juni 1885 wurde den Behörden ein Statut eines Unterhaltungsvereins eingereicht. In der Vorrede zu den einzelnen Stzungspunkten wird eine Aussage über die Gründer wie über die Vereinsziele gemacht: "Unter der Bezeichnung Unterhaltungs-Verein Ist von verschiedenen Handwerksgesellen welche sich in Einbeck aufhalten und theilweise darin ansessig einen Verein Gegründet deßen Zweck und Thätigkeit noch das nachstehende Statut geregeld wird. Zweck des Unterhaltungsverein soll sein 1. Vermeiden alles Öffendlichen Tanzlokahlen 2. Die Brüderliche Liebe unter den Vereins Mitgliedern zu pflegen und dießes noch getreues Zusammenhalten zu stärken."1123 Zweifel am rein geselligen Charakter dieses Vereins kommen allerdings bei der Lektüre der Statuten. So sollten auf den allmonatlichen Versammlungen Angelegenheiten besprochen und feste Beschlüsse, welcher Natur auch immer, gefasst werden. Über die Ordnung in diesen

\footnotetext{
1122 StAEin 065 - 11, Eingangsvermerk 24. November 1897 und Anlage

1123 StAEin 065 - 11, Eingangsvermerk 13. Juni 1885
} 
Versammlungen wird eine für die Zeit ungewöhnliche Formulierung gewählt: Der Präsident hatte die Sitzungen in "parlamentarischer Ordnung" zu führen. ${ }^{1124}$

Ein annähernd wortgleiches Statut wurde im September 1886 eingereicht. Auch trägt es die gleichen Namen der Vorstandsmitglieder. Bemerkenswert ist jedoch an diesem Schriftstück der behördliche Eingangsvermerk: Es wurde am selben Tag und von der selben Person, einem Schuhmacher Börries, übergeben, wie jenes des oben erwähnten Gesangvereins "Concordia". 1125 Daher muss im wesentlichen das über diesen Verein Gesagte auch für den Unterhaltungsverein gelten: Ein etwaiger politischer Charakter ist auf Grund des vorhandenen Quellenmaterials nicht $\mathrm{zu}$ belegen, doch es hat einen gewissen Anschein, dass der Verein der Sozialdemokratie zumindest nahestand, dies aber zu Zeiten des Sozialistengesetzes zu verbergen wusste.

Wie auch im Falle des Gesangvereins Concordia war über die weitere Wirkungsgeschichte des Unterhaltungsvereins, der 188518 Mitglieder zählte ${ }^{1126}$, nichts in Erfahrung zu bringen.

Die behördeninterne Vereinsliste von 1893 weist an geselligen Vereinen je einen Familienklub bei den Gastwirten Holtegel und Langhagen sowie einen Familienverein aus. Daneben finden sich in dieser Liste ein Herrenklub und eine Vereinigung mit der Bezeichnung Hemdsärmel \& Pfeifen Verein. ${ }^{1127}$ Die anderen einschlägigen Auflistungen enthalten keine weiteren Hinweise auf Vereine rein geselliger Natur.

$1124_{\text {ibid. }}$

${ }^{1125}$ Das Statut befindet sich disparat in der Akte über Gesang- und Musikvereine, StAEin

065 - 28, Eingang 29. September 1886

1126 Vgl.: StAEin 065 - 11. Eingangsvermerk 13. Juni 1885

1127Vgl.: StAEin 065 - 17, o. D. 


\section{12. 3. Die Bürgervereine}

Im Untersuchungszeitraum wurden in Einbeck verschiedene Bürgervereine gegründet. Von einer dieser Vereinigungen war bereits oben die Rede: Die Mitglieder des 1884 gegründeten Turn- und Fechtclubs stellten nach und nach aus Altersgründen den Sportbetrieb ein, mochten jedoch ihren Verein nicht aufgeben und wandelten ihn 1893 in den Bürger-Klub um. Zunächst hatte man beabsichtigt, den Club in Bürgerverein umzutaufen, doch der Magistrat hatte dies mit der Begründung untersagt, dass unter einem Bürgerverein eine Institution $\mathrm{zu}$ verstehen sei, die sich der Diskussion kommunaler Angelegenheiten widmete. Ein solcher Verein bedürfe einer besonderen Genehmigung. ${ }^{1128}$ Doch bereits 1895 wurde eine Umbenennung in BürgerVerein vollzogen. 1129 Das neue Statut deutet keineswegs auf die Erörterung öffentlicher Angelegenheiten hin, als Vereinszwecke definierten die Gründer "Gesellige Unterhaltung, Tanzfestlichkeiten mit unseren Familien". ${ }^{1130 ~ Z u ~}$ jenem Zeitpunkt zählte der Bürgerverein 50 Mitglieder. Dominierend in der Mitgliedschaft waren die Handwerker mit mindestens 29 Personen, davon 22 zweifelsfrei als Meister identifizierbar. Die nächst größere Gruppe waren die Gastwirte mit acht Männern, die weiteren Mitglieder rekrutierten sich, so weit es sich ermitteln ließ, im Wesentlichen aus dem Besitzbürgertum und der Kaufmannschaft. ${ }^{1131}$

Bereits Ende 1896 gab sich der Verein ein neues Statut. Dieses entsprach erstmals der Vorstellung, die sich der Magistrat von einem Bürgerverein machte. Vereinszweck waren nunmehr "Wahrnehmung der communalen Interessen, Besprechung öffentlicher Angelegenheiten und Vornahme geeigneter Schritte in Bezug auf solche, Errichtung und Förderung gemeinnütziger Anstalten, Leitung der Versammlungen für Kommunalwahlen."1132

Auch nahm der Bürgerverein Abschied von seiner Vereinsgeschichte. Sah man noch nach dem Statut von 1895 den 6. August 1884, an dem der Turn- und Fechtclub aus der Taufe gehoben wurde, als Gründungsdatum an, so nannte die neue Satzung den 6. August 1895, aus welchem Grunde auch immer. ${ }^{1133}$

\footnotetext{
1128 Vgl.: StAEin 065 - 24, Vermerk auf 20. August 1893

1129 Vgl.: StAEin 065 - 24, 4. Juni 1895

${ }^{1130}$ StAEin 065 - 24, Anlage zu 4. Juni 1895

$1131 \mathrm{Vgl}$.: Ibid.

1132 StAEin 065 - 24, Anlage zu 15. Dezember 1896

1133Vgl.: StAEin 065 - 24, Anlagen zu 4. Juni1895 und 15. Dezember 1895
} 
Des politischen Charakters wegen forderten die Behörden eine Mitgliederliste an. Diese enthält die Namen von 67 Personen. Für die Sozialstruktur des Bürgervereins zu diesem Zeitpunkt gilt im Wesentlichen das oben Gesagte. ${ }^{1134}$ In den folgenden Jahren hatte der Bürgerverein einen starken Zulauf. 1900 beabsichtigte der Vorstand ein Gesuch an den Kaiser zu richten, dass Einbeck wieder zur Garnisonsstadt gemacht werden solle. Der Magistrat sah durch ein solches Vorgehen die eigenen in diese Richtung gehenden Bemühungen konterkariert. Es entstand ein Schriftwechsel zwischen den städtischen Behörden und dem Regierungspräsidium, mit dem die Weitergabe des Schreibens nach Berlin vereitelt wurde. In einem der Schreiben wurde die Mitgliederzahl mit 156 angegeben. 1135

Über die weitere Entwicklung und Tätigkeit des Vereins ist kaum etwas bekannt. Lediglich einige Schriftstücke aus dem Jahr 1914 belegen, dass der Bürgerverein Einbeck bis zum Ende des Untersuchungszeitraumes bestand. 1136

Nachdem der Bürgerverein sich seines ausschließlich geselligen Charakters entledigt hatte, entstand rasch das Bedürfnis nach einer Nachfolgeorganisation. Am 2. September 1901 wurde erneut ein Bürgerclub gegründet. In $\S 1$ heißt es über die Vereinsziele: "Der Zweck des Bürgerclubs ist: Gesellige Unterhaltung und soll mindestens jeden Sommer ein Ausflug der Mitglieder in den Einbecker Stadtwald stattfinden."1137 Eine undatierte Mitgliederliste, vermutlich aus der Zeit der Gründung, weist 32 Personen aus. Unter diesen sind verschiedene Mitglieder des Bürgervereins vertreten, die übrigen legen allerdings den Schluss nahe, dass der Club sozial etwas weniger exklusiv war als seinerzeit der erste Bürgerclub. ${ }^{1138}$ Bis auf eine Nennung des Clubs in der Vereinsliste des Adressbuches 1911/12 sind keine weiteren Belege für die Fortexistenz oder gar für Vereinsaktivitäten bekannt.

Wie bereits in der Einleitung und im Kapitel über den Naturheilverein angedeutet, wuchs Einbeck im Untersuchungszeitraum erstmals im größeren Maße über seine mittelalterlichen Stadtgrenzen hinaus. Die Hauptentwicklungsachse der gewerblich genutzten Bereiche führte nach Osten,

\footnotetext{
1134 Vgl.: StAEin 065 - 24, o. D.

${ }^{1135} \mathrm{Vgl}$ : StAEin 065 - 24, 12. November 1900

1136 Vgl.: StAEin 065 - 24, 1914 passim

${ }^{1137}$ StAEin $065-24,20$. September 1901

1138 StAEin 065 - 24, o. D.
} 
während die Bebauung mit Wohnhäusern hauptsächlich nördlich der Altstadt erfolgte. 1891 wurde mit Wirkung zum 1. Januar 1892 der Verein zur Hebung des nördlichen Stadttheils gegründet. Sein Zweck war definiert als "die Wahrnehmung der Interessen des nördlichen Stadttheils und erstrebt die Hebung desselben namentlich durch: a. Vorstellungen und Anträge bei den städtischen Collegien und anderen Behörden; b. Vorträge und Verhandlungen in den Vereinsversammlungen; c. Mittheilungen in der Presse; d. Besprechungen und Stellungnahme zu den Communalwahlen." Mitglied konnte jeder Bürger oder Grundbesitzer der Nordstadt werden. ${ }^{1139}$

Aus dem Jahr 1903 ist ein Statut eines Nordstädter Bürgervereins erhalten. Die Formulierung der Aufgaben stimmt mit jener des zuvor genannten Vereins überein, lediglich wurde ein Punkt, "Rat- und Auskunftserteilung in allen kommunalen Angelegenheiten durch den Vorstand", ergänzt.1140 Dies deutet darauf hin, dass der Nordstädter Bürgerverein ein Nachfolger des Vereins zur Hebung des nördlichen Stadttheils war. Eintreten konnte jeder "Haus- und Grundbesitzer oder Bürger der Nordstadt, welcher ein Bürgergewinngeld gezahlt hat und volle Kommunalabgaben an die Stadt entrichtet".

Der Verein schloss sich dem Dachverband der Bürgervereine der Provinz Hannover an. ${ }^{1141}$ Die Existenz eines solchen lässt den Schluss zu, dass überall in der Provinz Bürgervereine gegründet wurden. Über die weitere Geschichte der organisierten Interessenvertretung der Bürger in Einbecks Nordstadt, so es sie denn gab, ist nichts bekannt. Die zitierten Statuten sind die einzig bekannten Quellen hierzu.

\footnotetext{
1139 StAEin 065 - 24, 1. Januar 1892

1140 StAEin 065 - 24, 1. Januar 1903

1141 Vgl.: ibid.
} 


\section{12. 4. Die Freiwillige Feuerwehr}

Das heute ganz Deutschland umfassende Netz von Freiwilligen Feuerwehren hat seinen Ursprung in den vierziger Jahren des 19. Jahrhunderts. Brandkatastrophen in Hamburg und Karlsruhe führten den Zeitgenossen drastisch die Unzulänglichkeiten des damaligen Feuerlöschwesens vor Augen. 1847 wurde im badischen Durlach die erste auf Freiwilligkeit ihrer Mitglieder basierende Feuerwehr gegründet. Nach dem Durlacher Vorbild wurden in der Folgezeit landauf landab Feuerwehren gegründet, die ersten im Königreich Hannover 1855 in Goslar und 1856 in Göttingen. Träger der Organisation waren häufig Turnvereine. 1142

In Einbeck regte der Magistrat erstmals 1866 die Gründung einer Freiwilligen Feuerwehr an. Diese sollte die Pflichtfeuerwehr, in der alle Einbecker Bürger, eingeteilt in sechs Kompanien, dienten, im Brandfalle unterstützen. Doch ein entsprechender Gründungsappell hatte nicht den gewünschten Erfolg. Zwar kam es zu der Gründung dieser ersten Freiwilligen Feuerwehr in Einbeck, doch hatte sie nur etwa ein Jahr Bestand. ${ }^{1143}$ Wie bereits in der Einleitung erwähnt, beschloss 1867 der Männerturnverein, eine Turnerfeuerwehr, das so genannte Turner-Rettungs-Corps, zu gründen. Jeder Turner dieses in jener Zeit einzigen Einbecker Turnvereins war verpflichtet, gleichzeitig auch Feuerwehrmann zu sein. ${ }^{1144}$ Der Kreis der Männer, die sich für Brandschutz- und -bekämpfung einsetzten, wurde mit dieser Gründung über den kleinen Kreis der Bürger im dienstfähigen Alter, die Plümer auf 175 Mann beziffert, hinaus auch auf andere Einwohner der Stadt erweitert. Das Jahr 1867 sieht die Freiwillige Feuerwehr als ihr Gründungsjahr an. Doch auch das Turner-Rettungs-Corps bestand nur kurze Zeit.

1872/73 reformierte der Magistrat daher das Pflichtfeuerwehrwesen. Nach der Feuerlösch- und Rettungsordnung von 1873 wurde nunmehr jeder männliche Einwohner der Stadt zwischen 20 und 60 Jahren zum Dienst herangezogen. An die Stelle der bisherigen Gliederung nach den sechs Stadtbezirken wurde die Feuerwehr nach ihren Aufgaben in fünf Abteilungen, Steiger, Handwerker, Spritzenmannschaft, Retter und Schutzmannschaft, gegliedert. Insgesamt umfasste die reformierte Pflichtfeuerwehr etwa 350

\footnotetext{
1142 Vgl.: Plümer, Erich: Aus der Geschichte des Einbecker Feuerlöschwesens. in: 125 Jahre Freiwillige Feuerwehr Stadt Einbeck. 25 Jahre Feuerwehr-Musikzug Einbeck-Moringen.

Einbeck 1992, SS. 31 - 63, S. 43

1143 Vgl.: Plümer, Erich: op. cit., S. 45

1144 Vgl.: Einbecksches Wochenblatt, 12. Oktober 1867
} 
Männer. Erstmals trat die Einbecker Feuerwehr uniformiert auf, ein schwarzer Drellrock und eine Mütze gehörten zur Ausrüstung eines Feuerwehrmannes. ${ }^{1145}$

War die Mitgliedschaft in der Feuerwehr Pflicht, so basierte die Zugehörigkeit zur Abteilung der Steiger, die im Brandfall die gefährlichsten Aufgaben zu übernehmen hatten, auf Freiwilligkeit. Aus dem Steigerkorps kam dann auch etwa 20 Jahre nach Gründung der Pflichtfeuerwehr der Impuls, erneut eine Freiwillige Feuerwehr zu gründen. Diese Gründung wurde mit der Errichtung einer Satzung am 1. März 1894 vollzogen. 78 Männer gehörten der neuem Wehr im Gründungsjahr an. Noch im selben Jahr trat man dem Hannoverschen Feuerwehrverband bei. 1146

Offenbar konnte die neue Feuerwehr ihre Mannschaften besser ausbilden und effizienter Hilfe leisten. Rasch verdrängte sie die Pflichtwehr. Der Magistrat gestattete es, neben neu angeschafften Geräten auch auf vorhandenes Material der städtischen Wehr zurückzugreifen. Bereits 1896 ging die gesamte Feuerwehrausrüstung in den Besitz der Freiwilligen über. Die Pflichtfeuerwehr dürfte schon um die Wende zum 20. Jahrhundert keine nennenswerte Bedeutung für das Löschwesen der Stadt gehabt haben. Plümer gibt an, dass sie 1902 aufgehoben wurde. 1147 Doch zumindest als Organisation muss sie länger bestanden haben: erst die Vereinsliste des Adressbuches 1911/12 führt die Freiwillige als einzige Feuerwehr auf.

Auf Grund der bereits in der Einleitung dargestellten Quellenlage war Nähreres über die Freiwillige Feuerwehr vor dem Ersten Weltkrieg nicht in Erfahrung zu bringen.

1145 Vgl.: Plümer, Erich: op. cit., SS. 45 ff.

1146 Vgl.: Faksimile eines Protokolls in: Plümer, Erich: op. cit., S. 47

1147 Vgl.: Plümer, Erich: op. cit., S. 53 


\section{12. 5. Weitere Vereine}

Der Vollständigkeit halber sollen im Folgenden noch jene Vereine aufgelistet werden, deren Existenz aus den an verschiedener Stelle zitierten Auflistungen belegt ist, über die jedoch nichts weiter in Erfahrung gebracht werden konnte. Es werden nur jene Vereinigungen aufgeführt, auf welche die in der Einleitung aufgestellte Vereinsdefinition zugetroffen haben dürfte.

Die Vereinsliste des Adressbuchs 1911/12 führt erstmals einen Tierschutzverein und einen Verein für Zoologie und Sammelsport auf, jene aus dem Juli 1912 zudem eine Esperanto-Gruppe und die Guttemplerloge "Familienheim".

Im einschlägigen Kapitel der Veröffentlichung anlässlich des 100-jährigen Jubiläums des Einbecker Geschichtsvereins werden, basierend auf einer Auswertung des Kreisblattes der Jahrgänge 1880 bis 1882 der Verein für wissenschaftliche Vorträge, der Verein gegen Bettelei, der Verein für Kunst und Wissenschaft und ein Schachklub aufgeführt. Fernerhin werden dort ein Photo-Verein von 1902 und der zum Zeitpunkt der Niederschrift der vorliegenden Arbeit noch bestehende Verein ehemaliger Einbecker Realgymnasiasten genannt. 1148

Am 6. Juni 1914 wurde ins Vereinsregister des Amtsgerichtes Einbeck ein Verein für Zoologie mit Sitz in Einbeck eingetragen, dessen Satzung am 26. April jenes Jahres errichtet worden war. Durch die Person des zweiten Vorsitzenden, eines Wegeaufsehers aus Gandersheim, ist ein gewisser überregionaler Charakter dieser Vereinigung nachzuweisen. ${ }^{149} \mathrm{Ob}$ der Verein aus dem bereits genannten Verein für Zoologie und Sammelsport hervorging konnte nicht in Erfahrung gebracht werden. Auch muss unklar bleiben, ob er, gegründet unmittelbar vor Ausbruch des Ersten Weltkrieges, überhaupt ein regelrechtes Vereinsleben entfalten konnte - aus der Nachkriegszeit sind dem Autor keinerlei Belege über das Fortbestehen des Vereins bekannt.

\footnotetext{
1148 Vgl.: Einbecker Geschichtsverein (Hg.): Stadt Einbeck. Zeitgenössische Fotografien und Dokumente. Gesammelt und bearbeitet von Erich Strauß, Hellmut Hainski und Andreas Heege. Duderstadt 1995, SS. 157 ff.. Der Verein ehemaliger Einbecker Realgymnasiasten wurde 1904 gegründet. Vgl. hierzu: Hülse, Horst: Überblick über die Geschichte der Schule. in:
} Goetheschule Einbeck. 450 Jahre Schule der Stadt Einbeck 1532 - 1982. Einbeck 1982, SS. 7 - 


\section{Gesamtschau und Ausblick}

\section{1. Zur statistischen Entwicklung des Einbecker Vereinswesens}

Wie die vorstehenden Einzel- und Gruppenbetrachtungen bereits zeigten, ist es nicht einfach, klare quantitative Angaben zur Entwicklung des Einbecker Vereinswesens zu machen. Schon die Beschäftigung mit den Gesangvereinen ermöglichte keine Querschnittsanalysen: Nicht einmal die Frage beispielsweise, wie viele dieser Vereine zugleich existierten, ist für jeden Zeitpunkt im Untersuchungsraum zweifelsfrei zu beantworten. Solche Unsicherheiten erschweren auch eine Betrachtung des Vereinswesens im Ganzen. Dennoch treten durch das erarbeitete Material gewisse grundlegende Entwicklungstendenzen zu Tage.

Eine Auswertung bezüglich der Gründungsjahre der im Hauptteil der vorliegenden Arbeit behandelten Vereine hatte folgendes Ergebnis:

Vereine

Zeit der Vereinsgründung

$\begin{array}{llllll}\text { nach } & \text { vor } & 1871 & 1880 \mathrm{er} & 1890 \mathrm{er} & 1900 \\ \text { Kategorie } & \text { UZ1150 } & -1879 & -1889 & -1899 & -1914 \\ \text { Gesang } & 5 & 1 & 3 & 3 & 3 \\ \text { Musik \& } & & & & & \\ \text { Theater } & 0 & 0 & 0 & 2 & 2 \\ \text { Turnen } & 1 & 0 & 3 & 1 & 0 \\ \text { Sport } & 0 & 0 & 1 & 4 & 5 \\ \text { Schützen } & 1 & 0 & 0 & 0 & 1 \\ \text { Militär } & 0 & 2 & 0 & 1 & 2 \\ \text { Politik } & 1 & 0 & 0 & 5 & 1 \\ \text { Sonstige } & 1 & 2 & 0 & 6 & 5 \\ \text { Summe } & 9 & 5 & 7 & 22 & 19\end{array}$

Dieses Ergebnis, gefasst in klare Zahlen, ist bei Weitem nicht so aussagekräftig, wie es auf den ersten Blick erscheinen mag. Mehrere Vereine wurden aus verschiedenen Gründen nicht in die Auswertung einbezogen. In vielen Fällen war das Gründungsdatum nicht einmal annähernd seriös zu schätzen und in das gewählte temporale Schema einzuordnen. Im Falle der 
politischen Vereine wurden, weil bei den Sozialdemokraten und der Welfenpartei diverse Organisationen auf einander folgten, nur die jeweils ersten Vereinsgründungen der verschiedenen Parteien berücksichtigt. Zudem stehen hinter den einzelnen Zahlen in der historischen Wirklichkeit sehr unterschiedliche Organisationen: Während beispielsweise die Sportvereine, deren Gründungen in die kleine Statistik einflossen, wie am Beispiel des Athleten-Clubs Vorwärts und der verschiedenen frühen Fußballvereine gezeigt wurde, kleine und zudem sehr kurzlebige Vereine waren, repräsentieren die Zahlen der Turnvereine große und dauerhafte Gründungen wie den TCE und den Turnklub Eintracht.

Dennoch treten durch die obige Statistik grundlegende Tendenzen der Vereinsentwicklung im Einbeck des Kaiserreiches deutlich zu Tage. Für den Untersuchungszeitraum insgesamt ist geradezu eine explosionsartige Vereinsgründungswelle zu verzeichnen. Die bereits in der Einleitung zitierte Aussage Ernst Schuberts, dass, obwohl um die Jahrhundertmitte bereits von einer "Zeit der Vereine" gesprochen wurde, diese damals noch bevorstand, 1151 lässt sich somit für den Fall der untersuchten Stadt selbst durch das dürftige statistische Material nur allzu deutlich unterstreichen.

Die völlige Entfaltung eines komplexen und vielfältigen Systems von Vereinen, das zumindest wesentliche Teile der gesamten Stadtgesellschaft Einbecks um- und überspannte, vollzog sich im Untersuchungszeitraum, verstärkt ab den achtziger Jahren des 19. Jahrhunderts, rasant ab der darauf folgenden Dekade.

Über die zeitliche und zahlenmäßige Entwicklung des Vereinswesens in Deutschland oder seinen Teilen fehlen konkretere Aussagen der Wissenschaft. Die wenigen vagen Angaben und Thesen sind vielfach nicht miteinander zusammenzuführen, da - dies wurde eingangs angedeutet - verschiedene Autoren sehr unterschiedliche Vereinsbegriffe zwar homophon, aber keineswegs synonym verwenden. So ist es sehr schwierig, die für Einbeck dargestellte Entwicklung mit allgemeinen Trends in Beziehung zu setzen.

Vieles über die Entwicklung des Einbecker Vereinswesens wurde in den einschlägigen Kapiteln dieser Untersuchung bereits gesagt und soll daher, um Redundanz zu vermeiden, nur kurz angerissen werden. Wesentliche Entwicklungen scheinen durchaus typisch zu sein und dürften sich in ähnlicher Weise auch andernorts abgespielt haben. Auf der Basis eines ersten,

${ }^{1151}$ Vgl.: Schubert, Ernst: Die Veränderung eines Königreichs. in: Hucker, Bernd Ulrich u. a. (Hgg.)Niedersächsische Geschichte. Göttingen 1997, SS. 374 - 418, S. 409 
vornehmlich von Kleinbürgern getragenen Vereinssystems entwickelte sich eine breite gesellschaftliche Subsphäre von verschiedensten Vereinen. Die ersten Vereinsgründungen im Untersuchungszeitraum bezogen ihren Impuls aus dem Eindruck des soeben gewonnenen Krieges gegen Frankreich und der daraus resultierenden Bildung des Deutschen Kaiserreiches: Wie im übrigen Land auch bildeten sich Militärvereine, um die Erinnerung an den von weitesten Kreisen der Bevölkerung vorbehaltlos positiv bewerteten Krieg wach zu halten. Auch die Gründung des Vaterländischen Frauenvereins in Berlin und seiner Zweigorganisationen fußte auf den Ereignissen der Zeit. Zugleich weist diese Vereinsgründung darauf hin, dass man durchaus weitere Kriege befürchtete - Hauptzweck dieser Vereine war es zunächst, die Mitglieder auf den Sanitätsdienst an verwundeten Soldaten vorzubereiten.

Sänger und Turner gab es in Einbeck bereits vor dem Untersuchungszeitraum, doch auch die Expansion des Vereinswesens in seiner Gesamtheit vor dem Ersten Weltkrieg spielte sich vorwiegend auf den Feldern des Männergesangs und der organisierten Leibesübungen ab. Hier ist vor allem ab den achtziger und stärker noch den neunziger Jahren des 19. Jahrhunderts eine vermehrte Gründungsaktivität $\mathrm{zu}$ verzeichnen. Diese scheint ebenso typisch zu sein wie das Aufkommen des Sports um die Wende zum 20. Jahrhundert. In diesem Kontext ist jedoch eine Besonderheit in der Vereinsentwicklung Einbecks zu verzeichnen. Verhältnismäßig früh kam der Fußball in die kleine Kreisstadt, zudem untypischerweise getragen von Kleinbürgertum und Arbeiterschaft.

Die allgemeine Organisationsgeschichte der Parteien ist in zeitlicher Hinsicht, über die Inhalte fehlt es an Quellen, am lokalen Beispiel exemplarisch nachzuvollziehen. Wies am Beginn des Untersuchungszeitraums nur die sozialdemokratische Partei eine mehr oder minder feste Organisation auf, so traten ab den neunziger Jahren vermehrt auch Organisationen der bürgerlichen Parteien auf. Die Gründe für die verhältnismäßig frühe Organisation der Sozialdemokraten - wie auch für die Gründung von verschiedenen sozialdemokratisch orientierten Vereinen im vorpolitischen Raum nach dem Fall des Sozialistengesetzes - dürften unter Anderem in der Gewerbestruktur Einbecks zu suchen sein, 1152 während die Ausbildung der

\footnotetext{
${ }^{1152}$ In anderen Städten, beispielsweise dem benachbarten Northeim, wurden solche Vereinigungen wesentlich später gegründet.
} 
Lokalorganisationen der anderen Parteien einem übergeordneten Zeittrend folgte, dessen Ursachen nicht im lokalen Bereich zu suchen sind. ${ }^{1153}$

Auch von verschiedenen Einbecker Besonderheiten war bereits die Rede. Der Geschichtsverein wurde hier verhältnismäßig spät und unter ungewöhnlichen Umständen gegründet - die Initiative ging vom Magistrat aus, der beabsichtigte, die Last des Unterhalts und Betriebs eines Museums auf die Schultern von Privatleuten zu legen. Das Auftreten eines Naturheilvereins, der sich im Wesentlichen der Freikörperkultur widmete, und der nach anfänglichen Schwierigkeiten $\mathrm{zu}$ einer allgemein akzeptierten mitgliederstarken Organisation heranwuchs, scheint für Südniedersachsen, wenn nicht gar generell für den ländlich-kleinstädtischen Raum, sehr ungewöhnlich zu sein.

Das starke Anwachsen des Vereinswesens im Einbeck des Kaiserreichs und anderswo fällt zusammen mit der Durchbruchsphase der Industrialisierung in einer vom traditionellen Handwerk geprägten Kleinstadt. Auf den Zusammenhang von Industrialisierung und Vereinsaktivität hat Klaus Tenfelde ebenso hingewiesen wie auf einen zeitlichen Abstand, den der Durchbruch des Vereinsgedankens auf dem Lande gegenüber den Großstädten aufwies. ${ }^{1154}$

Über die quantitative Entwicklung des Einbecker Vereinswesens bis zum Ersten Weltkrieg bestehen, dies wurde bereits mehrfach gesagt, so große Überlieferungslücken, dass es nicht einmal möglich ist, die Gesamtzahl der Vereine über den Untersuchungszeitraum hinweg exakt zu bestimmen. Noch weitaus schwieriger ist dies für die Zahl der Vereinsmitglieder. Von einigen Vereinen ließen sich sehr genaue Daten erheben, die bereits in den Einzeldarstellungen aufgeführt wurden, für andere Vereine fehlen diese. Doch selbst, wenn von allen Vereinen die Mitgliederzahlen vorlägen, wäre es unmöglich zu ermitteln, wie viele Menschen insgesamt den Vereinen angehörten - stichprobenartige Vergleiche verschiedener erhaltener Listen zeigten deutlich, dass Mehrfachmitgliedschaften nicht ungewöhnlich waren. Viele Familiennamen erschienen zudem in unterschiedlichen Schreibweisen, was bei einer Analyse mit den Methoden der elektronischen Datenverarbeitung zu Fehlern führen würde. Doch auch bei dieser Fragestellung gilt das über die Zahl der Vereine Gesagte: Die Untersuchung hat grundlegende Tendenzen klar

1153 Vgl. e. g.: Nipperdey, Thomas: Deutsche Geschichte 1866 - 1918. Zweiter Band:

Machtstaat vor der Demokratie. München 1992, S. 518

1154 Vgl.: Tenfelde, Klaus: Die Entfaltung des Vereinswesens während der industriellen

Revolution in Deutschland (1850 - 1873). in: Dann, Otto (Hg.): Vereinswesen und bürgerliche Gesellschaft in Deutschland (Historische Zeitschrift. Beihefte (Neue Folge), Beiheft 9).

München 1984, SS. 55 -114,passim 
aufgezeigt. Das Anwachsen der Zahl der Vereine fand seine Entsprechung in einer steigenden Zahl von Vereinsmitgliedern. Diese stieg sehr viel stärker an als die Gesamtbevölkerung. Gab es beispielsweise vor 1880 wohl kaum mehr als 50 Turnvereinsmitglieder in der Stadt, so waren es in den neunziger Jahren des 19. Jahrhunderts bereits 300 bis 400. Doppelmitgliedschaften sind in diesem Falle weit gehend auszuschließen, weil die Vereine, wie oben dargelegt, sich in ihren Vereinszielen und -aktivitäten sehr ähnelten, sich jedoch in ihrer sozialen Zusammensetzung zum Teil deutlich voneinander unterschieden, und mitunter gar in einerr gewissen Konkurrenz standen. Ähnliches gilt auch für die Militärvereine, die in dieser Zeit eine ähnliche Gesamtstärke aufwiesen,

Die Gesamtzahl der Personen, die in einem oder mehreren Vereinen Mitglieder waren, ist nicht einmal annähernd seriös zu schätzen. Ähnliches gilt allerdings auch für die Gesamtzahl derjenigen, die für eine Vereinsmitgliedschaft überhaupt in Frage kamen. Von allen Einwohnern Einbecks fielen hier zunächst die weiblichen fast völlig hinaus. Frauen erscheinen, abgesehen von den caritativen Vereinen, äußerst selten in den bekannten Listen. Von der verbleibenden Personenzahl wäre in Hinblick auf Kinder und Jugendliche noch etwa ein Drittel zu subtrahieren. ${ }^{1155}$ Hieraus errechnete sich zunächst für den Beginn des Untersuchungszeitraums eine Zahl von etwa 2000 potenziellen Mitgliedern, die bis zum Vorabend des Weltkrieges auf gut 3000 angewachsen wäre. Doch diese Zahlen wären weiter zu reduzieren. Zunächst kamen diejenigen kaum in Betracht, deren Aufenthalt in der Stadt nur befristet oder absehbar nur vorübergehender Natur war. Dies sind zunächst die auswärtigen Fachschüler, insbesondere des Technikums. Zwar erscheinen diese durchaus in Einbecker Vereinen, doch hatten sie daneben eigene Vereinigungen, die in dieser Studie nicht behandelt wurden, da sie unter der zu Grunde liegenden soziologischen Fragestellung weitgehend

\footnotetext{
${ }^{1155}$ Die Vereine hatten verschiedene Altersbegrenzungen, einige verlangten die Volljährigkeit, während andere bereits 17-Jährige aufnahmen, einige Turnvereine bildeten Schüler ab 14 Jahren aus, die teilweise gesondert in den vereinsinternen Statistiken erfasst wurden. Als Durchschnittsgrenzwert scheint 18 Jahre der Realität recht nahe zu kommen. Zum Anteil der Kinder und Jugendlichen an der Gesamtbevölkerung vgl.: Nipperdey, Thomas:
} Deutsche Geschichte 1866 - 1918. Erster Band: Arbeitswelt und Bürgergeist. München 1990, S. 30 
uninteressant sind und zudem kaum Quellenmaterial über sie existiert.1156 Daneben wiesen insbesondere die jungen Männer im Kleinbürger- und Arbeitermilieu eine hohe lokale Mobilität auf. Die Zahl der Personen, die nur mehr oder weniger kurz in der Stadt verweilten und sich deshalb keinem Verein anschlossen, ist ebenso wenig zu schätzen wie jene derer, die auf Grund ihres Broterwerbs über keine geregelte Freizeit verfügten und sich daher nicht regelmäßig im Verein engagieren konnten und jener, deren materielle Lage so schlecht war, dass sie es sich nicht leisten konnten, Beiträge zu zahlen.

Vor dem Hintergrund dieser Überlegungen scheint es zulässig zu sagen, dass der Vereinsgedanke im Untersuchungszeitraum in Einbeck weite Teile der hierfür in Frage kommenden Bevölkerung erfasste und sich das Vereinswesen $\mathrm{zu}$ einer wesentlichen, wenn nicht gar zu der bestimmenden Binnenstruktur der kleinstädtischen Gesellschaft entwickelte.

Verschiedentlich wird in der Literatur darauf hingewiesen, dass die Bildung von Vereinen eine nicht unwesentliche Rolle bei der Modernisierung Deutschlands und seiner Gesellschaft spielte. ${ }^{1157}$ Unter diesem Gesichtspunkt sind die Ergebnisse dieser Studie im Zusammenspiel mit dem eingangs zur gewerblichen Entwicklung Gesagten geeignet, zu belegen, dass sich in Einbeck im Untersuchungszeitraum der Wandel von der vorindustriellen Zeit hin zur modernen Gesellschaft vollzog.

1156 Das selbe gilt auch für die Schülervereine, die am Realgymnasium bestanden. Vgl. hierzu: Hülse, Horst: Überblick über die Geschichte der Schule. in: Goetheschule Einbeck. 450 Jahre Schule der Stadt Einbeck 1532 - 1982. Einbeck 1982, SS. 7 - 54, S. 32 ${ }^{1157}$ Vgl. e. g.: Best, Heinrich: Vorwort des Herausgebers in: Ders. (Hg.): Vereine in Deutschland. Vom Geheimbund zur freien gesellschaftlichen Organisation. Mit einer Literaturund Forschungsdokumentation von Helmut M. Artus. Bonn 1993, SS. 8 - 10, S. 9 und Tenfelde, Klaus: op. cit., passim 


\section{2. Zur sozialen Integrationskraft der untersuchten Vereine}

Auch wenn sie nicht exakt quantifizierbar ist, wurde oben eine deutliche Expansion des Vereinslebens zweifelsfrei nachgewiesen. Der Vereinsgedanke erfasste einen wesentlichen Teil der erwachsenen männlichen Bevölkerung. Auch sich im Kaiserreich zunehmend formierende gesellschaftliche Gruppen und Formationen wie die entstehende Lohnarbeiterschaft und der "Neue Mittelstand" der Angestellten wurden von der allgemeinen Tendenz, sich Vereinen anzuschließen oder eigene Vereine zu gründen, erfasst. Die erhaltenen Quellen zeigen die Tendenz auf, dass eine Vereinsmitgliedschaft für Männer, deren sozialer Ort oberhalb der Unterschichten sich befand, nicht ungewöhnlich, wenn nicht sogar die Regel war. In seiner Gesamtheit betrachtet übte das Vereinswesen also eine immense soziale Integrationskraft aus.

Allerdings tritt auch der zunächst widersprüchliche Befund deutlich zu Tage, dass der einzelne Verein nur sehr begrenzt in der Lage war, sozial integrierend zu wirken. Dies zeigt augenfällig das Beispiel der Militärvereine. Die drei großen dieser Vereine wiesen, dies kann angesichts der behördlichen Bestimmungen über diesen Vereinstypus nicht verwundern, eine nahezu vollständige Kongruenz der statutarischen Vereinszwecke - Pflege der Kameradschaft und der Liebe zu Vaterland und Herrscherhaus - auf. Unter diesem Gesichtspunkt hätte es nicht dreier separater Organisationen bedurft. Eine erste Segregation trat zwischen den Veteranen der so genannten Einigungskriege und den Reservisten ohne Feldzugserfahrung auf. Doch auch letztere bildeten auf Dauer nicht einen einzigen Verein - zusätzlich zum eher kleinbürgerlich-proletarisch dominierten Kriegerverein Kameradschaft von 1878 wurde 1896 mit dem Landwehr- und Reserveverein ein weiterer Zusammenschluss ehemaliger Soldaten gegründet, der seine Mitglieder vornehmlich aus dem Bürgertum mit seinen verschiedenen Untergruppen rekrutierte. Selbst der allgemeine Wertekonsens, der das Militär glorifizierte und dem gewesenen Soldaten ein gewisses Ansehen verlieh, trat hinter sozialen Unterschieden zurück. Zusammenfassend kann konstatiert werden: Der Militärvereinsgedanke war in so hohem Maße sozial integrierend, dass er sogar fundamentale politische Differenzen überbrücken konnte ${ }^{1158}$, es entwickelten sich jedoch innerhalb dieser Vereinsgattung verschiedene, sozial eher homogene Unterorganisationen. Die Integrationskraft des einzelnen Militärvereins war also eher gering.

${ }^{1158}$ Hierüber geben die Berichte über Sozialdemokraten in den Kriegervereinen ein beredtes 
Ein ähnliches Bild ergab die Untersuchung der anderen Massenbewegungen - der Gesangvereine und der Turner. Ursprünglich war die Pflege des deutschen Männergesangs eine Domäne von Kleinbürgern. Bereits vor 1871 gab es verschiedene Gesangvereine in der Stadt. Ebenfalls vor dem Untersuchungszeitraum war innerhalb der Sängerschaft eine ideologische Spaltung zu verzeichnen - in den sechziger Jahren des 19. Jahrhunderts hatte sich jener sozialdemokratische Gesangverein entwickelt, der bis 1878 unter dem Namen Liedertafel Lassallia auftrat. Bis ins 20. Jahrhundert blieb die soziale Basis des organisierten Gesangs im Wesentlichen auf Kleinbürgertum und Arbeiterschaft beschränkt. Die Vielzahl der, zum großen Teil erfolglosen, Neugründungen, darf hierüber nicht hinwegtäuschen und dürfte im Falle des welfisch gesonnenen MGV Sachsenroß ideologisch, in den anderen Fällen in der Praxis des mehrstimmigen Chorgesangs begründet liegen. Angehörige des gehobeneren Bürgertums und der Angestelltenschaft konnten in keinem dieser Vereine eine Heimat finden - als genug von ihnen bereit waren, sich dem Gesang zu widmen, erfolgte 1907 die Gründung des MGV Deutsches Lied. Auch die Gesangvereine wiesen also eine Tendenz zur sozialen Segregation auf. Zusätzlich, dies wurde bereits im einschlägigen Kapitel erörtert, bestanden innerhalb der Einbecker Sängerschaft politisch-ideologische Meinungsverschiedenheiten, die $\mathrm{zu}$ einer weiteren Ausdifferenzierung des organisierten Männergesangs führten.

Eine ähnliche Entwicklung, wenn auch in anderer Reihenfolge, vollzog sich auf dem Feld der Turnerei. An die Seite des von Kleinbügertum und Handwerkerschaft getragenen MTV von 1861 trat 1880 der vornehmlich von Kaufleuten und Angestellten frequentierte Turn-Club. Die Gründung des TV Germania im Jahre 1883 entzieht sich mangels erhaltener Dokumente einer sozialhistorischen Deutung. Die Geschichte des 1884 gegründeten Turn- und Fechtclubs, der relativ rasch zum Bürgerverein Einbeck mutierte, lässt vermuten, dass sich in ihm Vertreter sozialer Schichten organisierten, die sozial oberhalb der Klientel des Turn-Club zu verorten sind, in denen es allerdings keine dauerhaft ausreichende Basis für einen eigenen Turnverein gab. Die Arbeiterschaft gründete 1893 mit dem TC Eintracht als letzte soziale Formation einen Turnverein. Dieser entwickelte sich im frühen 20. Jahrhundert zu einem Zentrum der Arbeiterbewegung in Einbeck. Anders als im Falle der Liedertafel Lassallia vollzog sich die Ausbildung eines ideologischen Gegensatzes zu den anderen Vereinen jedoch erst Jahre nach der Gründung zunächst beabsichtigte man seitens der Eintracht, sich der Deutschen Turnerschaft anzuschließen. Konflikte mit den örtlichen DT-Vereinen ließen dieses Vorhaben scheitern, der Beitritt zum sozialdemokratisch gesonnenen 
Arbeiter-Turnerbund erfolgte jedoch erst im Jahre 1899. Auch in diesem Falle war die Vereinsgründung also sozial und nicht ideologisch begründet.

Als Grundphänomen bleibt festzuhalten, dass das Vereinswesen in seiner Gesamtheit eine enorme soziale Integrationskraft hatte, die einzelnen Vereine jedoch tendenziell sozial eher homogen und somit eher segregierend waren. Nur innerhalb des eindeutig bürgerlichen Spektrums war eine partielle gruppenübergreifende Integrationswirkung festzustellen. Als Mittel zur Erhaltung dieser Homogenität ist das Ballotement, also die Abstimmung einer Versammlung über zum Beitritt angemeldete Personen anzusehen, das in vielen Vereinen statutenmäßig vorgeschrieben war.

Die Trennung zwischen Kleinbürgertum und der entstehenden Lohnarbeiterschaft vollzog sich nicht entlang einer scharfen, klar erkennbaren sozialen Linie. Dies kann kaum überraschen in einer Stadt, in der wirkliche Großindustrie, wie es sie beispielsweise im Ruhrgebiet oder in Berlin gab, nicht zu finden war. Die Grenzen zwischen Handwerkern und Arbeitern waren fließend, die Lebensumstände ähnlich. Trennend in diesem Bereich der Gesellschaft, auch dies wurde bereits verschiedentlich angedeutet, waren weniger soziale Ungleichheiten als vielmehr politisch-ideologische Differenzen. Auch dies scheint für den Untersuchungszeitraum nicht ungewöhnlich zu sein: Auch in wesentlich stärker industrialisierten Zentren trat eine in sich homogene und kohärente, zu den Rändern hin scharf abgegrenzte Arbeiterklasse nicht real in Erscheinung, die organisierte Arbeiterbewegung erfasste nur einen Teil der Lohnarbeit verrichtenden Bevölkerung. ${ }^{1159}$ Sicherlich hat das Bestehen von sozialdemokratisch orientierten Vereinen im vorpolitischen Raum - neben der Eintracht der Arbeiter-Radfahrerverein Vorwärts und der Dramatische Club Thalia - jedoch neben der starken Lokalorganisation der Partei einen wesentlichen Beitrag dazu geleistet, dass sich in Einbeck wie andernorts zunehmend eine klare Trennungslinie zwischen Sozialdemokraten und der im politischen Sinne bürgerlichen Sphäre herausbildete.

${ }^{1159}$ Vgl. e. g.: Güldenpfennig, Sven: Der politische Diskurs des Sports. Zeiggeschichtliche Beobachtungen und theoretische Grundlagen. (Edition Sport \& Wissenschaft Band 16) Aachen 1992, S. 189 Überhaupt ist der Begriff Klasse, so oft er auch in der Literatur verwendet wird, recht unscharf. Dies zu diskutieren kann nicht die Aufgabe der vorliegenden Arbeit sein. Zu den Problemen des Begriffes sei hier verwiesen auf: Stuke, Horst: Bedeutung und Problematik des Klassenbegriffs. Begriffs- und sozialgeschichtliche Überlegungen im Umkreis einer historischen Klassentheorie. in: Engelhardt, Ulrich u. a. (Hgg.): Soziale Bewegung und politische Verfassung. Beiträge zur Geschichte der modernen Welt. Stuttgart 1976, SS. 46 - 82 


\section{3. Die innere Struktur der Vereine und der "Obrigkeitsstaat"}

Dem Deutschen Kaiserreich haftet der Ruf an, ein Obrigkeitsstaat mit einer bis in den privaten Bereich reichenden, weitgehend autoritären Binnenstruktur gewesen zu sein. In der geschichtswissenschaftlichen Forschung ist dies am deutlichsten von Hans-Ulrich Wehler formuliert worden ${ }^{1160}$, in literarischer Form prägte vor allem Heinrich Manns erstmals 1914 publizierter Roman "Der Untertan" dieses Bild. Thomas Nipperdey unternahm den Versuch, dieses allgemein verbreitete Klischee genauer $\mathrm{zu}$ betrachten und $\mathrm{zu}$ relativieren. Wehlers "Kaiserreich" griff er aus diesem wie anderen Gründen heftig an ${ }^{1161}$, und in einem Essay stellte er gar die provokative Frage: "War die wilhelminische Gesellschaft eine Untertanen-Gesellschaft?"1162 Partiell gelang es ihm, dieses Klischee in wesentlichen Teile zumindest zu relativieren. Er griff in seinen Darlegungen allerdings nicht auf die These Klaus Tenfeldes zurück, der gerade im Vereinswesen eine gesellschaftliche "Fundamentaldemokratisierung" erblickt. ${ }^{1163}$

Sicherlich wies die Gesellschaft des Kaiserreichs grundlegende autoritäre Strukturen auf, die von den politischen und administrativen Prozessen über die Justiz, die Bürokratie und die Bildungsinstitutionen bis in die Familien reichten. Dennoch waren der Staat und die Gesellschaft nicht so monolithischmilitärisch, wie es manchem auf den ersten Blick erscheinen mag. Neben anderen Aspekten, die bei Nipperdey und Ullmann nachzulesen sind und auf die daher nicht näher einzugehen ist, gibt nicht zuletzt die innere Beschaffenheit der Vereine hierauf einen Hinweis.

In fundamentalen strukturellen Punkten ähnelten sich all die vielen Statuten, die während der Arbeit an der vorliegenden Untersuchung gelesen und ausgewertet wurden. Wesentliches Strukturmerkmal bezüglich der Stellung des

\footnotetext{
${ }^{1160 V g l .: ~ W e h l e r, ~ H a n s-U l r i c h: ~ D a s ~ d e u t s c h e ~ K a i s e r r e i c h ~} 1871$ - 1918. in: Rürup, Reinhard; Wehler, Hans-Ulrich; Schulz, Gerhard: Deutsche Geschichte. Sonderausgabe. Band 3: 19. und 20. Jahrhundert. Göttingen 1985, SS. 201 - 404. [Erstmals erschien dieses Werk in den siebziger Jahren des 20. Jahrhunderts.] ${ }^{1161}$ Nipperdey, Thomas: Wehlers "Kaiserreich". Eine kritische Auseinandersetzung. in: ders.: Gesellschaft, Kultur, Theorie. Gesammelte Aufsätze zur Neueren Geschichte. (Kritische Studien zur Geschichtswissenschaft, Band 18). Göttingen 1976, SS. 360 -389

1162 Nipperdey, Thomas: War die wilhelminische Gesellschaft eine Untertanen-Gesellschaft? in: ders.: Nachdenken über die deutsche Geschichte. München 1990, SS. 208 - 224 [erstmals erschienen 1985] 1163 Vgl.: Tenfelde, Klaus: op. cit., SS. $111 \mathrm{f}$.
} 
einzelnen Mitgliedes zum Gesamtverein war die formale Gleichstellung - in Versammlungen hatte jeder das Recht, seine Meinung frei zu vertreten, eines jeden Stimme hatte bei Wahlen und Entscheidungen das gleiche Gewicht. ${ }^{1164}$

Die Vorstände waren turnusmäßig zu wählen, sie schuldeten der Vereinsversammlung zudem Rechenschaft über ihre Tätigkeit, und schon relativ geringfügige Ausgaben mussten von einer Versammlung genehmigt werden. Gegen Vorstandsbeschlüsse stand den Mitgliedern das Recht der Beschwerde zu.

Diese Strukturen sind im Ganzen gesehen ein Abbild der institutionalisierten Demokratie im Kleinen. Zwar ist nur in vier Statuten, jenen des Unterhaltungsvereins von 1885/86, des MGV Concordia, des Kriegervereins Kameradschaft und des MGV Deutsches Lied, von "parlamentarischen Regeln" beziehungsweise "parlamentarischer Ordnung" im Zusammenhang mit den Vereinsversammlungen zu lesen ${ }^{1165}$, doch müssen solche Formulierungen für die Gesamtheit des Vereinswesens als zutreffend erachtet werden. Mithin ist der Aussage Klaus Tenfeldes vorbehaltlos zuzustimmen, wenn er schreibt: "Was repräsentative Demokratie bedeutete, wurde im Verein zuallererst erlernt, [...] Artikulations- und Vertretungsformen wurden hier formalisiert, einer Prozedur unterworfen. Öffentliches und geschlossenes Versammlungswesen, Generalversammlung, Mehrheitsbildung, Vertretung nach außen [...] wurden wenn nicht im Verein geboren, so doch dort vor allem praktiziert." 1166

Im Vereinsleben, der umfassenden Zwischensphäre zwischen Individuum auf der einen und Gesamtgesellschaft und Staat auf der anderen Seite, waren die Bürger des Kaiserreiches keine unmündigen Untertanen, sondern selbstbewusst agierende und sich artikulierende Citoyens.

Diese Erkenntnis kann und soll nicht die militaristischen und autoritären Züge des Kaiserreiches verharmlosen oder gar fortdiskutieren. Insbesondere vor dem Hintergrund der zahlreichen Vereine und der nicht untersuchten anderen Vereinigungen illustriert sie jedoch, dass es im häufig als

1164 Einschränkend ist hierzu allerdings zu sagen, dass bei Stimmengleichheit in vielen Vereinen der Präsident zu entscheiden hatte. Andere Statuten sahen für diesen Fall den Losentscheid vor.

1165 StAEin 065 - 11, Eingangsvermerk 13. Juni 1885; StAEin 065 - 28, Eingangsvermerk

29. September 1886; StAEin 065 - 28, Unterakte MGV Concordia, Eingangsvermerk 29.

September 1886; StAEin 065 - 32, Anlage zu 12. März 1896; StAEin 065 - 28, Unterakte

MGV Deutsches Lied, 31. Juli 1907

1166 Tenfelde, Klaus: op. cit., SS. 111 
Obrigkeitsstaat charakterisierten Kaiserreich durchaus Binnenstrukturen einer im politischen Sinne bürgerlichen Gesellschaft gab. Neben allem zweifellos vorhandenen Untertanengeist, neben allen auf Befehl und Gehorsam basierenden Prozessen, neben allem Mangel an bürgerlicher politischer Kultur traten auch Entwicklungsendenzen hin zu Demokratie, Modernisierung und Pluralismus zu Tage. Diese wurden in der vorliegenden Studie anhand des Vereinslebens nur exemplarisch aufgezeigt, die Aussage dürfte jedoch für die gesamte Gesellschaft jener Zeit Gültigkeit haben.

Es würde an dieser Stelle zu weit führen, wenn die Frage diskutiert würde, ob im Vereinswesen mit seiner gelebten Demokratie an der Basis der Gesellschaft die Saat für die kommende Demokratie in Deutschland gelegt wurde. Jedoch scheint dem Autor dies der historischen Wirklichkeit eher zu entsprechen als die vielfach publizierte These, dass der wilhelminische Untertanengeist sich über die Jahre 1918 bis 1933 konserviert habe und letztlich für das Scheitern der Republik verantwortlich zu machen sei. 


\section{4. Vereine als Hort der Geselligkeit}

Die eben vorgestellten Ergebnisse sollen nicht den Eindruck erwecken, dass die Menschen des Kaiserreiches Vereine gründeten, ihnen beitraten und mehr oder minder dauerhaft angehörten, um in diesen Mikrokosmen erste Erfahrungen mit unmittelbar gelebter und praktizierter Demokratie zu machen. Ein solches Movens ist allenfalls für den Bereich der politischen Vereine anzunehmen. Für den Großteil der untersuchten Vereine ist der Impuls zu Gründung und Beitritt an anderer Stelle zu suchen. Bereits für die Frühzeit des Vereinswesens im Deutschland des ausgehenden 18. und beginnenden 19. Jahrhundert stellt Thomas Nipperdey eine wesentliche Triebfeder zur Gründung von Vereinen dar: "Die Vereinsgründer möchten sich jenseits der Beschränkungen von Haus, Stand, Beruf und traditionellem Zeremoniell in freier Geselligkeit $\mathrm{zu}$ 'vergnügter' Unterhaltung zusammenfinden."1167

"Geselligkeit" und "Unterhaltung" sind sehr allgemeine Begriffe, die zunächst nur eine geringe Aussagekraft haben. Erst ein Blick auf die Aktivitäten der Vereine kann diese in der gelebten Praxis stark von sozialen und kulturellen Gegebenheiten bestimmten Abstrakta mit Inhalt erfüllen. Eine Betrachtung der auf den ersten Blick erkennbaren Vereinszwecke würde in diesem Falle zu kurz greifen: Dass Turnvereine gegründet wurden, damit die Mitglieder gemeinsam Turnen konnten, Gesangvereine für den gemeinsamen Gesang, wäre eine triviale Erklärung, die dem Phänomen des Vereins kaum gerecht werden könnte. Zudem reichte sie nicht aus, um die oben skizzierte Tendenz zur sozialen Homogenität zu erklären. Denn wenn sich die Turner und Sportler nur auf die Leibesübung, die organisierten ehemaligen Soldaten nur auf die Glorifizierung des Krieges, des Militärs und des Herrscherhauses beschränkt hätten, dann hätte es kaum der Existenz verschiedener Vereine mit auf den ersten Blick identischer Zielsetzung bedurft. Pointiert formuliert: In weißer Turnerkluft am Barren, in Uniformrock auf der Sedanfeier sind alle gleich.

Auch in jenen Vereinen, deren Zwecke und Ziele spezieller waren als die der in der Tradition der frühen bürgerlichen Assoziationen stehenden Vereine, welche sich nur der Geselligkeit und zweckfreien Unterhaltung verschrieben, wurde neben dem Turnbetrieb, dem Gesang, den Schießübungen et cetera ein

\footnotetext{
${ }^{1167}$ Nipperdey, Thomas: Verein als soziale Struktur in Deutschland im späten 18. und frühen 19. Jahrhundert. in: Boockmann, Hartmut u. a. (Hgg.): Geschichtswissenschaft und
}

Vereinswesen im 19. Jahrhundert. (Veröffentlichungen des Max-Planck-Instituts für Geschichte, Band 1). Göttingen 1972, SS. 1 - 44, S. 5. 
teils freier, teils ritualisierter Umgang der Vereinsmitglieder untereinander gepflegt, sei es bei den verschiedenen Feiern und Festen, sei es beim so genannten gemütlichen Beisammensein nach dem Training oder nach Versammlungen. Dies ergab sich keineswegs zufällig, sondern wurde bereits bei der Gründung von Vereinen bewusst intendiert. Nicht selten definierten die Statuten, gewissermaßen als Nebenzweck, "Geselligkeit unter seinen Mitgliedern zu fördern"1168, "Förderung eines allgemeinen Freundschaftsverhältnisses"1169 oder Ähnliches. Doch auch das Fehlen solcher Bestimmungen bedeutet keineswegs, dass in den entsprechenden Vereinen kein über das Maß der gemeinsamen statutengemäßen Aktivität hinaus reichender Umgang gepflegt wurde. Die zeigt sich am Beispiel des TC Eintracht. In seinen Statuten findet sich kein Hinweis auf intendierte Geselligkeit am Rande oder außerhalb des unmittelbaren Turnbetriebs. 1170 Doch gerade dieser Verein ist einer der wenigen, dessen Protokolle vollständig erhalten sind und der Nachwelt einen gewissen Einblick in den Vereinsalltag ermöglichen. Die nicht seltenen Einträge über das gemütliche Ausklingen lesen sich beispielsweise wie folgt: "da unser Turnbruder und Turnwart Lohmann in den Ehestand getreten ist und wier ihn dazu beschenkt haben, so forderte er uns auf mit ihm einige Glas Bier zu leeren. Wodurch unser Herr Präses es vernachlässigte die Versammlung $\mathrm{zu}$ schließen so wurde dieselbe erst geschlossen, da wier schon 1/2 Stunde zum Fidelitas übergegangen waren 11 1/4 Uhr mit einem Gut Heil." 1171 "Unser Vorsitzende machte den Antrag, auf die scheidenden Mitglieder ein Fäßchen Bier zu trinken, welches auch bewilligt wurde."1172 "Stellt Turnbruder Nolte den Antrag, da wir bei der Maskerade einen schönen Überschuß hatten ein $\mathrm{Fa} ß$ Bier zu trinken. Turnbruder Christian war gegen den Antrag und sagte das schöne Sprichwort: Lerne, spare, leiste was, so hast du, kannst du, bist du was. Dasselbe wurde aber nicht erhört und der Antrag Nolte angenommen. Ferner erbot sich Turnbruder Ahrens zur Feier seiner Vermählung ein Faß Bier zu spendieren daselbe wurde mit großem Jubel begrüßt. Endlich wurde nach einigen nebensächlichen Debatten ins gemütliche

\footnotetext{
${ }^{1168}$ Statut des Bicycle Clubs, StAEin 065 - 25, 20. Februar 1898

${ }^{1169}$ Statut der Graphischen Liedertafel, StAEin 065 - 28, Unterakte Graphische Liedertafel,

5. Oktober 1898 Die Auswahl dieser wie der vorstehenden Belegstelle erfolgte mehr oder minder zufällig, es ließen sich etliche weitere anführen.

${ }^{1170}$ Vgl.: Das älteste erhaltene Statut dieses Vereins in StAEin 065 - 27, Anlage zu 5. März 1898

${ }^{1171}$ Eintracht Einbeck, Protokoll 9. August 1896

1172Eintracht Einbeck, Protokoll 3. Oktober 1896
} 
übergegangen."1173 "Hierauf wurde ein Packet von unserem früheren Turnwart Helmer geöffnet, welches einen schönen Stiefel1174 enthielt. Derselbe wurde mit Freuden begrüßt und auf sein Wohl etliche Male auf Vereinskosten geleert."1175 Diese willkürlich ausgewählten Auszüge stehen für viele weitere, die hier zu zitieren ermüdend wäre und die den angemessenen Rahmen dieser Betrachtung sprengen würden.

Die Hinweise in den Eintracht-Protokollen auf mehr oder weniger ritualisierte, durch den Genuss von Bier beförderte Geselligkeit, stellen keineswegs singuläre Befunde dar. Verschiedentlich war hiervon bereits in der vorliegenden Arbeit zu lesen, beispielsweise, dass im Schützenverein Stimmen laut wurden, die das permanente rituelle Trinken ablehnten, oder dass innerhalb des Turn-Clubs zumindest phasenweise Kommersrituale der Waffenstudenten imitiert wurden. Letzteres sollte jedoch nicht den Eindruck erwecken, dass solch rituelle Geselligkeit den Regelfall darstellte. Dass auch halboffizielle Feierlichkeiten wie die Amtseinführung eines neuen Schriftwartes durchaus in ungezwungene und ausgelassene spontane Feste mit nahezu infantilen Späßen münden konnten, illustriert ein launiger Protokolleintrag des MTV Einbeck aus dem Jahre 1876: "5. Wurde eine Deputation, bestehend aus Sartorisio, Faatz \& Koch gewählt um dem Wirth des Vereinslokals zu seinem so eben eingetroffenen Söhnlein zu gratulieren; als sie aber hinaustraten vor die Thür sah einer unter ihnen der da sich nennt Koch, die Frau des Wirthes stehen in der Thür, so da genannt wird, die des Kellers; sintemalen aber schon in alten Büchern geschrieben steht, daß ein Weib welches eben erst gebäret hat, nicht kann stehen in einer Thüre des Kellers, bemerkte unser Koch daß seine Turnbrüder ihm einen riesigen Bären aufgebunden, er sagte jedoch nichts zu seinen Kameraden sondern schwug still entblößte enrüstet sein Haupt und schlich betrübt von dannen. Sartorisio aber so da italiänisch ist und zu deutsch Poussirvogel heißt und einer aus dem Stamme derer von Bleiwitz der da sich nennt Faatz vollzogen getreulich den Auftrag so sie erhalten hatten indem sie sich schon ableckten die Lippen nach dem Biere, so sie hofften zu erhalten für ihren Glückwunsch. Kurzhage aber, welcher zur selbigen Zeit Hohepriester im Verein war ärgerte sich baß ob dieses Schwindels raufte sein Haar und schalt die Abgesandten wie einen Sklaven; diese aber schüttelten betrübt den Staub von ihren Füßen und machten sich eilig von dannen um aufzuklären ihre

\footnotetext{
1173 Eintracht Einbeck, Protokoll 5. März 1898

${ }^{1174}$ I. e. ein etwa 2 Liter fassendes, stiefelförmiges Glasgefäß, das zu rituellen Trinkspielen verwendet wird.
}

1175 Eintracht Einbeck, Protokoll 3. September 1898 
Brüder ob des Irrtums in welchem sie befangenwaren; als sie aber hineintraten in den Saal so ihre Brüder versamelt waren sahen sie ein daß sie waren betrogen worden, denn ihre lieben Brüder lagen am Boden hielten sich den Bauch lachten so laut sie konnten und freuten sich baß ob der Unthat so sie begangen hatten. Sartorisio aber so da italienisch ist u. zu deutsch Poussirvogel heißt und der aus dem Stamme von Bleiwitz trösteten sich schnell hierob indem sie großen Mengen Bieres vertilgten so da war ausgeworfen worden von dem Vergnügungsrath Burgtorff sintemalen er am selben Abend zum Schriftgelehrten ernannt war und von dem Bruder Rehse alldieweil er als keusche Jungfrau in den Bund aufgenommen zum Schluß begab sich das große Wunder, daß die aus dem Stamme der Turner selbigen Abends erst am anderen Morgen zu Hause kamen." 1176

Solche Hinweise auf quasi spontane Akte der Geselligkeit am Rande der Übungen oder Versammlungen fanden sich in allen größeren zusammenhängenden Protokollsammlungen verschiedener Vereine mit unterschiedlicher sozialer Zusammenstzung. Daher besteht keinerlei Grund zu der Annahme, dass sich solches in anderen Vereinen, deren Unterlagen verloren sind, nicht in ähnlicher Form zugetragen haben sollte. Ausgenommen hiervon dürften allenfalls solche Vereine gewesen sein, die in der aufklärerischen Tradition des frühen Vereinswesens standen, und sich der Erbauung und Belehrung ihrer zumeist aus dem gehobenen Bürgertum stammenden Mitglieder verschrieben hatten, wie dies beispielsweise beim Verein für Geschichte und Alterthümer der Fall war. Doch auch in solchen Fällen ist nicht auszuschließen, dass sich an die Versammlungen und Vorträge ausgedehnte Beisammensein anschlossen.

All die zitierten beredten Zeugnisse weisen anschaulich auf ein grundsätzliches Phänomen der gelebten Geselligkeit innerhalb der Vereine hin: Die gemeinsame Beschäftigung mit dem, was man unter Verwendung eines anachronistischen Terminus als Hobby bezeichnen könnte, reichte allein offenbar nicht aus, um ein dauerhaftes Zusammengehörigkeitsgefühl unter den Mitgliedern zu erzeugen. Die in gemeinsamer Runde verlebten Stunden, sei es im ernsten Gespräch oder bei albernen Scherzen, stifteten eine kollektive Identität. Insbesondere durch sie lässt sich die am Beispiel des Turn-Clubs aufgezeigte tiefe Bindung der Mitglieder an den Verein, die vielfach die aktive Turnerzeit um Jahre und Jahrzehnte überdauerte, erklären.

Die Geselligkeit in den Vereinen des Kaiserreiches beschränkte sich nicht auf gemeinschaftlichen Alkoholkonsum in mehr oder minder exzessiver Form. 
Jedoch hat es angesichts der Gebräuche beispielsweise in den im 19. Jahrhundert entstandenen Studentenverbindungen den Anschein, dass gerade gemeinsame Räusche in hohem Grade die innere Kohäsion einer Gruppe von Männern förderten. ${ }^{1177}$

Neben den geplanten oder spontanen Trinkgelagen wurde die Geselligkeit in den Vereinen auf verschiedene andere Weise gepflegt. Von gemeinsamen Essen, den sich im Laufe der Zeit von Wanderungen $\mathrm{zu}$ touristischen Ausflügen entwickelnden Turnfahrten und vor allem den Festen und Kränzchen war bereits an verschiedener Stelle dieser Untersuchung zu lesen. Die letzten beiden Punkte sind in diesem Zusammenhang besonders zu beachten. Sowohl die Teilnahme an Fahrten, als auch an Festen und Feiern, Maskenbällen und Kränzchen, beschränkte sich nicht auf die Vereinsmitglieder. Im Regelfalle wurden über solche Aktivitäten die Familien, Partner und Freunde in das Vereinsleben eingebunden. Für den Fall von Eintracht Einbeck konnte überdies nachgewiesen werden, dass zahlreiche Vergnügungsveranstaltungen auch zahlenden Vereinsfremden offenstanden. Wenn auch nicht alle, so entwickelten sich doch einzelne Vereine zu Anbietern auf dem durch die Einführung moderner Produktionsformen sich allmählich entwickelnden Markt der kommerziellen Freizeitangebote.

${ }^{1177}$ Dies scheint, nur am Rande bemerkt, sich bis zur Zeit der Niederschrift der vorliegenden Studie nicht grundlegend geändert zu haben. 


\section{5. Schlussbemerkungen und Ausblick}

Anders, als es das am Beginn dieser Arbeit stehende Zitat Max Webers nahe legt, ließen sich die Vereine nicht isoliert "zwischen den politisch organisierten oder anerkannten Gewalten - Staat, Gemeinde und offizielle Kirche - auf der einen Seite und der naturgewachsenen Gemeinschaft der Familie auf der anderen Seite" lokalisieren. Über die Einbindung der Angehörigen und Freunde der Vereinsmitglieder wurde soeben gesprochen. Überschneidungen mit der Sphäre der verschiedenen übergeordneten obrigkeitlichen Instanzen wurden an verschiedener Stelle, ohne dezidiert darauf hinzuweisen, thematisiert. Die Berührungen der städtischen Behörden, insbesondere des Magistrats, mit verschiedenen Vereinen reichten weit über den Rahmen der polizeilichen Aufgaben hinaus. Die Militärvereine wurden, da man ihnen einen positiven volkspädagogischen Einfluss beimaß, bei den übergeordneten Behörden protegiert und durch die Mitgliedschaft exponierter Vertreter der Behörden wie durch Teilnahme von Funktionsträgern bei den Festen und Feiern für die Öffentlichkeit sichtbar geehrt. Caritative Vereine wie der Vaterländische Frauenverein, der das Krankenhaus betrieb, und dadurch der Stadt den Unterhalt für eine eigene Krankenpflege abnahm, oder die Kolonne des Roten Kreuzes oder die Feuerwehr, die sich im Sanitäts-, Rettungs- und Löschwesen für die Stadtgemeinde einsetzten, wurden finanziell unterstützt. Am Beispiel des Vereins für Geschichte und Alterthümer konnte gar detailliert nachgewiesen werden, dass die unmittelbare Gründungsinitiative vom Magistrat ausging und dieser die Gründungsphase koordinierte und leitete. Die wenigen Befunde über die konfessionellen, vor allem die evangelischen Vereine, die in dieser Kategorie in einer Stadt mit einer zu etwa 90 v. H. lutherischen Bevölkerung 1178 naturgemäß dominierten, lassen vermuten, dass diese durch die Führungsrolle der Pastoren faktisch Unterabteilungen der Kirchengemeinden waren.

Es kann also festgehalten werden, dass sich das Vereinswesen in seiner Gesamtheit zu einem weit reichenden Zwischensystem zwischen dem durch die Erosion traditioneller vormoderner Bindungen zunehmend vereinzelnden Individuum und seiner unmittelbaren privaten Sphäre auf der einen, und den übergeordneten staatlichen und quasistaatlichen Institutionen auf der anderen Seite, entwickelte. Die vielfachen, kurz skizzierten und exemplarisch

1178 Vgl.: Hülse, Horst: Einbeck in der Gründerzeit. in: Einbecker Geschichtsverein (Hg.): Geschichte der Stadt Einbeck. Band 2: Vom Ende des 18. Jahrhunderts bis zum Ende des zweiten Weltkrieges. Einbeck 1992, SS. 71 - 138 
dargelegten Überschneidungen mit den beiden Polen des Weberschen Forschungsappells trugen dazu bei, dass die sich entwickelnde moderne Gesellschaft ein neues inneres Gefüge herausbildete, im Kleinen durch die örtlichen Vereine, im Großen durch deren Dachverbände. Dies erkannten, vielleicht unbewusst, bereits die Zeitgenossen. Plante der Magistrat, beispielsweise zu Volksfesten, die städtische Bevölkerung zu mobilisieren, so suchte er die Hilfe der Vereine. 1179

Dass zumindest teilweise auch versucht wurde, die sozialdemokratischen Vereine in das lose Netzwerk der städtischen Binnenstruktur einzubinden, wurde am Beispiel des Arbeitergesangvereins bereits angedeutet. In den Kapiteln über die sozialdemokratischen Gesangvereine und die verschiedenen Organisationen der sozialdemokratischen Partei wurde zudem gezeigt, dass das zweifellos für das Reich im Ganzen, insbesondere für Preußen, berechtigte Gesamtbild einer strengen, repressiven Praxis der Behörden gegen sozialistische Bestrebungen für den Fall Einbecks stark zu relativieren ist. Allerdings ergab sich keine befriedigende Deutung für diesen Befund. Ähnliche Untersuchungen für andere Kleinstädte könnten ein ähnliches, aber auch ein völlig unterschiedliches Bild ergeben.

Ein weiteres wesentliches Ergebnis der Untersuchung des Einbecker Vereinswesens zwischen Reichsgründung und dem Ersten Weltkrieg ist, dass sich das Vereinswesen sehr dynamisch, aber auch wechselvoll entwickelte. Zwar ist ein permanentes quantitatives Wachstum zu verzeichnen, auf dessen Ergebnissen bis ins 21. Jahrhundert eine wesentliche Binnenstruktur der kleinstädtischen Gesellschaft fußt - einige der behandelten Vereine konnten bereits ihr 100-jähriges Jubiläum feiern und auf ihre Vereinsgeschichte in kleinen Chroniken zurückblicken. Doch nicht alle Vereine waren auf Dauer erfolgreich, sie gingen bereits im Verlaufe des Untersuchungszeitraums wieder ein oder fielen späteren Zeitläuften zum Opfer. Über diese Vereine gibt es keine Jubiläumsschriften, doch müssen auch sie betrachtet werden, um die Dynamik des Vereinswesens in seiner Gesamtheit zu erfassen.

Die Impulse für diese Dynamik waren vielfältig. Über den Übergang von der traditionell-vormodernen hin zur industriell-bürgerlichen Wirtschaft und Gesellschaft ist bereits gesprochen worden, ebenso wie über Veränderungen der innenpolitischen Verfasstheit des Reiches, insbesondere nach dem Ende der Ära Otto von Bismarcks. Wirtschaftliche Prosperität und Moden hatten ebenfalls Einfluss auf die Bildung von Vereinen - dies wurde beispielsweise an der Ausbreitung des Radsports in weiten Kreisen der Bevölkerung verdeutlicht.

${ }^{1179}$ Vgl.: StAEin 340 - 4, 340 - 5 
Das Vereinsleben vor dem Ersten Weltkrieg, in Einbeck wie vermutlich andernorts, entwickelte sich nicht stetig, und es war zu keiner Zeit statisch, wie auch das gesamte Kaiserreich in den 43 Jahren von seiner Gründung bis zum Kriegsbeginn permanent tiefgreifenden dynamischen Entwicklungsprozessen unterworfen war.

Die aufgezeigten Prozesse endeten selbstverständlich nicht mit dem Ende des Untersuchungszeitraumes. Der Erste Weltkrieg brachte zwar, auch dies wurde bereits erwähnt, das Leben innerhalb der Vereine nahezu völlig zum Erliegen. Doch nach dem Krieg setzte sich die Entwicklung fort. Viele Vereine nahmen ihren Betrieb wieder auf. Neue Zeiten brachten neue Vereine hervor, neu aufkommende und Verbreitung findende Sportarten wie Wassersport und Tennis wurden teils von den bestehenden Vereinen aufgenommen, teils führten sie zu neuen Gründungen.

Ähnliches vollzog sich nach der Gleichschaltung im Nationalsozialismus und dem Zweiten Weltkrieg, diesmal unter den Strukturbedingungen zunächst des besetzten Deutschlands, später dann der Bundesrepublik. Nur einige wenige Beispiele seien hier aufgeführt, um die fortwährende Entwicklung der Vereinslandschaft illustrieren:.Von den vier großen Turnvereinen wurden nur Turn-Club und Eintracht wiedergegründet. Der organisierte Gesang wandelte sich tiefgreifend - von den Gesangvereinen des Kaiserreiches besteht nur mehr der MGV Harmonie, jedoch konnte sich trotz der großen Entfernung zur Nordseeküste ein Shanty-Chor etablieren. Der erhöhte Kapitalbedarf höherklassigen Amateurfußballs wie auch Nachwuchsmangel führte zur Fusion der Eintracht-Fußballer mit Einbeck 05 zur SVG Einbeck. Einwanderer, vor allem aus dem Mittelmeerraum, kamen, die teilweise von bestehenden Vereinen integriert wurden, teilweise eigene Vereine gründeten. Der permanente Wandel dauert an. An der Schwelle zum 21. Jahrhundert blicken viele Vereinsvorstände mit Skepsis in die Zukunft: Den Vereinen fehlt vielfach ausreichender Nachwuchs, sie überaltern. Es scheint fraglich, ob das Vereinswesen auch in Zukunft seine Rolle als eine wesentliche Binnenstruktur der Gesellschaft Deutschlands wird behaupten können, oder ob die Kommunikations- und Konsummöglichkeiten der sich formierenden globalen nachindustriellen Gesellschaft neue umfassende Subsysteme oder Strukturen hervorbringen werden.

Doch die Entwicklung des Einbecker Vereinswesens seit 1918 und seine Gegenwart können an dieser Stelle nur kurz und schlaglichtartig angesprochen werden. Eine eingehendere Beschäftigung mit diesen Themen und den sich daraus ergebenden Fragen muss bis auf Weiteres späterer Forschung vorbehalten bleiben. 


\section{Verzeichnis der benutzten Quellen und Literatur}

\section{Quellen}

\section{Stadtarchiv Einbeck:}

B XIV - 103 Der jüdische Frauenverein

I: G: F: I: -7 Der hiesige Männer-Turn-Verein

I: L: D: - 5 Die Veranstaltungen zur Jahrhundertfeier der Völkerschlacht bei Leipzig am 18. Oktober 1913

I: L: D: - 6 Feste und Feierlichkeiten 1894 - 1913

I: L: D: - $7 \quad$ Feste und Feierlichkeiten 1908 - 1925

011 - 2 Anträge auf Genehmigung zur Führung des Wappens

065 - $1 \quad$ Organisation der Arbeit

065 - 2 Arbeitsnachweisstellen

065 - 3 Aussperrungen und Streiks

065 - 5 Gesetz gegen die gemeingefährlichen

Bestrebungen der Sozialdemokratie

065 - 8 Vereinsgesetz vom 19. April 1908

065 - 9 Der kaufmännische Verband

065 - $10 \quad$ Naturheilverein Einbeck

065 - 11 Geselligkeits-Vereine

065 - 12 Haushaltsverein

065 - 13 Christlicher Männer und -Jünglingsverein

065 - 14 Frauenverein

065 - 17 Vereine, Versammlungen und öffentliche Aufzüge

065 - $18 \quad$ Kriegervereine

065 - $19 \quad$ Krieger - Verein Einbeck

065 - 20 Verein für Geflügel- und Singvögelzucht für den Kreis Einbeck

065 - $21 \quad$ Politische Vereine

065 - $22 \quad$ Fechtklub

065 - 23 Dilettanten - Club Walhalla

065 - 24 Turn- und Fechtklub jetzt Bürgerverein; Männer-Turnverein 1867, Bürger-Klub; Bürgerverein

065 - $25 \quad$ Fußball- und Radfahrvereine 


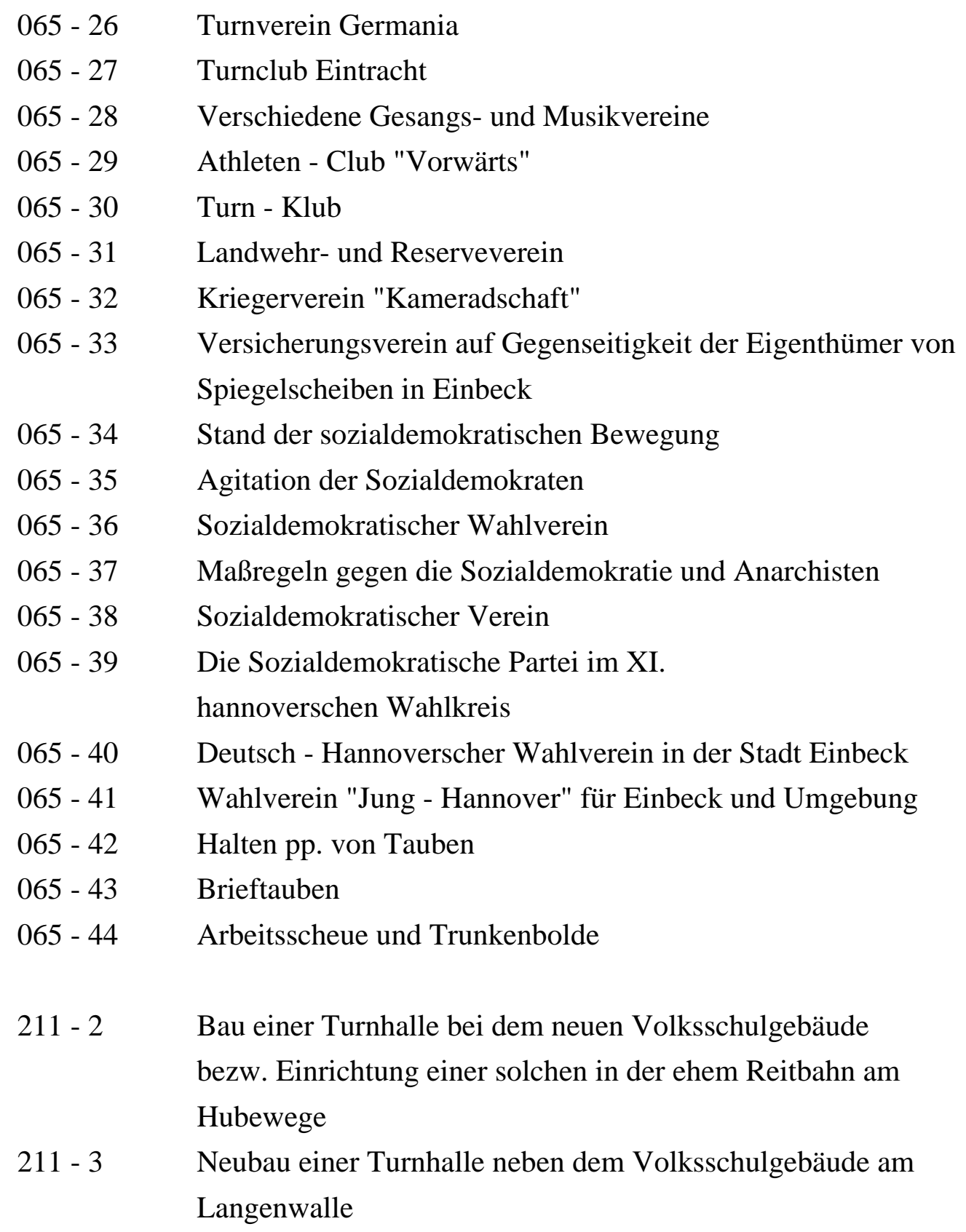

231 - 2 Die neue Turnhalle beim Schulgebäude am Hullersertore

331 - 2 Die allgemeine Volksbibliothek

340 - $1 \quad$ Reorganisation des Schützenfestes, Bestimmung eines anderweitigen Platzes für Abhaltung des Schützenfestes und Herrichtung eines dauernden Schießstandes

340 - $4 \quad$ Volksfest 1898

340 - 5 Abhaltung eines Volksfestes im Jahre 1899

350 - 1 Der Verschönerungs-Verein zu Einbeck 
352 - 1 Der Verein für Geschichte undAlterthümer der Stadt Einbeck und Umgegend

352 - 2 Das städtische Museum

431 - $1 \quad$ Der Schutz des Genfer Roten Kreuzes

431 - 2 Die hiesige freiwillige Sanitätskolonne vom Roten Kreuz

431 - 3 Der Zweig-Verein Einbeck des Gustav-Adolf-Vereins

548 - 2 Der Vaterländische Frauen-Verein

548 - $3 \quad$ Errichtung eines städtischen Krankenhauses

548 - $4 \quad$ Verträge zwischen a) dem Magistrat der Stadt Einbeck und dem

Vaterl. Frauen-Zweig-Verein, b) dem Vaterl. Frauen-Zweig-

Verein und dem leitenden Arzt, c) dem Vaterl. Frauen-Zweig-

Verein und dem Hausverwalter

548 - 5 Städtisches Krankenhaus, Vereins-Krankenhaus des

Vaterländischen Frauen-Zweig-Vereins

572 - 1 Verhandlungen betr. Benutzung des Tummelplatzes seitens der

Fußball spielenden Vereine

714 - $1 \quad$ Die städtische Badeanstalt

714 - $2 \quad$ Flußbad

714 - 4 Errichtung einer städtischen Badehalle und Beteiligung an

derselben

Photosammlung

34 a Vereine: diverse Vereine

34 b Vereine: Schützenverein und -feste

\section{Amtsgericht Einbeck}

Vereinsregister, Jahrgänge 1900 ff.

\section{Archivalien von Vereinen}

Männer-Turn-Verein Einbeck (im Besitz des Turnclubs Einbeck):

Statuten-, Mitglieder- und Kassenbuch 1867 - 1884

Protokollbuch 1875 - 1880

Protokollbuch 1880 - 1881 
Protokollbuch 1881 - 1882

Protokollbuch 1883 - 1887

Protokollbuch 1887 - 1891

Protokollbuch $1891-1898$

Protokollbuch 1898 - 1905

Kassenbuch 1884 - 1895

Mitgliederverzeichnis undatiert bis 1901

Handschrift des kleinen Bühnenstücks "Ein Schusterjungen-Streich" o. J.

Turn Club Einbeck:

Protokollbuch 1880 - 1933

Sportverein Eintracht Einbeck:

Protokollbuch 1893 - 1899

Protokollbuch 1899 - 1909

Protokollbuch 1909 - 1920

Einbecker Turnerschaft (im Besitz des Turnclubs Einbeck):

Protokollbuch 1914 - 1916

Männergesangverein Harmonie Einbeck:

Stammrolle

Kassenbuch 1910 - 1935

Protokollbuch 19. Juli 1903 - 8. April 1931

Schützenverein Einbeck:

Protokollbuch 1885 - 1925

\section{Zeitungen}

Einbecksches Wochenblatt diverse Jahrgänge

Kreisblatt für den Kreis Einbeck diverse Jahrgänge

\section{Festschriften}

Festbuch für das XV. Gauturnfest des Ober-Leine Gaues am 5., 6., und 7. Juli 1902 in Einbeck. Einbeck 1902 
Festschrift zum 50 jährigen Jubiläum des Landwirtschaftlichen Kreisvereins Einbeck 1855 - 1905. Einbeck 1905

Fest-Buch zum Gesang-Wettstreit Deutscher Männer-Gesang-Vereine in Einbeck am 15. Juni 1913 veranstaltet vom Männer-Gesang-Verein "Harmonie". Einbeck 1913

Festbuch zum 28. Stenographentage des Braunschweig-Hannoverschen Stenographen-Verbandes (System Gabelsberger) in Einbeck. 17. 18. 19. Juni 1911. Einbeck 1911

Festbuch für das 4. Bezirksturnfest vom 30. Juli bis 2. Juli 1961 in Einbeck. Einbeck 1961

Hundert Jahre Burschenschaft Thuringia. Die grün-weiß-blaue Burschenschaft. Bilder aus der Geschichte einer Lebensgemeinschaft 1868-1968. Zusammengestellt von Gustav Füllner - Wolfenbüttel. Als Festschrift herausgegeben vom Alt-Herren-Verband der Braunschweiger Burschenschaft Thuringia. Braunschweig 1968.

85 Jahre Sportverein Eintracht Einbeck. Einbeck 1978

90 Jahre Männer-Gesang-Verein "Harmonie" Einbeck. Einbeck 1978

100 Jahre Turn-Club Einbeck. Einbeck 1980

Goetheschule Einbeck. 450 Jahre Schule der Stadt Einbeck 1532 - 1982. Einbeck 1982.

Goetheschule Einbeck: Lehrerverzeichnis 1882 - 1982. Abiturientenverzeichnis 1904 - 1982. Einbeck 1982.

Festschrift zum 75-jährigen Vereinsjubiläum. Radportverein 1911 Einbeck e. v. Abteilung Rollsport. Einbeck 1986

90 Jahre Stenografenverein von 1896 e. V. Einbeck. Einbeck 1986 1838 - 1988. 150 Jahre Berufsbildende Schulen Einbeck. Einbeck 1988 
Sozialdemokratie in Einbeck 1869 - 1889, Einbeck 1989

125 Jahre Freiwillige Feuerwehr Stadt Einbeck. 25 Jahre Feuerwehr-Musikzug Einbeck-Morigen. Einbeck 1992

100 Jahre SV Eintracht Einbeck von 1893. Einbeck 1993

100 Jahre IG Medien Ortsverein Einbeck 1893 - 1993. Einbeck 1993

100 Jahre Männergesangverein Drüber. Einbeck-Drüber 1993

100 Jahre Geflügelzüchterverein Einbeck. Einbeck 1996

100 Jahre Stenografenverein Einbeck 1896 - 1996. Einbeck 1996

200 Jahre Freimaurerloge "Georg zu den drei Säulen" 1797 - 1997, Einbeck 1997

\section{Vereinsperiodika}

Verein für Geschichte und Alterthümer der Stadt Einbeck und Umgegend: Jahresberichte für die Jahre 1895, 1896, 1898, 1900, 1901 und 1902, 1906, 1907, 1908, 1909 bis 1912, 1913 bis 1915, erschienen jeweils im Folgejahr in Einbeck

\section{Adressbücher Stadt und Kreis Einbeck}

Jahrgang 1881

Jahrgang 1895/96

Jahrgang 1899/1900

Jahrgang 1902

Jahrgang 1904

Jahrgang 1907

Jahrgang 1911/1912

Juli 1912

Jahrgang 1922 


\section{Gesetze und Gesetzessammlungen}

Ebhardt, Christian Hermann (Hg.): Gesetze, Verordnungen und Ausschreiben für den Bezirk des Königl. Consistorii zu Hannover, welche in Kirchen- und Schulsachen ergangen sind. Zusammengestellt und mit Genehmigung des Königlichen Consistorii herausgegeben. Zweite Folge 1858 - 1868. Mit einem Nachtrage vom Jahre 1869. Hannover 1869

\section{Literatur}

Abendroth, Wolfgang: Das "Gesetz gegen die gemeingefährlichen Bestrebungen der Sozialdemokratie" vom 21. Oktober 1878 Sozialökonomischer Hintergrund und Analyse. in: Döring, Dieter; Kempen, Otto Ernst (Hgg.): Sozialistengesetz, Arbeiterbewegung und Demokratie. Köln; Frankfurt am Main 1979, SS. 13 - 27

Artus, Helmut M.: Verein - Konkrete Bilder zu einem abstrakten Phänomen. in: Best, Heinrich (Hg.): Vereine in Deutschland. Vom Geheimbund zur freien gesellschaftlichen Organisation. Mit einer Literatur- und Forschungsdokumentation von Helmut M. Artus. Bonn 1993, SS. 209 - 240

Aschoff, Hans Georg: Die welfische Bewegung und die Deutsch-hannoversche Partei zwischen 1866 und 1914. in: Niedersächsisches Jahrbuch für Landesgeschichte, Band 53 (1981). SS. 41 - 64

Aufgebauer, Peter: Einbeck im Mittelalter. in: Einbecker Geschichtsverein (Hg.): Geschichte der Stadt Einbeck. Band 1.Von den Anfängen bis zum Ende des 18. Jahrhunderts. Einbeck 1990, SS. 73 - 124

Aufgebauer, Peter: Bündnisse der Stadt Einbeck im Mittelalter. in: Einbecker Jahrbuch, Band 44 (1995), SS. 27 - 38

Aumann, Stefan: ...und wird gar weit geführet.Die Geschichte des Einbecker Bieres. (Studien zur Einbecker Geschichte; Bd. 14). Oldenburg 1998

Baron, Josef: Das deutsche Vereinswesen und der Staat im 19. Jahrhundert. Jur. Diss., Göttingen 1962 
Barmeyer, Heide: Gewerbefreiheit oder Zunftbindung? Hannover an der Schwelle des Industriezeitalters. in: Niedersächsisches Jahrbuch für Landesgeschichte, Band 46/47 (1974/75). SS. 231 - 262

Barmeyer, Heide: Bismarck, die Annexionen und das Welfenproblem 1866 1890. Der unvollendete nationale Verfassungsstaat in Verteidigung und Angriff. in: Niedersächsisches Jahrbuch für Landesgeschichte, Band 48 (1976). SS. $397-432$

Barmeyer, Heide: Die hannoverschen Nationalliberalen 1859 - 1885. in: Niedersächsisches Jahrbuch für Landesgeschichte, Band 53 (1981). SS. 65 - 86

Barmeyer, Heide: Hannovers Eingliederung in den preußischen Staat, Annexion und administrative Integration. Hildesheim 1983

Barmeyer-Hartlieb, Heide: Liberale Verwaltungsreform als Mittel zur Eingliederung Hannovers in Preußen 1866 - 1884/85. in: Sabelleck, Rainer (Hg.): Hannovers Übergang vom Königreich zur preußischen Provinz 1866. Beiträge zu einer Tagung am 2. 11. 1991 in Göttingen. (Schriftenreihe des Landschaftsverbandes Südniedersachsen, Band 1). Hannover 1995, SS. 125 142

Bausenwein, Christoph: Geheimnis Fusssball. Auf den Spuren eines Phänomens. Göttingen 1995.

Bausinger, Hermann: Vereine als Gegenstand Volkskundlicher Forschung. in: Zeitschrift für Volkskunde, 55. Jahrgang. Stuttgart 1959. SS. 98 - 104

Bausinger, Hermann: Verbürgerlichung - Folgen eines Interpretaments. in: Wiegelmann, Günter (Hg.): Kultureller Wandel im 19. Jahrhundert. Verhandlungen des 18. Deutschen Volkskunde-Kongresses in Trier vom 13. bis 18. September 1971. (Studien zum Wandel von Gesellschaft und Bildung im Neunzehnten Jahrhundert, Band 5). Göttingen 1973, SS. 24 - 49

Bausinger, Hermann: Bürgerlichkeit und Kultur. in: Kocka, Jürgen (Hg.): Bürger und Bürgerlichkeit im 19. Jahrhundert. Göttingen 1987, SS. 121 - 142

Bernett, Hajo: Das Problem einer alternativen Sportpraxis im deutschen Arbeitersport - untersucht am Beispiel der Leichtathletik. in: Teichler, Hans 
Joachim (Red.): Arbeiterkultur und Arbeitersport. 9. Fachtagung der DVSSektion Sportgeschichte vom 27. - 29. März 1985 an der Gustav-HeinemannAkademie der Friedrich-Ebert-Stiftung in Freudenberg. Clausthal-Zellerfeld 1985, SS. 50 - 76

Bernett, Hajo: Drei athletische "Meetings" im Jahre 1882. Eine exemplarische Rekonstruktion der Wettkämpfe des Hamburger Sport-Clubs. in: John, HansGeorg (Red.): Vom Verein zum Verband. Die Gründerzeit des Sports in Deutschland. 10. Fachtagung der dvs-Sektion Sportgeschichte vom 18. - 20. März 1986 in der Führungs- und Verwaltungsakademie des DSB in Berlin. Clausthal-Zellerfeld 1987, SS. 92 - 101

Bernett, Hajo: Leichtathletik im geschichtlichen Wandel. Schorndorf 1987

Best, Heinrich: Vorwort in: Ders. (Hg.): Vereine in Deutschland. Vom Geheimbund zur freien gesellschaftlichen Organisation. Mit einer Literaturund Forschungsdokumentation von Helmut M. Artus. Bonn 1993, SS. 7 - 10

Blank, Herbert: Die Turnerei in Einbeck: in: Festbuch für das 4. Bezirksturnfest vom 30. Juli bis 2. Juli 1961 in Einbeck. Einbeck 1961, SS. 25 $-54$

Block, Sigrid: Frauen und Mädchen in der Arbeitersportbewegung. (Arbeiterkultur und Arbeiterbewegung, Band 19). Münster 1987

Born, Karl Erich: Von der Reichsgründung bis zum Ersten Weltkrieg. (Grundmann, Herbert: Gebhardt Handbuch der Deutschen Geschichte, Taschenbuchausgabe, Band 16) 16. Auflage, München 1999.

Braatz, Thea: Das Kleinbürgertum in München und seine Öffentlichkeit von 1830 -1870. Ein Beitrag zur Mentalitätsforschung. (Miscellanea Bavarica Monacensia, Heft 68). München 1977

Brandt, Friedel: Chronik. in: 100 Jahre Turn-Club Einbeck. Einbeck 1980, SS. $7-21$

Brinckmann, Ilse: Dokumentation zur Geschichte der Stadt Einbeck 1918 1945. Einbeck o. J. 
Brosius ,Dieter: Bodo von Hodenberg - Ein hannoverscher Konservativer nach 1866. in: Niedersächsisches Jahrbuch für Landesgeschichte, Band 38 (1966). SS. $159-184$

Brosius, Dieter: Georg V. von Hannover - der König des monarchischen Prinzips. in: Niedersächsisches Jahrbuch für Landesgeschichte, Band 51 (1979). SS. 253 - 291

Brosius, Dieter: Hannover und Preußen vor 1866. in: Sabelleck, Rainer (Hg.): Hannovers Übergang vom Königreich zur preußischen Provinz 1866. Beiträge zu einer Tagung am 2. 11. 1991 in Göttingen. (Schriftenreihe des Landschaftsverbandes Südniedersachsen, Band 1). Hannover 1995, SS. 23 -30

Burschel, Peter: Erstarrung und Wandel. Einbeck 1600 - 1750. in: Einbecker Geschichtsverein (Hg.): Geschichte der Stadt Einbeck. Band 1.Von den Anfängen bis zum Ende des 18. Jahrhunderts. Einbeck 1990, SS. 191 - 202

Conze, Werner: Staatsnationale Entwicklung und Modernisierung im Deutschen Reich 1871 - 1914. in: Conze, Werner u. a. (Hgg.): Modernisierung und nationale Gesellschaft im ausgehenden 18. und im 19. Jahrhundert. Referate einer deutsch-polnischen Historikerkonferenz. (Giessener Abhandlungen zur Agrar- und Wirtschaftsforschung des europäischen Ostens, Band 99). Berlin 1979, SS. 59 - 70

Craig, Gordon A.: Deutsche Geschichte 1866 - 1945. Vom Norddeutschen Bund bis zum Ende des Dritten Reiches. München 1980

Czwalinna, Erich; Trump, Kurt: 125 Jahre Niedersächsische Schützen im Deutschen Schützenbund 1868-1993. Eine geschichtliche Dokumentation über das deutsche Schützenwesen im niedersächsischen Raum. Hannover 1993

Dann, Otto: Der politische Strukturwandel und das Problem der Nationsbildung in Deutschland um die Wende des 18. Jahrhunderts. in: Conze, Werner u. a. (Hgg.): Modernisierung und nationale Gesellschaft im ausgehenden 18. und im 19. Jahrhundert. Referate einer deutsch-polnischen Historikerkonferenz. (Giessener Abhandlungen zur Agrar- und Wirtschaftsforschung des europäischen Ostens, Band 99). Berlin 1979, SS. 48 58 
Dann, Otto: Die Anfänge politischer Vereinsbildung in Deutschland. in: Engelhardt, Ulrich u. a. (Hgg.): Soziale Bewegung und politische Verfassung. Beiträge zur Geschichte der modernen Welt. Stuttgart 1976, SS. 197 - 232

Dann, Otto: Vereinsbildung in Deutschland in historischer Perspektive. in: Best, Heinrich (Hg.): Vereine in Deutschland. Vom Geheimbund zur freien gesellschaftlichen Organisation. Mit einer Literatur- und Forschungsdokumentation von Helmut M. Artus. Bonn 1993, SS. 119 - 142

Denecke, Dietrich: Die sozio-ökonomische Gliederung südniedersächsischer Städte im 18. und 19. Jahrhundert. Historisch-geographische Stadtpläne und ihre Analyse. in: Niedersächsisches Jahrbuch für Landesgeschichte, Band 52 (1980). SS 25 - 38

Denk, Heinz: Schulturnen: Leibesübungen im Dienste autoritärer Erziehung. in: Ueberhorst, Horst (Hg.). Geschichte der Leibesübungen, Band 3/1. Berlin, München, Frankfurt am Main 1980, SS. 325 - 349

Deutscher Fußball-Bund(Hg.): 60 Jahre DFB. Eine Festschrift zum 60jährigen Bestehen des Deutschen Fußball-Bundes. Zusammengestellt und bearbeitet von Dr. Wilfried Gerhardt. Frankfurt am Main 1960

Dierker, Herbert: Arbeitersport im Spannungsfeld der Zwanziger Jahre. Sportpolitik und Alltagserfahrungen auf internationaler, deutscher und berliner Ebene. (Schriften des Fritz-Hüser-Instituts für deutsche und ausländische Arbeiterliteratur der Stadt Dortmund: Reihe 2, Forschungen zur Arbeiterliteratur, Band 6) Essen 1990

Dörries, Hans: Die Städte im oberen Leinetal. Göttingen, Northeim und Einbeck. Ein Beitrag zur Landeskunde Niedersachsens und zur Methodik der Stadtgeographie. (Meinardus, Wilhelm (Hg.): Landeskundliche Arbeiten des Geographischen Seminars der Universität Göttingen, Heft 1) Göttingen 1925

Dowe, Dieter; Klotzbach, Kurt: Programmatische Dokumente der deutschen Sozialdemokratie. Berlin, Bonn 1984

Düding, Dieter: Von der Opposition zur Akklamation - Die Turnbewegung im 19. Jahrhundert als politische Bewegung. in: Diekmann, Irene; Teichler, Joachim H. (Hgg.): Körper, Kultur und Ideologie. Sport und Zeitgeist im 19. 
und 20. Jahrhundert. (Studien zur Geistesgeschichte, Band 19). Bodenheim 1997, SS. 79 - 97

Dunning, Eric: Die Entstehung des Fußballsports. in: Hopf, Wilhelm (Hg.): Fussball. Soziologie und Sozialgeschichte einer populären Sportart. Bensheim 1979, SS. 42 - 53

Ehrenfeuchter, Bernhard: Politische Willensbildung in Niedersachsen zur Zeit des Kaiserreiches. Ein Versuch auf Grund der Reichstagswahlen von 1867 bis 1912, insbesondere seit 1890. Dissertation, Göttingen 1951

Eichberg, Henning: Sport im 19. Jahrhundert - Genese einer industriellen Verhaltensform. in: Ueberhorst, Horst (Hg.). Geschichte der Leibesübungen, Band 3/1. Berlin, München, Frankfurt am Main 1980, SS. 350 - 412

Einbecker Geschichtsverein (Hg.): Stadt Einbeck. Zeitgenössische Fotografien und Dokumente. Gesammelt und bearbeitet von Erich Strauß, Hellmut Hainski und Andreas Heege. Duderstadt 1995

Eisenberg, Christiane: Deutschland. in: Eisenberg, Christiane (Hg.):Fußball, soccer, calcio. Ein englischer Sport auf seinem Weg um die Welt. München 1997, SS. 94 - 129

Eisenberg, Christiane: "English sports" und deutsche Bürger. Eine Gesellschaftsgeschichte 1800 - 1939. Paderborn, München, Wien, Zürich 1999 (Zugl.: Dissertation, Hamburg 1996)

Engelhardt, Ulrich: Gewerkschaftliche Interessenvertretung als "Menschenrecht". Anstöße und Entwicklung der Koalitionsrechtsforderung in der preußisch-deutschen Arbeiterbewegung 1862/63 - 1865 (1869). in: Engelhardt, Ulrich u. a. (Hgg.): Soziale Bewegung und politische Verfassung. Beiträge zur Geschichte der modernen Welt. Stuttgart 1976, SS. 472 - 537

Ernst, Georg; Sindermann, Edmund (Bearbb.): Heimatchronik des Kreises Einbeck. (Heimatchroniken der Städte und Kreise des Bundesgebiets, Band 14) Köln 1955 
Evans, Richard J. (Hg.): Kneipengespräche im Kaiserreich. Die Stimmungsberichte der Hamburger Politischen Polizei 1892 - 1914. Reinbek 1989

Feise, Wilhelm: Das Brauwesen der Stadt Eimbeck. (Beiträge zur Entwicklung des Braugewerbes in den städtischen Gemeinwesen, Band 1). Berlin 1928

Feise, Wilhelm: Die Uebergabe der Stadt Einbeck an die kaiserliche Armee am 14 Oktober 1641. Einbeck o. J. [1941]

FIFA, SPI Group (Hgg.): 100 years of football: FIFA Museum collection = 1000 ans de football = 1000 anos de futbal = 100 Jahre Fußball. Berlin 1986

Fischer, Erich: Seminar Einbeck in: Buchwald, Gerd (Hg.): Beiträge zur Geschichte der Lehrerseminare und Präparandenanstalten in der ehemaligen Provinz Hannover. Berlin 1962. SS. 43 - 47

Foltin, Hans-Friedrich: Geschichte und Perspektiven der Vereinsforschung. in: Foltin, Hans-Friedrich; Kramer, Dieter (Hgg.): Hessische Blätter zur Volksund Kulturforschung. Giessen 1984, SS. 3 - 31

Freudenthal, Friedrich: Von Lüneburg nach Langensalza. 2. Auflage 1895, Reprint Bremen 1999

Freudenthal, Herbert, Vereine in Hamburg. Ein Beitrag zur Geschichte und Volkskunde der Geselligkeit. (Hävernick, Walter; Freudenthal, Herbert (Hgg.): Volkskundliche Studien, Band IV) Hamburg 1968

Friedemann, Peter: Rolle und Funktion des Arbeitersports in der Arbeiterbewegung. in: Teichler, Hans Joachim (Red.): Arbeiterkultur und Arbeitersport. 9. Fachtagung der DVS-Sektion Sportgeschichte vom 27. - 29. März 1985 an der Gustav-Heinemann-Akademie der Friedrich-Ebert-Stiftung in Freudenberg. Clausthal-Zellerfeld 1985, SS. 5 - 23

Friedemann, Peter: Die Krise der Arbeitersportbewegung am Ende der Weimarer Republik. in: Boll, Friedhelm: Arbeiterkulturen zwischen Alltag und Politik. Beiträge zum europäischen Vergleich in der Zwischenkriegszeit. Wien, München, Zürich 1986, SS. 229 - 240 
Friese, W. H.: Einbeck und seine Umgebungen. Ein Führer für Einheimische und Fremde. Einbeck o. J. [1890er Jahre]

Fülberth, Georg: Die Entwicklung der deutschen Sozialdemokratie von ihrer Gründung bis zum Revisionismusstreit (1863 - 1899). in: Freyberg, Jutta von u. a. (Hgg.): Geschichte der deutschen Sozialdemokratie. Von 1863 bis zur Gegenwart. 3. überarbeitete und erweiterte Auflage. Köln 1989, SS. 10 - 37

Fülberth, Georg: Vom Revisionismusstreit bis zum Ausbruch des Ersten Weltkrieges (1899 - 1914). in: Freyberg, Jutta von u. a. (Hgg.): Geschichte der deutschen Sozialdemokratie. Von 1863 bis zur Gegenwart. 3. überarbeitete und erweiterte Auflage. Köln 1989, SS. 38 - 52

Füllner, Gustav: Dr. Emil Kirchner und sein Institut. Aus der Geschichte des Einbecker "Technikums" 1871 - 1907. in: Einbecker Jahrbuch, Band 30 (1974), SS. $70-78$

Gerdes, Susanne: Juden in Einbeck im 19. Jahrhundert. in: Heege, Elke (Hg.)Verloren aber nicht vergessen. Jüdisches Leben in Einbeck. (Studien zur Einbecker Geschichte, Bd. 15). Oldenburg 1998. SS. 17 - 72

Glaser, Hermann: Die Kultur der Willhelminischen Zeit. Topographie einer Epoche. Frankfurt am Main 1984

Grebing, Helga: Zur Geschichte der Arbeiterbewegung in Niedersachsen 1866 - 1914. in: Niedersächsisches Jahrbuch für Landesgeschichte, Band 53 (1981). SS. $87-106$

Grüne, Hardy: 90 Jahre Deutscher Ligafußball. Kassel 1995

Güldenpfennig, Sven: Der politische Diskurs des Sports. Zeitgeschichtliche Beobachtungen und theoretische Grundlagen. (Edition Sport \& Wissenschaft Band 16) Aachen 1992

Hainski, Hellmut: 100 Jahre Einbecker Geschichtsverein. Rückblick, Aktivitäten, Ehrungen. In: Einbecker Jahrbuch, Band 44 (1995), SS. 5 - 26 
Hamann, Manfred: Politische Kräfte und Spannungen in der Provinz Hannover. in: Niedersächsisches Jahrbuch für Landesgeschichte, Band 53 (1981). SS. 1 40

Harland, Heinrich Ludolph: Geschichte der Stadt Einbeck nebst geschichtlichen Nachrichten über die Stadt und ehemalige Graffschaft Dassel, die um Einbeck liegenden Dörfer, Kirchen, Kapellen, Klöster Burgen und adeligen Sitze. 2 Bände, Einbeck 1854 - 1859.

Heege, Elke; Plümer, Erich: Fahrrad-Fabrik August Stukenbrok Einbeck. Die Geschichte eines Versandhauses. (Kleine Schriften es städtischen Museums Einbeck, Heft 4) Oldenburg 1996

Heege, Elke: "Laßt die jetzt passende Zeit nicht verstreichen, Bürger!". Die Revolution in Einbeck im Frühjahr 1848. in: Seeliger, Matthias (Hg.): 1848. (K)eine Revolution an Weser und Leine. Bielefeld, Gütersloh 1999, SS. 79 115

Heege, Elke: Brandschutz und Feuerlöschwesen am Beispiel der Stadt Einbeck. Unveröffentlichtes Manuskript

Heemann, Annegret: Männergesangvereine im 19. und frühen 20. Jahrhundert. Ein Beitrag zur städtischen Musikgeschichte Münsters. (Europäische Hochschulschriften: Reihe 36, Musikwissenschaft, Band 74) Frankfurt am Main, Bern, New York, Paris 1992 (Zugl.: Dissertation, Münster (Westfalen) 1991)

Heineken, Ph.[ilipp]: Das Fußballspiel. o. O. 1898. Nachdruck, Hannover 1993

Heimpel, Hermann: Geschichtsvereine einst und jetzt. in: Boockmann, Hartmut u. a. (Hgg.): Geschichtswissenschaft und Vereinswesen im 19. Jahrhundert. (Veröffentlichungen des Max-Planck-Instituts für Geschichte, Band 1). Göttingen 1972, SS. 45 - 73

Henning, Friedrich-Wilhelm: Die Industrialisierung in Deutschland 1800 bis 1914. 7. Auflage. Paderborn, München, Wien, Zürich 1989

Hentilä, Seppo: Vergleichende Aspekte zum Verhältnis des Arbeitersports in Deutschland, Schweden und Finnland vor dem 1. Weltkrieg. in: Teichler, Hans 
Joachim (Red.): Arbeiterkultur und Arbeitersport. 9. Fachtagung der DVSSektion Sportgeschichte vom 27. - 29. März 1985 an der Gustav-HeinemannAkademie der Friedrich-Ebert-Stiftung in Freudenberg. Clausthal-Zellerfeld 1985, SS. 24 - 34

Henze, Wilhelm: Schützenwesen und Schützensport in Niedersachsen. Bürgerwehr - Tradition - Sport. (Niedersächsisches Institut für Sportgeschichte Hoya: Materialien zur Niedersächsichen Sportgeschichte, Band 5). Göttingen 1997

Hertel, Günther: Das Heilwesen von Einbeck betrachtet ab Ausgang des Mittelalters bis ins 19. Jahrhundert. Dissertation, Göttingen 1962

Hobsbawm, Eric J. Nationen und Nationalismus. Mythos und Realität seit 1780. Frankfurt am Main 1991

Hoffmeister, Kurt: Ein Braunschweiger Lehrer als Begründer der Schulspiele in Deutschland. Prof. Dr. phil. Konrad Koch (1846 - 1911). in: Krüger, Arnd (Hg.): Beiträge zur niedersächsischen Sportgeschichte. Der Dr.-BernhardZimmermann- Preis 1984 (Schriftenreihe des niedersächsischen Instituts für Sportgeschichte, Hoya, Band 4). Duderstadt 1986, SS. 14 - 67

Hopf, Wilhelm: "Wie konnte Fußball ein deutsches Spiel werden?". in: Hopf, Wilhelm (Hg.): Fussball. Soziologie und Sozialgeschichte einer populären Sportart. Bensheim 1979, SS. 54 - 80

Huber, Ernst Rudolf: Deutsche Verfassungsgeschichte seit 1789. Band III. Bismarck und das Reich. Dritte überarbeitete Auflage. Stuttgart, Berlin, Köln, Mainz 1978

Hueber, Alfons: Das Vereinsrecht im Deutschland des 19. Jahrhunderts. in: Dann, Otto (Hg.): Vereinswesen und bürgerliche Gesellschaft in Deutschland (Historische Zeitschrift. Beihefte (Neue Folge), Beiheft 9). München 1984, SS. $115-132$

Hülse, Horst: Überblick über die Geschichte der Schule. in: Goetheschule Einbeck. 450 Jahre Schule der Stadt Einbeck 1532 - 1982. Einbeck 1982, SS. 7 $-54$ 
Hülse, Horst: Einbeck im Dreißigjährigen Krieg. in: Einbecker Geschichtsverein (Hg.): Geschichte der Stadt Einbeck. Band 1.Von den Anfängen bis zum Ende des 18. Jahrhunderts. Einbeck 1990, SS. 231 - 244

Hülse, Horst: Vom Dreißigjährigen Krieg bis zur Mitte des 18. Jahrhunderts. in: Einbecker Geschichtsverein (Hg.): Geschichte der Stadt Einbeck. Band 1.Von den Anfängen bis zum Ende des 18. Jahrhunderts. Einbeck 1990, SS. $245-272$

Hülse, Horst: Einbeck in der Gründerzeit. in: Einbecker Geschichtsverein (Hg.): Geschichte der Stadt Einbeck. Band 2: Vom Ende des 18. Jahrhunderts bis zum Ende des zweiten Weltkrieges. Einbeck 1992, SS. 71 - 138

Hüskens, Lydia Marie: Vereine und Politik - politische Vereine exemplarisch untersucht für den Kreis Geldern in den Reichsgründungsjahren und während des Kulturkampfes. Dissertation, Münster 1990

Illner, Eberhard: Bürgerliche Organisierung in Elberfeld 1775 -1850. (Bergische Forschungen Band XVIII). Neustadt/Aisch 1982

John, Hans-Georg: Leibesübungen im Dienste nationaler Bestrebungen: Jahn und die deutsche Turnbewegung. Teil II: Die Turnbewegung im deutschen Kaiserreich von 1871 bis 1918. in: Ueberhorst, Horst (Hg.). Geschichte der Leibesübungen, Band 3/1. Berlin, München, Frankfurt am Main 1980, SS. 278 $-324$

John, Hans-Georg: Die Anfänge des organisierten Schwimmsports in Deutschland am Ausgang des 19. und zu Beginn des 20. Jahrhunderts. in: John, Hans Georg (Red.): Vom Verein zum Verband. Die Gründerzeit des Sports in Deutschland. 10. Fachtagung der dvs-Sektion Sportgeschichte vom 18. - 20. März 1986 in der Führungs- und Verwaltungsakademie des DSB in Berlin. Clausthal-Zellerfeld 1987, SS. 41 - 65

Jungmann, Wolf Bernd: Baugeschichte der Martinskirche in Markoldendorf. in: Einbecker Jahrbuch, Band 45 (1996), SS.97 - 132

Kaufhold, Karl Heinrich: Historische Grundlagen der niedersächsischen Wirtschaft. in: Niedersächsisches Jahrbuch für Landesgeschichte, Band 57 (1985). SS. 69 - 108 
Kaufhold, Karl Heinrich. Die Wirtschaft in der frühen Neuzeit: Gewerbe, Handel und Verkehr. Abschnitte 1 -5. in: van den Heuvel, Christine, von Boetticher, Manfred (Hgg.): Geschichte Niedersachsens. Band 3, 1. Politik, Wirtschaft und Gesellschaft von der Reformation bis zum Beginn des 19. Jahrhunderts. Hannover 1998, SS. 347 - 574

Kaufhold, Karl Heinrich: Städtische Bevölkerungs- und Sozialgeschichte in der frühen Neuzeit. in: van den Heuvel, Christine, von Boetticher, Manfred (Hgg.): Geschichte Niedersachsens. Band 3, 1. Politik, Wirtschaft und Gesellschaft von der Reformation bis zum Beginn des 19. Jahrhunderts. Hannover 1998, SS. 731 $-840$

Kempen, Otto Ernst: Das "Sozialistengesetz" als ein Wendepunkt in der deutschen Verfassungsgeschichte - Darstellung und Analyse im Rahmen der verfassungsrechtlichen Entwicklung. in: Döring, Dieter; Kempen, Otto Ernst (Hgg.): Sozialistengesetz, Arbeiterbewegung und Demokratie. Köln; Frankfurt am Main 1979, SS. 28 - 50

Knoll, Joachim H.: "Der Ball ist rund und das Spiel dauert 90 Minuten" Fußball und Zeitgeist im 20. Jahrhundert. in: Diekmann, Irene; Teichler, Joachim H. (Hgg.): Körper, Kultur und Ideologie. Sport und Zeitgeist im 19. und 20. Jahrhundert. (Studien zur Geistesgeschichte, Band 19). Bodenheim 1997, SS. 248 - 276

Koch, Alfred: Turnen und Sport im Rahmen der Vorbeugenden Gesundheitspflege. in: Fiebig, Franz (Hg.): Vorbeugende Gesundheitspflege in der täglichen Praxis. Stuttgart 1960, SS. 77 - 92

Koch, Eberhard: Geschichte der SPD in Einbeck und Uslar. Von den Anfängen bis zum Wiederaufbau der lokalen Organisationen nach 1945. Eine vergleichende Studie. Examensarbeit, ungedruckt. Göttingen 1976

Koch, Eberhard: Woher wir kommen - Die 120-jährige Geschichte der Einbecker Sozialdemokratie. in: Sozialdemokratie in Einbeck 1869 - 1889, Einbeck 1989, o. P.

Koch, Eberhard: Woher wir kommen - 125 Jahre SPD in Einbeck. in: Einbecker Jahrbuch, Band 44 (1995), SS. 165 - 178 
Kocka, Jürgen: Lohnarbeit und Klassenbildung. Arbeiter und Arbeiterbewegung in Deutschland 1800 - 1875. Berlin, Bonn 1983

Kocka, Jürgen: Bürgertum und Bürgerlichkeit als Probleme der deutschen Geschichte vom späten 18. bis zum frühen 20. Jahrhundert. in: Kocka, Jürgen (Hg.): Bürger und Bürgerlichkeit im 19. Jahrhundert. Göttingen 1987, SS. 21 63

Kocka, Jürgen: Klassengesellschaft im Krieg. Deutsche Sozialgeschichte 1914 - 1918. Frankfurt am Main 1988

Kötzschke, Richard: Geschichte des deutschen Männergesanges hauptsächlich des Vereinswesens. Dresden 1927

Kramer, Dieter: Sozialkulturelle Lage und Ideologie der Arbeiterschaft im 19. Jahrhundert. in: Wiegelmann, Günter (Hg.): Kultureller Wandel im 19. Jahrhundert. Verhandlungen des 18. Deutschen Volkskunde-Kongresses in Trier vom 13. bis 18. September 1971. (Studien zum Wandel von Gesellschaft und Bildung im Neunzehnten Jahrhundert, Band 5). Göttingen 1973, SS. 112 145

Kratzsch, Gerhard: Vereine mit ideellen Zwecken im 19. Jahrhundert. Ein Beitrag zur Vereinsgeschichte der Provinz Westfalen. in: Dollinger, Heinz u. a. (Hgg.): Weltpolitik. Europagedanke. Regionalismus. Festschrift für Heinz Dollinger zum 65. Geburtstag am 30. Januar 1982. Münster 1982, SS. 193 218

Kühn, Fritz: Die Arbeitersportbewegung. Ein Beitrag zur Klassengeschichte der Arbeiterschaft. Mit einem Vorwort von Arno Klönne. (Arbeiterkultur, Band 4). Münster 1981 (ursprünglich Diss. Rostock 1922)

Langenfeld, Hans: Die Entwicklung der deutschen Turn- und Sportvereine im 19. Jahrhundert. in: Krüger, Arnd (Hg.): Die Entwicklung der Turn- und Sportvereine. Sporthistorisches Symposium 18. - 20. 11. 1980 in Berlin (West). (Jahrbuch des Forums für Sportgeschichte 1983) Berlin 1984, SS. 15 - 50

Leuschner, Jörg: Osterode - Politisches, verwaltungsmäßiges und wirtschaftliches Zentrum des Südwestharzes von 1807 bis 1918. in: Ders.(Hg.): Osterode. Welfensitz und Bürgerstadt im Wandel der Jahrhunderte. Hildesheim, Zürich, New York 1993, SS.321 - 423 
Lehmann, Albrecht: Zur volkskundlichen Vereinsforschung. in: Dann, Otto (Hg.): Vereinswesen und bürgerliche Gesellschaft in Deutschland (Historische Zeitschrift. Beihefte (Neue Folge), Beiheft 9). München 1984, SS. 133 - 150

Lepsius, M. Rainer: Zur Soziologie des Bürgertums und der Bürgerlichkeit. in: Kocka, Jürgen (Hg.): Bürger und Bürgerlichkeit im 19. Jahrhundert. Göttingen 1987, SS. 79 - 100

Lichtenthaler, Charles: Geschichte der Medizin. Die Reihenfolge ihrer Epochen-Bilder und die treibenden Kräfte ihrer Entwicklung. Ein Lehrbuch für Studenten, Ärzte, Historiker und geschichtlich Interessierte. Band II: Frühneuzeit (1500 - 1800) eigentliche Medizinische Moderne (1800 - 1939) Zeitgeschichte und Futurologie. Köln-Lövenich 1974

Lidtke, Vernon L.: Die kulturelle Bedeutung der Arbeitervereine. in: Wiegelmann, Günter (Hg.): Kultureller Wandel im 19. Jahrhundert. Verhandlungen des 18. Deutschen Volkskunde-Kongresses in Trier vom 13. bis 18. September 1971. (Studien zum Wandel von Gesellschaft und Bildung im Neunzehnten Jahrhundert, Band 5). Göttingen 1973, SS. 146 - 159

Martens, René: FC St. Pauli. You'll never walk alone. Göttingen 1997

Mayer, Paul Yogi: Deutsche Juden und Sport. in: Diekmann, Irene; Teichler, Joachim H. (Hgg.): Körper, Kultur und Ideologie. Sport und Zeitgeist im 19. und 20. Jahrhundert. (Studien zur Geistesgeschichte, Band 19). Bodenheim 1997, SS. 119 - 146

Mende, Michael: Der fortgesetzte Wandel: Hannovers Industrialisierung und Infrastruktur vor und nach 1866. in: Sabelleck, Rainer (Hg.): Hannovers Übergang vom Königreich zur preußischen Provinz 1866. Beiträge zu einer Tagung am 2. 11. 1991 in Göttingen. (Schriftenreihe des Landschaftsverbandes Südniedersachsen, Band 1). Hannover 1995, SS. 143 - 172

Meyer, Erich: Biedermeier und Revolution. Die Zeit von 1813 bis 1850 im Spiegel des Einbeckschen Wochenblattes. 2 Halbbände (Schriftenreihe zur Geschichte der Stadt Einbeck, Band 3) Einbeck 1982 
Meyer, Erich: Die November-Revolution 1918/1919 in Einbeck. Sonderdruck der Berichtes von Erich Meyer aus den Jahrbüchern 34 und 35 des Geschichtsvereins. Einbeck 1988

Mittendorf, Hans-Norbert: Die jüdische Gemeinde in Mackensen im 18. und 19. Jahrhundert. in: Einbecker Jahrbuch, Band 36 (1985), SS. 93 - 103

Mittendorf, Hans-Norbert: Georg Steinberg. Seine Lebensumstände - sein Werk. in: Einbecker Jahrbuch, Band 38 (1987), SS. 157 - 170

Mittendorf, Hans-Norbert: Einbecker Geschichte vom Ende des 18. Jahrhunderts bis zur Annexion des Königreichs Hannover durch Preußen. in: Einbecker Geschichtsverein (Hg.): Geschichte der Stadt Einbeck. Band 2: Vom Ende des 18. Jahrhunderts bis zum Ende des zweiten Weltkrieges. Einbeck 1992, SS. 7 - 70

Mommsen, Hans: Die Auflösung des Bürgertums seit dem späten 19. Jahrhundert. in: Kocka, Jürgen (Hg.): Bürger und Bürgerlichkeit im 19. Jahrhundert. Göttingen 1987, SS. 288 - 315

Müller, Wolfgang: Die Geschichte der KWS Kleinwanzlebener Saatzucht AG, vormals Rabbethge \& Giesecke, von 1838 - 1980. in: Einbecker Jahrbuch, Band 38 (1987), SS. 193 - 202

N. N.: Zur Einbecker Nachbarschaft 1905. Einbeck o. J. [1905]

N. N.: Einbeck in Wort und Bild. Heimatliches Gedenkblatt der heutigen Kreis- und alten Hansestadt nebst einem chronologischen Abriß. Einbeck o. J. [1907]

Nedden, W.: Geschichte der Sparkasse der Stadt Einbeck. Einbeck 1913

Neumann, Hannes: Leibesübungen im Dienste nationaler Bestrebungen: Jahn und die deutsche Turnbewegung. Teil I: Von den Anfängen bis zur Reichsgründung. in: Ueberhorst, Horst (Hg.). Geschichte der Leibesübungen, Band 3/1. Berlin, München, Frankfurt am Main 1980, SS. 257 - 277

Niemeyer, Karl-Heinz: 70 Jahre Fußball ... und kein Ende. Auszüge aus der Geschichte des Fußballsports im Kreise Peine. in: Krüger, Arnd (Hg.): Beiträge 
zur niedersächsischen Sportgeschichte. Der Dr.-Bernhard-Zimmermann- Preis 1984 (Schriftenreihe des niedersächsischen Instituts für Sportgeschichte, Hoya, Band 4). Duderstadt 1986, SS. 68 - 86

Nipperdey, Thomas: Die Organisation der deutschen Parteien vor 1918. (Beiträge zur Geschichte des Parlamentarismus und der politischen Parteien, Bd. 18). Düsseldorf 1961

Nipperdey, Thomas: Verein als soziale Struktur in Deutschland im späten 18. und frühen 19. Jahrhundert. in: Boockmann, Hartmut u. a. (Hgg.): Geschichtswissenschaft und Vereinswesen im 19. Jahrhundert. (Veröffentlichungen des Max-Planck-Instituts für Geschichte, Band 1). Göttingen 1972, SS. 1 - 44

Nipperdey, Thomas: Grundprobleme der deutschen Parteigeschichte im 19. Jahrhundert. in: ders.: Gesellschaft, Kultur, Theorie. Gesammelte Aufsätze zur Neueren Geschichte. (Kritische Studien zur Geschichtswissenschaft, Band 18). Göttingen 1976, SS. 89 - 112

Nipperdey, Thomas: Die Organisation der bürgerlichen Parteien in Deutschland vor 1918. in: ders.: Gesellschaft, Kultur, Theorie. Gesammelte Aufsätze zur Neueren Geschichte. (Kritische Studien zur Geschichtswissenschaft, Band 18). Göttingen 1976, SS. 279 - 318

Nipperdey, Thomas: Jugend und Politik um 1900. in: ders.: Gesellschaft, Kultur, Theorie. Gesammelte Aufsätze zur Neueren Geschichte. (Kritische Studien zur Geschichtswissenschaft, Band 18). Göttingen 1976, SS. 338 - 359

Nipperdey, Thomas: Wehlers "Kaiserreich". Eine kritische Auseinandersetzung. in: ders.: Gesellschaft, Kultur, Theorie. Gesammelte Aufsätze zur Neueren Geschichte. (Kritische Studien zur Geschichtswissenschaft, Band 18). Göttingen 1976, SS. 360 - 389

Nipperdey, Thomas: Deutsche Geschichte 1806 - 1866. Bürgerwelt und starker Staat. München 1983

Nipperdey, Thomas: Kommentar: "Bürgerlich" als Kultur. in: Kocka, Jürgen (Hg.): Bürger und Bürgerlichkeit im 19. Jahrhundert. Göttingen 1987, SS. 143 - 148 
Nipperdey, Thomas: Deutsche Geschichte 1866 - 1918. Erster Band: Arbeitswelt und Bürgergeist. München 1990

Nipperdey, Thomas: War die wilhelminische Gesellschaft eine UntertanenGesellschaft? in: ders.: Nachdenken über die deutsche Geschichte. München 1990, SS. $208-224$

Nipperdey, Thomas: Deutsche Geschichte 1866 - 1918. Zweiter Band: Machtstaat vor der Demokratie. München 1992.

Nipperdey, Thomas; Rürup, Reinhard: Antisemitismus - Entstehung, Funktion und Geschichte eines Begriffs. in: Nipperdey, Thomas(Hg.): Gesellschaft, Kultur, Theorie. Gesammelte Aufsätze zur Neueren Geschichte. (Kritische Studien zur Geschichtswissenschaft, Band 18). Göttingen 1976, SS. 113 - 132

Ostertag, Heiger: Der Deutsche Krieg von 1866. in: Sabelleck, Rainer (Hg.): Hannovers Übergang vom Königreich zur preußischen Provinz 1866. Beiträge zu einer Tagung am 2. 11. 1991 in Göttingen. (Schriftenreihe des Landschaftsverbandes Südniedersachsen, Band 1). Hannover 1995, SS. 31 - 58

Ostertag, Heiger: Die Königlich Hannoversche Armee im Juni 1866. in: Sabelleck, Rainer (Hg.): Hannovers Übergang vom Königreich zur preußischen Provinz 1866. Beiträge zu einer Tagung am 2. 11. 1991 in Göttingen. (Schriftenreihe des Landschaftsverbandes Südniedersachsen, Band 1). Hannover 1995, SS. 59 - 78

Pabst, Klaus: Deutsche Geschichtsvereine vor dem Ersten Weltkrieg. in: Geschichtsvereine. Entwicklungen und Perspektiven lokaler und regionaler Geschichtsarbeit (Bensberger Protokolle, Band 62). Bergisch Gladbach 1990, SS. 9 - 32

Pfeiffer, Lorenz; Vogt, Martin: Basketball - ein Stiefkind der deutschen Turnund Sportbewegung? Zur Geschichte des Basketballsports in Deutschland. in: John, Hans Georg (Red.): Vom Verein zum Verband. Die Gründerzeit des Sports in Deutschland. 10. Fachtagung der dvs-Sektion Sportgeschichte vom 18. - 20. März 1986 in der Führungs- und Verwaltungsakademie des DSB in Berlin. Clausthal-Zellerfeld 1987, SS. 102 - 130 
Pfister, Gertrud; Langenfeld, Hans: Die Leibesübungen für das weibliche Geschlecht - ein Mittel zur Emanzipation der Frau? in: Ueberhorst, Horst (Hg.). Geschichte der Leibesübungen, Band 3/1. Berlin, München, Frankfurt am Main 1980, SS. 485 - 521

Pfister, Gertrud: Sportstätten und Sportvereine in Berlin an der Wende vom 19. zum 20. Jahrhundert. in: John, Hans Georg (Red.): Vom Verein zum Verband. Die Gründerzeit des Sports in Deutschland. 10. Fachtagung der dvs-Sektion Sportgeschichte vom 18. - 20. März 1986 in der Führungs- und Verwaltungsakademie des DSB in Berlin. Clausthal-Zellerfeld 1987, SS. 11 40

Pfister, Gertrud: Zur Geschichte des Körpers und seiner Kultur - Gymnastik und Turnen im gesellschaftlichen Modernisierungsprozeß. in: Diekmann, Irene; Teichler, Joachim H. (Hgg.): Körper, Kultur und Ideologie. Sport und Zeitgeist im 19. und 20. Jahrhundert. (Studien zur Geistesgeschichte, Band 19). Bodenheim 1997, SS. 11 - 47

Pischke, Gudrun: Die Landesteilungen der Welfen im Mittelalter. (Veröffentlichungen des Instituts für Historische Landesforschungen der Universität Göttingen, Band 24), Hildesheim 1987.

Pitz, Ernst: Deutschland und Hannover im Jahre 1866. in: Niedersächsisches Jahrbuch für Landesgeschichte, Band 38 (1966). SS. 86 - 158

Plümer, Erich: Einbecker Schützenwesen. in: N. N. [Festschrift zum 100jährigen Bestehen des Schützenvereins Einbeck und/oder zum Schützenfest 1962]. o. O. [1962], SS. 15 - 25

Plümer, Erich: Bürger und Brauer im spätmittelalterlichen Einbeck. Zur Sozialund Wirtschaftsgeschichte der Stadt. in: Niedersächsisches Jahrbuch für Landesgeschichte, Band 58 (1986). SS. 117 - 197

Plümer, Erich. Aus der Geschichte des Einbecker Feuerlöschwesens. in: 125 Jahre Freiwillige Feuerwehr Stadt Einbeck. 25 Jahre Feuerwehr-Musikzug Einbeck-Moringen. Einbeck 1992, SS. 31 - 63 
Poggel, Marianne: Soziale Voraussetzungen für die Bildung einer gewerkschaftlichen Organisation in der Papierindustrie. Examensarbeit, ungedruckt. Göttingen 1979

Preising, Wulf: Die Spielbewegung in Deutschland: Die Entwicklung einer gesellschaftlichen Bedeutung des Spiels. in: Ueberhorst, Horst (Hg.). Geschichte der Leibesübungen, Band 3/1. Berlin, München, Frankfurt am Main 1980, SS. 413 - 442

Querfeld, Werner: Kultur- und Vereinsleben in der Stadt Greiz während des 19. Jahrhunderts. Ein Beitrag zur Geschichte des Partikularismus in Deutschland. (Schneider, Friedrich (Hg.): Beiträge zur mittelalterlichen, neueren und allgemeinen Geschichte, Band 27). Jena 1957

Quest, Thorsten: Soziale Merkmale der Entwicklung der Arbeiterbewegung im ländlichen Raum. Examensarbeit, ungedruckt. Göttingen 1979

Rabenstein, Rüdiger: Radsport und Gesellschaft. Ihre sozialgeschichtlichen Zusammenhänge in der Zeit von 1867 bis 1914. 2. Auflage, Hildesheim, München, Zürich 1996

Rehbein, Franz: Das Leben eines Landarbeiters. Herausgegeben und mit einem Nachwort von Urs J. Diederichs und Holger Rüdel. Unveränderter Nachdruck der von Paul Göhre bearbeiteten Ausgabe. Hamburg 1985

Ritter, Gerhard A.: Die Arbeiterbewegung im Wilhelminischen Reich. Die Sozialdemokratische Partei und die Freien Gewerkschaften 1890 - 1900. (Berges, Wilhelm u. a. (Hgg.) Studien zur europäischen Geschichte aus dem Friedrich-Meinecke-Institut der Freien Universität Berlin, Band III). Berlin 1959

Ritter, Gerhard A.: Arbeiter, Arbeiterbewegung und soziale Ideen in Deutschland. Beiträge zur Geschichte des 19. und 20. Jahrhunderts. München 1996

Rohkrämer, Thomas: Der Militarismus der "kleinen Leute". Die Kriegervereine im Deutschen Kaiserreich 1871 - 1914. (Beiträge zur Militärgeschichte, Band 29), München 1990 
Rohmeyer, Berthold: Geschichte von Lüthorst und Portenhagen. Zugleich ein Beitrag zur Geschichte des ehemaligen Amtes, Gerichtes und der Parochie Luthardessen mit ihren vergangenen 7 Dörfern und eine Darstellung der Beziehungen Wilhelm Buschs zu Lüthorst als seiner zweiten Heimat und Dassel. 2. erw. Auflage unter Mitarbeit von Wilhelm Overdick. Dassel 1978

Römer, Christof: Niedersachsen im 18. Jahrhundert (1714 - 1815) in: van den Heuvel, Christine, von Boetticher, Manfred (Hgg.): Geschichte Niedersachsens. Band 3, 1. Politik, Wirtschaft und Gesellschaft von der Reformation bis zum Beginn des 19. Jahrhunderts. Hannover 1998, SS. 219 346

Rürup, Reinhard: Deutschland im 19. Jahrhundert 1815 - 1871. in: Rürup, Reinhard; Wehler, Hans-Ulrich; Schulz, Gerhard: Deutsche Geschichte. Sonderausgabe. Band 3: 19. und 20. Jahrhundert. Göttingen 1985, SS. 1 - 200

Rüschemeyer, Dietrich: Bourgeosie, Staat und Bildungsbürgertum. Idealtypische Modelle für die vergleichende Erforschung von Bürgertum und Bürgerlichkeit. in: Kocka, Jürgen (Hg.): Bürger und Bürgerlichkeit im 19. Jahrhundert. Göttingen 1987, SS. 101 - 120

Sabelleck, Rainer: Einquartierung. Zum Verhältnis zwischen Zivilbevölkerung und Militär. in: Sabelleck, Rainer (Hg.): Hannovers Übergang vom Königreich zur preußischen Provinz 1866. Beiträge zu einer Tagung am 2. 11. 1991 in Göttingen. (Schriftenreihe des Landschaftsverbandes Südniedersachsen, Band 1). Hannover 1995, SS. 79 - 100

Sachse, Wieland: Zur Sozialstruktur Göttingens im 18. und 19. Jahrhundert. in: Niedersächsisches Jahrbuch für Landesgeschichte, Band 58 (1986). SS. 27 - 54

Sachse, Wieland: Wirtschaft und Gesellschaft des Landes Hannover im Übergang vom Königreich zur preußischen Provinz (1815 - 1866). in: Sabelleck, Rainer (Hg.): Hannovers Übergang vom Königreich zur preußischen Provinz 1866. Beiträge zu einer Tagung am 2. 11. 1991 in Göttingen. (Schriftenreihe des Landschaftsverbandes Südniedersachsen, Band 1). Hannover 1995, SS. 13 -22

Sahner, Heinz: Vereine und Verbände in der modernen Gesellschaft. in: Best, Heinrich (Hg.): Vereine in Deutschland. Vom Geheimbund zur freien 
gesellschaftlichen Organisation. Mit einer Literatur- und Forschungsdokumentation von Helmut M. Artus. Bonn 1993, SS. 11 - 118

Saldern, Adelheid von: Arbeiterkulturbewegung in Deutschland in der Zwischenkriegszeit. in: Boll, Friedhelm: Arbeiterkulturen zwischen Alltag und Politik. Beiträge zum europäischen Vergleich in der Zwischenkriegszeit. Wien, München, Zürich 1986, SS. 29 - 70

Schäfer, Wolfgang: Die Anfänge des Fußballs in Lippoldsberg. in: Hopf, Wilhelm (Hg.): Fussball. Soziologie und Sozialgeschichte einer populären Sportart. Bensheim 1979, SS. 131 - 138

Scharf, Helmut: Kleine Kunstgeschichte des deutschen Denkmals. Darmstadt 1984

Scheibner, Richard: Duderstadt, Einbeck, Gandersheim. Ein Beitrag zur Geschichte des städtischen Bürgerhauses Niedersachsens. Dresden 1909

Scheuch, Erwin K.: Vereine als Teil der Privatgesellschaft. in: Best, Heinrich (Hg.): Vereine in Deutschland. Vom Geheimbund zur freien gesellschaftlichen Organisation. Mit einer Literatur- und Forschungsdokumentation von Helmut M. Artus. Bonn 1993, SS. 143 -208

Schloßmacher, Norbert:Düsseldorf im Bismarckreich. Politik und Wahlen. Parteien und Vereine. (Düsseldorfer Schriften zur Neueren Landesgeschichte und zur Geschichte Nordrhein-Westfalens, Band 15). Düsseldorf 1985

Schmitt, Heinz: Das Vereinsleben der Stadt Weinheim an der Bergstraße. Volkskundliche Untersuchung zum kulturellen Leben einer Mittelstadt. (Weinheimer Geschichtsblatt, Nummer 25). Weinheim an der Bergstraße 1963

Schneider, Gerhard: Herrschergeburtstagsfeiern in der preußischen Provinz Hannover (1867 - 1871). in: Sabelleck, Rainer (Hg.): Hannovers Übergang vom Königreich zur preußischen Provinz 1866. Beiträge zu einer Tagung am 2. 11. 1991 in Göttingen. (Schriftenreihe des Landschaftsverbandes Südniedersachsen, Band 1). Hannover 1995, SS. 173 - 224

Schneider, Karl Heinz: Geschichtsvereine und ihre Geschichtslandschaften. Räumliche Organisation und regionale Probleme. in: Geschichtsvereine. 
Entwicklungen und Perspektiven lokaler und regionaler Geschichtsarbeit (Bensberger Protokolle, Band 62). Bergisch Gladbach 1990, SS. 53 - 70

Schönberger, Klaus: Die Arbeitersportbewegung in württembergischen Landgemeinden und ihre Zerschlagung 1933. in: Teichler, Hans Joachim (Red.): Arbeiterkultur und Arbeitersport. 9. Fachtagung der DVS-Sektion Sportgeschichte vom 27. - 29. März 1985 an der Gustav-Heinemann-Akademie der Friedrich-Ebert-Stiftung in Freudenberg. Clausthal-Zellerfeld 1985, SS. $168-182$

Schubert, Ernst: Die Schlacht bei Langensalza. in: Sabelleck, Rainer (Hg.): Hannovers Übergang vom Königreich zur preußischen Provinz 1866. Beiträge $\mathrm{zu}$ einer Tagung am 2. 11. 1991 in Göttingen. (Schriftenreihe des Landschaftsverbandes Südniedersachsen, Band 1). Hannover 1995, SS. 101 124

Schubert, Ernst: Der Zustand des Landes um 1820. in.: Hucker, Bernd Ulrich u. a. (Hgg.)Niedersächsische Geschichte. Göttingen 1997, SS. 337 - 349

Schubert, Ernst: Die Veränderung eines Königreichs. in: Hucker, Bernd Ulrich u. a. (Hgg.)Niedersächsische Geschichte. Göttingen 1997, SS. 374 - 418

Schubert, Ernst: Verfassung und Verfassungskämpfe im frühen 19. Jahrhundert. in: Hucker, Bernd Ulrich u. a. (Hgg.)Niedersächsische Geschichte. Göttingen 1997, SS. 419 - 479

Schubert, Ernst: Niedersachsen um 1900. in: Hucker, Bernd Ulrich u. a. (Hgg.)Niedersächsische Geschichte. Göttingen 1997, SS. 480 - 493

Schult, Johannes: Geschichte der Hamburger Arbeiter 1890 -1919. Hannover 1967

Schulz, Carl: Seminar Einbeck in: Buchwald, Gerd (Hg.): Beiträge zur Geschichte der Lehrerseminare und Präparandenanstalten in der ehemaligen Provinz Hannover. Berlin 1962. SS. 174 - 180

Schulze-Marmeling, Dietrich. Der gezähmte Fußball. Zur Geschichte eines subversiven Sports. Göttingen 1992 
Schulze-Marmeling, Dietrich; Steffen, Werner: Borussia Dortmund. Der Ruhm, der Traum und das Geld. Göttingen 1994

Schütte, Ulrich: Zwischen Fakten und Anekdoten - ein kritischer Überblick zur historischen Literatur über die Anfänge der Leichtathletik. in: John, Hans Georg (Red.): Vom Verein zum Verband. Die Gründerzeit des Sports in Deutschland. 10. Fachtagung der dvs-Sektion Sportgeschichte vom 18. - 20. März 1986 in der Führungs- und Verwaltungsakademie des DSB in Berlin. Clausthal-Zellerfeld 1987, SS. 66 - 91

Seeliger, Matthias: Mit Gott für Fürst und Vaterland. Kriegervereine im Kaiserreich. Holzminden 1993

Siemann, Wolfram: Die deutsche Revolution von 1848/49. (Moderne Deutsche Geschichte, Band 5). Frankfurt am Main 1985

Siemann, Wolfram: Gesellschaft im Aufbruch. Deutschland 1849 - 1871. (Moderne Deutsche Geschichte, Band 6). Frankfurt am Main 1990

Siewert, H.-Jörg: Zur Thematisierung des Vereinswesens in der deutschen Soziologie. in: Dann, Otto (Hg.): Vereinswesen und bürgerliche Gesellschaft in Deutschland (Historische Zeitschrift. Beihefte (Neue Folge), Beiheft 9). München 1984, SS. 151 - 180

Spörer, Claus: Volksbildungs-Bestrebungen und kulturelles Leben. in: Ernst, Georg; Sindermann, Edmund (Bearbb.): Heimatchronik des Kreises Einbeck. (Heimatchroniken der Städte und Kreise des Bundesgebiets, Band 14) Köln 1955, SS. 152 - 160

Spörer, Claus: Einbeck im Jahre 1853. Bürgerliches Leben am Vorabend der Industrialisierung. Die Königliche Familie in Rotenkirchen. Ein Zeitbild. Aus dem Jahrgang 1853 des "Einbeckschen Wochenblattes" zusammengestellt und eingeleitet von C. S.. (Schriftenreihe zur Geschichte der Stadt Einbeck, Band 2) Einbeck 1980

Spörer, Claus: Der Niedergang der Stadt im Siebenjährigen Krieg (1756 1763). in: Einbecker Geschichtsverein (Hg.): Geschichte der Stadt Einbeck. Band 1.Von den Anfängen bis zum Ende des 18. Jahrhunderts. Einbeck 1990, SS. 273 - 306 
Spörer, Claus: Einbeck im späten 18. Jahrhundert (1765 - 1800). Lebensformen und Lebensumstände der Bürger einer südhannoverschen Landstadt im Zeitalter der Aufklärung und der Französischen Revolution. Ein Beitrag zur Kulturgeschichte des Alltags. 2 Teilbände. (Studien zur Einbecker Geschichte, Band 11) Einbeck; Oldenburg 1997

Steinberg, Georg: Nahharkels. Jugenderinnerungen aus Mackensen in plattdeutscher Sprache. Nachdruck des Prosateils Vör föwtig Jahr up'n Dörpe aus Nahharkels, Hannover 1899, Einbeck 1986

Steinberg, Georg: Beim 3. Jägerbataillon. Herausgegeben und mit einem Nachwort versehen von Rainer Sabelleck. (Jüdische Bibliothek, Band 1). Mannheim 1991

Stiller, Eike: Jugend im Arbeitersport. Lebenswelten im Spannungsfeld von Verbandkultur und Sozialmilieu von 1893 - 1933. (Arbeiterkultur und Arbeiterbewegung, Band 26). Münster; Hamburg 1995

Stollberg, Gunnar: Die Naturheilvereine im Deutschen Kaiserreich. in: Archiv für Sozialgeschichte, Band 28 (1988), SS. 287 - 305

Stuke, Horst: Bedeutung und Problematik des Klassenbegriffs. Begriffs- und sozialgeschichtliche Überlegungen im Umkreis einer historischen Klassentheorie. in: Engelhardt, Ulrich u. a. (Hgg.): Soziale Bewegung und politische Verfassung. Beiträge zur Geschichte der modernen Welt. Stuttgart 1976, SS. $46-82$

Tecklenburg, A[ugust]; Dageförde, K[arl]: Geschichte der Provinz Hannover für Lehrer, Lehrerbildungs- und andere Lehranstalten der Provinz sowie für Schul- und Volksbibliotheken. Hannover-List, Berlin 1906

Teichler, Hans-Joachim: Arbeitersport als soziales und politisches Phänomen im wilhelminischen Klassenstaat. in: Ueberhorst, Horst (Hg.). Geschichte der Leibesübungen, Band 3/1. Berlin, München, Frankfurt am Main 1980, SS. 443 $-484$

Tenfelde, Klaus: Die Entfaltung des Vereinswesens während der industriellen Revolution in Deutschland (1850 - 1873). in: Dann, Otto (Hg.): Vereinswesen 
und bürgerliche Gesellschaft in Deutschland (Historische Zeitschrift. Beihefte (Neue Folge), Beiheft 9). München 1984, SS. 55 -114

Tilly, Richard H.: Vom Zollverein zum Industriestaat. Die wirtschaftlichsoziale Entwicklung Deutschlands 1834 bis 1914. München 1990

Tölke, Gerd: In Einbeck wurde 1855 einer der ersten Stenografenvereine Norddeutschland gegründet. in: Einbecker Jahrbuch, Band 38 (1987), SS.183 192

Tölke, Gerd: Die Bevölkerungsentwicklung Einbecks von 1821 bis 1994. in: Einbecker Jahrbuch, Band 43, (1994), SS. 169 - 176

Töpperwien, Rolf: Die Entstehung und Entwicklung der Turnbewegung in Niedersachsen während des 19. Jahrhunderts. in: Krüger, Arnd (Hg.): Beiträge zur niedersächsischen Sportgeschichte. Der Dr.-Bernhard-Zimmermann- Preis 1984 (Schriftenreihe des niedersächsischen Instituts für Sportgeschichte, Hoya, Band 4). Duderstadt 1986, SS. 114 - 116

Tuchman, Barbara: August 1914. Frankfurt am Main 1990

Ueberhorst, Horst: Sinn und Aufgabe einer Sportgeschichte in der modernen Geschichtswissenschaft. in: Ueberhorst, Horst (Hg.). Geschichte der Leibesübungen, Band 3/1. Berlin, München, Frankfurt am Main 1980, SS. 7 25

Ullmann, Hans-Peter: Interessenverbände in Deutschland. Frankfurt am Main 1988

Ullmann, Hans-Peter: Das Deutsche Kaiserreich 1871 - 1918. (Moderne Deutsche Geschichte, Band 7). Frankfurt am Main 1995

Ullrich, Volker: Die nervöse Grossmacht. Aufstieg und Untergang des deutschen Kaiserreichs 1871 - 1918. Frankfurt am Main 1997

Väth, Heinrich: Profifußball. Zur Soziologie der Bundesliga. Frankfurt am Main, New York 1994 
van den Heuvel, Gerd: Niedersachsen im 17. Jahrhundert (1618 - 1714). in: van den Heuvel, Christine, von Boetticher, Manfred (Hgg.): Geschichte Niedersachsens. Band 3, 1. Politik, Wirtschaft und Gesellschaft von der Reformation bis zum Beginn des 19. Jahrhunderts. Hannover 1998, SS. 117 218

Vierhaus, Rudolf: Bürgerliche Hegemonie oder proletarische Emanzipation: der Beitrag der Bildung. in: Kocka, Jürgen (Hg.): Arbeiter und Bürger im 19. Jahrhundert. Varianten ihres Verhältnisses im europäischen Vergleich. (Schriften des Historischen Kollegs, Kolloquien 7). München 1986, SS. 53 - 64

Vierhaus, Rudolf: Der Aufstieg des Bürgertums vom späten 18. Jahrhundert bis 1848/49. in: Kocka, Jürgen (Hg.): Bürger und Bürgerlichkeit im 19. Jahrhundert. Göttingen 1987, SS. 64 - 78

Wallner, Ernst M.: Die Rezeption stadtbürgerlichen Vereinswesens durch die Bevölkerung auf dem Lande. in: Wiegelmann, Günter (Hg.): Kultureller Wandel im 19. Jahrhundert. Verhandlungen des 18. Deutschen VolkskundeKongresses in Trier vom 13. bis 18. September 1971. (Studien zum Wandel von Gesellschaft und Bildung im Neunzehnten Jahrhundert, Band 5). Göttingen 1973, SS. 160 - 173

Walter, Hubert: Bevölkerungsgeschichte der Stadt Einbeck. Hildesheim 1960

Wehler, Hans-Ulrich: Zur Funktion und Struktur der nationalen Kampfverbände im Kaiserreich. in: Conze, Werner u. a. (Hgg.): Modernisierung und nationale Gesellschaft im ausgehenden 18. und im 19. Jahrhundert. Referate einer deutsch-polnischen Historikerkonferenz. (Giessener Abhandlungen zur Agrar- und Wirtschaftsforschung des europäischen Ostens, Band 99). Berlin 1979, SS. 113 - 124

Wehler, Hans-Ulrich: Das deutsche Kaiserreich 1871 - 1918. in: Rürup, Reinhard; Wehler, Hans-Ulrich; Schulz, Gerhard: Deutsche Geschichte. Sonderausgabe. Band 3: 19. und 20. Jahrhundert. Göttingen 1985, SS. 201 404

Wehler, Hans-Ulrich: Bürger, Arbeiter und das Problem der Klassenbildung 1800 - 1870. Deutschland im internationalen Vergleich. in: Kocka, Jürgen (Hg.): Arbeiter und Bürger im 19. Jahrhundert. Varianten ihres Verhältnisses 
im europäischen Vergleich. (Schriften des Historischen Kollegs, Kolloquien 7). München 1986, SS. 1 - 64

Wehler, Hans Ulrich: Wie bürgerlich war das Deutsche Kaiserreich? in: Kocka, Jürgen (Hg.): Bürger und Bürgerlichkeit im 19. Jahrhundert. Göttingen 1987, SS. $243-280$

Wetterich, Jörg: Bewegungskultur und Körpererziehung in der sozialistischen Jugendarbeit 1893 bis 1933. Lebensstile und Bewegungskonzepte im Schnittpunkt von Arbeitersportbewegung und Jugendbewegung. (Arbeiterkultur und Arbeiterbewegung, Band 28). Münster; Hamburg 1993

Wiese, Hartmut: Industrie und Stadtentwicklung ausgewählter Kleinstädte Südniedersachsens. -Alfeld, Einbeck und Northeim- (Forschungen zur niedersächsischen Landeskunde, Band 110) Göttingen, Hannover 1978 (zugl. Dissertation, Kiel 1878)

Wilhelms, Günter: Vom Handwerksbetrieb zum Fabrikunternehmen. 147 Jahre Unternehmensgeschichte der Firma Gurt- und Bandweberei E. Oppermann, Einbeck. in: Einbecker Jahrbuch, Band 44 (1995), SS. 129 - 164

Wilkens, Christa: Bildung und Freizeit für Arbeiter während des Kaiserreichs. Der Bildungsverein für Arbeiter in Lüneburg und seine bürgerlichen Förderer. in: Niedersächsisches Jahrbuch für Landesgeschichte, Band 64 (1992). SS. 341 $-388$

Wunderer, Hartmann: Arbeitervereine und Arbeiterparteien. Kultur- und Massenorganisationen in der Arbeiterbewegung (1890-1933). Frankfurt am Main, New York 1980

Zimmermann, Ernst: Gestern, heute und morgen. in: Deutscher Schützenbund (Hg.): Wir Schützen, Stuttgart 1961, SS. 113 - 116 